\title{
The Effect of Steel Fibre-Reinforced Grout on the Tension Stiffening Behaviour of Reinforced Concrete Masonry
}

\author{
A thesis submitted to \\ the Faculty of Graduate and Postdoctoral Affairs \\ in partial fulfillment of the requirements for the degree of \\ Master of Applied Science in Civil Engineering \\ By \\ Jonathan David Grimes, B.Eng \\ Department of Civil \& Environmental Engineering \\ Carleton University
}

The M.A.Sc. in Civil Engineering is a joint program

with Ottawa University administered by the

Ottawa-Carleton Institute for Civil Engineering

January 2014

C2014 Jonathan Grimes 


\begin{abstract}
This thesis presents the results of an experimental program designed to investigate the influence of steel fibre reinforced grout on the tension stiffening effect in reinforced concrete masonry. In particular; variables such as steel fibre content, steel reinforcement ratio, unit type, fibre aspect ratio and loading type are investigated to determine their effect on the tension stiffening behavior of steel fibre reinforced concrete masonry.

A background review is conducted whereby reinforced concrete masonry, fibre reinforced concrete, and the tension stiffening effect were all examined. The constituent materials of reinforced concrete masonry are reviewed as well as the standard testing procedures for determining structural properties. The applicability of fibre reinforced technologies to grout is discussed as well as an in-depth look at steel fibre reinforced concrete. Although fibre reinforced grout is not the exact same as fibre reinforced concrete, the concept of reinforcing a brittle material remains the same. The mechanics of fibre pullout are discussed along with methods used to reduce fibre pullout such as using hooked end steel fibres. The behavior of fibre reinforced concrete in both tension and compression is discussed through both indirect and direct testing methods. Finally the tension stiffening effect in concrete is discussed and industry relevant models are discussed such as the Stevens et al model, the Vecchio and Collins model and the Gopalaratnam and Shah model. Factors affecting tension stiffening in reinforced concrete are discussed as well as the tension stiffening behavior of reinforced concrete with steel fibre reinforcement. The limited amount of research in reinforced masonry with regards to tension stiffening is summarized.

The experimental study consisted of forty-two direct tension specimens constructed and tested at the structures lab at Carleton University to investigate the effect of fibre reinforcement and other parameters mentioned above on tension stiffening in reinforced concrete masonry. All specimens had the same overall dimensions and were all fully grouted with a single deformed reinforcing bar at the centre of each specimen. The bar sizes ranged from 10M to $20 \mathrm{M}$ with the main reinforcing bar size being $15 \mathrm{M}$.

The results of the experimental program show that the addition of fibre reinforcement to the grout can be beneficial to the post-cracking performance, increase crack control and increase the toughness of reinforced masonry elements.
\end{abstract}




\section{AKNOWLEDGEMENTS}

I would like to thank all who have helped make this journey a success. My most sincere appreciation goes out to my thesis supervisor Dr. Ted Sherwood; first for his encouragement in starting a Master to Applied Science degree, and second for his invaluable help in all phases of the research. Without his expertise and guidance, this research could not have been completed and I thank him greatly.

I would also like to thank all the staff members in the structural lab at Carleton University who facilitated the experimental work. Stanley Conley was vital in setting up the experimental setup and testing program, Jason Arnott was highly involved in the materials testing and Pierre Trudel crafted many of customized parts required for the experimental testing. Special thanks also go out to my colleagues Bishoy Samy Alfy, Salah Sarhat, and Joshua Woods for their helping hands in the laboratory.

This project would not have been possible without the financial and technical help from the masonry industry. The Canadian Masonry Design Centre graciously donated the masonry materials for the experimental testing. Special thanks go to Bekaert Corporation for donating the steel fibres, SIKA Canada for donating the high range water reducer and BASF Canada for donating the shrinkage reducing admixture.

Lastly I would like to thank my friends and family who have given me ample support and encouragement along the way. A special thanks to Lauren McAllister who has been supportive and patient and stood by me all the way. 


\section{Table of Contents}

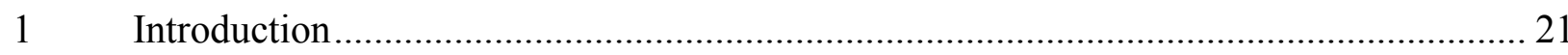

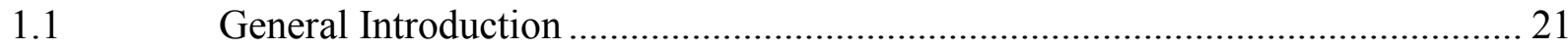

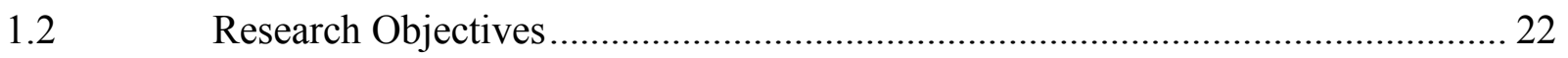

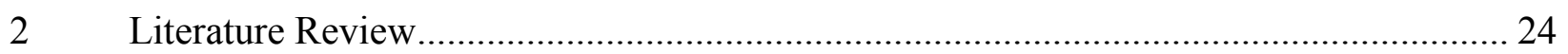

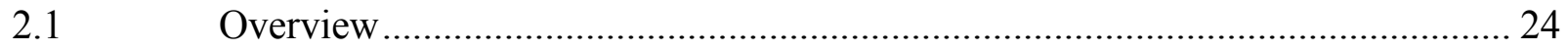

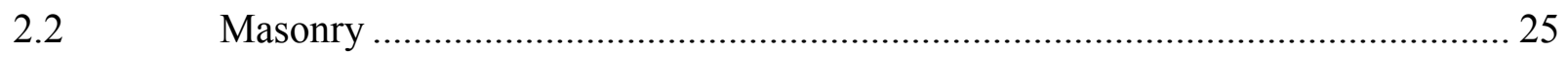

2.2.1 Introduction to Masonry …………………………........................................ 25

2.2.2 Reinforced Masonry Materials ......................................................................... 27

2.2.2.1 Hollow Load-Bearing Concrete Units.................................................. 27

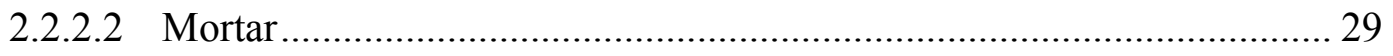

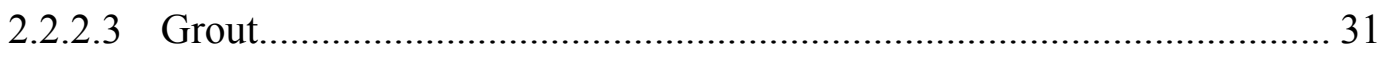

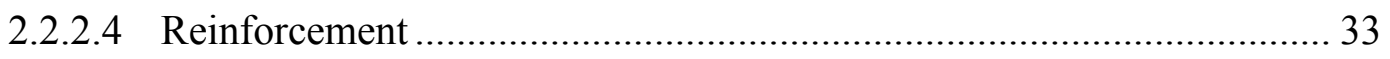

2.2.3 Masonry Testing and Structural Properties.......................................................... 34

2.2.3.1 Concrete Block Properties................................................................... 35

2.2.3.2 Mortar Properties............................................................................... 36

2.2.3.3 Grout properties.................................................................................. 37

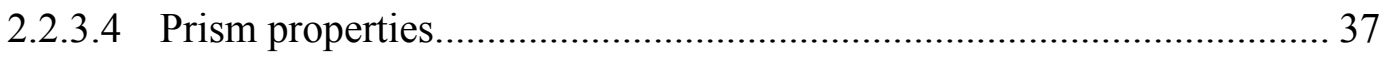

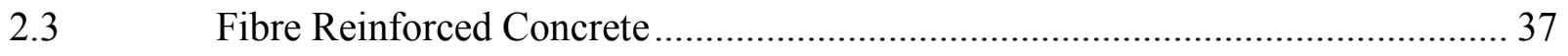

2.3.1 Applicability to Grout ..................................................................................... 39

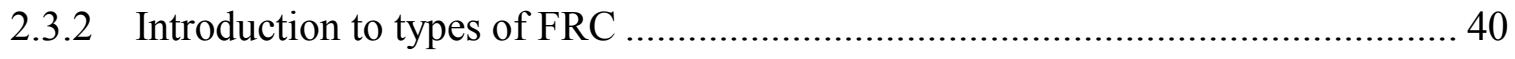

2.3.3 In depth look at Steel Fibre Reinforced Concrete................................................. 41

2.3.3.1 Steel Fibre Types............................................................................. 42

2.3.3.1.1 Hooked end steel fibres............................................................. 42

2.3.3.1.2 Crimped steel fibres .............................................................. 43

2.3.3.1.3 Spiral Steel Fibres ................................................................... 44

2.3.3.2 Steel Fibre Reinforced Concrete Properties affecting Performance ...... 45

2.3.3.2.1 Fibre Volume Fraction ................................................................... 45

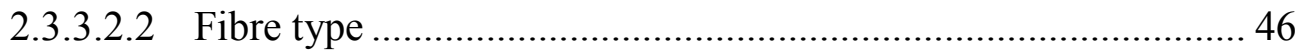

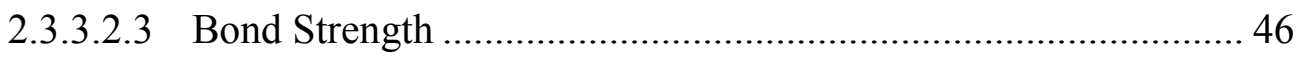

2.3.3.2.4 Fibre Dimensions ...................................................................... 46 


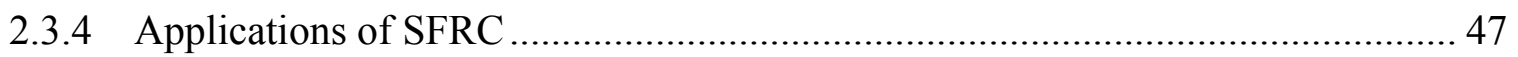

2.3.5 Behaviour of Steel Fibre Reinforced Concrete in Tension ................................... 48

2.3.5.1 Mechanics of fibre pullout from matrix ................................................. 48

2.3.5.2 Behaviour of SFRC in pure tension .................................................... 52

2.3.5.3 Direct Tension Testing Methods ............................................................ 54

2.3.5.4 Indirect Tension Testing Methods......................................................... 56

2.3.6 Behaviour of SFRC in compression ............................................................ 58

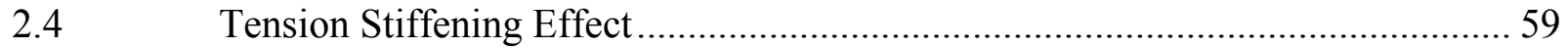

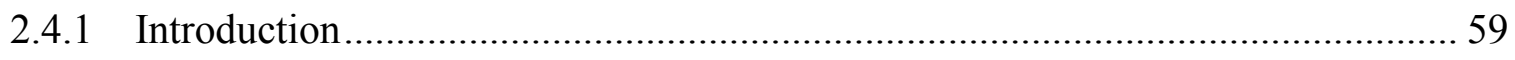

2.4.2 Tension Stiffening in Reinforced Concrete ........................................................ 60

2.4.2.1 Previous Research and Models ............................................................... 63

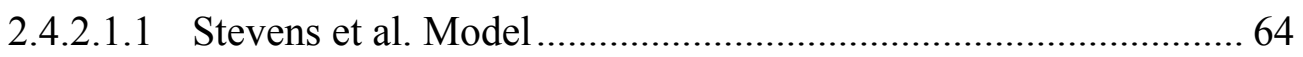

2.4.2.1.2 Vecchio and Collins Model ......................................................... 65

2.4.2.1.3 Gopalaratnam and Shah Model................................................... 67

2.4.2.2 Factors affecting the magnitude of tension stiffening ............................ 70

2.4.2.3 Bond between Reinforcement and Concrete......................................... 71

2.4.2.4 Effects of Shrinkage on Tension Stiffening and Cracking.................... 71

2.4.2.5 Tension Stiffening Behavior of High Strength Concrete ........................ 74

2.4.2.6 Tension Stiffening with Steel Fibres ..................................................... 74

2.4.3 Tension Stiffening in Reinforced Masonry............................................................ 82

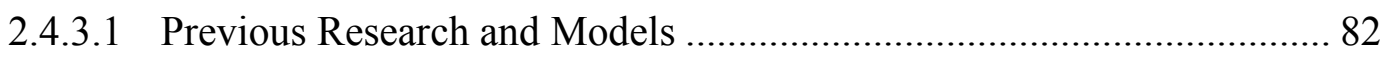

2.4.3.1.1 Nunn et al. Research ................................................................. 83

2.4.3.1.2 Atkinson and Hammons Research ................................................ 84

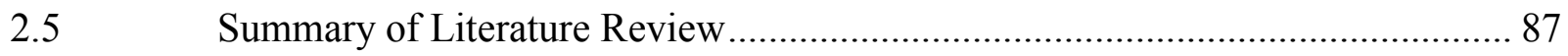

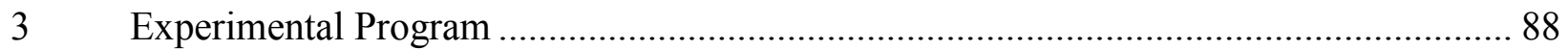

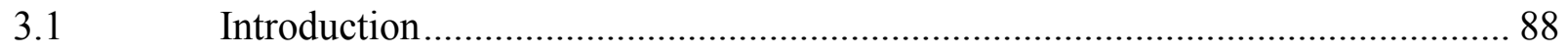

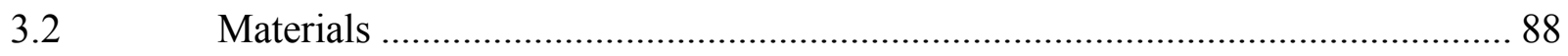

3.2.1 Hollow Concrete Masonry Units ....................................................................... 88

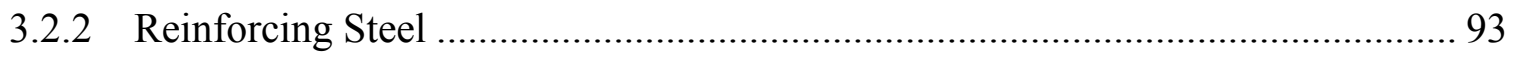

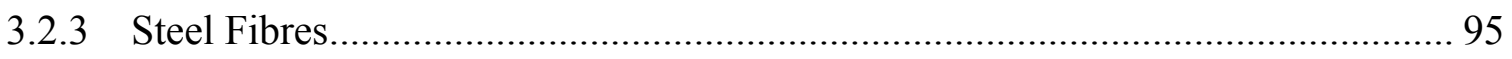

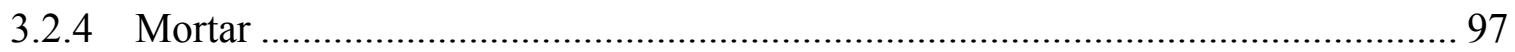




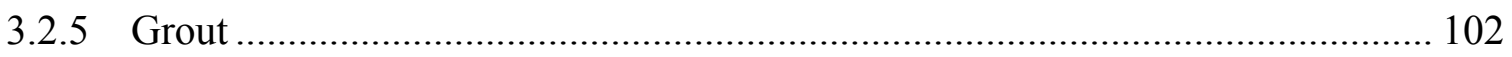

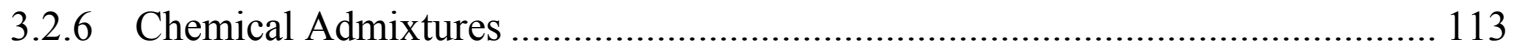

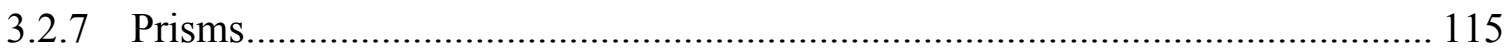

3.3 Construction of Test Specimens …………................................................. 119

3.3.1 Pre construction preparations....................................................................... 124

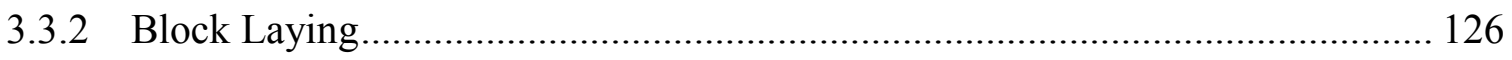

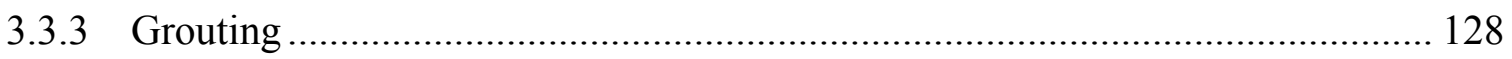

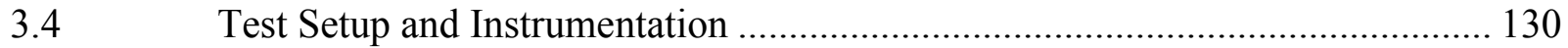

3.4.1 Linear Variable Displacement Transducers (LVDTs) ........................................ 133

3.4.2 Demountable Mechanical Gauges (Demec gauges) ………………………....... 134

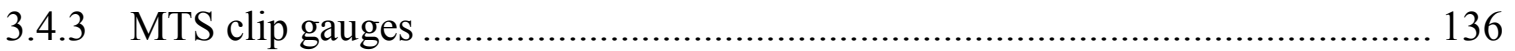

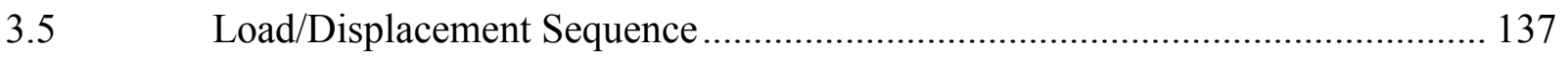

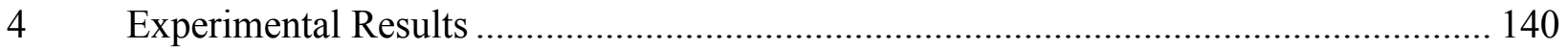

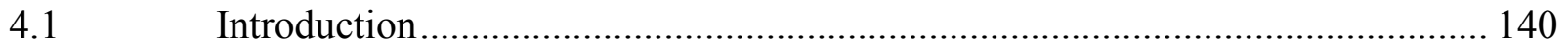

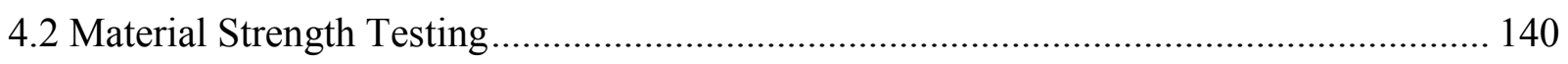

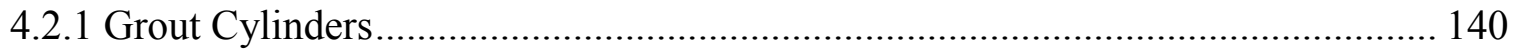

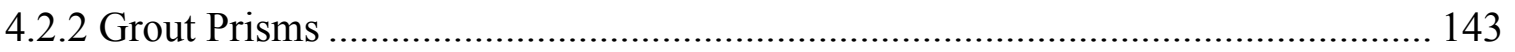

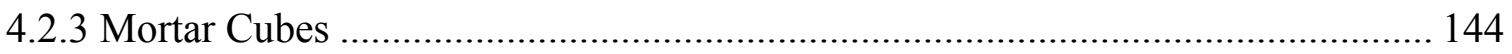

4.2.4 Masonry Prisms ……………………………………..................................... 146

4.2.5 Reinforcing Steel Coupons ................................................................................. 147

4.2.6 Concrete Masonry Units ................................................................................ 149

4.3 Specimens tested under Monotonic Load ..................................................................... 151

4.3.1 Specimen 10M00-1 .................................................................................. 152

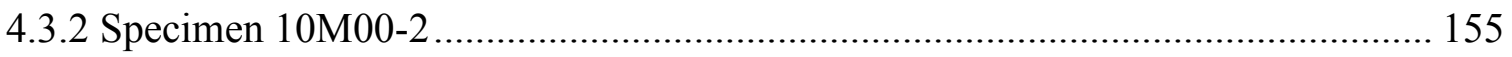

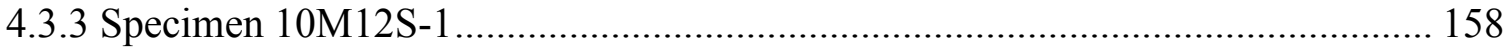

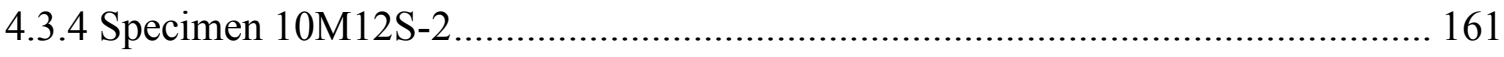

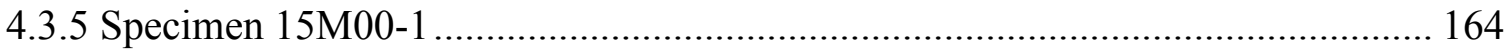

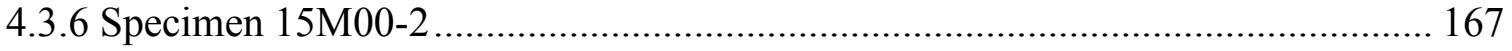

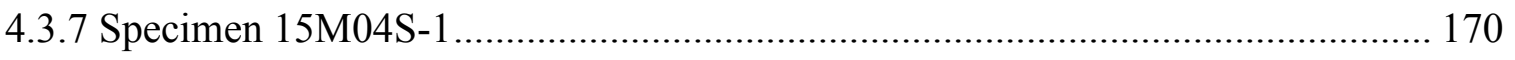

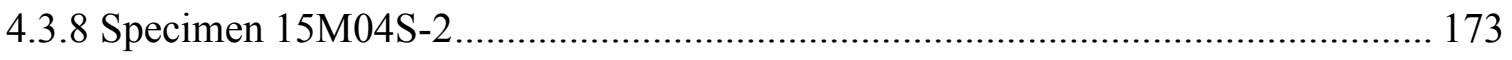

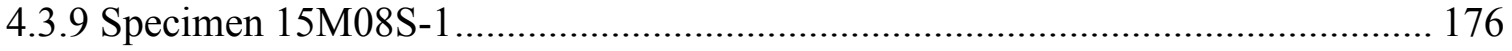




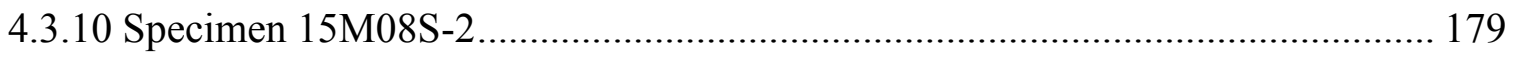

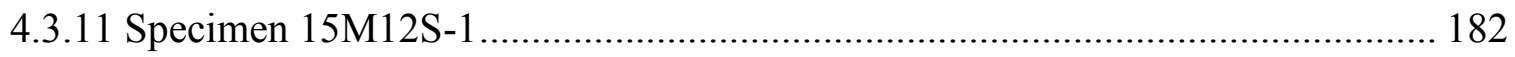

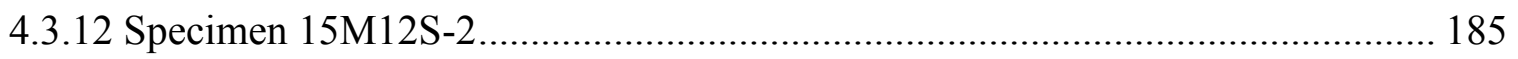

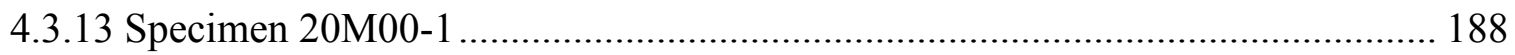

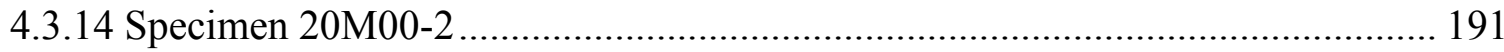

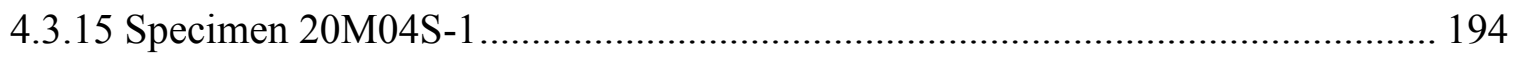

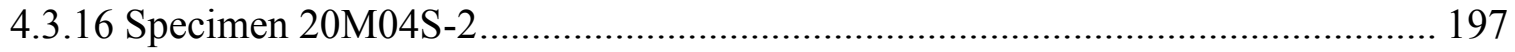

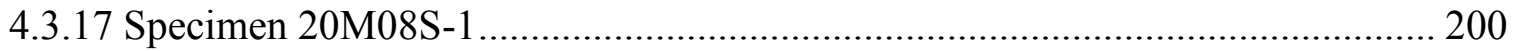

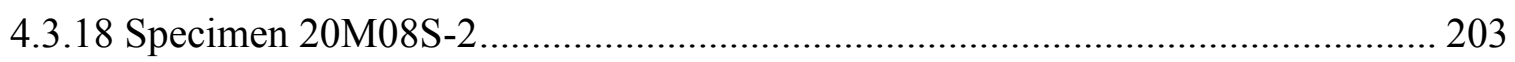

4.3.19 Specimen 20M12S-1 .............................................................................. 206

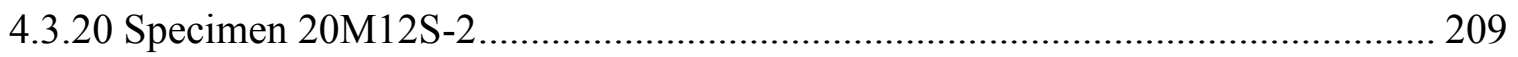

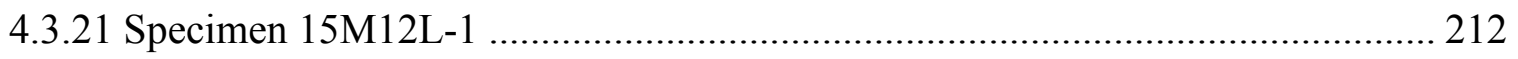

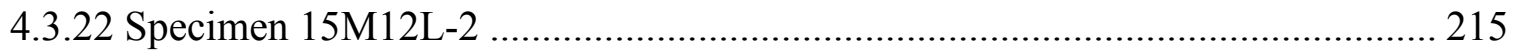

4.3.23 Specimen L15M00-1 ................................................................................ 218

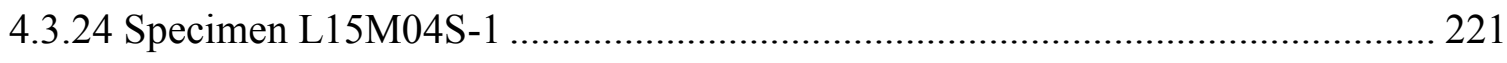

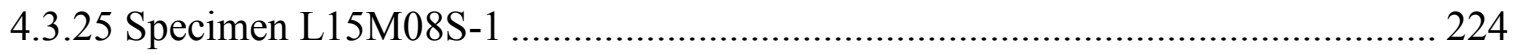

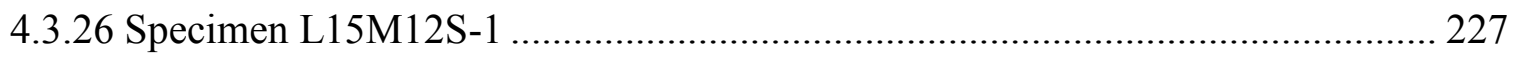

4.4 Specimens tested under Cyclic Load .................................................................... 230

4.4.1 Cyclic Load at Service Loads ...................................................................... 230

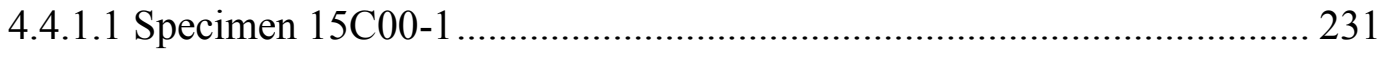

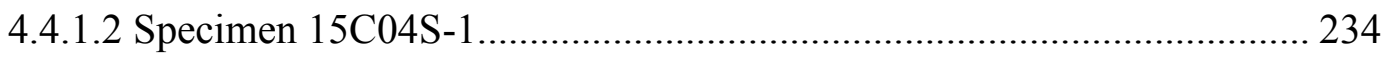

4.4.1.3 Specimen 15C08S-1................................................................... 237

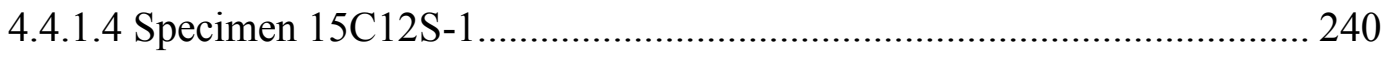

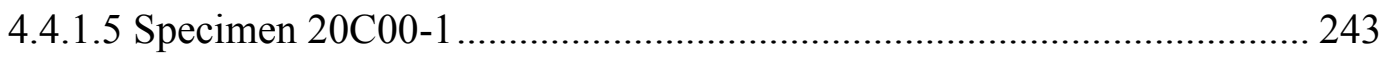

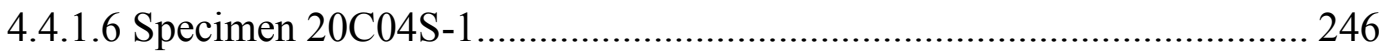

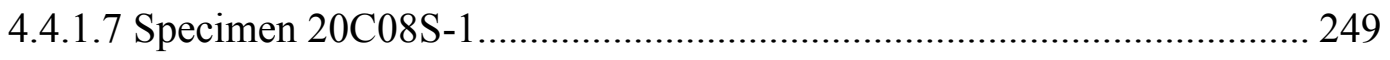

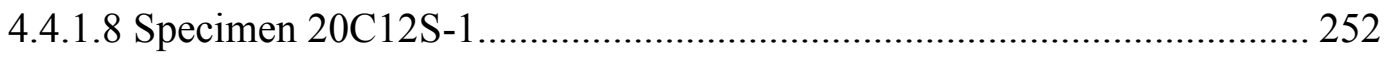

4.4.2 Cyclic Load at Post-Yield Loads ....................................................................... 255

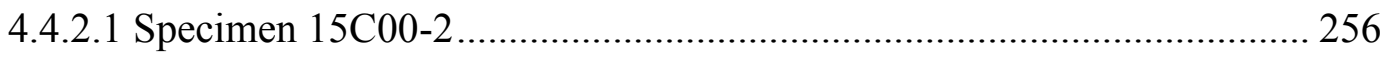

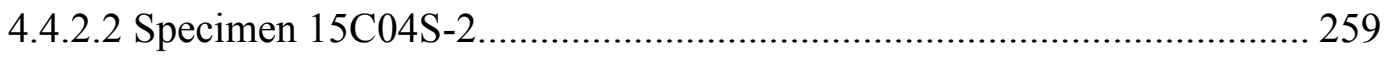

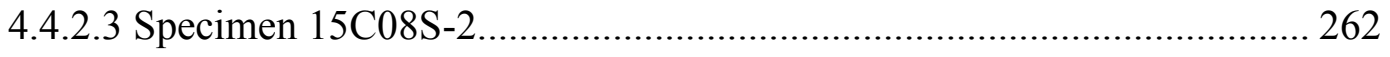




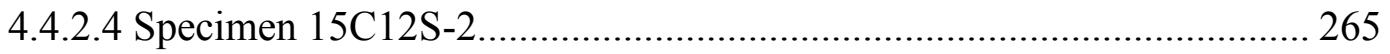

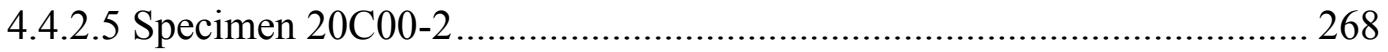

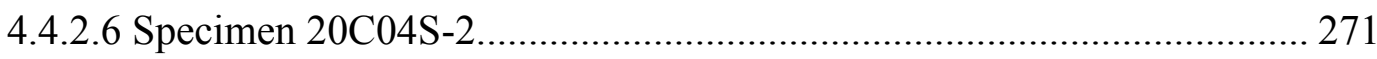

4.4.2.7 Specimen 20C08S-2_...................................................................... 274

4.4.2.8 Specimen 20C12S-2.................................................................... 277

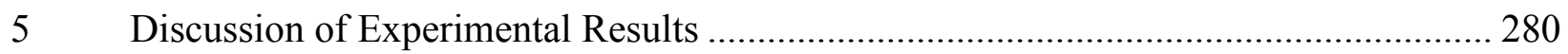

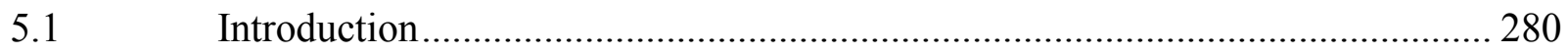

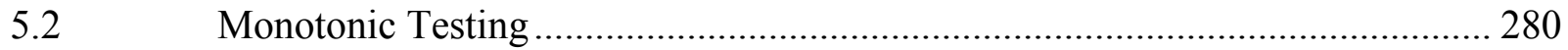

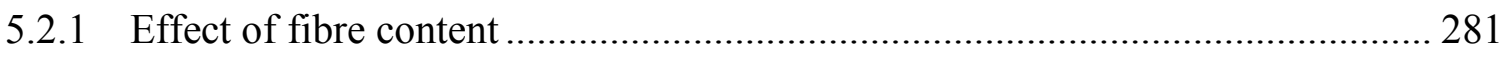

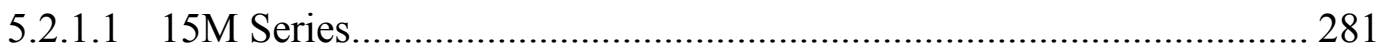

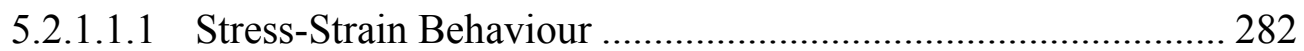

5.2.1.1.2 Effect of Fibre Content on Crack Widths and Crack Spacing .. 285

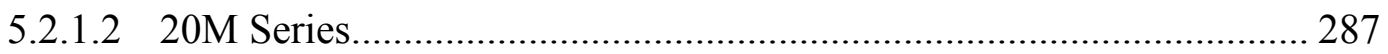

5.2.1.2.1 Stress Strain Behaviour........................................................... 288

5.2.1.2.2 Effect of Fibre Content on Crack Widths and Crack Spacing.. 291

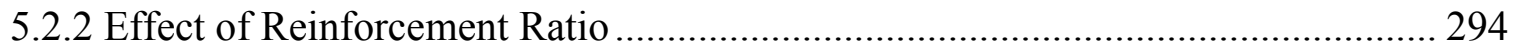

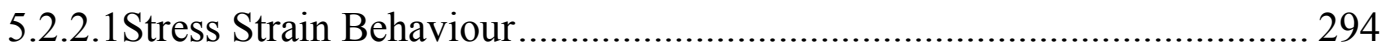

5.2.2.2 Crack Width and Crack Spacing .......................................................... 296

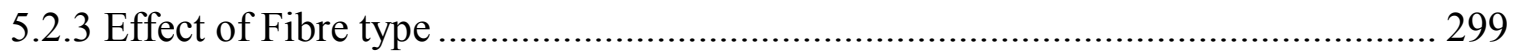

5.2.3.1 Stress Strain Behaviour................................................................... 300

5.2.3.2 Crack Width and Crack Spacing .......................................................... 302

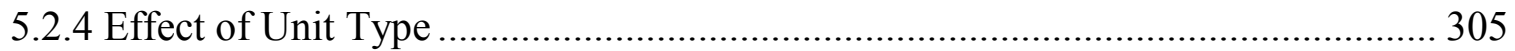

5.2.3.1 Stress Strain Behaviour....................................................................... 306

5.2.3.2 Crack Width and Crack Spacing........................................................... 311

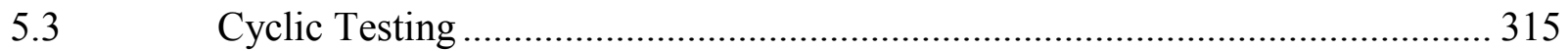

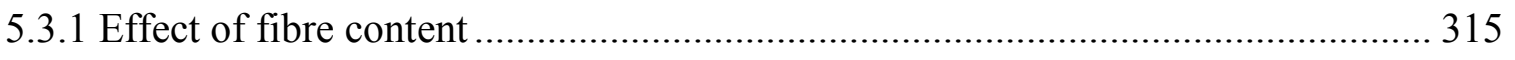

5.3.1.1 Stress Strain Behaviour.................................................................... 315

5.3.1.2 Crack Width and Crack Spacing........................................................... 322

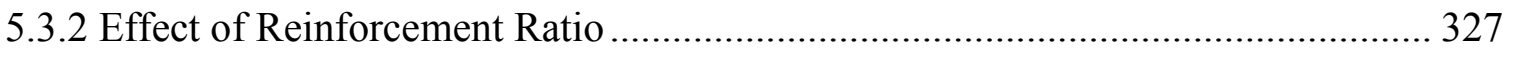

5.3.2.1 Stress Strain Behaviour........................................................................ 327

5.3.2.2 Crack Width and Crack Spacing........................................................... 338 
5.4 Proposed Tension Stiffening Relationship for Steel Fibre Reinforced Concrete Masonry 343

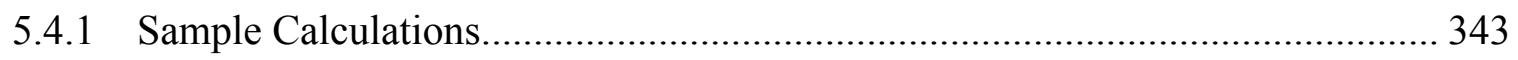

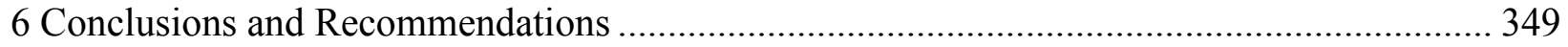

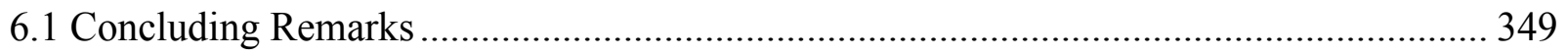

6.2 Recommendations for further research ..................................................................... 351

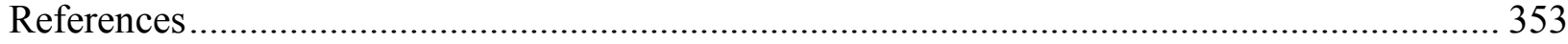




\section{LIST OF FIGURES}

Figure 1-1: Thesis layout ...................................................................................................... 23

Figure 2-1: Typical concrete units available in the construction market.................................. 26

Figure 2-2: Basic Concrete Masonry Unit Terminology ...................................................... 27

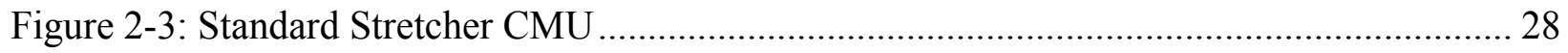

Figure 2-4: Absorbent grout sample cast using masonry units lined with paper...................... 33

Figure 2-5: Various arrangements of both joint and longitudinal reinforcement in masonry

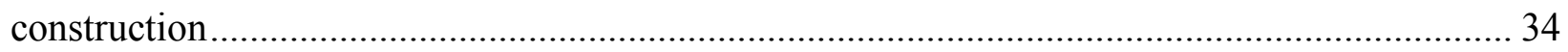

Figure 2-6: Typical mortar flow test .............................................................................. 36

Figure 2-7: Fracture surface of steel fibre reinforced concrete................................................. 38

Figure 2-8: Typical hooked end steel fibre ...................................................................... 43

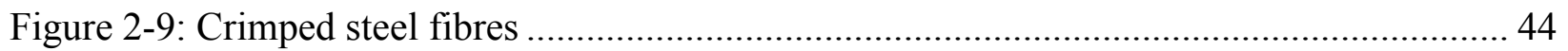

Figure 2-10:Pullout behaviour of straight steel fibres ...................................................... 49

Figure 2-11: Pullout load as a function of end slip for straight steel fibres............................. 49

Figure 2-12: Pullout behaviour of hooked end steel fibres.................................................. 51

Figure 2-13: Stages of pullout of hooked end steel fibres ................................................... 52

Figure 2-14: Improvement of uniaxial tensile behaviour using SFRC ................................... 54

Figure 2-15: Typical dogbone tension specimen dimensions and test setup ........................... 55

Figure 2-16: Comparison of large vs. small scale dog bone tension tests ............................... 56

Figure 2-17: Typical test setup of ASTM C1550 round panel test......................................... 57

Figure 2-18: Typical round panel test for tensile strength of FRC (ASTM C1550).................. 57

Figure 2-19: Double punch test for indirect tension testing of FRC ........................................ 58

Figure 2-20: Load sharing between concrete and reinforcing steel ....................................... 61

Figure 2-21: Secondary cracks forming around reinforcement deformations .......................... 62

Figure 2-22: Strain variation along the length of tension member .......................................... 62

Figure 2-23: Decay of average stress in the cracked concrete as a function of concrete strain.... 63

Figure 2-24: Post-cracking contribution of cracked concrete proposed by Stevens et al........... 65

Figure 2-25: Post cracking contribution from cracked concrete proposed by Vecchio \& Collins 66

Figure 2-26:Tension Stiffening model based on Gopalaratnam and Shah Test Results and crack

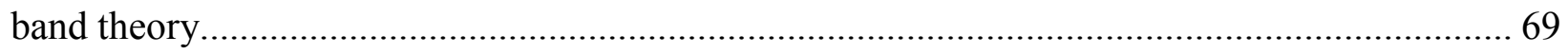

Figure 2-27: Typical response of a reinforced concrete tension member................................. 72

Figure 2-28: a) effect of shrinkage on member response b) details of computing shrinkage

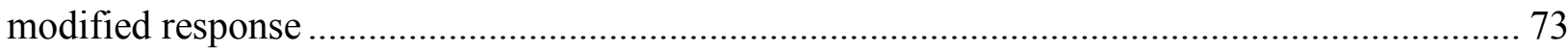

Figure 2-29: Typical Response of FRC tension specimen.................................................... 76

Figure 2-30: Bond Factors for average post cracking tensile strength of concrete .................... 78

Figure 2-31: Tensile response of axially loaded member and calculation of bond factor ........... 78

Figure 2-32: Distribution of stresses between cracks in R/FRC members ............................... 79

Figure 2-33: Comparison of proposed tension stiffening model and test results by a)Bischoff and

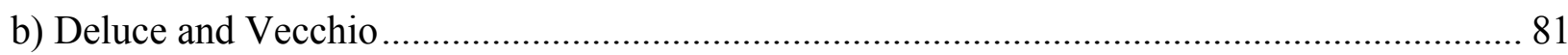


Figure 2-34: Tensile stiffness as a function of tensile strain .............................................. 84

Figure 2-35: Stress-strain relationship of entire response (Specimen 8CO-6-3) ...................... 85

Figure 2-36: Stress-strain relationship at low strain levels (8CO-6-3) .................................... 85

Figure 2-37: Degradation of effective modulus as a function of strain (8CO-6-3) .................. 86

Figure 2-38: Average steel stiffness vs. average strain for 14 specimens tested........................ 86

Figure 2-39: Comparison between the stiffness degradation of concrete vs. masonry ............... 87

Figure 3-1: Standard CMU capped with Hydrostone ....................................................... 89

Figure 3-2: Hydrostone cured with tempered glass plates placed on level plane....................... 89

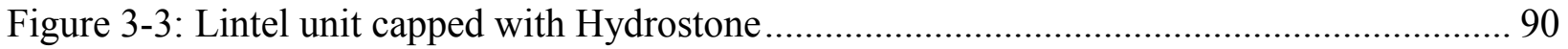

Figure 3-4: Hydrostone cured with tempered glass plate placed on a level plane..................... 90

Figure 3-5: Compressive strength testing of Lintel CMU .................................................. 91

Figure 3-6: Compressive strength testing of standard CMU ................................................ 92

Figure 3-7: Stress strain behaviour of standard CMU using strain gauges.............................. 93

Figure 3-8: 2 inch MTS clip gauge installed on reinforcing steel ........................................... 94

Figure 3-9: 500kN MTS testing machine testing reinforcing steel......................................... 95

Figure 3-10: Bekaert Dramix RC65/60BN hooked end steel fibres ........................................ 96

Figure 3-11: Bekaert Dramix ZP305 hooked end steel fibres ................................................ 96

Figure 3-12: Scale and aluminum pans used to measure all materials ..................................... 97

Figure 3-13: Mortar cube moulds ..................................................................................... 98

Figure 3-14: Typical mortar cube failure under compressive load ........................................ 99

Figure 3-15: Mortar flow table (filling mould adn striking off) ............................................ 99

Figure 3-16: Mortar flow table (removal of mould) ........................................................... 100

Figure 3-17: Mortar flow table (measuring flow after 25 blows) .......................................... 100

Figure 3-18: Typical compressive failure of mortar cube .................................................... 101

Figure 3-19: Mortar cubes tested for compressive strength in Instron 5582 ......................... 101

Figure 3-20: Barrel type concrete mixer used for experimental work.................................... 103

Figure 3-21: Materials being added to mixer................................................................... 103

Figure 3-22: Content of mixture being poured from mixer to wheel barrow .......................... 104

Figure 3-23: Steel fibres added manually into mixer......................................................... 105

Figure 3-24: Grout slump test (filling slump cone) ........................................................... 106

Figure 3-25: Grout slump test (removing slump cone)..................................................... 106

Figure 3-26: Grout slump test (final grout slump measurement) ......................................... 107

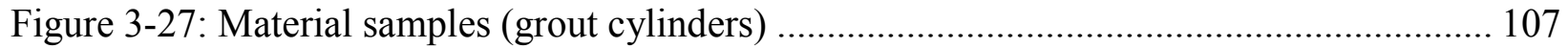

Figure 3-28: Material samples (absorbent grout prisms) ................................................... 108

Figure 3-29: Material samples (grout beam for toughness testing) ......................................... 108

Figure 3-30: Grout cylinder tested under compressive load with apparatus to record deformation

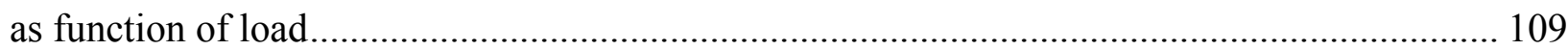

Figure 3-31: Absorbent grout prism tested under compressive load with DEMEC gauge to record

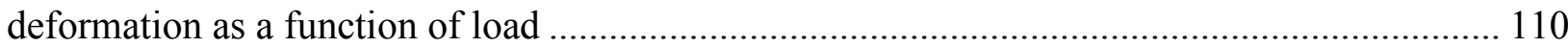

Figure 3-32: Grout cylinder tension splitting test ........................................................... 110 
Figure 3-33: Material samples being capped with sulfur compound 112

Figure 3-34: Grout cylinder placed on a level plane with sulfur hardening onto cylinder end .. 112 Figure 3-35: Absorbent grout cylinder capped with sulfur compound .................................. 113

Figure 3-36: Chemical admixtures being added to the mixer at the end of the mixing cycle ... 114

Figure 3-37: Fibre reinforced grout mix after addition of chemical admixtures ..................... 115

Figure 3-38: Prisms constructed with same procedure as specimens .................................. 116

Figure 3-39: Prisms cured in same environment as specimens prior to grouting .................... 116

Figure 3-40: Prisms grouted with fibre grout and non-fibre grout ...................................... 117

Figure 3-41: Prisms capped with a level surface Hydrostone compound............................... 118

Figure 3-42: Prisms with LVDTs mounted to measure displacement under compressive load. 118

Figure 3-43: Typical failure of non-fibre-reinforced prism under compressive load................ 119

Figure 3-44: Isometric view of typical test specimen (standard units) .................................. 122

Figure 3-45: Isometric view of typical test specimen (lintel units) ...................................... 123

Figure 3-46: Design of typical test specimen (standard units) ........................................... 124

Figure 3-47: Design of typical test specimen (lintel units) ............................................... 124

Figure 3-48: Plywood bases with reinforcing steel held in centre (view from above) .............. 125

Figure 3-49: Timber support structure with caulking between rebar and base (view from below)

125

Figure 3-50: View of rebar held in place by timber support structure (view from below)........ 126

Figure 3-51: Mortar being mixed in wheelbarrow ........................................................ 127

Figure 3-52: Bottom row of blocks placed such that rebar is centered in cross section............ 127

Figure 3-53: Typical specimen being constructed ............................................................. 128

Figure 3-54: Grout being placed into centre of specimen..................................................... 129

Figure 3-55: Excess grout removed from top of specimen with pointed trowel ...................... 129

Figure 3-56: Reinforcing steel being vibrated to consolidate grout ....................................... 130

Figure 3-57: Specimen being lifted into MTS machine with lifting device and overhead crane 131

Figure 3-58: Lifting device being removed from specimen after top hydraulic grip activated .. 131

Figure 3-59: Summary of instrumentation on typical specimen......................................... 133

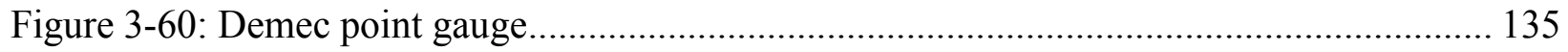

Figure 3-61: Demec point installed on typical specimen.................................................. 135

Figure 3-62: MTS clip gauge (1inch) at bottom of specimen............................................. 136

Figure 3-63: MTS clip gauge (2inch) installed at top of specimen ...................................... 137

Figure 3-64: Load displacement history for specimens tested under cyclic load prior to yield . 138

Figure 4-1: Summary of stress strain responses of grout cylinders ...................................... 142

Figure 4-2: Stress strain relationship of absorbent grout prisms ......................................... 144

Figure 4-3: Stress strain relationship of typical mortar cube ................................................ 145

Figure 4-4: Average compressive strengths of grouted masonry prisms.............................. 146

Figure 4-5: Stress strain responses for masonry prisms ................................................. 147

Figure 4-6: Stress strain response of typical 10M bar .................................................... 147

Figure 4-7: Stress strain response of typical 15M bar .................................................... 148 
Figure 4-8: Stress strain response of typical 20M bar ................................................... 148

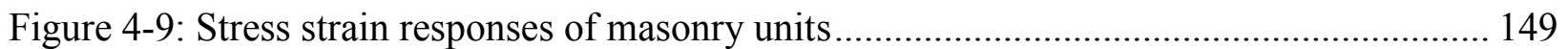

Figure 4-10: Typical compression failure of standard block ................................................ 150

Figure 4-11: Typical compression failure of lintel block ................................................... 150

Figure 4-12: Entire stress strain response (10M00-1) ........................................................ 154

Figure 4-13: Stress strain response prior to yielding of reinforcing steel (10M00-1) .............. 154

Figure 4-14: Average and maximum crack width (10M00-1) .............................................. 154

Figure 4-15: Entire stress strain response (10M00-2)....................................................... 157

Figure 4-16: Stress strain response prior to yielding of reinforcing steel (10M00-2) .............. 157

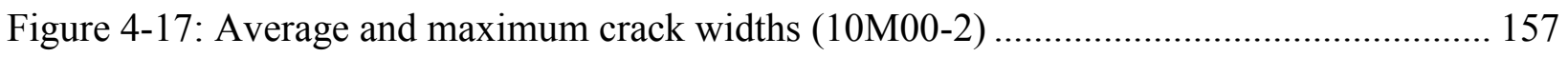

Figure 4-18: Entire Stress strain response (10M12S-1) .................................................... 160

Figure 4-19: Stress strain response prior to yielding of reinforcing steel (10M12S-1) ............ 160

Figure 4-20: Average \& maximum crack widths (10M12S-1)............................................ 160

Figure 4-21: Entire stress strain response (10M12S-2) .................................................... 163

Figure 4-22: Stress strain response prior to yielding of reinforcing steel.............................. 163

Figure 4-23: Average \& maximum crack widths (10M12S-2) ............................................ 163

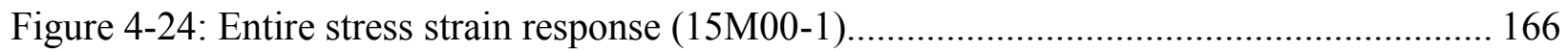

Figure 4-25: Stress strain response prior to yielding of reinforcing steel (15M00-1) .............. 166

Figure 4-26: Average \& maximum crack widths (15M00-1) ............................................ 166

Figure 4-27: Entire stress strain response (15M00-2)........................................................ 169

Figure 4-28: Stress strain response prior to yielding of reinforcing steel (15M00-2) .............. 169

Figure 4-29: Average \& maximum crack widths (15M00-2) ............................................... 169

Figure 4-30: Entire stress stain response (15M04S-1) ..................................................... 172

Figure 4-31: Stress strain response prior to yielding of reinforcing steel (15M04S-1) ............. 172

Figure 4-32: Average \& maximum crack widths (15M04S-1) ............................................. 172

Figure 4-33: Entire stress strain response (15M04S-2) ...................................................... 175

Figure 4-34: Stress strain response prior to yielding of reinforcing steel (15M04S-2) ............ 175

Figure 4-35: Average \& maximum crack widths (15M04S-2)......................................... 175

Figure 4-36: Entire stress strain response (15M08S-1) ..................................................... 178

Figure 4-37: Stress strain response prior to yielding of reinforcing steel (15M08S-1) ............ 178

Figure 4-38: Average \& maximum crack widths (15M08S-1) ............................................ 178

Figure 4-39: Entire stress strain response (15M08S-2) …........................................... 181

Figure 4-40: Stress strain response prior to yielding of reinforcing steel (15M08S-2) ............ 181

Figure 4-41: Average \& maximum crack widths (15M08S-2) ............................................ 181

Figure 4-42: Entire stress strain response (15M12S-1) ....................................................... 184

Figure 4-43: Stress strain response prior to yielding of reinforcing steel (15M12S-1) ............ 184

Figure 4-44: Average \& maximum crack widths (15M12S-1)............................................ 184

Figure 4-45: Entire stress strain response (15M12S-2) .................................................... 187

Figure 4-46: Stress strain response prior to yielding of reinforcing steel (15M12S-2) ............ 187

Figure 4-47: Average \& maximum crack widths (15M12S-2)........................................ 187 
Figure 4-48: Entire stress strain response (20M00-1).................................................... 190

Figure 4-49: Stress strain response prior to yielding of reinforcing steel (20M00-1) ............... 190

Figure 4-50: Average \& maximum crack widths (20M00-1) ................................................. 190

Figure 4-51: Entire stress strain response (20M00-2).................................................... 193

Figure 4-52: Stress strain response prior to yielding of reinforcing steel (20M00-2) .............. 193

Figure 4-53: Average \& maximum crack widths (20M00-2) ................................................ 193

Figure 4-54: Entire stress strain response (20M04S-1) ................................................... 196

Figure 4-55: Stress strain response prior to yielding of reinforcing steel (20M04S-1) ............. 196

Figure 4-56: Average \& maximum crack widths (20M04S-1) .......................................... 196

Figure 4-57: Entire stress strain response (20M04S-2) .................................................. 199

Figure 4-58: Stress strain response prior to yielding of reinforcing steel (20M04S-2) ............. 199

Figure 4-59: Average \& maximum crack widths (20M04S-2) ............................................ 199

Figure 4-60: Entire stress strain response (20M08S-1) .................................................... 202

Figure 4-61: Stress strain response prior to yielding of reinforcing steel (20M08S-1) ............. 202

Figure 4-62: Average \& maximum crack widths (20M08S-1) .............................................. 202

Figure 4-63: Entire stress strain response (20M08S-2) ..................................................... 205

Figure 4-64: Stress strain response prior to yielding of reinforcing steel (20M08S-2) ............. 205

Figure 4-65: Average \& maximum crack widths (20M08S-2) ............................................ 205

Figure 4-66: Entire stress strain response (20M12S-1) ................................................. 208

Figure 4-67: Stress strain response prior to yielding of reinforcing steel (20M12S-1) ............ 208

Figure 4-68: Average \& maximum crack widths (20M12S-1) ........................................... 208

Figure 4-69: Entire stress strain response (20M12S-2) ................................................ 211

Figure 4-70: Stress strain response prior to yielding of reinforcing steel (20M12S-2) ............ 211

Figure 4-71: Average \& maximum crack widths (20M12S-2) .............................................. 211

Figure 4-72: Entire stress strain response (15M12L-1) ..................................................... 214

Figure 4-73: Stress strain response prior to yielding of reinforcing steel (15M12L-1)............ 214

Figure 4-74: Average \& maximum crack widths (15M12L-1) ............................................. 214

Figure 4-75: Entire stress strain response (15M12L-2) ................................................. 217

Figure 4-76: Stress strain response prior to yielding of reinforcing steel (15M12L-2)............ 217

Figure 4-77: Average \& maximum crack widths (15M12L-2) ............................................ 217

Figure 4-78: Entire stress strain response (L15M00-1) ............................................... 220

Figure 4-79: Stress strain response prior to yielding of reinforcing steel (L15M00-1)............ 220

Figure 4-80: Average \& maximum crack widths (L15M00-1) ........................................... 220

Figure 4-81: Entire stress strain response (L15M04S-1) ................................................... 223

Figure 4-82: Stress strain response prior to yielding of reinforcing steel (L15M04S-1).......... 223

Figure 4-83: Average \& maximum crack widths (L15M04S-1) .......................................... 223

Figure 4-84: Entire stress strain relationship (L15M08S-1) .............................................. 226

Figure 4-85: Stress strain response prior to yielding of reinforcing steel (L15M08S-1).......... 226

Figure 4-86: Average \& maximum crack widths (L15M08S-1) ......................................... 226

Figure 4-87: Entire stress strain response (L15M12S-1) .................................................. 229 
Figure 4-88: Stress strain response prior to yielding of reinforcing steel (L15M12S-1).......... 229

Figure 4-89: Average \& maximum crack widths (L15M12S-1) ........................................... 229

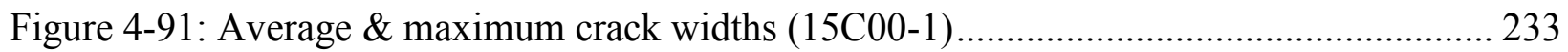

Figure 4-90: Stress strain response throughout cycling(15C00-1) ....................................... 233

Figure 4-92: Stress strain response throughout cycling (15C04S-1) ..................................... 236

Figure 4-93: Average \& maximum crack widths (15C04S-1) .............................................. 236

Figure 4-94: Stress strain response throughout cycling (15C08S-1) ..................................... 239

Figure 4-95: Average \& maximum crack widths (15C08S-1)........................................... 239

Figure 4-96: Stress strain response throughout cycling (15C12S-1) .................................. 242

Figure 4-97: Average \& maximum crack widths (15C12S-1) ......................................... 242

Figure 4-98: Stress strain response throughout cycling (20C00-1) ....................................... 245

Figure 4-99: Average \& maximum crack widths (20C00-1) ............................................ 245

Figure 4-100: Stress strain response throughout cycling (20C04S-1) ................................... 248

Figure 4-101: Average \& maximum crack width (20C04S-1) ............................................. 248

Figure 4-102: Stress strain response throughout cycling (20C08S-1) .................................. 251

Figure 4-103: Average \& maximum crack widths (20C08S-1).......................................... 251

Figure 4-104: Stress strain response throughout cycling (20C12S-1) .................................... 254

Figure 4-105: Average \& maximum crack widths (20C12S-1) ............................................. 254

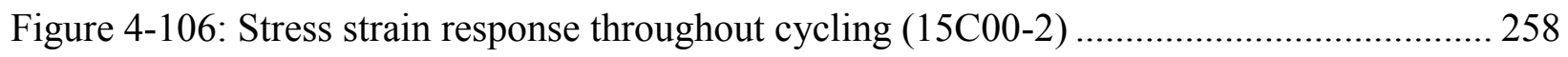

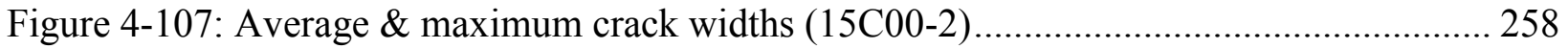

Figure 4-108: Stress strain relationship throughout cycling (15C04S-2) ............................. 261

Figure 4-109: Average \& maximum crack widths (15C04S-2)......................................... 261

Figure 4-110: Stress strain response throughout cycling (15C08S-2) ................................... 264

Figure 4-111: Average \& maximum crack widths (15C08S-2) ............................................. 264

Figure 4-112: Stress strain response throughout cycling (15C12S-2) .................................... 267

Figure 4-113: Average \& maximum crack widths (15C12S-2) ......................................... 267

Figure 4-114: Stress strain response throughout cycling (20C00-2) ..................................... 270

Figure 4-115: Average \& maximum crack widths (20C00-2) ........................................... 270

Figure 4-116: Stress strain response throughout cycling (20C04S-2) ................................... 273

Figure 4-117: Average \& maximum crack widths (20C04S-2)............................................ 273

Figure 4-118: Stress strain response throughout cycling (20C08S-2) ................................. 276

Figure 4-119: Average \& maximum crack widths (20C08S-2) ........................................ 276

Figure 4-120: Stress strain response throughout cycling (20C12S-2) ..................................... 279

Figure 4-121: Average \& maximum crack widths (20C12S-2) ........................................... 279

Figure 5-1: Stress strain response of $15 \mathrm{M}$ series prior to yielding of reinforcing bar .............. 283

Figure 5-2: Stress strain response of 15M series after yielding of reinforcing bar.................. 284

Figure 5-3: Percent increase in stress vs. bare bar response at 0.002 strain for $15 \mathrm{M}$ series ....... 284

Figure 5-4: Average crack widths as a function of strain for 15M specimens ....................... 286

Figure 5-5: Maximum crack widths as a function of strain for 15M specimens ..................... 286

Figure 5-6: Stress strain response of 20M series prior to yielding of reinforcing bar .............. 289 
Figure 5-7: Stress strain response of 20M series after yielding of reinforcing bar.................. 290

Figure 5-8: Percent increase in stress vs. bare bar response at 0.002 strain for 20M series ....... 290

Figure 5-9: Average crack widths as a function of strain for 20M specimens ........................ 292

Figure 5-10: Maximum crack widths as a function of strain for 20M specimens ................... 292

Figure 5-11: Stress strain response of specimens with no fibres prior to yield ....................... 295

Figure 5-12: Stress strain response of specimens with 1.2\% ZP305 fibres prior to yield ......... 295

Figure 5-13: Average and maximum crack widths at stresses of $240 \mathrm{MPa}$ and $360 \mathrm{MPa}$ as a

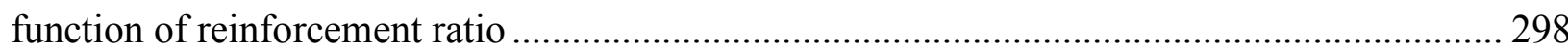

Figure 5-14: Stress strain response of specimens with different fibre types .......................... 301

Figure 5-15: Percent increase in stress over bare bar response at a strain of 0.002 for different

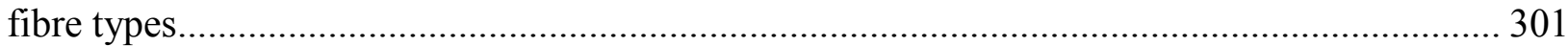

Figure 5-16: Average crack width as a function of stress to compare effect of fibre type ........ 304

Figure 5-17: Maximum crack width as a function of stress to compare effect of fibre type...... 304

Figure 5-18: Stress strain response of specimens containing no fibres and different unit types 307

Figure 5-19: Stress strain response of specimens containing 0.4\% ZP305 and different unit types

Figure 5-20: Stress strain response of specimens containing 0.8\% ZP305 and different unit types

Figure 5-21: Stress strain response of specimens containing 1.2\% ZP305 and different unit types

Figure 5-22: Grout core cross sectional areas .................................................................. 309

Figure 5-23: Stress strain response of lintel unit specimens ............................................. 311

Figure 5-24: Average crack widths as a function of steel stress for standard and lintel unit

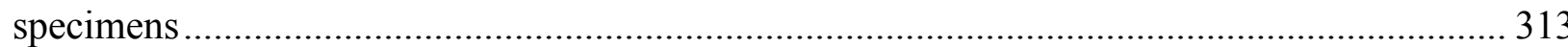

Figure 5-25: Grout core cracking behaviour with varying fibre content .............................. 313

Figure 5-26: Maximum crack widths as a function of steel stress for standard and lintel unit

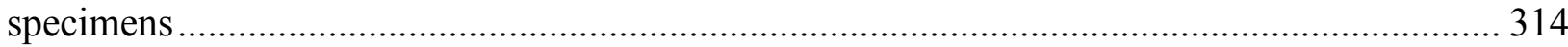

Figure 5-27: Stress strain response of 15M specimens under cyclic load at service loads ........ 316

Figure 5-28: Average stiffness of 15M specimens under cyclic load in the service load range. 317

Figure 5-29: Stress strain response of 15M specimen with no fibres under cyclic load at high

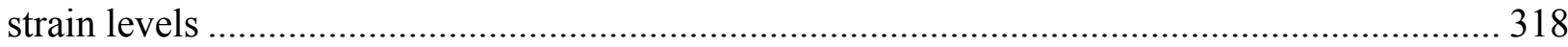

Figure 5-30: Stress strain response of $15 \mathrm{M}$ specimen with $0.4 \%$ ZP305 fibres under cyclic load at

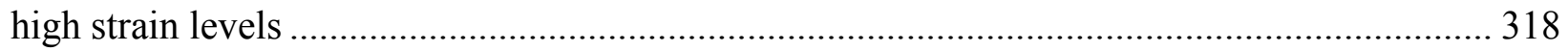

Figure 5-31: Stress strain response of $15 \mathrm{M}$ specimen with $0.8 \%$ ZP305 fibres under cyclic load at

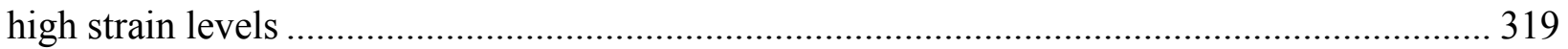

Figure 5-32: Stress strain response of 15M specimen with 1.2\% ZP305 fibres under cyclic load at high strain levels ........................................................................................................... 319

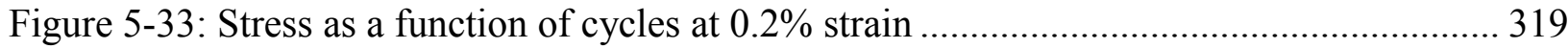

Figure 5-34: Stress as a function of cycles at $0.4 \%$ strain ................................................. 320

Figure 5-35: Stress as a function of cycles at $0.6 \%$ strain ................................................. 320 
Figure 5-36: Average crack width after cycling vs. monotonic at $180 \mathrm{MPa}$.......................... 323

Figure 5-37: Average crack width after cycling vs. monotonic at $240 \mathrm{MPa}$.......................... 324

Figure 5-38: Average crack width after cycling vs. monotonic at $360 \mathrm{MPa}$........................... 324

Figure 5-39: Maximum crack width after cycling vs. monotonic at $180 \mathrm{MPa}$....................... 324

Figure 5-40: Maximum crack width after cycling vs. monotonic at $240 \mathrm{MPa}$........................ 325

Figure 5-41: Maximum crack width after cycling vs. monotonic at $360 \mathrm{MPa}$......................... 325

Figure 5-42: Stress strain response of $15 \mathrm{M} \& 20 \mathrm{M}$ specimens with no fibres cycled at service

loads

Figure 5-43:Stress strain response of $15 \mathrm{M} \& 20 \mathrm{M}$ specimens with $0.4 \%$ ZP305 fibres cycled at service loads...

Figure 5-44: Stress strain response of $15 \mathrm{M} \& 20 \mathrm{M}$ specimens with $0.8 \%$ ZP305 fibres cycled at

service loads....

Figure 5-45: Stress strain response of $15 \mathrm{M} \& 20 \mathrm{M}$ specimens with $1.2 \%$ ZP305 fibres cycled at service loads. 330

Figure 5-46: Average modulus on final reload vs. steel stress for specimens with varying reinforcement ratios

Figure 5-47: Stress strain response for specimens with no fibres under cyclic load in the postyield range

Figure 5-48: Stress strain response for specimens with 0.4\% ZP305 fibres under cyclic load in the post-yield range.

Figure 5-49: Stress strain response for specimens with 0.8\% ZP305 fibres under cyclic load in the post-yield range. 334

Figure 5-50: Stress strain response for specimens with 1.2\% ZP305 fibres under cyclic load in the post-yield range 334

Figure 5-51: Average modulus on final reload vs. strain subjected cyclically in the post-yield range. 337

Figure 5-52: Average crack width after cycling vs. steel stress for 15M and 20M specimens .. 339 Figure 5-53: Maximum crack width after cycling vs. steel stress for 15M and 20M specimens 340 Figure 5-54: Proposed tension stiffening equation for reinforced masonry (no fibres) ............ 344 Figure 5-55: Proposed tension stiffening equation for reinforced masonry $(0.4 \%$ ZP305)....... 345 Figure 5-56: Proposed tension stiffening equation for reinforced masonry $(0.8 \%$ ZP 305)....... 346 Figure 5-57: Proposed tension stiffening equation for reinforced masonry $(1.2 \%$ ZP305)....... 347 


\section{LIST OF TABLES}

Table 2-1: Minimum compressive strength of mortar from CSA A179 ……............................. 30

Table 2-2: Volumetric proportions for fine and coarse grout from CSA A179.......................... 31

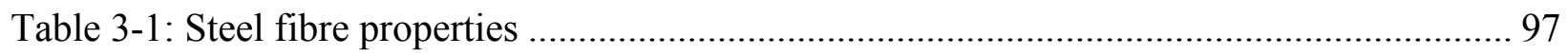

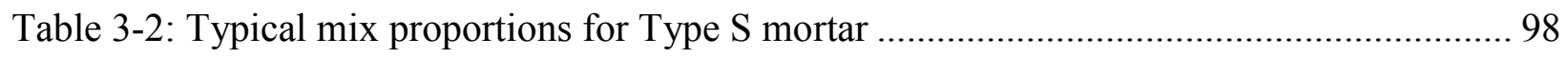

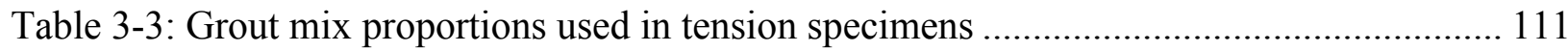

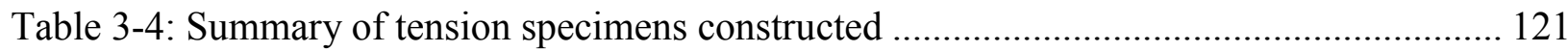

Table 4-1: Summary of grout cylinder compressive strength and displacement at failure ........ 141

Table 4-2: Average tensile splitting force of grout cylinders .................................................. 143

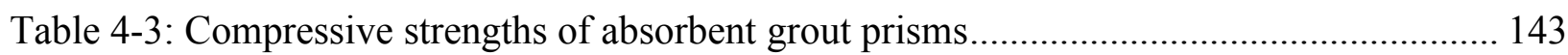

Table 4-4: Average compressive strengths of Type S mortar............................................... 145

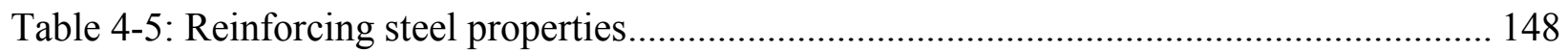

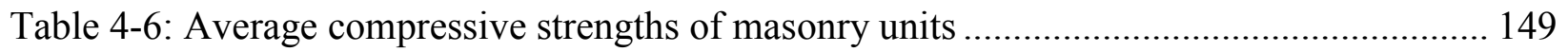

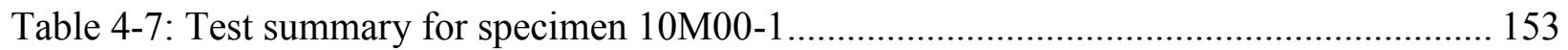

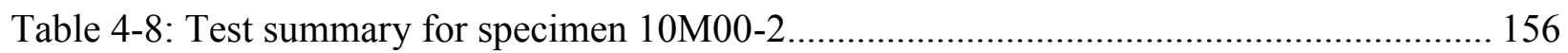

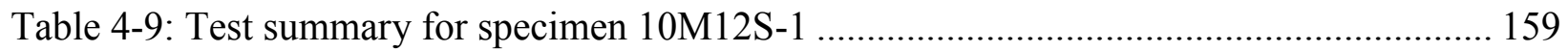

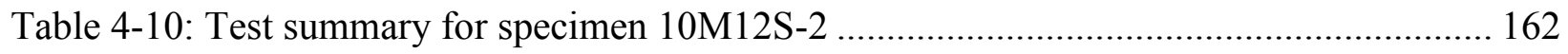

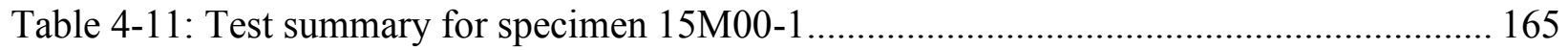

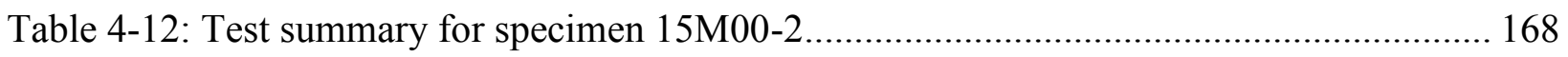

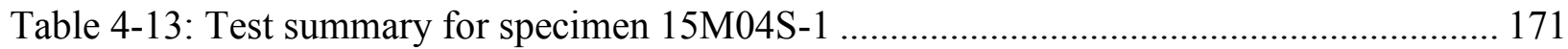

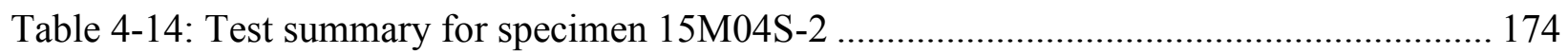

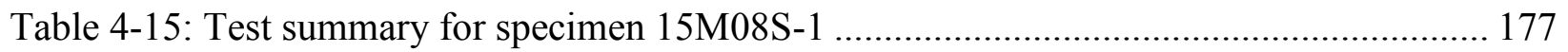

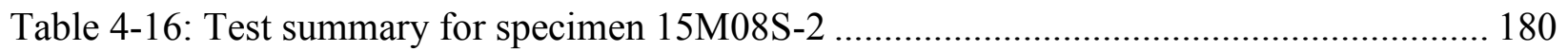

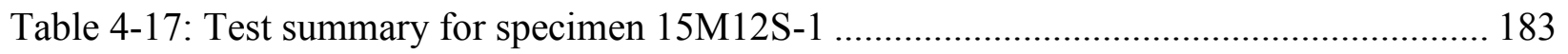

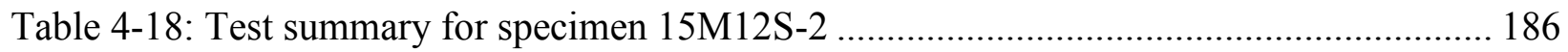

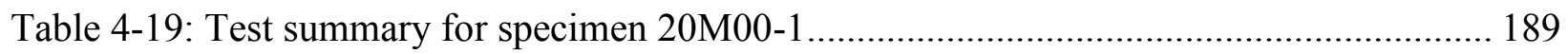

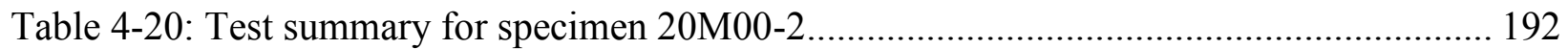

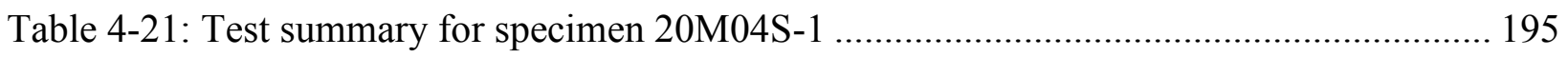

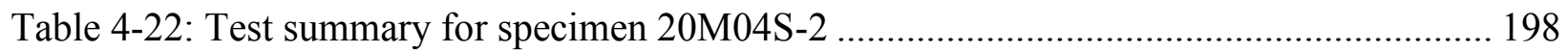

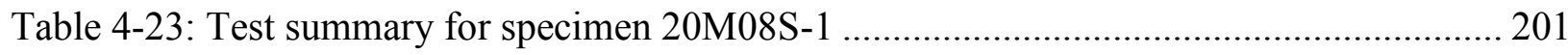

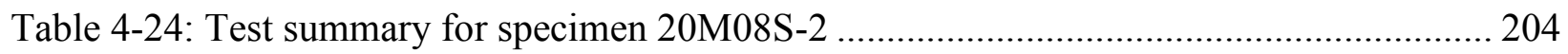

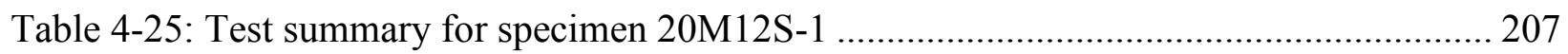

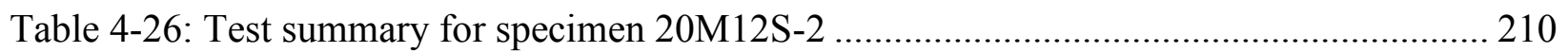

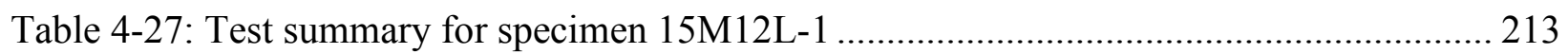

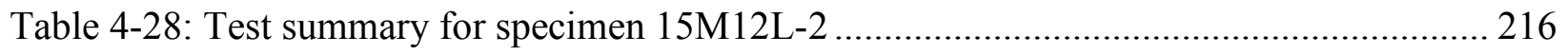

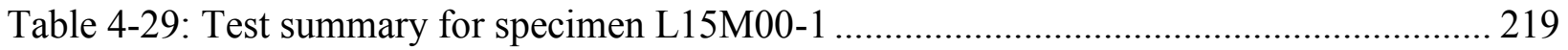

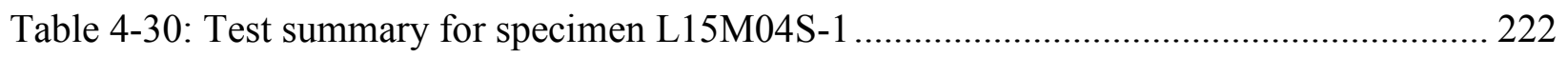

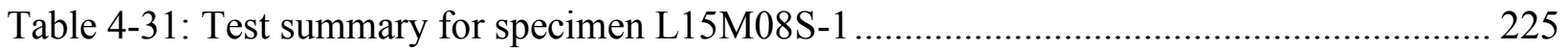

Table 4-32: Test summary for specimen L15M12S-1 ......................................................... 228 
Table 4-33: Test summary for specimen 15C00-1 ........................................................... 232

Table 4-34: Test summary for specimen 15C04S-1 ........................................................ 235

Table 4-35: Test summary for specimen 15C08S-1 .......................................................... 238

Table 4-36: Test summary for specimen 15C12S-1 ......................................................... 241

Table 4-37: Test summary for specimen 20C00-1 ................................................................. 244

Table 4-38: Test summary for specimen 20C04S-1 ........................................................ 247

Table 4-39: Test summary for specimen 20C08S-1 .......................................................... 250

Table 4-40: Test summary for specimen 20C12S-1 ............................................................ 253

Table 4-41: Test summary for specimen 15C00-2 ................................................................. 257

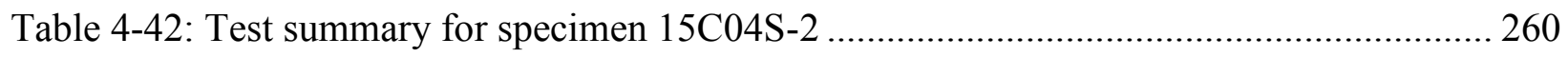

Table 4-43: Test summary for specimen 15C08S-2 ......................................................... 263

Table 4-44: Test summary for specimen 15C12S-2 …........................................................ 266

Table 4-45: Test summary for specimen 20C00-2 ............................................................... 269

Table 4-46: Test summary for specimen 20C04S-2 …....................................................... 272

Table 4-47: Test summary for specimen 20C08S-2 ...................................................... 275

Table 4-48: Test summary for specimen 20C12S-2 ....................................................... 278

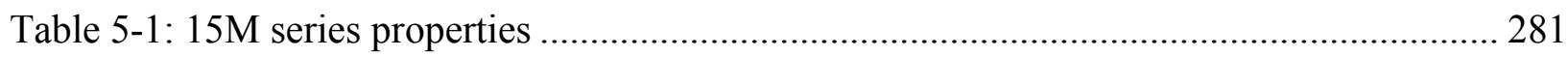

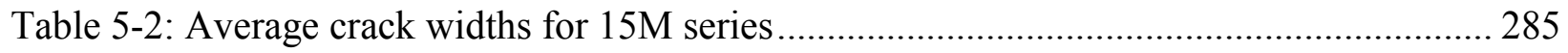

Table 5-3: Maximum crack widths for 15M series............................................................... 285

Table 5-4: Cracking pattern for 15M series at steel stress of 540MPa .................................. 287

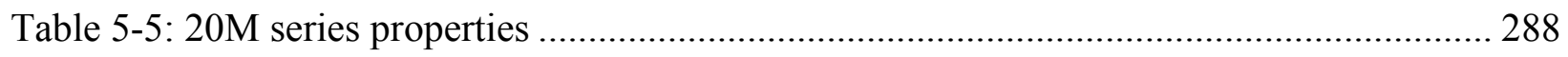

Table 5-6: Average crack widths for 20M series .............................................................. 291

Table 5-7: Maximum crack widths for 20M series.............................................................. 291

Table 5-8: Cracking pattern for 20M series at steel stress of 540MPa ................................. 293

Table 5-9: Properties of specimens used to study effect of reinforcement ratio ...................... 294

Table 5-10: Average crack widths of specimens to investigate effect of reinforcement ratio ... 296

Table 5-11: Maximum crack widths of specimens to investigate effect of reinforcement ratio 297

Table 5-12: Crack patterns for specimens with varying reinforcement ratios at a steel stress of

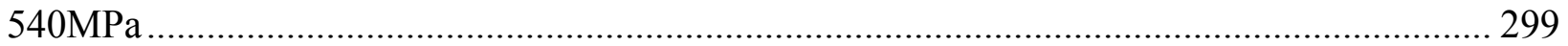

Table 5-13: Average crack widths in specimens with different fibre types ........................... 303

Table 5-14: Maximum crack widths in specimens with different fibre types ......................... 303

Table 5-15: Crack patterns for $30 \mathrm{~mm}$ vs. $60 \mathrm{~mm}$ fibres at a steel stress of 540MPa ................ 305

Table 5-16: Properties of specimens used to study effect of unit type ................................... 306

Table 5-17: Crack patterns of specimens with different unit types ...................................... 310

Table 5-18: Average crack widths for specimens with different unit types ............................ 312

Table 5-19: Maximum crack widths for specimens with different unit types ........................ 312

Table 5-20: Summary of performance of 15M specimens under cyclic load in the service range

Table 5-21: Summary of performance of 15M specimens under cyclic load in the post-yield range. 
Table 5-22: Stress at given strain levels before and after cycling ....................................... 321

Table 5-23: Stress at given strain levels under monotonic load ............................................. 322

Table 5-24: Average and maximum crack widths after cycling at service loads .................... 322

Table 5-25: Average and maximum crack widths under monotonic load at equivalent stresses 323

Table 5-26: Crack patterns after cycling at service loads vs. monotonic ................................. 326

Table 5-27: Summary of performance of $15 \mathrm{M}$ and 20M specimens under cyclic load at service

loads

Table 5-28: Summary of performance of specimens with different reinforcement ratios under cyclic loads in the post-yield range.

Table 5-29: Stress levels before and after cycling at strain levels exceeding yield strain for 15M specimens

Table 5-30: Stress levels before and after cycling at strain levels exceeding yield strain for 20M specimens 336

Table 5-31: Average and maximum crack widths of 15M after cyclic loading in the service load range. 338

Table 5-32: Average and maximum crack widths of 20M after cyclic loading in the service load

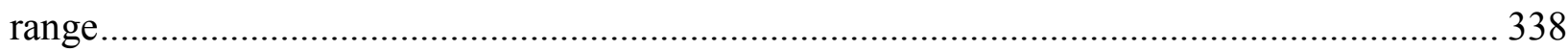

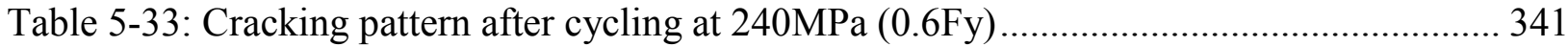

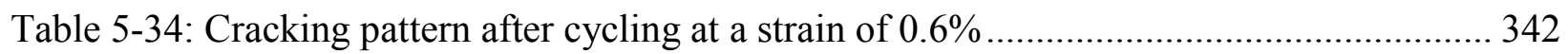

Table 5-35: Sample tension stiffening calculations for 15M specimens (no fibres) ................. 344

Table 5-36: Sample tension stiffening calculations for 15M specimens (0.4\% ZP305) ........... 345

Table 5-37: Sample tension stiffening calculations for 15M specimens (0.8\% ZP305) ........... 346

Table 5-38: Sample tension stiffening calculations for 15M specimens (1.2\% ZP305) ........... 347

Table 5-39: Summary of proposed tension stiffening equations for reinforced masonry with or without steel fibres 


\section{Introduction}

\subsection{General Introduction}

Modern Canadian reinforced masonry construction typically consists of hollow concrete blocks bonded together with mortar and reinforced in the horizontal and vertical directions with rebar placed in the voids. These rebars are bonded to the concrete blocks by grout which is pumped into the voids after the structural element has been assembled.

In many ways, masonry is fundamentally similar to concrete, however it exhibits a significantly lower tensile strength. Tensile strengths for reinforced masonry are typically in the range of 0.4 to $0.8 \mathrm{MPa}$, whereas tensile strengths for concrete range from about 2 to $3 \mathrm{MPa}$. Masonry is brittle in tension much like concrete. As such, reinforcing the material in tension is critical. A difference between the two materials is that reinforcement is significantly harder to place within masonry than in concrete. The concrete blocks act as obstructions to the reinforcement and do not allow traditional reinforcement cages to be constructed and placed easily within an element. An additional difference between reinforced masonry and reinforced concrete construction is the level of ductility that can be achieved when designing elements for seismic resistance. Generally reinforced masonry elements have less ductility than equivalent concrete elements due to the inability to provide adequate confinement to concrete in compression.

In order to improve the tensile strength of reinforced masonry and reduce rebar requirements, perhaps fibre reinforced grout can be used. Furthermore, fibre-reinforced concrete has been shown to have enhanced ductility when compared to regular concrete (Johnston and Coleman (1974)), hence it is possible that some of these benefits can be added to masonry if fibre-reinforced grout is used. Some of the notable benefits of adding fibre reinforcement to concrete are that it improves the cracking resistance, reduces crack widths, it improves the ductility of the member, and it improves the shear and moment resistance of a member. In reinforced concrete at locations where high stresses occur such as beam-column connections, reinforcement can become congested, however the use of fibre reinforced concrete can reduce 
the main reinforcement requirements thus alleviating the congestion. It is thought that the use of fibre-reinforced grout could likewise reduce the challenges of placing rebar within reinforced masonry by reducing rebar requirements.

This thesis will investigate the advantage/benefits of using fibre reinforced grout in reinforced concrete masonry.

\subsection{Research Objectives}

The objective of this research is to investigate the influence of steel fibre reinforced grout on the overall tensile performance of reinforced masonry as well as to investigate the degree to which the tension stiffening behavior is enhanced by the addition of steel fibres to the grout.

Through the experimental testing of a series of 42 direct tension specimens, tested under both monotonic and cyclic loading, variables such as bar diameter, fibre volume fraction, fibre length, and unit type will be investigated to determine their influence on the tension stiffening behavior.

With the experimental data collected, an equation describing the tension stiffening behavior of fibre reinforced structural masonry will be developed. With the added performance achieved by the addition of steel fibres within the grout matrix, the viability of masonry as a competitive structural material can be increased.

A layout of the five chapters included in this thesis is shown in Figure 1-1. 


\section{Chapter 2: Literature Review}

-Discusses the previous research conducted on fibre reinforced concrete, the tension stiffening effect in concrete, and the tension stiffening effect in masonry

\section{Chapter 3: Experimental Program}

-Discusses the experimental program on 42 direct tension specimens including materials, construction, test setup and instrumentation

\section{Chapter 4: Experimental Results}

-Dicusses the results of the experimental program including material strength testing and tensile specimen testing

\section{Chapter 5: Discussion of Experimental Results}

-Discusses the experimental results and the influence of various test parameters on the tensile performance of the specimens. An equation for the tension stiffening effect in fibre reinforced concrete masonry is proposed

\section{Chapter 6: Conclusion and Recommendations}

-Discusses the conclusions drawn from the research and proposes recommendations for future research

Figure 1-1: Thesis layout 


\section{Literature Review}

\subsection{Overview}

In this section, a detailed review of fibre reinforced concrete (FRC) technologies will be presented. Although the thesis is focused on fibre reinforced grout (FRG) technologies, there has not been a significant amount of research conducted in this area, and for this reason FRC technologies will be discussed as they are closely related to FRG. Although not currently accepted by many widely recognized national reinforced concrete codes such as CSA A23.3 (CSA Committee A23.3 (2014)), it has been widely researched and proven that discontinuous fibres within the concrete matrix positively influence the behavior and strength of reinforced concrete elements (Bischoff (2003)). These positive influences can include increased strength, increased post-cracking stiffness, enhanced energy absorption characteristics and improved response to cyclic loads. Another notable benefit of fibre reinforcement is that service load deflections can be limited by decreasing crack widths and enhancing the stiffness of concrete in tension. Fibres have been shown to be a viable complement to traditional reinforcement to increase tensile performance and hence reduce reinforcement requirements in various structural applications. ACI 318 permits the use of steel fibres in place of minimum stirrups, for example, as shear reinforcement (ACI Committee 318 (2008)).

In addition to a discussion of FRC, the tension stiffening effect as studied in reinforced concrete will be reviewed and its applicability to reinforced concrete masonry will be analyzed. As there is not a great deal of published research in the area of tension stiffening in reinforced concrete masonry, tension stiffening behavior in reinforced concrete will be reviewed in relation to the work being conducted herein. Although localized strain will happen at the precise crack location, the bond between the main reinforcement and the concrete matrix also causes tension to develop in the un-cracked concrete regions. This phenomenon is largely due to the mechanical interaction of the bar deformations with the surrounding concrete although there is also a certain portion of the tensile load that is carried by the adhesion between the matrix and the bar itself. The average stiffness of the cracked composite member is increased as compared with the 
reinforcing bar alone. This phenomenon and behavior which is exhibited in reinforced concrete and masonry when subjected to axial tension is termed "tension stiffening"

\subsection{Masonry}

\subsubsection{Introduction to Masonry}

Masonry is one of humanity's oldest building materials. Collectively, masonry construction consists of structural or other building elements built with stone, tile, concrete blocks, clay blocks, concrete bricks, clay bricks of mud/adobe bricks, or varying combinations thereof, typically bonded together using mortar and/or grout, and often reinforced using steel reinforcement. The International Building Code (IBC (2009)), for example defines masonry as "a built-up construction or combination of building units or materials of clay, shale, concrete, glass, gypsum, stone or other approved units bonded together with or without mortar or grout or other accepted methods of joining”.

The most common type of new masonry construction in Canada for structural applications consists of concrete block assemblies using hollow units such as those illustrated in Figure 2-1. These assemblies may or may not be reinforced with steel rebars within the hollow cores, with the cores being grouted after the rebar have been placed. Concrete block assemblies also find widespread use in non structural applications such as partition walls. Stone and clay brick units see widespread use as veneer walls, but few new buildings are built using stone and brick for structural elements. 


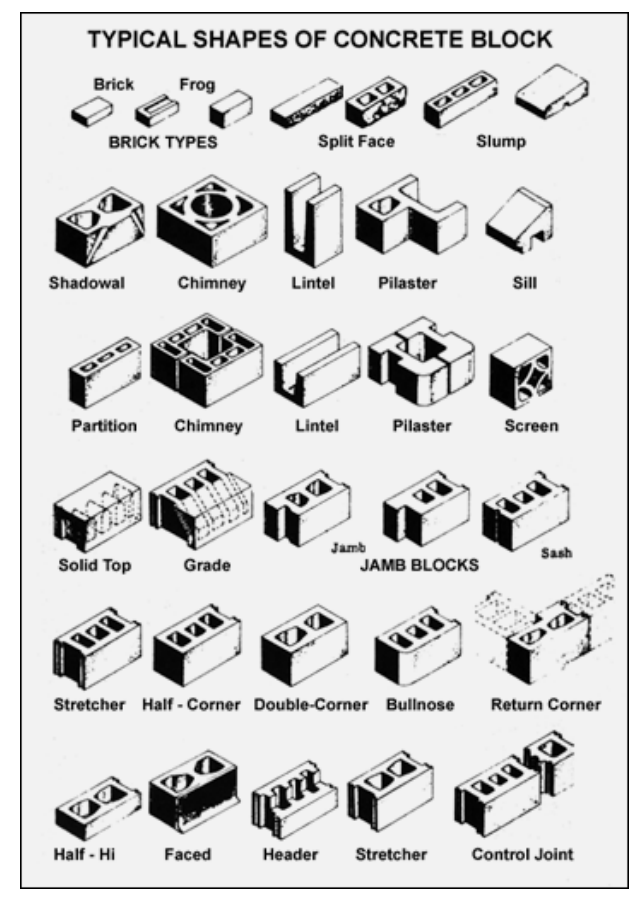

Figure 2-1: Typical concrete units available in the construction market

[Adapted from Delhi (2013)]

Concrete block masonry units are available in a variety of shapes and sizes and are premanufactured in a controlled plant facility. They can be ordered in a range of dimensions as well as specified compressive strengths. Concrete masonry units are held together by mortar which is placed on the areas between the units. The mortar is usually mixed on site and is a mixture of sand, Portland cement, lime and water. The mix proportions vary slightly, and the amount of water is often governed by the mason's desire for workability. The quality control of the mortar is assured by testing mortar cubes under a standard compression test. Different mortar strengths are used for structural versus non-structural applications.

Masonry voids are often filled with a flowable grout. This grout behaves much like concrete, and is a mixture of water, Portland cement, and either fine aggregate, or both fine and coarse aggregate. Masonry grout is fundamentally a high slump concrete where the main concern is its flowability because it is crucial that there are no voids when the grout is poured into voids, especially around the reinforcement. The grout serves to bond the rebar to the masonry units when creating flexural or axial elements such as beams, columns or walls. 
Some basic masonry terminology is provided in Figure 2-2. Reinforced concrete is a composite material made up of two materials (concrete and steel), whereas reinforced masonry is a more complex composite material consisting of 4 constituent materials (masonry units, grout, mortar, and steel). Blocks are typically laid in a running bond pattern whereby the units in consecutive courses are offset by half a masonry unit as seen in Figure 2-2. A "head joint" refers to the mortar joints between the ends (heads) of the units. A "bed joint" refers to the mortar joint between the tops and bottoms of the units in consecutive courses. In addition, a cell is the void in the middle of the masonry unit in which reinforcement and/or grout can be placed.

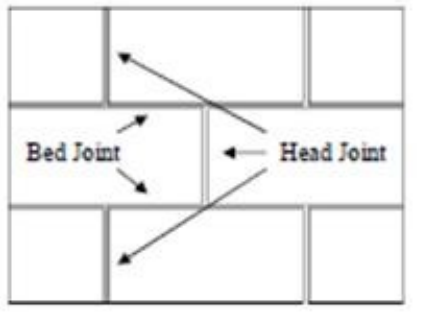

(a) Wall section with running bond

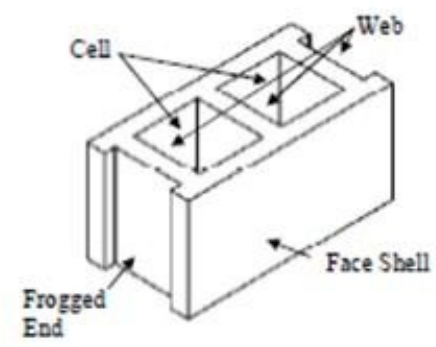

(b) Stretcher block

Figure 2-2: Basic Concrete Masonry Unit Terminology

[Adapted from Ring (2009)]

\subsubsection{Reinforced Masonry Materials}

\subsubsection{Hollow Load-Bearing Concrete Units}

Today, the most common type of hollow load-bearing concrete masonry unit (CMU) is cast with two full cores and varying overall dimensions. This unit is called a standard stretcher unit. Standard widths of units are $90 \mathrm{~mm}, 140 \mathrm{~mm}, 190 \mathrm{~mm}, 240 \mathrm{~mm}$, and $290 \mathrm{~mm}$. The compressive strength of the units usually ranges from 10-40 MPa. When specifying a block size, it is customary to give the width, height and length of the unit in that order (Figure 2-1). For example, 190x190x190mm units will be used in building the direct tension test specimens for this research. 


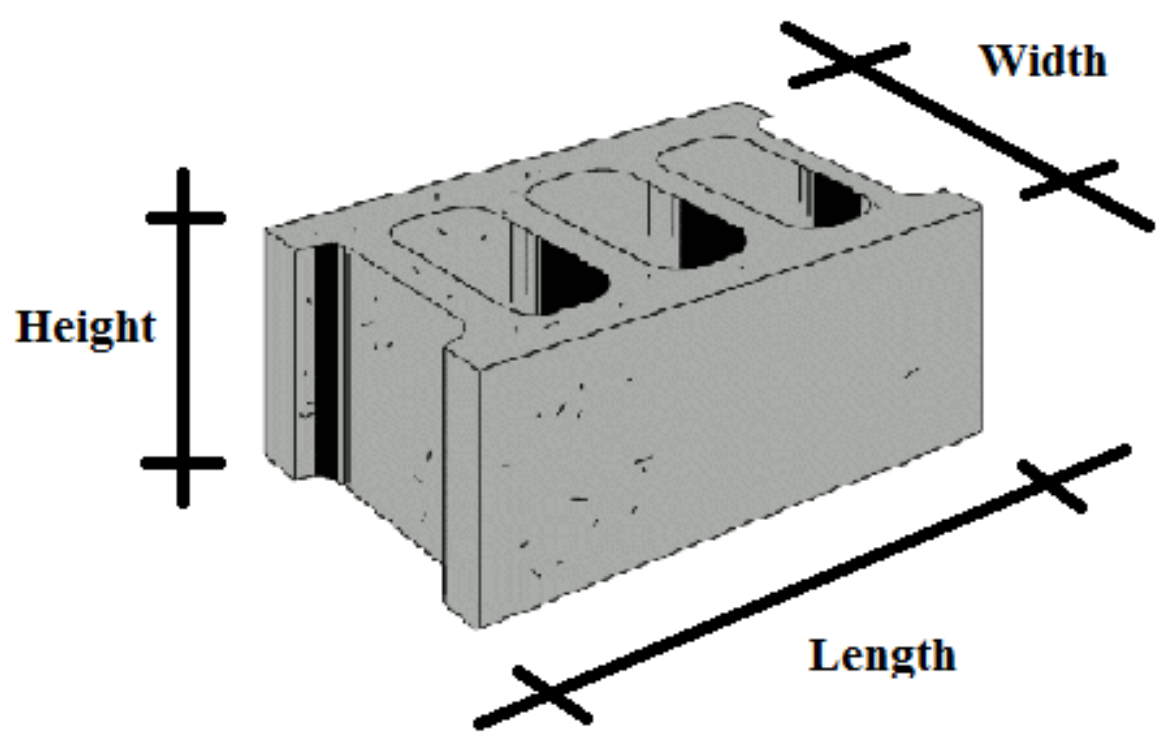

Figure 2-3: Standard Stretcher CMU

CMU manufacturing plants are often highly automated. The blocks are made primarily of Portland cement, aggregate and water however other types of materials are often added to the concrete mix such as fly ash of blast furnace slag. Zero slump concrete is used to manufacture CMUs, wherein the concrete is pressed into molds and vibrated extensively to achieve smooth sides. This dry cast concrete process is beneficial as high early strength can be achieved and the plant can turn over the concrete units much quicker. Accelerated curing processes are used whereby the fresh concrete elements are covered with a tarp and are exposed to either high or low pressure steam.

Concrete masonry units are classified by CSA A165.1 and the classification is based on solid content, compressive strength, density, and moisture control (CSA Committee A165.1 (2009)). Blocks must be tested and verified by analysis to prove that they meet safety and serviceability requirements of CSA S304.1 if they are being used in a structural application (Drysdale and Hamid (2005), CSA Committee S304.1 (2004)). Hollow blocks are advantageous over solid blocks because of their reduced weight, ease of handling and ease of placing of the reinforcement however other design criteria should be considered as well. The percent of the block which is solid in relation to the entire cross section of the block is usually about $50-60 \%$ for hollow blocks. 


\subsubsection{Mortar}

Mortar is a mixture of cement, fine aggregate, lime, and water and is used to bond masonry units together along bed joints and head joints. It connects the units together and allows the top block to bear uniformly on the bottom block and transfer the structural loads which are imposed upon it. Also, the mortar joint which is typically $10 \mathrm{~mm}\left(3 / 8^{\prime \prime}\right)$ wide provides weather tightness to the masonry assemblage and therefore it must often withstand harsh environmental conditions in addition to the imposed structural load. The mortar joint provides an area whereby the masonry designer can specify joint reinforcement which typically has a diameter of less than $10 \mathrm{~mm}$ so that it can be contained within the joint. It should also be noted that the mortar joint thickness will have slight variations due to the workmanship of the mason as well as due to the minor variations in the dimensions of the interlocking blocks.

Mortar is typically made by mixing pre-specified proportions of cement, sand, lime and water. The water is added to the fresh mix in order to attain the desired workability by the masonry contractor. The cement gives the mixture strength, the lime workability, and the sand acts as inexpensive filler (Drysdale and Hamid (2005)).

Mortar design and use in Canada is governed by CSA Code A179 (CSA Committee A179 (2009)). The different types of mortar are defined by the relative volumes of the constituent materials. In the new edition of the CSA A179 published in 2004, it was determined that only two types of masonry mortar were required in modern day masonry construction in Canada. These two types are Type $\mathrm{S}$ and Type N. Type $\mathrm{S}$ is intended for structural applications and Type $\mathrm{N}$ is intended for non-structural applications or when high compressive and lateral strengths are not required (Drysdale and Hamid (2005)).

Mortar can be prescribed according to CSA A179 by either the property specification or the proportion specification. The proportion specification is prescriptive in nature and prescribes mortar based on specific proportions of materials as well as standard mixing procedures. This method lends itself well to standard construction and when standard materials are available to the contractor. Whenever standard materials are not available to the contractor and alternate materials or mixing procedures must be used, the performance based property specification can 
be used. As long as the structural performance of the given mix and mixing procedure can be scientifically demonstrated, the mix will be approved for use. The code does not allow for interplay between the property and proportion specifications, meaning that only one may be chosen for the given design (Drysdale and Hamid (2005)).

Mortar is commonly tested during the mixing process for workability by means of an apparatus called a flow table. The flow table imparts an impact force to the table by cranking a rotating cam. This impact causes the mortar to consolidate and the respective workability can be observed.

The most common measure of a mortar performance is a simple compression test. Mortar cubes $50 \mathrm{~mm} \times 50 \mathrm{~mm} \times 50 \mathrm{~mm}$ are taken from the fresh mortar mix and are allowed to cure for either 7 or 28 days. At this time they are tested in compression and the compressive strength of the mortar can be calculated.

Table 2-1 summarizes the strength required when obtained from compression tests on standard mortar cubes at the respective time intervals by CSA A179. Other types of mortar such as types $\mathrm{M}, \mathrm{O}$ and $\mathrm{K}$ have been omitted from this discussion as they are not currently recognized as modern mortar mixes. If a restoration project is being undertaken however, in situ tests and analysis should be conducted to understand the type of mortar that was used.

Table 2-1: Minimum compressive strength of mortar from CSA A179

[Adapted from Drysdale and Hamid (2005)]

\begin{tabular}{|c|c|c|c|c|}
\hline \multirow{2}{*}{ Mortar Type } & \multicolumn{4}{|c|}{ Minimum Compressive strength (MPa) } \\
\cline { 2 - 5 } & \multicolumn{2}{|c|}{ 7 Day Test } & 28 Day Test \\
\cline { 2 - 5 } & Job Site & Laboratory & Job Site & Laboratory \\
\hline $\mathrm{S}$ & 5 & 7.5 & 8.5 & 12.5 \\
\hline $\mathrm{N}$ & 2 & 3 & 3.5 & 5 \\
\hline
\end{tabular}


Grout is a highly flowable mix of cementitious materials, aggregate, and water and is commonly pumped or poured into hollow block concrete masonry construction. Grouting the cells in a masonry element will serve to bond reinforcement contained within the cells to the surrounding masonry units (Drysdale and Hamid (2005)). The reinforcement can either be placed horizontally in lintel, knock-out or depressed web units or placed vertically where hollow cells in successive courses line up.

The grout differs primarily from traditional concrete in that it has a much higher slump, usually in the range of $200-250 \mathrm{~mm}$. This high slump is required because the cavities in which the grout must flow are often very confined and the high slump grout assures that there will be no voids left in the masonry element (Sherwood (2011)). Also, the concrete masonry units have the capability to absorb a large volume of water after pouring which reduces the water cement ratio in the grout hence increasing the grout strength.

Grouts are a mix of water, Portland cement, and either fine aggregate, or both fine and coarse aggregate. The recommended volumetric proportions based on grout type are summarized in Table 2-2 below:

Table 2-2: Volumetric proportions for fine and coarse grout from CSA A179 [Adapted from Drysdale and Hamid (2005)]

\begin{tabular}{|c|c|c|c|c|}
\hline \multirow{2}{*}{ Grout Type } & \multicolumn{4}{|c|}{ Parts by Volume } \\
\cline { 2 - 5 } & Portland & Hydrated Lime or & \\
\cline { 4 - 5 } & Cement & Lime putty & Fine aggregate & Coarse aggregate \\
\hline Fine & 1 & $0-1 / 10$ & 2.25 to 3 & 0 \\
\hline Coarse & 1 & $0-1 / 10$ & 2.25 to 3 & 1 to 2 \\
\hline
\end{tabular}

Usually a fine grout is preferred versus a coarse grout due to the fact that typically the voids within the masonry are small and can be made even smaller by the protrusions of mortar fins extending from the mortar joints into the grout columns. If the grout spaces are deemed to be 
large enough, however, the designer may choose to specify a coarse grout where the maximum aggregate size is generally no larger than $10 \mathrm{~mm}$.

Admixtures can be added to grout to reduce the effects of shrinkage as well as to increase the workability of the fresh grout mix. Typically, admixtures would contain a slightly expansive agent which causes the grout to expand within the wall hence counteracting the shrinkage effects as the water is absorbed into the masonry units. Also, a water-reducing admixture can be used to reduce the water cement ratio while still keeping the same workability however the designer must be careful to ensure that the water cement ratio is not reduced so significantly that the stiffness of the grout becomes noticeably large.

The compressive strength of grouted masonry is not highly dependent on the compressive strength of the grout (Drysdale and Hamid (2005)).. This is a common misconception of many designers as often the grout strength is specified to match the compressive strength of the masonry $\mathrm{f}_{\mathrm{m}}$. The most important characteristic of the grout is that it is highly flowable (Sherwood (2011)). If the grout is not highly flowable due to reductions in water to attain higher strengths, there is a large risk that there will be regions in the masonry which end up ungrouted and this is extremely undesirable. The in-situ strength of grout is much higher than the cylinder strength of grout since cylinder moulds are non-absorbent and do not accurately simulate the behavior of grout inside masonry elements. Often, the in-situ strength is up to $50 \%$ larger than the cylinder strength due to the decrease in water cement ratio of the grout when the water is absorbed by the units (Drysdale and Hamid (2005)). One way to simulate the in-situ strength, other than extracting grout cores from a masonry unit, is to cast grout samples in absorbent molds. Molds can be lined with paper towel and masonry units can be aligned such that a $89 \mathrm{~mm}$ x $89 \mathrm{~mm} \times 178 \mathrm{~mm}$ sample can be cast (see Figure 2-4). The compressive strength of the sample cast the absorbent mold will be much closer to the true in-situ strength. 


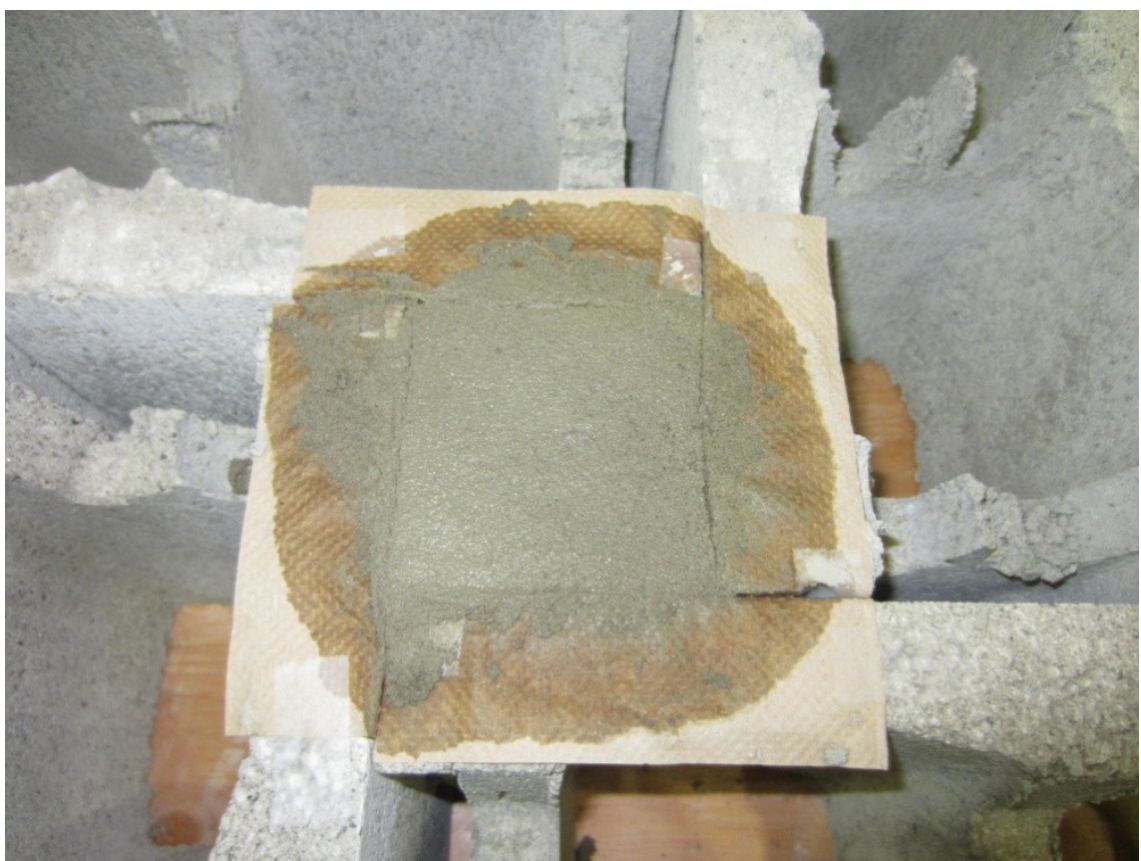

Figure 2-4: Absorbent grout sample cast using masonry units lined with paper

\subsubsection{Reinforcement}

Reinforcement is used in masonry construction much in the same way as it is used in traditional reinforced concrete construction. Reinforcement is used to increase the tensile and shear strengths as well as to render the masonry element more ductile in the event of a seismic load (Drysdale and Hamid (2005)). Crack widths are reduced as well. Additionally, reinforcement can increase the load bearing capacity of a masonry wall.

Currently, reinforcement in masonry construction includes joint reinforcement and reinforcing bars (see Figure 2-5). The reinforcing steel used is the same as that used in reinforced concrete however the difference is that the reinforcing steel must be placed within the voids of a masonry element. Fibre reinforced polymer bars are currently being researched as a possible material for reinforcing masonry (Sherwood and Sarhat (2011)). Currently CSA S304.1 allows the use of fibre reinforced polymer bars in Canadian masonry design.

Joint reinforcement is typically smaller gauge reinforcement that is laid in between consecutive courses in a masonry element. It is typically specified in otherwise unreinforced masonry or in reinforced masonry to satisfy reinforcement spacing requirements in the horizontal 
direction. Due to the fact that the bars are less than $10 \mathrm{~mm}$ in diameter, they can be conveniently be placed within the mortar joint of a wall, significantly improving the out of plane flexural resistance. Joint reinforcement is usually ladder or truss type (Drysdale and Hamid (2005)).. The joint reinforcement is commonly made of wire which has a yield strength exceeding $480 \mathrm{MPa}$. The limited ductility of the wire joint reinforcement is a design concern for areas with high seismic risk, and should be a concern of designers when specifying joint reinforcement.
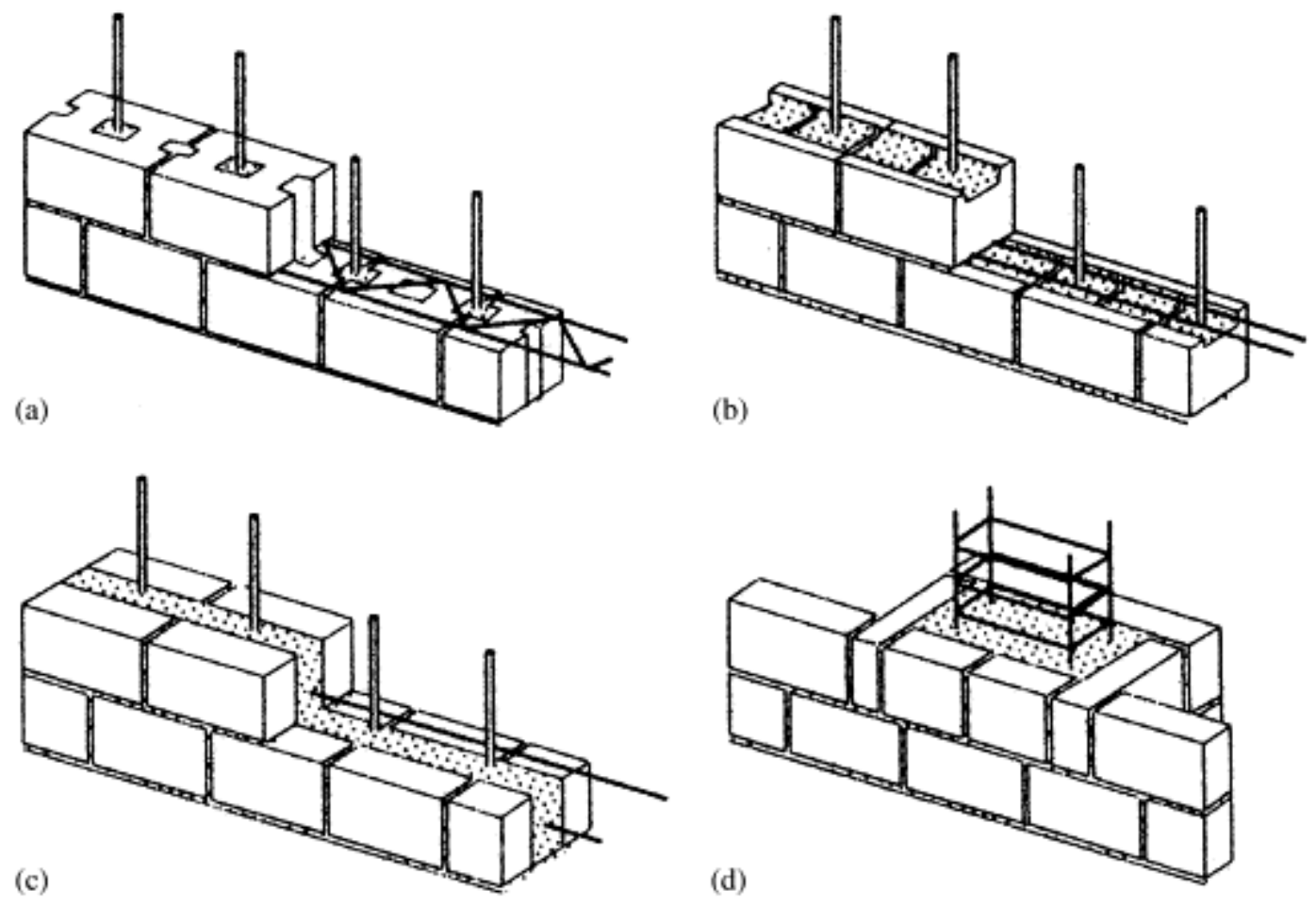

Figure 2-5: Various arrangements of both joint and longitudinal reinforcement in masonry construction Adapted from (Ring (2009))

Reinforcement is also used to control both shrinkage and thermal cracking within a masonry element. Fibre reinforcement will be discussed within this thesis as a possible alternative to traditional steel reinforcement to reduce shrinkage and thermal cracking.

\subsubsection{Masonry Testing and Structural Properties}

The quality of masonry is highly dependent on workmanship. Masonry codes must reflect this fact and take it into account. Inspectors must be vigilant in assuring both the materials 
regulations and the construction practices are strictly followed so that the final product is not only structurally safe, but serviceable as well in terms of durability and other factors. This section will outline some of standard testing procedures which are in place in the CSA codes and others to assure the quality of masonry designs. CSA S304.1 governs the design practices, CSA A179 governs mortar and grout, and CSA A165 governs concrete blocks.

\subsubsection{Concrete Block Properties}

Concrete masonry units are classified based on solid content, compressive strength, density and moisture control.

A concrete masonry unit is considered to be solid if the net area is $100 \%$ of the gross cross sectional area, it is considered semi-solid if the net area is greater than $75 \%$ of the gross cross sectional area and is considered hollow if the net area is less than or equal to $75 \%$ of the gross cross sectional area. Hollow units are by far the most common type of blocks as they are easy to handle, they are lighter, and they are convenient for placing reinforcement within them (Drysdale and Hamid (2005)).

Compression tests on hollow concrete masonry units loaded over the net area result in a conical shear-compression failure, much like concrete cylinders. The compressive strength of hollow blocks tested in this manner range from 10 to $40 \mathrm{MPa}$ and is based on the net area of the block. The modulus of elasticity can be taken as 500-1000 times the unit compressive strength and the Poisson's ratio can be taken as 0.2 . There is no widely accepted way to test concrete masonry units in tension, although the tensile strength is usually in the range of $10-20 \%$ of the compressive strength as is common in concrete.

Although Canadian codes do not explicitly prescribe a method for testing concrete masonry units for absorption, it is a very important quality of the masonry unit. Water must be absorbed from the mortar and grout in order to attain a good bond between the constituent materials, however if too much water is absorbed the mortar and grout can become too stiff and jeopardize the durability of the masonry composite. 


\subsubsection{Mortar Properties}

Quality control measures on mortar are important as mortar is a material that is often mixed on site, with water added to the mortar mix in order for the mortar to reach the desired consistency of the mason. The quality control measures for masonry mortar are to standardize the workability and the strength. The workability is measured by a test performed on a standard mortar flow table and the compressive strength is assessed by performing a standard compression test on standard sized mortar cubes.

The workability must be measured on the job site by the masonry contractor as there is no field test to measure workability. In a laboratory environment, the workability is measured on a mortar flow table (see Figure 2-6). A 100mm diameter standard cone of mortar is placed on the flow table and is subjected to 25 blows imparted to the mortar by a cam on a crank. The mortar flow is usually required to be $100-115 \%$ for typical laboratory made mortar, but mortar flow of up to $130 \%$ may be required for masonry mortar made on the job site (Drysdale and Hamid (2005)).

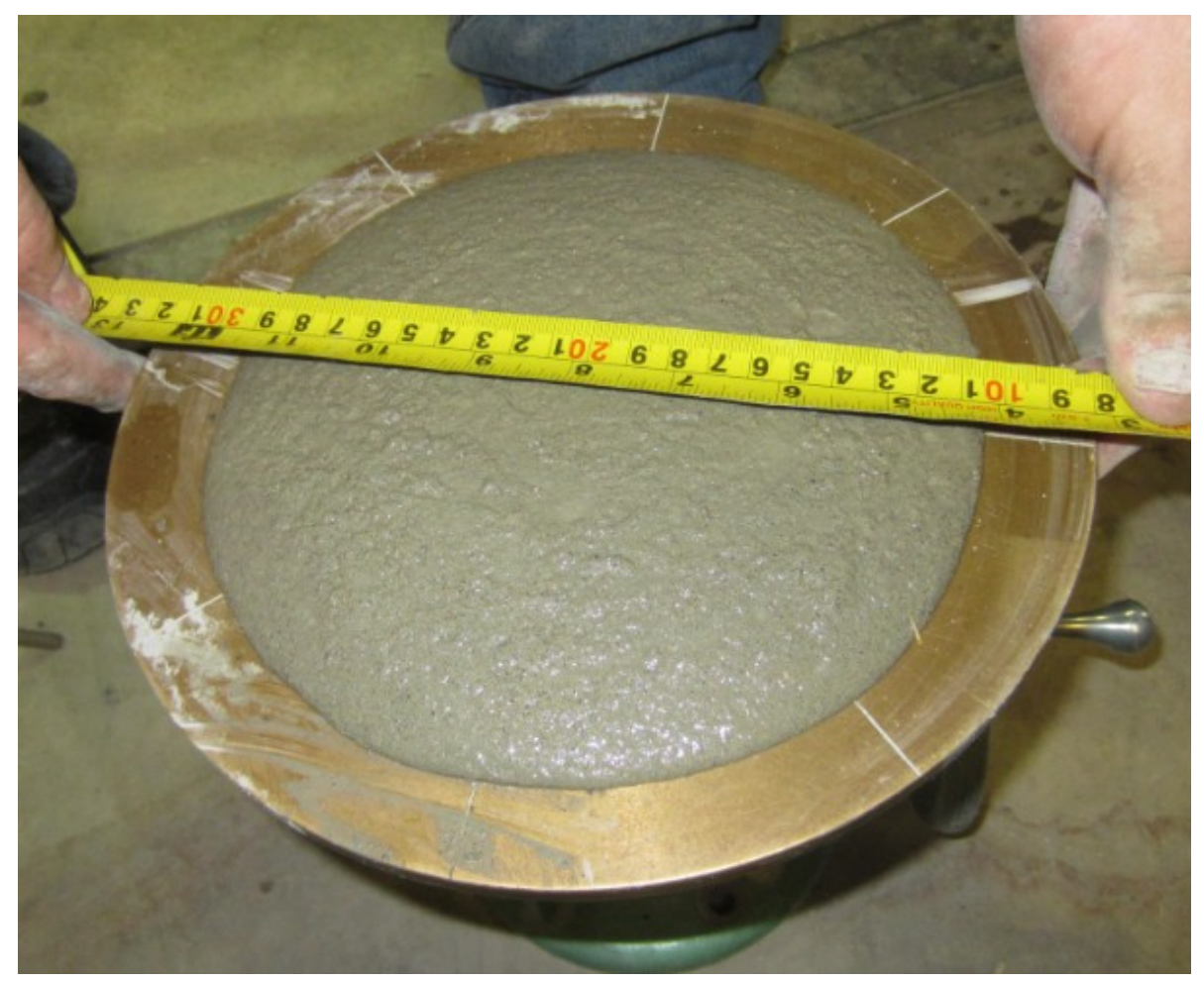

Figure 2-6: Typical mortar flow test 
When the property specification is used, the compressive strength must exceed the minimum values required by CSA A179. In a laboratory environment, the mortar strength is tested on mortar cubes and should be greater than $7.5 \mathrm{MPa}$ at 7 days and greater than $12.5 \mathrm{MPa}$ at 28 days for structural Type $\mathrm{S}$ mortar.

\subsubsection{Grout properties}

The two main properties which are of importance to the designer are the flowability and the compressive strength. The flowability ensures a good bond between the reinforcement, blocks and the grout itself. The compression strength serves as a measure of quality control of the grout although the strength itself does not have a great effect on the overall compressive strength of the masonry. CSA A179 suggests the lower compressive strength limits for fine and course grouts respectively to be $10 \mathrm{MPa}$ and $12 \mathrm{MPa}$ at 28 days.

The flowability of the grout can be measured by a standard slump test. The slump of masonry grout should be in the range of $200-250 \mathrm{~mm}$. The desired slump should be chosen at the designers discretion based on the sizes of the voids in the masonry element.

\subsubsection{Prism properties}

Masonry prisms are built to calculate the strength of the masonry composite. Due to the fact that there are 3 constituent materials in unreinforced masonry, and all have different structural properties, the combined behaviour in a prism is rather complex. Prism compressive strengths are lower when subjected to a load parallel to the bed joint versus perpendicular to the bed joint (Drysdale and Hamid (2005)).

\subsection{Fibre Reinforced Concrete}

Since early civilization humans have been reinforcing brittle structural materials with fibres. It was quickly discovered and appreciated that the bond created between a given matrix and a fibre would allow tensile loads to be carried across a crack, hence improving the overall structural performance of the member. Unreinforced brittle materials fracture very suddenly in 
tension and are not able to transfer any tensile loads after cracking, but fibres give the material that very ability. Randomly distributed fibres within the matrix span the tensile cracks and are able to transfer loads as long as they are not pulled from the matrix and either side of the crack.

Perhaps the earliest example of fibre reinforcement is a pueblo house built around 1540 $\mathrm{AD}$ in which the builders used sun-baked adobe reinforced with straw. This structure demonstrates that fibre reinforced structures can stand the test of time as it is still standing today, and is believed to be the oldest house in the United States (ACI Committee 544 (2002)).

In recent history, many different fibre types have been researched regarding their potential as a reinforcing material for reinforced concrete. In addition to organic materials such as straw; materials such as asbestos, steel, glass and other synthetic fibres have been used as types of fibre reinforcement. Perhaps the most widely accepted fibre types in industry today are steel fibres (see Figure 2-7). Steel fibres will be discussed in more detail in a later section of this thesis.

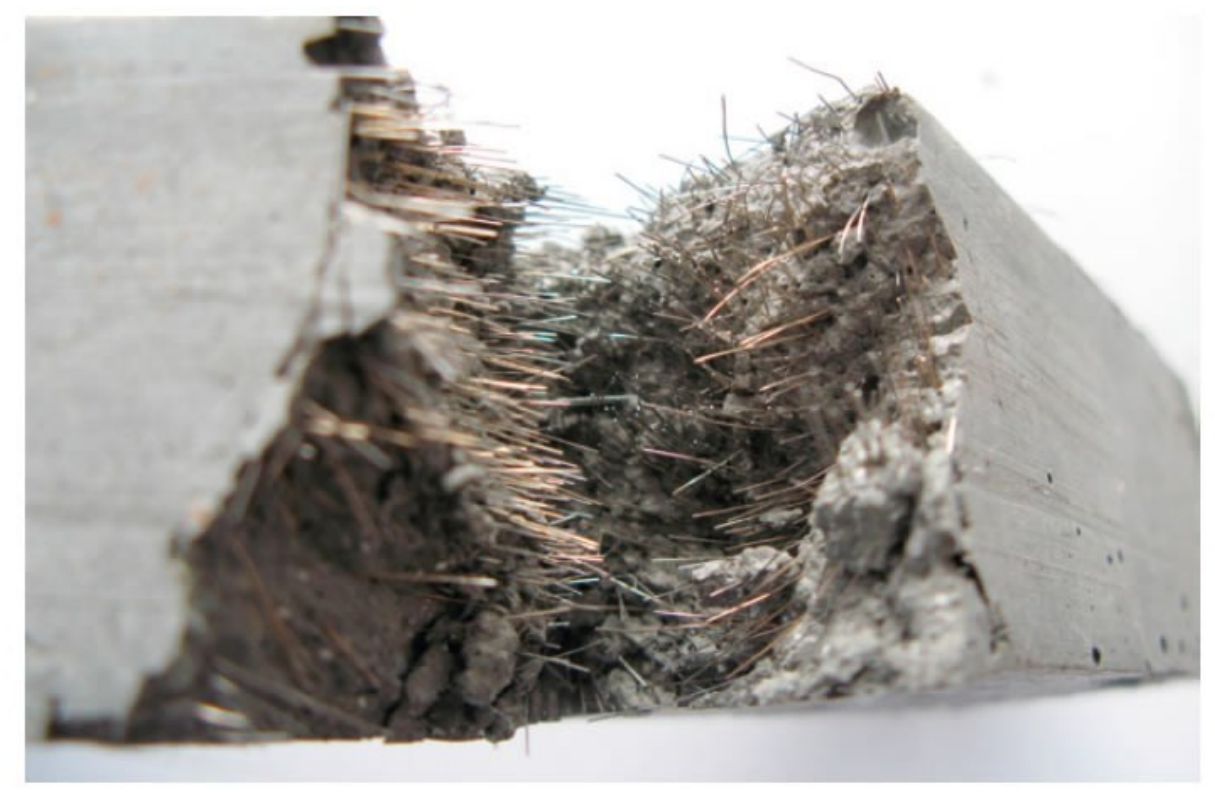

Figure 2-7: Fracture surface of steel fibre reinforced concrete

[Adapted from Sika (2013)] 
Fibre reinforced concrete is a very active area of research in structural engineering, and the potential uses for fibre reinforced concrete in industry are promising. Research and development of fibre reinforced technologies is continual, as fibre reinforcement poses a very viable alternative or supplement to traditionally reinforced concrete in certain applications. As soon as fibre reinforcing technologies can be proven to be sufficiently consistent so as to assure adequate strength and durability, their use can be incorporated into prescriptive structural concrete codes for use in certain applications. Currently ACI 318 permits the use of steel fibre reinforcement as an alternative to stirrups to meet minimum shear reinforcement requirements (ACI Committee 318 (2008)).

\subsubsection{Applicability to Grout}

Creating a grout with increased tensile strength is of great interest for many different structural engineering applications. Possible uses for fibre reinforced grout include:

- Offshore applications

- Structural repair, and

- Strengthening reinforced concrete masonry

Several researchers have published articles on specific uses of fibre reinforced grout. For example, Bayasi and Downey (1995) report on the use of FRG in reinforced piles, and Wight et al. (2007) report on the use of fibres to reinforce masonry around openings.

Having fully grouted the cells surrounding the openings with fibre reinforced grout, Wight performed shake table testing on unbounded pre-stressed walls. The zinc plated steel fibres were used as a replacement to traditional reinforcement for shrinkage which is prescribed by the code around openings in reinforced masonry walls. The fibres provided a certain level of confinement within the grout columns, but didn't add any confinement to masonry units themselves, so evidently this method of confinement was not as successful as other methods of masonry confinement.

Research has also been conducted at the University of Beira Interior in Portugal by Oliveria and Bernardo (1998) on the use of fibre reinforced grout in structural masonry. In this research, 
Dramix ZP 306 fibres were incorporated in fully grouted masonry specimens and tested under flexure. The results showed that an improvement in flexural strength of up to $105 \%$ was achieved by incorporating $1.5 \%$ of the Dramix ZP306 fibres into the grout mix. The ductility of the walls in flexure was also improved with increasing ductility improvements as the longitudinal steel reinforcement ratio decreased.

\subsubsection{Introduction to types of FRC}

Steel fibre reinforced concrete is one of the most common types of FRC used in civil engineering applications. It is a mix of hydraulic cements, fine and coarse aggregates, and steel fibres. The failure of steel FRC is reached when either the steel fibres break or they are pulled out of the cement matrix as seen above in Figure 2-5.

The mechanics in which the steel fibres interact with the concrete matrix are still an active area of research. Steel fibres come in a variety of shapes and sizes, and typically the ends of the fibres are altered such that the pullout of the fibres from the matrix is minimized. This can be achieved by crimping the ends or by providing hooked ends, similar to the way reinforcing steel is detailed to improve pullout resistance.

Steel fibre reinforced concrete must be prescribed alongside strict quality control measures and placing procedures. Due to the fact that SFRC in a relatively new product, training of the construction trades may be required.

A typical application where steel fibre reinforced concrete is advantageous is in tunnel lining or rock stabilization. In this application, steel fibres are incorporated into a steel fibre reinforced shotcrete slurry and sprayed on the surface to the strengthened or stabilized. The use of steel fibre reinforcement eliminates the need of placing mesh or placing reinforcing steel to complement the brittle shotcrete (ACI Committee 544 (2002)).

There is a need for developing rational design procedures which allow the use of SFRC in load carrying members. Also, the ductility of SFRC needs to be analyzed for the possibility of its use in seismic design and construction. 
The concept of glass fibre reinforced concrete (GFRC) is the same as SFRC however the fibres are made of glass rather than steel. The first research on GFRC took place in the 1960's when borosilicate glass fibres and soda-lime-silica glass fibres were used. Due to the highly alkaline environment of the cement matrix, these fibres did not prove to have long term durability and they lost load carrying capacity quite rapidly (Larner et al. (1976)).

Continued research, however has led to the development of an alkali resistant glass fibre. These glass fibres are extensively used in the production of architectural wall panels around the world (Smith and Walker (1980)). GFRC provides good performance and is advantageous to designers due to its light weight.

Many other fibre types other than steel and glass have been used to reinforce brittle materials such as concrete. These fibres are categorized as synthetic fibres for use in synthetic fibre reinforced concrete (SFRC).

Synthetic fibres are man-made fibres which are a result of research in both the petrochemical industry and the textile industry. Synthetic fibres that have been tested in Portland cement based matrices include: acrylic, aramid, carbon, nylon, polyester, polyethylene and polypropylene (ACI Committee 544 (2002)). These fibres are not widely researched as their applications are highly industry specific. Often times, specific research with a particular type of fibre will be conducted to prove its validity for one single very specific type of application.

\subsubsection{In depth look at Steel Fibre Reinforced Concrete}

As mentioned above, steel fibres are the most widely used fibres in today's construction industry. From tunneling to bridge decks, steel fibres are being specified, although its growth in popularity amongst designers is somewhat stunted by a lack of detailed design guidelines (ACI Committee 544 (2002)).

Although SFRC has proven structural benefits, the use of SFRC is primarily in areas where it is not used as primary reinforcement but rather to compliment the main reinforcement and control cracking. Research has proven that steel fibres increase the diagonal tension capacity of concrete as well as the energy absorption characteristics for uncommon loads such as seismic or blast loads (Narayanan and Darwish (1987)). For this reason, SFRC has the potential for 
widespread structural engineering applications; more research is simply required to provide engineers with detailed design guidelines and equations for using this advanced composite material.

\subsubsection{Steel Fibre Types}

Steel fibres used for reinforcing cementitious materials must be short enough in length that they can be incorporated into a fresh concrete mix without altering the mixing procedures. If the fibres are too long, balling can occur whereby the discrete fibres attach to one another causing the fibre distribution to the irregular within the overall mix. Usually the steel fibres have an aspect ratio (ratio of length to diameter) of about 20-100. The fibres are generally made of traditional carbon steel and may have other alloys such as zinc. If the cementitious matrix exposes the fibres to a corrosive environment or other adverse environmental conditions, then the fibres may need to be made of a different type of steel so as to resist the detrimental effects caused by the surrounding material (ACI Committee 544 (2002)).

The four main types of steel fibres as described by ASTM A820 are as follows:

- Type I: Cold-drawn wire

- Type II: Cut sheet

- Type III: Melt extracted

- Type IV: Other fibres

As can be seen from the above descriptions of the different fibre types, ASTM classifies the fibre type based on the material used for their manufacturing. The fibres that will be used in this series of laboratory testing are made of cold drawn wire. They are made of standard carbon steel, as we do not expect to expose them to a corrosive environment.

\subsection{Hooked end steel fibres}

Hooked end steel fibres are the most common type of steel fibre used by researchers in the structural engineering field (see Figure 2-8). They have significantly higher pullout strength 
versus other alternatives such as straight fibres. After initial debonding of the fibre from the cement matrix, the hooked ends of the fibre must be deformed by the applied load before they are able to pull out of the cement matrix.

The fibres used in this experimental research will be of this type and were provided by Bekaert steel wire. The type of steel fibre is called Dramix and two lengths will be used: $30 \mathrm{~mm}$ (Dramix ZP305) and 60mm (Dramix RC65/60BN). The fibres come with an adhesive bonding several individual fibres together which dissolves into the matrix as the fibres are slowly added to the mix. The steel fibres randomly orient and evenly distribute themselves within the matrix.

ZP305 fibres are by far the most common type of steel fibre used in industry and in research. This is why they were selected for use in this study. Since they are widely available, it is thought that they will be more readily accepted into industry should the concept of fibre reinforced grout be accepted by the masonry industry.

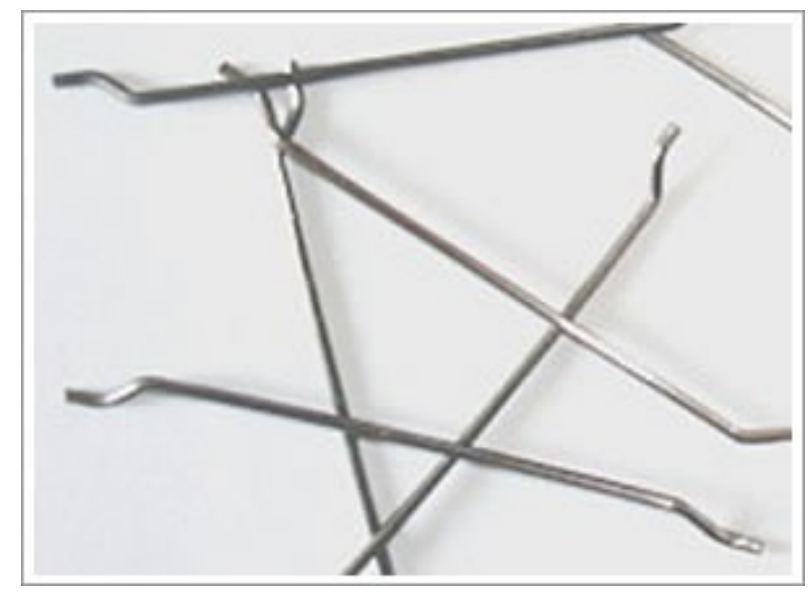

Figure 2-8: Typical hooked end steel fibre [Adapted from www.steelfiber.org]

\subsection{Crimped steel fibres}

Crimping the ends of steel fibres is another way to increase their pull out resistance. In the manufacturing process, the individual fibres are crimped giving them a wavy appearance which gives them the same ability as the hooked end steel fibres to resist pullout. The fibres are forced to straighten after initial debonding which dissipates the energy imparted to the element by the externally applied load. Without these fibre profiles to improve the pull out resistance, the 
ductility improvements generated by the steel fibres wouldn't be nearly as substantial. Figure 29 shows typical crimped steel fibres.

Crimped steel fibres are currently produced under the name brand "Fiber mesh" and are the second most common type of steel fibre used in modern day construction as well as in research. The toughness of the FRC produced with crimped ends, however, isn't as high as with the use of hooked end steel fibres (Banthia \& Sappakittipakorn (2007)). Crimped fibres may also exhibit slightly higher relative workability when incorporated into a fresh mix.

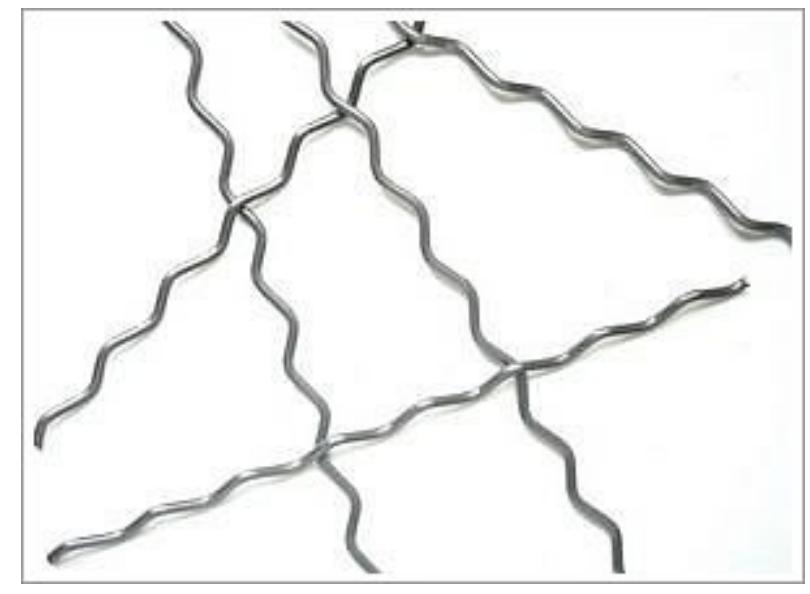

Figure 2-9: Crimped steel fibres

[Adapted from www.steelfiber.org]

\subsection{Spiral Steel Fibres}

A new type of fibre on the market for use in fibre reinforced concrete and grouts are spiral fibres. Spiral or twisted steel fibres are as they sound: a helically shaped steel fibre. Their shape is derived from the desire for increased pull out strengths as in other types of steel fibres. During the manufacturing process, the triangular shaped steel wire is twisted into a helical shape and cut into discrete fibres. These fibres are triangular in cross section which improves the bond characteristics due to the fact that a triangular prism will have a larger surface area that a circular prism with the same volume of steel. 
During failure, the twisted fibres must be unscrewed out of the cement matrix whereas hooked end steel fibres must be pulled out or forced to straighten. For this reason, the failure mechanism of twisted steel fibres is by torsion rather than by friction.

\subsubsection{Steel Fibre Reinforced Concrete Properties affecting Performance}

Steel fibres have been successfully used in construction projects around the world to help improve the performance of reinforced concrete. Added benefits obtained from the use of fibre reinforced concrete include increased durability and mechanical properties. Most notably: flexural strength, toughness, ductility, impact strength, resistance to fatigue, and resistance to cracking and spalling are all enhanced with the incorporation of fibres into the concrete $\operatorname{mix}($ Shah \& Baston (1987)). This section outlines some of the properties of a FRC mix affecting the performance of the composite material.

\subsection{Fibre Volume Fraction}

Typically fibre volume fractions are in the range of $0.25 \%-1.5 \%$ by volume however, in this study the upper bound of fibre reinforcement will be set at $1.2 \%$. Since the grout must flow into small cavities the upper bound for fibre content was slightly lower than $1.5 \%$. Typically, lower volume percentages of fibres are used in non-structural applications whereby the fibres are primarily used for crack control and overall durability, whereas higher fibre percentages are often prescribed for structural applications (Aoude (2008)). An example of a non-structural application might be a slab in an industrial facility, whereas a structural application might be the use of FRC in a reinforced concrete frame or bridge deck. Often, steel fibers at moderate dosages are used in areas where traditional steel reinforcement is not possible or is extremely difficult to place due to congestion. As example of this type of application would be a beam-column connection in a reinforced concrete frame. 


\subsection{Fibre type}

The fibre shape and material are critical to the composite's overall performance. Pullout behavior can be significantly enhanced by using techniques to increase the pullout resistance. As was mentioned in Section 2.3.3.1, some of these techniques include providing hooked end steel fibres, spiral steel fibres or crimped steel fibres. FRC is still an active area of research however, and researchers are actively investigating ways to improve the pullout resistance of the steel fibres.

Steel fibres have relatively high strengths and moduli of elasticity. Fibres come in various strengths, the minimum being $345 \mathrm{MPa}$ as outlined by ASTM Standard A820 (ASTM Committee A820 (2011)). ASTM A820 provides the criteria for steel fibres used for fibre reinforced concrete. They outline minimum tensile strength, minimum bending strength as well as tolerances for length and diameter of the fibres.

\subsection{Bond Strength}

The performance of the SFRC is highly dependent on the bond strength between the fibres and the cement matrix. Although there are end details that allow the fibres to have a mechanical anchorage into the cement matrix, the performance still relies on the bond and friction between the fibres and matrix after the onset of pullout.

Kutzing (2000) proposed that the bond strength of straight fibers was correlated to the compressive strength of the matrix. As the compressive strength of the matrix increased, so did the bond or shear strength between the fibres and the matrix. The research showed that for regular strength concrete with a compressive strength of less than $50 \mathrm{MPa}$, the bond shear strength between the fibre and the matrix was found to be 2.0-3.0MPa (Kützing (2000)).

\subsection{Fibre Dimensions}

Fibres come in a variety of lengths and diameters and are typically categorized based on their aspect ratio, meaning the ratio of their length to diameter $\left(\mathrm{L}_{\mathrm{f}} / \mathrm{D}_{\mathrm{f}}\right)$. The higher the aspect ratio, the better the performance in both tension and compression; however the workability of the 
concrete in the fresh state and consequently the ability to evenly distribute the fibres throughout the mix are diminished. Typically aspect ratios of 80 or less are used in past experimental work in SFRC (Aoude (2008)).

Longer fibres are better at improving the post cracking behavior of SFRC due to their ability to transfer load across the cracks with limited risk of pullout of the fibres, whereas short fibres are typically better at reducing the onset of cracking. This is due to the fact that longer fibres with larger diameters have larger volumes and hence there will be a smaller number of fibres to distribute within the cement matrix. With a smaller quantity of fibres, there will be less fibres crossing the crack hence before the onset of pullout the performance of the shorter fibres will be better.

\subsubsection{Applications of SFRC}

SFRC can be used in a variety of structural engineering applications, either as the sole means of reinforcement of in combination with traditional steel reinforcement. SFRC is an option in areas where structural loads such as flexural loads are not excessive, but traditional reinforcement may be either difficult of impractical to place.

Precast concrete elements are an area where fibre reinforced concrete is desirable for many reasons. For one, due to the fact that the construction of the elements takes place in a plant facility, the quality control of the production can be much more closely and effectively monitored. Also, the high early strength of SFRC is desirable for precast applications due to the fact that production can be quicker.

The addition of steel fibres decreases the tendency for tensile crack formation and for this reason SFRC is effective for use in structural applications where increased durability is required. With the use of SFRC, the corrosion of reinforcement is less likely and cost savings due to extended service life of a structure are tremendous. It has also been proven that steel fibres can increase the shear strength of a material. ACI 318 currently allows the use of steel fibres in design to replace minimum stirrup required in reinforced concrete (ACI Committee 318 (2008)).

Many other uses for FRC are currently on the construction market such as: 
- Industrial floor slabs (increased impact resistance)

- Foundations (improved performance under dynamic loads)

- Concrete pipes (better early age strength, increased rupture resistance, no reinforcement work required)

- Stabilization of slopes and banks

- Repair and strengthening work

\subsubsection{Behaviour of Steel Fibre Reinforced Concrete in Tension}

\subsubsection{Mechanics of fibre pullout from matrix}

The overall tensile behavior of a SFRC structural element can be directly correlated to the pullout behavior of the fibres from the surrounding matrix. Many different factors influence the fiber's resistance to pullout including their bond characteristics as well as their geometry.

In the initial stages of loading, the tensile loads are transferred through a bond between the fibre and the surrounding matrix. After further load is applied to the member debonding occurs and the fibre slips along the interface between the fibre and the matrix. During the slipping phase, the deformed shape of the fibre as well as its surface characteristics plays a critical role in reducing slippage and eventually failure (see Figure 2-10).

To predict the pullout of straight round fibres from a cementitious matrix, Hannant (1978) proposed the following equation:

$$
F=\tau_{\text {bond }} \times \pi \times D_{f} \times \frac{L_{f}}{2}
$$

Where $\tau_{\text {bond }}$ is the frictional shear strength of the bond between the fibre and the surrounding matrix $D_{f}$ is the diameter of the fibre and $L_{f}$ is the length of the fibre. For straight fibers, the stages of pullout are partial debonding, full debonding and frictional pullout. The three stages in the pullout process are depicted in Figure 2-11. 
(a)

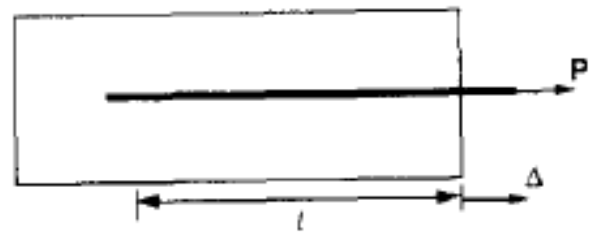

(b)

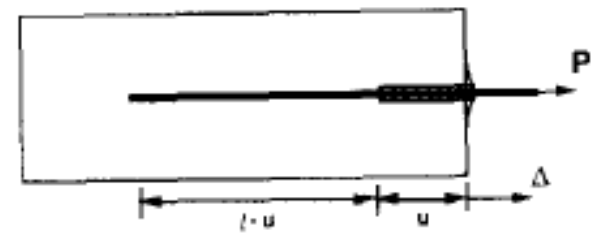

(c)

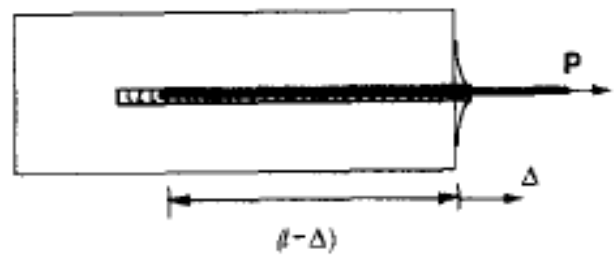

Figure 2-10:Pullout behaviour of straight steel fibres

[Adapted from Naaman et al. (1991)]

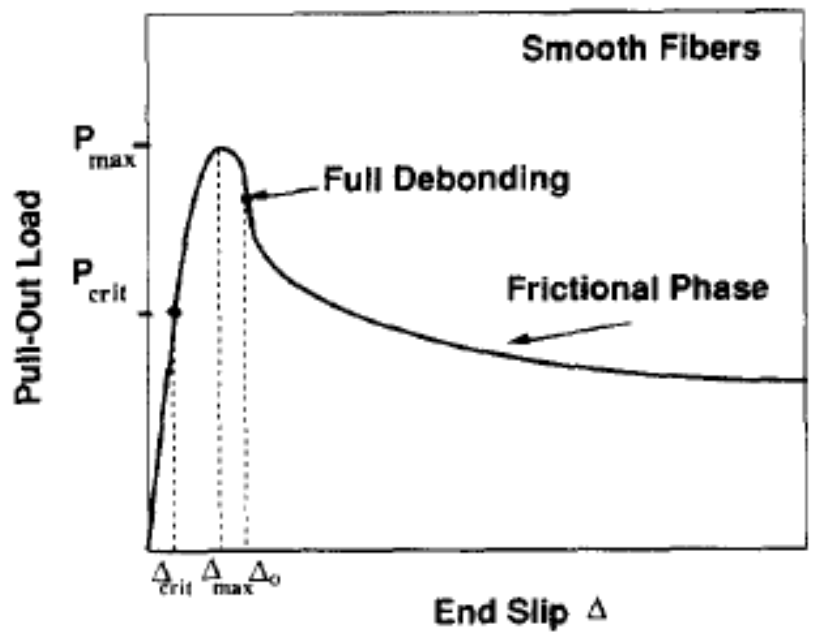

Figure 2-11: Pullout load as a function of end slip for straight steel fibres

[Adapted from Naaman et al. (1991)] 
When dealing with the pullout of hooked end steel fibres, the mechanics are more complex. Due to their geometry, deformed steel fibres and hooked end steel fibres in particular have superior pullout resistance to straight fibres.

Many researchers have proposed models to predict the pullout behavior of hooked end steel fibres. Alwan et al. (1991) proposed a model whereby the model for the pullout of a straight fibre was modified to account for the resistance provided by the hooked ends. This model is summarized in Figure 2-12. Initially, the response will be fully elastic until initial debonding of the fibres occurs at $\mathrm{P}_{\mathrm{cr}}$.

After the debonding has occurred, shear and frictional forces will govern the next stage up until complete debonding of the fibre occurs at $\mathrm{P}_{1}$. At this load, a straight fibre would pull out of the matrix gradually with decreasing amounts of frictional force as the fibre is deformed further and further.

The third stage includes the mechanical clamping effects due to the shape of the fibre. The additional load resistance which is observed at this stage is due to the fact that the fibres are forced to straighten before they are able to be pulled out of the matrix. Eventually whenever the fibres are straightened out and the frictional stresses are no longer high enough to resist the applied load, the fibres pull out of the matrix and the member fails. Figure 2-13 shows the four stages of pullout of typical hooked end steel fibres. 


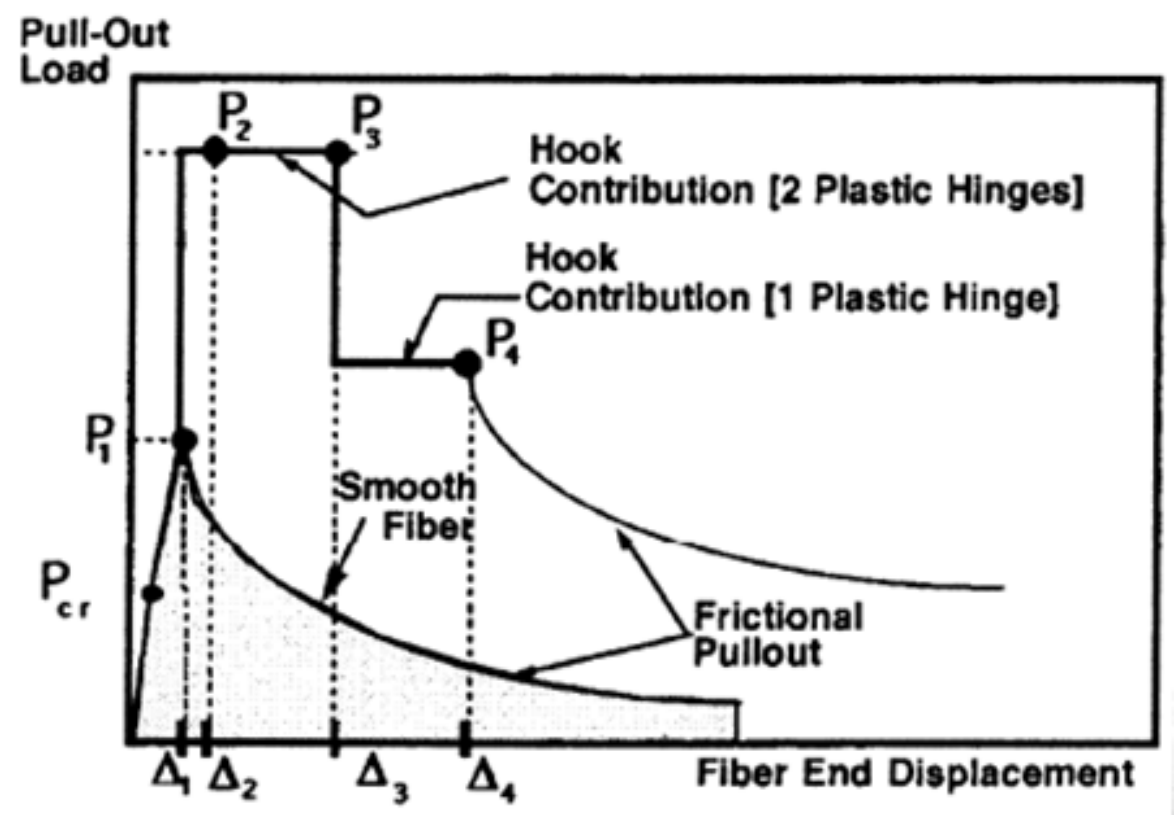

Figure 2-12: Pullout behaviour of hooked end steel fibres

[Adapted from Alwan et al. (1999)]

The following equations can be used to estimate the loads $\mathrm{P}_{3}$ and $\mathrm{P}_{4}$ :

$$
\begin{gathered}
P_{3}=P_{1}+\Delta P^{\prime} \\
P_{4}=P_{1}+\Delta P^{\prime \prime} \\
\Delta P^{\prime}=\frac{\left[\frac{f_{f y} \pi r_{f}^{2}}{3 \cos \theta}\right]\left[1+\frac{\mu \cos \beta}{(1-\mu \cos \beta)}\right]}{[1-\mu \cos \beta]} \\
\Delta P^{\prime \prime}=\frac{\left[\frac{f_{f y} \pi r_{f}{ }^{2}}{6 \cos \theta}\right]}{[1-\mu \cos \beta]}
\end{gathered}
$$

$\mathrm{P}_{3}$ and $\mathrm{P}_{4}$ represent the first and second pullout plateaus respectively. The pullout load contribution is accounted for by the parameters $\Delta P^{\prime}$ and $\Delta P^{\prime \prime}$ which account for the formation of plastic hinges at the hook locations. $F_{\text {fy }}$ refers to the yield strength of the fibre, $r_{f}$ refers to the radius of the fibre, $\mu$ refers to the frictional coefficient at the interface between the fibre and the matrix and $\theta$ and $\beta$ are related to the angles of inclination of the hooked ends of the steel fibre. 
When substituting values for Dramix ZP305 fibres, we can take $\theta=45, \beta=67.5$ and a coefficient of friction was assumed $\mu=0.5$. Substuting these values into the equation yields $\Delta P^{\prime}=152 N$.

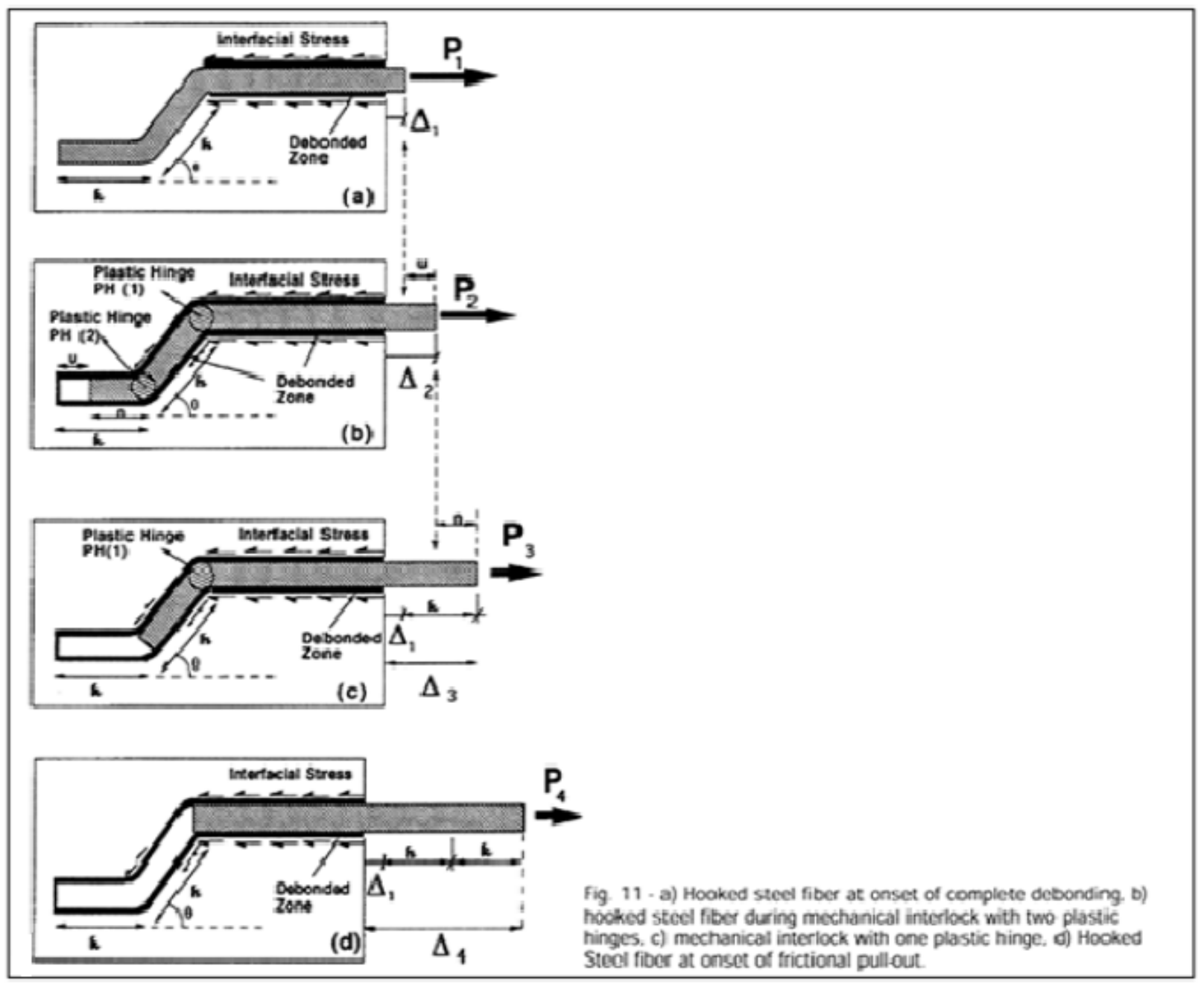

Figure 2-13: Stages of pullout of hooked end steel fibres

[Adapted from Alwan et al. (1999)]

\subsubsection{Behaviour of SFRC in pure tension}

In direct tension, steel fibres offer a significant increase in strength. Strength increases in the order of $30-40 \%$ have been reported by the addition of $1.5 \%$ steel fibres by volume (Johnson \& Gray, 1978). 
The SFRC will have greater fracture toughness than regular concrete due to the fact that the steel fibres are able to bridge the cracks after they form and transfer tensile stresses across the crack. The overall improvement in uniaxial tensile strength is highly dependent on the quantity of fibres present in the SFRC (Fantilli (2009)).

Note that in ordinary concrete; failure is impending as soon as the first crack opens. The concrete element is not able to transfer any load after initial cracking as there is no longer anything connecting the two sides of the element to enable the transfer of load. When fibres are introduced at a low fibre volume content, the area under the load-deformation curve or the toughness of the specimen is increased as a higher amount of stress can be generated at the same displacement or strain. It is not until higher fibre volume fractions where significant increases in toughness are observed. We can see in Figure 2-14c) that as the strain increases past $\varepsilon_{\mathrm{cr}}$, the stress continues to increase until it reaches a stress which is significantly higher than the stress which was required to crack the concrete. 


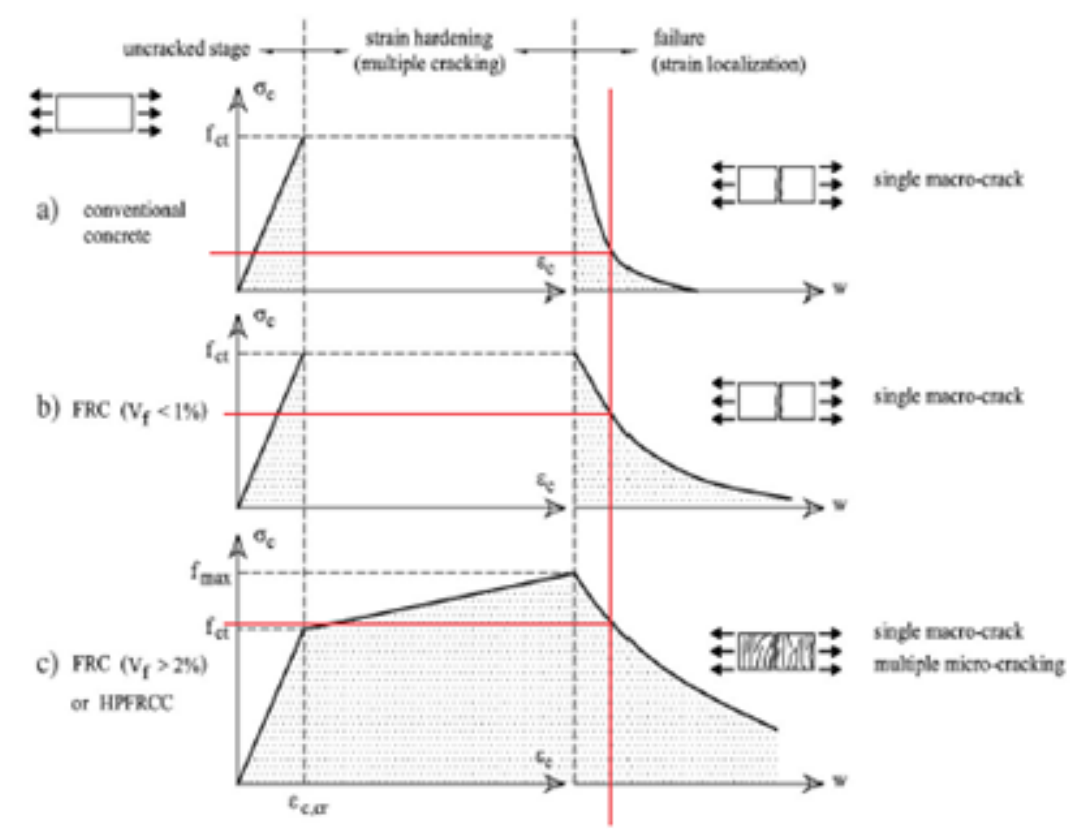

a) $\sigma c-\varepsilon_{c}$ and $\sigma_{c}-w$ diagrams for ordinary concretes

b) $\sigma_{c}-\varepsilon_{c}$ and $\sigma_{c}-$ w diagrams for FRC with low fiber volume fraction $\left(V_{f}<1 \%\right)$

c) $\sigma_{c}-\varepsilon_{c}$ and $\sigma_{c}-$ w diagrams for HPFRC with high fiber volume fraction $\left(V_{f}>2 \%\right)$

Figure 2-14: Improvement of uniaxial tensile behaviour using SFRC

[Adapted from Fantilli (2009)]

Fibre volume fractions as high as $1.5 \%$ are easily attainable with normal concrete mixes and mixing procedures; however when fibre volume fractions exceed this threshold serious workability issues may occur. Modern research into high performance concretes and self consolidating concrete have allowed researchers to create concretes which have increased amounts of fibres by simply adding chemical admixtures to change the rheology of the concrete in its fresh state. Engineers, however, should be very careful as it is extremely important to research the compatibility and overall effects of all additives before prescribing their use in any SFRC design.

\subsubsection{Direct Tension Testing Methods}

One of the most common ways to obtain the stress-strain relationship of a fibre reinforced concrete specimen is to test "dog-bone" shaped specimens whereby the load can be transferred 
directly to the FRC materials by imparting the load to the ends of the tension specimen. The figure below shows the typical shape of the specimen and the way the loads are applied to the specimens in a typical test setup.
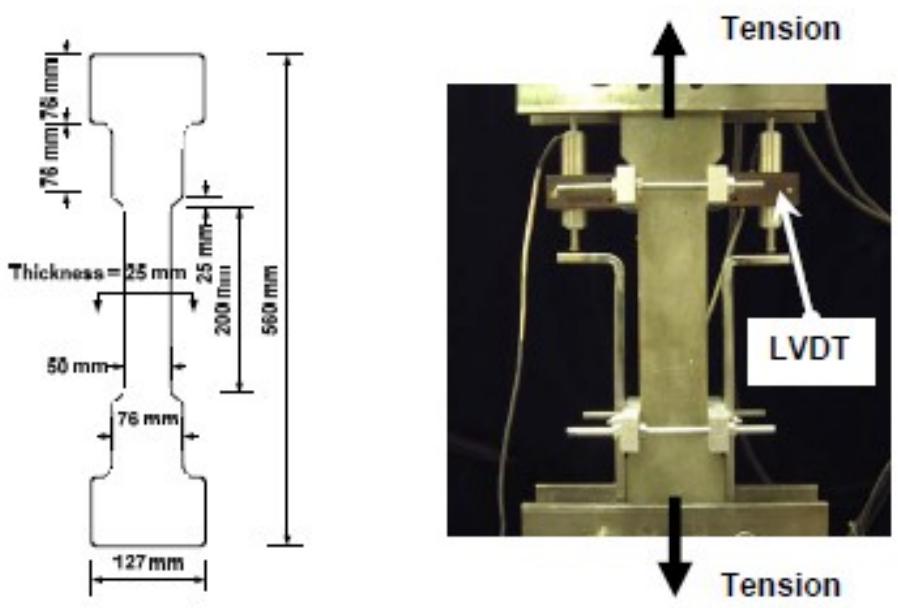

Figure 2-15: Typical dogbone tension specimen dimensions and test setup

[Adapted from Chao et al. (2006)]

One drawback from this type of direct tension testing is that typically small scale samples are tested which are not necessarily representative of the true fibre distribution and variation in the structural element. Chao et al (2006) tested a series of relatively large scale HPFRC dog bone specimens at the University of Michigan whereby they incorporated an unstressed prestressing strand in the specimen to observe the tension stiffening behavior around the reinforcement. The results of their tests were compared to typical dog bone testing on smaller scale samples. 


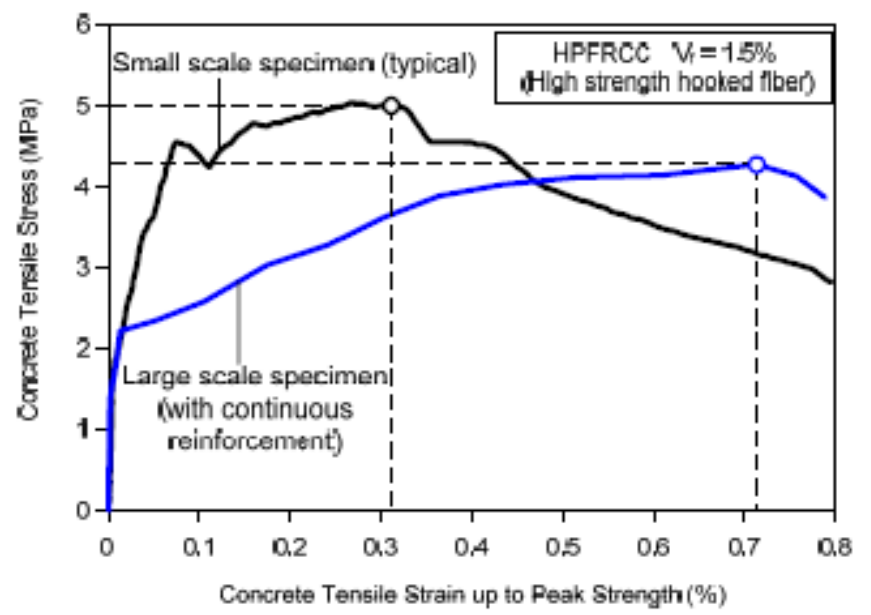

Figure 2-16: Comparison of large vs. small scale dog bone tension tests

[Adapted from Chao et al. (2006)]

Although this testing procedure works very well in theory, its practical applications are somewhat limited. It requires a special test setup and the test are not simple to setup and run. Also, there is a definite size effect which can be observed in the figure above whereby the large scale specimens have a much higher strain at the maximum stress level. For this reason, the size of test specimens should be standardized so that FRC materials can be accurately compared with regards to their structural performance.

\subsubsection{Indirect Tension Testing Methods}

Although there are many different indirect tension testing methods, only two will be discussed in this section: the ATSM round panel test and the double punch test.

The ASTM round panel test is governed by ASTM Standard C1550-12a. The test involves a round panel of FRC material measuring $800 \mathrm{~mm}$ in diameter and $75 \mathrm{~mm}$ in thickness. These panels are subjected to a point load in the center and are supported by three symmetrically arranged pivots on the underside (ASTM International (2013)). The test setup is depicted in the Figure 2-15. 


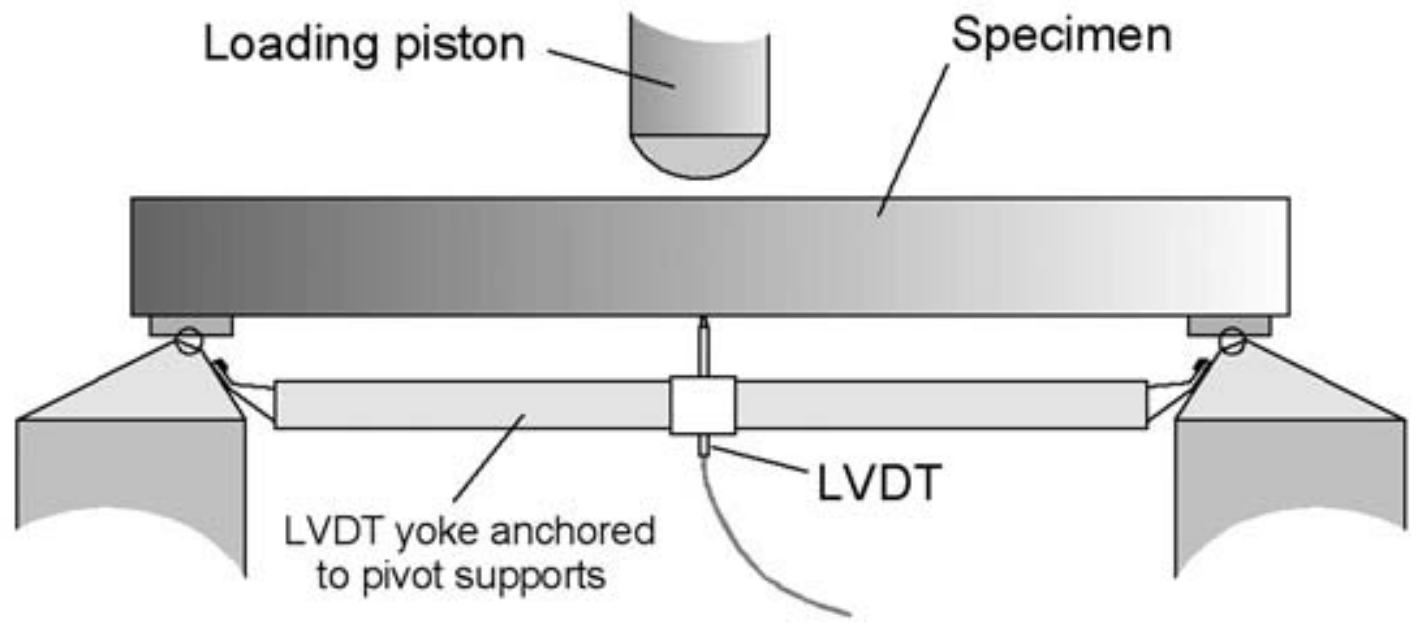

Figure 2-17: Typical test setup of ASTM C1550 round panel test

[Adapted from ASTM International (2013)]

The load is applied through a hemispherical loading piston at a prescribed rate of displacement and both the load and displacement at the centre are recorded. The test is continued up to a prescribed central displacement and the energy absorbed by the specimen up to the final displacement is related to the toughness of the FRC material.

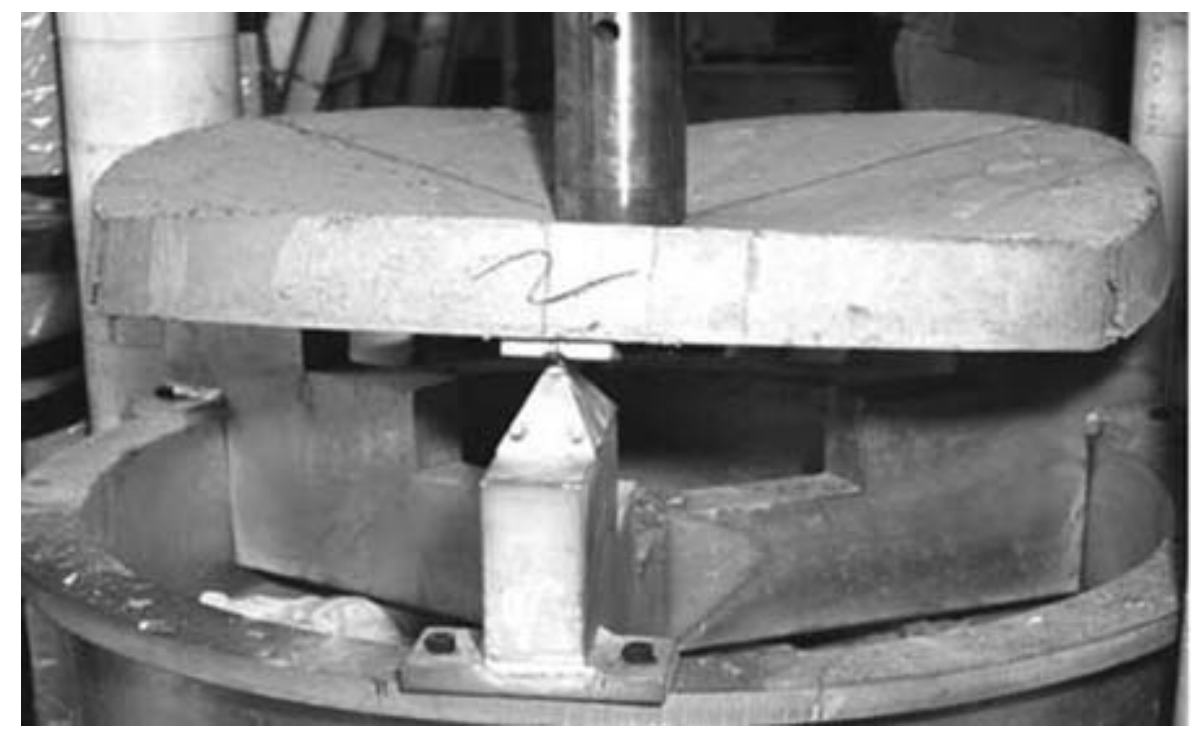

Figure 2-18: Typical round panel test for tensile strength of FRC (ASTM C1550)

[Adapted from ASTM International (2013)] 
The second method of indirect tension testing of fibre reinforced concrete materials is called the double punch test or the Barcelona test (Molins et al. (2009)). This test method is not based on imparting flexural loads to the test specimens and instead a concentrated axial load is applied to a cylindrical specimen. The test is an adaptation of the Brazilian test which is used to measure similar characteristics in plain concrete. Cylindrical specimens measuring $150 \mathrm{~mm}$ in height and $150 \mathrm{~mm}$ in diameter are tested. Loads are imparted to the cylinder by circular punches having a diameter of $25 \%$ of the cylinder diameter.

As the concentrated load is applied through the punches, splitting cracks will appear at 120 degree increments around the circumference of the cylinder. The relationship between the crack width and the load allows the calculation of the tensile strength of the FRC material. The test setup is depicted in the figure below.
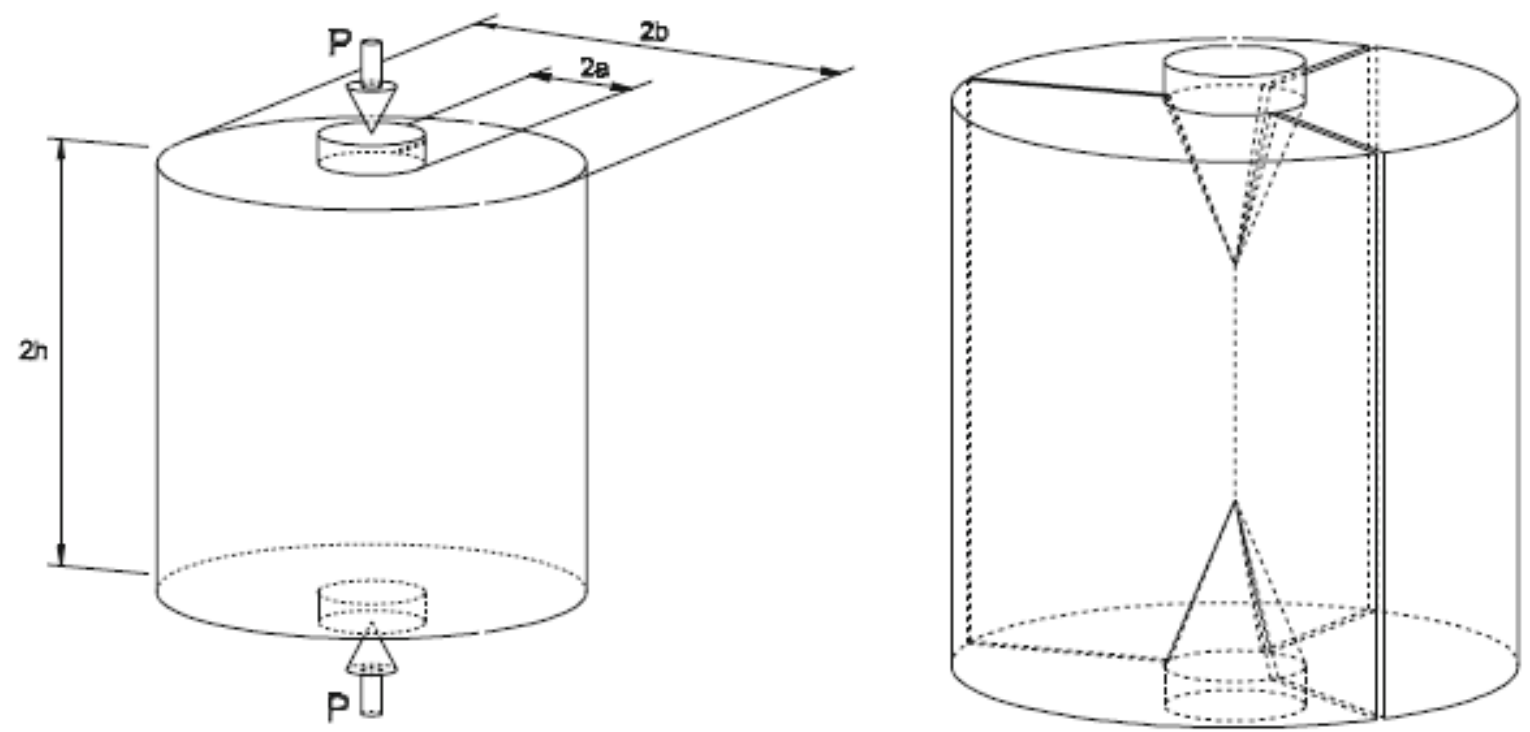

Figure 2-19: Double punch test for indirect tension testing of FRC

[Adapted from Molins et al (2009)]

\subsubsection{Behaviour of SFRC in compression}

Both the early-age and later-age strength of concrete are improved by the addition of steel fibres. In the initial stages of curing, the relative increase in concrete strength reaches its maximum. This is due to the fact that in the early stages, the concrete is not able to transfer much 
compressive strength at all as curing and hydration are needed to create strength. The steel fibres, however, are immediately able to transfer load as the steel has the same strength at the time of casting as when the concrete has cured.

In the hardened state the steel contribute to increasing the overall compressive strength of the composite. Their only contribution is due their increased modulus of elasticity over that of concrete. The maximum increase of compression strength caused by the addition of steel fibres is approximately 30\% (Minelli (2005)).

Steel fibres are able to span cracks in the concrete matrix. Under compressive loads, lateral cracks are spanned by randomly oriented steel fibres and this is where the strength increase is generated. The steel fibres add very little strength in the direction of the applied load.

Although the peak compressive strength in the direction of the applied load is not significantly enhanced by the addition of steel fibres, the toughness of the material is improved to a great extent. Due to the fact that the lateral expansion outwards due to Poisson's effect is restricted by the steel fibres, the area beneath of the stress strain curve of the composite can be up to 10 times greater than that of plain concrete. The increases area comes from the descending branch of the load displacement curve, as the response of the fibre reinforced concrete after peak load is much more ductile.

\subsection{Tension Stiffening Effect}

\subsubsection{Introduction}

In many applications tensile stresses in concrete after cracking are ignored as it is not possible for tensile stresses to be transferred across a crack, however this assumption is not entirely correct. It is possible for uncracked concrete present between principal tensile cracks to carry a portion of the tensile load (Collins and Mitchell (1997)). These uncracked portions carry a portion of the load, and contribute to the overall stiffness of the cracked composite. At a crack location, the entire stress must be carried by the steel crossing the crack. Beginning at the crack 
interface, there is a transfer of stress from the steel to the uncracked concrete portion which results from the mechanical interaction between the deformations on the reinforcing steel and the surrounding concrete.

The increased stiffness that results in the mechanical interlock between the reinforcing steel and the concrete can have a significant effect on the overall structural response. If the properties of the reinforcing steel alone are used, as is typically done when the contribution of concrete after cracking is ignored, then the structural deformations such as deflections can be overestimated (Atkinson \& Hammons (1997)).

Although accurate models have been created to model the tension stiffening behavior of reinforced concrete, accurate models are much less prominent in reinforced masonry. The complex interactions between the reinforcing steel and the surrounding concrete become even more complex when there are randomly oriented steel fibres which are also able to transfer loads across primary cracks.

\subsubsection{Tension Stiffening in Reinforced Concrete}

To easily visualize the concept of tension stiffening, we can look at how the axial load is shared by the steel and the concrete throughout the loading process. This load sharing is shown in Figure 2-20. Initially, the load is equally shared by all of the constituent materials as they are all subjected to an equal amount of strain. Once tensile cracks initiate, however, all of the load at the crack location must be carried by steel as there is no concrete available to share the load.

If the variation of force along the member is known, then the variation of the strain along the member can be calculated. With this strain, we are able to calculate the deformation of the member. By integrating the strain over the entire member, we are essentially calculating the average strain in the member. The steel strain at a crack is equal to $N / A_{s} E_{s}$, so long as the steel has not yielded at the crack location. The average strain in the steel however is $N_{s} / A_{s} E_{s}$ where $N_{s}$ is the average force in the bar and can be calculated by subtracting the contribution from the concrete $\left(\mathrm{N}_{\mathrm{s}}=\mathrm{N}-\mathrm{N}_{\mathrm{c}}\right)($ Collins and Mitchell (1997)).

As further cracks develop, the average concrete stress will continue to decrease as more and more of the load is carried by the steel at the crack locations. Another tensile crack will form 
as soon as the tensile load carried by the concrete in a given uncracked region reaches the cracking stress of the concrete. Once the tensile load can no longer reach the cracking stress in any uncracked portion, then the cracks are fully developed and no further cracking will occur. The failure will happen by localized yielding of the reinforcing bar.
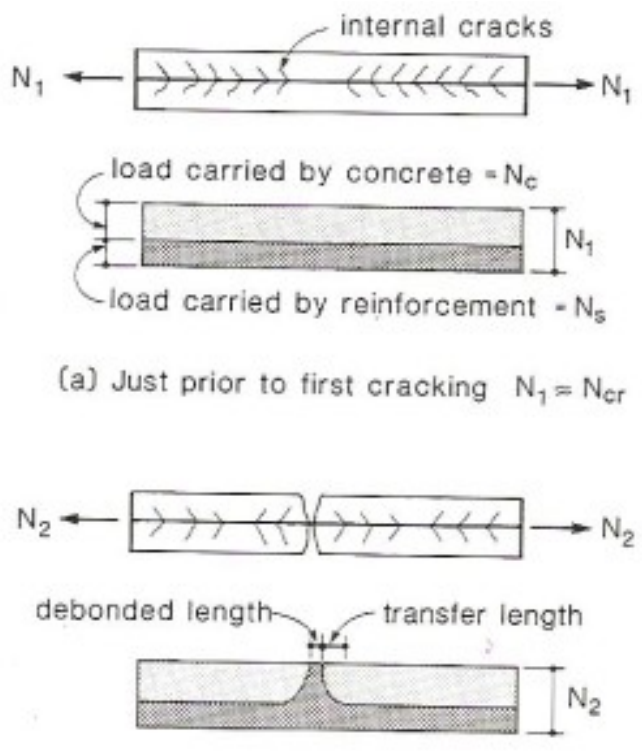

(b) Just after first cracking $\mathrm{N}_{2} \approx \mathrm{N}_{1}$

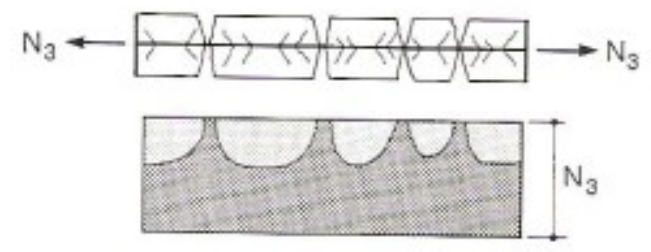

(c) Cracks fully developed $\mathrm{N}_{3}>\mathrm{N}_{2}$

Figure 2-20: Load sharing between concrete and reinforcing steel

[Adapted from Collins and Mitchell (1997)]

Beginning at the crack interface, a portion of the stress is gradually transferred to the uncracked concrete by the mechanical interaction between the reinforcement deformations and the concrete. The force is transmitted radially outwards from the bar to the surrounding concrete and secondary cracks begin to form around the reinforcement in addition to the primary cracks which extend to the element's surface. The mechanical interaction between the reinforcing steel and the surrounding concrete is shown in Figure 2-21. 


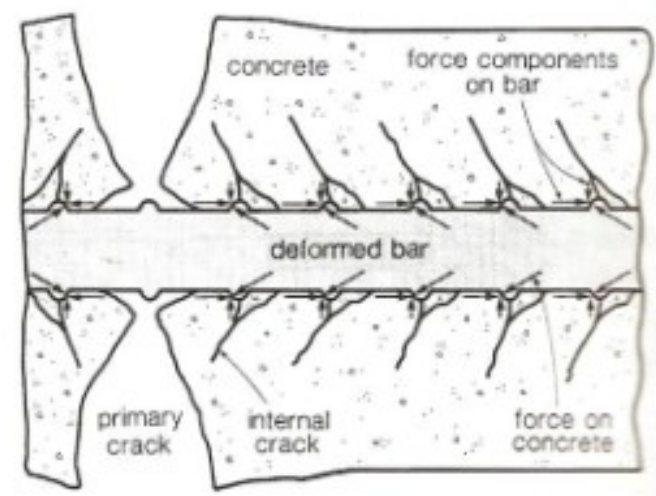

Figure 2-21: Secondary cracks forming around reinforcement deformations

[Adapted from Collins and Mitchell (1997)]

The results of a test on a heavily instrumented tension specimen tested by Scott and Gill (1987) are shown in Figure 2-22. The specimen was instrumented with strain gauges along the entire length of the reinforcing bar to monitor the strain at different locations. It can easily be seen that the strain in the steel at a crack location is greatly increased and becomes more and more pronounced as the load approaches the load at which the steel reinforcement yields.

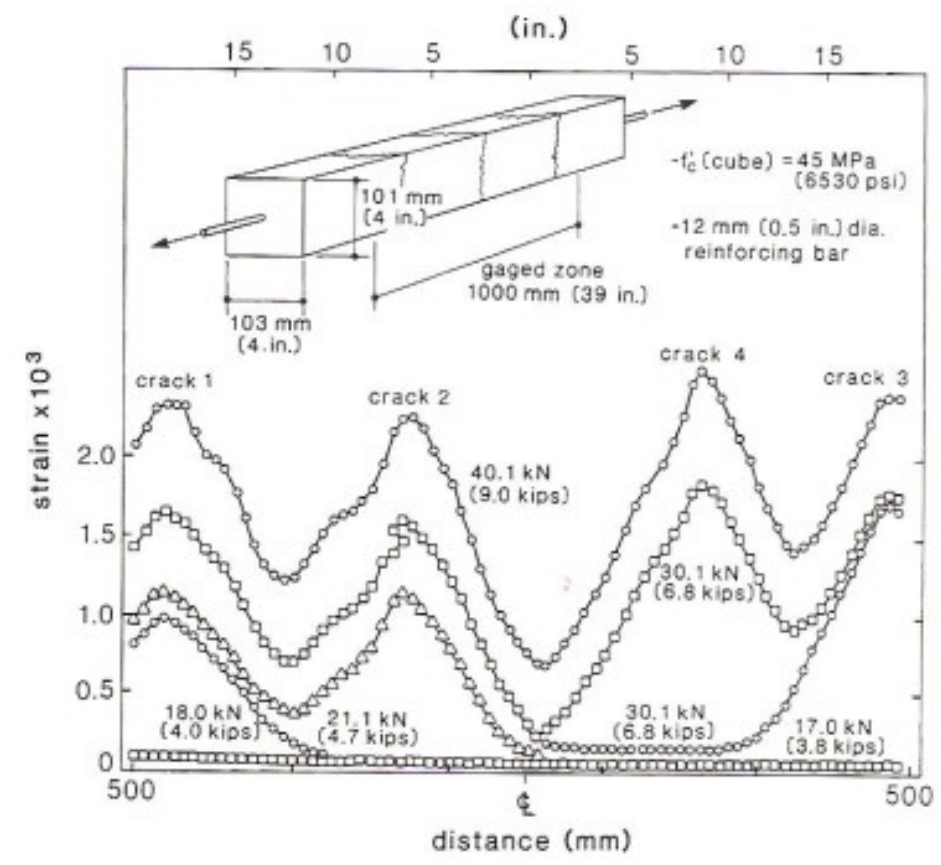

Figure 2-22: Strain variation along the length of tension member

[Adapted from Collins and Mitchell (1997)] 
Using an average stress in the concrete is merely an approximation to easily calculate the displacement of a member at a given load. As we can see in the above figures, the strain in the concrete is clearly not uniform but with an average approach we can accurately describe the displacement when including the tension stiffening effects.

Figure 2-21 shows the decay of the average stress in the concrete by many different researchers and the trend line shows the normalized theoretical average stress vs. average strain relationship proposed by Collins and Mitchell.

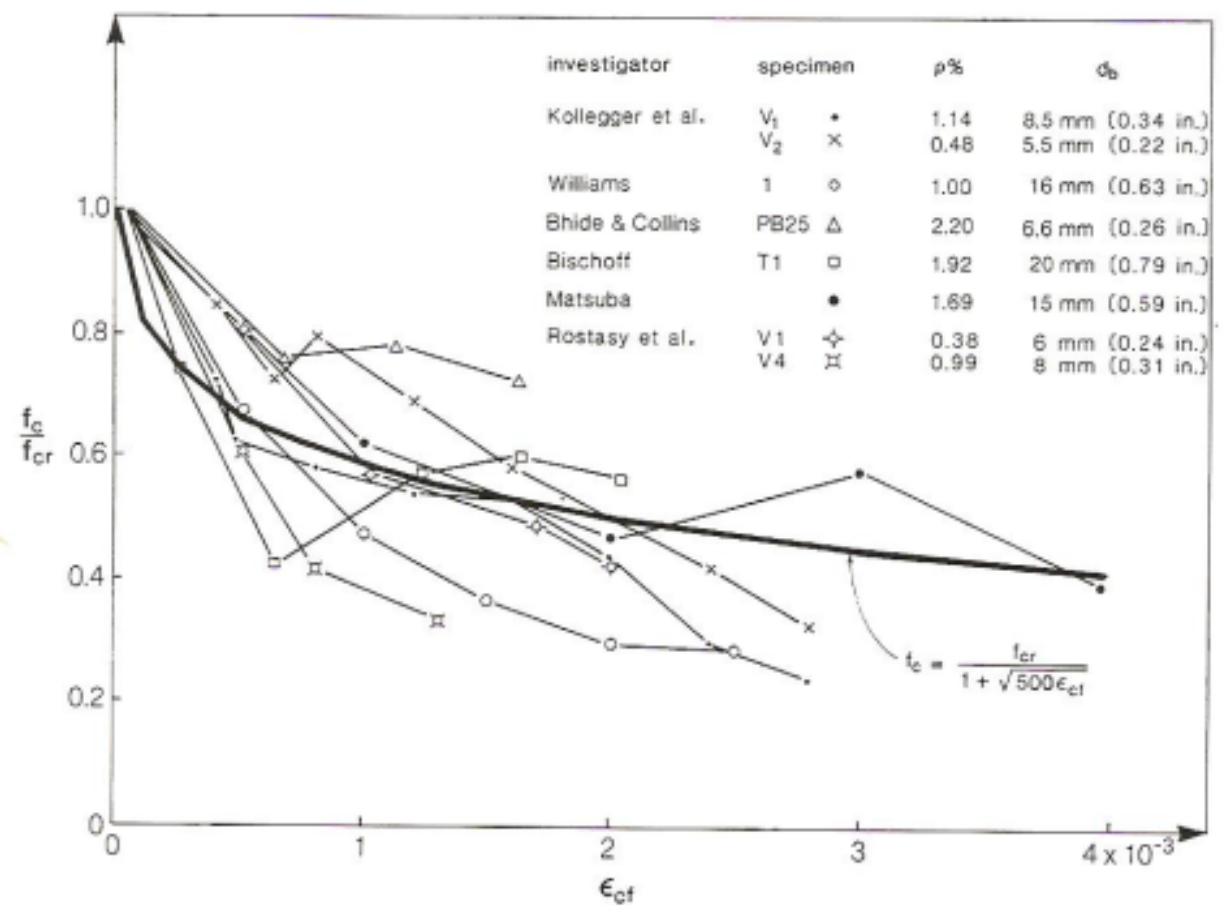

Figure 2-23: Decay of average stress in the cracked concrete as a function of concrete strain [Adapted from Collins \& Mitchell (1997)]

\subsubsection{Previous Research and Models}

The tension stiffening phenomenon is an area which has been researched extensively in reinforced concrete. It is very important to fully understand the post-cracking behavior of reinforced concrete to develop accurate material models for the use in analytical models. 
There are two basic approaches when dealing with the tension stiffening effect. The first approach is to create a model which has a descending branch on the concrete stress-strain curve and the other is to increase the steel stiffness in a modified stress-strain relationship for the reinforcing steel. The total steel stress then accounts for the total stress in the steel as well as the stress carried by the uncracked concrete between principal tensile cracks.

The first type of model is far more popular in the literature, so it will be discussed in further detail, outlining some of the most widely accepted models for the tension stiffening effect in concrete.

\subsection{Stevens et al. Model}

Stevens et al. (1987) developed a post cracking model for reinforced concrete which had the following equation for the descending branch of the stress strain curve:

$$
f_{m}=f_{m c r}\left[\alpha+(1-\alpha) e^{-\lambda_{t}\left(\varepsilon_{m}-\varepsilon_{m c r}\right)}\right]
$$

Where for $n$ groups of reinforcing with properties $\rho_{\mathrm{si}}, d_{b i}$, and oriented at $\theta_{i}$ to the $\mathrm{x}$ axis:

$$
\begin{gathered}
\alpha=\sum_{i=1}^{n}\left[\cos ^{2} \Delta \theta_{i}+\sin ^{2}\left(\frac{4 \Delta \theta_{i}^{2}}{\pi}\right)\right] \alpha_{i} \\
\lambda_{t}=\frac{270}{\sqrt{\alpha}} \text { and } \lambda \leq 1000 \\
\alpha_{i}=C_{t} \frac{\rho_{\mathrm{si}}}{d_{b i}}
\end{gathered}
$$

$\rho_{s}$ and $d_{b}$ are the reinforcement percentage and the diameter of reinforcement bars, respectively $C_{t}=$ constant $=75 \mathrm{~mm}$ (unit of length)

$\Delta \theta_{\mathrm{i}}=\theta-\theta_{\mathrm{i}}$ where $\theta_{\mathrm{i}}$ is the orientation of the particular reinforcing group and $\theta$ is the direction of principal stress.

$f_{m}$ and $\varepsilon_{\mathrm{m}}$ are the stress and strain in the principle direction and $\varepsilon_{\mathrm{mcr}}$ is the cracking strain of the masonry 
In this model, the bond between the steel and the concrete as well as the alignment of the reinforcement with the direction of principle stress are accounted for in $\alpha$ as they are deemed to influence the tension stiffening behavior.

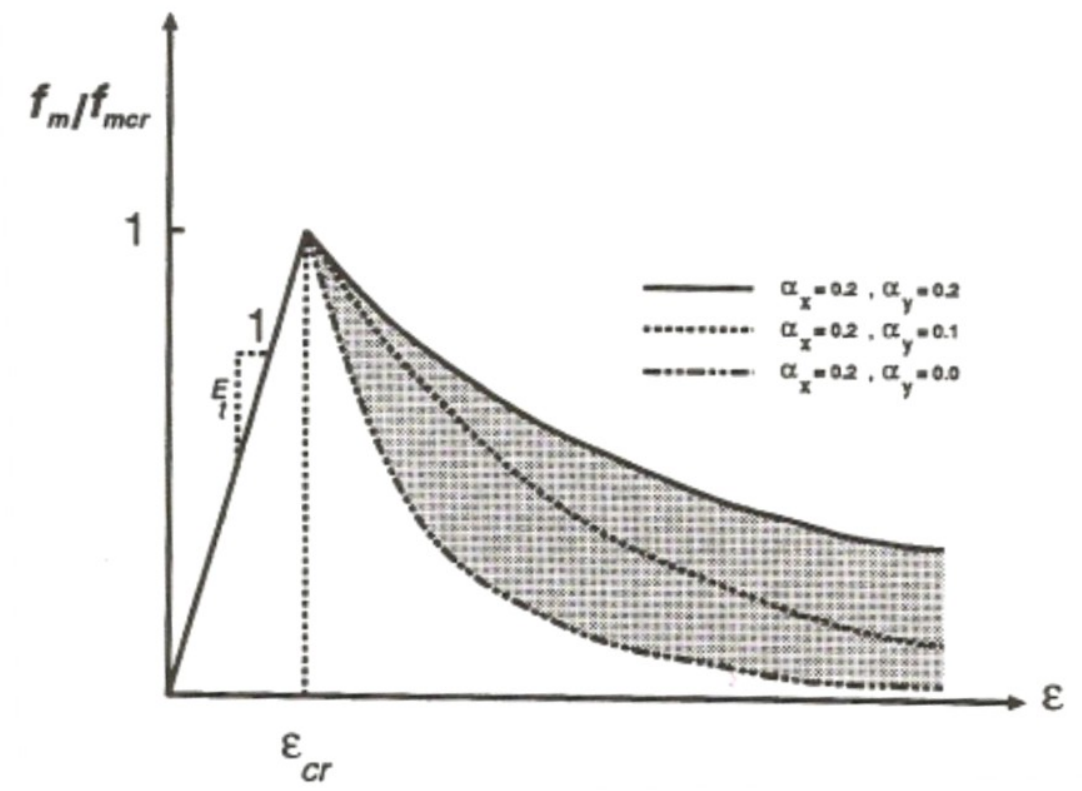

Figure 2-24: Post-cracking contribution of cracked concrete proposed by Stevens et al.

[Adapted from Stevens et al. (1987)]

\subsection{Vecchio and Collins Model}

Vecchio and Collins later proposed a much simpler model for the tension stiffening behavior of concrete (Vecchio and Collins (1988)). They suggested a simple equation for the descending branch of the stress-strain relationship after cracking based on the modified compression field theory with the following form:

$$
f_{c}=\frac{f_{c r}}{1+\sqrt{200 \varepsilon_{c f}}}
$$

Where $f_{c}$ and $\varepsilon_{c f}$ are the stress and strain in the concrete in the principal direction. 


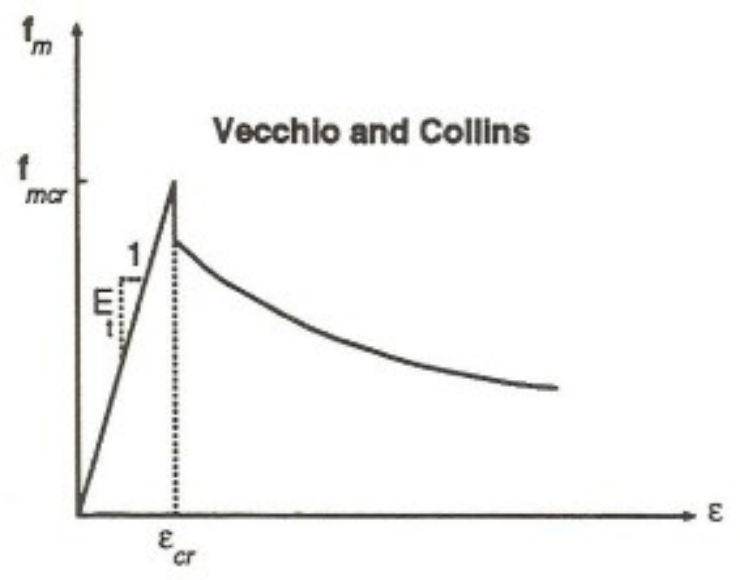

Figure 2-25: Post cracking contribution from cracked concrete proposed by Vecchio \& Collins [Adapted from Vecchio and Collins (1998)]

This model accounts for the fact that the stress will decrease suddenly when the first primary crack opens.

Collins and Mitchell (1997) later proposed a modification to the equation developed under the modified compression field theory developed by Vecchio and Collins. This suggested relationship for the post-cracking behavior of reinforced concrete is as follows:

$$
f_{c}=\frac{\alpha_{1} \alpha_{2} f_{c r}}{1+\sqrt{500 \varepsilon_{c f}}}
$$

where $\alpha_{1}=$ factor accounting for bond characteristics of reinforcement

$$
\begin{aligned}
& \alpha_{1}=1.0 \text { for deformed reinforcing bars } \\
& \alpha_{1}=0.7 \text { for plain bars, wires, or bonded strands } \\
& \alpha_{1}=0 \text { for unbounded reinforcement } \\
& \alpha_{2}=\text { factor accounting for sustained or repeated loading } \\
& \alpha_{2}=1.0 \text { for short-term loading } \\
& \alpha_{2}=0.7 \text { for sustained and/ or repeated loads }
\end{aligned}
$$




\subsection{Gopalaratnam and Shah Model}

This model is based on experimental testing performed by Gopalaratnam and Shah (1985) and the crack band theory by Bazant and Oh (1983).

This model is based on a series of tension tests performed on concrete, mortar and paste specimens. Two distinct equations are used to predict the behavior of the concrete: one equation for the ascending part of the stress-strain relationship and another for the descending part of the stress-strain relationship after cracking of the concrete.

The equation proposed for the ascending branch of the stress-strain relationship is derived from an expression defining the compressive behavior of concrete up to the peak stress value:

$$
f_{m}=f_{m c r}\left[1-\left(1-\frac{\varepsilon_{m}}{\varepsilon_{m c r}}\right)^{A}\right]
$$

Where:

$$
\begin{aligned}
& f_{m}=\text { tensile stress } \\
& f_{m c r}=\text { peak value of } f_{m} \\
& \varepsilon_{m}=\text { tensile strain } \\
& \varepsilon_{m c r}=\text { value of strain, } \varepsilon_{m} \text {, at } f_{m c r} \\
& A=E_{t} \varepsilon_{m c r} / f_{m c r} \\
& E_{t}=\text { initial tangent modulus }
\end{aligned}
$$

The equation forming the descending branch is based on stress and crack widths. Gopalaratnam decided that it was more appropriate to write an equation for the descending branch in terms of stress and average crack width due to the localized nature of the deformations in the post-peak range. The relationship that they developed between average stress and average crack width was: 


$$
f_{m}=f_{m c r}\left(e^{-k w^{\lambda}}\right)
$$

where $\mathrm{w}$ is the average crack width, and $\mathrm{k}$ and $\lambda$ are constants.

Bazant and Oh (1983) have proposed a theory called the "crack band model" wherein they propose a zone called the fracture process zone which is where the micro-cracking is occurring before the principal and secondary cracking. This fracture process zone has a width of $w_{c}$ and is a function of maximum aggregate size.

With this model, the total strain in a given element is now broken into three distinct parts. They developed a new term called the fracture process strain which is defined as the ratio of the sum of the microcrack openings, $\delta_{f}$, and the crack band width, $w_{c}$.

$$
\varepsilon_{f}=\frac{\delta_{f}}{w_{c}}
$$

Where

$$
w_{c}=\eta d_{a}
$$

Where

$$
\begin{aligned}
& w_{c}=\text { crack band width } \\
& \eta=\text { constant }(1.5 \text { to } 4) \\
& d_{a}=\text { maximum aggregate size }
\end{aligned}
$$

Therefore if we put together the results of Gopalaratnam and Shah with the crack band model developed by Banzant and Oh alongside previous knowledge of the relationship between cracking stress and crack width the total strain in a zone loaded in tension is as follows:

$$
\varepsilon_{t}=\varepsilon_{e}+\varepsilon_{m p}+\varepsilon_{f}
$$

where

$\varepsilon_{e}=\frac{f_{m}}{E_{t}}$ 
$\varepsilon_{m p}=\varepsilon_{m c r}-\frac{f_{m c r}}{E_{t}}$

$\varepsilon_{f}=\frac{1}{w_{c}}\left(-\frac{1}{k} \ln \frac{f_{m}}{f_{m c r}}\right)^{\frac{1}{\lambda}}$

and

$$
\varepsilon_{t}=\frac{f_{m}}{E_{t}}+\varepsilon_{m c r}-\frac{f_{m c r}}{E_{t}}+\frac{1}{w_{c}}\left(-\frac{1}{k} \ln \frac{f_{m}}{f_{m c r}}\right)^{\frac{1}{\lambda}}
$$

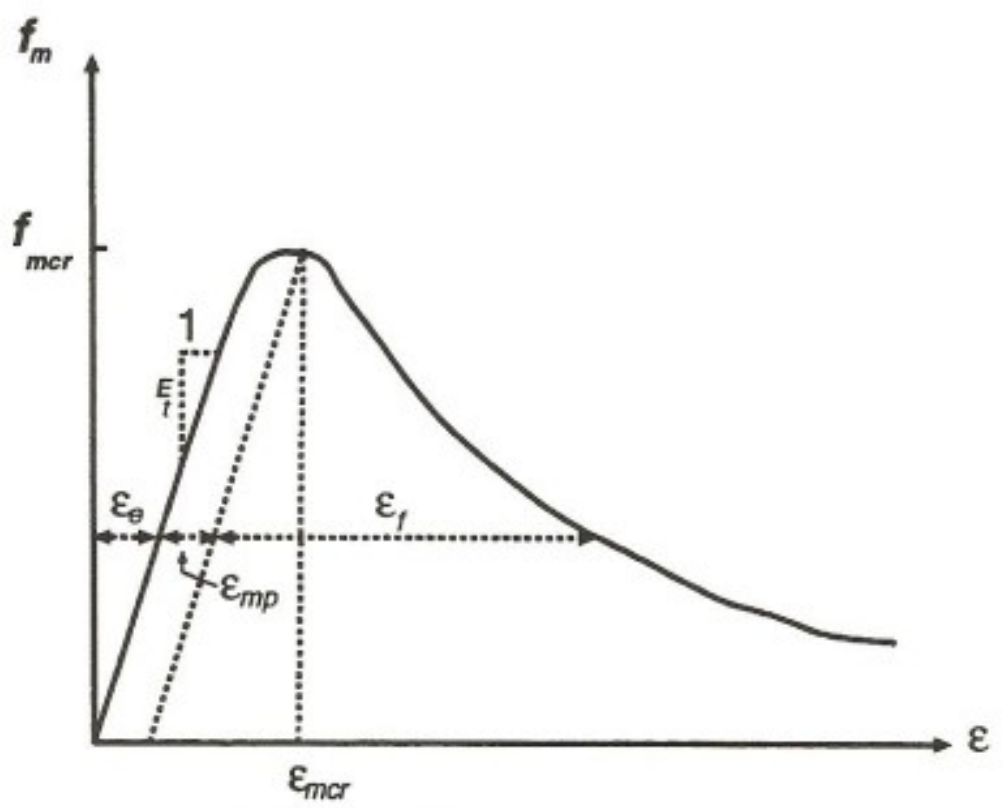

Figure 2-26:Tension Stiffening model based on Gopalaratnam and Shah Test Results and crack band theory [Adapted from Bazant and Oh, (1983)]

When using this model for concrete masonry, the cracking stress depends on the direction of tensile loading in relation to the bed joints in the masonry. The tensile failure stress is related to the angle, $\phi$, measured from the vertical axis by:

$$
f(\phi)_{m c r}=f_{m c r}\left(1.0+0.006 \phi-7.8 \times 10^{-5} \phi^{2}\right)
$$

where $f_{m c r}$ is the cracking stress for uniaxial tension normal to the bed joint and $\phi$ is in degrees. This empirical normalizing equation was suggested by Nunn (1980). 


\subsubsection{Factors affecting the magnitude of tension stiffening}

Williams (1986) tested a series of large scale reinforced concrete elements under direct tension. These tests differ from the tests performed by Vecchio and Collins (1988) which were on small panels tested under a general state of in-plane stress.

Williams' test specimens were $2500 \mathrm{~mm}$ by $1500 \mathrm{~mm}$ by $250 \mathrm{~mm}$. The specimens were monitored for crack width, crack progression, crack spacing and tension stiffening effects. The parameters of the testing program are shown in the table below:

Group $1 \quad$ Fixed steel percentage (bar size and spacing varied)

Group 2 Fixed bar spacing (varying bar sizes and reinforcement ratio)

Group 3 Fixed bar size $(20 \mathrm{~mm})$, (varying spacing and percentage)

Group $4 \quad$ Fixed bar size and spacing (varying cover distance)

Group $5 \quad$ Fixed bar size, spacing, and cover (with and without transverse steel)

For Group 1 tests, it was found that the crack spacing was smaller for the smaller reinforcement placed at closer spacing. For Group 2 tests, yielding of the $8 \mathrm{M}$ and $10 \mathrm{M}$ rebars occurred before full crack development was established. This is due to the fact that the reinforcement ratio was too low.

The results of the tests showed that the tension stiffening effect was more pronounced for elements with smaller bars. Smaller bars have a higher perimeter to cross-sectional area causing them to have more contact area between the concrete and the bar. For this reason, the concrete is able to carry more stress when the load is imparted to small bars.

The presence of transverse steel decreased the concrete stress at high levels of strain. 


\subsubsection{Bond between Reinforcement and Concrete}

Experimental studies have shown that the adhesive bond between the reinforcement and the steel is destroyed at low levels of steel stress (Gerstle and Ingraffea (1991)), (Goto (1971)). Therefore, the transfer of stress from the steel to the surrounding concrete in the uncracked portions must come from the mechanical interaction between the ribs on the reinforcing steel and the surrounding concrete. In concrete, the cracks emanate from the reinforcing steel and extend radially outwards towards the element's surface. The crack width at the surface of an element has been experimentally observed to be larger than at the surface of the reinforcing steel (Lutz and Gergely (1967)).

\subsubsection{Effects of Shrinkage on Tension Stiffening and Cracking}

Bischoff (2001) reported the results of a testing program which consisted of axially loaded specimens to investigate the effect of shrinkage on cracking and tension stiffening in reinforced concrete. The results are summarized in Figure 2-27 and Figure 2-28. The test results demonstrate that estimates of tension stiffening are influenced by shrinkage and will be underestimated if the initial member shortening caused by shrinkage is not included in the member response calculations.

If shrinkage is ignored in member calculations, the tension stiffening effect appears to be greatly reduced however, this is not the case. This apparent reduction in the tension stiffening becomes more and more pronounced as the reinforcement ratio increases. Shrinkage effects on cracking are somewhat more ill-defined as the crack widths do not seem to be affected by the initial shrinkage.

Either the load sharing approach or the strain stiffening approach lead to the same bond factor $(\beta)$, which is used to characterize the tension stiffening. The bond factor represents the normalized value of the average tensile strength in the concrete after cracking. Collins and Mitchell (1997) proposed a bond factor of $\beta=\frac{1}{1+\sqrt{\left(500 \varepsilon_{m}\right)}}$

Bischoff (2001) proposed that the measured values of $\beta$ can be corrected to account for shrinkage by using the following expression to correct $\beta_{\text {exp }}$ : 


$$
\beta=\beta_{\exp }\left(1+\frac{n \rho}{1+n \rho} \frac{\varepsilon_{s h}}{f_{c r} / E_{c}}\right)-\frac{n \rho}{1+n \rho} \frac{\varepsilon_{s h}}{f_{c r} / E_{c}}
$$

where

$\beta_{\text {exp }}=$ the measured bond factor when shrinkage is ignored

$n=$ ratio $\mathrm{E}_{\mathrm{s}} / \mathrm{E}_{\mathrm{c}}$ between the steel and concrete moduli

$\rho=$ the reinforcement ratio $\left(\mathrm{A}_{\mathrm{s}} / \mathrm{A}_{\mathrm{c}}\right)$

$\varepsilon_{s h}=$ concrete shrinkage strain (negative for shortening)

$f_{c r}=$ tensile strength of the concrete

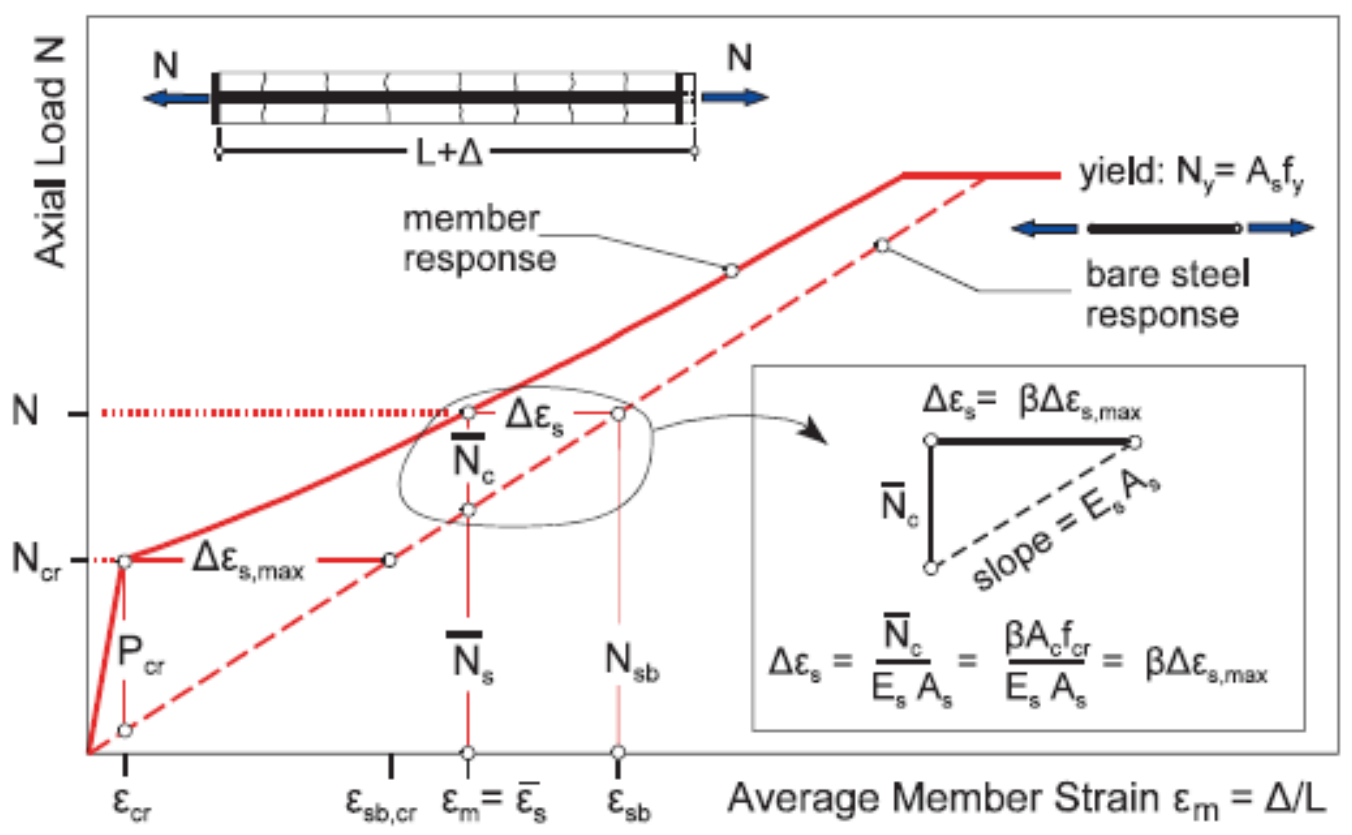

Figure 2-27: Typical response of a reinforced concrete tension member

[Adapted from Bischoff (2001)] 

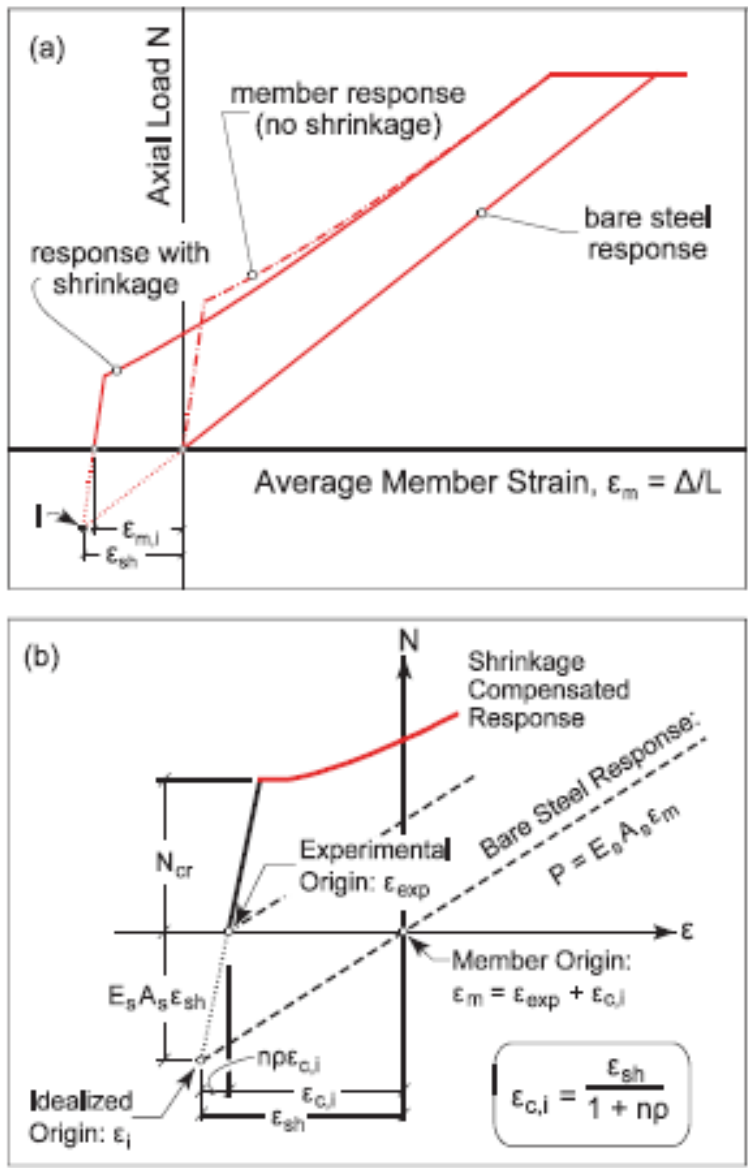

Figure 2-28: a) effect of shrinkage on member response b) details of computing shrinkage modified response [Adapted from Bischoff (2001)] 


\subsubsection{Tension Stiffening Behavior of High Strength Concrete}

Perera and Mutsuyoshi (2011) have conducted a series of direct tension tests on instrumented specimens at Saitama University in Japan. Tension behavior of both normal strength and high strength concrete specimens was investigated. Five concrete strengths were used $(40,50,100,125,145 \mathrm{MPa})$ and the results of 5 tension tests were reported.

The tension stiffening effect is highly dependent on concrete strength when the concrete strength is $100 \mathrm{MPa}$ or higher. As the concrete strength was increased from $40 \mathrm{MPa}$ to $145 \mathrm{MPa}$, the tension stiffening effect became smaller and smaller.

The normalized stress factor, $\beta$, of HSC members is proposed as the following:

$$
\beta=2.5\left(1-0.135 \ln \varepsilon_{m}\right)
$$

\subsubsection{Tension Stiffening with Steel Fibres}

According to Mindess (1995) there are two roles played by fibres in reinforced concrete:

1) Fibers may permit the residual stress carrying capacity in design as a fiber reinforced concrete matrix is able to carry a considerable amount of load over large deflections.

2) Fibers enhance the bond between the reinforcement and the matrix due to the fact that fibres span secondary cracks emanating from the deformations on the rebar.

Abrishami and Mitchell (1997) investigated the effect of steel fibres on the tensile behavior of reinforced concrete elements subjected to pure tension. Aspects studied included the tension stiffening effect as well as cracking characteristics (see Figure 2-29).

The presence of steel fibres controlled the splitting cracks and hence led to significant improvements in the tension stiffening in both the normal strength concrete and high strength concrete specimens. After yielding of the reinforcing steel, only those specimens with steel fibers showed increases in stress with increasing amounts of strain.

A prediction of the tension stiffening effect in fibre reinforced concrete was developed as follows. 
First the average strain the in steel was assumed to be the same as the overall strain in the specimen. If the strain in the steel is known, the stress in the steel can be calculated and with this the average stress in the concrete can be calculated.

$$
f_{c}=\frac{N-E_{S} A_{s} \varepsilon}{A_{c}}
$$

Where

$\mathrm{A}_{\mathrm{s}}=$ cross-sectional area of the reinforcing bar

$\mathrm{E}_{\mathrm{s}}=$ modulus of elasticity of the reinforcing bar

Using this approach, the influence of the fibres in improving the tensile response are automatically included in the $f_{c}$ term.

After the yielding of the reinforcing steel, large deformations occur whereby the steel fibres contribute by carrying loads across cracks. The force at the crack in the steel fibre can be determined as follows:

$$
N_{f}=N-N_{y}
$$

The tension in the steel fibres at the crack location, $N_{f}$, after the yielding of the primary reinforcement was expressed as:

$$
N_{f}=A_{f} E_{f} \varepsilon_{f}
$$

In which the strain was assumed to conservatively be taken as equal to any increased strain which took place after yielding of the primary reinforcement:

$$
\varepsilon_{f}=\varepsilon-\varepsilon_{y}
$$

The effective area of the steel fibres, $A_{f} I$, was written as follows:

$$
A_{f}=\frac{1}{2} \times \frac{1}{3} V_{f} A_{c}
$$


Where $V_{f}$ is the percent of fibers in the specimen by volume and $A_{c}$ is the net area of concrete. Also, it was assumed that half of the fibers cross the cracking plane and one third of the fibers are aligned effectively in plane with the tensile load.

$$
N_{f}=\frac{1}{6} V_{f} E_{f} A_{c}\left(\varepsilon-\varepsilon_{y}\right) \geq \frac{1}{6} V_{f} A_{g} f_{y f}
$$

Where

$f_{y f}=$ yield strength of the steel fibres

$N_{f}$ is a linear equation for the axial tension in the reinforced concrete specimen after yielding of the primary reinforcing steel. A linear elastic approximation is used up until first cracking, and afterwards the equation proposed by Collins and Mitchell is used.

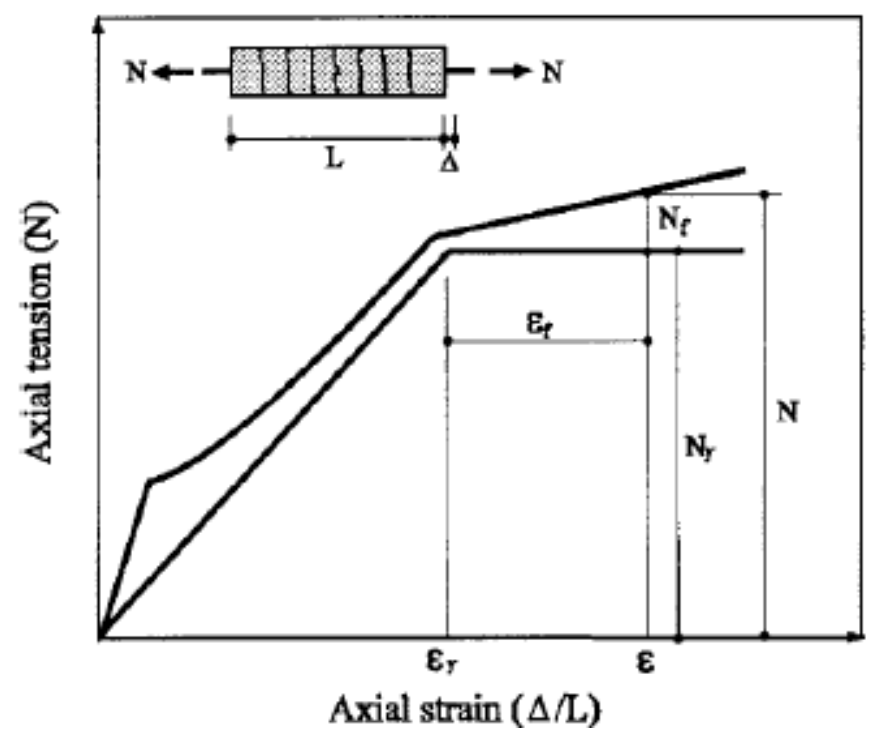

Figure 2-29: Typical Response of FRC tension specimen

[Adapted from Abrishami and Mitchell (1997)]

The second study available which studies the effect of fibre reinforcement on the tension stiffening behavior in reinforced concrete is by Bischoff (2003). This study investigated the postcracking behavior of direct tension specimens using both plain concrete and steel fibre reinforced concrete (see Figure 2-31). Both monotonic and cyclic loads were used in the experimental program and shrinkage effects were considered. Tension stiffening results are used to determine 
the average tensile response after cracking and an equation is developed to approximate the tension stiffening behavior of SFRC using a smeared crack approach. Specimens with SFRC exhibited closer crack spacings and smaller crack widths than plain concrete specimens. The resultant bond factor from this study was:

$$
\beta_{f}=\beta_{c}+0.4 \frac{P_{f}}{P_{c r}}
$$

where

$\beta_{c}=$ the bond factor for plain concrete

$P_{f}=$ the tensile capacity of fiber concrete at a crack

$P_{c r}=$ the cracking capacity of the concrete

Once the steel yields, the bond factor is controlled simply by the capacity of the concrete at a crack and the bond factor becomes:

$$
\beta_{f}=\frac{P_{f}}{P_{c r}}
$$

The bond factors mentioned above represent average values for the tensile contribution of the cracked concrete normalized with the cracking strength. Figure 2-30 compares the bond factors proposed for both the plain and fiber reinforced cases with experimental work conducted by Bischoff (2001). The results are also compared with CEB (Comite Euro-International du Beton (CEB-FIP), 1993) which proposes a constant bond factor of 0.4 and the model suggested by Collins and Mitchell (1997), discussed earlier. The main difference for the different normalized bond factor for FRC is due to the contribution of the fibres at crack locations. This phenomenon is accounted for in the equation proposed above. 


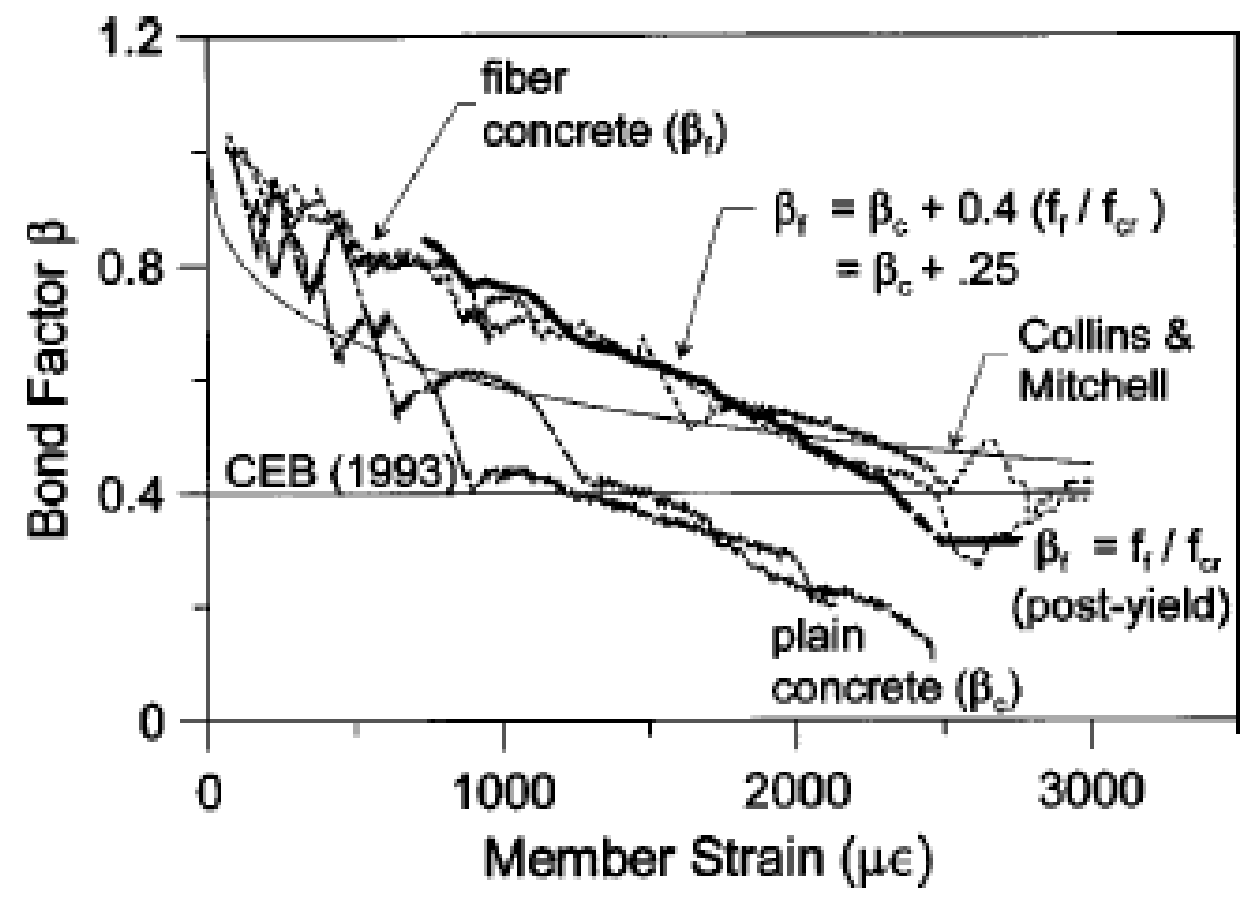

Figure 2-30: Bond Factors for average post cracking tensile strength of concrete [Adapted from Bischoff (2003)]

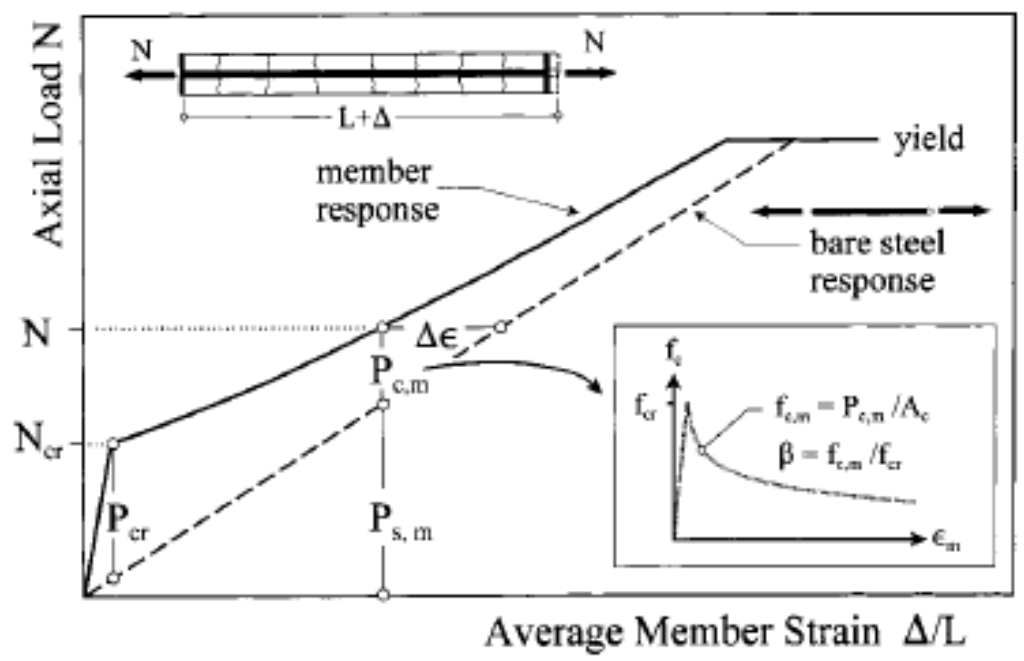

Figure 2-31: Tensile response of axially loaded member and calculation of bond factor [Adapted from Bischoff (2003)] 
A series of tests was also performed at the University of Toronto to study the effect of a combination of steel fibre reinforced concrete and conventional reinforcement on tension stiffening and crack widths. A series of papers were published discussing the cracking behaviour of fibre-reinforced concrete elements with conventional reinforcement as well as the tension stiffening behaviour of steel fibre-reinforced concrete containing conventional reinforcement.

The tension stiffening behaviour was analytically investigated with regards to tensile stresses developed in the reinforcing bars, tensile stresses induced in the steel fibres bridging a crack, and the bond mechanism between the reinforcing bar and the concrete matrix. A tension stiffening model was developed which was able to accurately predict the behaviour of reinforced concrete elements reinforced with steel fibers subjected to direct tension. This research is practical because it allows the analysis of members co-reinforced with both conventional reinforcement and steel fibre reinforcement.

The diverse embedment model was developed whereby both the uniform frictional bond stresses and mechanical anchorage effects were used to model the pullout behaviour of a steel fibre from the matrix. Using this model, elements using straight and hooked-end steel fibres can be analyzed accurately.

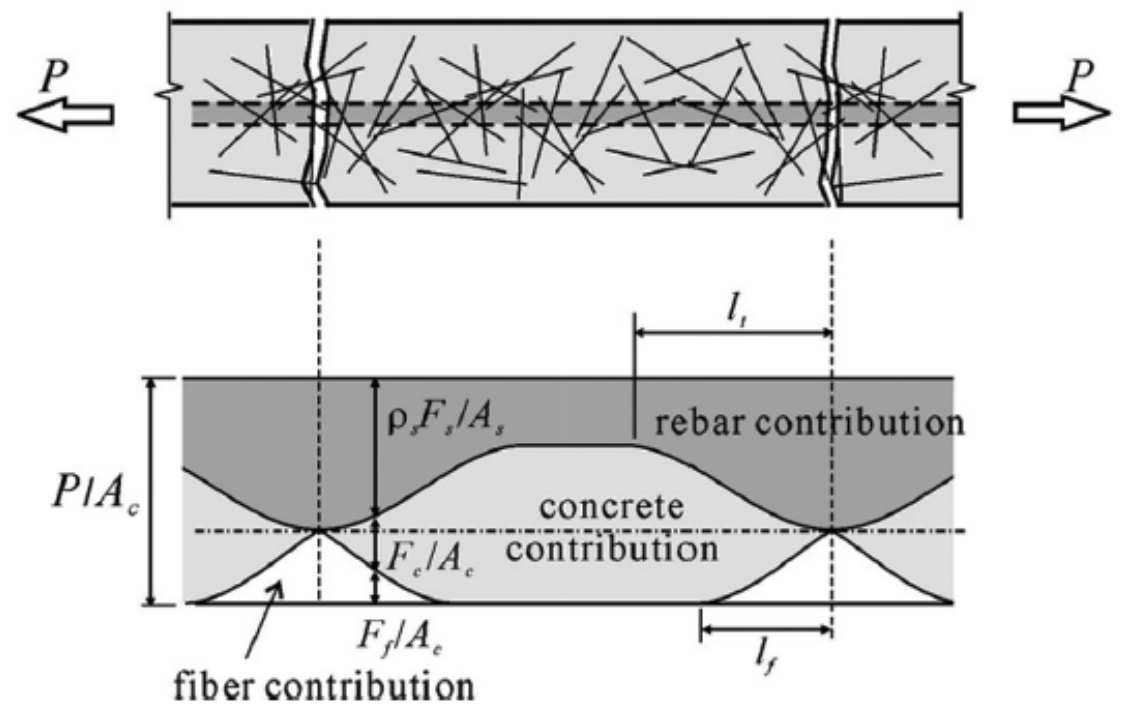

Figure 2-32: Distribution of stresses between cracks in R/FRC members

Adapted from (Lee et al. (2013)) 
Figure 2-32 shows the distribution of stresses in members reinforced with with conventional reinforcement and steel fibre reinforcement. It is shown that the steel fibres also carry a portion of the tensile load at the crack location. In this study, the contributors to tensile stress resistance are divided into two categories. The first is the contribution from the steel fibres which can be analyzed using the diverse embedment model and the second is due to the concrete matrix which can be obtained by subtracting the fibre contribution.

Deluce and Vecchio (2013) tested a series of 48 uniaxially stressed FRC specimens. The crack widths and crack spacing aligned with the proposed cracking model by Lee et al. (2013). Crack spacing is very important when analyzing the tension stiffening effect proposed by Lee because the stress attained by the steel fibres is based on the crack widths. The crack width is calculated by multiplying the average strain by the crack spacing. Based on the axial force strain relationship from Deluce and Vecchio the crack analysis procedure was validated and can be used to make reasonable evaluation of the tension stiffening effect in FRC members coreinforced with conventional steel reinforcement.

The conventional tension-stiffening model for RC members was modified to take into account the effect of the steel fibres as follows:

$$
f_{c, T S}=\frac{f_{c r}}{1+\sqrt{3.6 c_{f} M \varepsilon_{t, a v g}}}
$$

Where $c_{f}$ is the coefficient to consider the effect of steel fibres. The bond parameter $M$ is calculated from:

$$
M=\frac{A_{c}}{\sum d_{b s} \pi}
$$

Where $A_{c}$ is the cross sectional area of the concrete and $d_{b s}$ is the diameter of the reinforcing bar and $\mathrm{c}_{\mathrm{f}}$ is defined as follows for hooked-end steel fibres:

$$
c_{f}=0.6+\frac{1}{0.034}\left(\frac{l_{f}}{d_{f}}\right) \frac{\left(100 V_{f}\right)^{1.5}}{M^{0.8}}
$$


The linear inverse proportional relationships defined in $\mathrm{c}_{\mathrm{f}}$ adequately capture the effect of fibre volumetric ratio and fibre aspect ratio respectively from the analytical modeling done.

Figure 2-33 shows a comparison of the proposed tension stiffening model with experimental results by both Bischoff (2001) and Deluce and Vecchio (2013). The proposed tension stiffening equation shows accurate prediction prior to yielding of the reinforcing steel which means that accurate predictions are made regarding the bond mechanism between the reinforcing steel and the concrete matrix. Also, the model accurately predicts the post-yield behaviour and the fibre contribution to tensile capacity in the post-yield range.
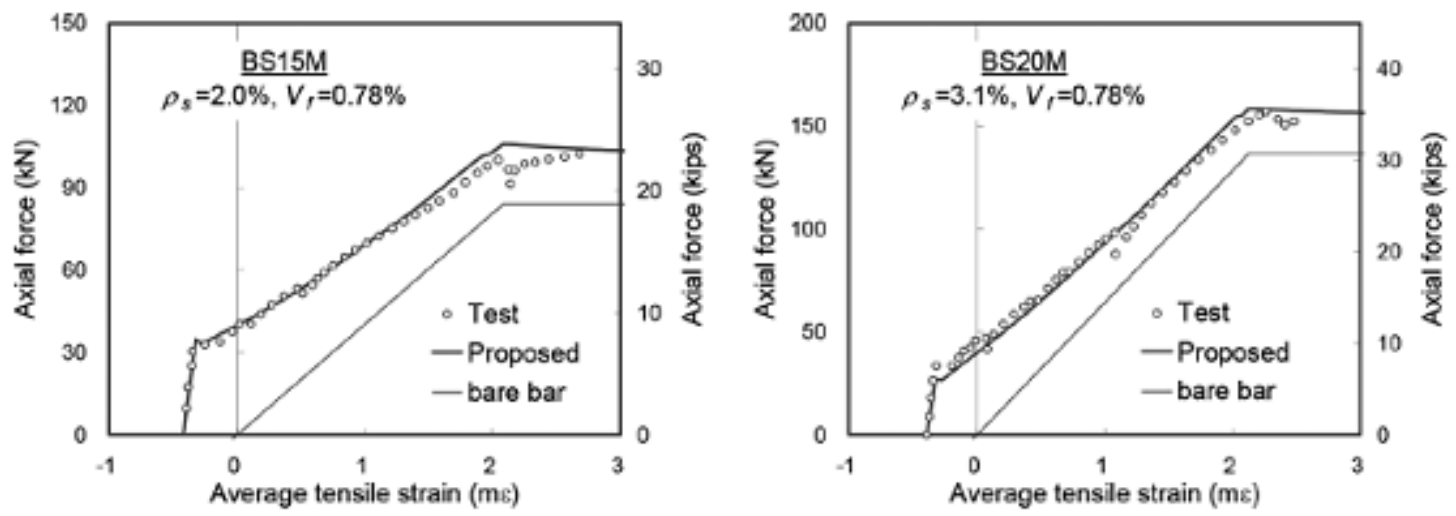

(a)
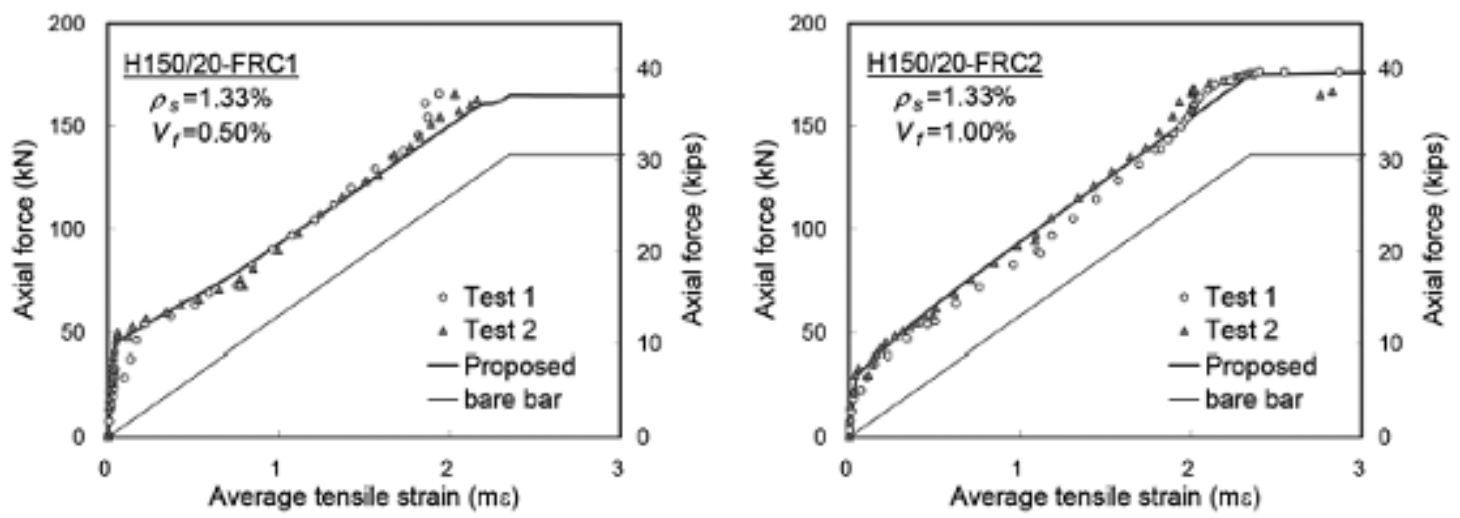

(b)

Figure 2-33: Comparison of proposed tension stiffening model and test results by a)Bischoff and b) Deluce and Vecchio (Adapted from Lee et al. (2013)) 


\subsubsection{Tension Stiffening in Reinforced Masonry}

Analytical modeling requires correct representation of material behavior and although much research has been conducted in reinforced concrete on tension stiffening, little research has comparatively been done in reinforced masonry. In order to correctly predict quantities such as deflections and strength in analytical programs, the tensile behavior must be well known. The phenomenon of tension stiffening in reinforced concrete is well documented and researched as discussed in Section 2.4.2, however the tension stiffening behavior of reinforced concrete masonry has not been investigated to the same extent. This tensile behavior in the post-cracked state is extremely important to understand when analyzing structural elements such as walls under both in plane and out of plane flexural loading.

Before masonry materials crack in tension, their behavior is approximately linear elastic. Whenever the load reaches a level at which cracking occurs, a redistribution of stresses occurs and the steel must carry the entire load across the crack (see Figure 2-31). The portion of masonry that remains uncracked in between the principle tensile cracks carry a portion of the tensile load through mechanical interlock with the reinforcing steel as well as through the adhesive bond between the reinforcement and the grout. For this reason, and similar to in reinforced concrete, the post cracking behavior is influenced and becomes slightly stiffer than the bare steel response. The degradation of this tensile stress in the masonry will be discussed further in this section and the published research will be discussed.

\subsubsection{Previous Research and Models}

The tension stiffening effect is most pronounced for lightly reinforced elements subjected to loads in the service range (Massicotte et al. (1990)). For this reason, masonry is an ideal material for studying the tension stiffening effect in more detail due to the fact that these are the typical reinforcement and loading details of a typical reinforced masonry element.

Several analytical models have been proposed which look at the behavior of every single reinforcing bar and crack in the structure, but this approach is not realistic for analyzing large structural elements (Soric and Tulin, (1987)) (Gupta and Maestrini, (1990)). Instead, averaged values for the contribution of cracked masonry in tension to overall stiffness of the elements are 
more appropriate. For example, averaged properties of reinforcement geometry and bar-grout bond behavior were employed to model the masonry behavior by Seible et al. (1990).

Due to the fact that masonry elements are typically lightly reinforced, the tension stiffening behavior is important to be analyzed because it can significantly reduce the calculated deflections. In modern design codes, these deflections are often used as criteria for determining the overall performance of a structural element, therefore it is important that these deflections are accurately calculated.

\subsection{Nunn et al. Research}

Nunn et al. (1978) and Nunn et al. (1980) conducted a series of three tests on reinforced masonry wall panels and findings on the tension stiffening behavior were reported. The three wall panels were cut from larger walls and each had differing angles between the panel edge and the masonry bed joint. A stiff biaxial load frame induced biaxial loads to the wall specimens varying the loads proportionally such that zero stress occurred at the masonry head joints.

Through the tests, Nunn et al were able to evaluate the tensile stiffness degradation as a function of tensile strain. The proposed curve is shown in Figure 2-32, where the curve has the form $1 / \varepsilon$ and becomes asymptotic to the steel stiffness at strains of about $2 \times 10^{5}$. 


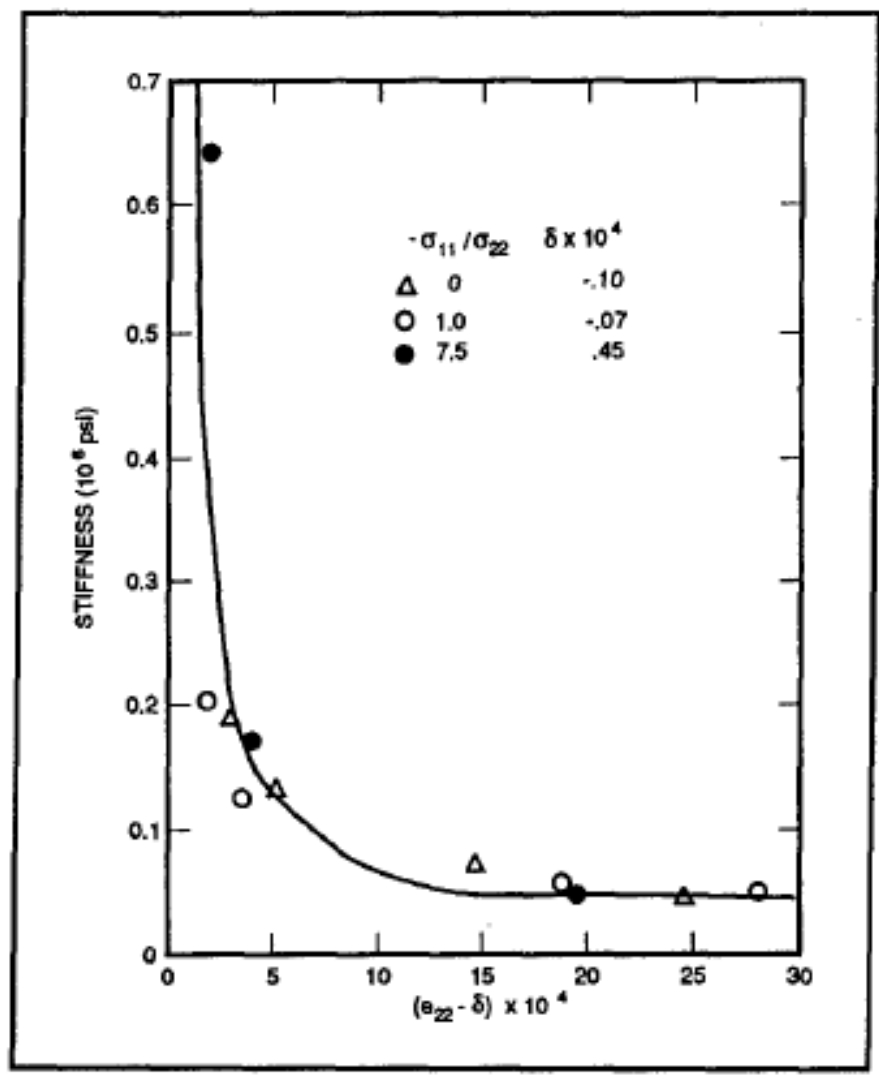

Figure 2-34: Tensile stiffness as a function of tensile strain

[Adapted from Nunn (1980)]

\subsection{Atkinson and Hammons Research}

Atkinson and Hammons (1997) conducted a series of 33 direct tension tests on both concrete masonry and clay unit masonry specimens. All specimens were constructed using a stack bond pattern using half-width units to provide a single vertical cell. This study was a part of a larger study investigating the behaviour of reinforced masonry for the development of limit states design criteria. The specimens were instrumented with externally mounted LVDT's to observe the load deformation behavior and to conclude if the tension stiffening behavior was similar to that of concrete. All specimens were analyzed based on the LVDT's to calculate average strain in the specimen and the stress in the specimen was based on the steel area of the main reinforcement. The stress strain behavior of a typical specimen is shown in Figures 2-35 and 2-36. Figure 2-35 shows the entire stress strain response whereas Figure 2-36 shows the stress strain response prior to the yielding of the reinforcing steel. The primary variable in the 
research was the steel reinforcement ratio. By varying both the bar size and the cross sectional area of the specimen, a wide range of reinforcement ratios was obtained.

After cracking, they observed that the effective stiffness rapidly decreased and at a stain of approximately 4 times that required to crack the element, the stiffness was reduced to that of the bare bar. It was seen that the loss of stiffness added by the concrete unit, grout, and mortar is far more rapid than the loss of stiffness observed in reinforced concrete.

They also observed that for small reinforcement ratios, the ductility after yielding of the reinforcing bar was significantly reduced. For large reinforcing ratios, the stress-strain response followed the same general flat yielding zone as the bare bar (see Figure 2-35), whereas with smaller reinforcement ratios this yielding zone was not present. This is partially due to the fact that the number of cracks decreases as the reinforcement ratio decreases causing the total strain to be distributed over a smaller number of cracks. Also, the transfer distance of the stress to the surrounding concrete becomes smaller as the bar size decreases because there is less force being imparted. This decreases the unbonded length of the bar and hence decreases the length of bar in which the strain is localized at a given crack location.

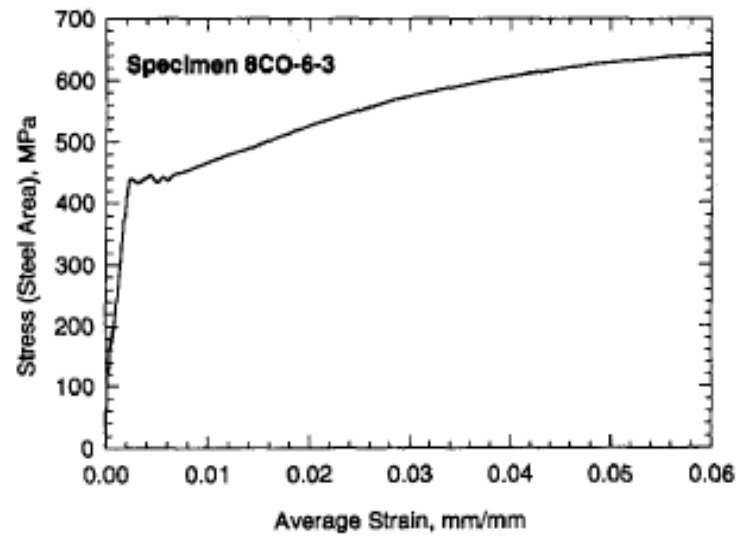

Figure 2-35: Stress-strain relationship of entire response (Specimen 8CO-6-3) [Adapted from Atkinson and Hammons (1997)]

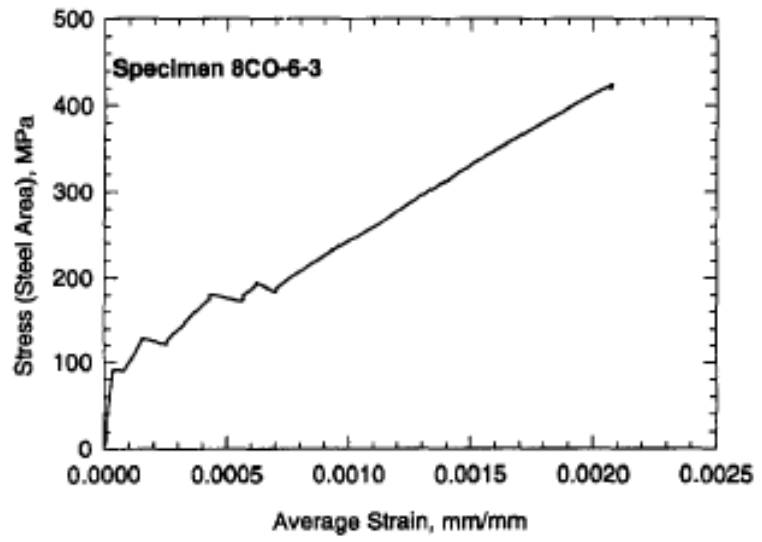

Figure 2-36: Stress-strain relationship at low strain levels (8CO-6-3) [Adapted from Atkinson and Hammons (1997)] 
Figure 2-37 shows the effective effective modulus based on the steel area vs. the average strain in the specimen. The figure shows that the modulus rapidly decreases in magnitude at very low levels of overall strain. This drop in stiffness is much more pronounced than in reinforced concrete.

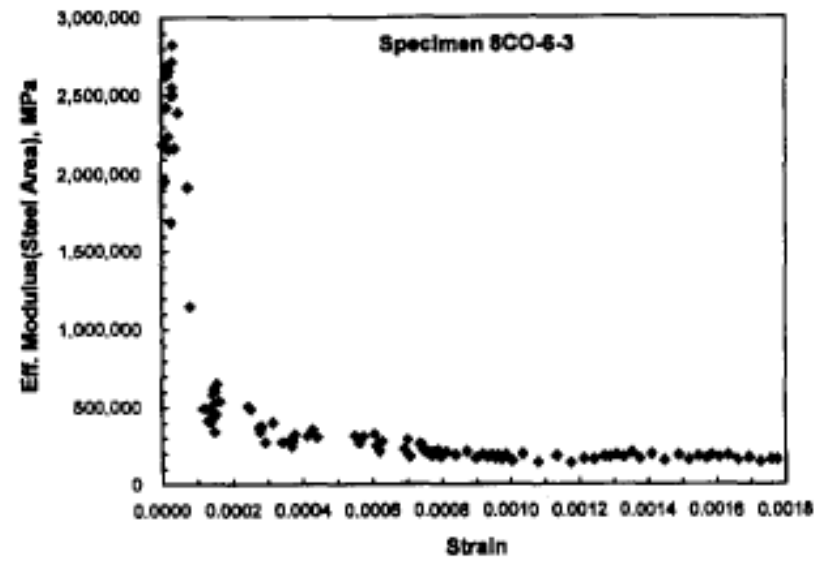

Figure 2-37: Degradation of effective modulus as a function of strain (8CO-6-3) [Adapted from Atkinson and Hammons (1997)]

Figures 2-38 and 2-39 similarly show the decrease in steel referenced stiffness as a function of the overall strain. At 3.7 times the strain required to crack the specimen, the stiffness is essentially the same as the bare reinforcing steel showing no contribution from the cracked masonry. Figure 2-39 shows the stepped decrease in stiffness for reinforced concrete along with the sharp decrease in stiffness for reinforced masonry.

\begin{tabular}{c|c|c}
\hline \hline $\begin{array}{c}\text { Steel } \\
\text { referenced } \\
\text { stiftness } \\
(\mathrm{MPa})\end{array}$ & $\begin{array}{c}\text { Average strain } \\
\left(10^{-\epsilon}\right)\end{array}$ \\
$(1)$ & $(2)$ & $\varepsilon / \varepsilon_{e}$ \\
30 & 256 & $(3)$ \\
60 & 131 & 3.7 \\
150 & 55 & 1.9 \\
300 & 15 & 0.8 \\
\hline \hline
\end{tabular}

Figure 2-38: Average steel stiffness vs. average strain for 14 specimens tested

[Adapted from Atkinson and Hammons (1997)] 


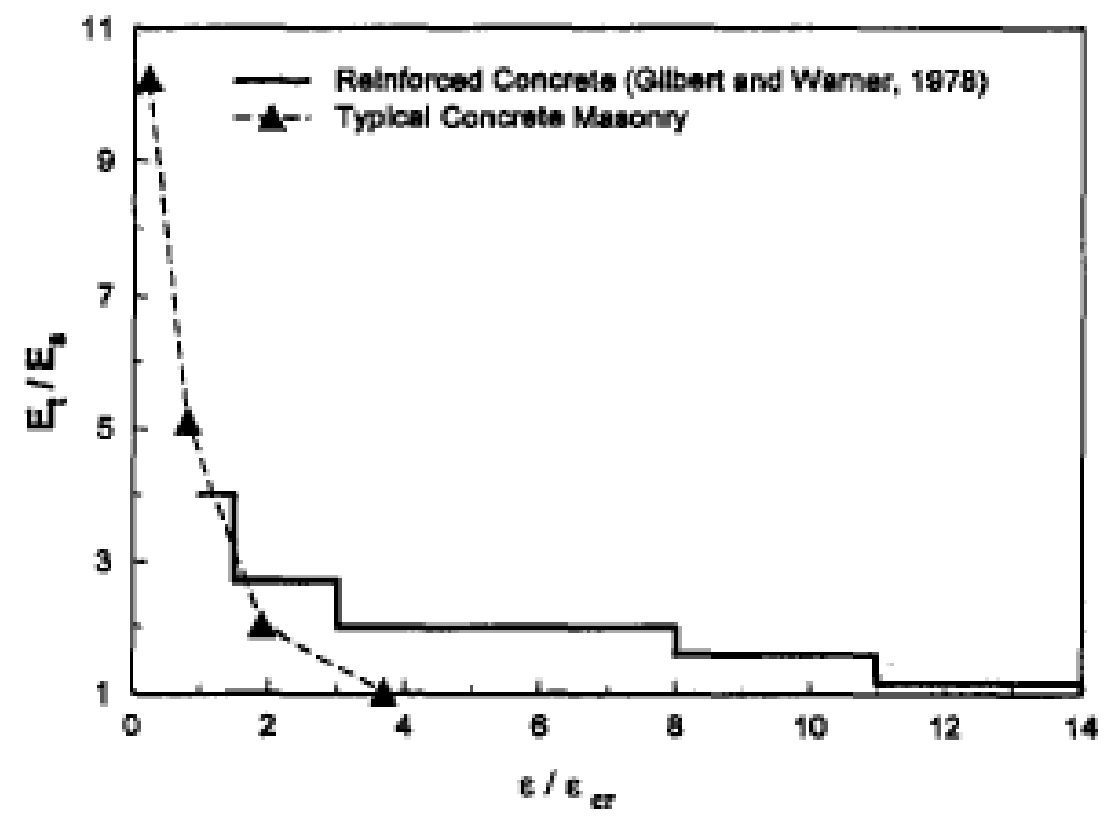

Figure 2-39: Comparison between the stiffness degradation of concrete vs. masonry

[Adapted from Atkinson and Hammons (1997)]

\subsection{Summary of Literature Review}

Although much research has been done in the area of tension stiffening for reinforced concrete, a comparable amount has not been conducted in reinforced concrete masonry. Due to concrete masonry's tendency to rapidly lose stiffness after cracking (see Figure 2-35), it is thought that steel fibre reinforced grout could significantly improve masonry's post-cracking performance, namely the decrease in stiffness added by the surrounding cracked masonry materials as a function of strain.

By conducting a large volume of experimental work with a wide range of variables, the potential for fibre reinforced grout in a wide range of masonry construction applications will be investigated. It is also hoped that the findings of this thesis will initiate further related research. It is thought that fibre reinforced concrete masonry could be beneficial not only for their increased stiffness but also for seismic enhancement in shear walls for example, and for increased shear strength in flexural members. 


\section{Experimental Program}

\subsection{Introduction}

Although there has been significant research into the uniaxial compressive behavior of reinforced masonry, much less research has been done regarding the uniaxial tensile behavior. The main purpose of this experimental research is to investigate the effect of steel fibre reinforced grout on the tensile performance of reinforced masonry elements subjected to a uniaxial tensile load. Parameters such as the ductility, crack control, and the tension stiffening effect will be examined.

A series of 42 direct tension specimens were constructed at the Carleton University structural lab under controlled laboratory conditions and were tested against various performance measures. This section discusses the construction of the tension specimens as well as the material properties of the constituent materials in both the fresh and hardened states. Shrinkage effects were neglected so as to provide a conservative approximation of the tensile behavior.

\subsection{Materials}

\subsubsection{Hollow Concrete Masonry Units}

The hollow concrete masonry units were all made by Permacon in a single batch, and were delivered to Carleton University by Merkley Supply Ltd. of Ottawa. Thirteen standard lintel units were obtained from a different lot which was ordered for a separate set of experimental masonry tests at Carleton University.

The standard half unit blocks measured $190 \mathrm{~mm} \times 190 \mathrm{~mm} \times 190 \mathrm{~mm}$ and were tested in the structural lab for compressive strength. The standard lintel units which measured $190 \mathrm{~mm} \times 190 \mathrm{~mm} \times 390 \mathrm{~mm}$ were also tested in the lab for compressive strength to assure that the unit compressive strengths were similar. 
To measure the unit compressive strength, blocks were capped with hydro stone, a gypsum based product which attains a high early compressive strength, prior to compressive testing (see Figure 3.1 to Figure 3.4). This assured that there would not be any stress concentrations imposed on the blocks from irregularities in the outer surfaces of the block.

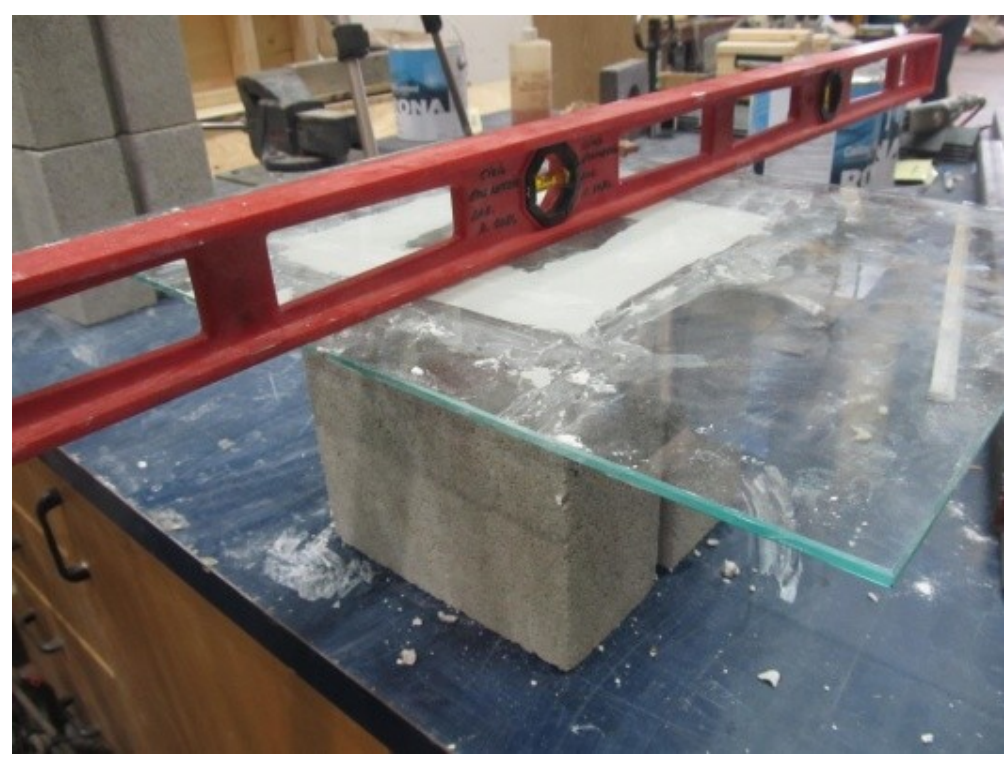

Figure 3-1: Standard CMU capped with Hydrostone

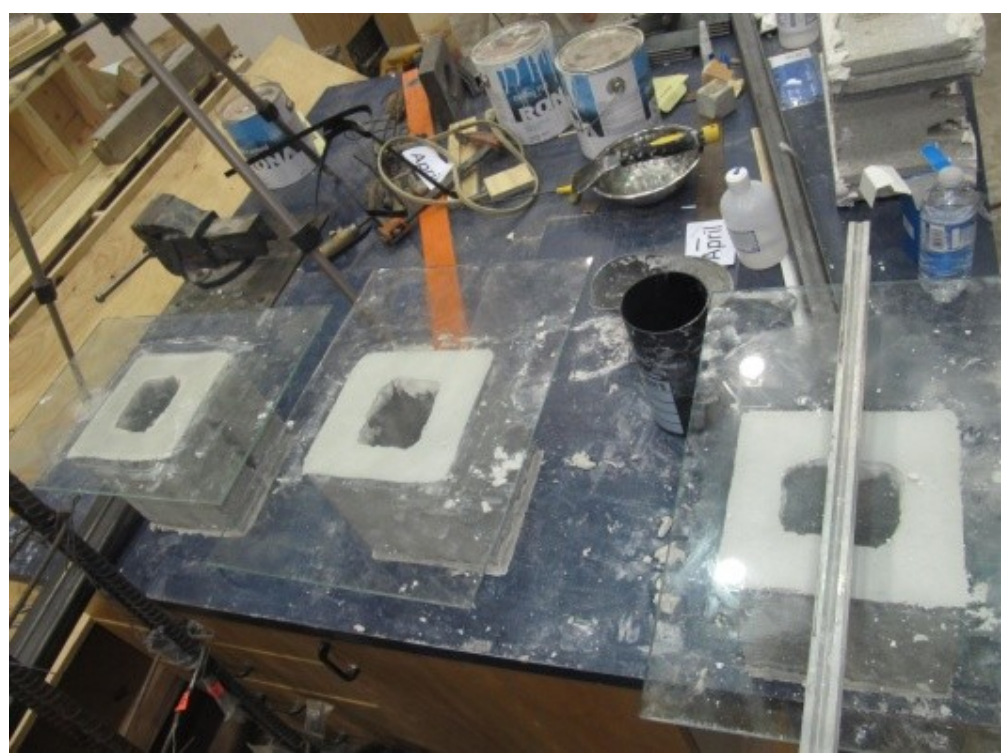

Figure 3-2: Hydrostone cured with tempered glass plates placed on level plane 


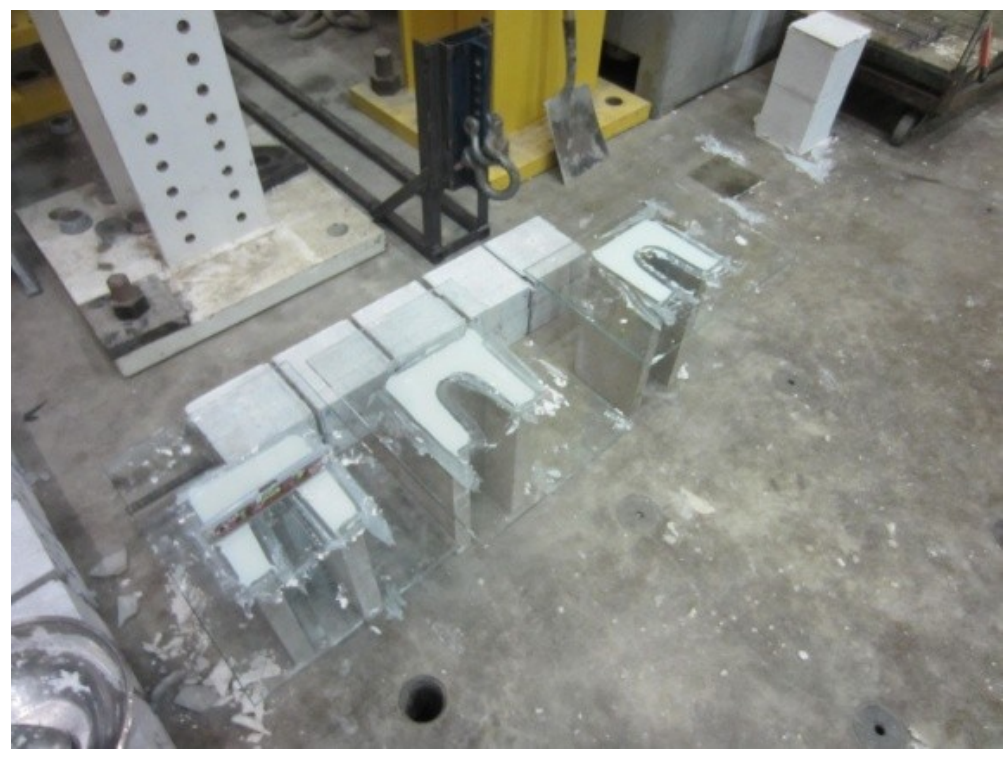

Figure 3-3: Lintel unit capped with Hydrostone

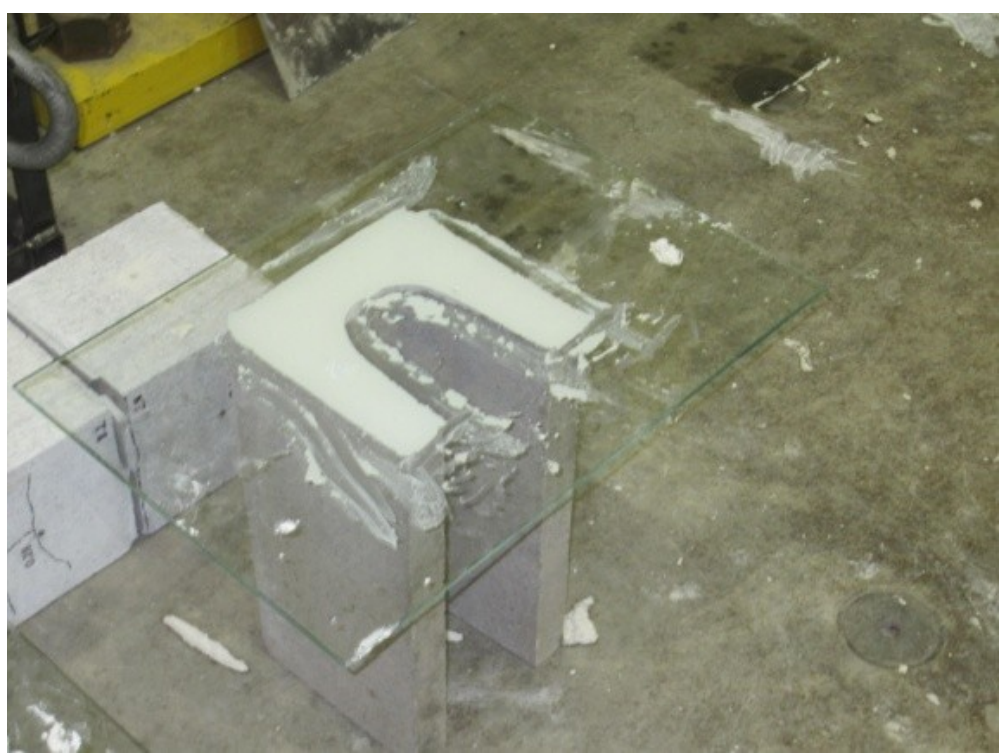

Figure 3-4: Hydrostone cured with tempered glass plate placed on a level plane 
The blocks were tested as per CSA A165.1 and were all cured well past 28 days before compressive testing. The blocks were chosen at random from the pallets to ensure that a full representation of the compressive strength of the entire lot would be obtained.

The blocks were carefully measured to assure that they were within the dimensional tolerances outlined in CSA A165.1. Also, the compressive strength of the units was based on the net area; therefore the net area of the units was measured. Units being tested in compression can be seen in Figure 3-5 and Figure 3-6.

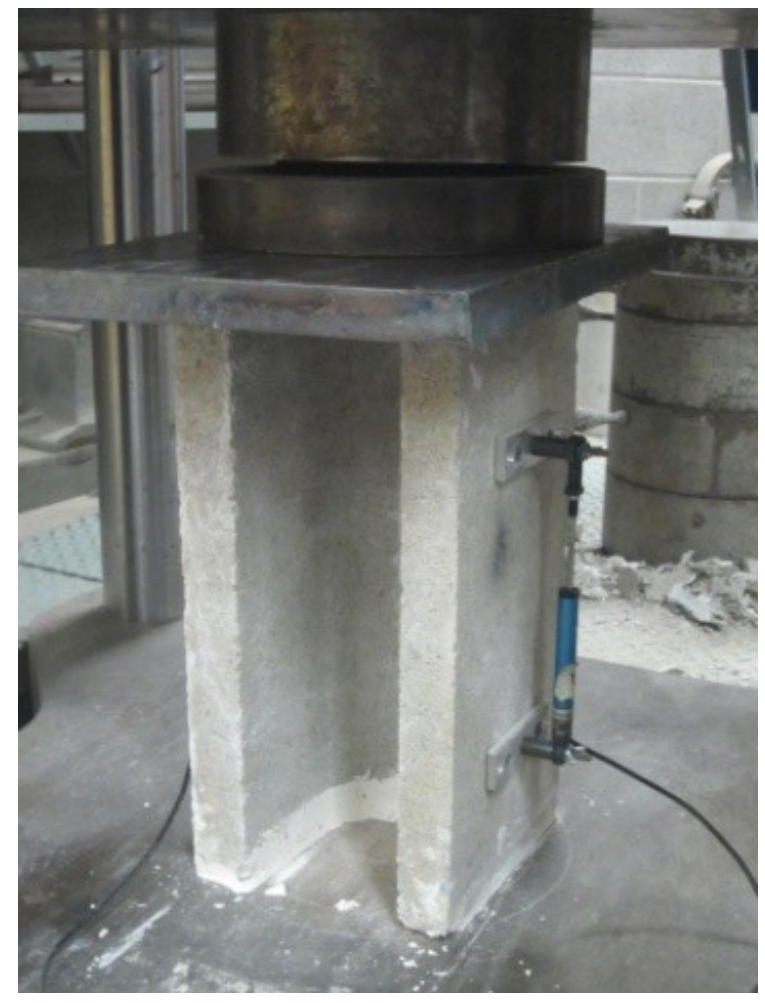

Figure 3-5: Compressive strength testing of Lintel CMU 


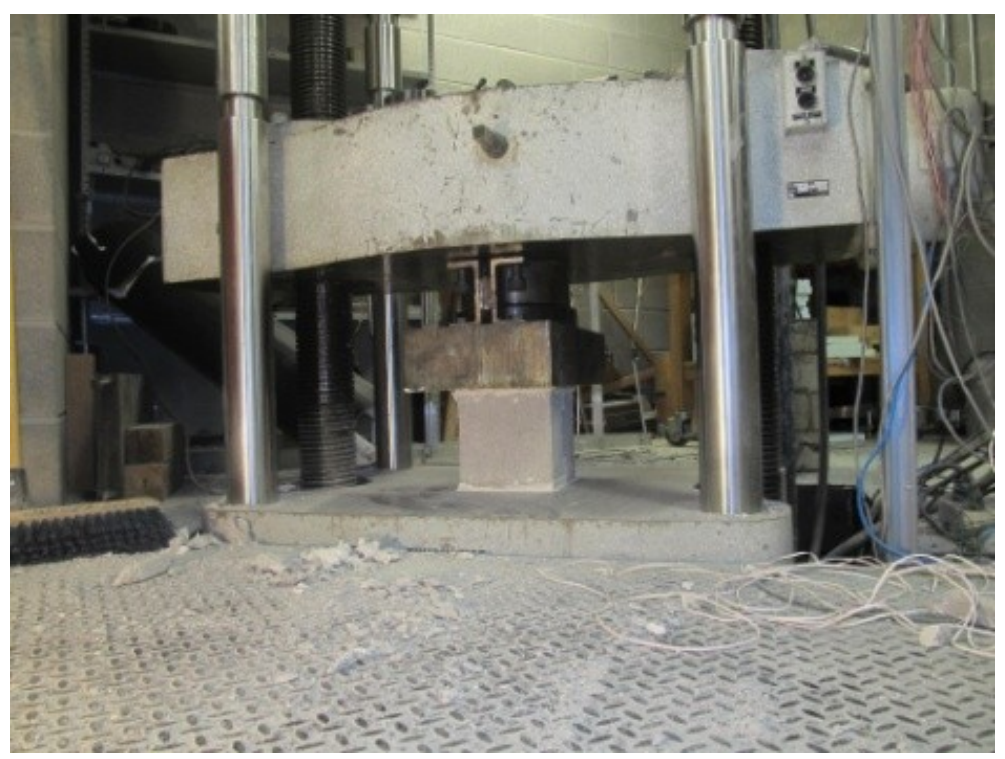

Figure 3-6: Compressive strength testing of standard CMU

Concrete strain gauges were installed on the standard $190 \mathrm{~mm}$ half units to measure the stress strain relationship of the standard concrete blocks (see Figure 3-7). LVDT's were installed on the lintel units to measure the stress strain relationship of the lintel units (see Figure 3-5). All LVDT's were mounted on the masonry units by means of machined aluminum brackets. The brackets were affixed to the masonry units by two masonry screws and washers were used as spacers between the brackets and the masonry to assure that there were small contact areas, hence eliminating any risk of slip due to increased stress applied over the washer's surface. 


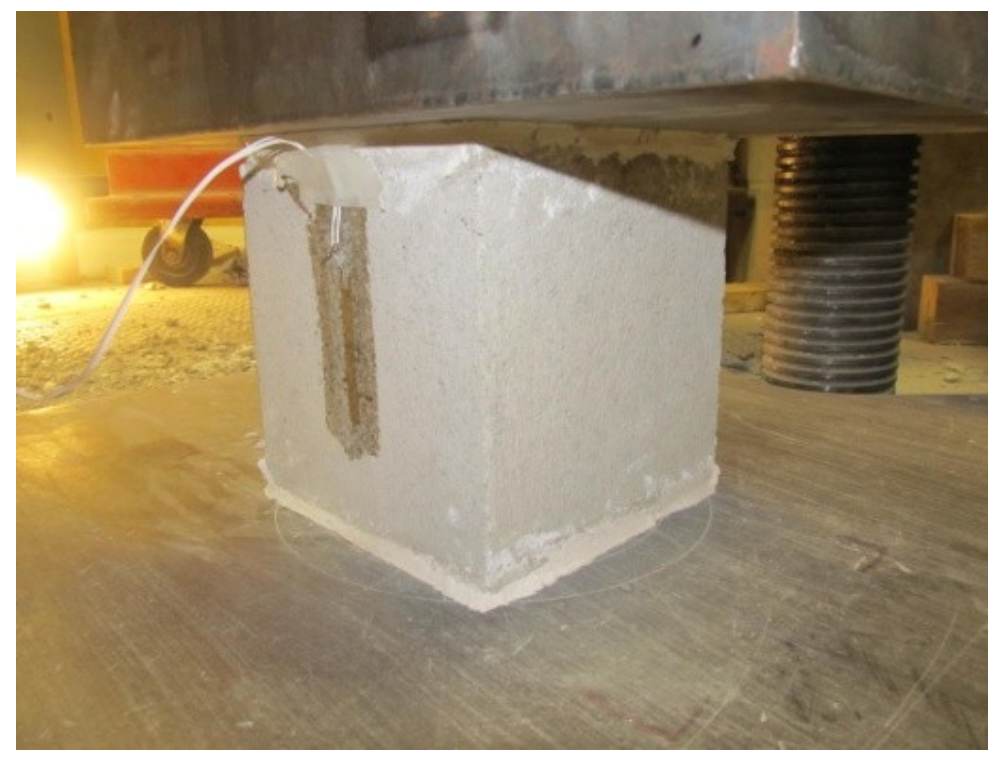

Figure 3-7: Stress strain behaviour of standard CMU using strain gauges

The masonry unit compressive strength data from the tests outlined above are available in section 4.2.6.

\subsubsection{Reinforcing Steel}

Standard deformed reinforcing bars with a specified yield stress of 400MPa were used in the construction of the specimens. Three different sizes were used within the specimens as longitudinal reinforcement: 10M, 15M, and 20M. All three sizes of reinforcing bars were used with the standard units whereas only $15 \mathrm{M}$ bars were used within the lintel type units. Reinforcing steel with diameters of $20 \mathrm{~mm}$ or less were chosen as typically small size reinforcement is used in reinforced masonry.

Standard steel reinforcement coupon tests were performed according to ASTM A370 in the MTS tensile testing machine at Carleton University (see Figures 3-8 and 3-9). The testing machine used had a $500 \mathrm{kN}$ capacity and is able to attain a loading rate based on either load or displacement. For the steel reinforcement tests, the MTS testing apparatus was set to load under displacement control. Due to the fact that large displacements occur with very little increase in load at the onset of yielding, it is very difficult to control the loading rate if using load control. To avoid load rate effects on the steel reinforcement the displacement based control was set at 
$2 \mathrm{~mm} / \mathrm{min}$ and then increased to $5 \mathrm{~mm} / \mathrm{min}$ after the onset of yielding of the reinforcement. This loading rate was determined to be adequate for accurate recording of the data as the data was recorded at a frequency of $5 \mathrm{~Hz}$.

The reinforcing bars were extended into the jaws of the hydraulically activated grips approximately $85 \mathrm{~mm}$ allowing a clear distance of $530 \mathrm{~mm}$ between the grips. The jaws clamped onto the reinforcing bars with a compressive stress of approximately 20MPa which is within the tolerance given by MTS so as to not create fatigue in steel surrounding the grip area. A clip gauge with a 2 inch gauge length was placed in the center of the standard reinforcing steel coupon and recorded data throughout the test at a rate of $5 \mathrm{~Hz}$. Also, a punch was used to create indentation in the steel coupon along the longitudinal rib of the reinforcing bar to measure overall strain throughout the test and especially at rupture of the reinforcing bar. The initial distance between the punch marks was $200 \mathrm{~mm}$ and the final distance between the punch marks was measured with a precise dial caliper.

Three bars of each size were tested under monotonic tensile load and the average values are reported in Section 4.2.5.

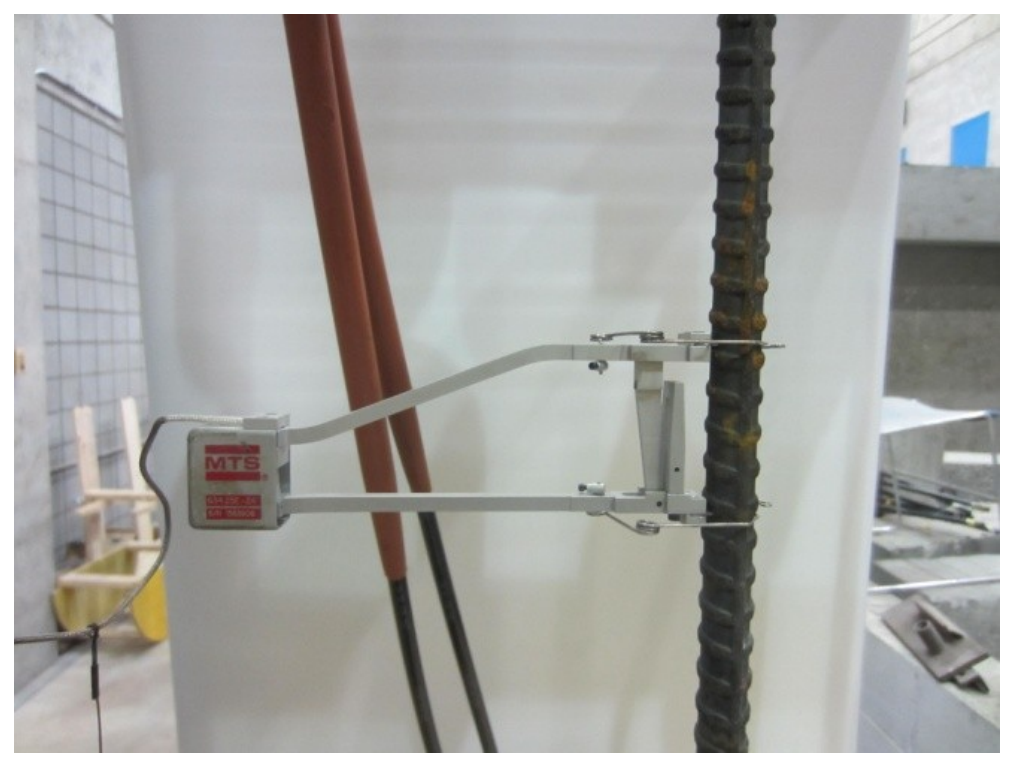

Figure 3-8: 2 inch MTS clip gauge installed on reinforcing steel 


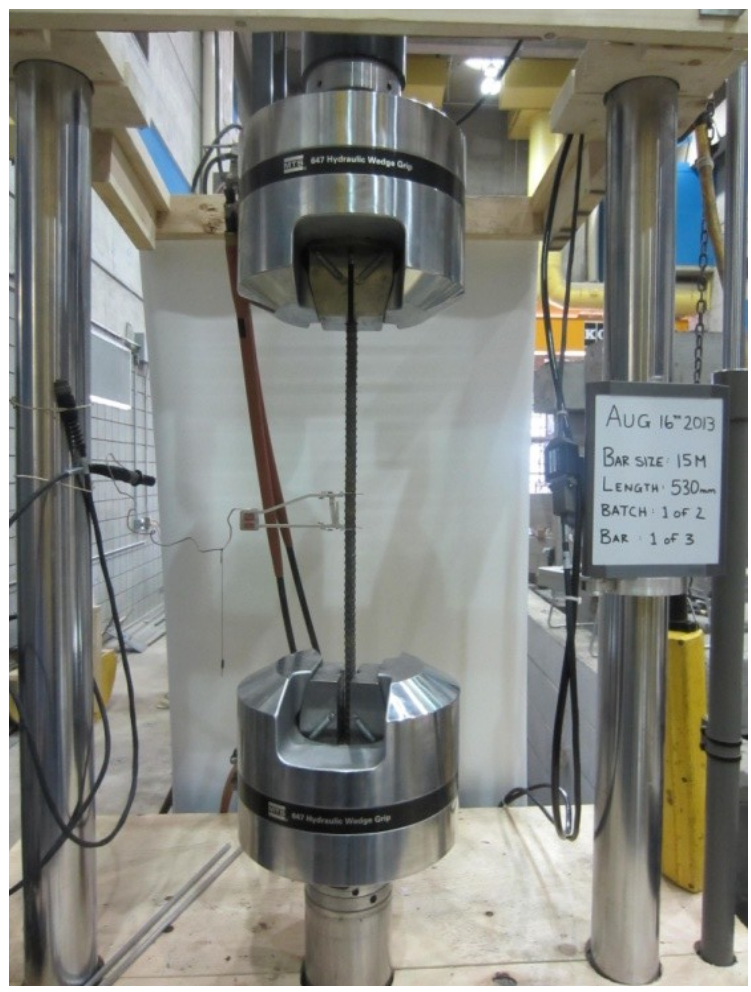

Figure 3-9: 500kN MTS testing machine testing reinforcing steel

\subsubsection{Steel Fibres}

Two types of steel fibres manufactured by Bekaert were used in the experimental work. Both of the fibre types are hooked end steel fibres which improves their pullout resistance and overall structural performance. The majority of the specimens contained varying percentages of Dramix ZP305 fibres, and two specimens were cast using Dramix RC65/60BN fibres to investigate the influence of fibre length on the performance of fibre reinforced grout (see Figures 3-10 and 3-11). Both of the fibres were manufactured by Bekaert Corporation and were bundled together in dissolvable glue for ease of incorporation into cementitious mixtures. Steel fibre properties are summarized in Table 3-1.

Dramix ZP305 fibres are considered to be normal strength steel fibres and have a tensile strength of $1345 \mathrm{MPa}$. These fibres have a length of $30 \mathrm{~mm}$ and a diameter of $0.55 \mathrm{~mm}$ giving them an aspect ratio of approximately 55. These fibres are one of the most common type of 
fibres used in modern fibre reinforced concrete research and were the primary type of fibres used in this experimental program.

Dramix RC65/60BN fibres are considered to be normal strength fibres and have a tensile strength of 1000MPa. These fibres have a length of $60 \mathrm{~mm}$ and a diameter of $0.90 \mathrm{~mm}$ giving them an aspect ratio of approximately 67 . These fibres were used in two specimens having a $15 \mathrm{M}$ bar (15M12S-1 \& 15M12S-2) to investigate the feasibility of incorporating longer fibres into the cells surrounding reinforcement in concrete block masonry construction. The structural performance of these fibres was also investigated.

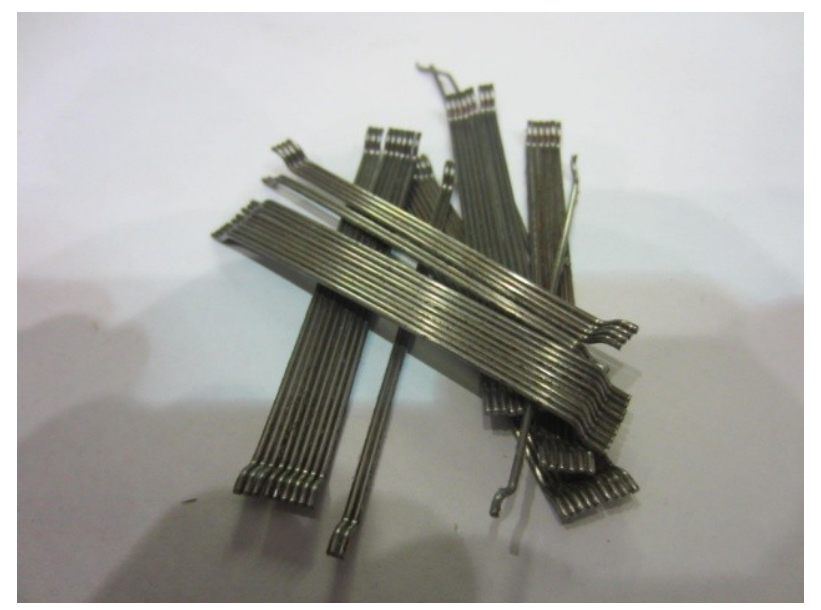

Figure 3-10: Bekaert Dramix RC65/60BN hooked end steel fibres

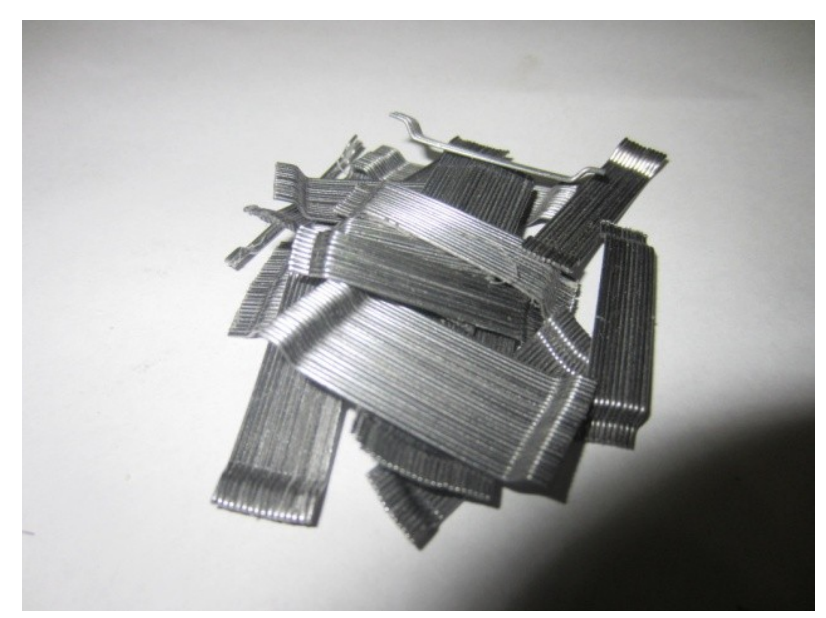

Figure 3-11: Bekaert Dramix ZP305 hooked end steel fibres 
The first type of fibres $(30 \mathrm{~mm})$ were incorporated at three different fibre contents $(0.4 \%$, $0.8 \%$, and $1.2 \%$ ) into the grout whereas the second type of fibres $(60 \mathrm{~mm})$ were only incorporated at $1.2 \%$ since it wasn't one of the primary variables. The different grouts were tested to see if there was a noticeable increase in performance when the fibre content was increased.

Table 3-1: Steel fibre properties

\begin{tabular}{|c|c|c|c|c|}
\hline Fibre Type & $\begin{array}{c}\text { Tensile Stength } \mathrm{f}_{\mathrm{fy}} \\
(\mathrm{MPa})\end{array}$ & $\begin{array}{c}\text { Length } \mathrm{L}_{\mathrm{f}} \\
(\mathrm{mm})\end{array}$ & $\begin{array}{c}\text { Diameter } \mathrm{D}_{\mathrm{f}} \\
(\mathrm{mm})\end{array}$ & $\begin{array}{c}\text { Aspect Ratio } \mathrm{L}_{\mathrm{f}} / \mathrm{D}_{\mathrm{f}} \\
(\mathrm{mm} / \mathrm{mm})\end{array}$ \\
\hline Dramix ZP-305 & 1345 & 30 & 0.55 & 55 \\
\hline Dramix RC65/60BN & 1000 & 60 & 0.90 & 67 \\
\hline
\end{tabular}

\subsubsection{Mortar}

A standard structural "Type S" mortar in accordance with CSA A179 was mixed for all specimens. The specimens were mortared together on three separate days, however the mortar mix design was held constant throughout. The constituent materials were accurately weighed prior to each batch to ensure consistency in both the workability and the strength of the mortar (see Figure 3-12). The mortar was mixed manually in a wheel barrow.

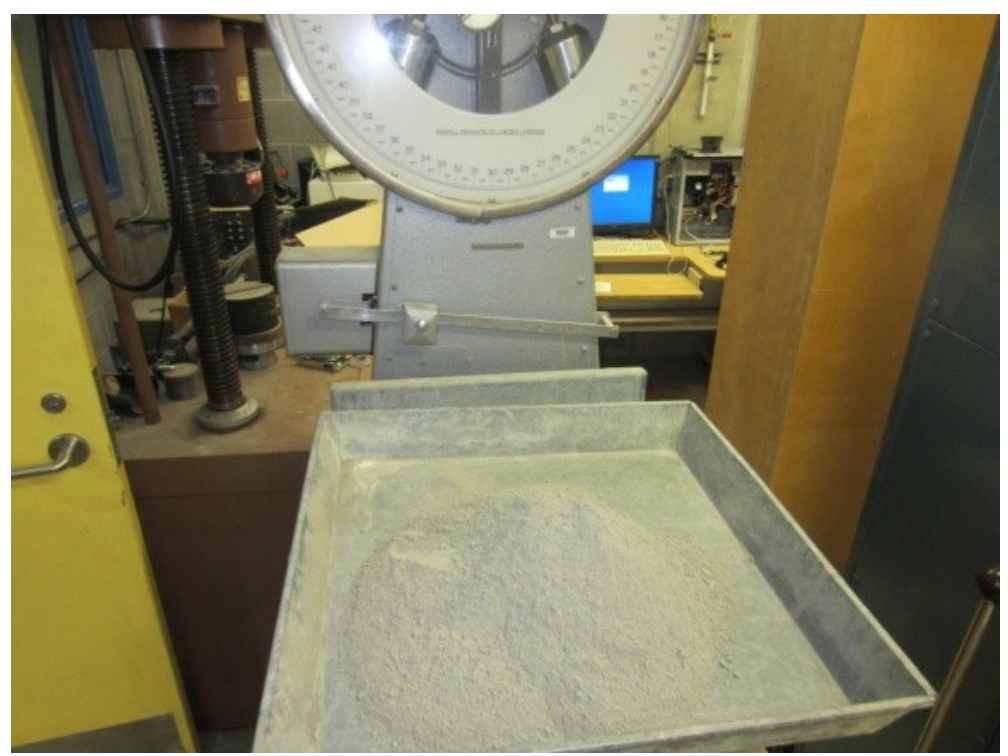

Figure 3-12: Scale and aluminum pans used to measure all materials 
Material densities were assumed to be $1505 \mathrm{~kg} / \mathrm{m}^{3}$ for cement, $640 \mathrm{~kg} / \mathrm{m}^{3}$ for lime, and $1280 \mathrm{~kg} / \mathrm{m}^{3}$ for masonry sand. The volumetric proportions used for the mix were 1:0.5:4 (cement: lime: sand). Water was added to the mix in order to achieve the desired workability, as would be done on a job site. A standard mortar flow table was used to determine the mortar flow and determine if the mortar had the correct workability (100-115\%). Six mortar cubes measuring $50 \mathrm{~mm} \times 50 \mathrm{~mm} \times 50 \mathrm{~mm}$ were taken from each mortar mix for quality control testing (see Figure 3-13).

Table 3-2: Typical mix proportions for Type $\mathrm{S}$ mortar

\begin{tabular}{cc}
\hline Material & Mass \\
\hline Cement & $7.7 \mathrm{~kg}$ \\
Sand & $26.2 \mathrm{~kg}$ \\
Lime & $1.6 \mathrm{~kg}$ \\
Water & $6.8 \mathrm{~kg} *$ \\
Total & $\mathbf{4 3 . 3 \mathrm { kg }}$ \\
\hline *water volume varied based on workability requirements \\
\hline
\end{tabular}

The brass mold was placed on the mortar flow table, filled with mortar rodded 20 times using two different lifts and then the top was struck off to ensure the exact volume of mortar desired was present in the mold (see Figure 3-15 and 3-16).

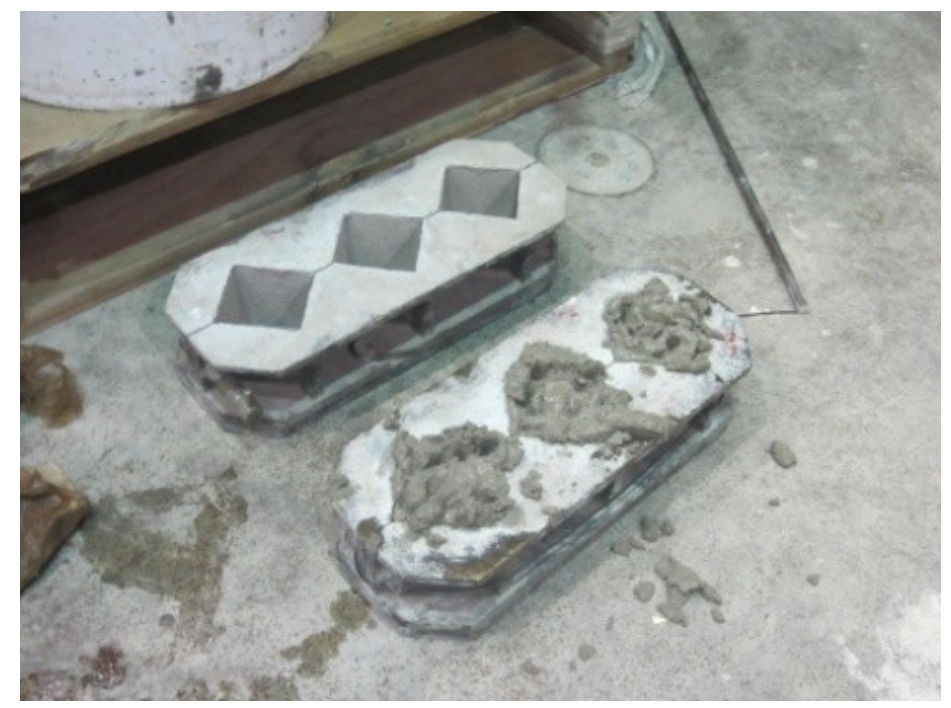

Figure 3-13: Mortar cube moulds 


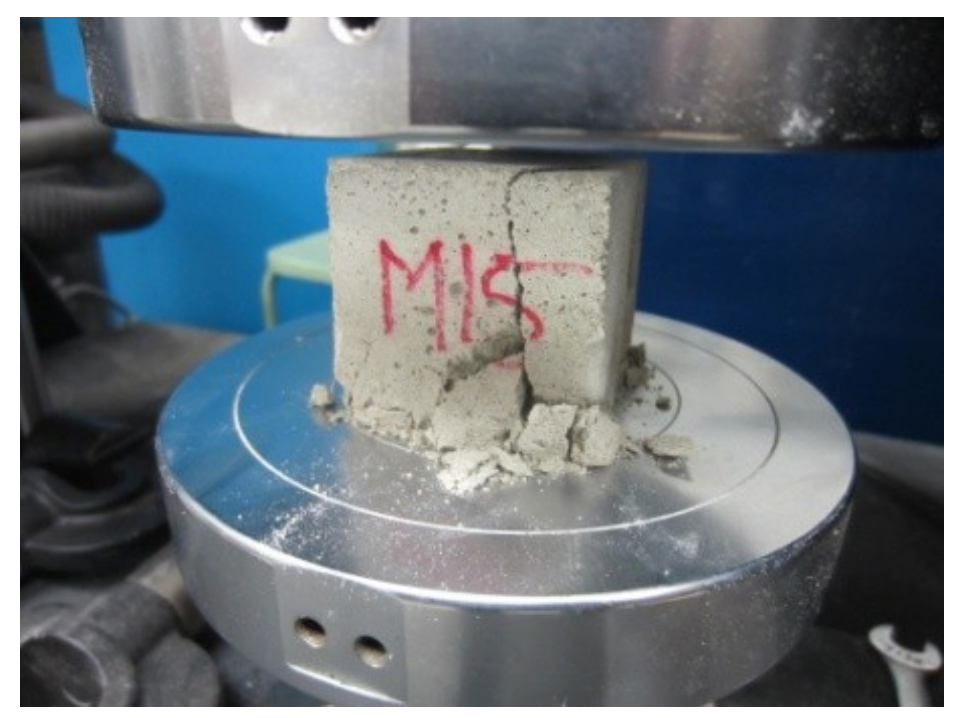

Figure 3-14: Typical mortar cube failure under compressive load

The mortar table was then struck 25 times using the hand crank and cam. After the blows were imparted to the table, the resulting mortar flow was measured to determine whether the mortar had the desired workability (see Figure 3-17). If the mortar had the desired workability, mortar cube samples were taken at this time; if not, more water was added and the process was repeated (see Figure 3-13).

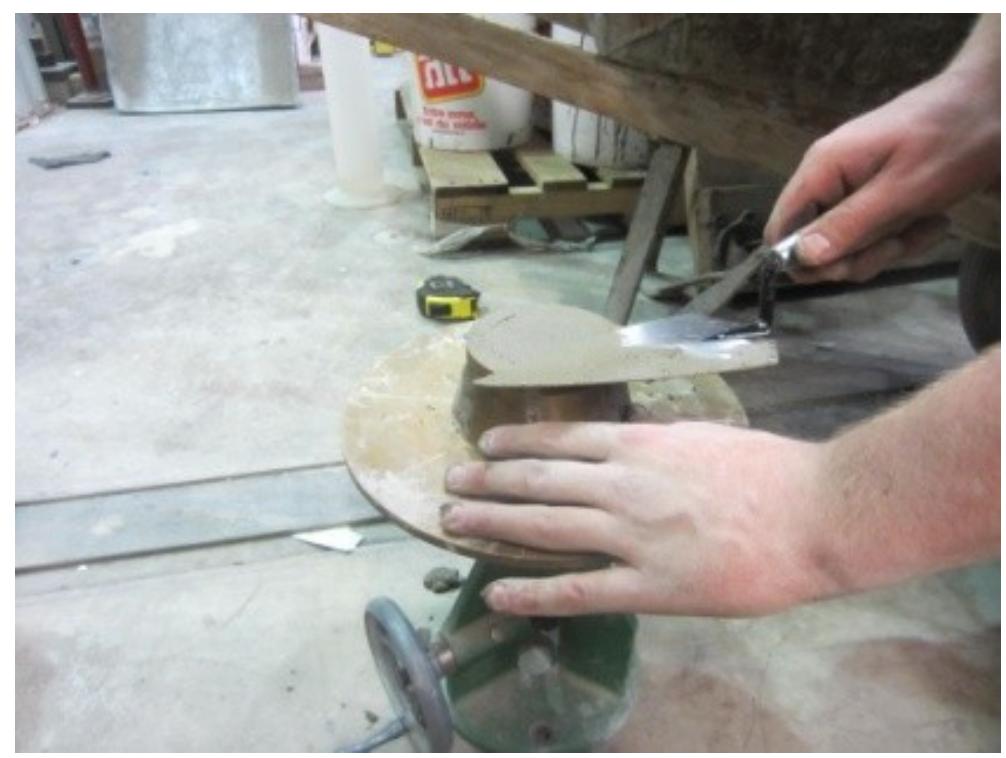

Figure 3-15: Mortar flow table (filling mould adn striking off) 


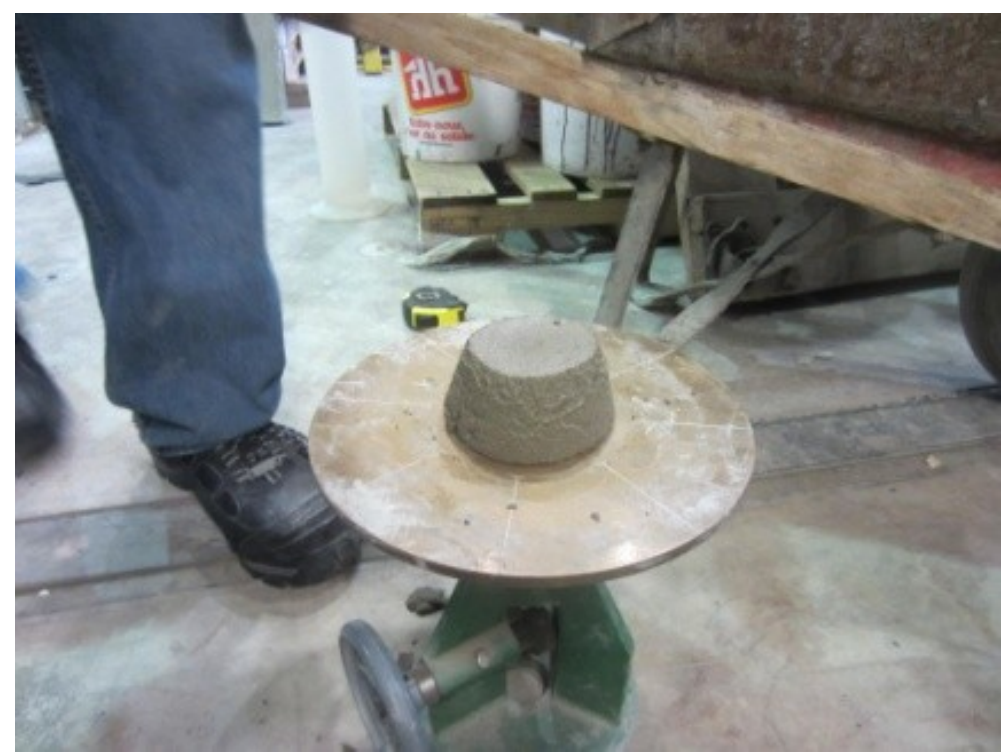

Figure 3-16: Mortar flow table (removal of mould)

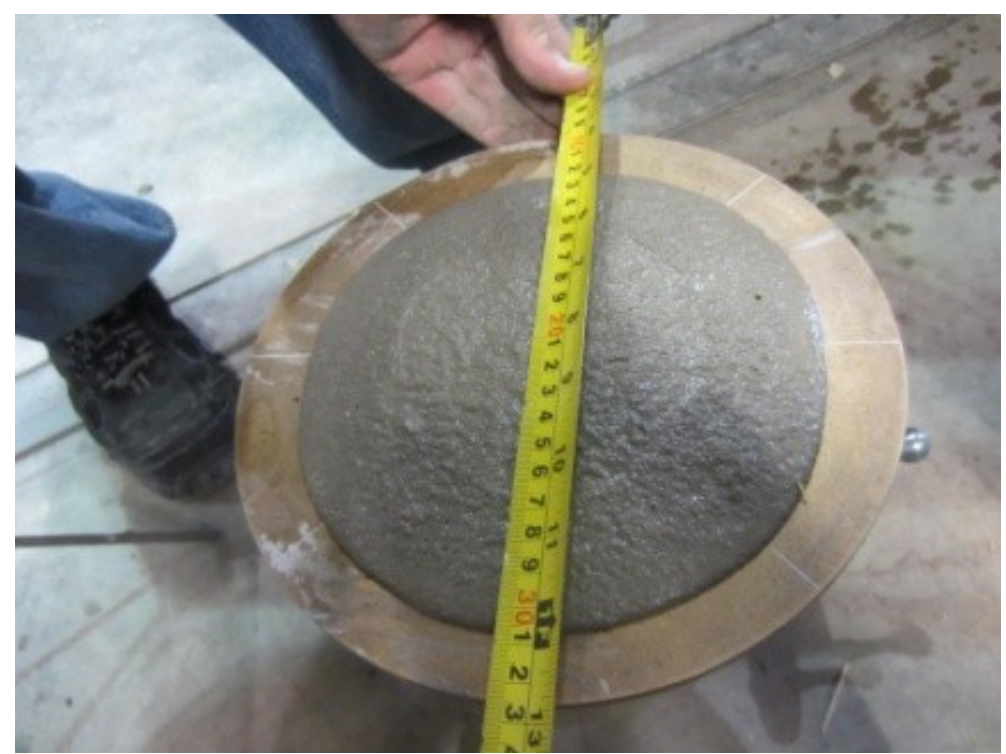

Figure 3-17: Mortar flow table (measuring flow after 25 blows)

Mortar cubes were tested for maximum compressive load to assure that the strength was within the limits outlined by CSA A179 (see Figure 3-18 ). The mortar cubes were tested on the Instron 5582 (see Figure 3-19), a gear driven compressive tester with a maximum capacity of $100 \mathrm{kN}$. The load was applied under displacement control, with the head displacement being 
$0.75 \mathrm{~mm} / \mathrm{min}$. Given this loading rate, the mortar cubes failed in approximately $60-75$ seconds. All mortar cubes were well within the minimum compressive strength outlined in CSA A165 for "Type S" mortar. The compressive strengths of the mortar cubes are summarized in the experimental results section of this thesis.

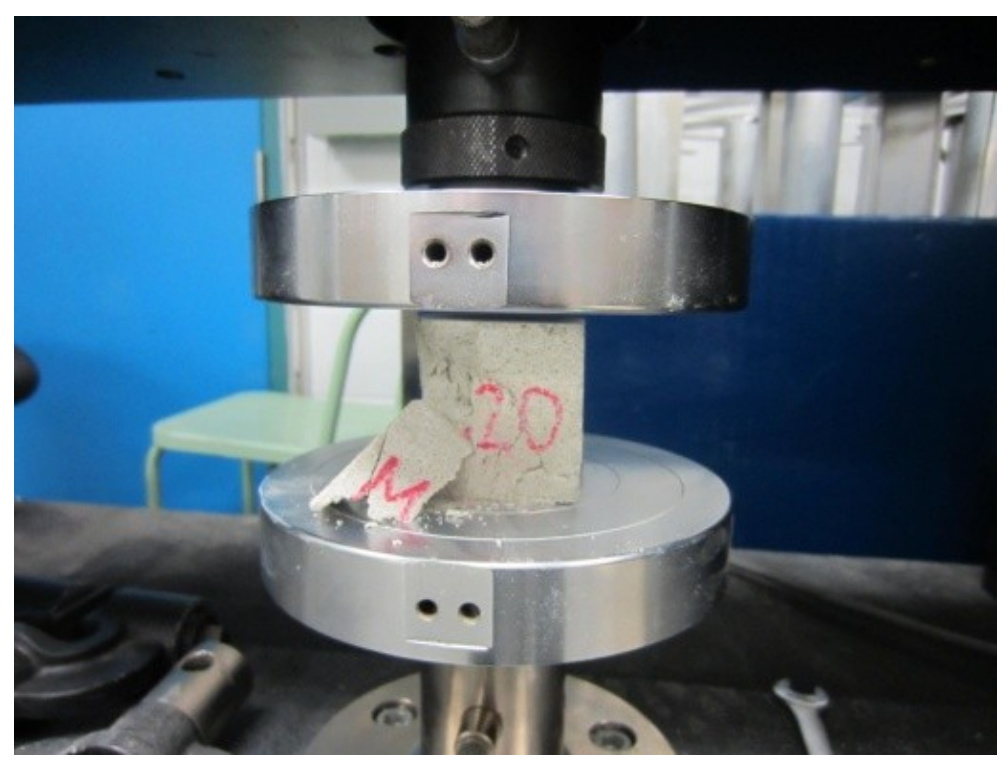

Figure 3-18: Typical compressive failure of mortar cube

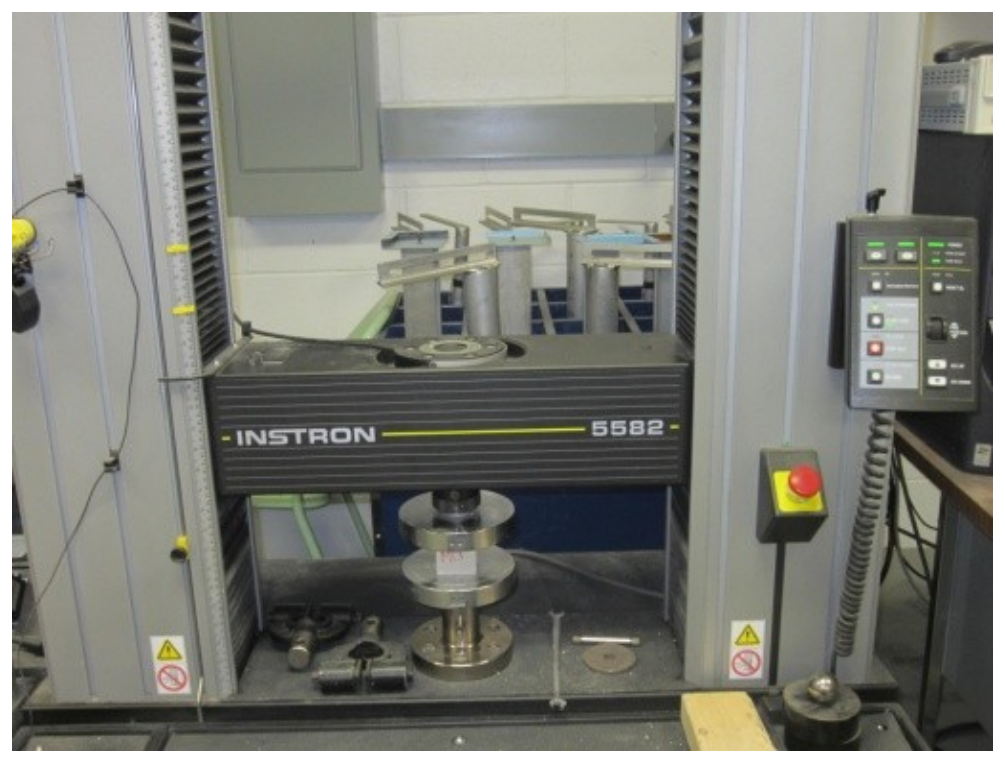

Figure 3-19: Mortar cubes tested for compressive strength in Instron 5582 


\subsubsection{Grout}

Grout was the principle variable in the experimental program. Typically either a fine or coarse grout is specified for the design of grouted masonry assemblages. For the purpose of this study, only a fine grout was investigated. Grout was investigated instead of trying to implement self consolidating concrete as grout simply adding fibre to existing masonry grout might be widely accepted in the masonry industry. Experiments with self-consolidating concrete could be conducted to further advance the concept of fibre reinforced materials being used inside masonry to improve its performance.

The mix proportions were 3:1 (sand: cement) by mass. When assuming sand has a density of $1280 \mathrm{~kg} / \mathrm{m}^{3}$ and cement has a density of $1505 \mathrm{~kg} / \mathrm{m}^{3}$ this equates to roughly $3.5: 1$ (sand: cement) by volume (see Table 3-3). Water was added to the dry ingredients in order to achieve an optimal slump of $250 \mathrm{~mm}$.

The constituent materials were mixed using a traditional barrel type concrete mixer (see Figure 3-20). After the materials were carefully weighed, the dry ingredients were added to the barrel and mixed for approximately 2 minutes to assure the cement and sand were homogeneously distributed throughout the mix. After this the water was added gradually. First, $50 \%$ of the total water was added followed by a mixing cycle of approximately 1 minute. Next $25 \%$ of the total water was added and another mixing cycle of approximately 1 minute took place. Next, half of the remaining water was added and another mixing cycle took place. Eventually, all of the water was added and the mix was thoroughly mixed for approximately 5 minutes (see Figure 3-21 and Figure 3-22). 


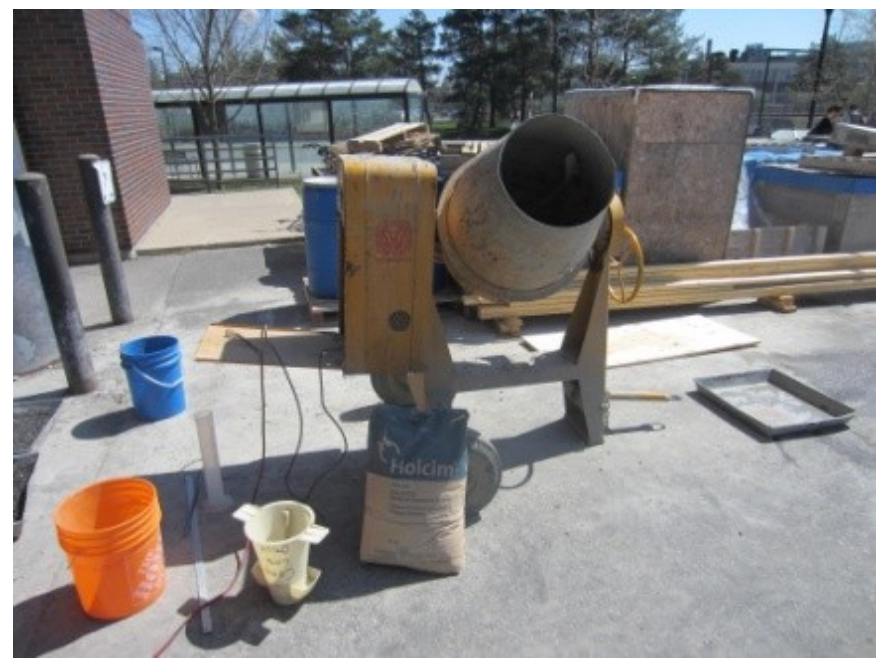

Figure 3-20: Barrel type concrete mixer used for experimental work

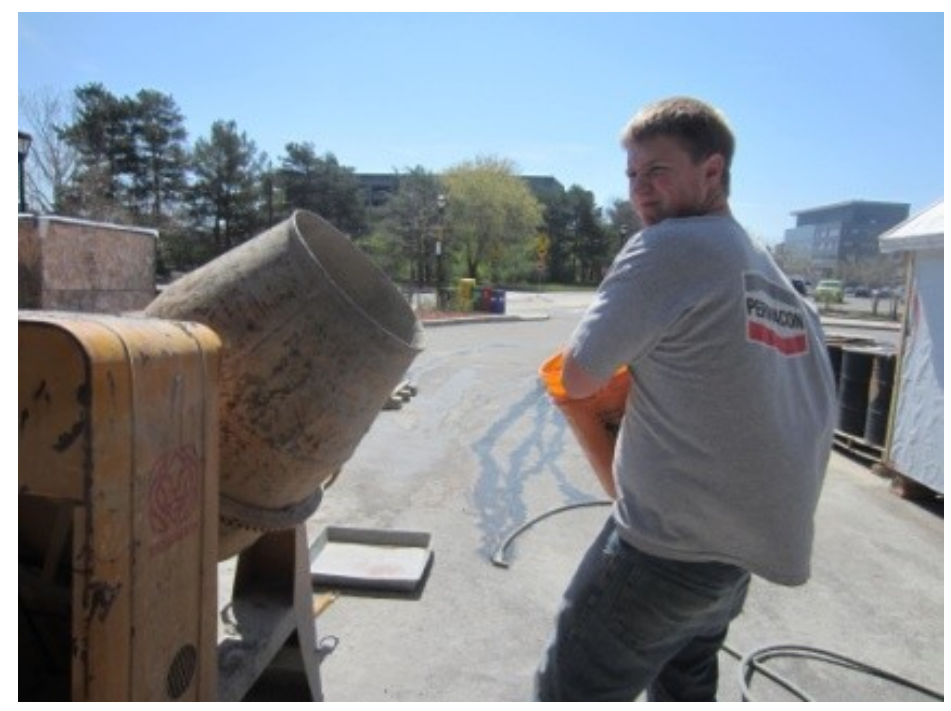

Figure 3-21: Materials being added to mixer 


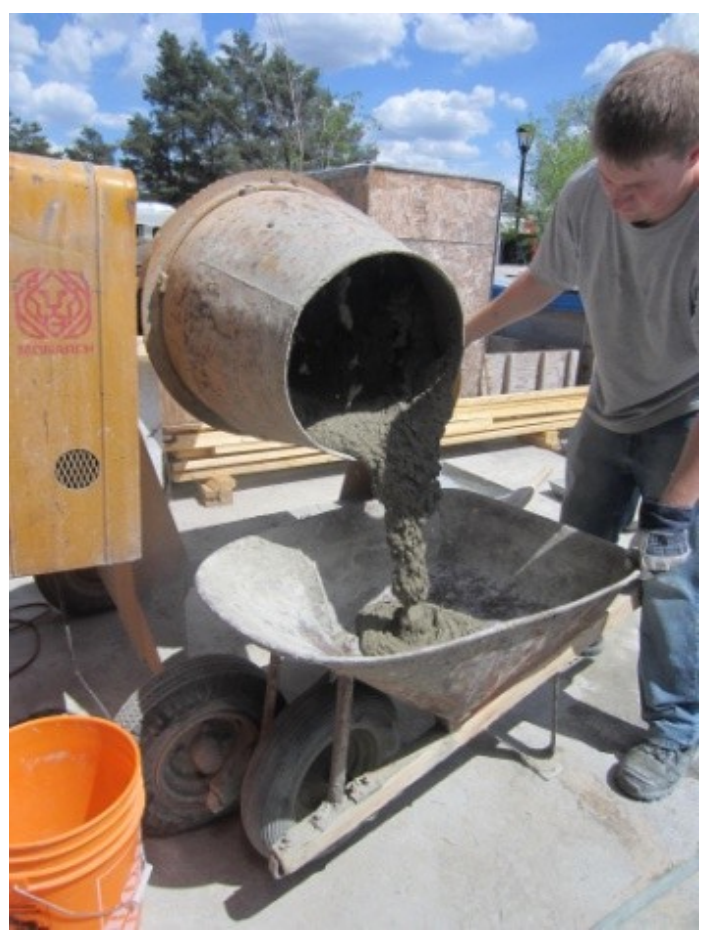

Figure 3-22: Content of mixture being poured from mixer to wheel barrow

In addition to the traditional fine grout, mentioned above, fibre reinforced grout was also used in the experimental program. Steel fibres of different lengths were incorporated into the grout mix at different volume fractions (see Figure 3-23). Dramix ZP305 fibres (30mm) were added at $0.4 \%, 0.8 \%$, and $1.2 \%$ and Dramix RC65/60BN fibres $(60 \mathrm{~mm})$ were added at $1.2 \%$ in their respective specimens as outlined in Table 3-1. 


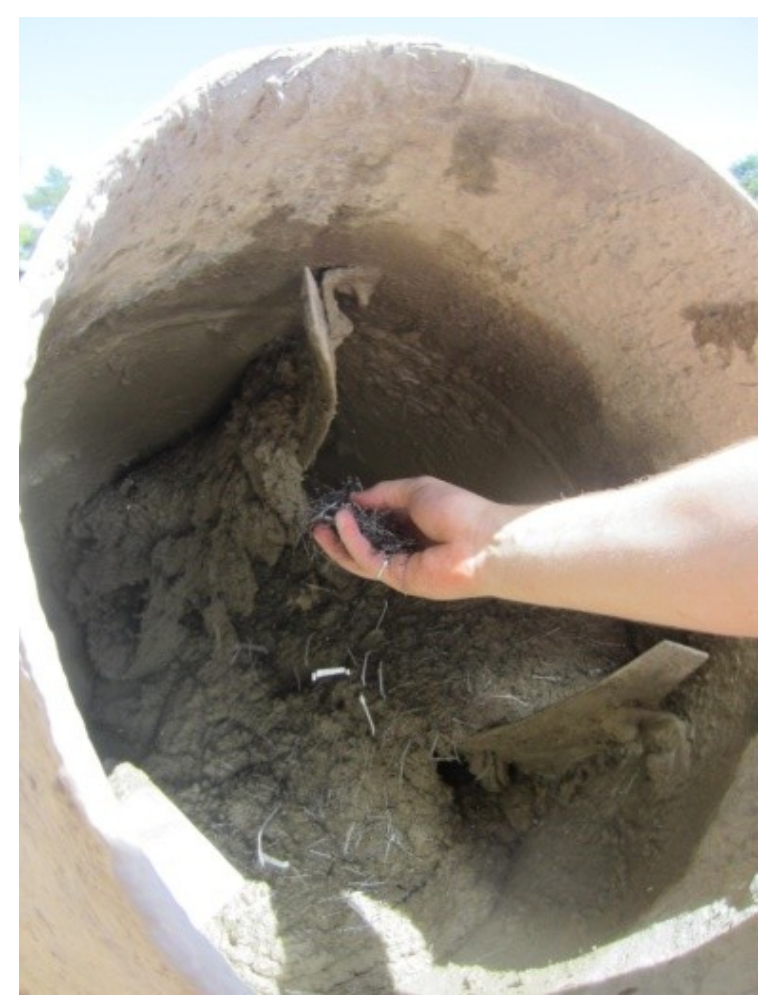

Figure 3-23: Steel fibres added manually into mixer

Workability of both the non-fibre reinforced grout and fibre reinforcement grout were measured by a standard slump cone test in order to compare the workability (see Figure 3-24 to Figure 3-26). Typically other methods are used to measure the workability of fibre reinforced materials, however this was the only way to compare the fibre reinforced grout with the traditional grout.

The slump cone was filled in 3 lifts of $100 \mathrm{~mm}$, with each lift being rodded 25 times to ensure consolidation in the cone. A typical slump of the grout was $250 \mathrm{~mm}$, as a high range water reducer was used to increase the workability as the increasing volumes of fibres were added. The types of chemical admixtures added as well as dosages are discussed in section 3.2.6. 


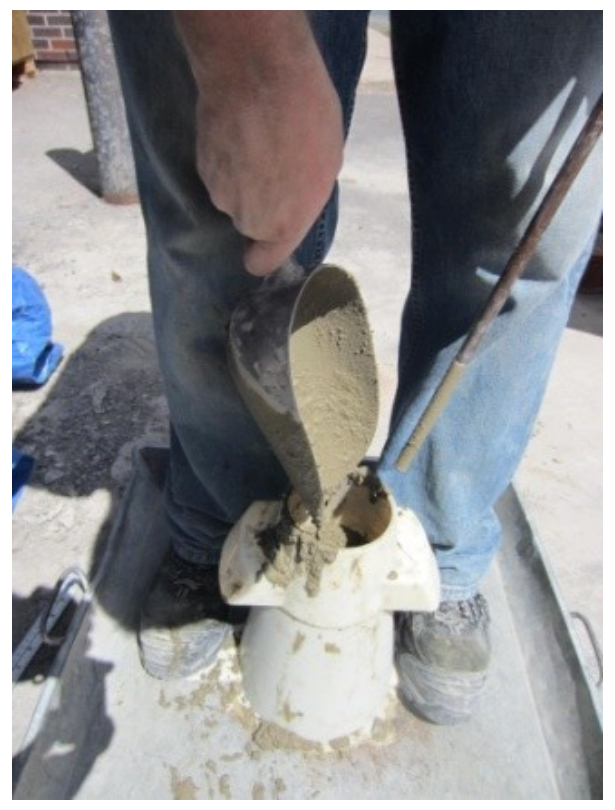

Figure 3-24: Grout slump test (filling slump cone)

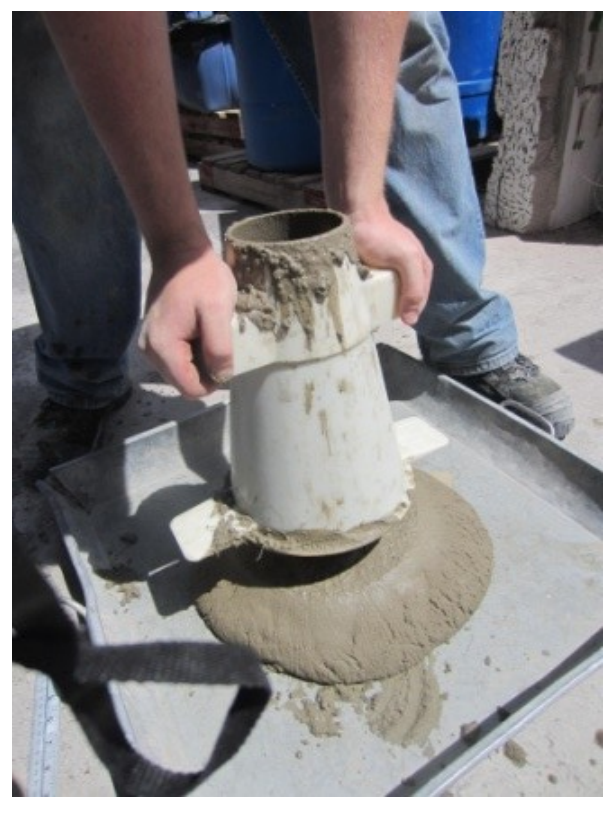

Figure 3-25: Grout slump test (removing slump cone) 


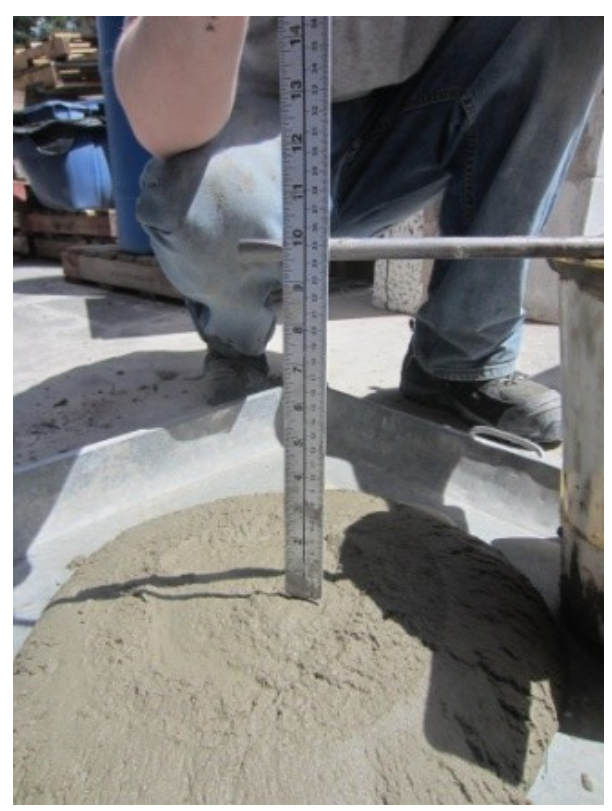

Figure 3-26: Grout slump test (final grout slump measurement)

Grout samples for compressive testing were taken in two different forms. The first set of samples were cast in non-absorbent cylinder molds and the second set were cast in absorbent square molds to achieve a sample strength more representative of the in place strength (see Figures 3-27 and 3-28). The grout strength in masonry assemblages is often considerably higher than the cylinder strength due to the fact that the water cement ratio is lowered resulting from the absorbency of the masonry units. From each grout mix the following material samples were collected: 4 cylinders, 2 absorbent prisms, and 1 beam for toughness testing (see Figures 3-27 to 3-29).

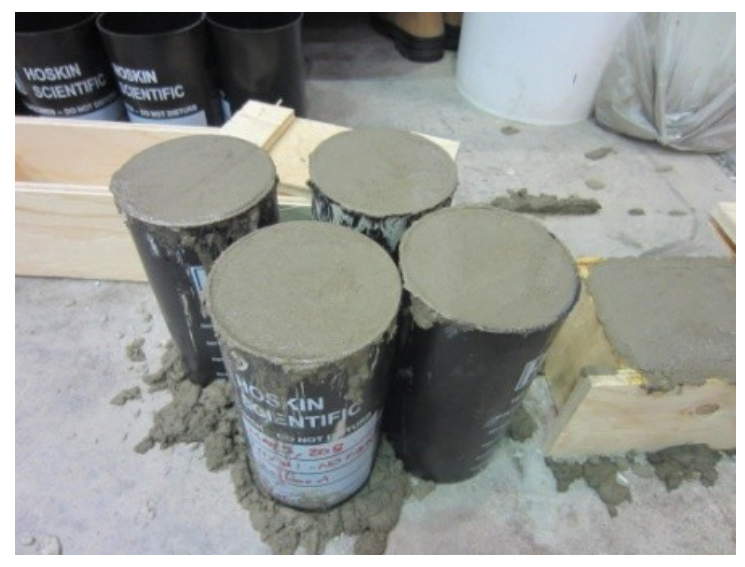

Figure 3-27: Material samples (grout cylinders) 


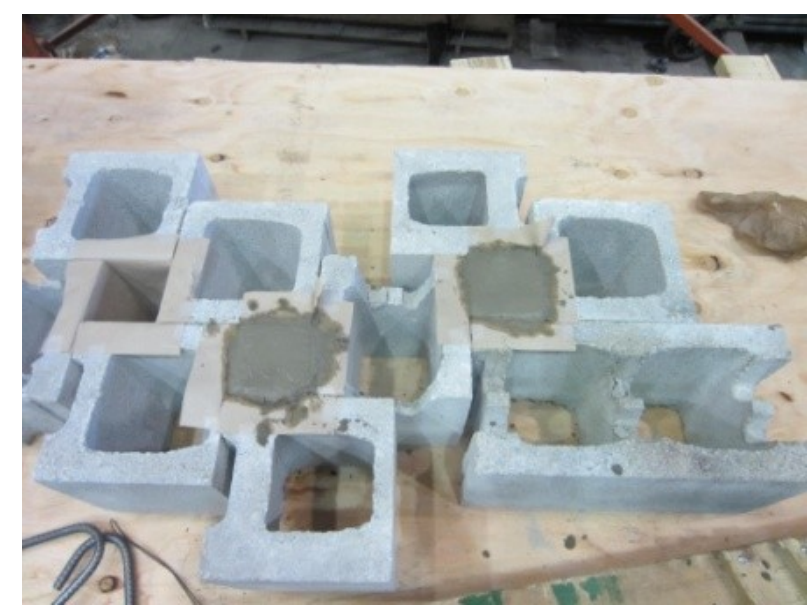

Figure 3-28: Material samples (absorbent grout prisms)

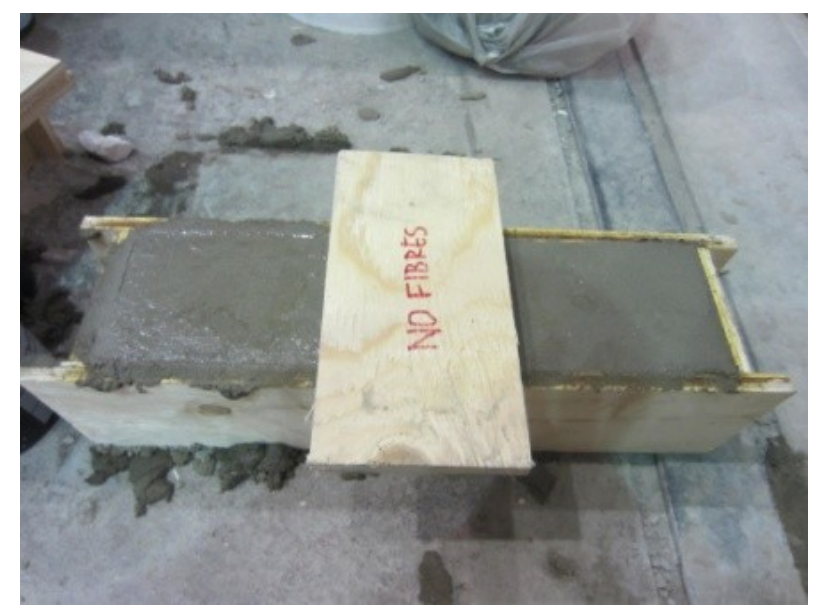

Figure 3-29: Material samples (grout beam for toughness testing)

All of the grout samples were tested on or close to the date of testing of their representative specimen. Each grout mix filled approximately 2-3 specimens as well as providing all of the material samples required.

All grout samples were tested on the Tinius Olsen 400 kip compressive testing frame at Carleton University (see Figures 3-30 to 3-32). A total of 52 grout cylinders and 18 absorbent samples were tested. A test apparatus created to measure the deformation of concrete cylinders was used to track the deformation of the grout cylinders as a function of the compressive load (See Figure 3-30), and this data was used to create the stress strain profile for the grout. Some experimental error was observed in the LVDT measurements due to the fact that the displacement was only measured on one side of the cylinder. For the absorbent prisms, Demec points were installed on the surface of the prism with an epoxy and the distance between the 
points was measured at $15 \mathrm{kN}$ increments throughout the test. Although continuous data cannot be recorded as with the LVDT used in the cylinder testing, the numbers are extremely accurate and the stress-strain relationship for the in-situ grout can still be traced. The fourth cylinder cast from each batch of grout was used to perform a tension splitting test. The tension splitting test gives a good approximation of the tensile strength of the test without actually performing a direct tension test such as a dogbone test.

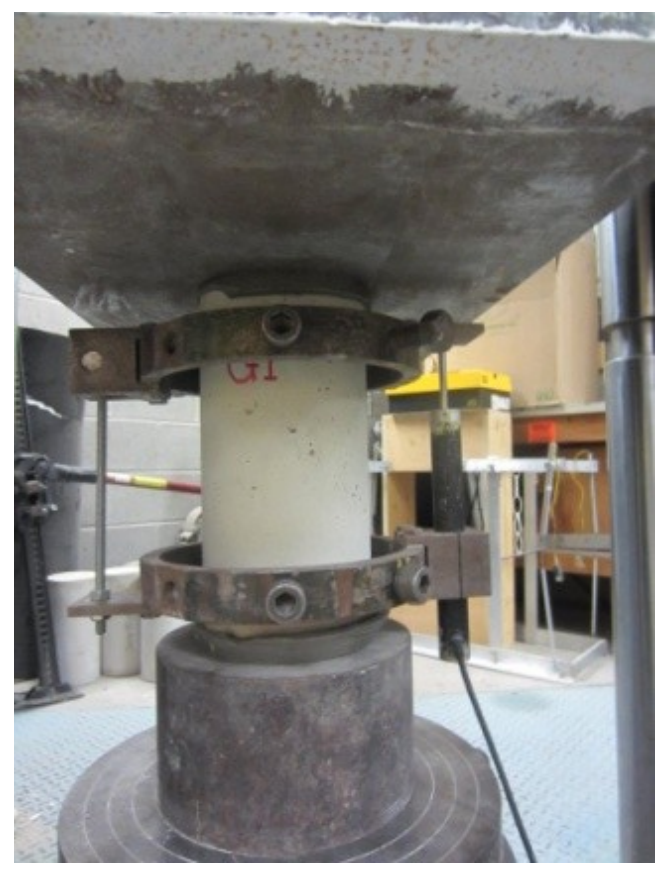

Figure 3-30: Grout cylinder tested under compressive load with apparatus to record deformation as function of load 


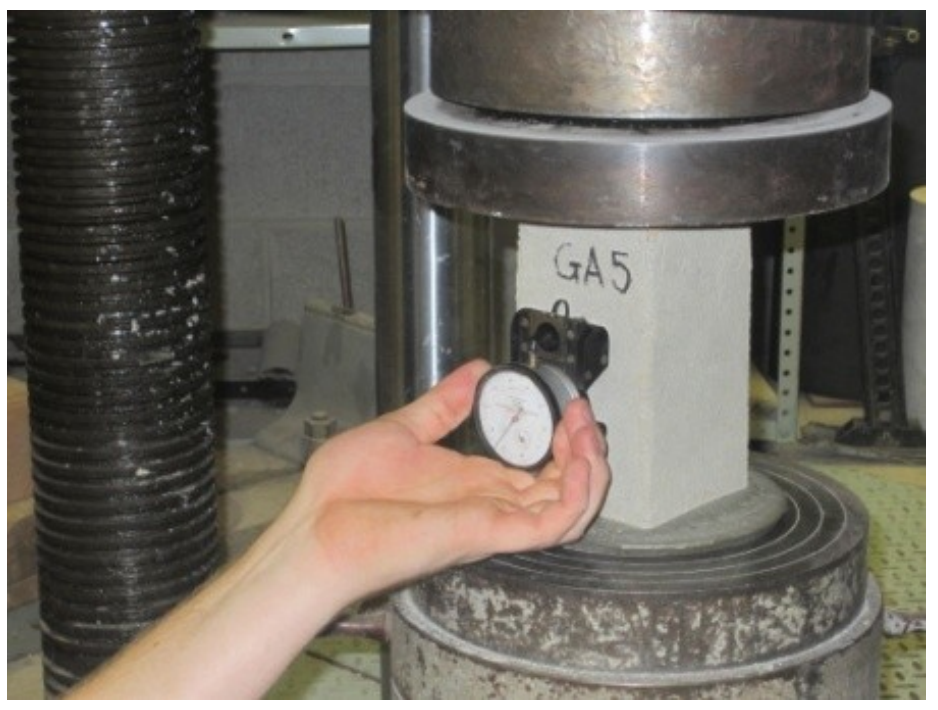

Figure 3-31: Absorbent grout prism tested under compressive load with DEMEC gauge to record deformation as a function of load

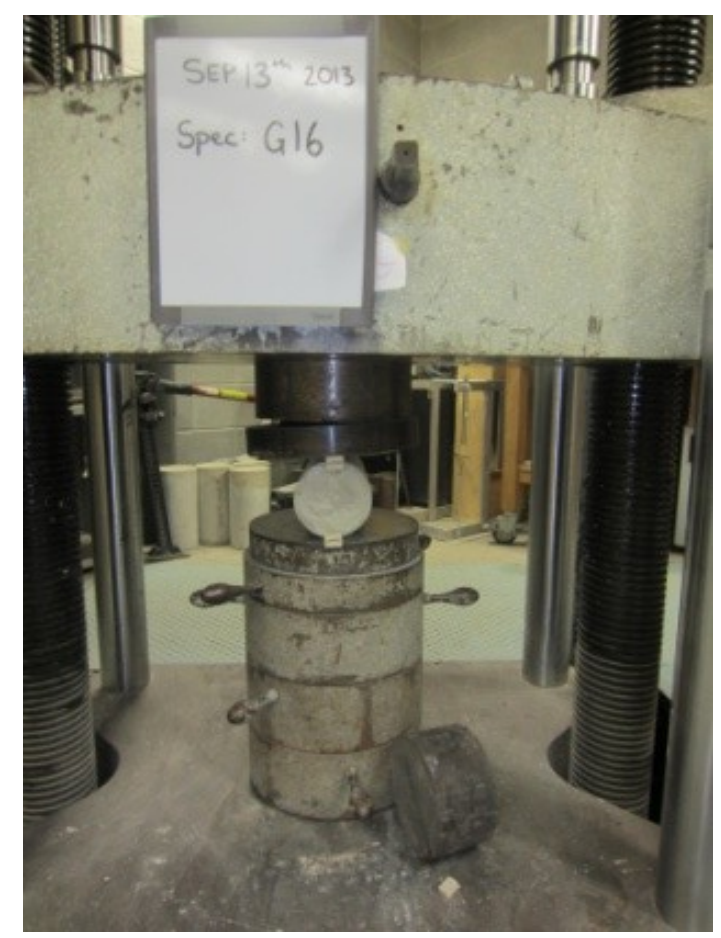

Figure 3-32: Grout cylinder tension splitting test 
Table 3-3: Grout mix proportions used in tension specimens

\begin{tabular}{|c|c|c|c|}
\hline \multicolumn{2}{|c|}{ Typical Grout Mix ( No Fibres) } & \multicolumn{2}{|c|}{ Typical Grout Mix (1.2\% fibres) } \\
\hline Material & Quantity & Material & Quantity \\
\hline Cement & $20 \mathrm{~kg}$ & Cement & $20 \mathrm{~kg}$ \\
\hline Sand & $60 \mathrm{~kg}$ & Sand & $60 \mathrm{~kg}$ \\
\hline Water & $13.65 \mathrm{~kg}$ & Water & $13.65 \mathrm{~kg}$ \\
\hline $\begin{array}{l}\text { High Range Water } \\
\text { Reducer }\end{array}$ & $0 \mathrm{ml}$ & $\begin{array}{c}\text { High Range Water } \\
\text { Reducer }\end{array}$ & $90 \mathrm{~mL}$ \\
\hline $\begin{array}{c}\text { Shrinkage reducing } \\
\text { agent }\end{array}$ & $175 \mathrm{~mL}$ & $\begin{array}{c}\text { Shrinkage reducing } \\
\text { agent }\end{array}$ & $175 \mathrm{~mL}$ \\
\hline Dramix ZP305 & $0 \mathrm{~kg}$ & $\begin{array}{c}\text { Dramix ZP305/ Dramix } \\
\text { RC65/60BN }\end{array}$ & $6.95 \mathrm{~kg}$ \\
\hline Slump & $250 \mathrm{~mm}$ & Slump & $250 \mathrm{~mm}$ \\
\hline
\end{tabular}

\begin{tabular}{|c|c|c|c|}
\hline \multicolumn{2}{|c|}{ Typical Grout Mix (0.4\% fibres) } & \multicolumn{2}{|c|}{ Typical Grout Mix (0.8\% fibres) } \\
\hline Material & Quantity & Material & Quantity \\
\hline Cement & $20 \mathrm{~kg}$ & Cement & $20 \mathrm{~kg}$ \\
\hline Sand & $60 \mathrm{~kg}$ & Sand & $60 \mathrm{~kg}$ \\
\hline Water & $13.65 \mathrm{~kg}$ & Water & $13.65 \mathrm{~kg}$ \\
\hline $\begin{array}{l}\text { High Range Water } \\
\text { Reducer }\end{array}$ & $65 \mathrm{ml}$ & $\begin{array}{c}\text { High Range Water } \\
\text { Reducer }\end{array}$ & $65 \mathrm{~mL}$ \\
\hline $\begin{array}{c}\text { Shrinkage reducing } \\
\text { agent }\end{array}$ & $175 \mathrm{~mL}$ & $\begin{array}{c}\text { Shrinkage reducing } \\
\text { agent }\end{array}$ & $175 \mathrm{~mL}$ \\
\hline Dramix ZP305 & $2.32 \mathrm{~kg}$ & Dramix ZP305 & $4.64 \mathrm{~kg}$ \\
\hline Slump & $230 \mathrm{~mm}$ & Slump & $240 \mathrm{~mm}$ \\
\hline
\end{tabular}


Prior to compressive testing, all compressive specimens were capped with a sulfur capping compound, Forney "Hi-Cap" capping compound, in order to reduce the risk of stress concentrations due to deformations in the surfaces coming into contact with the head of the tester (see Figure 3-33 and 3-35). The sulfur compound was heated to approximately 265 degrees Fahrenheit in order for it to reach liquid state and the cylinders and prisms were dipped into a tray filled with the compound holding one edge on a level plane and allowing the compound to harden onto the cylinder. Any mild inclination of the sulfur surfaces can be corrected by the rotation of the upper head on the testing apparatus.

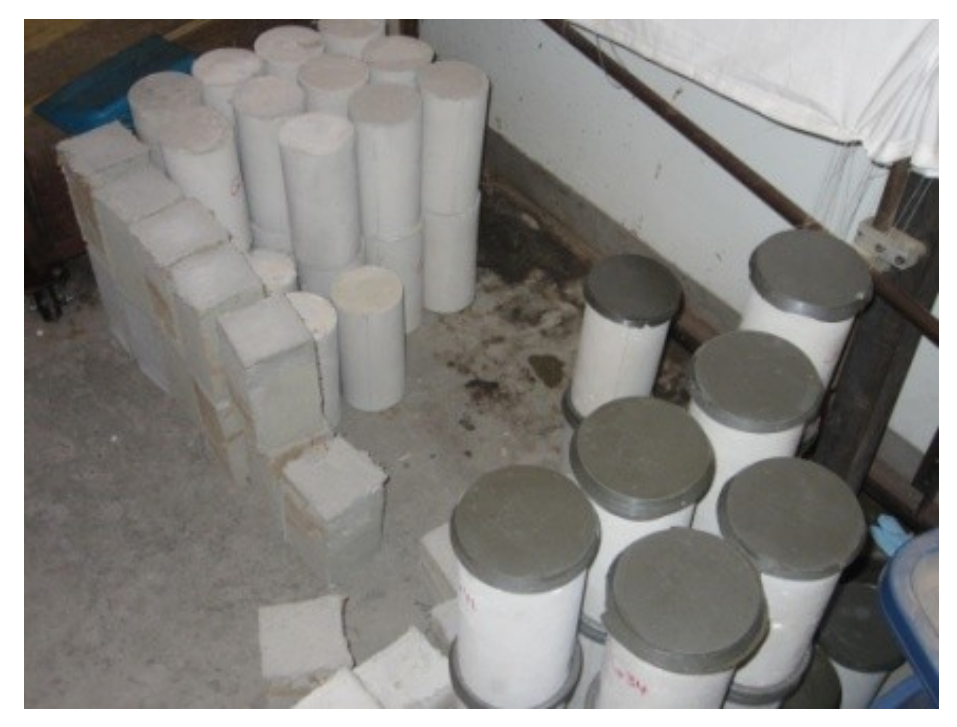

Figure 3-33: Material samples being capped with sulfur compound

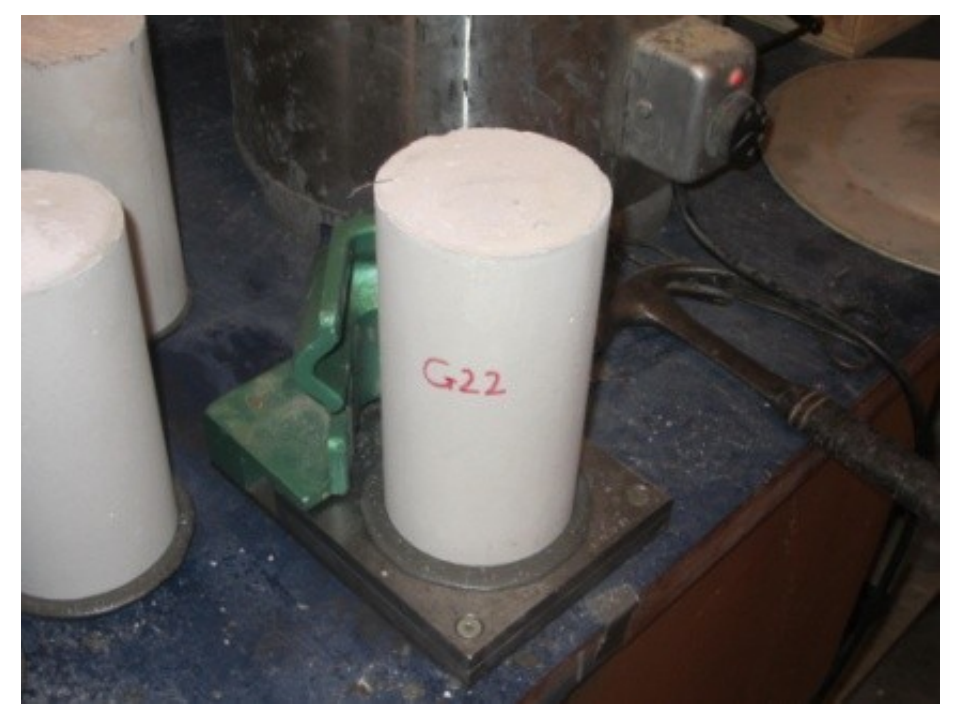

Figure 3-34: Grout cylinder placed on a level plane with sulfur hardening onto cylinder end 


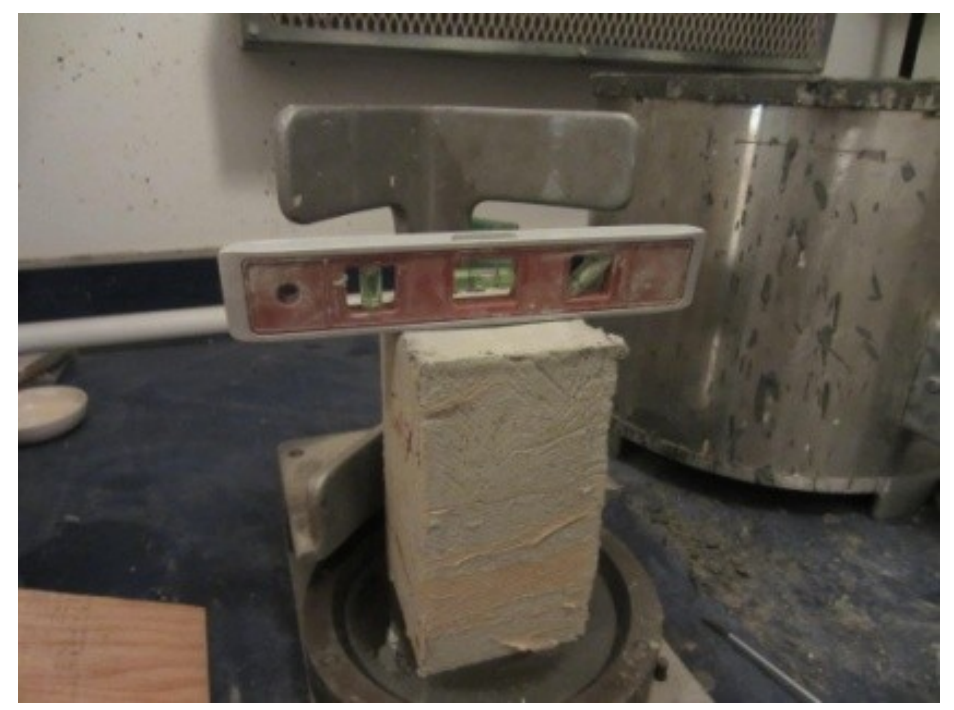

Figure 3-35: Absorbent grout cylinder capped with sulfur compound

\subsubsection{Chemical Admixtures}

It is common practice in the construction industry to incorporate chemical admixtures into concrete to improve its workability and increase the ease with which is can be finished. In this experimental program, chemical admixtures were used to increase the workability of the grout for ease of grouting the specimens, as well as to decrease shrinkage effects which could potentially decrease the bond between the grout column and the blocks.

The workability was noticeably affected by the addition of fibres due to the fact that the initial grout mix without any fibres did not have any high range water reducer present. As the volume of fibres added increased, the amount of high range water reducer was increased to counteract the decreased workability (see Table 3-3). With the addition of the high range water reducer, the same slump was attainable without the addition of any additional water to the mix (see Figure 3-37). This was an effective way of assessing the effect of steel fibres as the water cement ratio was held constant in all mixes.

The high range water reducer used was Sika Viscocrete 2100, which is marketed as allowing the placement of concrete with water cement ratios as low as 0.25 with minimal vibration. The admixture was used in the experimental program at a dosage of $390 \mathrm{~mL} / 100 \mathrm{~kg}$ of cementitious materials which is within the manufacturers recommended range for use in 
conventional concrete applications. The admixture was added to the mix at the end of the batching cycle as was suggested by the manufacturer.

The shrinkage reducing admixture used was BASF MasterLIFE SRA 20, which is marketed as reducing drying shrinkage by as much as $80 \%$ at 28 days. The admixture was used in the experimental program at a dosage of $5 \mathrm{~L} / \mathrm{m}^{3}$ which is within the manufacturer's suggested range. The shrinkage reducing admixture was also added to the mix at the end of the batching cycle as suggested by the manufacturer (see Figure 3-36). The admixture was said to be compatible with all types of water reducers.

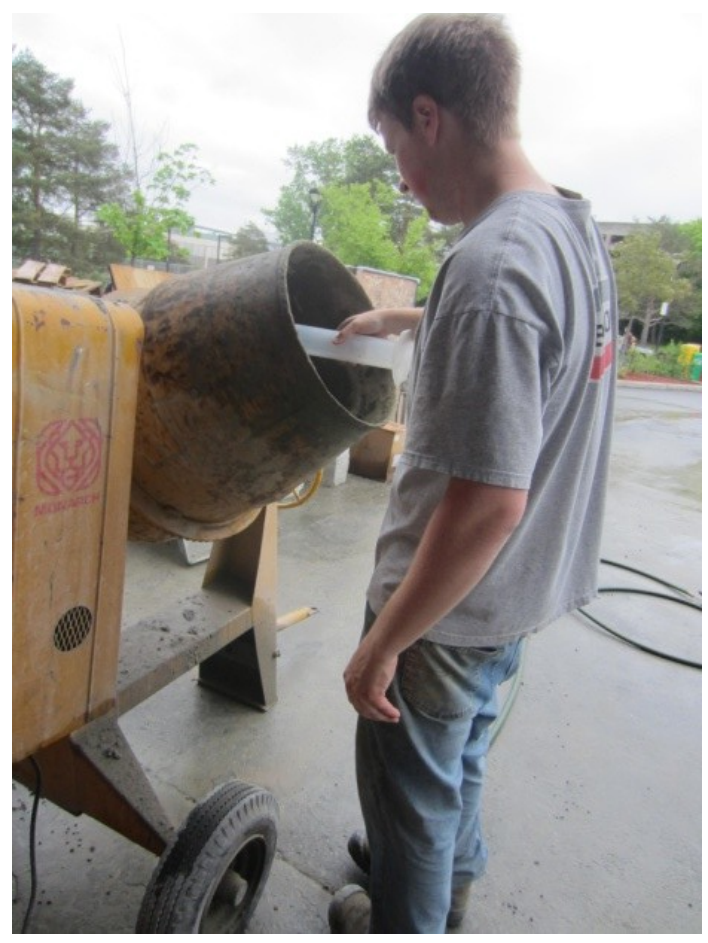

Figure 3-36: Chemical admixtures being added to the mixer at the end of the mixing cycle 


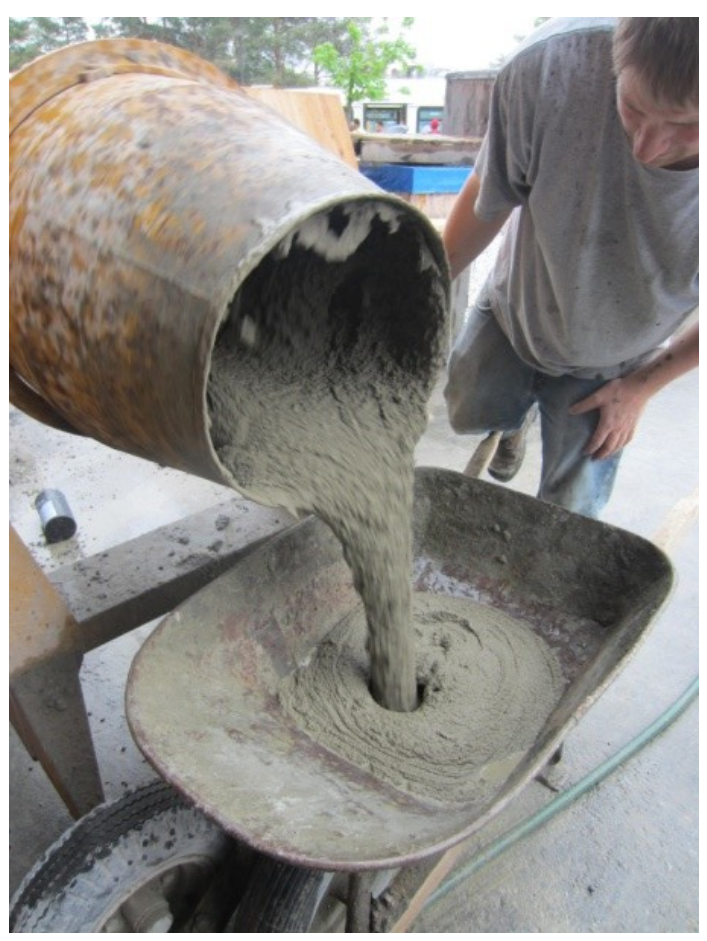

Figure 3-37: Fibre reinforced grout mix after addition of chemical admixtures

\subsubsection{Prisms}

Due to the composite nature of masonry as a structural material, prisms must be constructed with the constituent materials to investigate the complex behavior that takes place between the different materials under a given type of loading. In order to determine the compressive strength of masonry, prisms must be constructed with the same blocks, mortar, and grout as was used in the masonry assemblage (see Figure 3-38 to 3-40). When this prism is tested in compression, the compressive strength of the masonry assemblage can be determined.

Prisms were constructed alongside the tension specimens using the exact same materials, workmanship, and curing environment. Three prisms were constructed for each different grout mix. The prisms were constructed and tested as per ASTM Standard C1314-12 (ASTM International, 2012). 


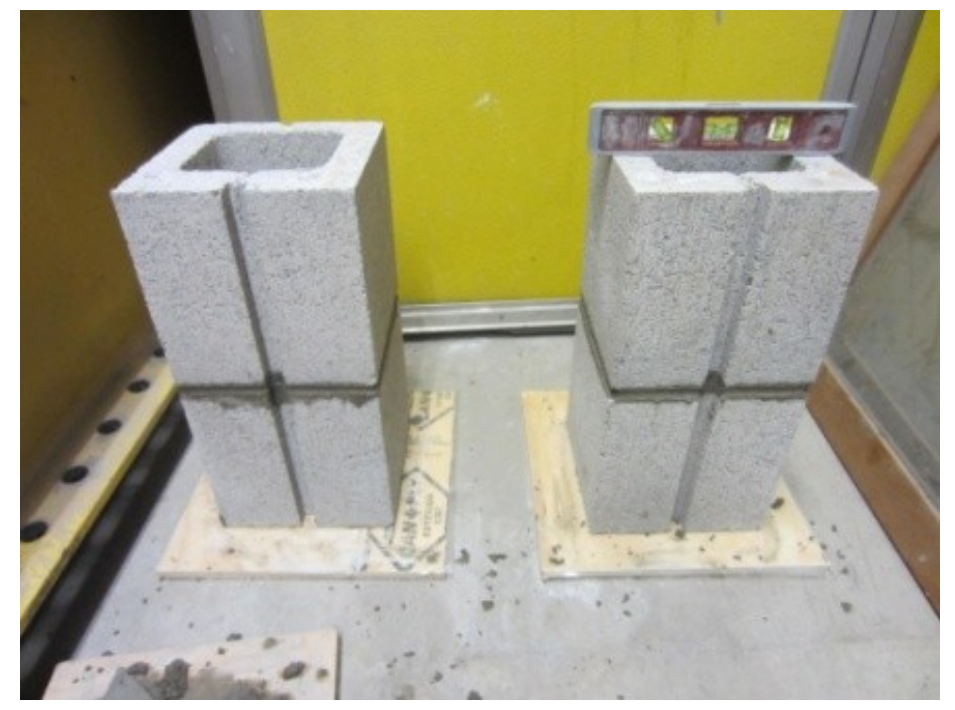

Figure 3-38: Prisms constructed with same procedure as specimens

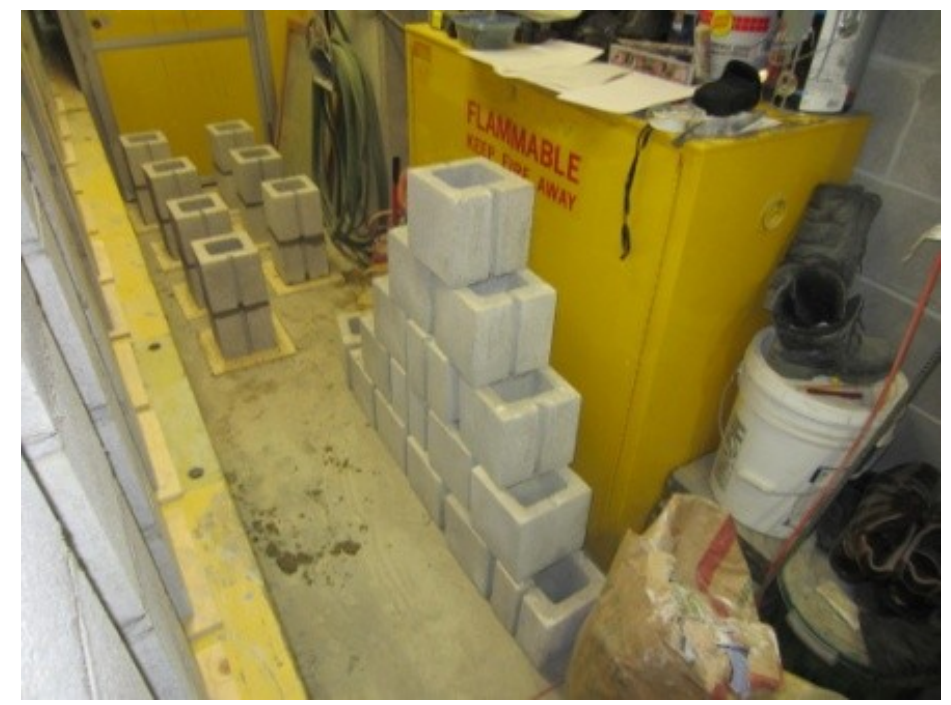

Figure 3-39: Prisms cured in same environment as specimens prior to grouting 


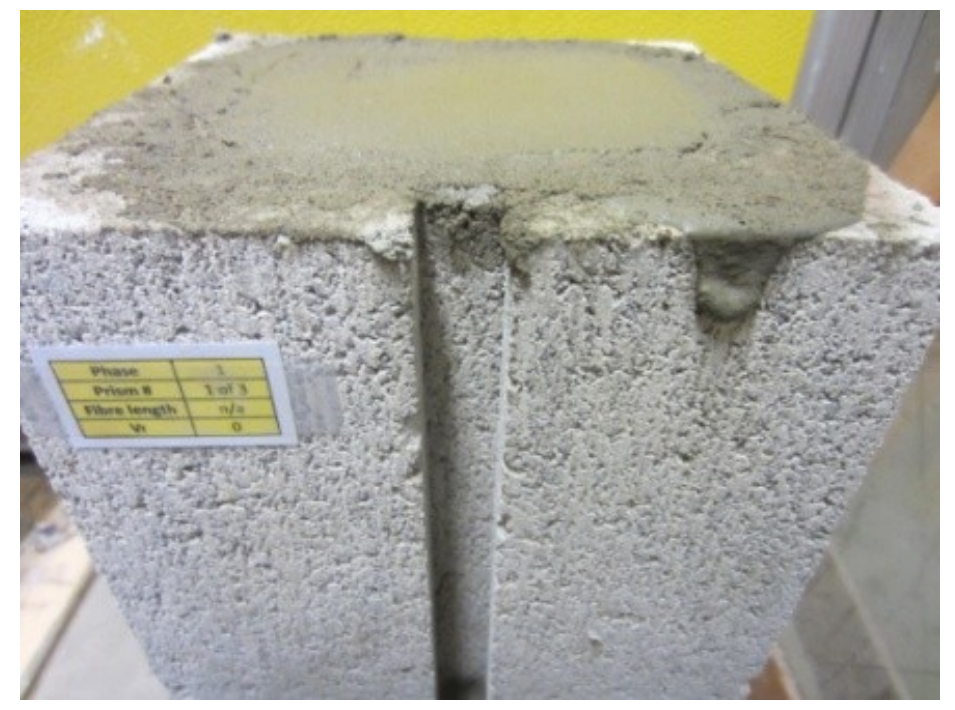

Figure 3-40: Prisms grouted with fibre grout and non-fibre grout

After the prisms were allowed to cure alongside the direct tension specimens, they were capped with hydro stone, a gypsum based product which achieves very high early strength. The hydro stone was placed evenly over the top surface of the prism and a lightly oiled tempered glass plate was pushed downwards on a level plane so as to create a completely level plane for use in compressive testing (see Figure 3-41).

The prisms were tested in compression around the same day as the corresponding direct tension specimens were tested in the Tinius Olsen 400 kip compressive testing frame. LVDT's were mounted on the two opposing sides of the prisms in order to more accurately trace the relationship between the compressive load and the compressive displacement of the prism (see Figure 3-42 and 3-43). It should be noted that a significant increase in compressive strength was not observed between the prisms which were grouted with non fibre-reinforced grout vs. those which were grouted with fibre reinforced grout. 


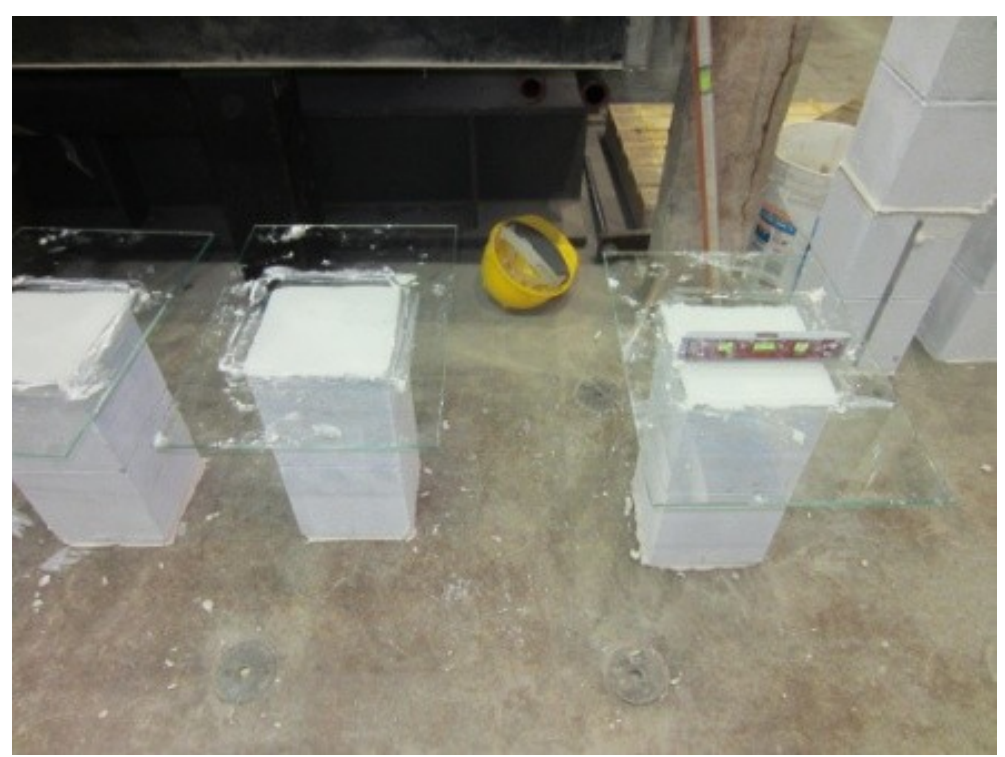

Figure 3-41: Prisms capped with a level surface Hydrostone compound

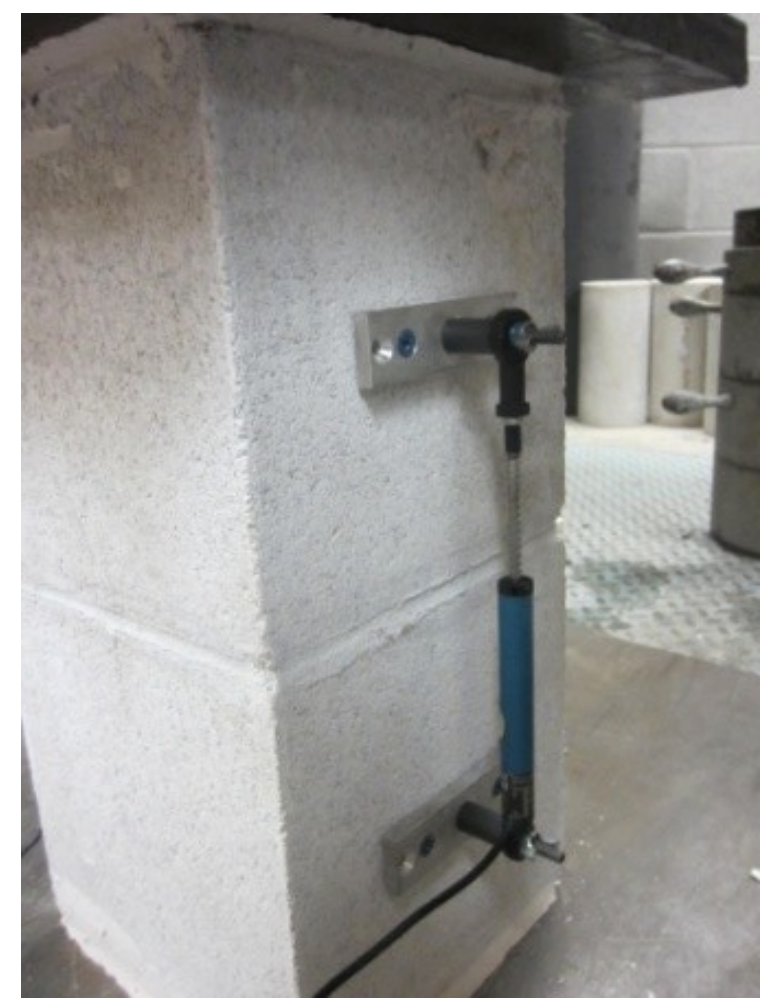

Figure 3-42: Prisms with LVDTs mounted to measure displacement under compressive load 


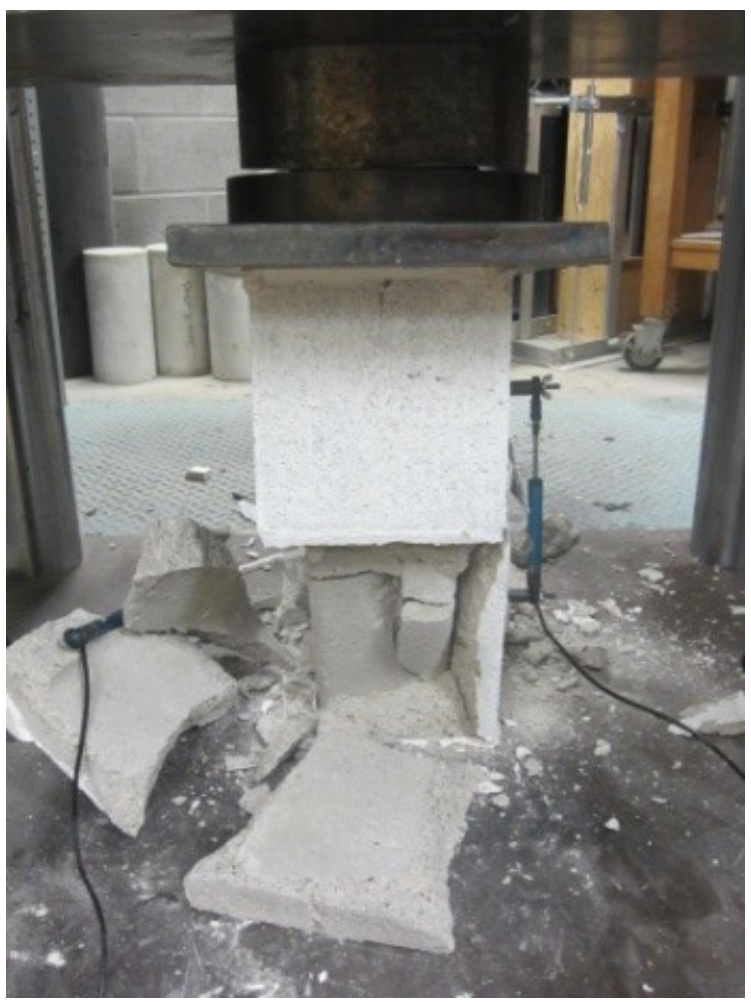

Figure 3-43: Typical failure of non-fibre-reinforced prism under compressive load

\subsection{Construction of Test Specimens}

The experimental program involved the construction of 42 direct tension specimens each with identical overall geometry, although with variations to the constituent materials. Each specimen measured $990 \mathrm{~mm}$ in height and measured $190 \mathrm{~mm}$ square in cross section. The first 38 specimens constructed consisted of 5 half units measuring $190 \mathrm{~mm} \times 190 \mathrm{~mm} \times 190 \mathrm{~mm}$ and the final 4 specimens consisted of two full lintel units measuring $390 \mathrm{~mm} \times 190 \mathrm{~mm} \times 190 \mathrm{~mm}$ as well as a half lintel unit measuring 190mmx190mmx190mm (see Figure 3-44 to Figure 3-47). A single deformed reinforcing bar was embedded in the center of each specimen and was extended $200 \mathrm{~mm}$ past the end of the last concrete masonry unit on each end for ease of gripping in the tensile testing apparatus as well as for instrumentation. The reinforcing bar sizes included 10M, $15 \mathrm{M}$, and 20M. A standard structural mortar classified as "Type S" by CSA S304 was used to bond all specimens together and all specimens were fully grouted using various types of grout. 
There were two different lengths of fibres used in the construction of the specimens and each type of fibre had a different aspect ratio. The fibres were incorporated into the grout mix at different volume percentages to investigate the influence on the tensile performance.

A summary of the test specimens constructed is shown in Table 3-4. 
Table 3-4: Summary of tension specimens constructed

\begin{tabular}{|c|c|c|c|c|c|c|}
\hline $\begin{array}{l}\text { Specimen } \\
\text { Name }\end{array}$ & Unit Type & $\begin{array}{l}\text { Loading } \\
\text { Type }\end{array}$ & $\begin{array}{l}\text { No. of } \\
\text { Rebar }\end{array}$ & $\begin{array}{c}\rho=A_{s} / 36100 \\
(\%)\end{array}$ & $\begin{array}{l}\text { Fibre Type } \\
\text { For grout }\end{array}$ & $\begin{array}{r}V_{f} \\
(\%)\end{array}$ \\
\hline $10 \mathrm{M} 00-1$ & Standard & Monotonic & $10 \mathrm{M}$ & 0.277 & None & 0.0 \\
\hline 10M00-2 & Standard & Monotonic & $10 \mathrm{M}$ & 0.277 & None & 0.0 \\
\hline 10M12S-1 & Standard & Monotonic & $10 \mathrm{M}$ & 0.277 & ZP-305 & 1.2 \\
\hline 10M12S-2 & Standard & Monotonic & $10 \mathrm{M}$ & 0.277 & ZP-305 & 1.2 \\
\hline $15 \mathrm{M} 00-1$ & Standard & Monotonic & $15 \mathrm{M}$ & 0.554 & None & 0.0 \\
\hline $15 \mathrm{M} 00-2$ & Standard & Monotonic & $15 \mathrm{M}$ & 0.554 & None & 0.0 \\
\hline 15M04S-1 & Standard & Monotonic & $15 \mathrm{M}$ & 0.554 & ZP-305 & 0.4 \\
\hline $15 \mathrm{M} 04 \mathrm{~S}-2$ & Standard & Monotonic & $15 \mathrm{M}$ & 0.554 & ZP-305 & 0.4 \\
\hline 15M08S-1 & Standard & Monotonic & $15 \mathrm{M}$ & 0.554 & ZP-305 & 0.8 \\
\hline $15 \mathrm{M} 08 \mathrm{~S}-2$ & Standard & Monotonic & $15 \mathrm{M}$ & 0.554 & ZP-305 & 0.8 \\
\hline 15M12S-1 & Standard & Monotonic & $15 \mathrm{M}$ & 0.554 & ZP-305 & 1.2 \\
\hline $15 \mathrm{M} 12 \mathrm{~S}-2$ & Standard & Monotonic & $15 \mathrm{M}$ & 0.554 & ZP-305 & 1.2 \\
\hline $20 \mathrm{M} 00-1$ & Standard & Monotonic & $15 \mathrm{M}$ & 0.554 & None & 0.0 \\
\hline $20 \mathrm{M} 00-2$ & Standard & Monotonic & $15 \mathrm{M}$ & 0.554 & None & 0.0 \\
\hline 20M04S-1 & Standard & Monotonic & $15 \mathrm{M}$ & 0.554 & ZP-305 & 0.4 \\
\hline 20M04S-2 & Standard & Monotonic & $15 \mathrm{M}$ & 0.554 & ZP-305 & 0.4 \\
\hline 20M08S-1 & Standard & Monotonic & $15 \mathrm{M}$ & 0.554 & ZP-305 & 0.8 \\
\hline 20M08S-2 & Standard & Monotonic & $15 \mathrm{M}$ & 0.554 & ZP-305 & 0.8 \\
\hline 20M12S-1 & Standard & Monotonic & $15 \mathrm{M}$ & 0.554 & ZP-305 & 1.2 \\
\hline 20M12S-2 & Standard & Monotonic & $15 \mathrm{M}$ & 0.554 & ZP-305 & 1.2 \\
\hline 15M12L-1 & Standard & Monotonic & $15 \mathrm{M}$ & 0.554 & RC65/60BN & 1.2 \\
\hline $15 \mathrm{M} 12 \mathrm{~L}-2$ & Standard & Monotonic & $15 \mathrm{M}$ & 0.554 & $\mathrm{RC} 65 / 60 \mathrm{BN}$ & 1.2 \\
\hline $15 \mathrm{C} 00-1$ & Standard & Cyclic & $15 \mathrm{M}$ & 0.554 & None & 0.0 \\
\hline $15 \mathrm{C} 00-2$ & Standard & Cyclic & $15 \mathrm{M}$ & 0.554 & None & 0.0 \\
\hline $15 \mathrm{C} 04 \mathrm{~S}-1$ & Standard & Cyclic & $15 \mathrm{M}$ & 0.554 & ZP-305 & 0.4 \\
\hline $15 \mathrm{C} 04 \mathrm{~S}-2$ & Standard & Cyclic & $15 \mathrm{M}$ & 0.554 & ZP-305 & 0.4 \\
\hline $15 \mathrm{C} 08 \mathrm{~S}-1$ & Standard & Cyclic & $15 \mathrm{M}$ & 0.554 & ZP-305 & 0.8 \\
\hline $15 \mathrm{C} 08 \mathrm{~S}-2$ & Standard & Cyclic & $15 \mathrm{M}$ & 0.554 & ZP-305 & 0.8 \\
\hline $15 \mathrm{C} 12 \mathrm{~S}-1$ & Standard & Cyclic & $15 \mathrm{M}$ & 0.554 & ZP-305 & 1.2 \\
\hline $15 \mathrm{C} 12 \mathrm{~S}-2$ & Standard & Cyclic & $15 \mathrm{M}$ & 0.554 & ZP-305 & 1.2 \\
\hline $20 \mathrm{C} 00-1$ & Standard & Cyclic & $20 \mathrm{M}$ & 0.831 & None & 0.0 \\
\hline $20 \mathrm{C} 00-2$ & Standard & Cyclic & $20 \mathrm{M}$ & 0.831 & None & 0.0 \\
\hline 20C04S-1 & Standard & Cyclic & $20 \mathrm{M}$ & 0.831 & ZP-305 & 0.4 \\
\hline $20 \mathrm{C} 04 \mathrm{~S}-2$ & Standard & Cyclic & $20 \mathrm{M}$ & 0.831 & ZP-305 & 0.4 \\
\hline $20 \mathrm{C} 08 \mathrm{~S}-1$ & Standard & Cyclic & $20 \mathrm{M}$ & 0.831 & ZP-305 & 0.8 \\
\hline $20 \mathrm{C} 08 \mathrm{~S}-2$ & Standard & Cyclic & $20 \mathrm{M}$ & 0.831 & ZP-305 & 0.8 \\
\hline 20C12S-1 & Standard & Cyclic & $20 \mathrm{M}$ & 0.831 & ZP-305 & 1.2 \\
\hline $20 \mathrm{C} 12 \mathrm{~S}-2$ & Standard & Cyclic & $20 \mathrm{M}$ & 0.831 & ZP-305 & 1.2 \\
\hline L15M00-1 & Lintel & Monotonic & $15 \mathrm{M}$ & 0.554 & ZP-305 & 0.0 \\
\hline L15M04S-1 & Lintel & Monotonic & $15 \mathrm{M}$ & 0.554 & ZP-305 & 0.4 \\
\hline L15M08S-1 & Lintel & Monotonic & $15 \mathrm{M}$ & 0.554 & ZP-305 & 0.8 \\
\hline L15M12S-1 & Lintel & Monotonic & $15 \mathrm{M}$ & 0.554 & ZP-305 & 1.2 \\
\hline \multicolumn{7}{|c|}{$\begin{array}{l}\text { Steel Areas: } \\
10 \mathrm{M}-100 \mathrm{~mm}^{2} \\
15 \mathrm{M}-200 \mathrm{~mm}^{2} \\
20 \mathrm{M}-300 \mathrm{~mm}^{2}\end{array}$} \\
\hline
\end{tabular}




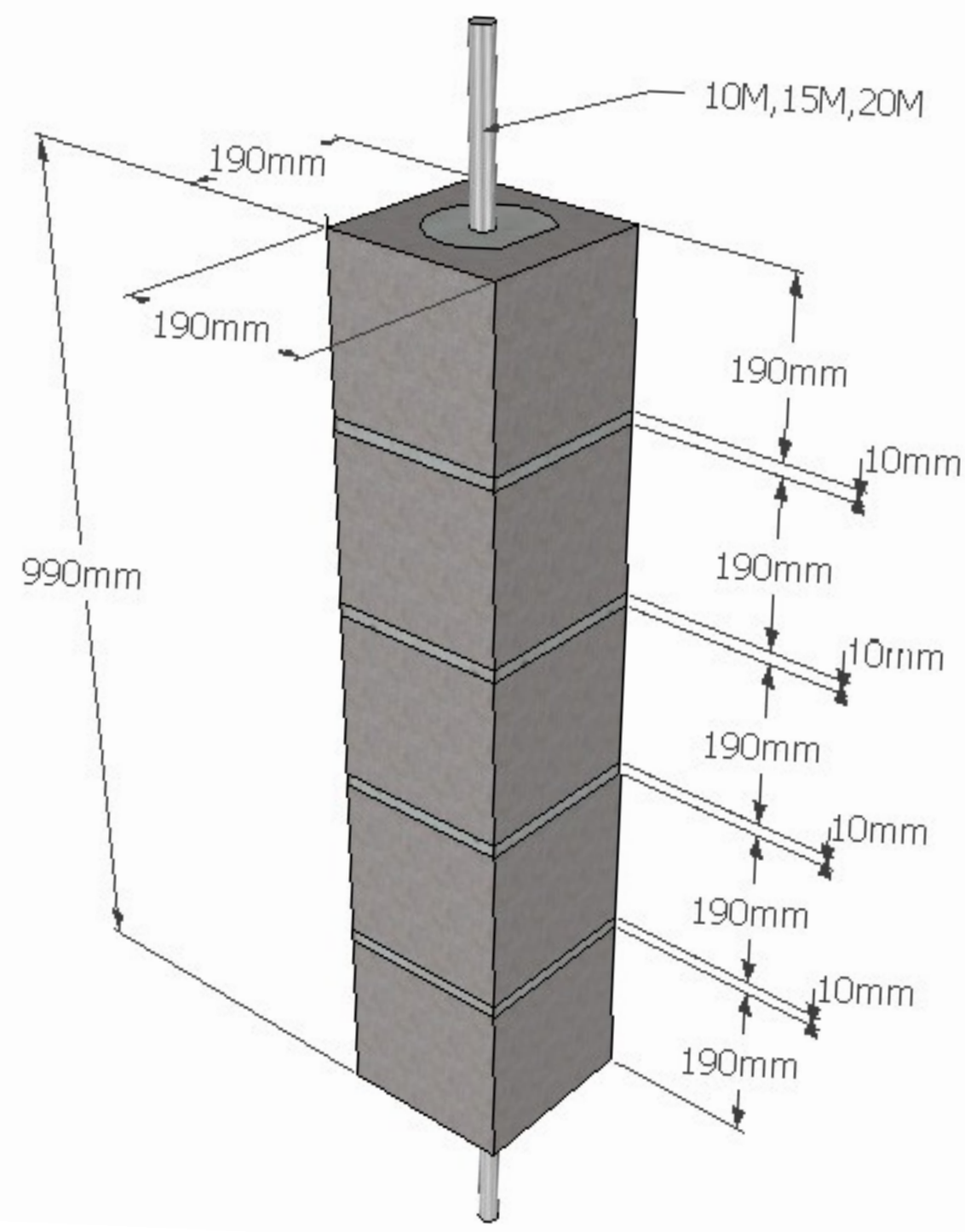

Figure 3-44: Isometric view of typical test specimen (standard units) 


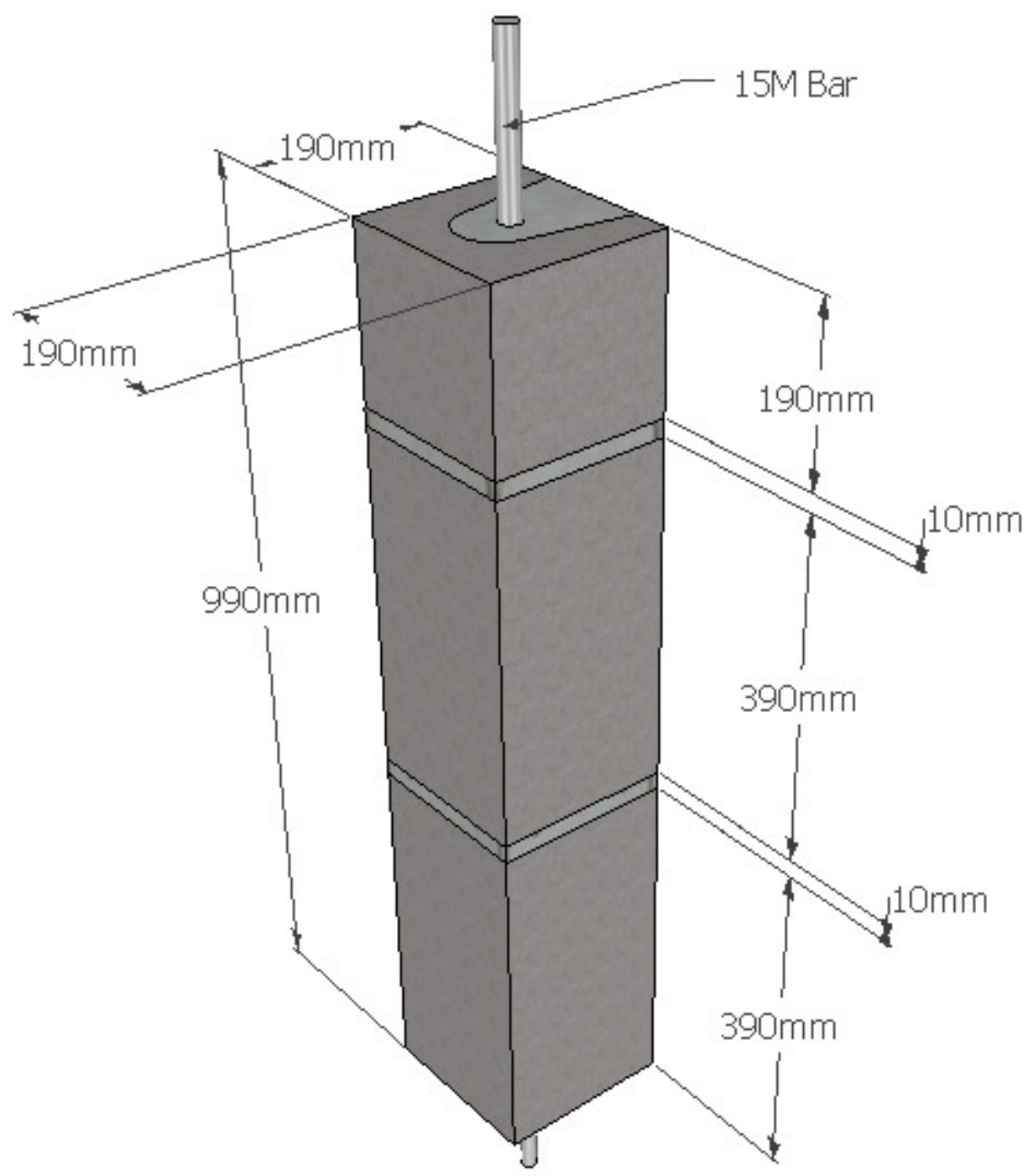

Figure 3-45: Isometric view of typical test specimen (lintel units) 


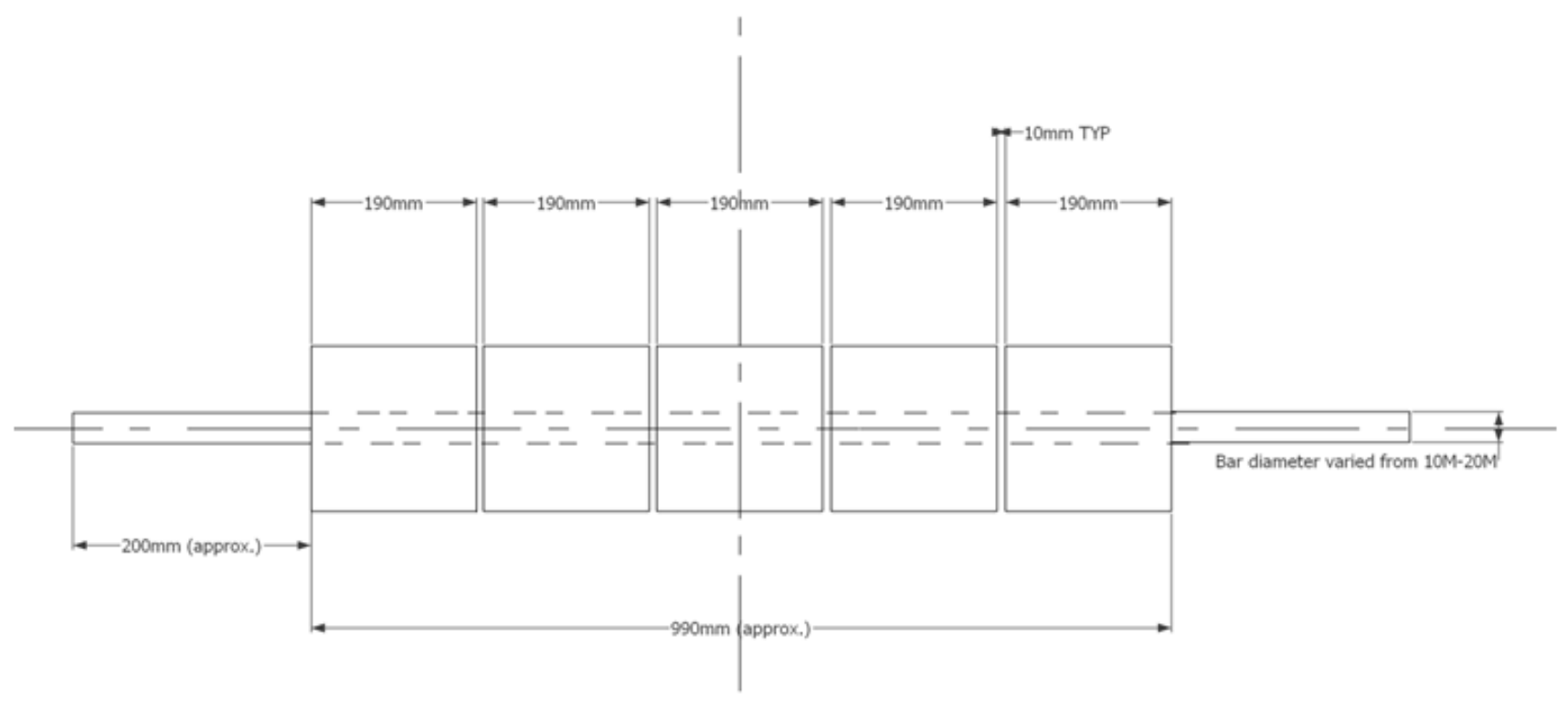

Figure 3-46: Design of typical test specimen (standard units)

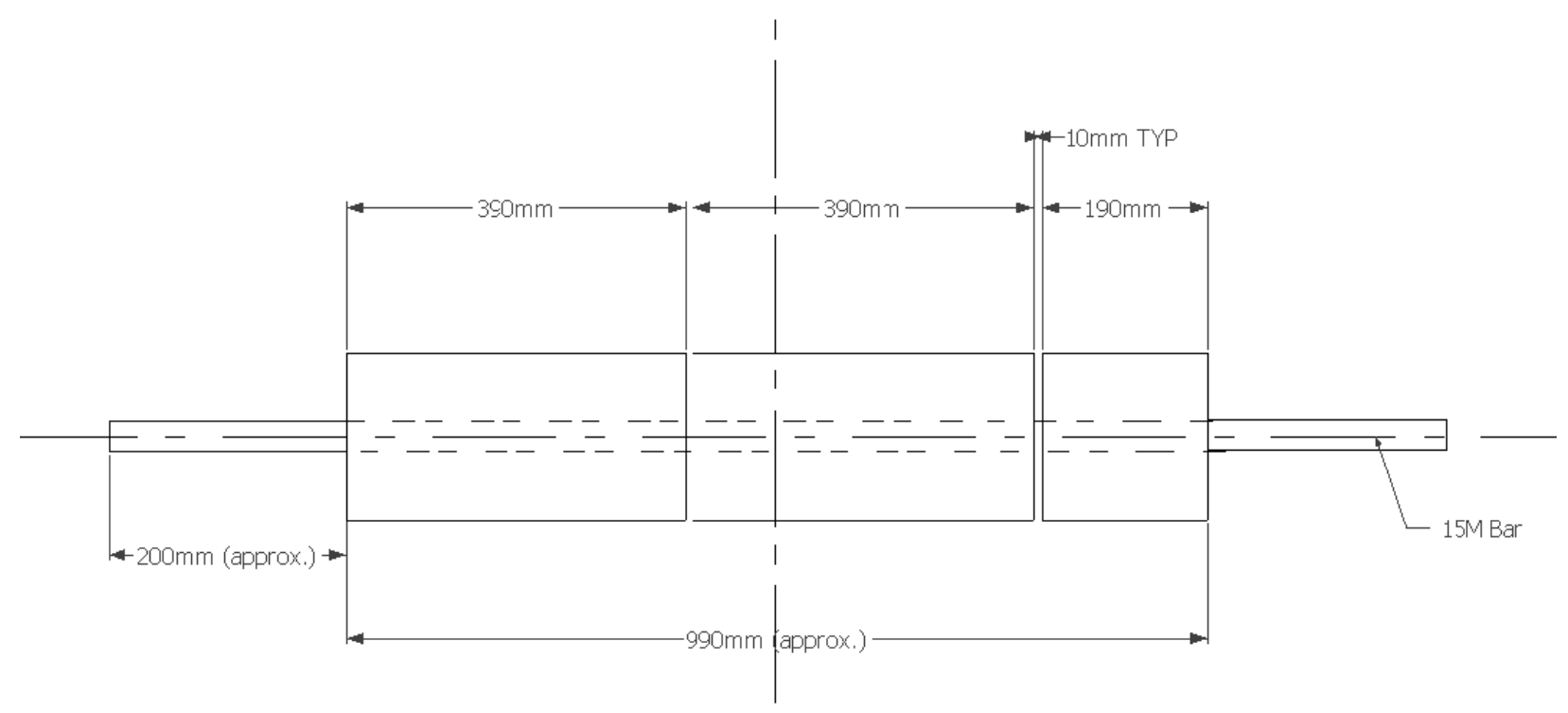

Figure 3-47: Design of typical test specimen (lintel units)

\subsubsection{Pre construction preparations}

The first step in construction of the test specimens was to cut a series of plywood bases 10 " by 10 ". Next a $190 \mathrm{~mm}$ by $190 \mathrm{~mm}$ square was traced onto the plywood bases and the centre of this square was located. A hole corresponding to the bar size was drilled directly at this centre 
of the square. These bases were prepared so that the test specimens could be constructed upon them. The holes in the middle were used to centre the bar in the specimens by threading the bar through the holes. A timber support structure was constructed underneath each base to assure that the reinforcement bar would extend $200 \mathrm{~mm}$ from the end of the specimen and be held in place during the grouting process. Caulking was applied between the bar and the base in order to eliminate any leakage of the grout mixture before the grout cured.

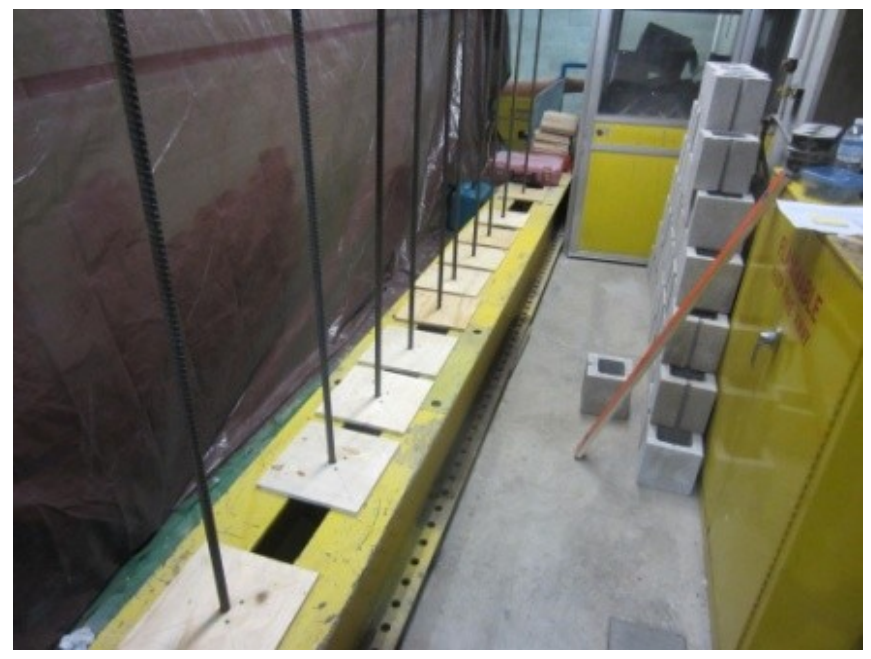

Figure 3-48: Plywood bases with reinforcing steel held in centre (view from above)

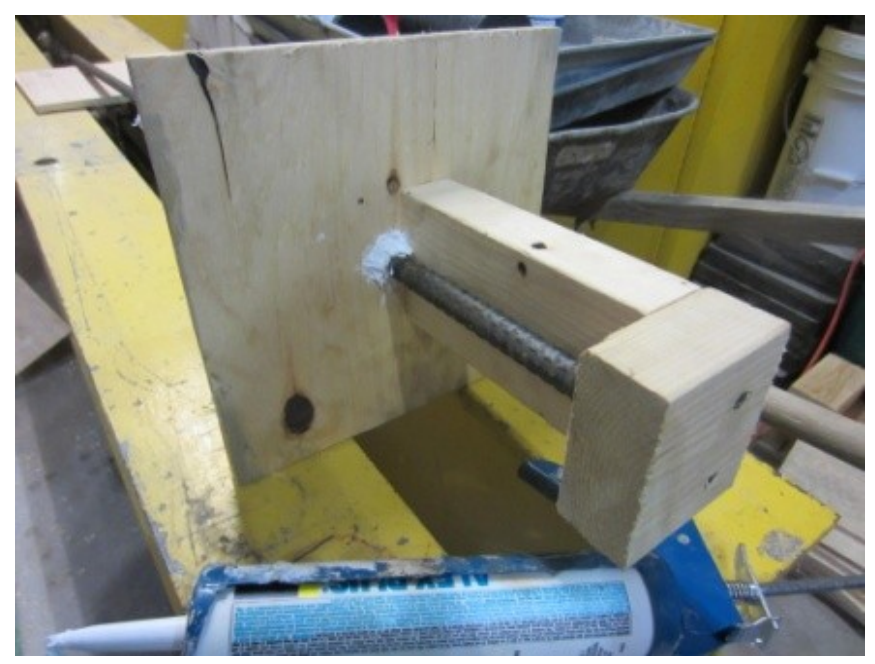

Figure 3-49: Timber support structure with caulking between rebar and base (view from below) 


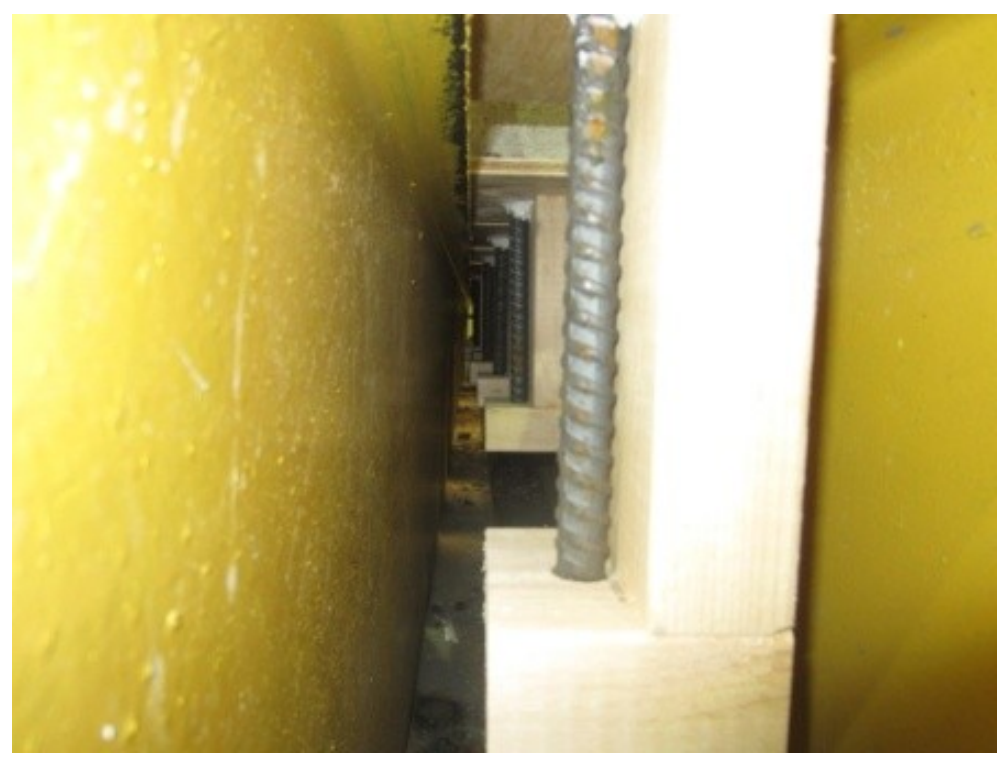

Figure 3-50: View of rebar held in place by timber support structure (view from below)

\subsubsection{Block Laying}

The specimens were made in three separate batches due to the availability of space at the time of construction. The blocks were brought inside one week prior to being laid to assure that any surface moisture present on the blocks which could affect the bond between the block and the mortar was eliminated. This also assured that the specimens were all built using blocks of a uniform temperature.

Type S mortar mix with 1:0.5:4.5 parts cement, lime, and sand respectively by volume. The mix was checked for workability using the standard mortar flow table. The sample on the flow table was rodded to assure consolidation of the mortar and then 25 blows were imparted to the table to make the mortar flow outwards. Water was added to the mortar mix to ensure the mortar flow was measured to be $100 \%$ or greater. Reworking of the mortar was not permitted to assure consistent mortar strengths and bond strengths.

Six mortar cubes, each measuring 50mmx50mmx50mm were cast from each mortar mix. Three were tested at 28 days and the other three were tested on the day that the specimens were tested. The mortar cubes were covered with a plastic sheet from the time of casting to the time of testing and kept in the laboratory during this time. 
Throughout the construction process, the block being laid was carefully leveled in two different directions. The overall height of the specimen was also monitored to assure that the mortar joints were as close to $10 \mathrm{~mm}$ as possible. The mortar joints were tooled such that they had a slightly inward facing curvature. Figures 3-51 to 3-53 summarize the laying of the blocks.

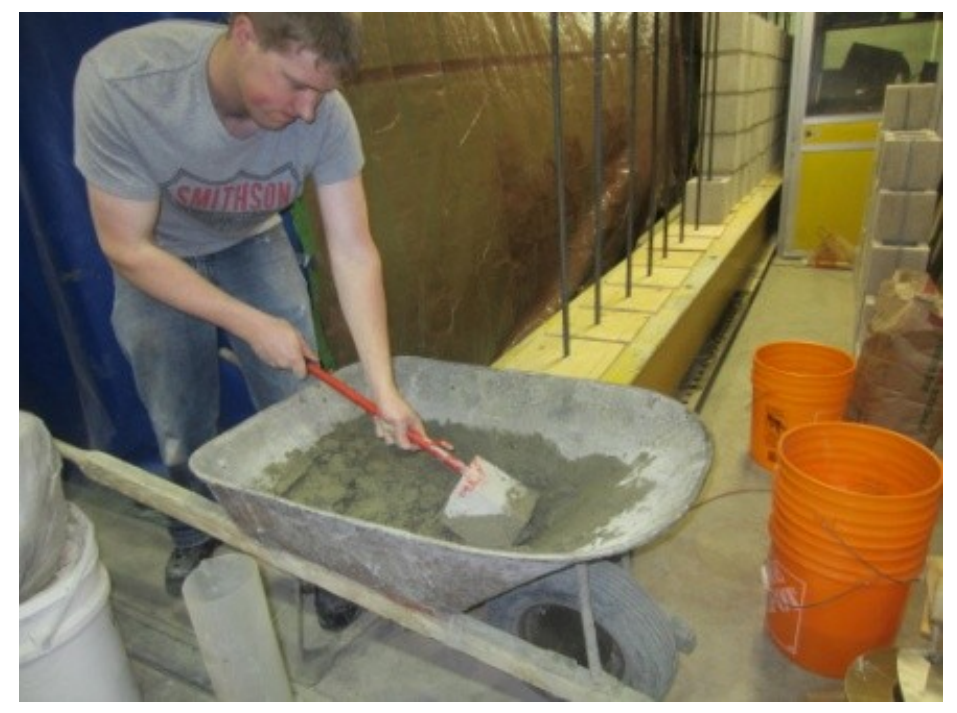

Figure 3-51: Mortar being mixed in wheelbarrow

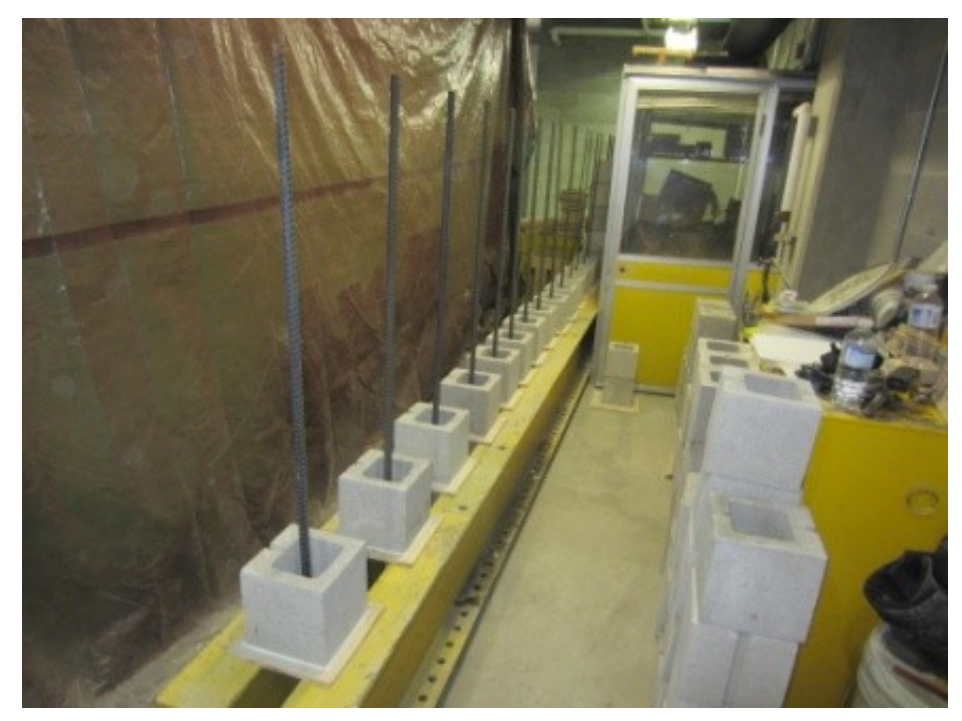

Figure 3-52: Bottom row of blocks placed such that rebar is centered in cross section 


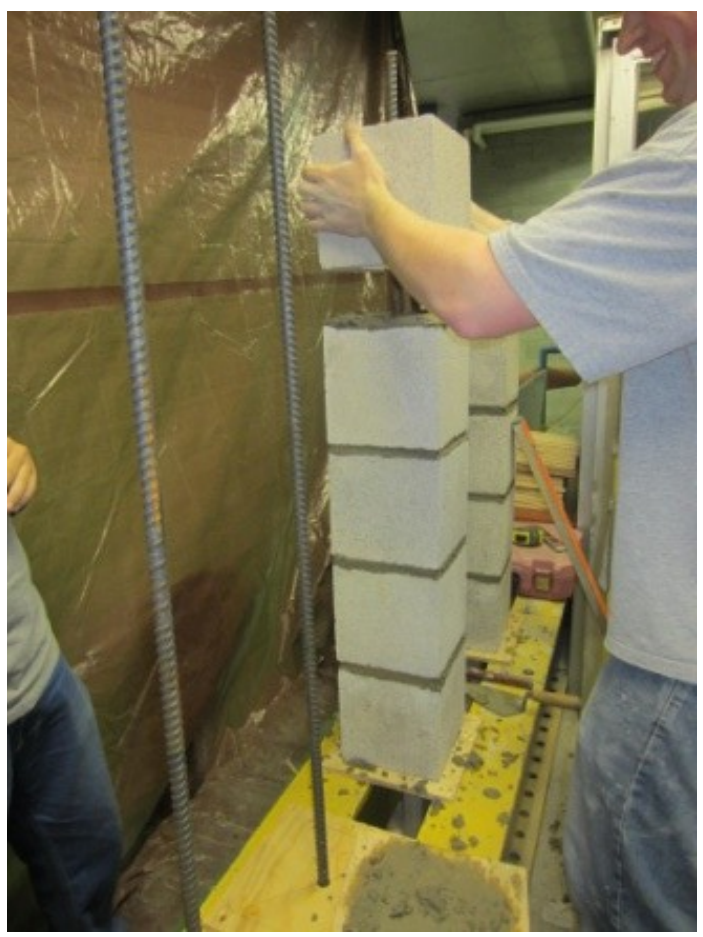

Figure 3-53: Typical specimen being constructed

\subsubsection{Grouting}

Specimens were allowed to cure for approximately one week prior to grouting to allow the mortar time to cure and to avoid damage during the vibration of the grout. Grout was mixed in small batches with a rotating barrel type mixer and two to four specimens along with the respective material samples were cast from each batch. Figures 3-54 and 3-55 show the placing of the grout in the specimens.

The grout was transported from the mixer to the specimens by wheelbarrow and was placed in the specimens with a pail and funnel. The first batch of specimens was vibrated with a pencil type vibrator but it was found that the vibration was too strong and exerted too much force on the mortar joints. Therefore, on subsequent batches the vibration was induced to the bar with a handheld plate vibrator and the bar was vibrated for approximately 20 seconds (see Figure 356) . Consolidation was observed to occur because the grout level was observed to drop during the vibration process. 


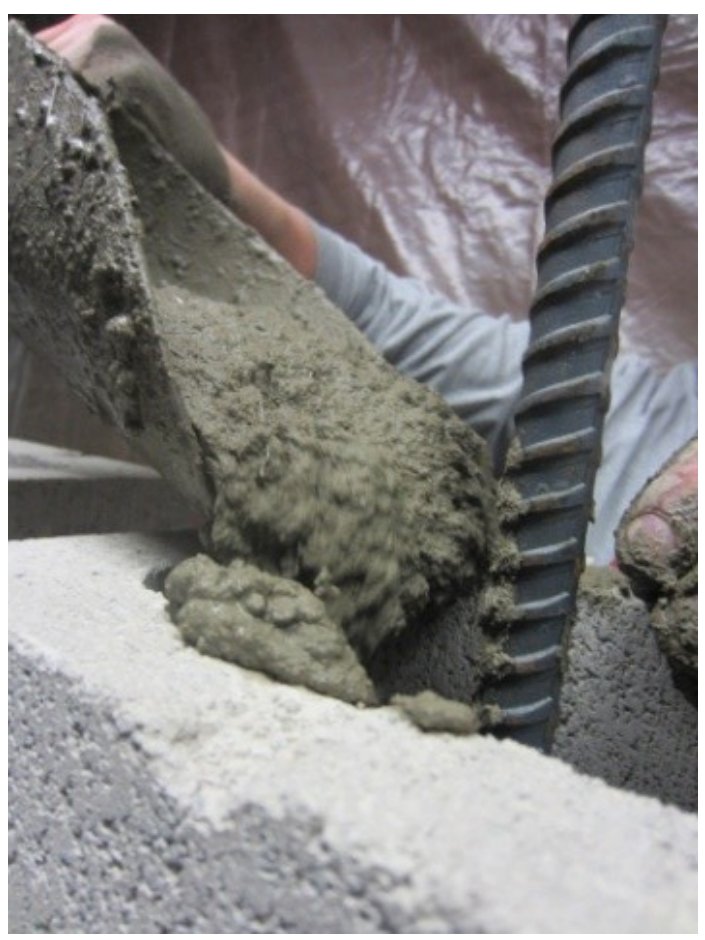

Figure 3-54: Grout being placed into centre of specimen

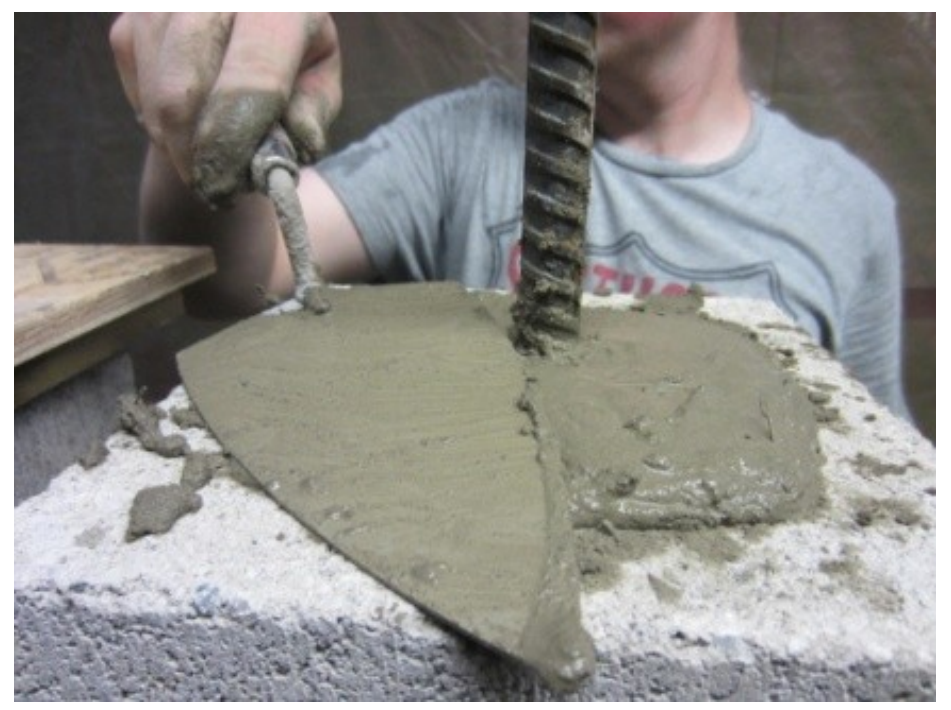

Figure 3-55: Excess grout removed from top of specimen with pointed trowel 


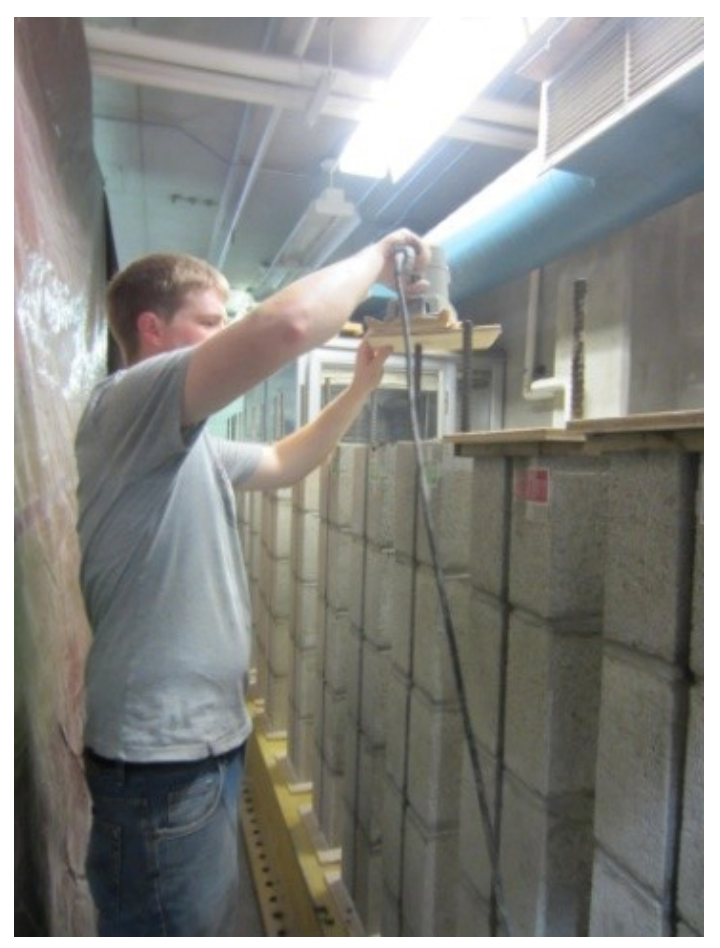

Figure 3-56: Reinforcing steel being vibrated to consolidate grout

\subsection{Test Setup and Instrumentation}

All tests on the tension stiffening specimens were performed on the 500kN MTS tensile testing machine in the structures lab at Carleton University. A lifting device was used to lift the specimens into and out of the testing frame (see Figure 3-58 and Figure 3-59). 


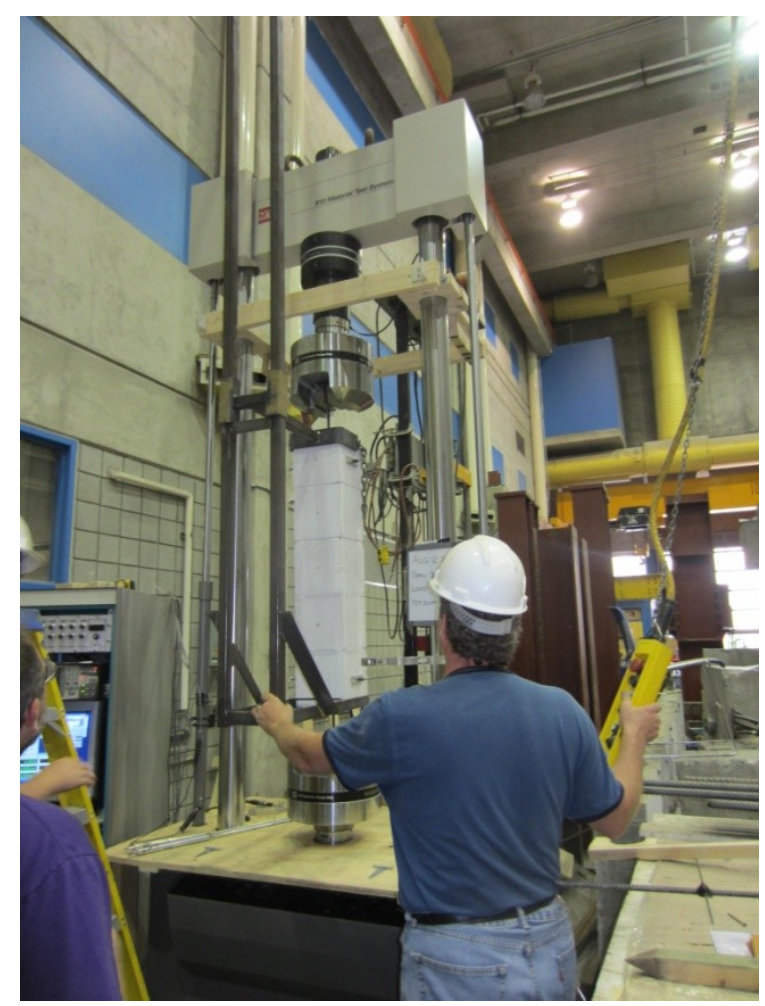

Figure 3-57: Specimen being lifted into MTS machine with lifting device and overhead crane

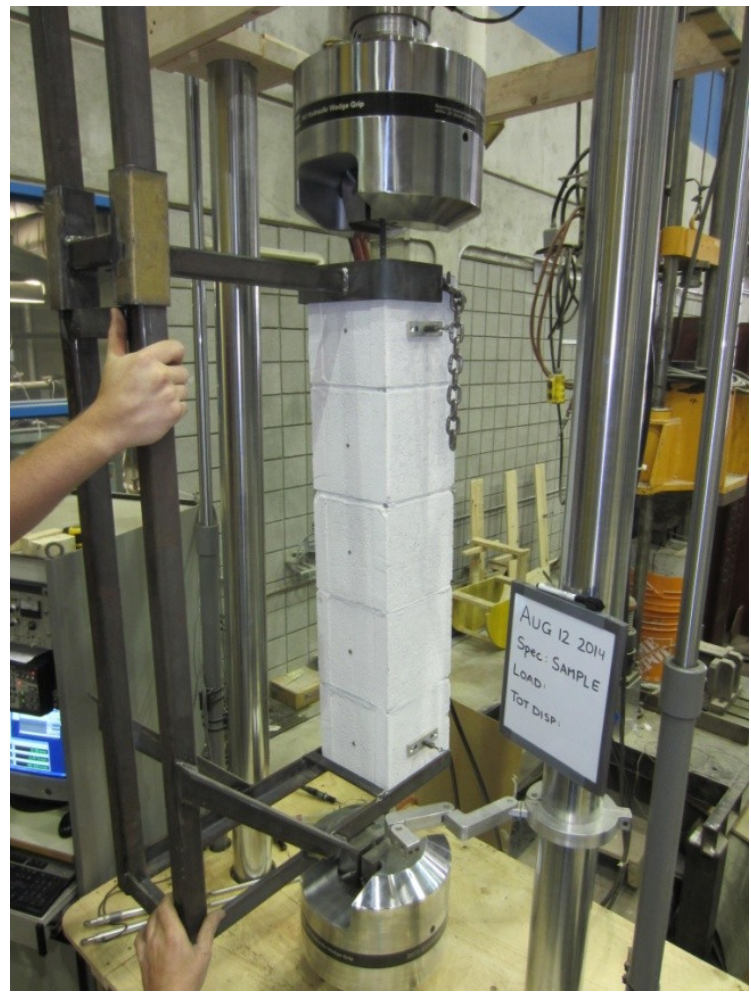

Figure 3-58: Lifting device being removed from specimen after top hydraulic grip activated 
The specimens were gripped by hydraulically activated grips which compressed the bar to approximately $20 \mathrm{MPa}$. The bars were gripped on the entirety of the last $85 \mathrm{~mm}$ of the bar.

All instrumentation was mounted onto the specimen at zero tensile load and initial readings were taken as a baseline measurement. As the second grip closed, the self weight of the specimen was removed by precompressing the specimen such that there was no load imparted prior to measurement. Linear Variable Differential Transducers (LVDT's) were used to monitor the overall deformation at a gauge length of $800 \mathrm{~mm}$. To complement the LVDT's, DEMEC points were installed over the same gauge length to monitor the localized deformation which could potentially take place over a single crack. Two MTS clip gauges with respective gauge lengths of 1 inch and 2 inches were installed on the top and bottom of the specimen to monitor the bar pullout at high tensile loads. Also, a dial gauge was installed at the top and bottom of the specimen to observe the deformation which took place outside the range of the LVDT's and DEMEC points. Detailed discussion of the individual instrumentation components in provided in the subsequent sections. Figure 3-59 shows a summary of a typical instrumented specimen.

A data acquisition system by MTS was used to record data from all electronic devices such as the clip gauges and the LVDT's at a frequency of $5 \mathrm{~Hz}$. 


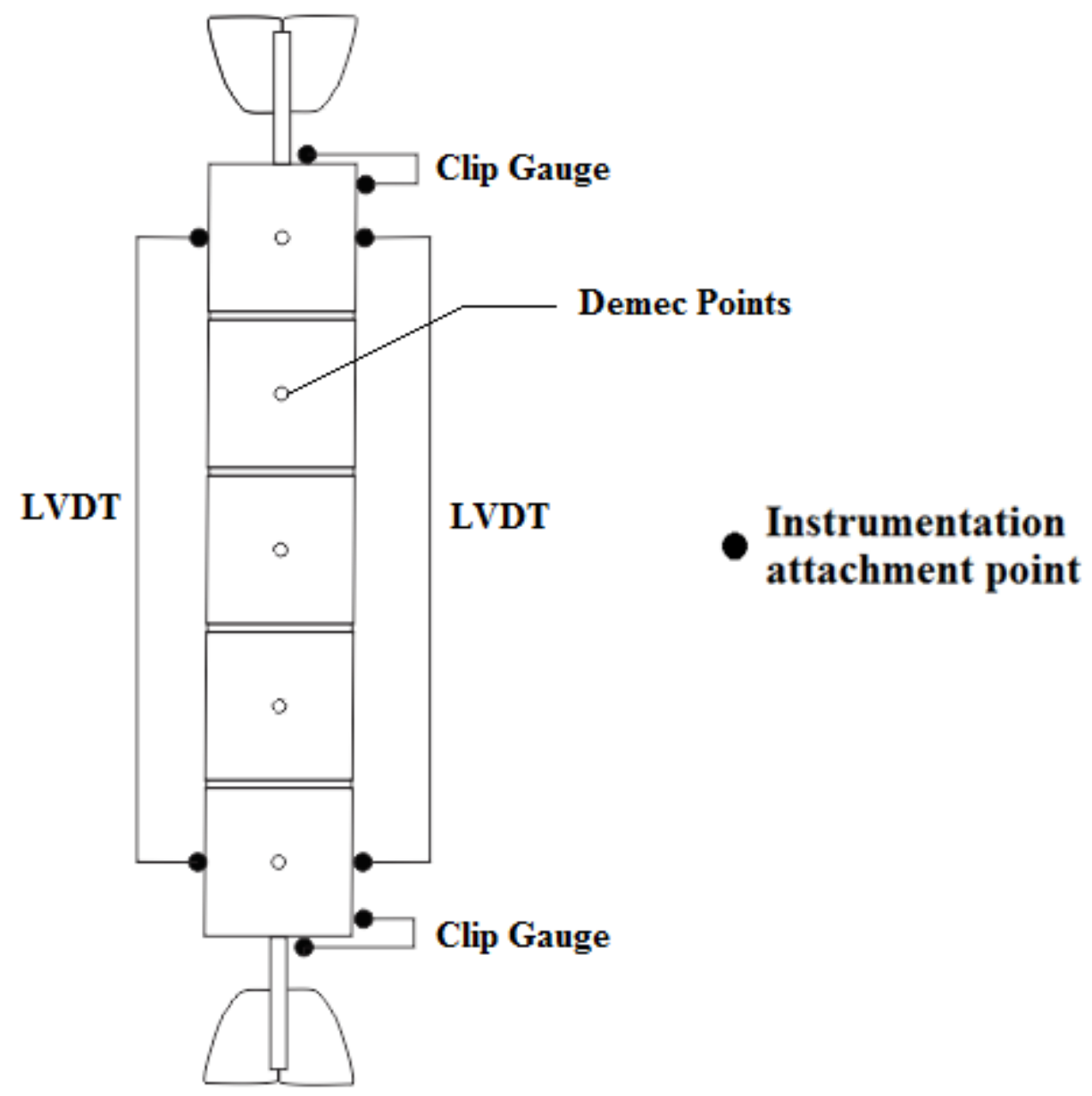

Figure 3-59: Summary of instrumentation on typical specimen

\subsubsection{Linear Variable Displacement Transducers (LVDTs)}

LVDTs were used to measure displacements on the surface of the specimens. LVDTs are a type of electrical transformer used for measuring linear displacement. Two LVDTs were mounted on each specimen, one on the east side and the other on the west side, and the average displacement was calculated. The LVDTs each had a gauge length of $800 \mathrm{~mm}$. 
In order to mount the LVDTs on the specimens, aluminum brackets were machined. The brackets were mounted onto the specimens with masonry screws in pre drilled holes. The holes were drilled to a depth of $25 \mathrm{~mm}$. After the holes were drilled, the excess dust was blown away from the hole with compressed air. A steel washer was used to space the aluminum bracket from the specimen and reduce the contact area. Once the brackets were mounted, there was very limited risk of slippage of the LVDT and accurate data was recorded.

The LVDTs were carefully labeled and the same LVDT was consistently placed on the same side of the specimen. Also, the respective LVDTs always had the same orientation after final installation with the moving shaft facing upwards.

The LVDTs were zeroed using the offset function on the data acquisition system prior to the initial loading.

\subsubsection{Demountable Mechanical Gauges (Demec gauges)}

Demountable mechanical gauges were used to measure the displacements at the centre line of the specimens on the sides that were not equipped with LVDTs. Demec gauges consist of a dial gauge attached to an Invar main bar with two conical locating points. One conical point is fixed and the other is allowed to rotate on a shaft. This rotation caused a steel plate to be pushed and this movement is tracked by the dial gauge. Each division on the dial gauge represents a specific amount of strain.

Epoxy glue was used to mount the Demec disks on the specimens at $200 \mathrm{~mm}$ intervals and masking tape was used to hold the discs in place while the epoxy was allowed to cure. This allowed the use of the demec point recordings to measure the total strain over an $800 \mathrm{~mm}$ gauge length to compare with the average LVDT readings. Demec point readings were taken at each load stage as well as before the loading began at zero load level. Each Demec reading was taken twice to assure that the readings were accurate. 


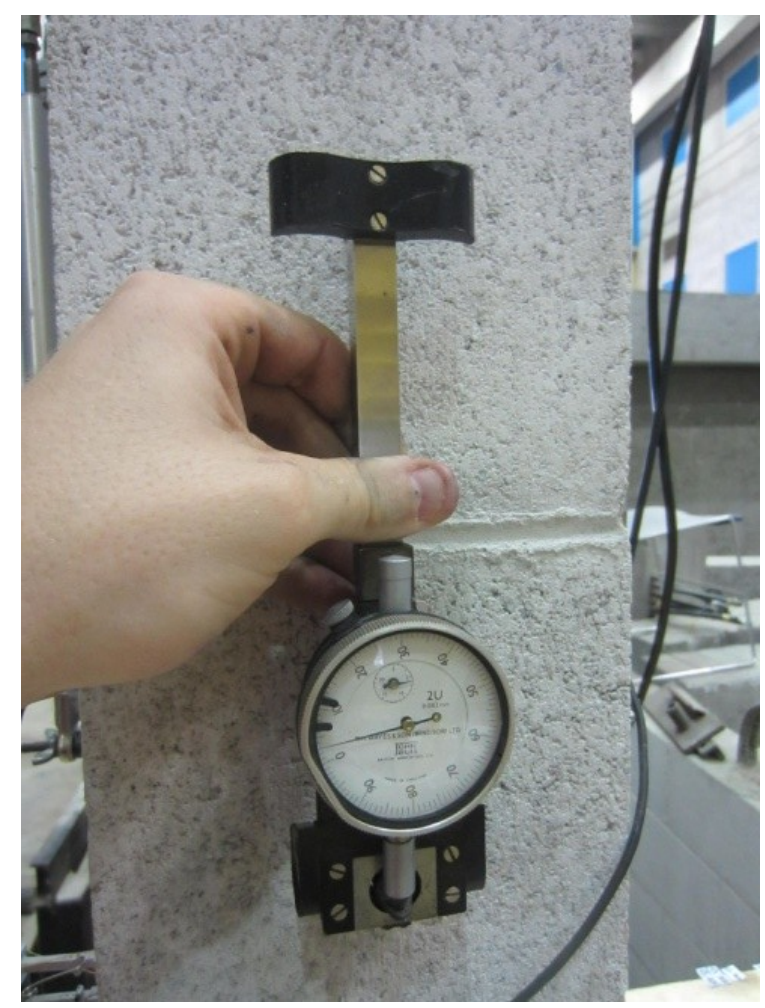

Figure 3-60: Demec point gauge

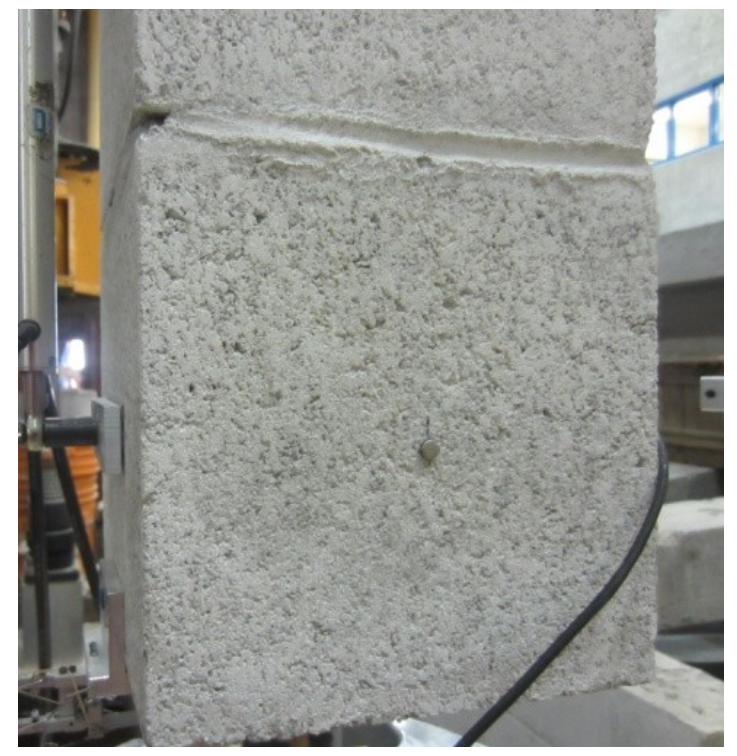

Figure 3-61: Demec point installed on typical specimen 


\subsubsection{MTS clip gauges}

Custom brackets were machined to accommodate the use of standard MTS clip gauges to measure the pullout behavior of the reinforcement from the grout matrix. A hole was drilled in the centre of the specimen approximately $20 \mathrm{~mm}$ from the end. Custom inserts were machined to extend the arms of the clip gauge so that they could effectively measure the pullout.

The bottom arm of the clip gauge was mounted to the custom bracket which was attached to the outer shell of the masonry unit. The top arm of the clip gauge extended down to the grout surface approximately $5 \mathrm{~mm}$ from the location of the reinforcing steel.

If any pullout was observed, the clip gauges tracked the displacement of the grout core relative to the outer shell of the masonry unit.

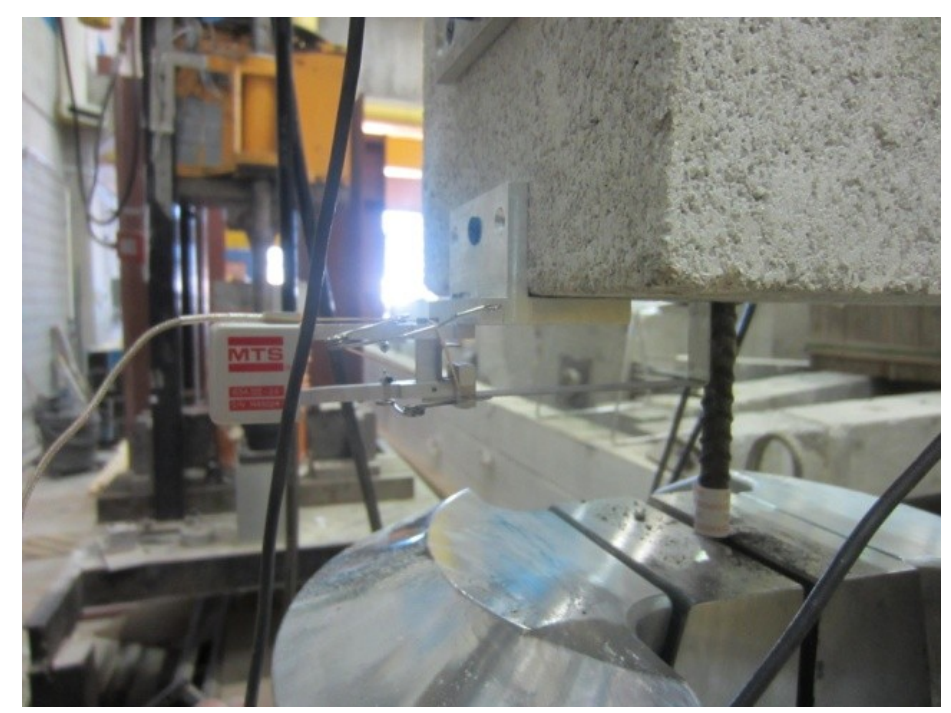

Figure 3-62: MTS clip gauge (1inch) at bottom of specimen 


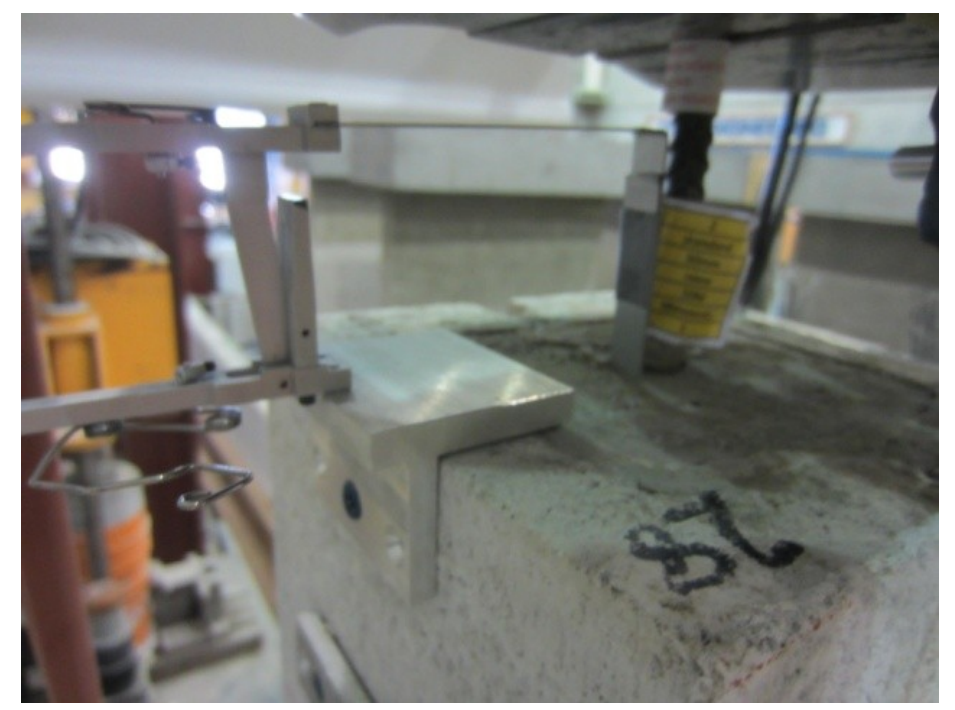

Figure 3-63: MTS clip gauge (2inch) installed at top of specimen

\subsection{Load/Displacement Sequence}

There were three different load/displacement sequences used in the tests depending on the specimen being tested and the data that was desired from each of the tests.

The first set of specimens was tested under monotonic load. These specimens included the following specimens: 10M00-1, 10M00-2, 10M12S-1, 10M12S-2, 15M00-1, 15M00-2, 15M04S-1, 15M04S-2, 15M08S-1, 15M08S-2, 15M12S-1, 15M12S-1, 15M12L-1, 15M12L-2, 20M00-1, 20M00-2, 20M04S-1，20M04S-2, 20M08S-1，20M08S-2, 20M12S-1，20M12S-2, L15M00-1, L15M04S-1, L15M08S-1, L15M12S-1. The displacement of the head was $0.75 \mathrm{~mm} / \mathrm{min}$ while in the elastic range, $1.5 \mathrm{~mm} / \mathrm{min}$ while in the yield plateau, and was increased to $4 \mathrm{~mm} / \mathrm{min}$ when the bar entered strain hardening. All rates were observed to be slow enough such that load rate effects were eliminated and the loading was considered to be static. Note that there were duplicates tested of each specimen type to ensure that the results were repeatable and to assure that there were no considerable variations in workmanship. Load stages were taken at steel stresses of $60 \mathrm{MPa}, 180 \mathrm{MPa}, 240 \mathrm{MPa}, 360 \mathrm{MPa}, 400 \mathrm{MPa}, 430 \mathrm{MPa}, 470 \mathrm{MPa}$, and approximately $540 \mathrm{MPa}$ or as close to ultimate as possible. 
The second set of specimens was tested under cyclic load to observe the effect of cycling the load at low levels of load (prior to yield). This set of specimens was tested under load control so that the load could be cycled to simulate the cycling of load that could happen in the tension reinforcement of a reinforced masonry beam subjected to service conditions. First the specimens were stressed to $180 \mathrm{MPa}$ and the load was cycled from $180 \mathrm{MPa}$ to $60 \mathrm{MPa} 20$ times. Next the stress was increased to $240 \mathrm{MPa}$ and the load was cycled from $240 \mathrm{MPa}$ to $60 \mathrm{MPa} 20$ times. Next the stress was increased to $360 \mathrm{MPa}$ and the load was cycled from $360 \mathrm{MPa}$ to $60 \mathrm{MPa} 20$ times. Next the stress was increased to $400 \mathrm{MPa}$ and the load was cycled from $400 \mathrm{MPa}$ to $60 \mathrm{MPa} 20$ times. After all the cycling was completed, the test apparatus switched into displacement control and the specimen was loaded under displacement control at a rate of $4 \mathrm{~mm} / \mathrm{min}$. All cycling took place at $1 \mathrm{kN} / \mathrm{sec}$ which was deemed to be acceptably slow based on a literature review of similar testing. The following specimens were tested under this loading regime: $15 \mathrm{C} 00-1,15 \mathrm{C} 04 \mathrm{~S}-1$, 15C08S-1, 15C12S-1, 20C00-1, 20C04S-1, 20C08S-1, and 20C12S-1. The cyclic load history for this set of tests is depicted below.

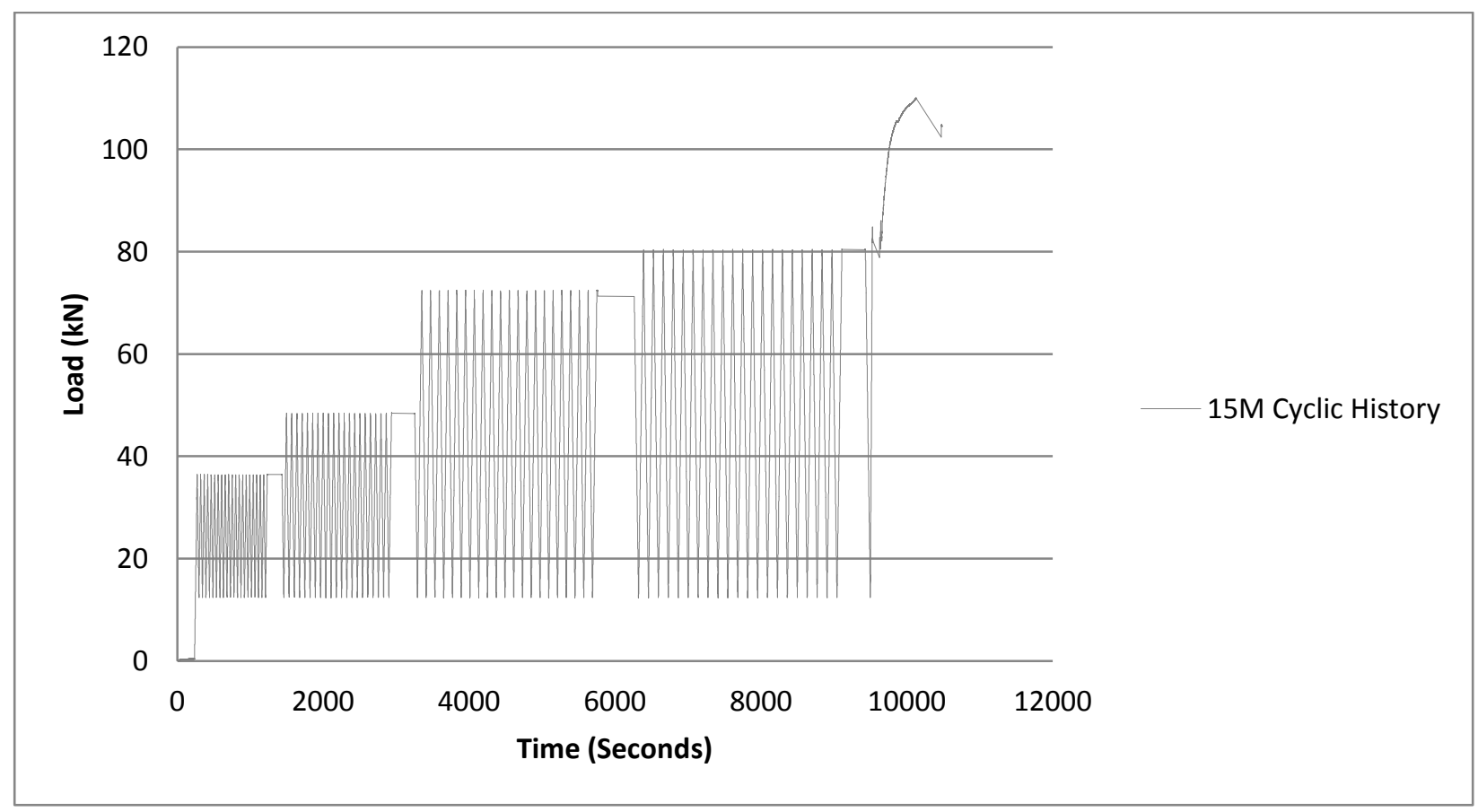

Figure 3-64: Load displacement history for specimens tested under cyclic load prior to yield 
The third set of specimens was tested under cyclic loading, but was tested to investigate the effect of cyclic loading at high levels of stress (post yield). This type of loading simulated the loading that a masonry element might undergo in an extreme loading event such as a blast or an earthquake. The LVDT's mounted on the side of the specimen were used to control the test procedure. Once the LVDT's measured an average displacement corresponding to yielding of the reinforcement bar $(0.2 \%$ strain), the load on the specimen was then cycled from that given LVDT displacement to zero load and the load was cycled 20 times. Next, the specimen was loaded until an LVDT displacement corresponding to twice that of the yield displacement was observed ( $0.4 \%$ strain). At this point, the load was cycled back down to zero load and this process was repeated 20 times. In the next stage, the specimen was loaded until an LVDT displacement corresponding to three times that of the yield displacement was observed $(0.6 \%$ strain). At this point, the load was cycled back down to zero and was repeated 20 times. The following specimens were tested under this loading regime: 15C00-2, 15C04S-2, 15C08S-2 15C12S-2, 20C00-2, 20C04S-2, 20C08S-2, and 20C12S-2. 


\section{Experimental Results}

\subsection{Introduction}

The results of the 42 direct tension specimens along with the results of material testing are discussed in this chapter. The stress-strain behaviour, cracking behaviour, and major events in the loading process are presented for each test specimen. Although the results of each individual test are presented here, the data is discussed and compared in chapter 5. Note that the shrinkage effects were neglected to conservatively approximate the tension stiffening behavior of fibre reinforced concrete masonry.

\subsection{Material Strength Testing}

Material strength testing was carried out on all material samples collected in the experimental phase of the research. Test specimens included grout cylinders, grout prisms, mortar cubes, masonry prisms and reinforcing steel coupons. Due to the fact that the quality of a constructed masonry element is highly dependent on the workmanship, quality control measures on the constituent materials are paramount. The testing details for each type of material are detailed in chapter 3 of this thesis.

\subsubsection{Grout Cylinders}

Grout cylinders were cast in non-absorbent molds and for this reason do not accurately represent the grout strength inside the masonry element. Due to the fact that the masonry is able to absorb a considerable amount of water from the fresh grout mix, the water-cement ratio of the in-situ grout can be lowered substantially which in turn increases the strength.

The cylinders cast were $200 \mathrm{~mm}$ in height and had a diameter of $100 \mathrm{~mm}$. Four cylinders were cast from each grout mix and the cylinders were poured in three lifts with rodding of each individual lift. The grout cylinders were capped with a sulfur compound as described in Chapter 3 and tested in a 400kip compressive testing frame. 
Three types of tests were performed on the grout cylinders and the data acquisition system recorded data at intervals of 1.0 seconds. In the first type of test, an apparatus to measure the displacement of the cylinder throughout the compressive test was used. An LVDT mounted along the longitudinal axis of the specimen tracked the compressive displacement and with this, the compressive strain was calculated. The second type of test was strictly compressive strength test. The third type of test was a split cylinder test to indirectly measure the tensile strength of the grout from the splitting strength. From each lot of cylinders, representative of one grout mix, 1 cylinder was tested to measure the displacement under compressive load, 2 cylinders were strictly tested for compressive strength, and 1 cylinder was tested for tension splitting.

Table 4-1: Summary of grout cylinder compressive strength and displacement at failure

\begin{tabular}{|c|c|c|c|c|}
\hline Grout Type & $\begin{array}{c}\text { Avg. } \\
\text { Compressive } \\
\text { Strength } \\
\text { Based on 9 } \\
\text { cylinders }\end{array}$ & $\begin{array}{c}\text { Displacement at } \\
\text { Maximum Load }\end{array}$ & $\boldsymbol{\varepsilon}_{\mathbf{c}}^{\mathbf{c}^{\prime}}$ & $\mathbf{E}$ \\
\hline No Fibres & $23.6 \mathrm{MPa}$ & $0.635 \mathrm{~mm}$ & 0.0043 & $10444 \mathrm{MPa}$ \\
\hline $0.4 \% \mathrm{ZP} 305$ & $31.7 \mathrm{MPa}$ & $0.677 \mathrm{~mm}$ & 0.0049 & $15494 \mathrm{MPa}$ \\
\hline $0.8 \% \mathrm{ZP} 305$ & $28.2 \mathrm{MPa}$ & $0.741 \mathrm{~mm}$ & 0.0056 & $10499 \mathrm{MPa}$ \\
\hline $1.2 \% \mathrm{ZP} 305$ & $29.1 \mathrm{MPa}$ & $0.548 \mathrm{~mm}$ & 0.0040 & $12316 \mathrm{MPa}$ \\
\hline $1.2 \%$ & $29.3 \mathrm{MPa} *$ & $0.504 \mathrm{~mm}$ & 0.0040 & $8900 \mathrm{MPa}$ \\
\hline $\mathrm{RC} 65 / 60 \mathrm{BN}$ & & & & \\
\hline
\end{tabular}

*based on 3 cylinders

As seen in Table 4-1, the compressive strength was reasonably constant overall volume fractions of fibres. The grout mix with $0.4 \%$ of the $30 \mathrm{~mm}$ fibres (ZP305) had a higher compressive strength than the other mixes, perhaps due to the fact that the fibres were able to be distributed very evenly throughout the mix. Figure 4-1 shows the stress strain relationships of grout cylinders with varying fibre content. For all grout mixes using ZP305 fibres, the stress strain relationships for 3 cylinders are traced. For the grout mixes using RC65/60BN fibres, the stress strain relationship for one cylinder is traced. The displacement results for the cylinders had a considerable amount of experimental error, which accounts for the variability in values such as the strains and stiffnesses. 

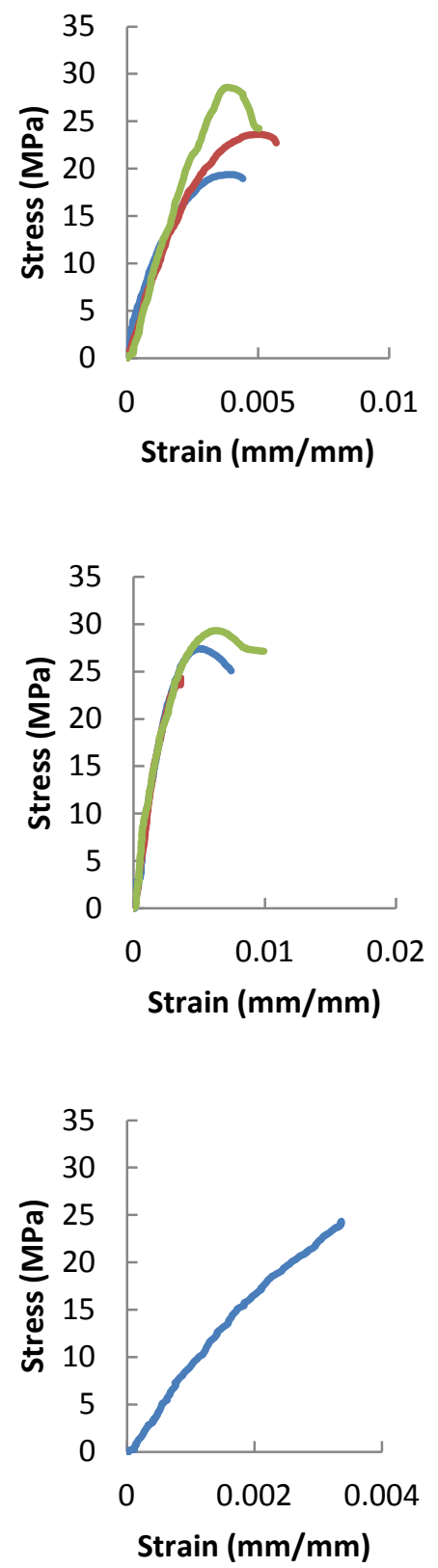
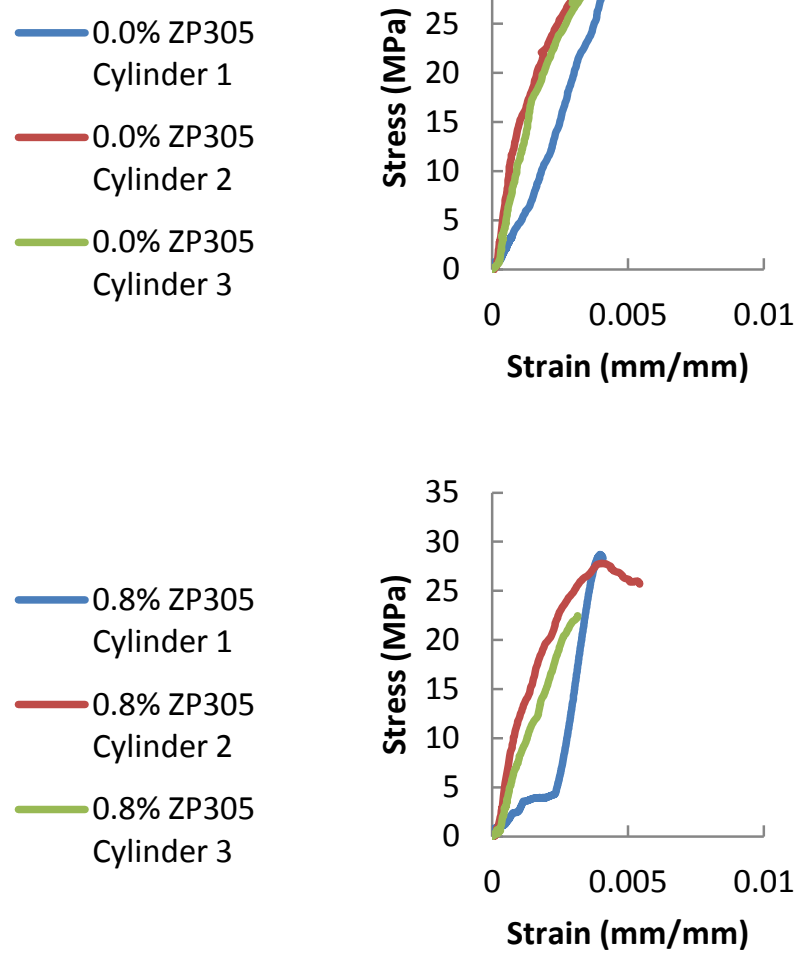

1.2\% ZP305

Cylinder 1

1.2\% ZP305

Cylinder 2

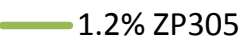

Cylinder 3

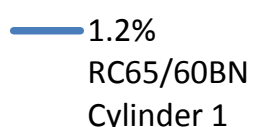

Cylinder 1

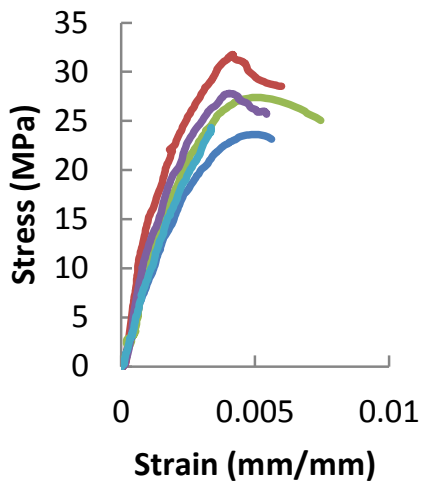

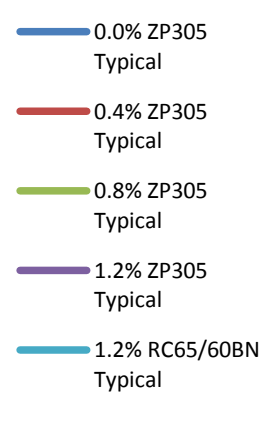

Figure 4-1: Summary of stress strain responses of grout cylinders 
Table 4-2: Average tensile splitting force of grout cylinders

\begin{tabular}{|c|c|c|}
\hline Grout Type & $\begin{array}{c}\text { Avg. Tensile Splitting Force } \\
(\mathrm{P}) \text {, based on } 3 \text { cylinders }\end{array}$ & $\begin{array}{c}\text { Avg. Tensile Strength } \\
\left(\mathrm{f}_{\mathrm{t}}=2 \mathrm{P} / \pi \mathrm{DL}\right)\end{array}$ \\
\hline No Fibres & $79.2 \mathrm{kN}$ & $2.52 \mathrm{MPa}$ \\
\hline $0.4 \%$ ZP305 & $121.5 \mathrm{kN}$ & $3.87 \mathrm{MPa}$ \\
\hline $0.8 \% \mathrm{ZP} 305$ & $131.1 \mathrm{kN}$ & $4.17 \mathrm{MPa}$ \\
\hline $1.2 \% \mathrm{ZP} 305$ & $158.6 \mathrm{kN}$ & $5.05 \mathrm{MPa}$ \\
\hline $1.2 \%$ RC65/60BN & $153.4 \mathrm{kN} *$ & $4.88 \mathrm{MPa}$ \\
\hline
\end{tabular}

*based on 1 cylinder

Table 4-2 shows the results of the tension splitting tests performed on standard grout cylinders. The cylinders were placed on edge and the load was imparted to two mineral fibre strips in order to reduce stress concentrations. The tensile strength is increased significantly as fibres volume fractions are increased. The tensile strength approximately doubled when the fibre volume was increased from 0 to $1.2 \%$ ZP305 fibres.

\subsubsection{Grout Prisms}

Grout prisms were tested under compressive load and the displacement was measured by demec points and a demec gauge (see Figure 4-2). A series of four compressive prisms were tested for each grout type with the exception of the $1.2 \%$ long $(\mathrm{RC} 65 / 60 \mathrm{BN})$ where only 1 specimen had reliable data. The mix with the longer fibres had workability issues, therefore the three unreliable grout prisms were not entirely consolidated and the compressive strength could not accurately be measured.

Table 4-3 below summarizes the compressive strengths of the grout prisms along with the compressive strain at failure. The pattern of grout prism strengths generally follows the pattern of the cylinder strengths discussed previously. In the cases where fibres were present, a very ductile failure was observed.

Table 4-3: Compressive strengths of absorbent grout prisms

\begin{tabular}{|c|c|c|}
\hline Grout Type & $\begin{array}{c}\text { Avg. Compressive Strength } \\
\text { Based on 4 prisms }\end{array}$ & $\begin{array}{c}\text { Compressive Strain at } \\
\text { Maximum Stress }\end{array}$ \\
\hline No Fibres & $23.8 \mathrm{MPa}$ & $0.41 \%$ \\
\hline $0.4 \%$ ZP305 & $35.4 \mathrm{MPa}$ & $0.31 \%$ \\
\hline $0.8 \% \mathrm{ZP} 305$ & $33.5 \mathrm{MPa}$ & $0.51 \%$ \\
\hline $1.2 \% \mathrm{ZP} 305$ & $35.1 \mathrm{MPa}$ & $0.52 \%$ \\
\hline $1.2 \% \mathrm{RC} 65 / 60 \mathrm{BN}$ & $35.0 \mathrm{MPa} *$ & $0.28 \%$ \\
\hline
\end{tabular}


*based on 1 prism

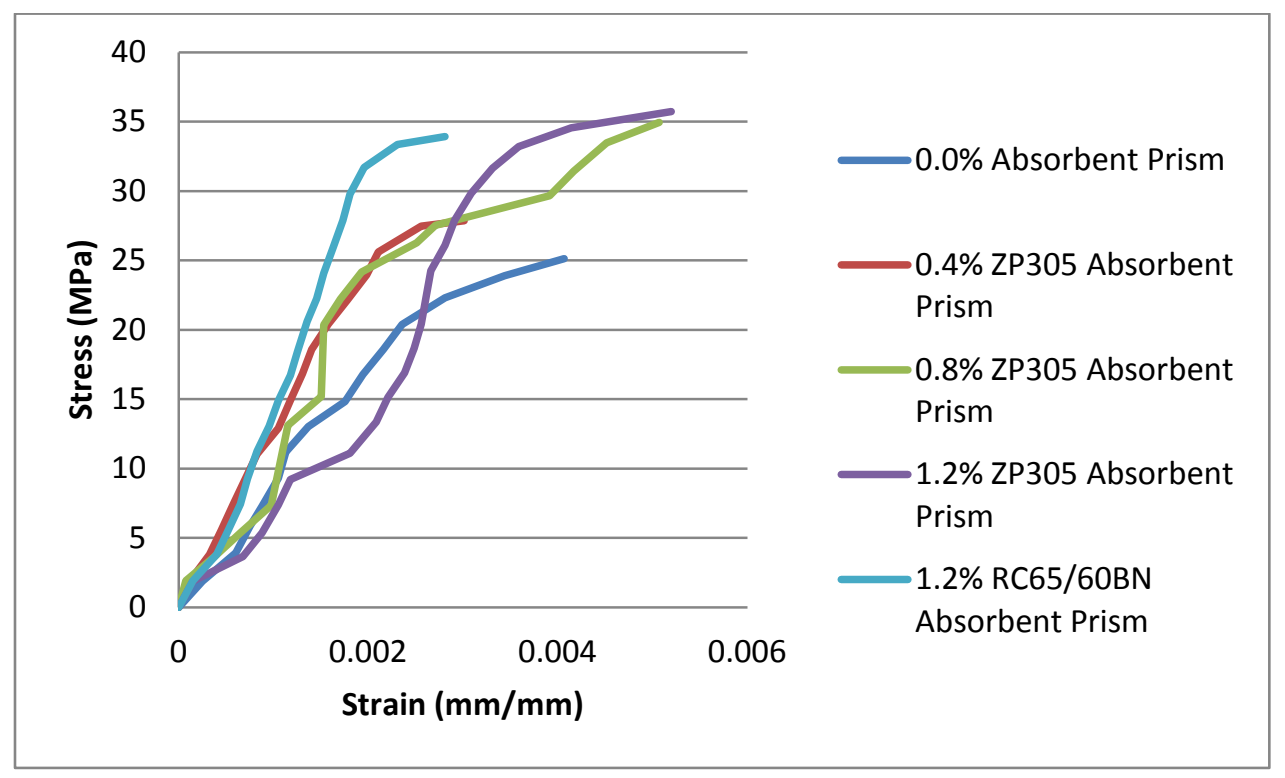

Figure 4-2: Stress strain relationship of absorbent grout prisms

\subsubsection{Mortar Cubes}

Standard mortar cubes were tested as described in the experimental program. Compression tests were performed under displacement control. CSA A179-04 states that the minimum compressive strength of a standard Type S mortar cube tested at 28 days should be 12.5MPa.

The mortar cubes were tested at a rate of $0.75 \mathrm{~mm} / \mathrm{min}$ which caused failure of the mortar cubes in 60-80seconds.

The results of the mortar cube compression tests are summarized Table 4-4 below. 
Table 4-4: Average compressive strengths of Type S mortar

\begin{tabular}{|c|c|c|}
\hline Mortar Batch (Type S) & $\begin{array}{c}\text { Average Compressive Strength } \\
\text { (MPa) }\end{array}$ & Number of samples \\
\hline Batch 1 & 17.1 & 6 \\
\hline Batch 2 & 15.2 & 6 \\
\hline Batch 3 & 14.7 & 6 \\
\hline Batch 4 & 17.0 & 6 \\
\hline Batch 5 & 20.7 & 6 \\
\hline Batch 6 & 17.4 & - \\
\hline Average & 17.0 & \\
\hline
\end{tabular}

Figure 4-3 shows the typical response of a mortar cube under compressive load showing a peak compressive stress of approximately $16 \mathrm{MPa}$ and a compressive strain of $2.3 \%$. The compressive stress is based on an area of $2500 \mathrm{~mm}^{2}$ and the compressive strain is based on the head displacement. The response shown in Figure 4-3 is for a typical mortar cube taken from batch 1 .

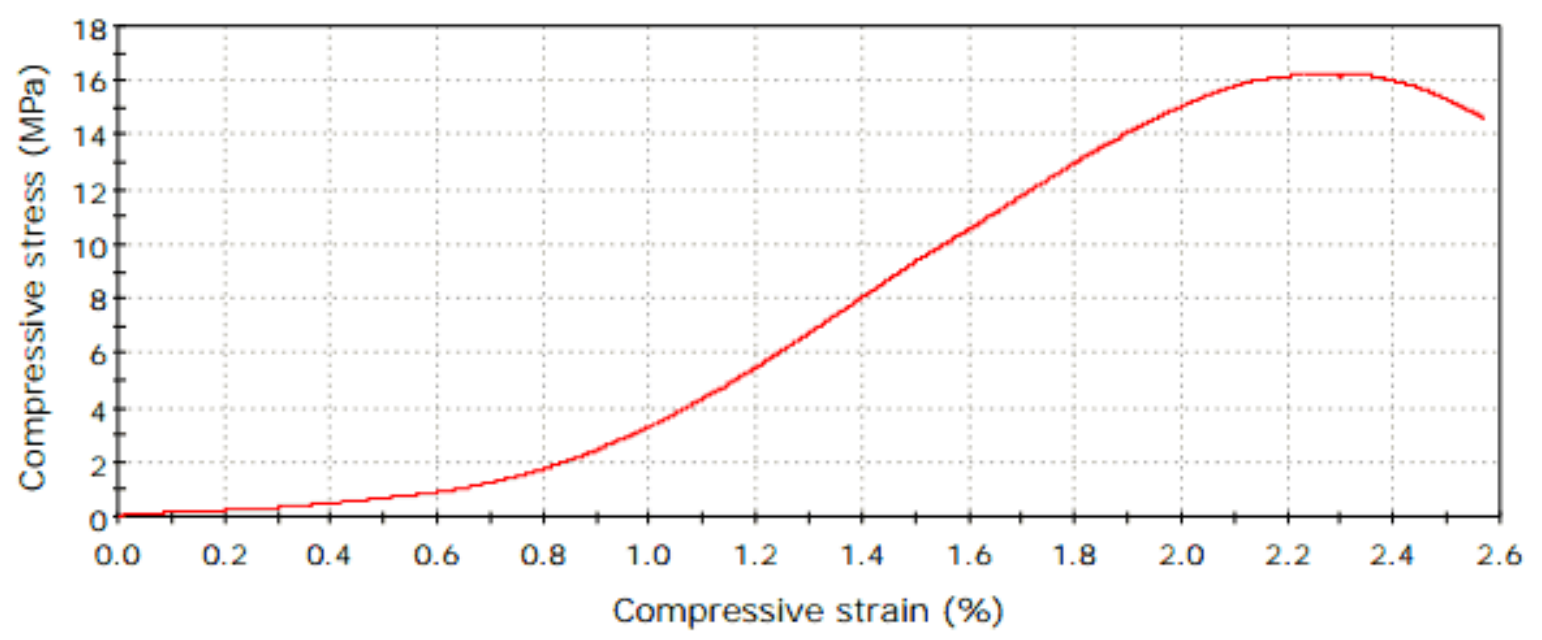

Figure 4-3: Stress strain relationship of typical mortar cube 


\subsubsection{Masonry Prisms}

Masonry prisms were constructed as described in Chapter 3 to represent the material properties when combined as a composite material. Masonry prisms were constructed with one mortar joint connecting two blocks. All prisms were fully grouted.

Three masonry prisms were built for each grout type. Two prisms were tested with no additional instrumentation and the third prism was instrumented with two LVDTs on opposing sides to measure the compressive displacement as a function of compressive force throughout the loading.

The results of the compressive prism testing are shown in Table 4-4 below.

\begin{tabular}{|c|c|c|c|c|c|}
\hline $\begin{array}{c}\text { Prism Type } \\
\text { (fully grouted) }\end{array}$ & $\begin{array}{c}\text { Average } \\
\text { Compressive } \\
\text { Strength } \\
\text { (MPa) }\end{array}$ & $\begin{array}{c}\text { Number of } \\
\text { samples }\end{array}$ & $\begin{array}{c}\text { Displacement at } \\
\text { max comp stress. }\end{array}$ & $\boldsymbol{\varepsilon}_{\mathbf{c}}^{\prime}$ & $\begin{array}{c}\mathbf{E} \\
\text { (MPa) }\end{array}$ \\
\hline No fibres & 24.5 & 3 & $0.283 \mathrm{~mm}$ & 0.0014 & 34394 \\
\hline $0.4 \%$ ZP305 & 25.5 & 3 & $0.269 \mathrm{~mm}$ & 0.0013 & 30612 \\
\hline $0.8 \%$ ZP305 & 28.2 & 3 & $0.292 \mathrm{~mm}$ & 0.0015 & 32116 \\
\hline $1.2 \%$ ZP305 & 25.7 & 3 & $0.323 \mathrm{~mm}$ & 0.0016 & 25827 \\
\hline $\begin{array}{c}1.2 \% \\
\text { RC65/60BN }\end{array}$ & 24.8 & 3 & $0.347 \mathrm{~mm}$ & 0.0017 & 26093 \\
\hline
\end{tabular}

Figure 4-4: Average compressive strengths of grouted masonry prisms 


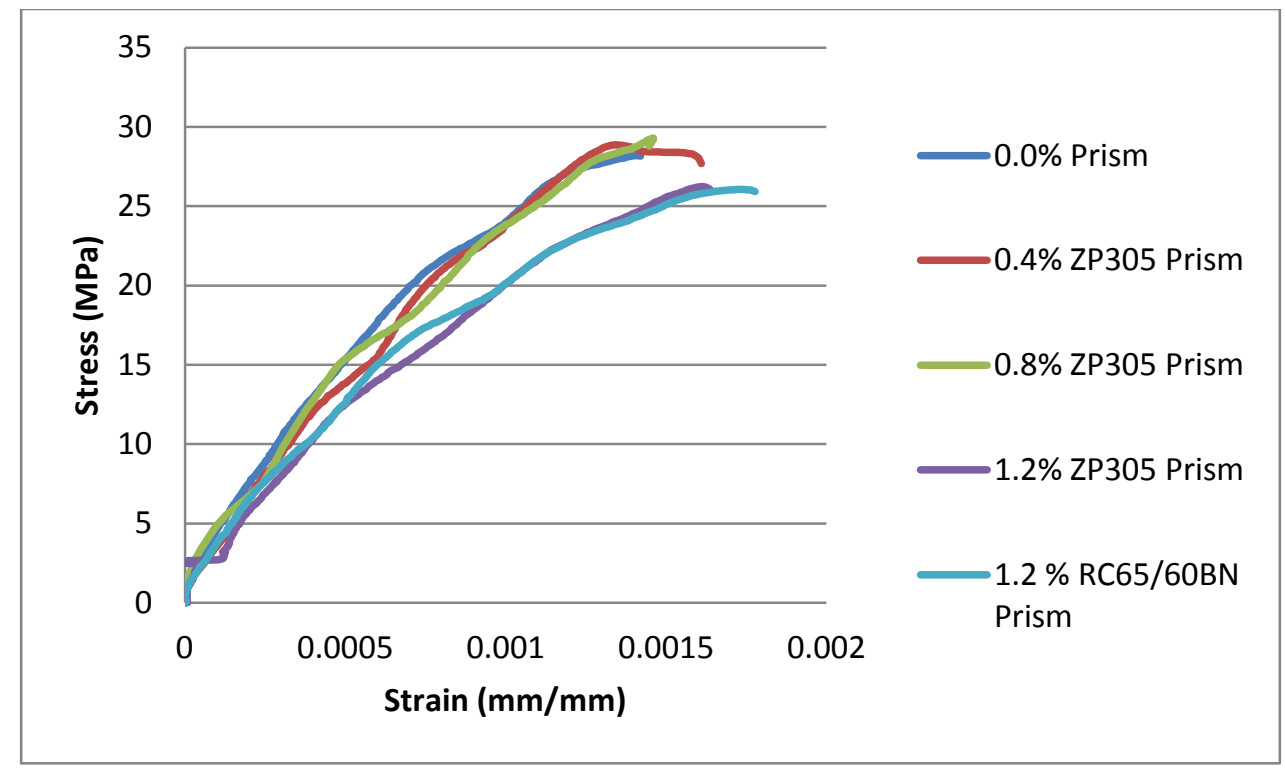

Figure 4-5: Stress strain responses for masonry prisms

\subsubsection{Reinforcing Steel Coupons}

The stress-strain responses of the reinforcing bars and their typical stress-strain curves are shown in Figures 4-6 to 4-8. Key properties of the reinforcing bars include yield stress $\left(f_{y}\right)$, ultimate stress $\left(\mathrm{f}_{\mathrm{u}}\right)$, yield strain $\left(\varepsilon_{\mathrm{y}}\right)$ and ultimate strain $\left(\varepsilon_{\mathrm{u}}\right)$. The key properties are summarized in Table 4-5. All properties listed in Table 4-5 are mean properties based on three coupons for each bar size

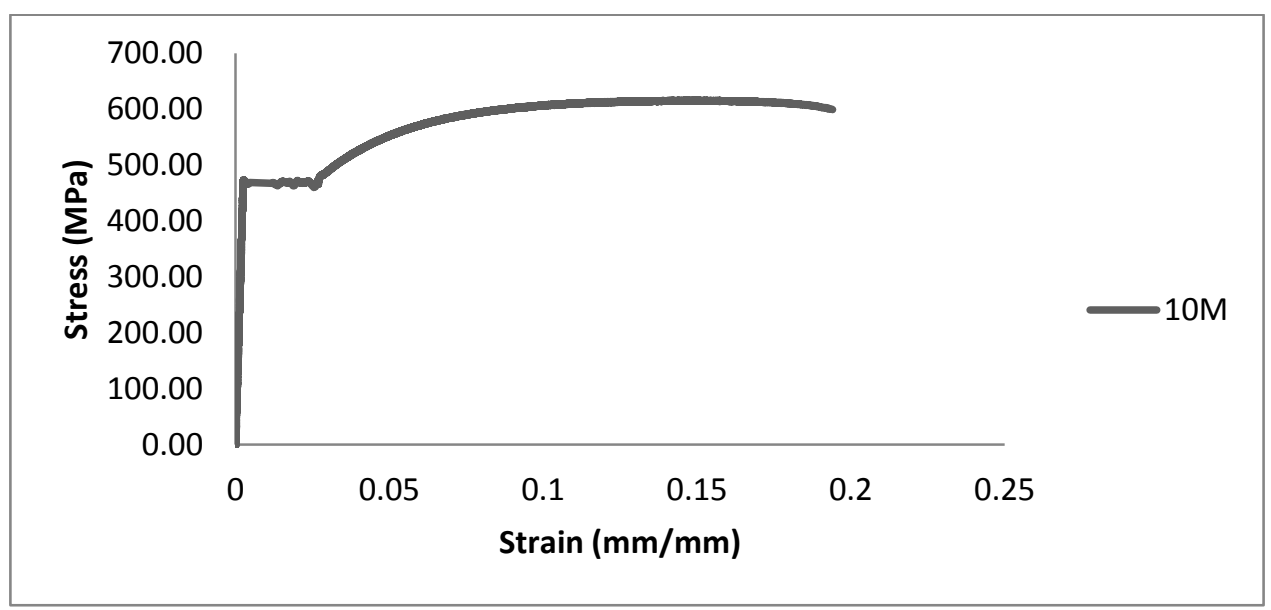

Figure 4-6: Stress strain response of typical 10M bar 


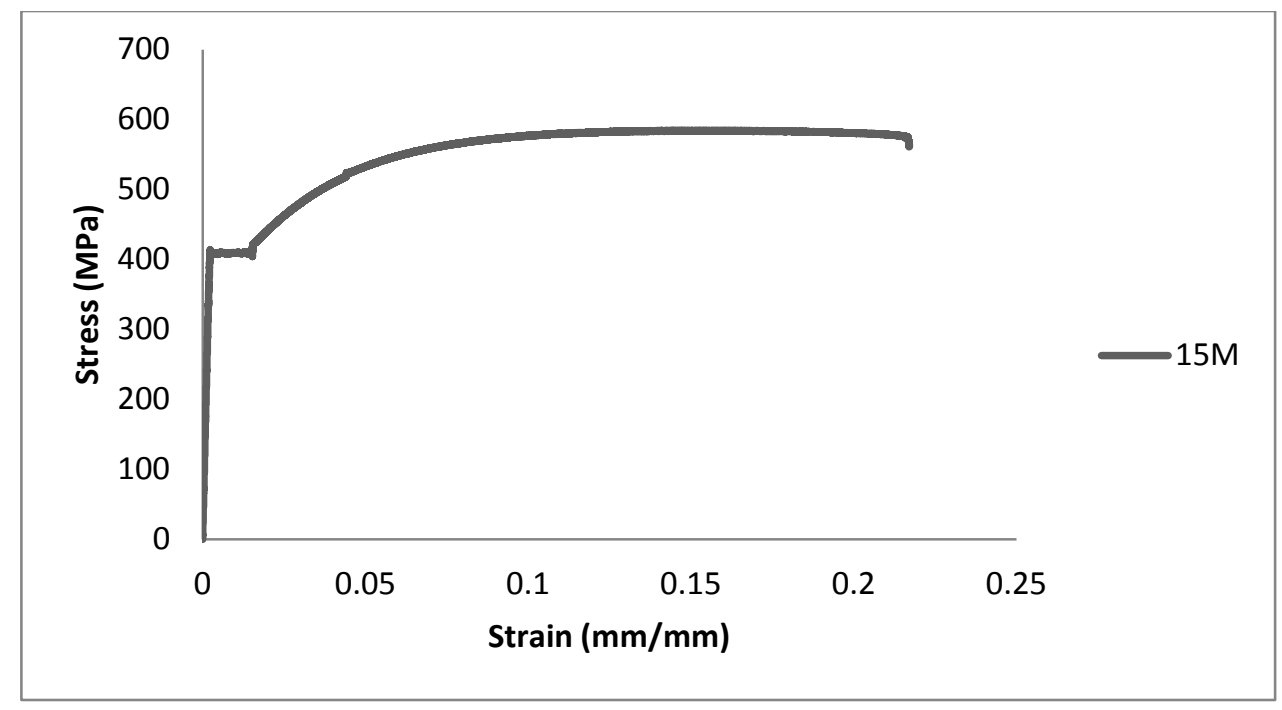

Figure 4-7: Stress strain response of typical 15M bar

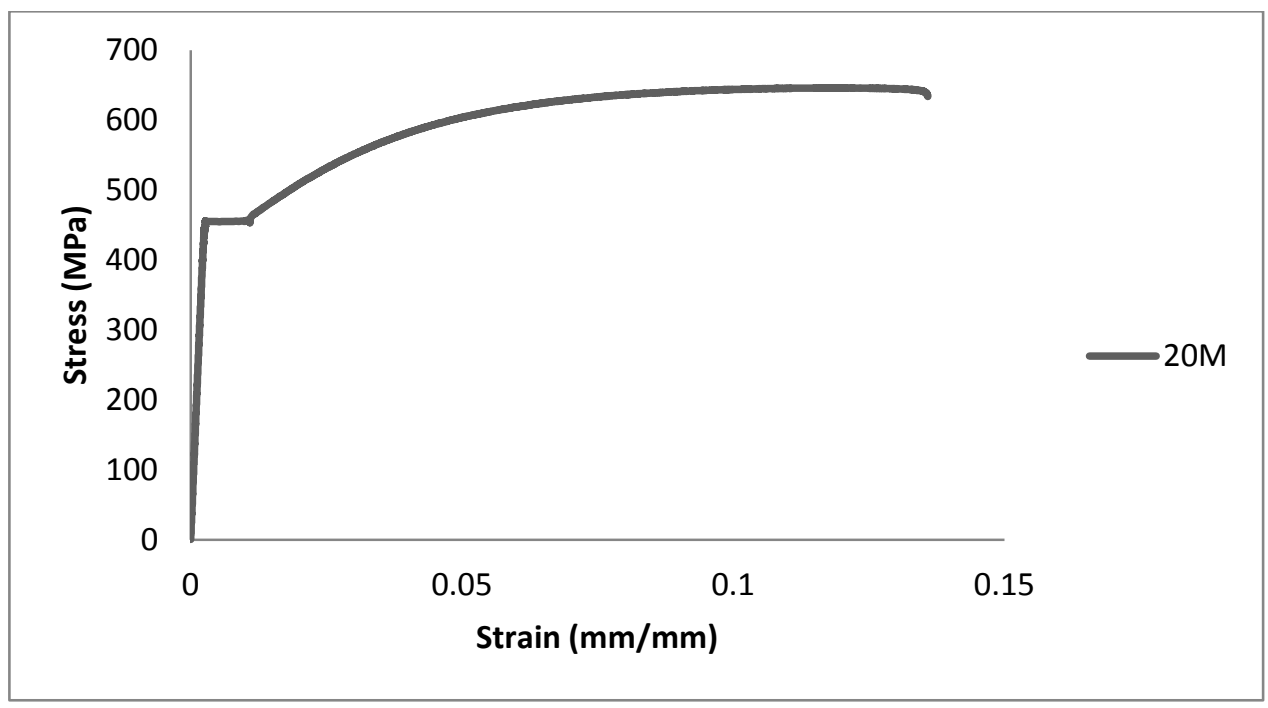

Figure 4-8: Stress strain response of typical 20M bar

Table 4-5: Reinforcing steel properties

\begin{tabular}{|c|c|c|c|c|c|}
\hline Bar Size & Steel Area $\left(\mathbf{m m}^{2}\right)$ & $\mathbf{f}_{\mathbf{y}}(\mathbf{M P a})$ & $\boldsymbol{\varepsilon}_{\mathbf{y}}(\mathbf{m m} / \mathbf{m m})$ & $\mathbf{f}_{\mathbf{u}}(\mathbf{M P a})$ & $\boldsymbol{\varepsilon}_{\mathbf{u}}(\mathbf{m m} / \mathbf{m m})$ \\
\hline $10 \mathrm{M}$ & 100 & 467 & 0.0023 & 615 & 0.1566 \\
& & & & & \\
\hline $15 \mathrm{M}$ & 200 & 409 & 0.0022 & 583 & 0.1643 \\
& & & & & \\
\hline $20 \mathrm{M}$ & 300 & 455 & 0.0027 & 645 & 0.1287 \\
\hline
\end{tabular}




\subsubsection{Concrete Masonry Units}

Two types of hollow masonry units were used in the experimental testing: standard half unit stretcher units with a slight groove in one side along with standard lintel units. Compressive strength testing was performed on 3 blocks of each type to determine the average compressive strength (see Table 4-6). Although compressive strength is not paramount for the type of testing being performed, it still acts as a good measure of both consistency in the manufacturing as well as so detect any defects in the material batch. Typical failures for each type of block are shown in Figure 4-10 and Figure 4-11.

The table below summarizes the compressive strength testing which was performed as outlined in Section 3.2.1.

Table 4-6: Average compressive strengths of masonry units

\begin{tabular}{|c|c|c|c|}
\hline Block Type & $\begin{array}{c}\text { Overall Block } \\
\text { Dimensions (mm) }\end{array}$ & $\begin{array}{c}\text { Number of Samples } \\
\text { Average Compressive } \\
\text { Strength (MPa) }\end{array}$ \\
\hline Half stretcher & $190 \times 190 \times 190$ & 3 & 31.3 \\
\hline Lintel Units & $190 \times 190 \times 390$ & 3 & 28.1 \\
\hline
\end{tabular}

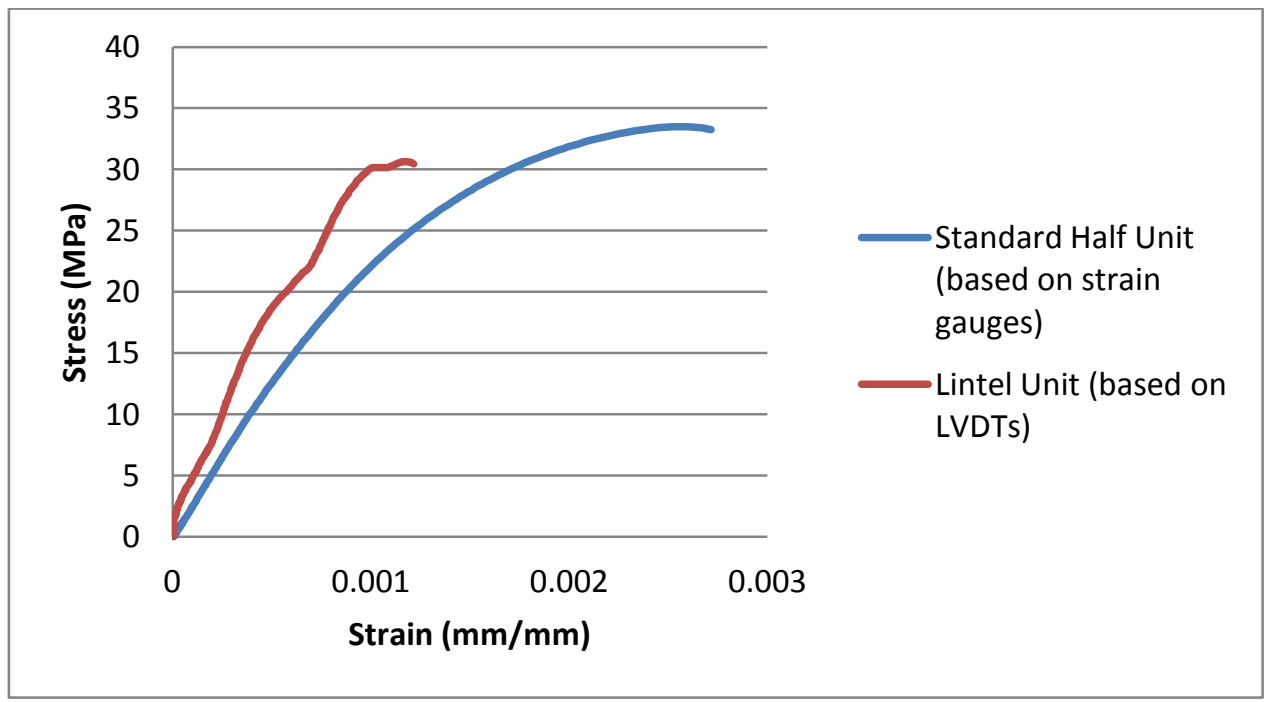

Figure 4-9: Stress strain responses of masonry units 


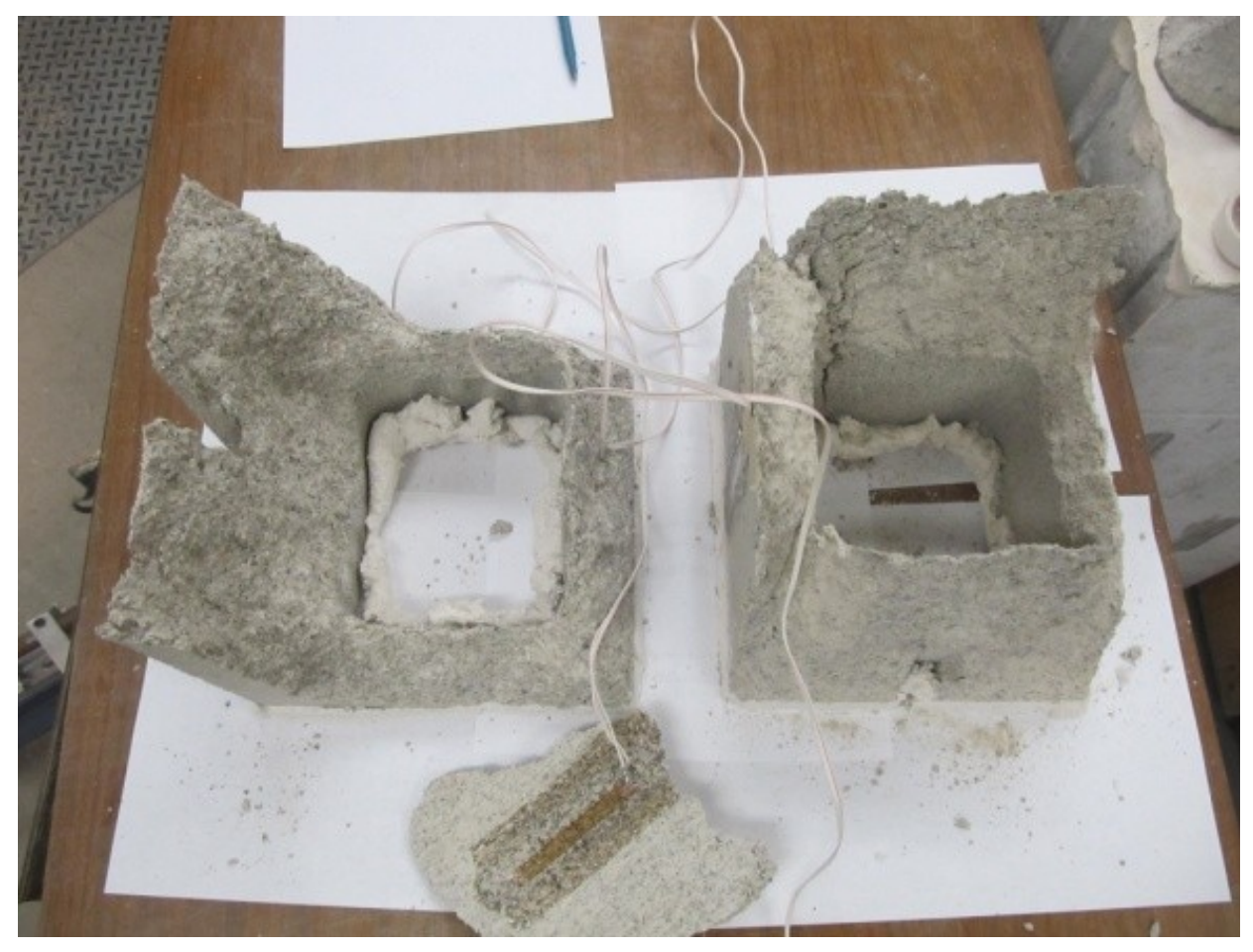

Figure 4-10: Typical compression failure of standard block

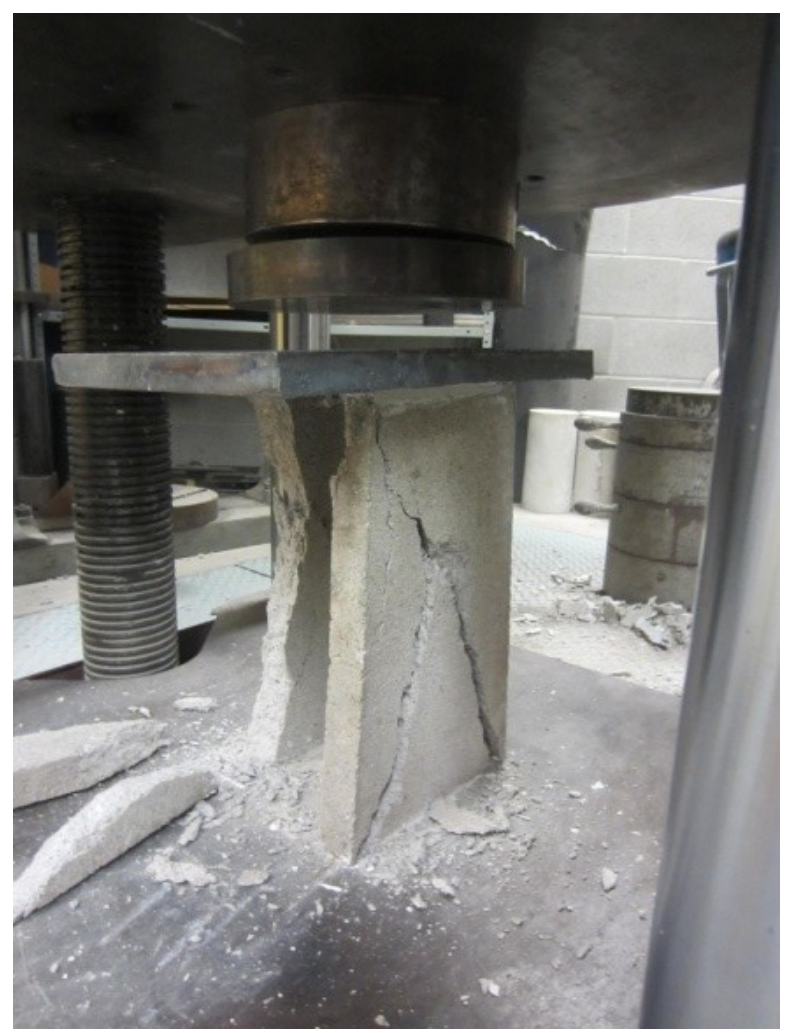

Figure 4-11: Typical compression failure of lintel block 


\subsection{Specimens tested under Monotonic Load}

The majority of the specimens were tested under monotonic load. The monotonic load was applied under displacement control by the test apparatus at three different loading rates. The first rate of $0.75 \mathrm{~mm} / \mathrm{min}$ was used in the elastic region, the second rate of $1.5 \mathrm{~mm} / \mathrm{min}$ was used in the yield plateau region of the response and the third rate was $4.0 \mathrm{~mm} / \mathrm{min}$ and was used in the strain hardening region of the reinforcing steel.

The use of 3 different loading rates was used to speed up the test process due to the large number of specimens. Atkinson and Hammons (1997) found that $1.5 \mathrm{~mm} / \mathrm{min}$ was an appropriate loading rate, however a slightly slower loading rate was used in the elastic range $(0.75 \mathrm{~mm} / \mathrm{min})$ to assure that enough data could be collected and that there was no influence on the point at which the onset of yielding was observed. Once the strain hardening range was entered, the rate was increased to $4 \mathrm{~mm} / \mathrm{min}$ because large displacements were needed in order to increase the load any significant amount. Using this loading regime, it took approximately 3 hours to reach the ultimate state which was deemed to be a strain of $6 \%$ over the $800 \mathrm{~mm}$ gauge length of the longitudinal LVDT's (including pauses in the loading at pre-defined load stages).

The loading apparatus allowed the user to pause the loading process at any point during the test if for any reason there were uncharacteristic measurements or observations that had to be taken on any of the specimens. The load was paused at pre-defined load stages which included load stages before cracking, after cracking but before yielding of the steel, at yielding of the steel, nearing the end of the yield plateau, the onset of strain hardening, and at approximately $6 \%$ strain. 


\subsubsection{Specimen 10M00-1}

This specimen was tested on September $24^{\text {th }}, 2013$ with its duplicate specimen being tested on the same day. This specimen was tested under monotonic load as discussed above, and was the first specimen to be tested from the $10 \mathrm{M}$ specimens. The specimen contained a single $10 \mathrm{M}$ deformed reinforcing bar located in the centre of a single fully grouted masonry cell. The grout contained no fibres and this specimen served as the control specimen for the $10 \mathrm{M}$ monotonic tests.

First cracking appears at the third load stage at a load of $24.2 \mathrm{kN}$. The load was paused at this load and lines were traced parallel to each crack with a felt-tip marker. Each crack was measured at 4 locations for width: East and West sides of the North face and East and West sides of the South face. The crack initiated at the second mortar joint from the bottom of the specimen and had an initial width of $0.16 \mathrm{~mm}$. Cracking progressed through the following load stages until at a load of $44.0 \mathrm{kN}$ cracking was present at the top three mortar joints and had an average width of approximately $0.59 \mathrm{~mm}$. All cracks were perpendicular to the application of the load at this point and were initiated by the weakness in bond between the blocks and the mortar.

At a load of $50 \mathrm{kN}$, the first crack through the block appeared. The crack seems to have initiated from a bond splitting crack that appeared to form at the center of the second block from the bottom of the specimen. At this load, the bottom mortar joint has cracked. Average crack width is increasing rapidly. At a load of approximately $54 \mathrm{kN}$ no new cracks are forming and the cracks present are simply getting wider. The test reached a maximum load of approximately $57.2 \mathrm{kN}$ at a strain of $6.4 \%$ as measured by the LVDTs on the East and West faces of the specimen. A summary of the important events in the loading process as well as sequential pictures of the specimen at the given load stages is provided in the Table 4-7

Figure 4-12 shows the entire stress-strain relationship of the specimen whereas Figure 413 shows the stress-strain relationship prior to yielding. Figure 4-14 shows both the average crack width and maximum crack as a function of stress. The stress is based on the steel area of the given specimen 
Table 4-7: Test summary for specimen 10M00-1

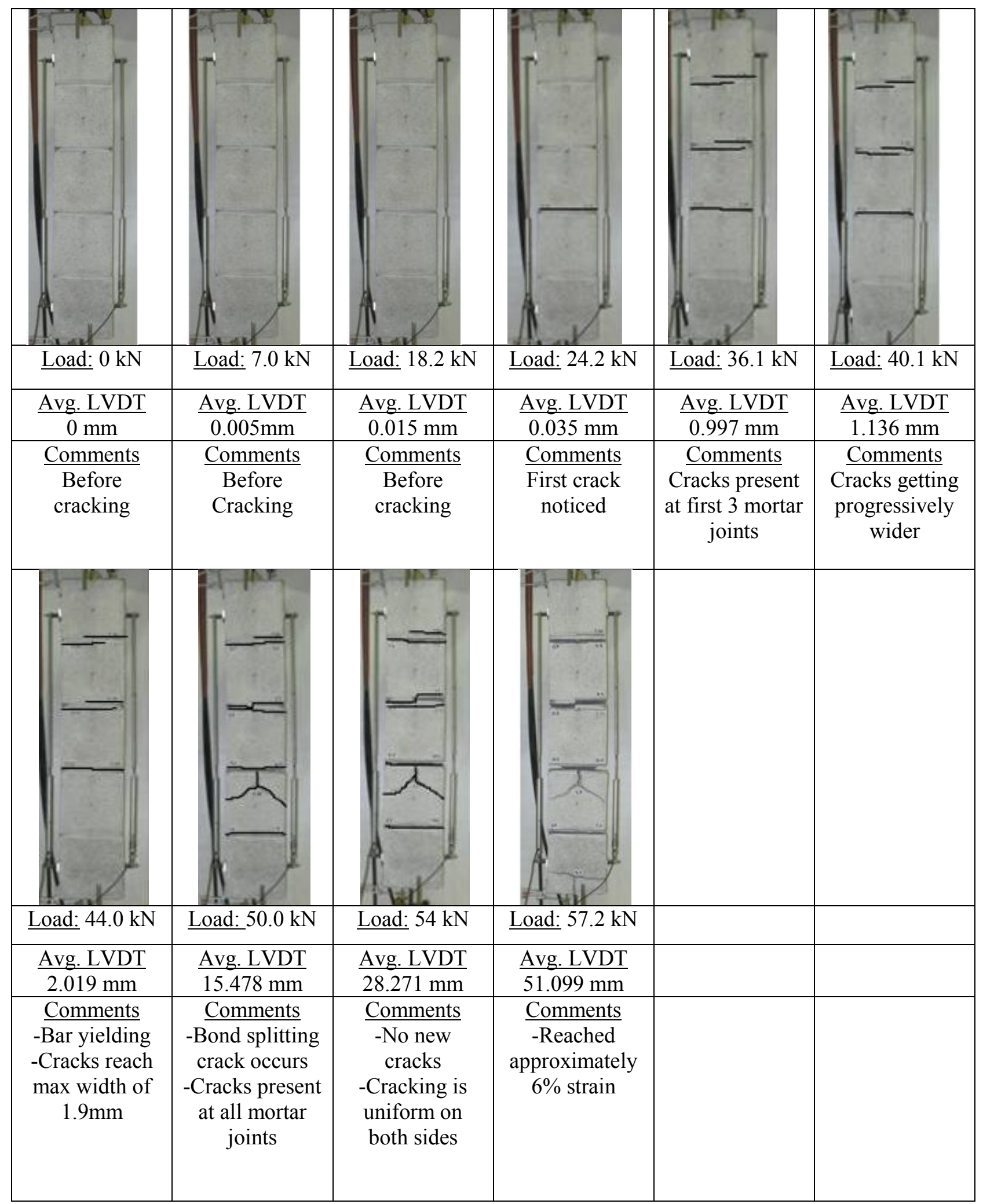




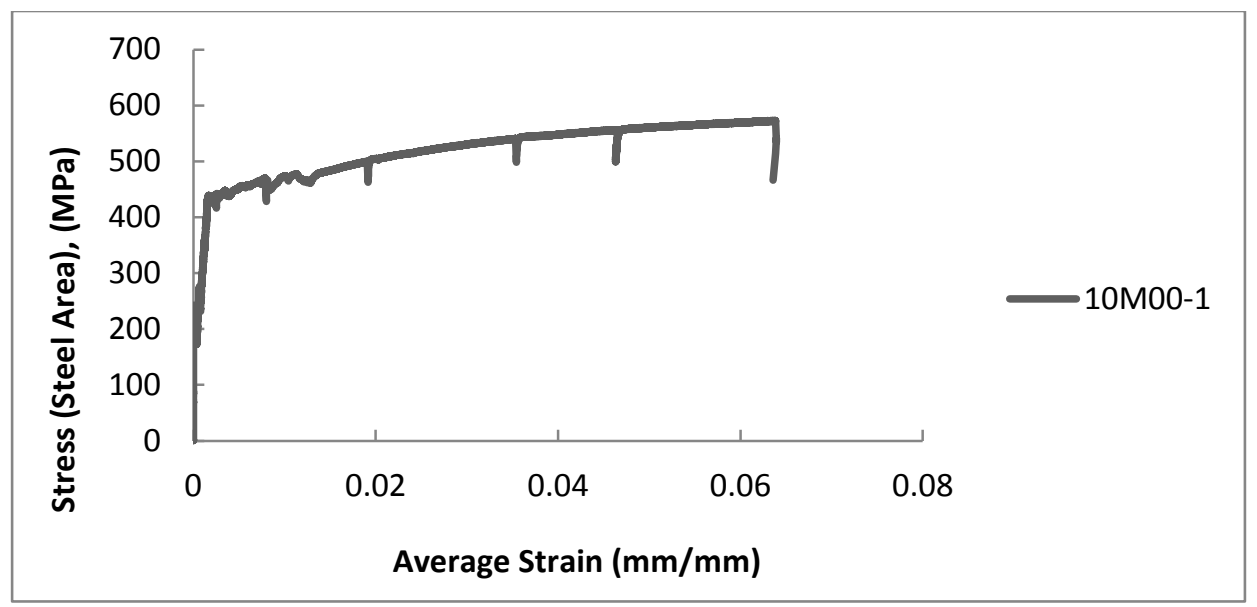

Figure 4-12: Entire stress strain response (10M00-1)

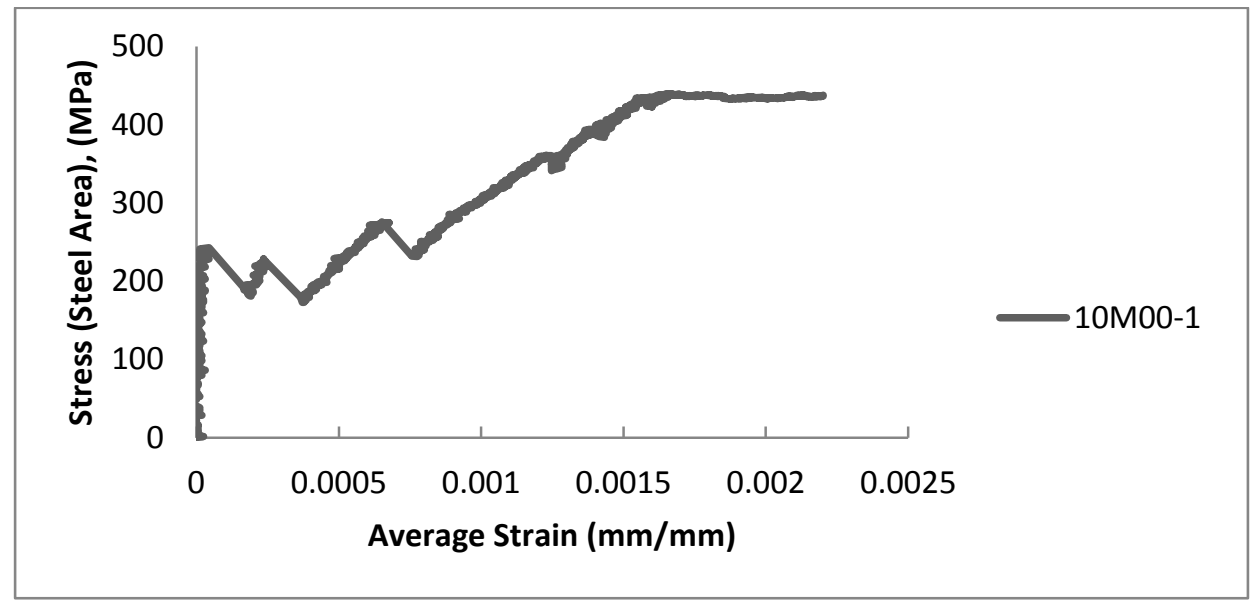

Figure 4-13: Stress strain response prior to yielding of reinforcing steel (10M00-1)

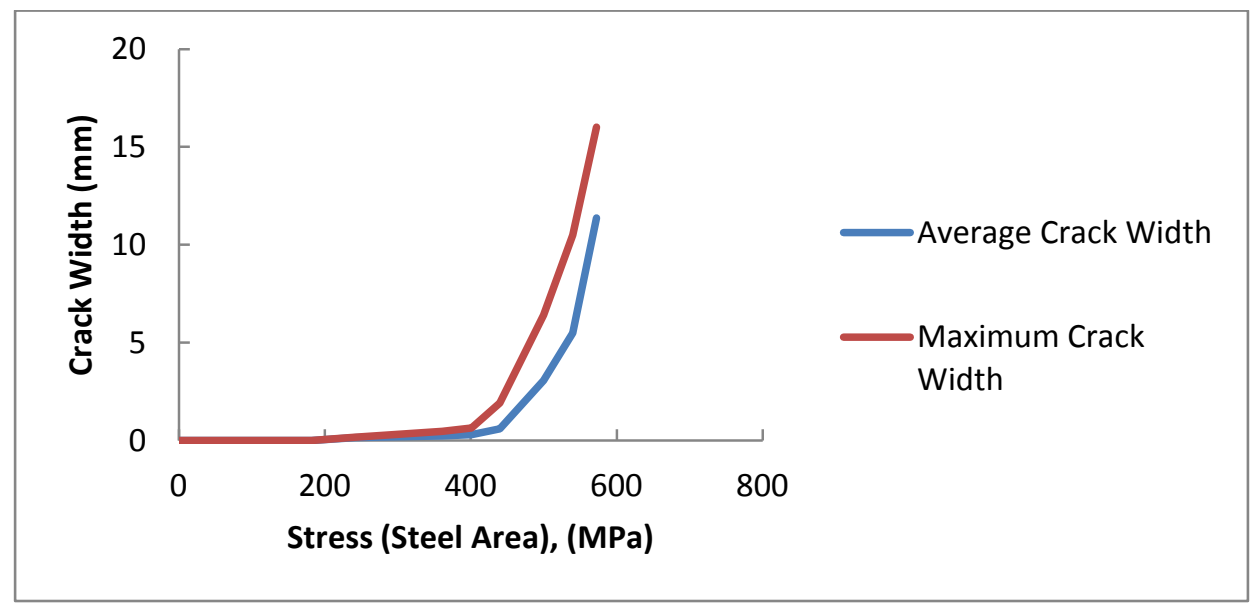

Figure 4-14: Average and maximum crack width (10M00-1) 


\subsubsection{Specimen 10M00-2}

This specimen served as a duplicate to $10 \mathrm{M} 00-1$ to ensure that the results were repeatable

for all specimens, including the control specimens. This specimen was identical to10M00-1 and was loaded with the same loading sequence. The same load steps were taken in order to compare the results.

First cracking appears at the third load stage at a load of $24.2 \mathrm{kN}$. The load was paused at this load and lines were traced parallel to each crack with a permanent marker. Each crack was measured at 4 locations for width: East and West sides of the North face \& East and West sides of the South face. The crack initiated at the top two mortar joints of the specimen and had an average initial width of $0.14 \mathrm{~mm}$. Cracking progressed through the following load stages until at a load of $40.0 \mathrm{kN}$ cracking was present at all four mortar joints and had an average width of approximately $0.28 \mathrm{~mm}$. All cracks were perpendicular to the application of the load at this point and were initiated by the weakness in bond between the blocks and the mortar.

At no point in the test did any of the masonry units crack. The test reached a maximum load of approximately $57.5 \mathrm{kN}$ at a strain of $6.1 \%$ as measured by the LVDTs on the East and West faces of the specimen. A summary of the important events in the loading process as well as sequential pictures of the specimen at the given load stages is provided in the Table 4-8.

Figure 4-15 shows the entire stress-strain relationship of the specimen whereas Figure 416 shows the stress-strain relationship prior to yielding. Figure 4-17 shows both the average crack width and maximum crack as a function of stress. The stress is based on the steel area of the given specimen 
Table 4-8: Test summary for specimen 10M00-2

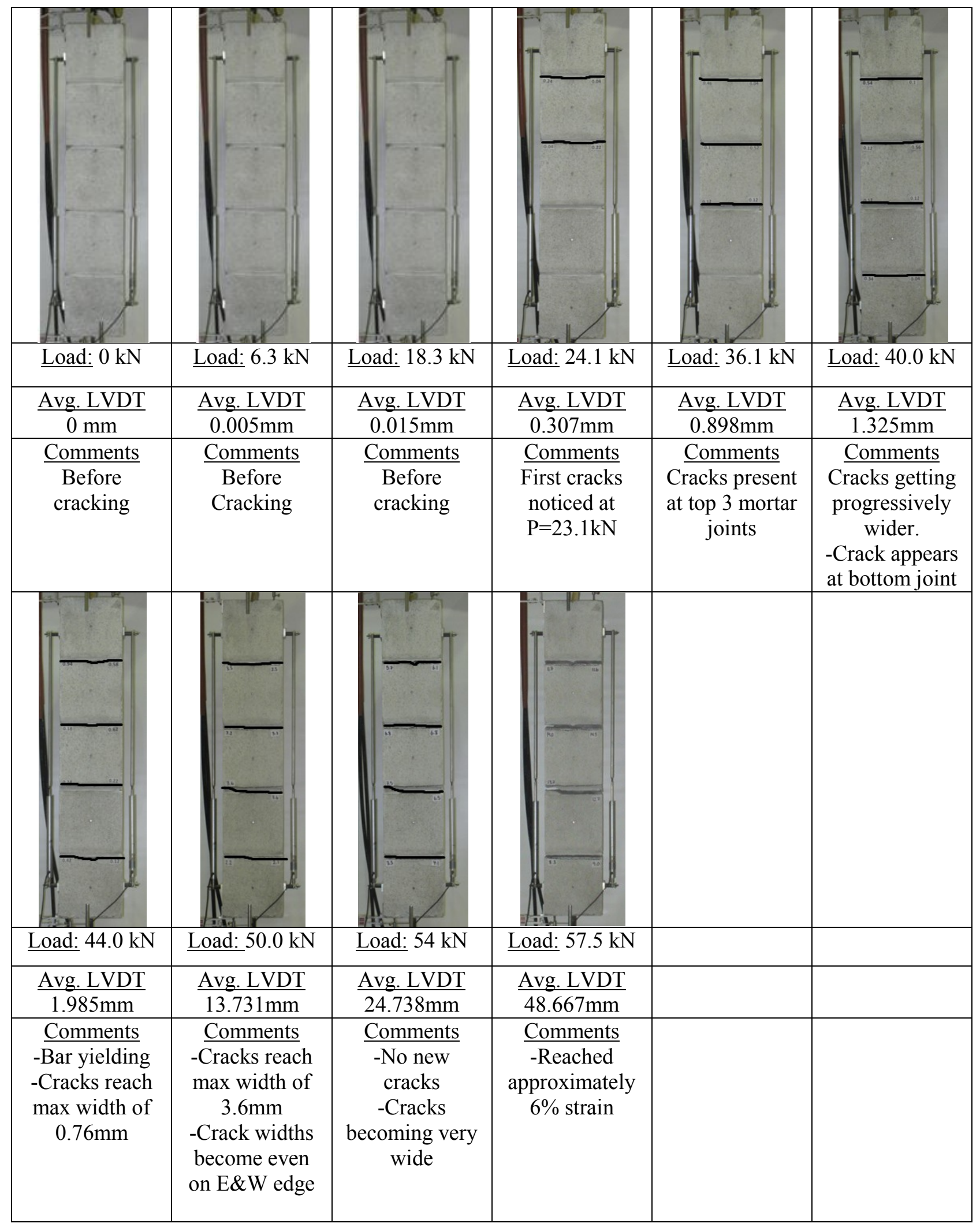




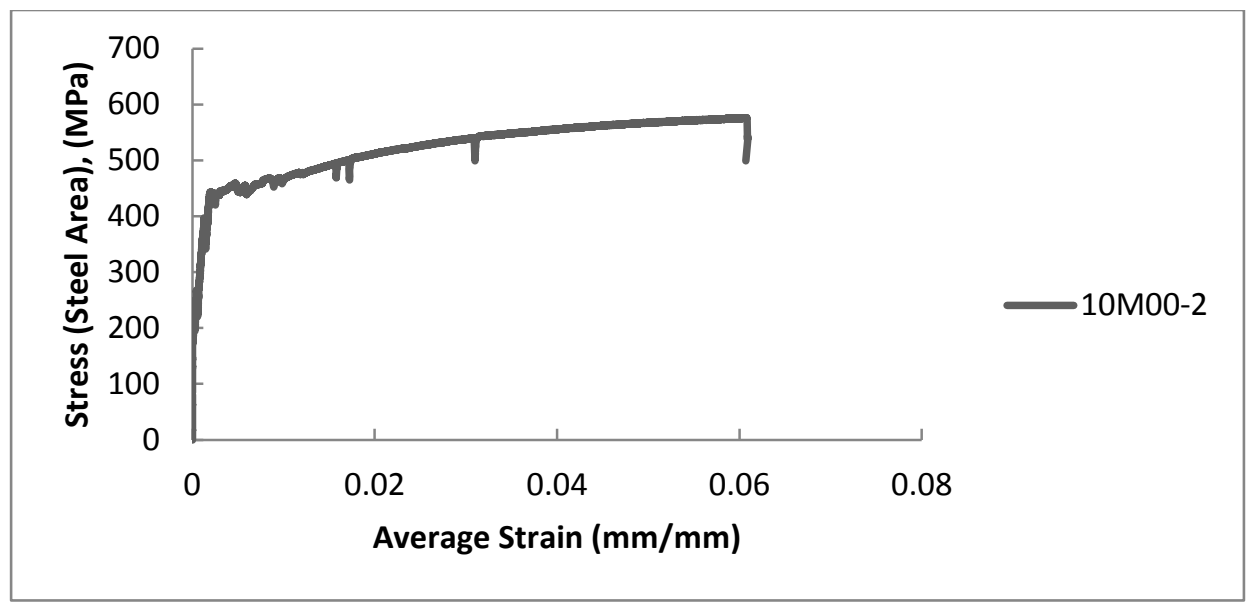

Figure 4-15: Entire stress strain response (10M00-2)

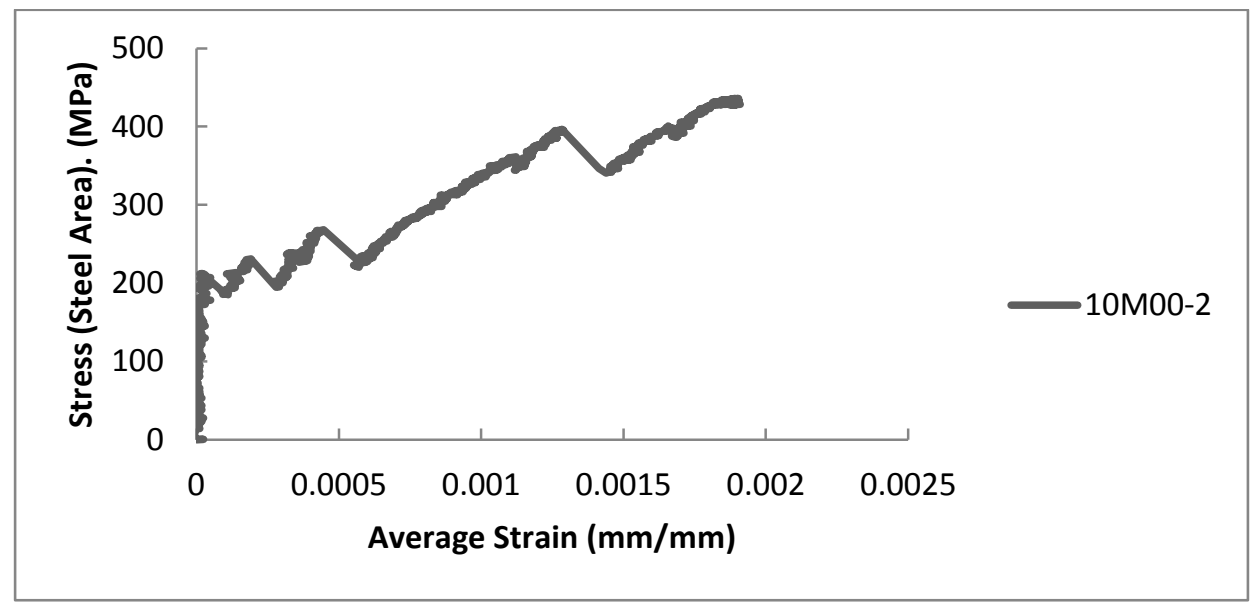

Figure 4-16: Stress strain response prior to yielding of reinforcing steel (10M00-2)

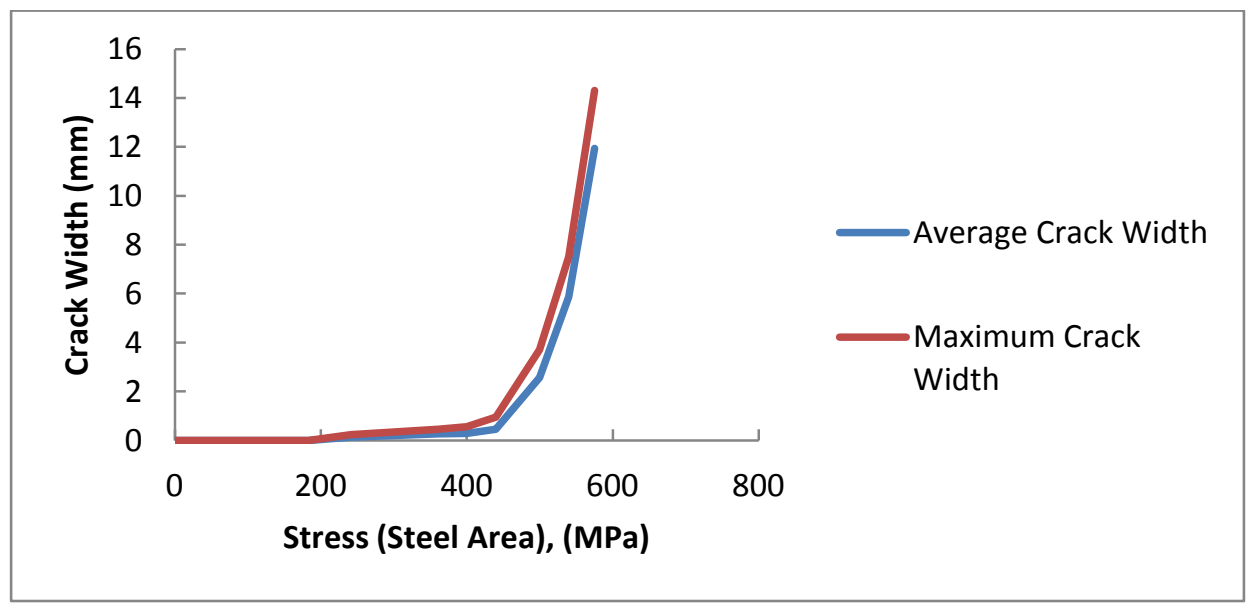

Figure 4-17: Average and maximum crack widths (10M00-2) 


\subsubsection{Specimen 10M12S-1}

This specimen was tested on September $27^{\text {th }}, 2013$ with its duplicate specimen being tested two days prior. This specimen is part of the $10 \mathrm{M}$ monotonic set and includes Dramix ZP305 fibres incorporated at $1.2 \%$ of the total volume. This specimen included a $10 \mathrm{M}$ standard deformed reinforcing bar encased in a single cell fully grouted with fibre reinforced grout.

First cracking occurred only on the back side of the specimen and was very gradual. There was no visible large drop in stress as the loading progressed (see Figure 4-18). The reasoning behind the crack opening on the back side only is because of the fibre reinforced grout. The fibres spanned the tensile cracks and didn't allow them to open. Even at a load of $40.1 \mathrm{kN}$, there is only a single tensile crack at the top mortar joint on the back side with an average width of $0.31 \mathrm{~mm}$. Table 4-9 shows the South side of the specimen at load stages 5 and 6 due to the fact that the cracks only formed on the backside during these stages.

As the loading progressed, the second mortar joint from the bottom of the specimen cracked, and then the third mortar joint began to crack however the width of the cracks increased very slowly. At a load of $59 \mathrm{kN}$, we approached the end of the stroke of the test apparatus therefore the test had to be terminated. This was due to the fact that the fibres increased the tensile capacity dramatically at a low reinforcement ratio. Due to the increased capacity in the concrete surrounding the bar, the bar yielded in the area between the grips and the specimen causing an increase in the required stroke to impart displacement to the specimen itself. The tension stiffening effect is dramatically increased, although it is hard to access the ductility of the specimen because it was not possible to keep imparting extra load to encourage cracking.

Even at a bar stress of approximately $590 \mathrm{MPa}$, the specimen only had a strain of $0.15 \%$. The loading was stopped before the specimen showed any signs of impending failure.

Figure 4-18 shows the entire stress-strain relationship of the specimen whereas Figure 4-19 shows the stress-strain relationship prior to yielding. In this case they are very similar as large strains were not attainable. Figure 4-20 shows both the average crack width and maximum crack as a function of stress. The stress is based on the steel area of the given specimen 
Table 4-9: Test summary for specimen 10M12S-1

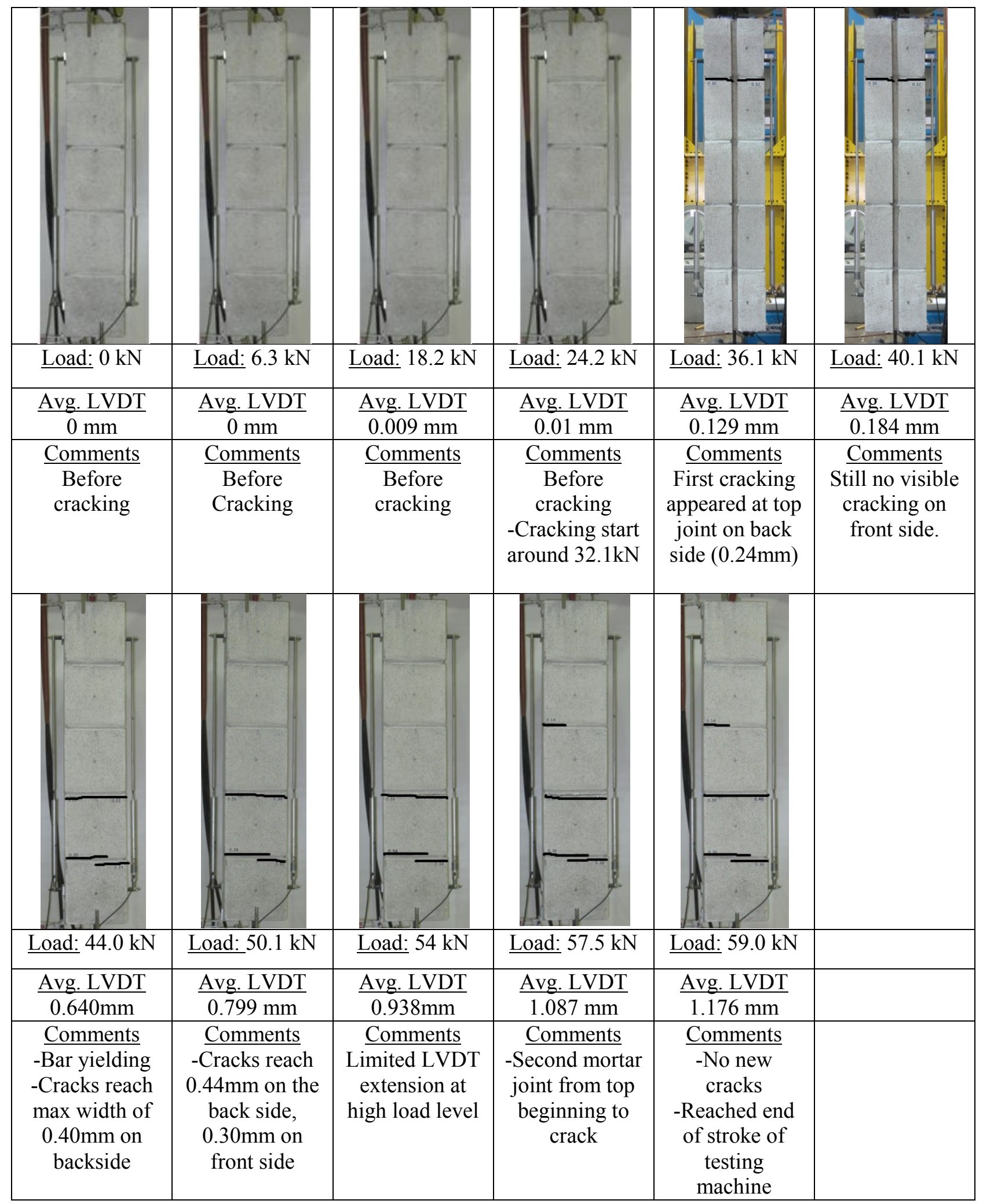




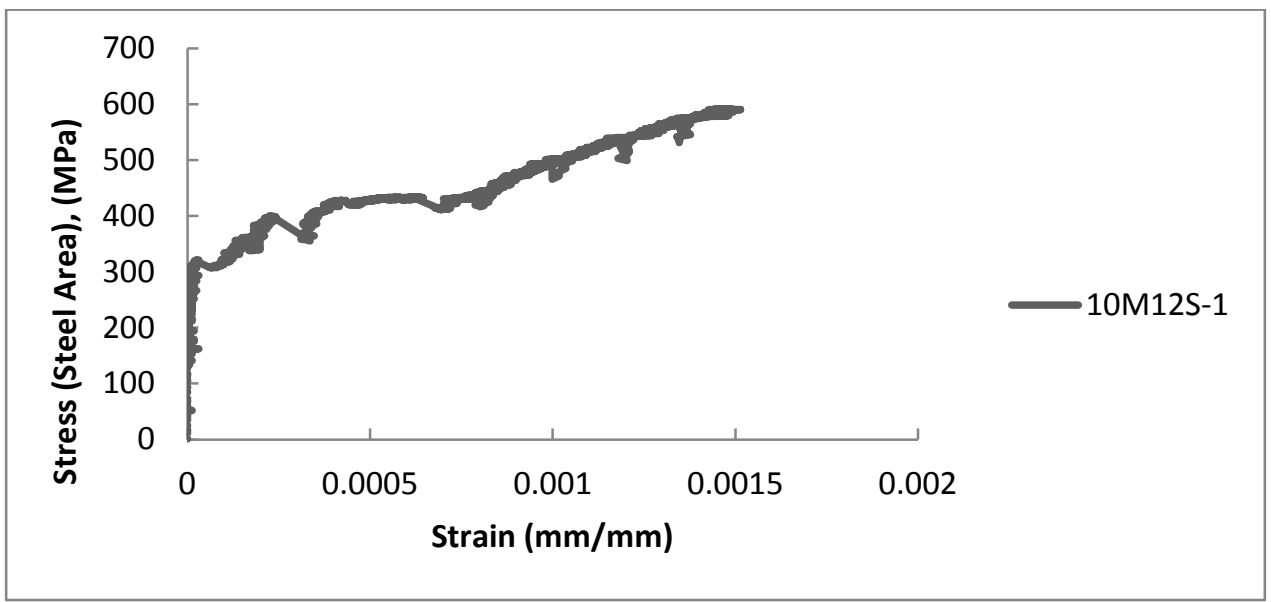

Figure 4-18: Entire Stress strain response (10M12S-1)

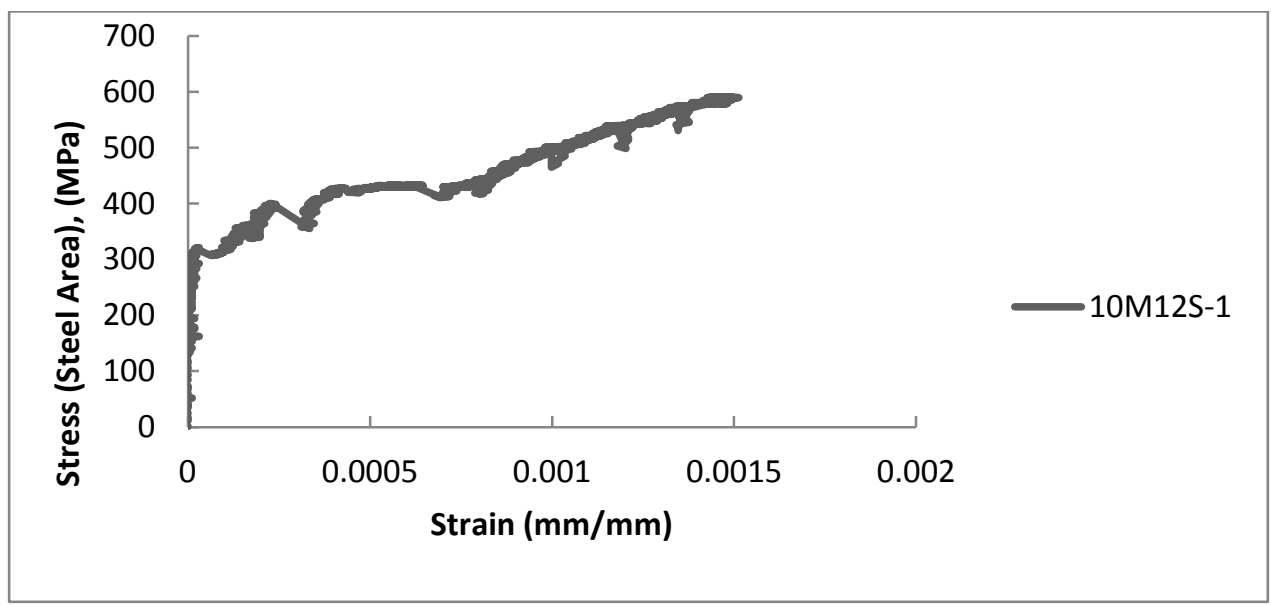

Figure 4-19: Stress strain response prior to yielding of reinforcing steel (10M12S-1)

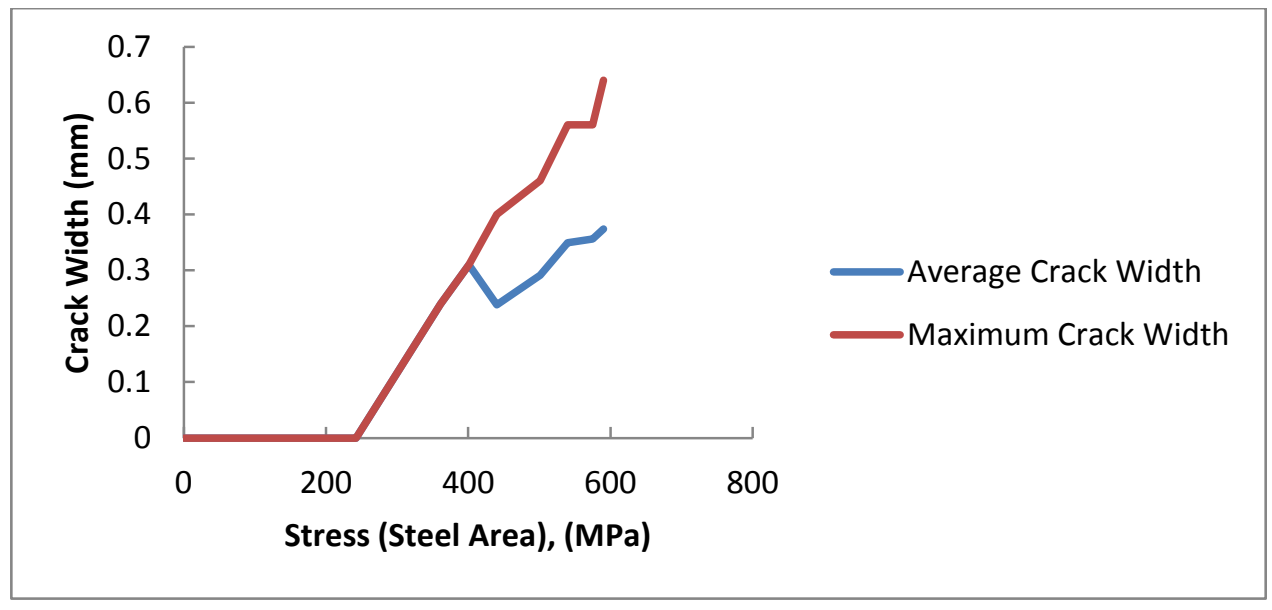

Figure 4-20: Average \& maximum crack widths (10M12S-1) 


\subsubsection{Specimen 10M12S-2}

This specimen was tested on September $25^{\text {th }}, 2013$ and served as a duplicate for the specimen $10 \mathrm{M} 12 \mathrm{~S}-1$. This specimen is part of the $10 \mathrm{M}$ monotonic set and includes Dramix ZP305 fibres incorporated at $1.2 \%$ of the total grout volume. This specimen included a $10 \mathrm{M}$ standard deformed reinforcing bar encased in a single cell fully grouted with fibre reinforced grout.

Overall, the performance of this specimen was very similar to $10 \mathrm{M} 12 \mathrm{~S}-1$. The first cracking was observed around a load of $33.4 \mathrm{kN}$ when the specimen began to crack around the top mortar joint. At a load of $37.2 \mathrm{kN}$, a second crack formed at the second mortar joint from the top. The load increased rapidly with little displacement of the LVDTs, potentially because the bars outside the range of the specimen are were entering strain hardening and hence showing increased strength and ductility properties.

As the loading progressed, crack widths were minimal. For example, at a load of $54 \mathrm{kN}$ the maximum crack width was only $0.46 \mathrm{~mm}$. At the final load stage, the load reached a value of $63.5 \mathrm{kN}$ at an average LVDT displacement of $1.290 \mathrm{~mm}$. At this time, the displacement of the head was reaching its maximum stroke and therefore the test was stopped.

Again in this test, the fibres added to the tensile strength within the bounds of the specimen causing the bare bar in the area between the loading grips and the specimen to yield prior to yielding within the specimen.

Figure 4-21 shows the entire stress-strain relationship of the specimen whereas Figure 422 shows the stress-strain relationship prior to yielding. In this case they are very similar as large strains were not attainable due to the steel yielding outside the specimen limits. Figure 4-23 shows both the average crack width and maximum crack as a function of stress. The stress is based on the steel area of the given specimen 
Table 4-10: Test summary for specimen 10M12S-2

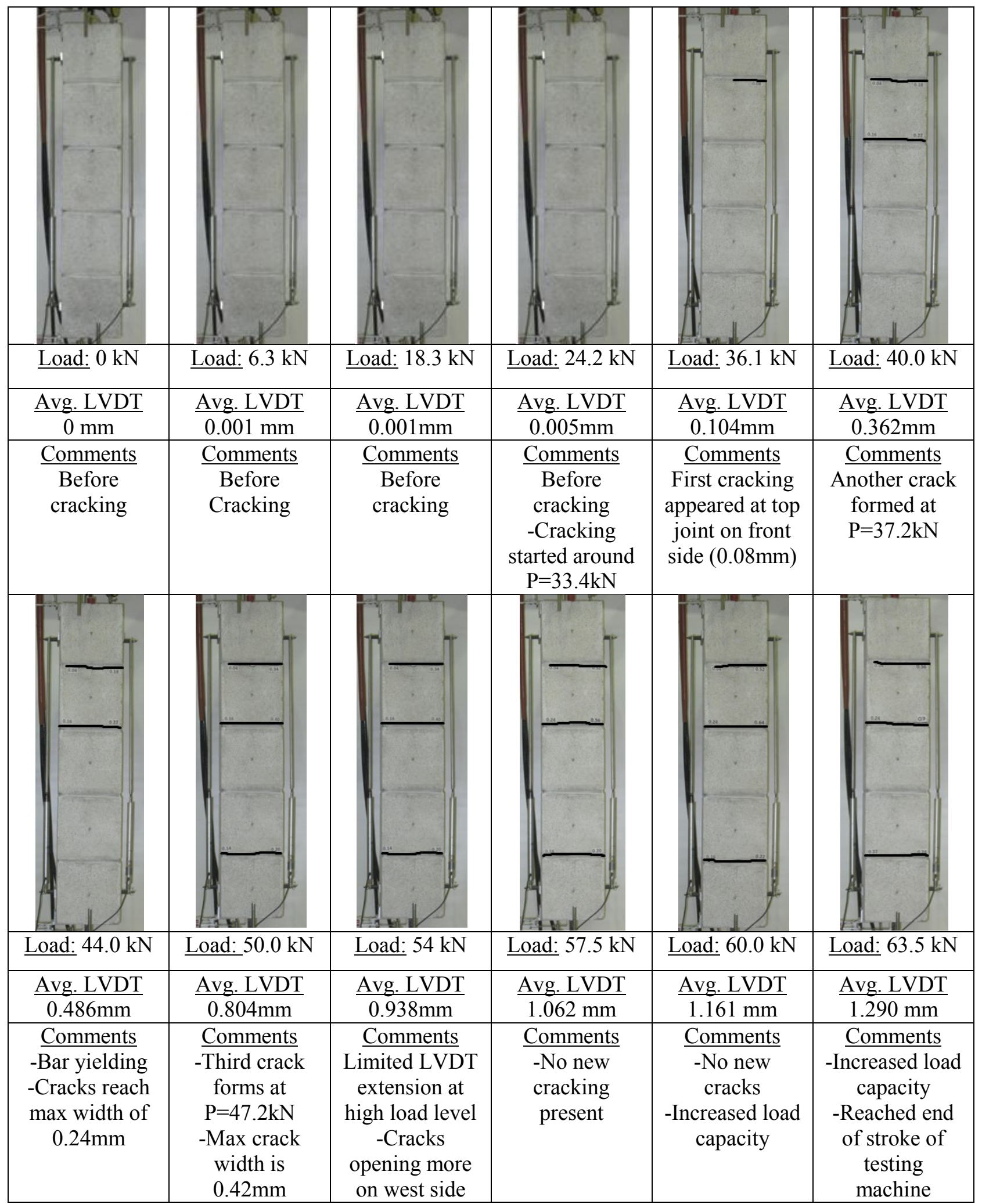




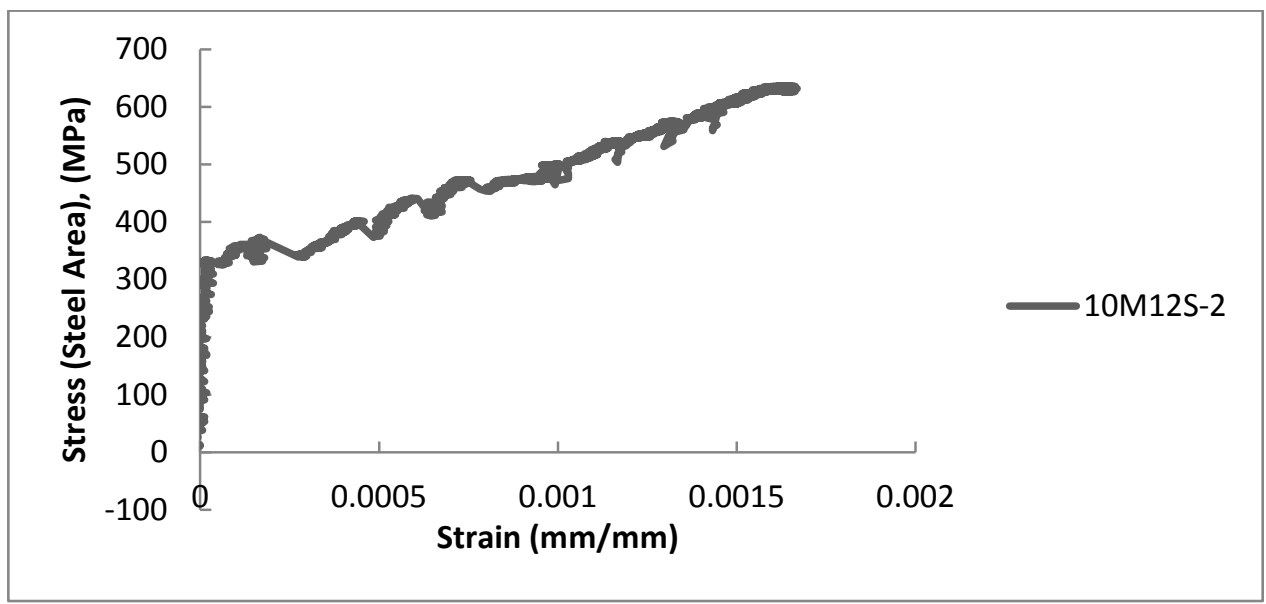

Figure 4-21: Entire stress strain response (10M12S-2)

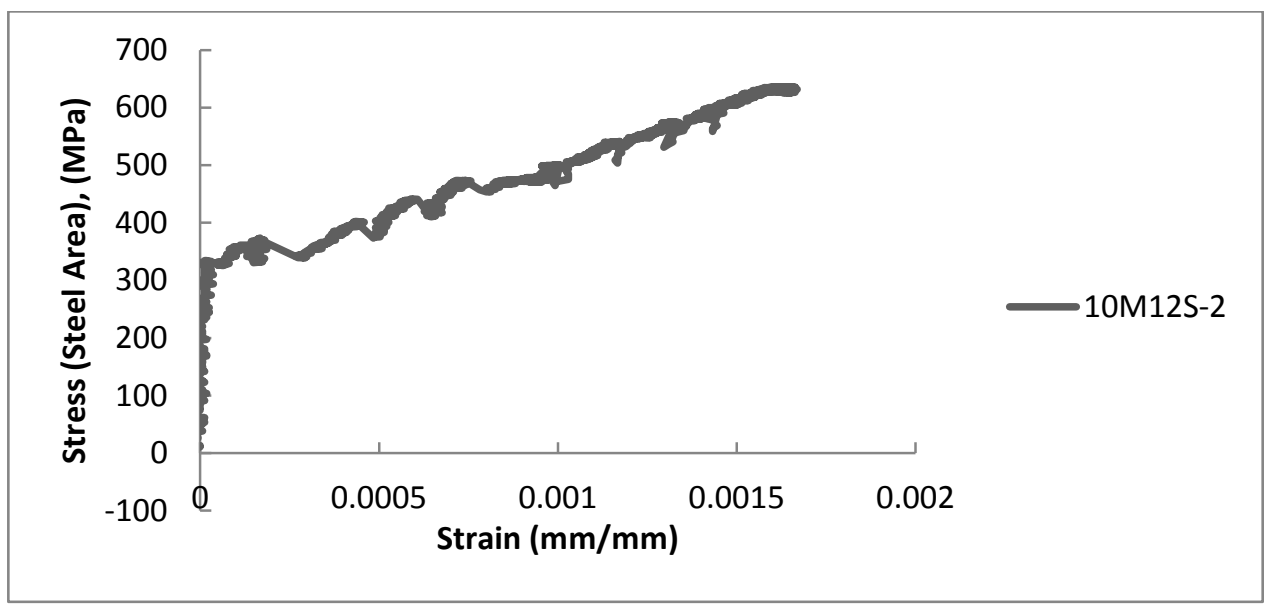

Figure 4-22: Stress strain response prior to yielding of reinforcing steel

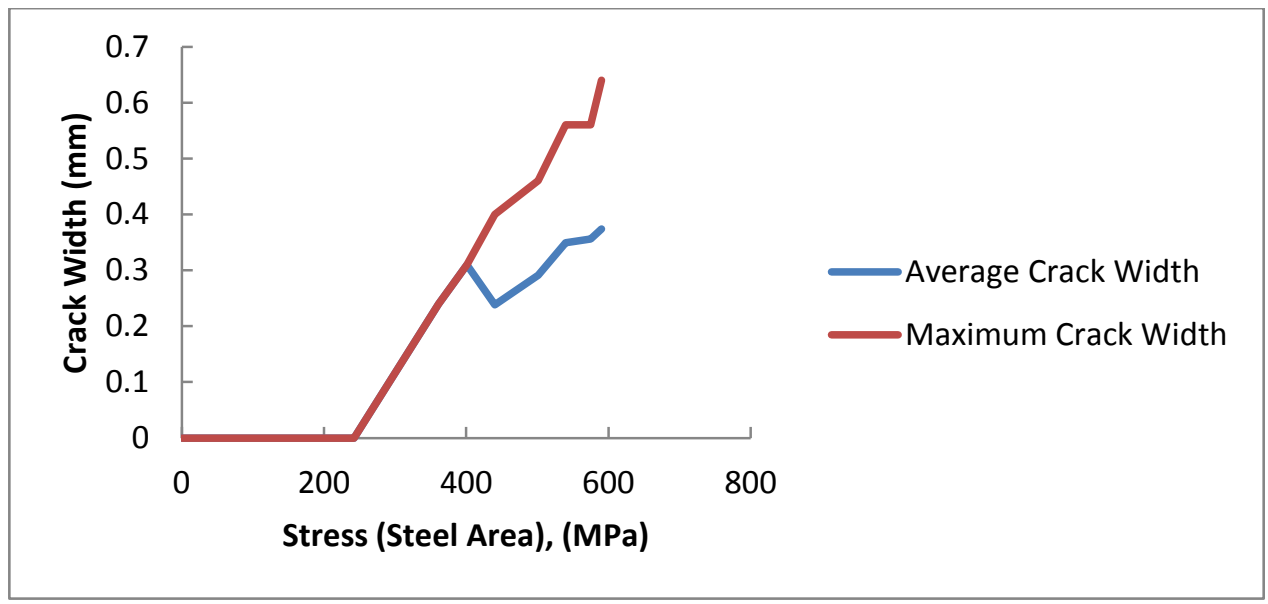

Figure 4-23: Average \& maximum crack widths (10M12S-2) 


\subsubsection{Specimen 15M00-1}

This specimen was tested on August 22, 2013 and was the first specimen to be tested of the $15 \mathrm{M}$ specimens tested under monotonic load. A duplicate to this specimen was tested at a later date. This specimen contained no fibres and served as a control specimen for all specimens tested in the $15 \mathrm{M}$ monotonic series. The bottom two mortar joints were observed to have slight cracking prior to the beginning of the test. It is thought that this cracking occurred due to excessive vibration imparted by the pencil type vibrator as this specimen was grouted on the first day of grouting. Later specimens were not vibrated with a pencil vibrator to avoid breaking the fragile specimens.

The first cracking was observed at a load of approximately $34.8 \mathrm{kN}$ at the bottom mortar joint. The next cracks formed at $43.6 \mathrm{kN}$ and $53 \mathrm{kN}$ and the cracks got progressively wider. All cracks originated at the interface between the mortar and the concrete masonry unit.

By the load stage at $72 \mathrm{kN}$, the specimen was cracked at all mortar joint locations. Once the reinforcing steel approached its yield stress, the crack widths increased rapidly. The crack widths were observed to have the same widths on both the East and West sides of each of the faces measured.

The test was terminated when the crack widths became very wide and the overall strain over the gauge length of the LVDTs reached approximately $4.7 \%$.

Figure 4-24 shows the entire stress-strain relationship of the specimen whereas Figure 425 shows the stress-strain relationship prior to yielding. Figure 4-26 shows both the average crack width and maximum crack as a function of stress. The stress is based on the steel area of the given specimen 
Table 4-11: Test summary for specimen 15M00-1

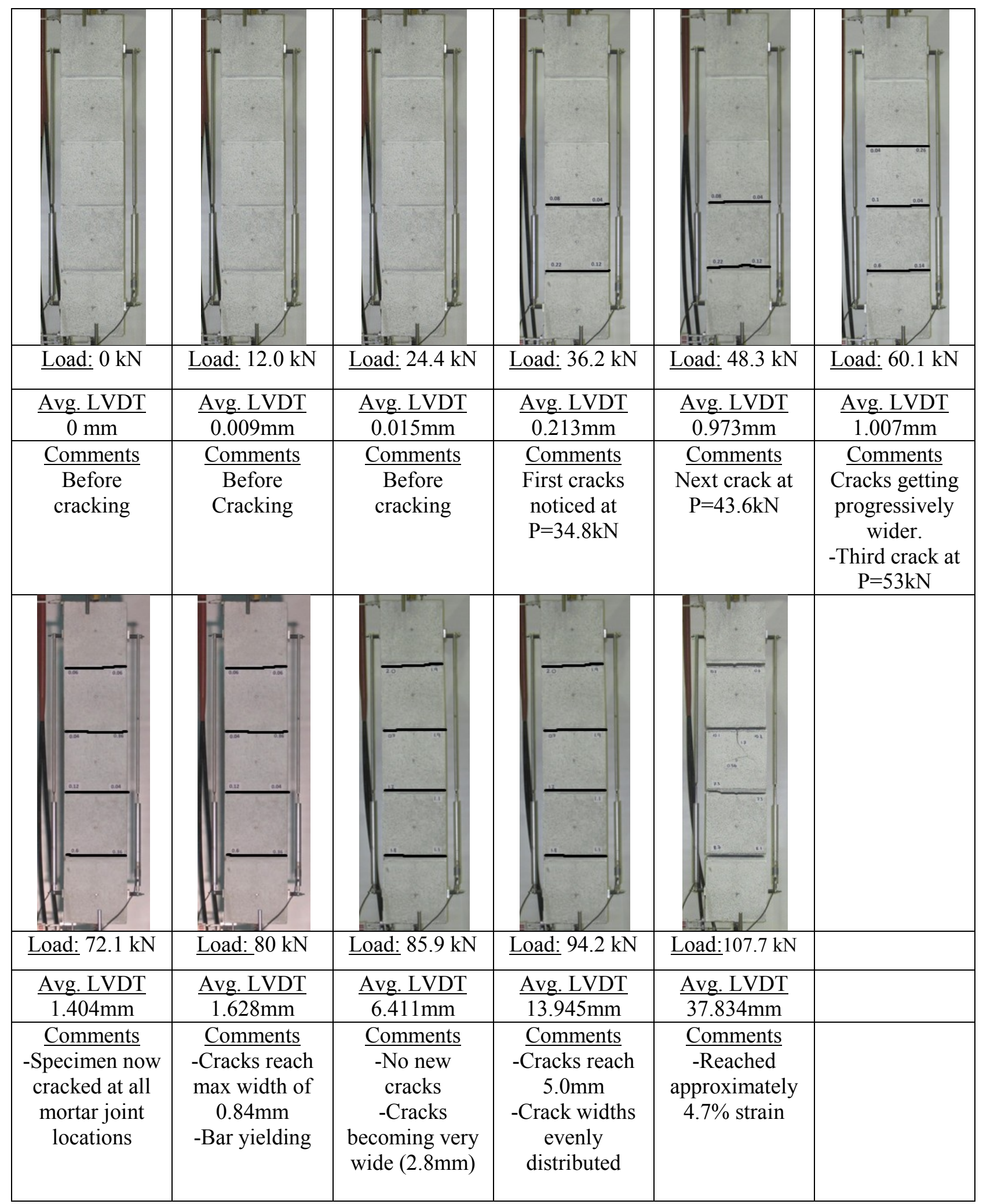




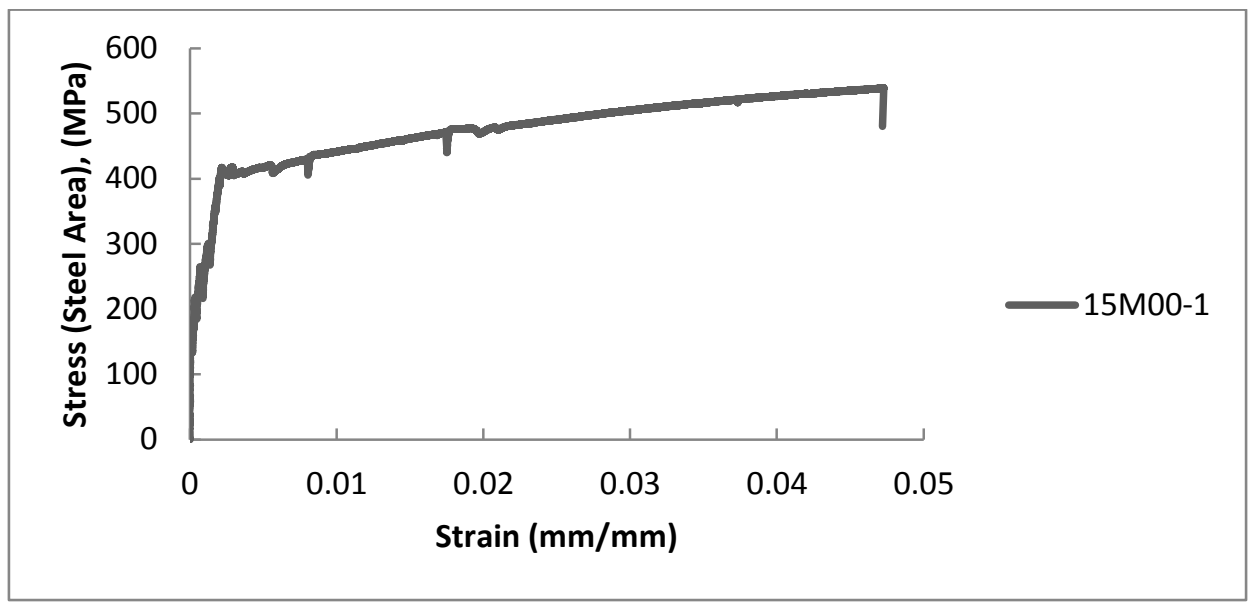

Figure 4-24: Entire stress strain response (15M00-1)

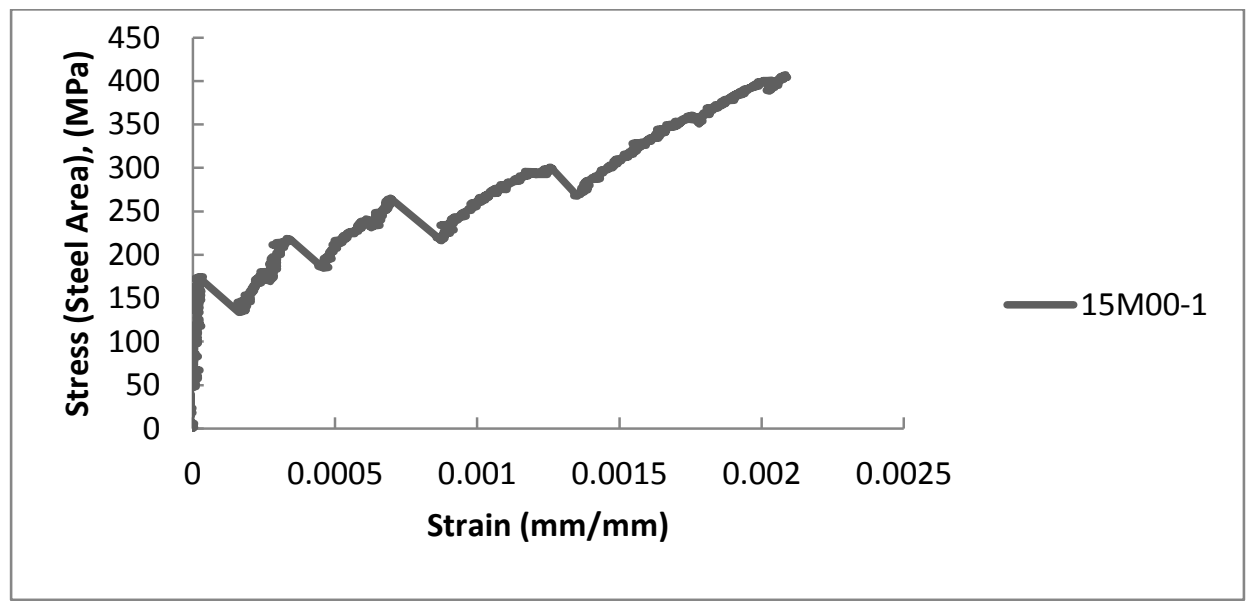

Figure 4-25: Stress strain response prior to yielding of reinforcing steel (15M00-1)

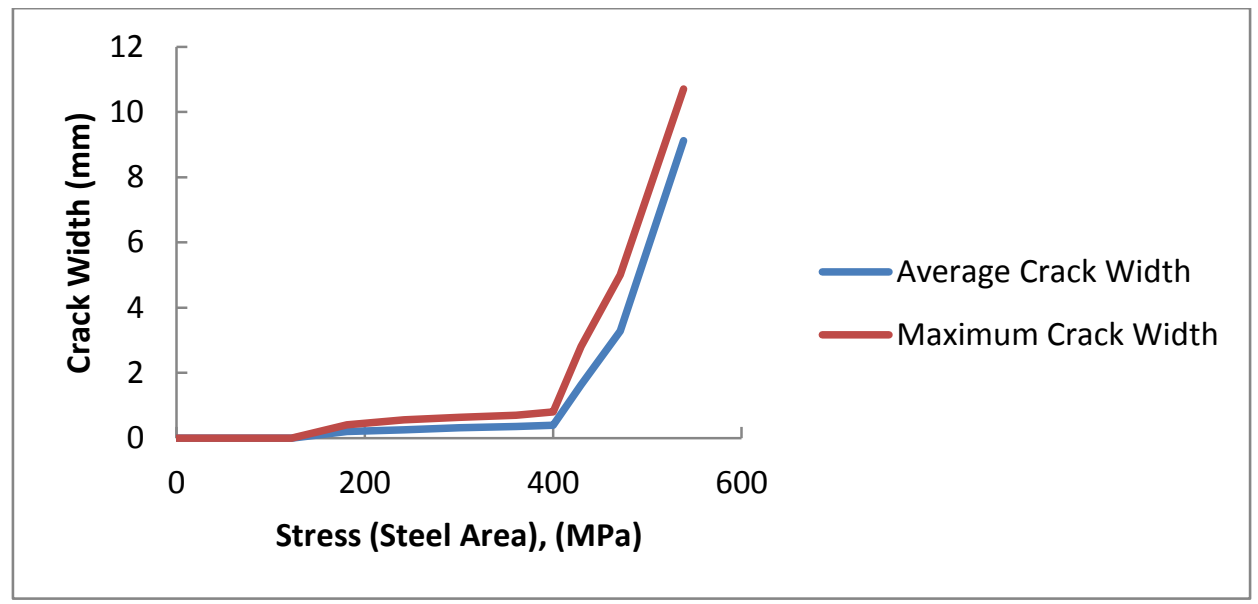

Figure 4-26: Average \& maximum crack widths (15M00-1) 


\subsubsection{Specimen 15M00-2}

This specimen was tested on August 29, 2013 and was the duplicate specimen for 15M00-1.This specimen contained no fibres and served as a control specimen for all specimens tested in the $15 \mathrm{M}$ monotonic series. The top mortar joint was observed to have slight cracking prior to the beginning of the test. Like $15 \mathrm{M} 00-1$, it is thought that this cracking occurred due to excessive vibration imparted by the pencil type vibrator as this specimen was grouted on the first day of grouting.

The first cracking was observed at a load of approximately $26.6 \mathrm{kN}$ at the middle mortar joint. The next cracks formed at $35.3 \mathrm{kN}$ and $61.5 \mathrm{kN}$ and the cracks got progressively wider.

At a load of approximately $72 \mathrm{kN}$, a third crack formed at the bottom mortar joint. At this point no cracks are wider than $0.62 \mathrm{~mm}$. Once the reinforcing steel approached its yield stress, the crack widths increased rapidly. The crack widths were observed to have the same widths on both the East and West sides of each of the faces measured. As the load entered the strain hardening regime of the reinforcing steel, a fourth crack initiated near the top of the specimen through the top block. It is though that perhaps this crack is due to the impending pullout of the reinforcing steel.

At a load of approximately $107.7 \mathrm{kN}$, the centre block cracked. The test was terminated when the crack widths became very wide and the overall strain over the gauge length of the LVDTs reached approximately 5.1\%.

Figure 4-27 shows the entire stress-strain relationship of the specimen whereas Figure 428 shows the stress-strain relationship prior to yielding. Figure 4-29 shows both the average crack width and maximum crack as a function of stress. The stress is based on the steel area of the given specimen. 
Table 4-12: Test summary for specimen 15M00-2

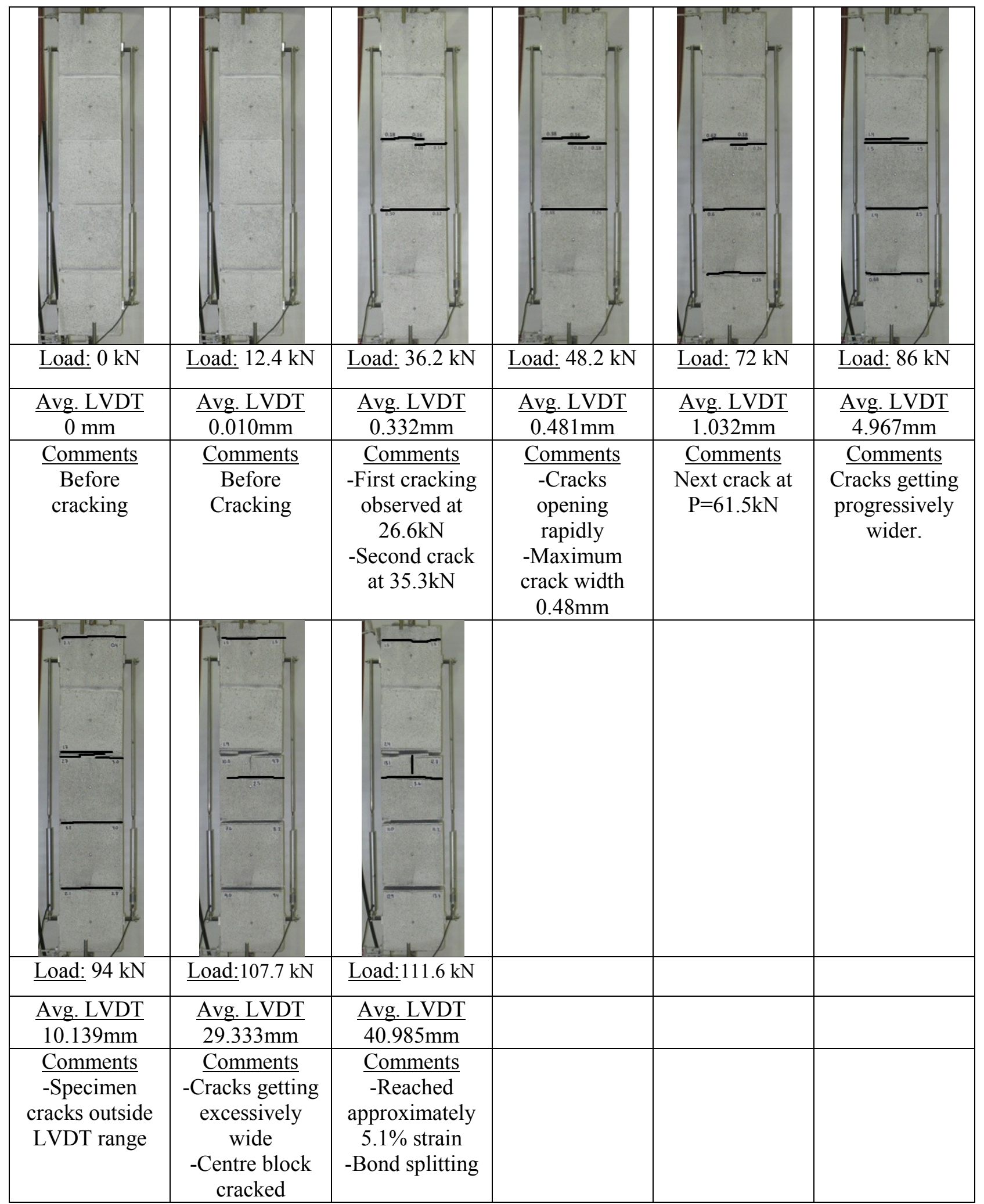




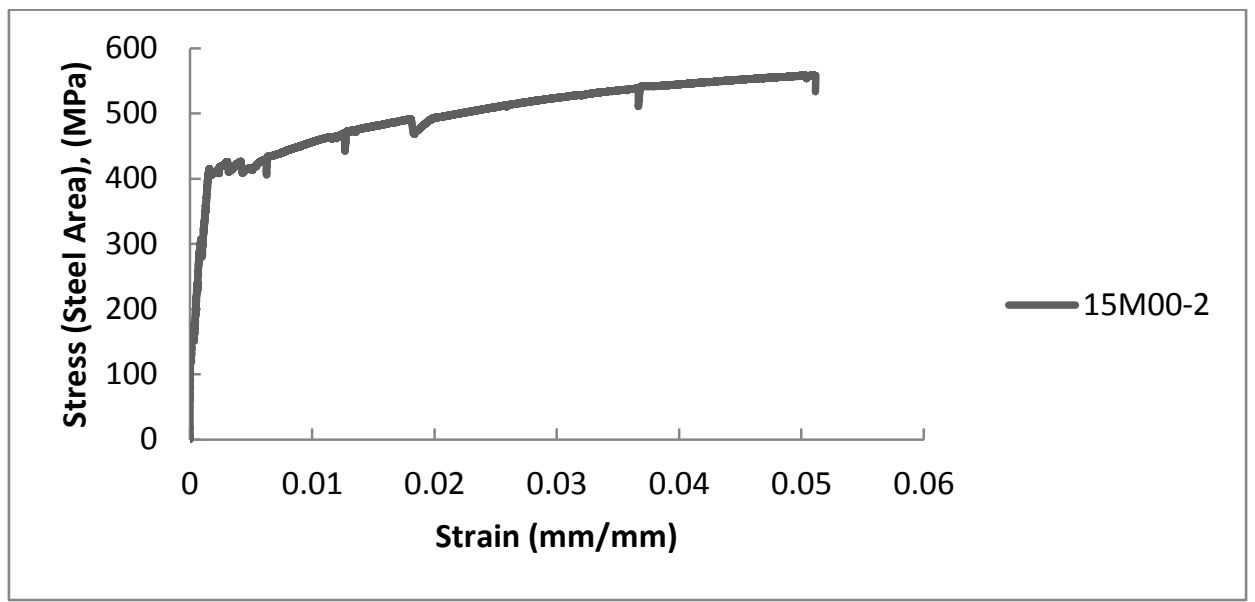

Figure 4-27: Entire stress strain response (15M00-2)

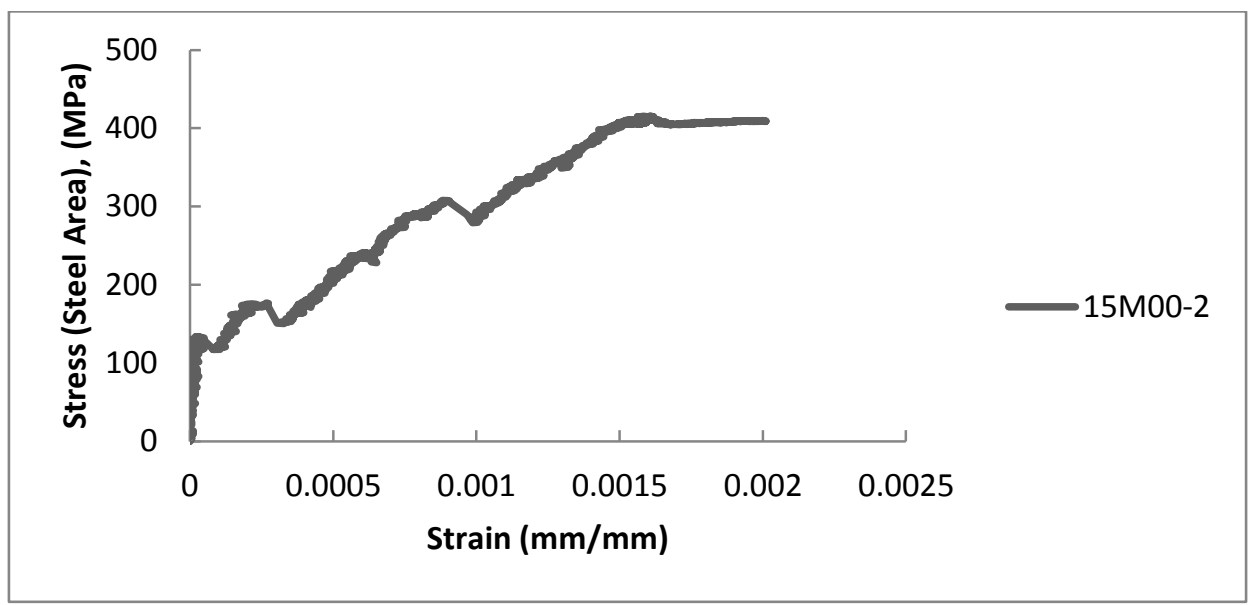

Figure 4-28: Stress strain response prior to yielding of reinforcing steel (15M00-2)

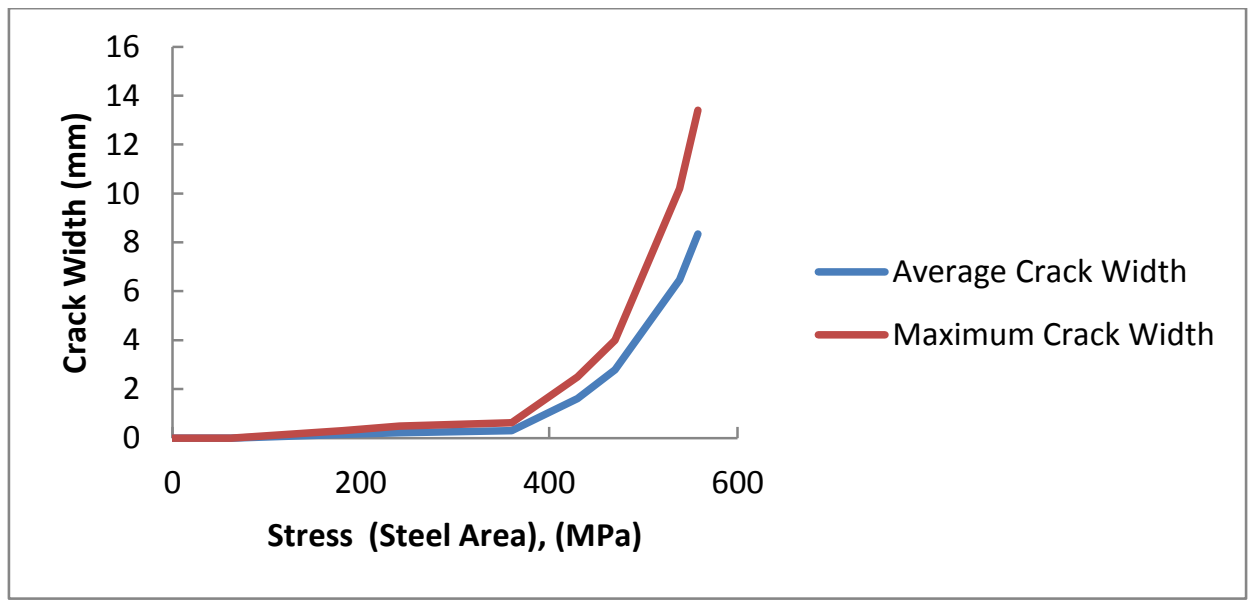

Figure 4-29: Average \& maximum crack widths (15M00-2) 


\subsubsection{Specimen 15M04S-1}

This specimen was tested on August 23, 2013 and was the first of two identical specimens. A duplicate to this specimen was tested at a later date. This specimen contained Dramix ZP305 steel fibres at $0.4 \%$ of the total grout volume. This specimen was cast to observe the effect of fibre reinforced grout on the tensile behaviour of a uniaxially loaded tension member. Later tests will incorporate increased volume fractions of fibres to investigate the critical fibre content for improving the tensile behaviour.

The first cracking was observed at a load of approximately $32 \mathrm{kN}$ at the second mortar joint from the bottom. The next two cracks formed very gradually and no noticeable drop in load was observed as the cracks opened. The fourth crack was accompanied by a sudden loss of load when the load reached $61.6 \mathrm{kN}$. It should also be noted that the cracks did not tend to extend the entire width of the specimen. This is due to the fact that the fibre contribution clamps the cracks shut and does not allow them to open evenly.

Once the reinforcing steel approached its yield stress, the cracking pattern stabilized until loads approached ultimate. The crack widths were fairly narrow as only one or two cracks tended to open up widely. Due to this attribute, the average crack width is much lower than the maximum crack width at the same respective load level.

The test was terminated when the load was no longer increasing at any significant rate and the moving head was approaching its maximum stroke.

Figure 4-30 shows the entire stress-strain relationship of the specimen whereas Figure 431 shows the stress-strain relationship prior to yielding. Figure 4-32 shows both the average crack width and maximum crack as a function of stress. The stress is based on the steel area of the given specimen 
Table 4-13: Test summary for specimen 15M04S-1

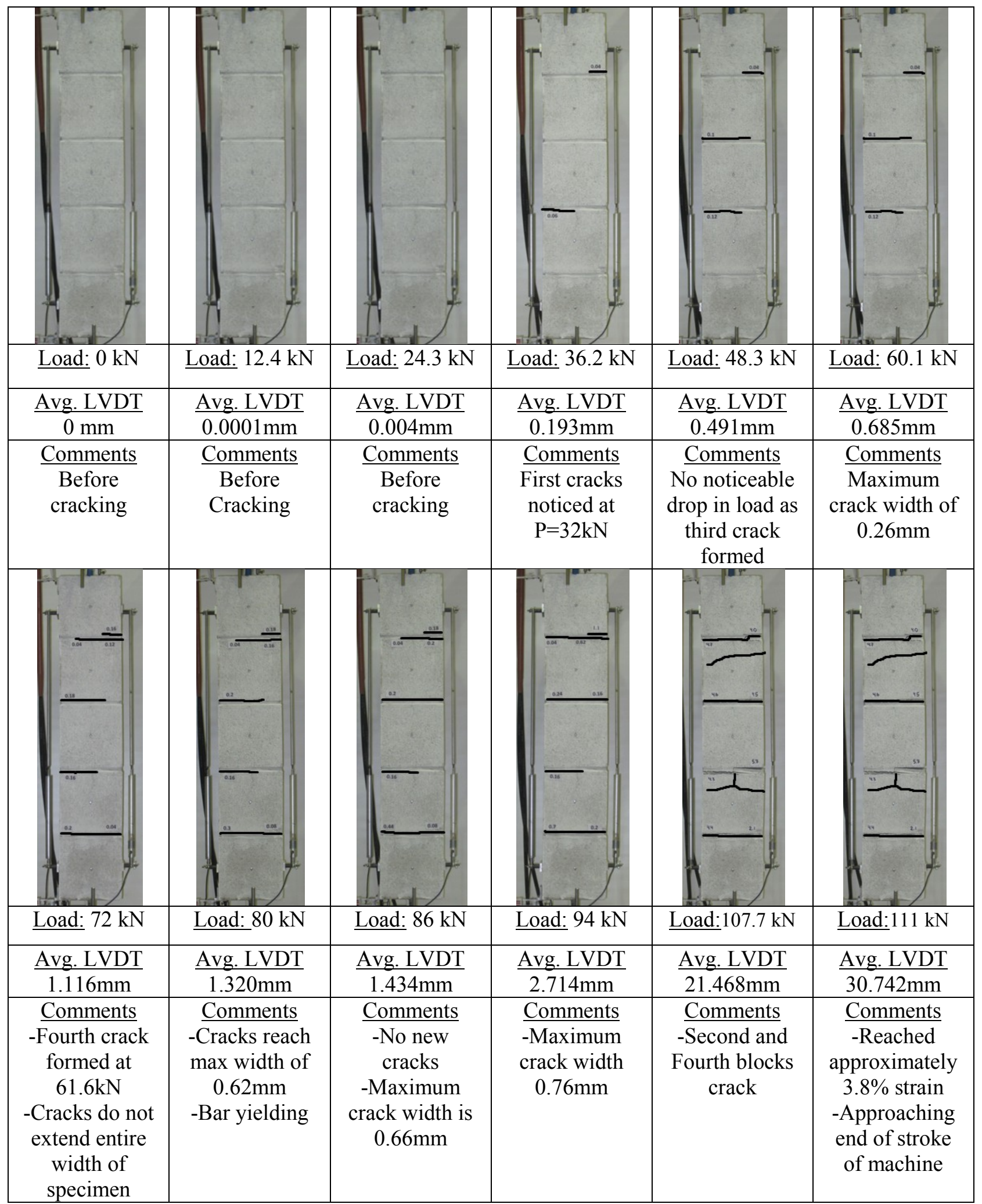




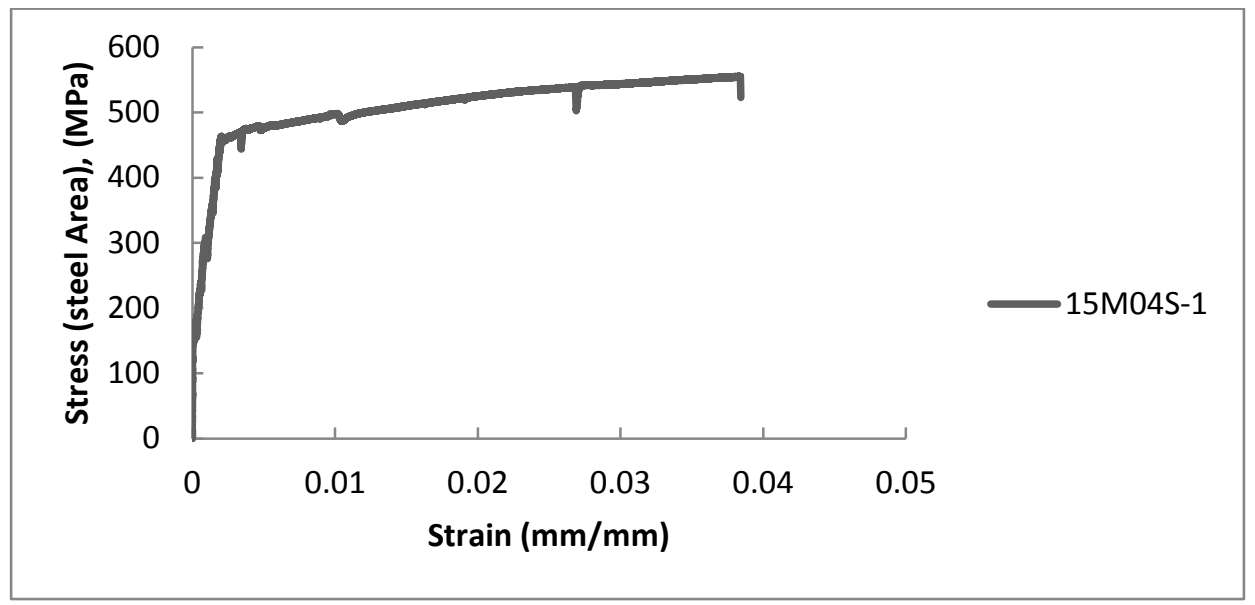

Figure 4-30: Entire stress stain response (15M04S-1)

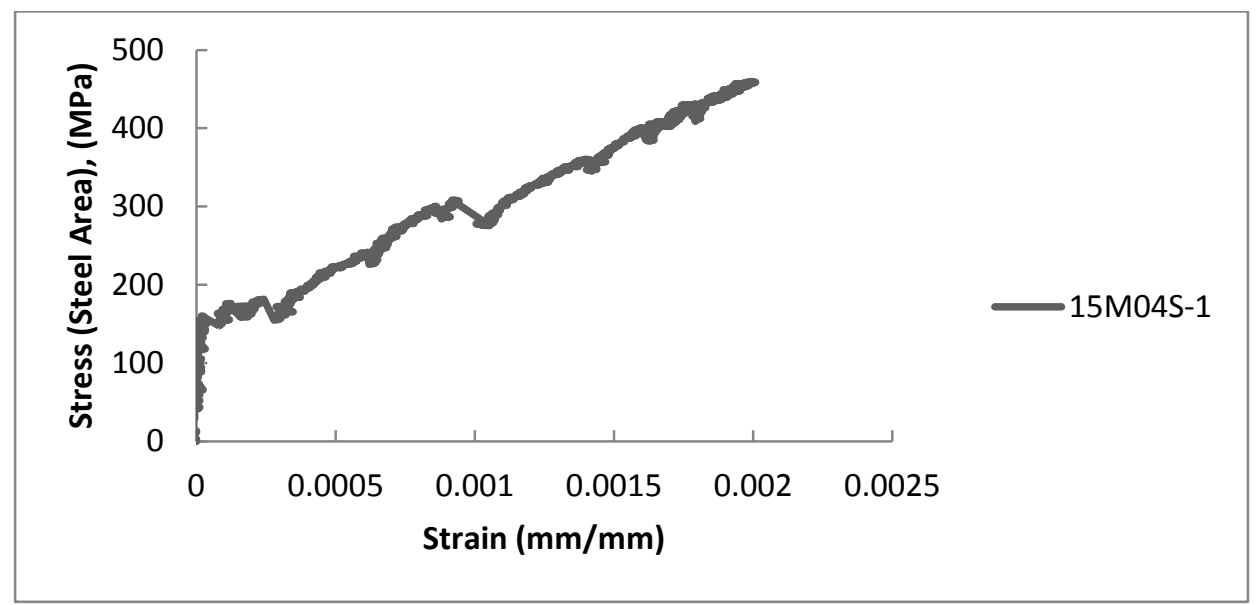

Figure 4-31: Stress strain response prior to yielding of reinforcing steel (15M04S-1)

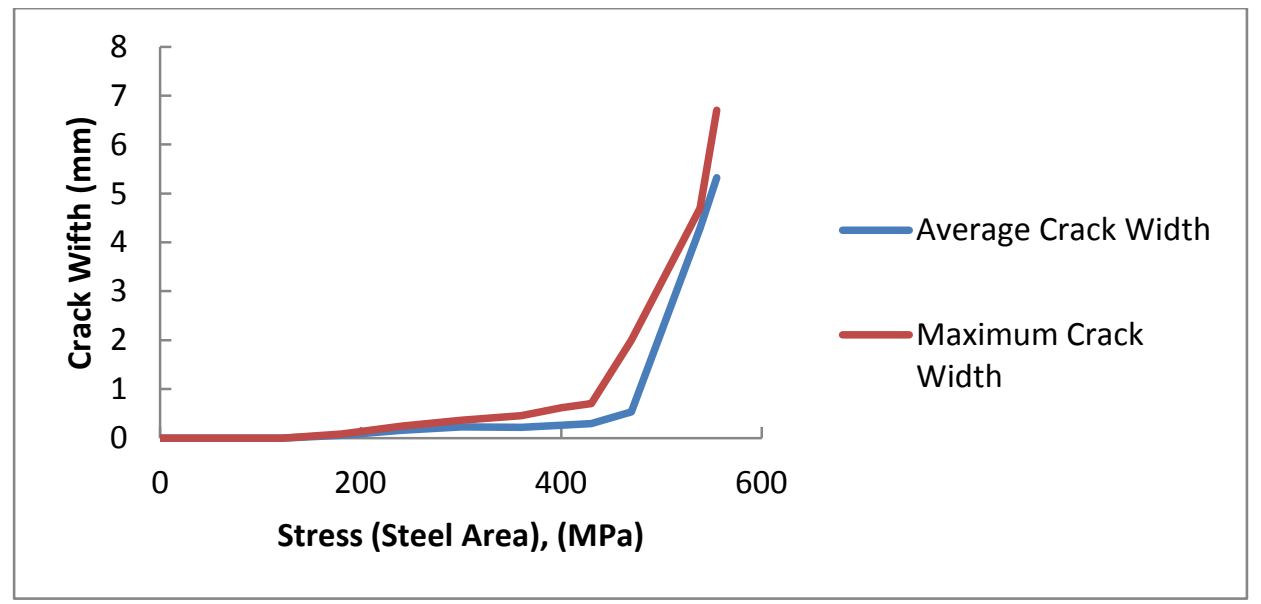

Figure 4-32: Average \& maximum crack widths (15M04S-1) 


\subsubsection{Specimen 15M04S-2}

This specimen was tested on August 28, 2013 and was the second of two identical specimens. This specimen contained Dramix ZP305 steel fibres at $0.4 \%$ of the total grout volume. This specimen was cast to prove that the results of $15 \mathrm{M} 04 \mathrm{~S}-1$ were repeatable.

The first cracking was observed at a load of approximately $29.5 \mathrm{kN}$ at the second mortar joint from the bottom. The next crack developed at the third mortar joint from the bottom at a load of approximately $45.3 \mathrm{kN}$. The next crack was accompanied by a sudden loss of load when the load reached $67.4 \mathrm{kN}$. It should also be noted that the cracks did not tend to extend the entire width of the specimen. This is due to the fact that the fibre contribution clamps the cracks shut and does not allow them to open evenly. Also, the cracking pattern seemed to develop quicker on the backside then on the front side. As can be seen in table 4-14, the cracks are twice as prominent on the backside as on the front side at the same load level. At a load of approximately $100 \mathrm{kN}$, the second block from the top cracked near its centre.

The average crack width remains fairly close to the maximum crack width and the cracks are fairly evenly spaced.

The test was terminated when the load was no longer increasing at any significant rate and the moving head was approaching its maximum stroke. The maximum load reached was $112.5 \mathrm{kN}$.

Figure 4-33 shows the entire stress-strain relationship of the specimen whereas Figure 434 shows the stress-strain relationship prior to yielding. Figure 4-35 shows both the average crack width and maximum crack as a function of stress. The stress is based on the steel area of the given specimen. 
Table 4-14: Test summary for specimen 15M04S-2

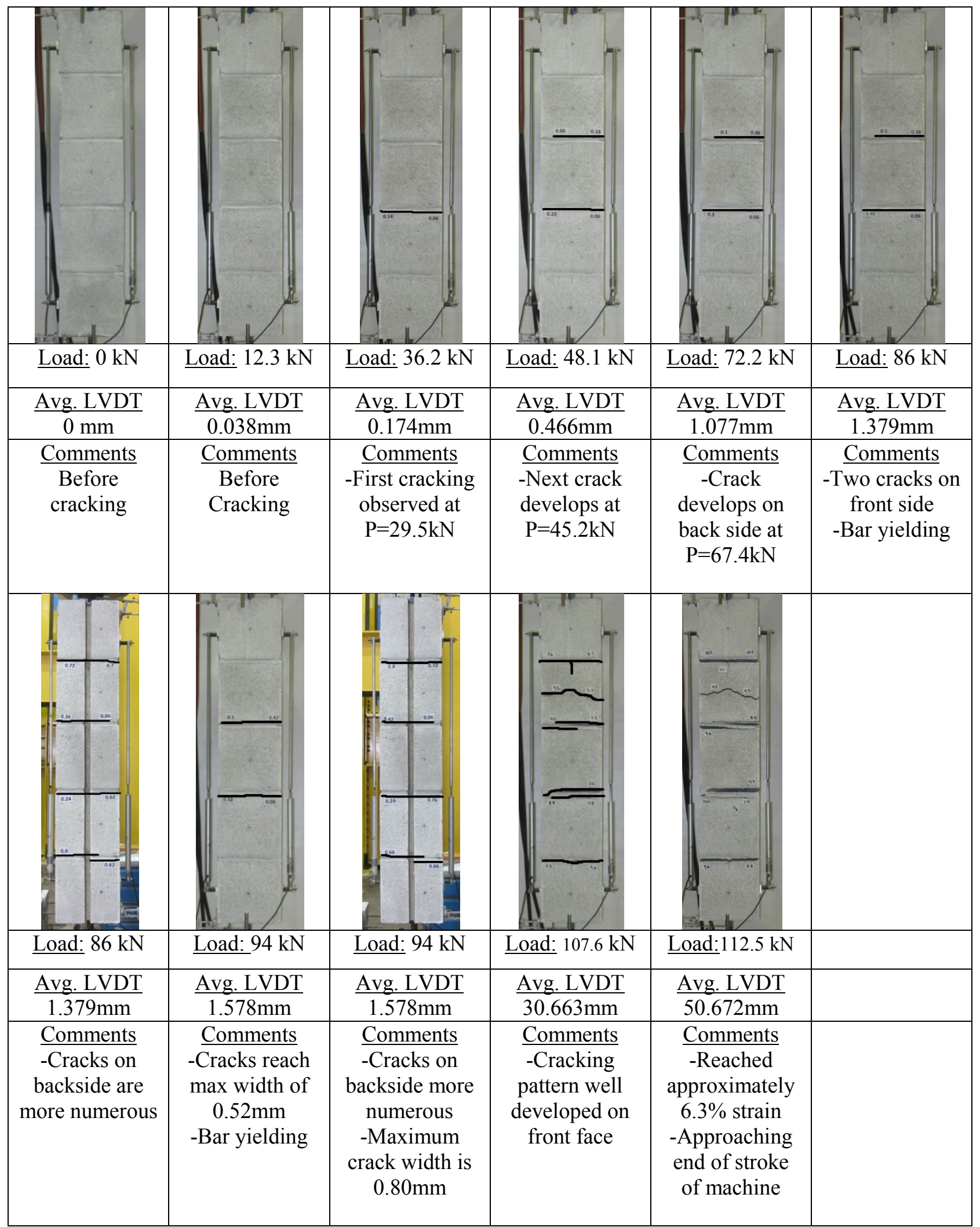




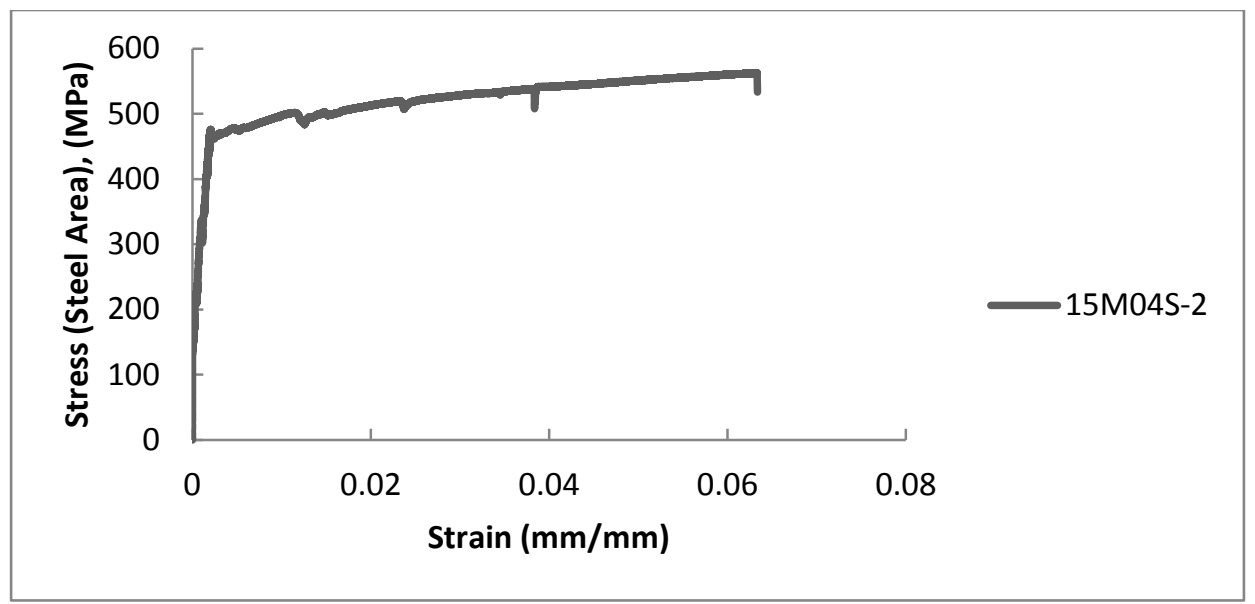

Figure 4-33: Entire stress strain response (15M04S-2)

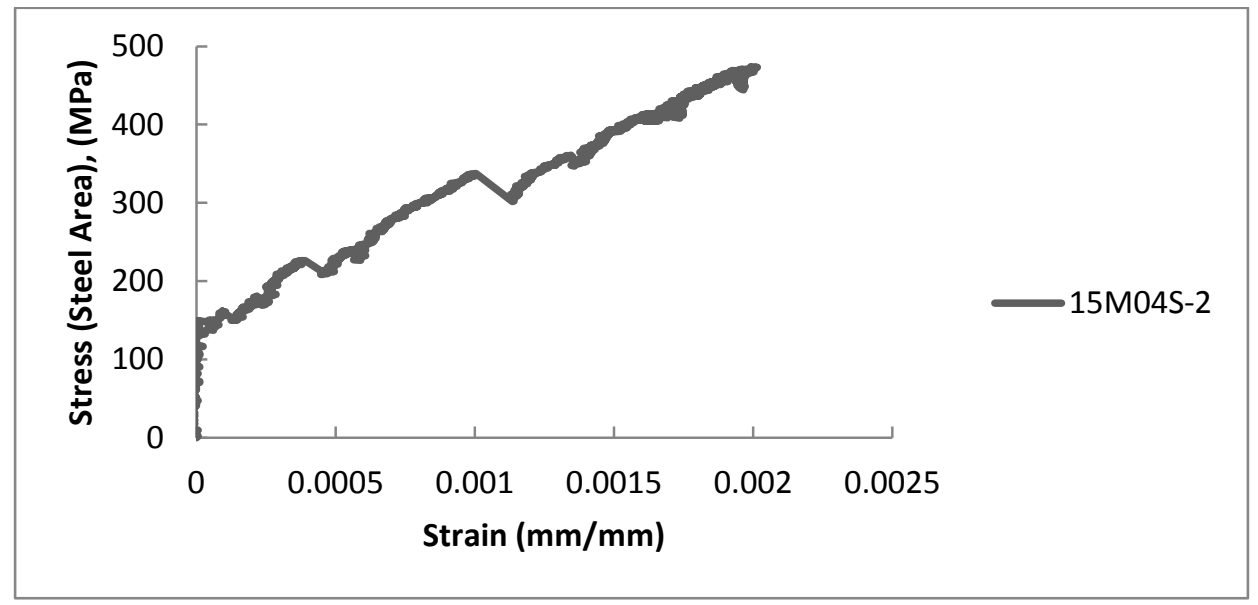

Figure 4-34: Stress strain response prior to yielding of reinforcing steel (15M04S-2)

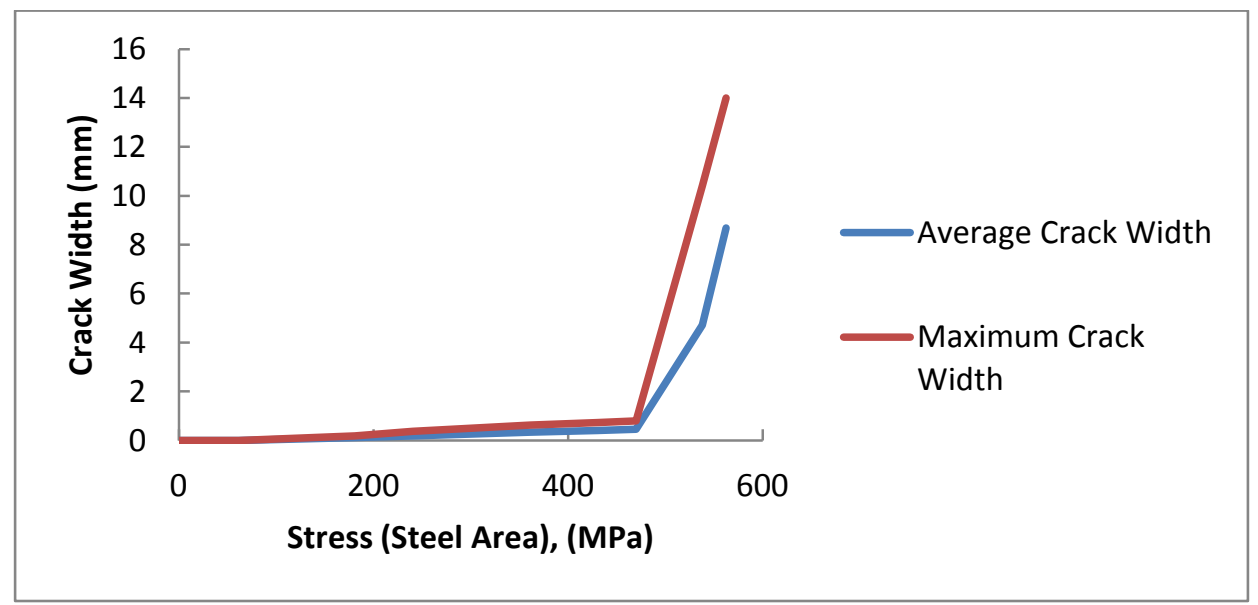

Figure 4-35: Average \& maximum crack widths (15M04S-2) 


\subsubsection{Specimen 15M08S-1}

This specimen was tested on August $26^{\text {th }}, 2013$ and was the next specimen in the $15 \mathrm{M}$ monotonic series of tests. A duplicate to this specimen was tested the following day. This specimen contained standard units and contained a grout with $0.8 \%$ ZP305 steel fibres by volume. This specimen was cast to investigate the contribution of an increased volume of steel fibres to the tension stiffening behaviour and the overall tensile performance.

First cracking occurred at a load of approximately $43.3 \mathrm{kN}$. By a load of approximately $60 \mathrm{kN}$, the cracking pattern was already developed and would remain this way for the majority of the remainder of the test. More cracks did not initiate until the load reached approximately $107.6 \mathrm{kN}$. The crack widths were all very similar early on in the test until the load reached levels which caused the steel to enter strain hardening. At the load stage taken at $107.9 \mathrm{kN}$, it was noticed that the bottom block had cracked at its centre.

The test was terminated when the load was no longer increasing at any significant rate and the moving head was approaching its maximum stroke. The maximum load reached was $111.1 \mathrm{kN}$ at a head displacement of $56.83 \mathrm{~mm}$.

Figure 4-36 shows the entire stress-strain relationship of the specimen whereas Figure 437 shows the stress-strain relationship prior to yielding. Figure 4-39 shows both the average crack width and maximum crack as a function of stress. The stress is based on the steel area of the given specimen. 
Table 4-15: Test summary for specimen 15M08S-1

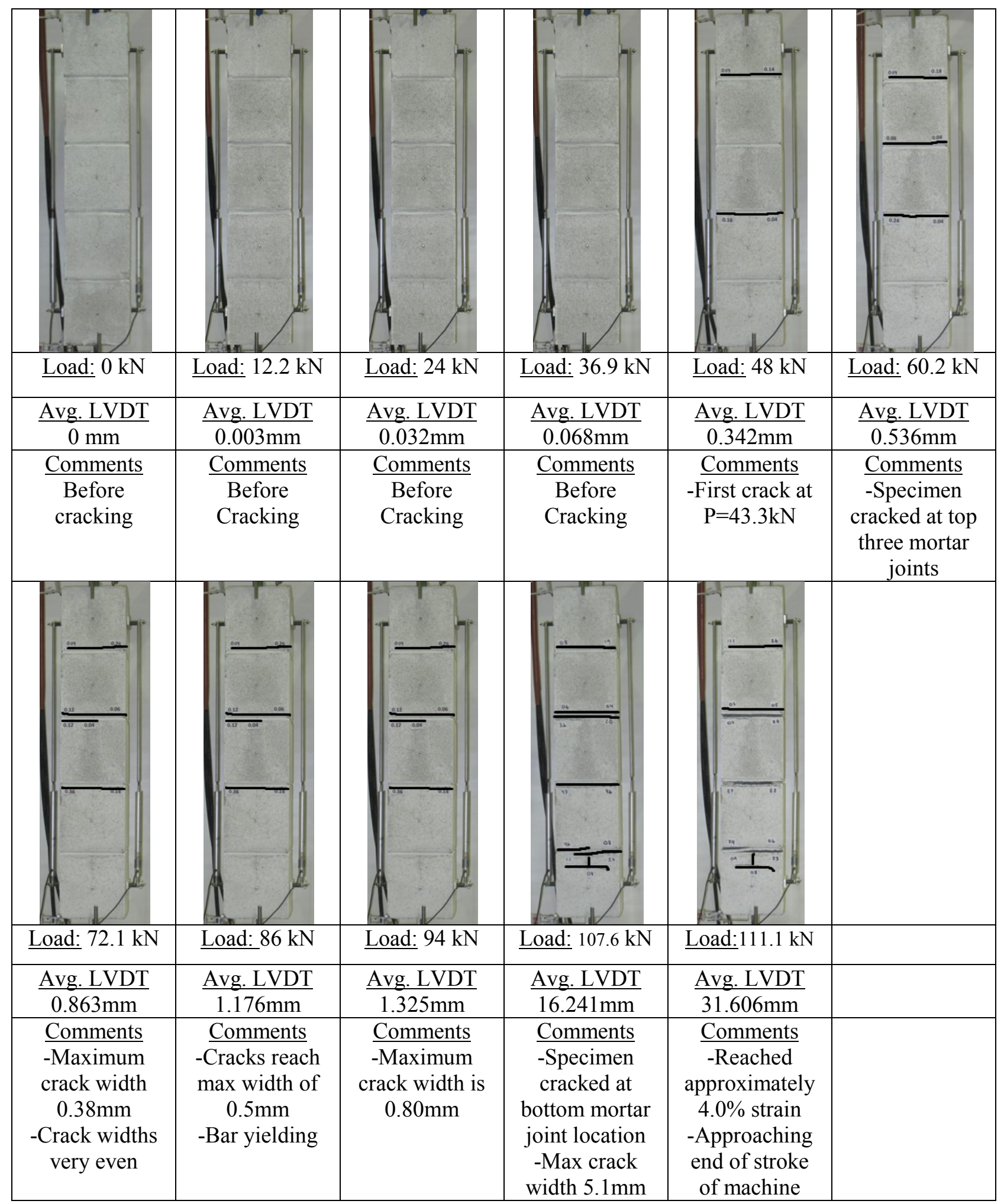




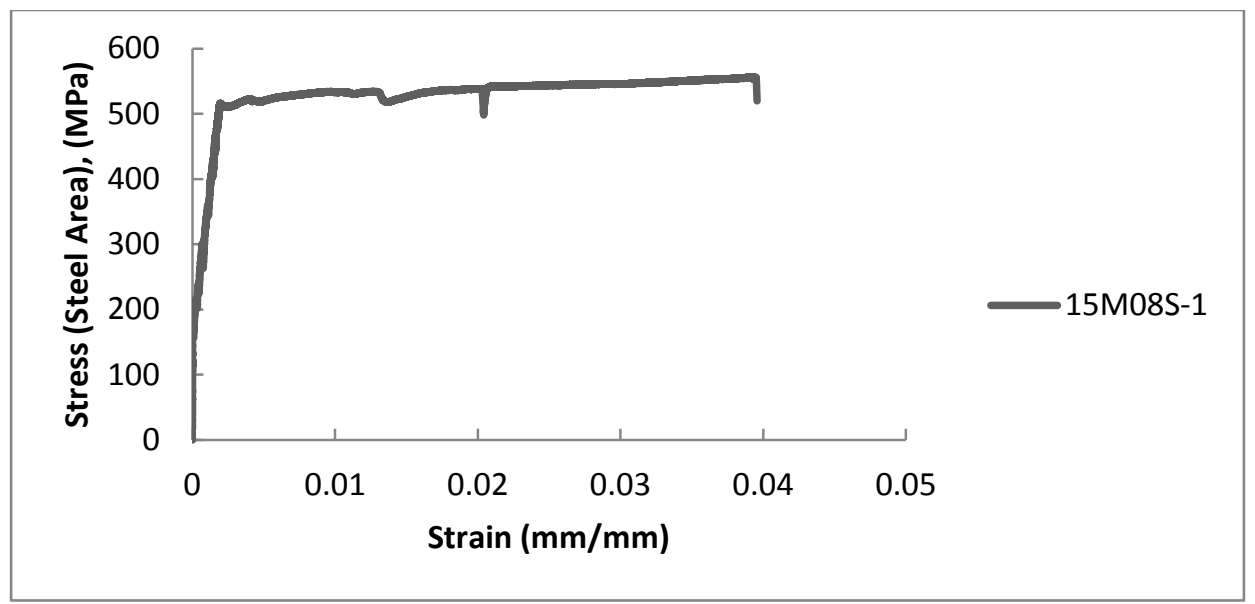

Figure 4-36: Entire stress strain response (15M08S-1)

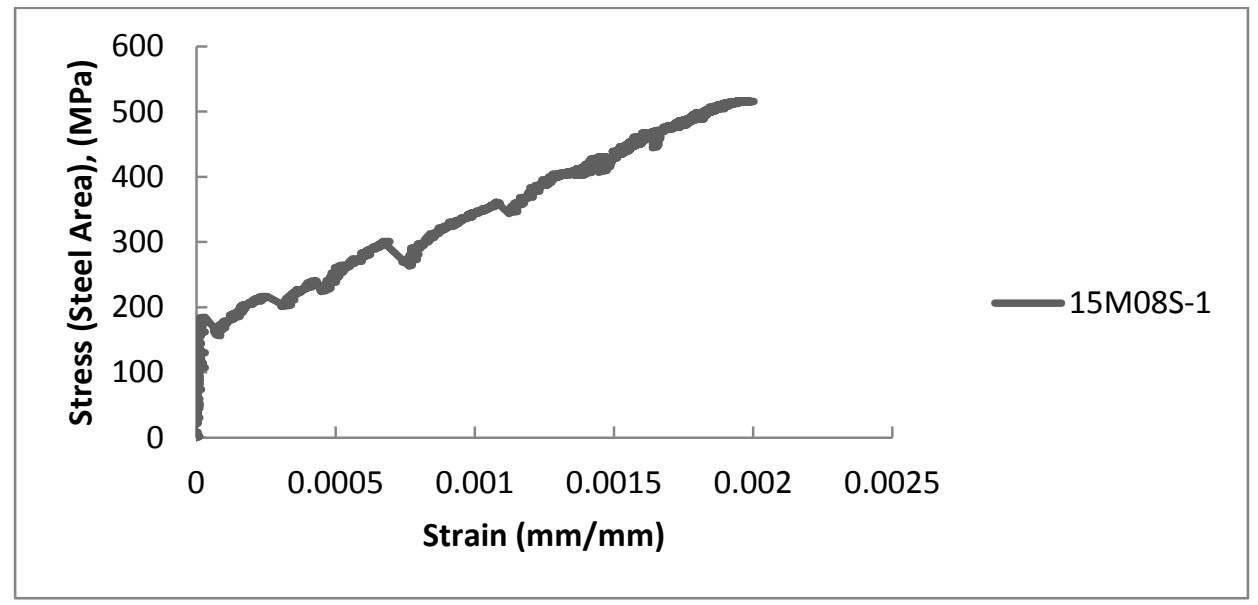

Figure 4-37: Stress strain response prior to yielding of reinforcing steel (15M08S-1)

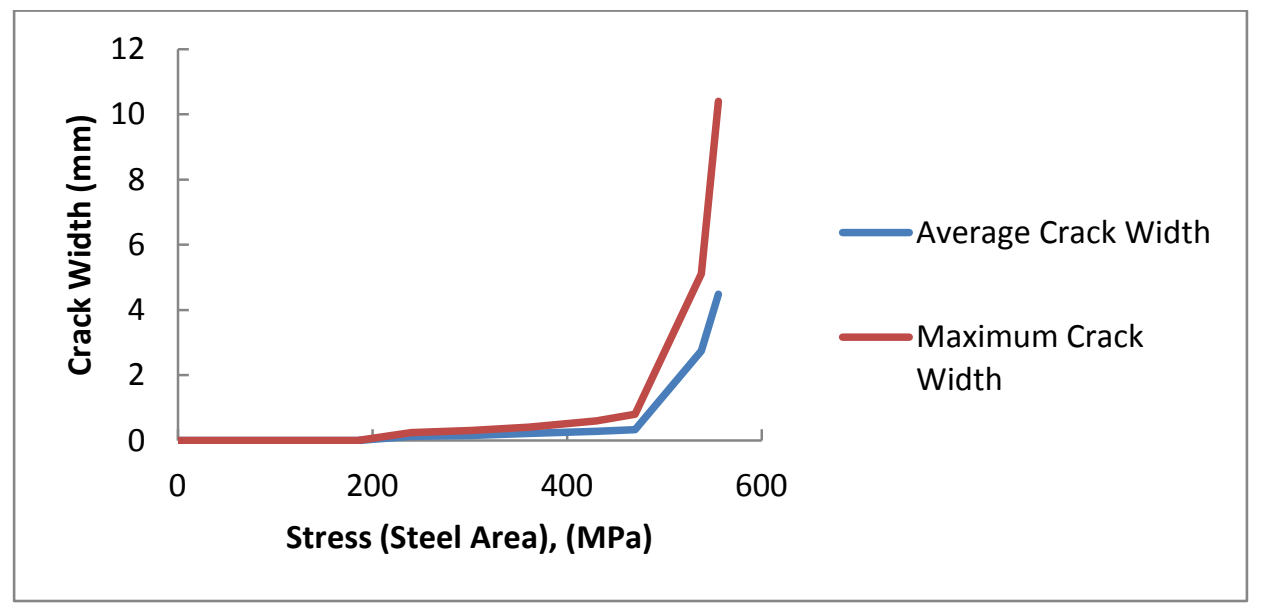

Figure 4-38: Average \& maximum crack widths (15M08S-1) 


\subsubsection{Specimen 15M08S-2}

This specimen was tested on August 27 $7^{\text {th }}, 2013$ and was a duplicate to $15 \mathrm{M} 08 \mathrm{~S}-1$ which was tested the previous day. This specimen contained standard units and contained a grout with $0.8 \%$ ZP305 steel fibres by volume. This specimen was cast to investigate the contribution of an increased volume of steel fibres to the tension stiffening behaviour and the overall tensile performance.

First cracking occurred at a load of approximately $32.5 \mathrm{kN}$. The second crack formed at a load of approximately $44.5 \mathrm{kN}$. These first two cracks did not increase in width rapidly due to the influence of the steel fibres. At a load of $48.2 \mathrm{kN}$, the maximum crack width was maintained at $0.18 \mathrm{~mm}$. Up until the load entered the strain hardening range of the reinforcing steel, there were three cracks present, all of which were initiated at a mortar joint. Once the load passed approximately $90 \mathrm{kN}$, all mortar joints were cracked. As the load increased, the second crack from the bottom became very wide, while the other three cracks kept approximately the same width. Less load stages were taken for this specimen due to the fact that it was a duplicate specimen and full load stages were taken for 15M08S-1.

The test was terminated when the load was no longer increasing at any significant rate and the moving head was approaching its maximum stroke. The maximum load reached was $114.7 \mathrm{kN}$ at a head displacement of $91.84 \mathrm{~mm}$.

Figure 4-39 shows the entire stress-strain relationship of the specimen whereas Figure 440 shows the stress-strain relationship prior to yielding. Figure 4-41 shows both the average crack width and maximum crack as a function of stress. The stress is based on the steel area of the given specimen. 
Table 4-16: Test summary for specimen 15M08S-2

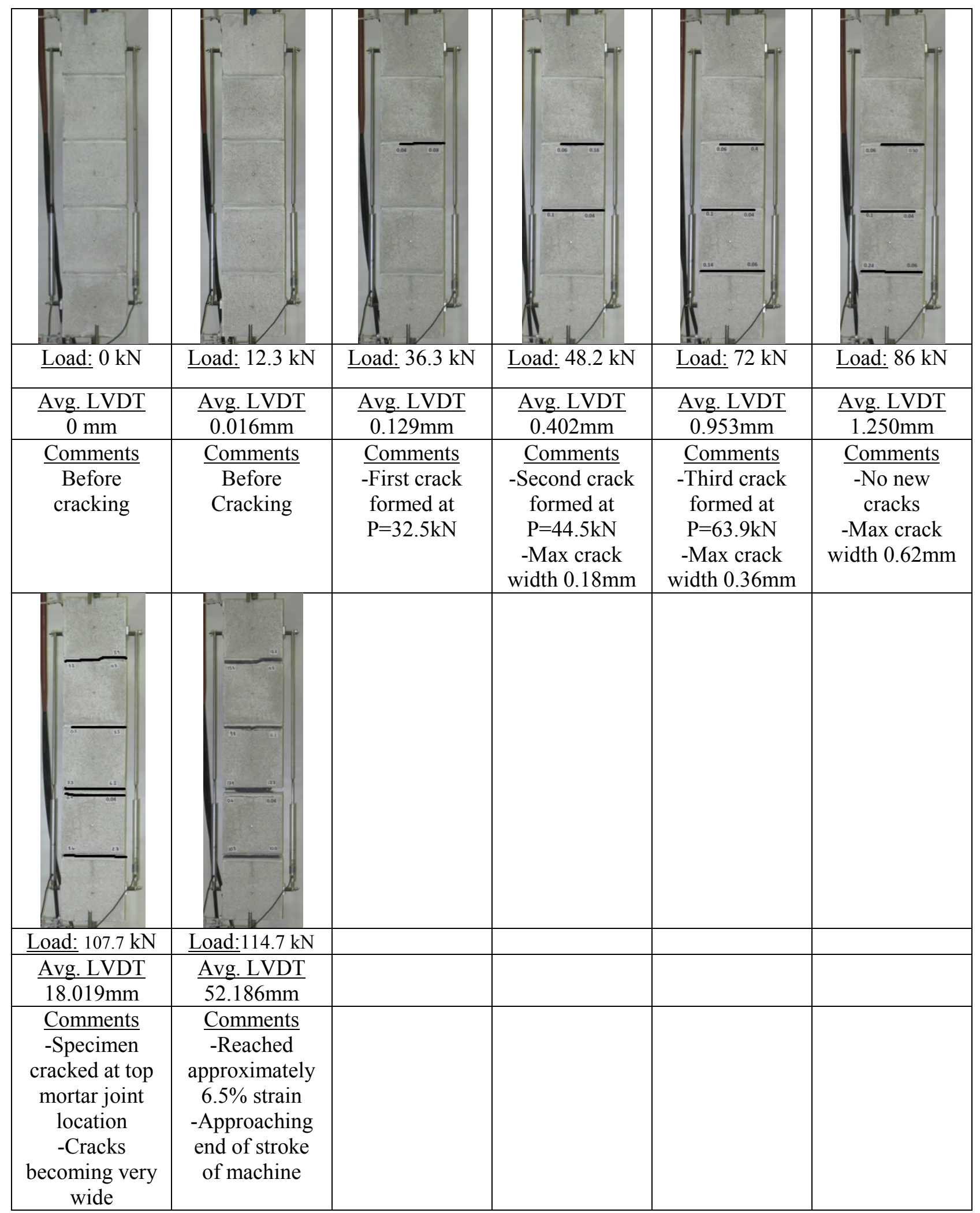




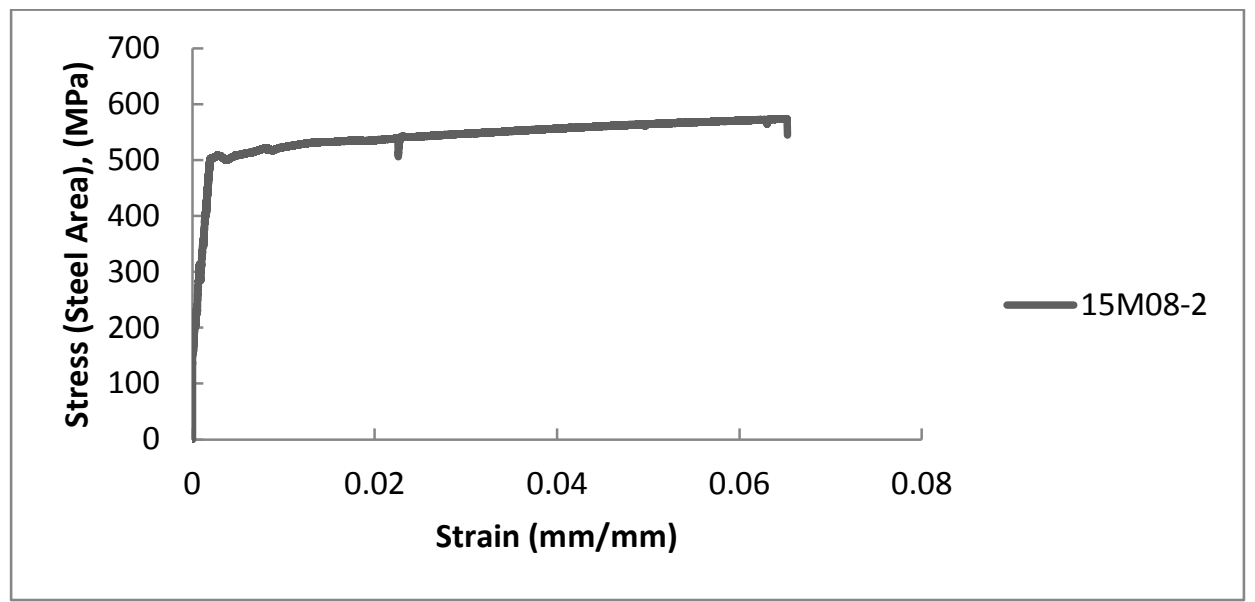

Figure 4-39: Entire stress strain response (15M08S-2)

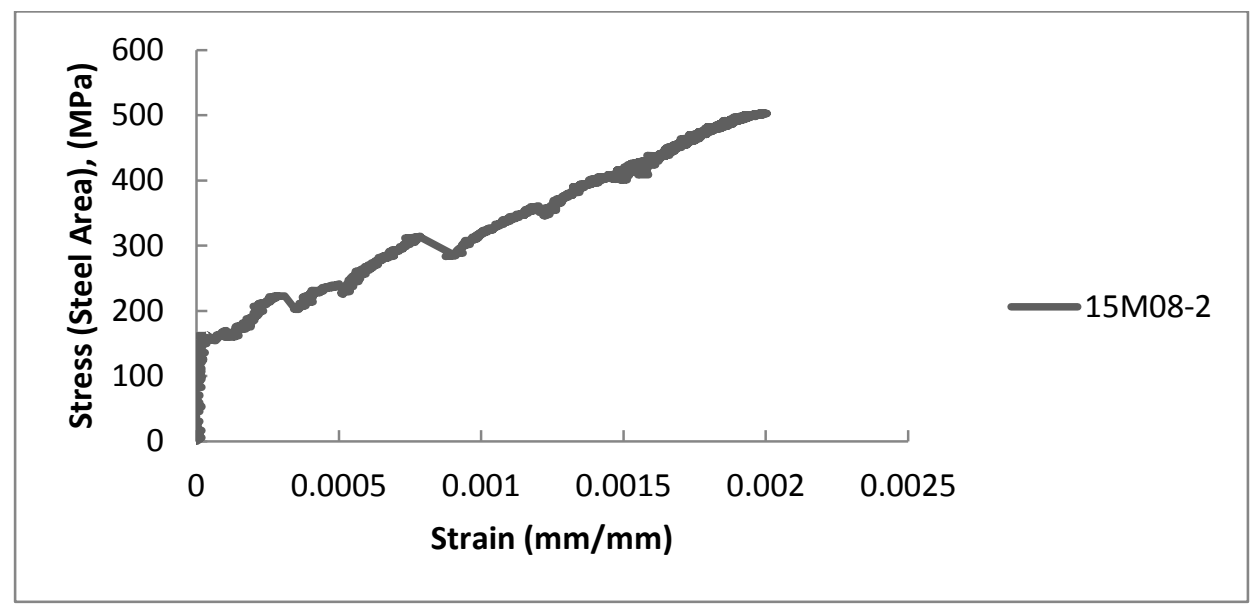

Figure 4-40: Stress strain response prior to yielding of reinforcing steel (15M08S-2)

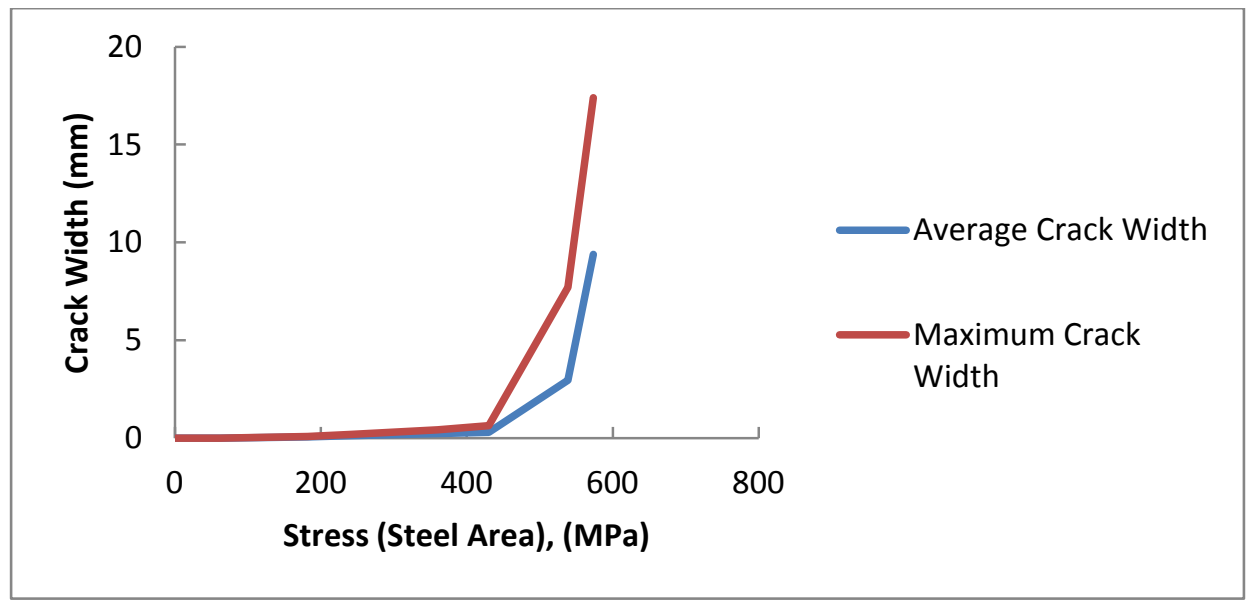

Figure 4-41: Average \& maximum crack widths (15M08S-2) 


\subsubsection{Specimen 15M12S-1}

This specimen was tested on August $15^{\text {th }}, 2013$ and was the first specimen of the $15 \mathrm{M}$ monotonic set to be tested. The duplicate specimen was tested at a later date. This specimen contained standard units and contained a grout with $1.2 \%$ ZP305 steel fibres by volume. This specimen was cast to investigate the contribution of a dramatically increased volume of steel fibres to the tension stiffening behaviour and the overall tensile performance. It should be noted that the top mortar joint was partially pre-cracked before the loading began. This damage is thought to have occurred during the vibration process as with specimens 15M00-1 and 15M00-2. This crack was not monitored.

First cracking was observed at a load of approximately $43.4 \mathrm{kN}$ and the second crack quickly formed afterwards at a load of approximately $46.7 \mathrm{kN}$. Crack widths maintained very low at early stages of the loading process. Even at a load of $72 \mathrm{kN}$, approaching the yield stress of the bare reinforcing steel, the crack widths only rose to a maximum of $0.32 \mathrm{~mm}$. At a load of approximately $90 \mathrm{kN}$, the final crack formed in the specimen. The loading continued until a maximum load of $106.5 \mathrm{kN}$ where it was stopped. The load was stopped due to the fact that this was the very first specimen and the stopping criterion was not yet well defined. In the duplicate test for this specimen, the specimen was loaded to a higher strain to observe the behaviour at high levels of strain.

Figure 4-42 shows the entire stress-strain relationship of the specimen whereas Figure 443 shows the stress-strain relationship prior to yielding. Figure 4-44 shows both the average crack width and maximum crack as a function of stress. The stress is based on the steel area of the given specimen. 
Table 4-17: Test summary for specimen 15M12S-1

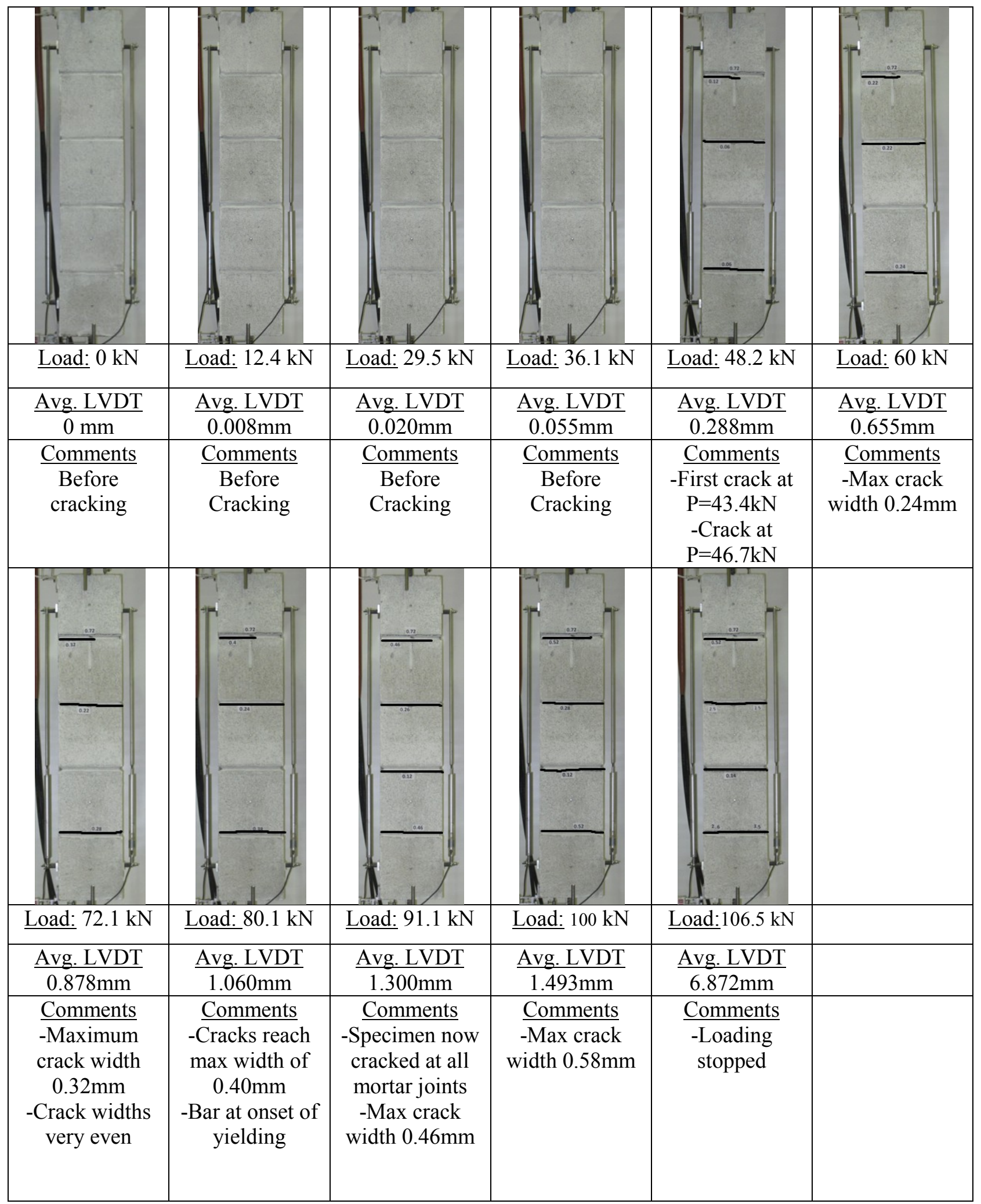




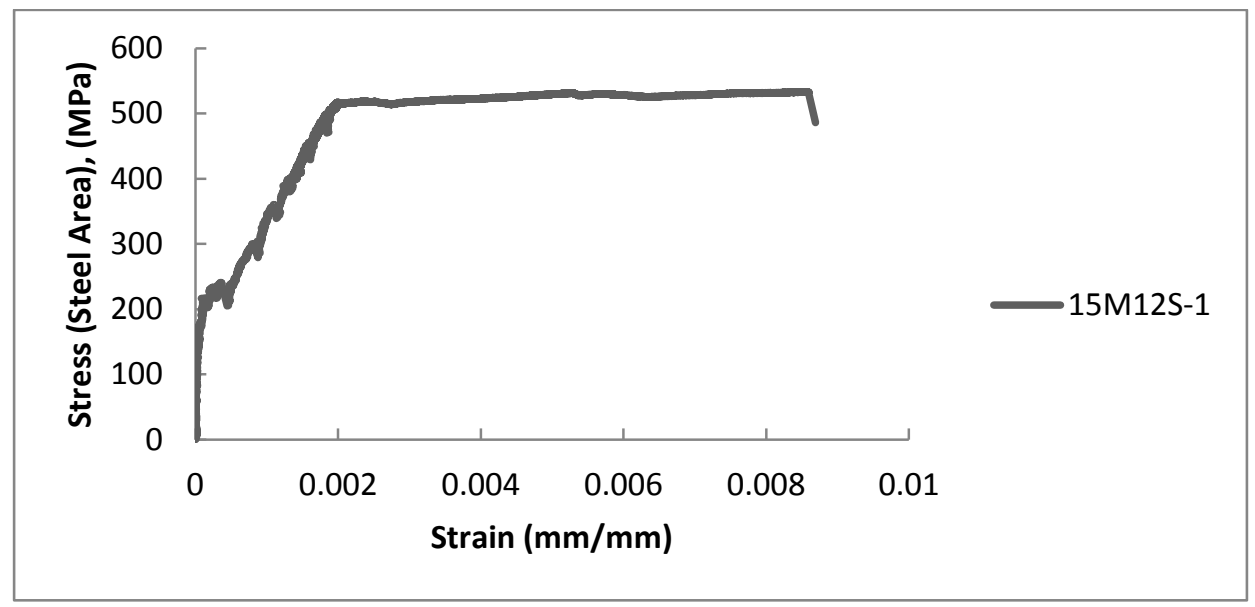

Figure 4-42: Entire stress strain response (15M12S-1)

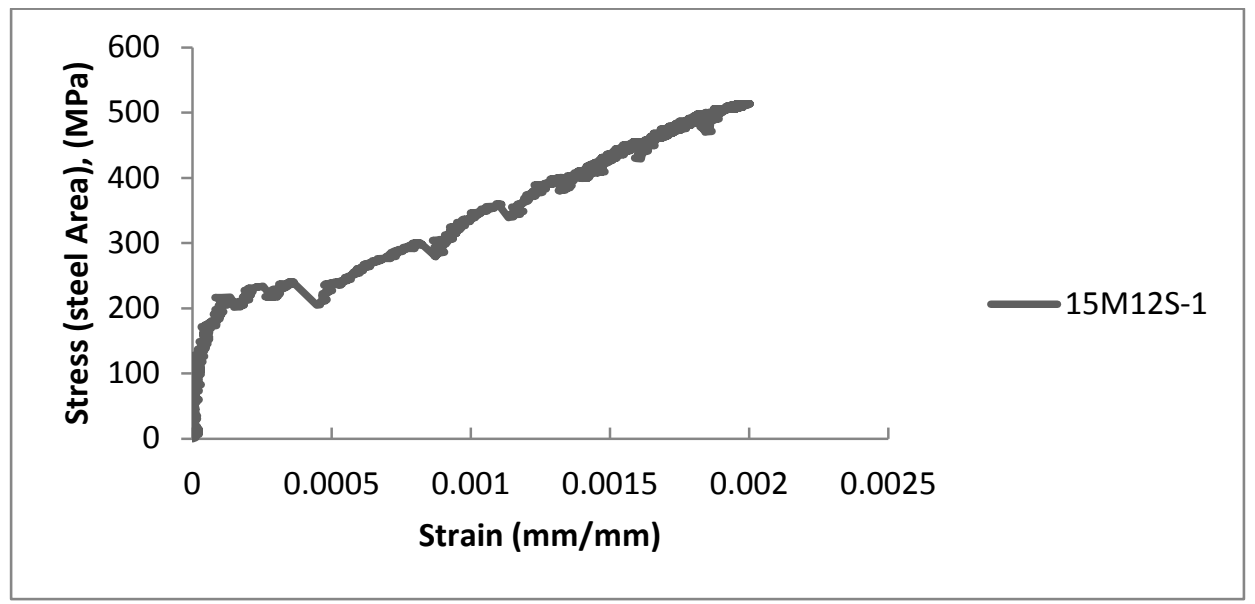

Figure 4-43: Stress strain response prior to yielding of reinforcing steel (15M12S-1)

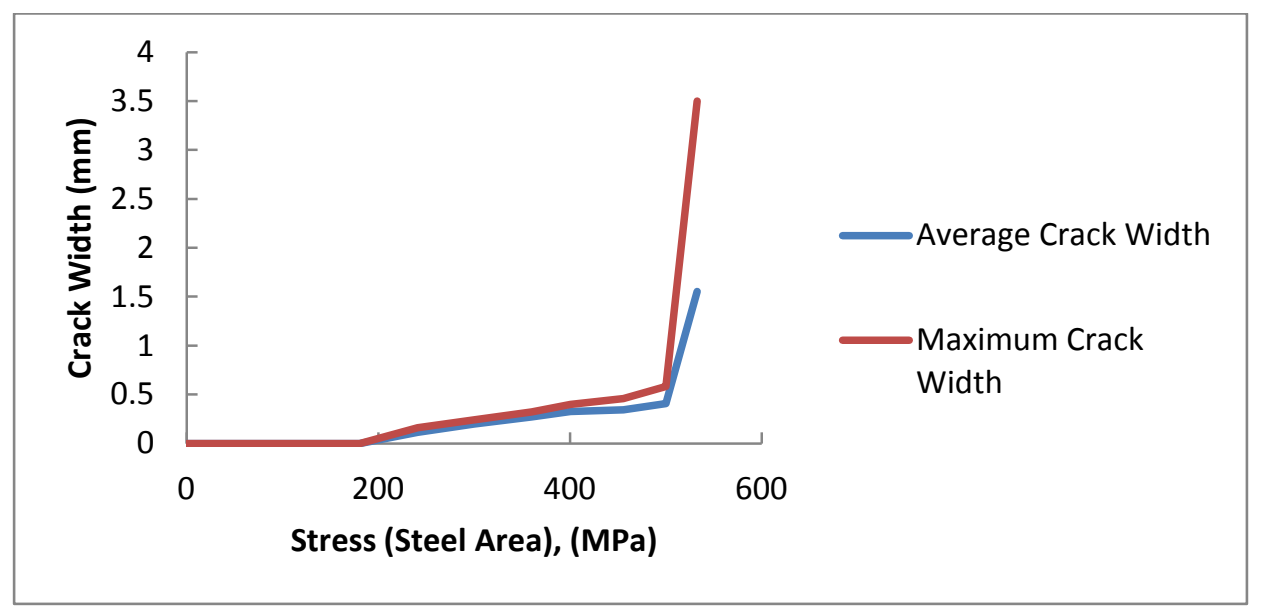

Figure 4-44: Average \& maximum crack widths (15M12S-1) 


\subsubsection{Specimen 15M12S-2}

This specimen was tested on August $28^{\text {th }}, 2013$ and was a duplicate for $15 \mathrm{M} 12 \mathrm{~S}-1$. This specimen contained standard units and contained a grout with 1.2\% ZP305 steel fibres by volume. This specimen was cast to investigate the contribution of a dramatically increased volume of steel fibres to the tension stiffening behaviour and the overall tensile performance. It should be noted that the middle two mortar joints were partially pre-cracked before the loading began. This damage is thought to have occurred during the vibration process as with specimens 15M00-1 and 15M00-2. This crack was not monitored.

First cracking was observed at a load of approximately $46.1 \mathrm{kN}$ and the second and third cracks quickly formed afterwards at loads of approximately $52.6 \mathrm{kN}$ and $54.0 \mathrm{kN}$ respectively. Crack widths maintained very low at early stages of the loading process. Even at a load of $80 \mathrm{kN}$, approaching the yield stress of the bare reinforcing steel, the crack widths only rose to a maximum of $0.62 \mathrm{~mm}$. The cracks on the North (front) face of the specimen were much narrower than on the back side. This fact is reflected in the average crack widths summarized in the Table 4-18. After reaching a load corresponding to the yielding of the bare reinforcing steel, the cracking pattern somewhat stabilized. No new cracks formed after this point. The North face cracked at two locations, and the South face cracked at 4 locations. The maximum crack width read was $2.1 \mathrm{~mm}$ at the final load stage. Although large levels of stress were imparted to specimens, large strains were not observed. This is due to the fact that the fibres were able to carry a significant amount more load. The test was stopped when the maximum stroke of the testing apparatus was reached.

Figure 4-45 shows the entire stress-strain relationship of the specimen whereas Figure 446 shows the stress-strain relationship prior to yielding. Figure 4-47 shows both the average crack width and maximum crack as a function of stress. The stress is based on the steel area of the given specimen. 
Table 4-18: Test summary for specimen 15M12S-2

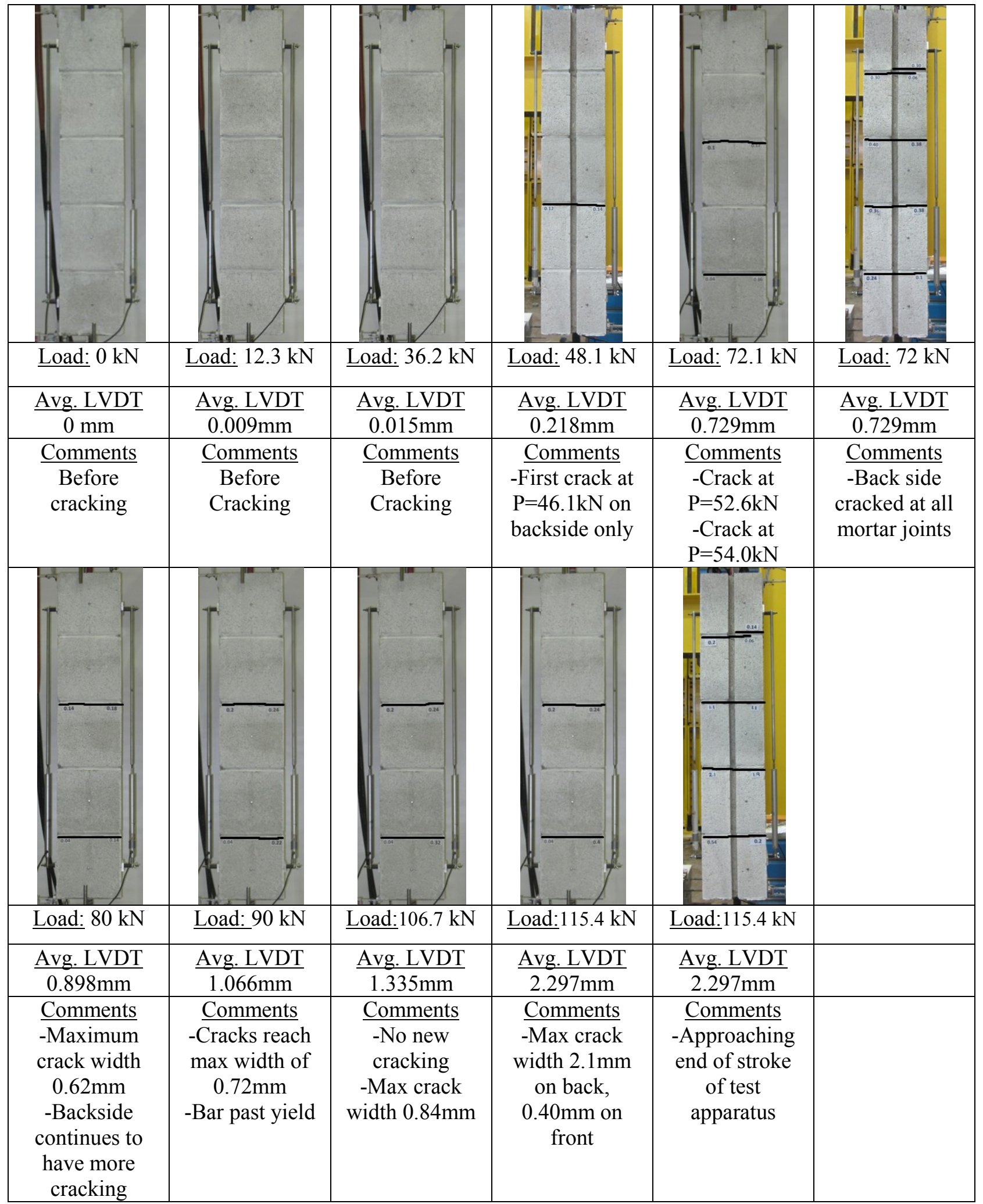




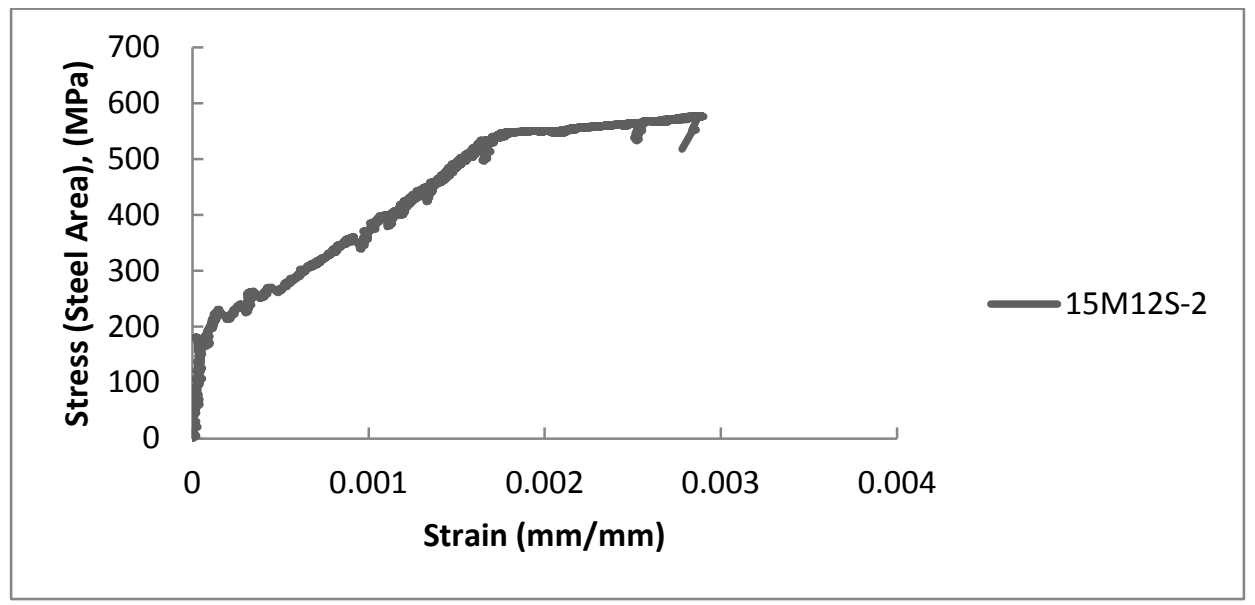

Figure 4-45: Entire stress strain response (15M12S-2)

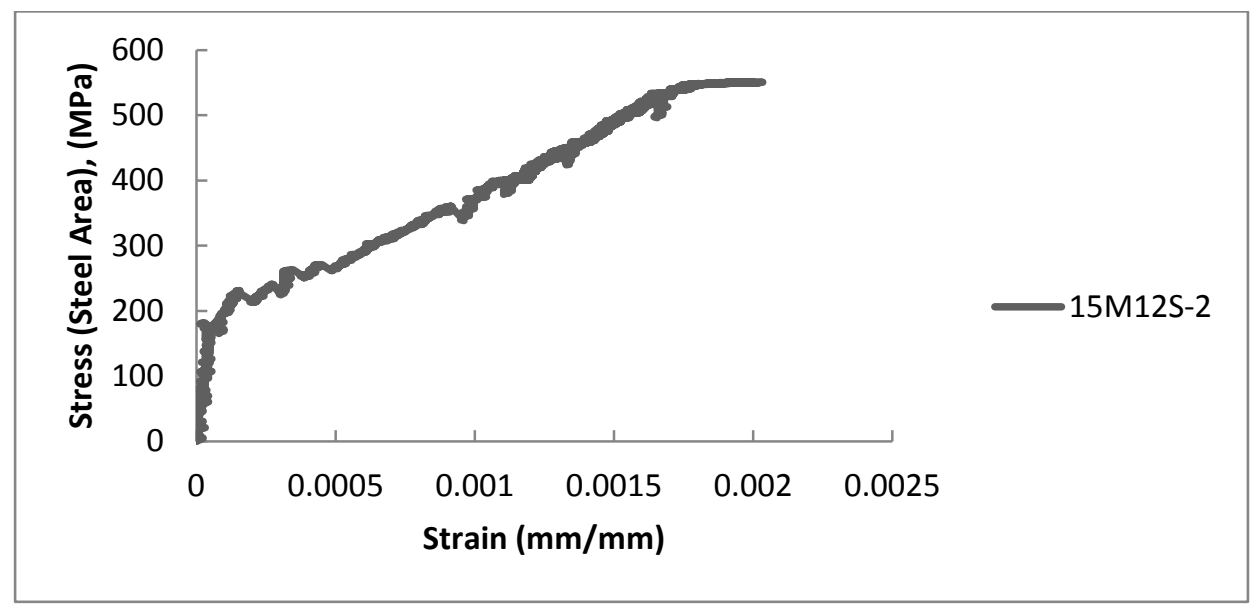

Figure 4-46: Stress strain response prior to yielding of reinforcing steel (15M12S-2)

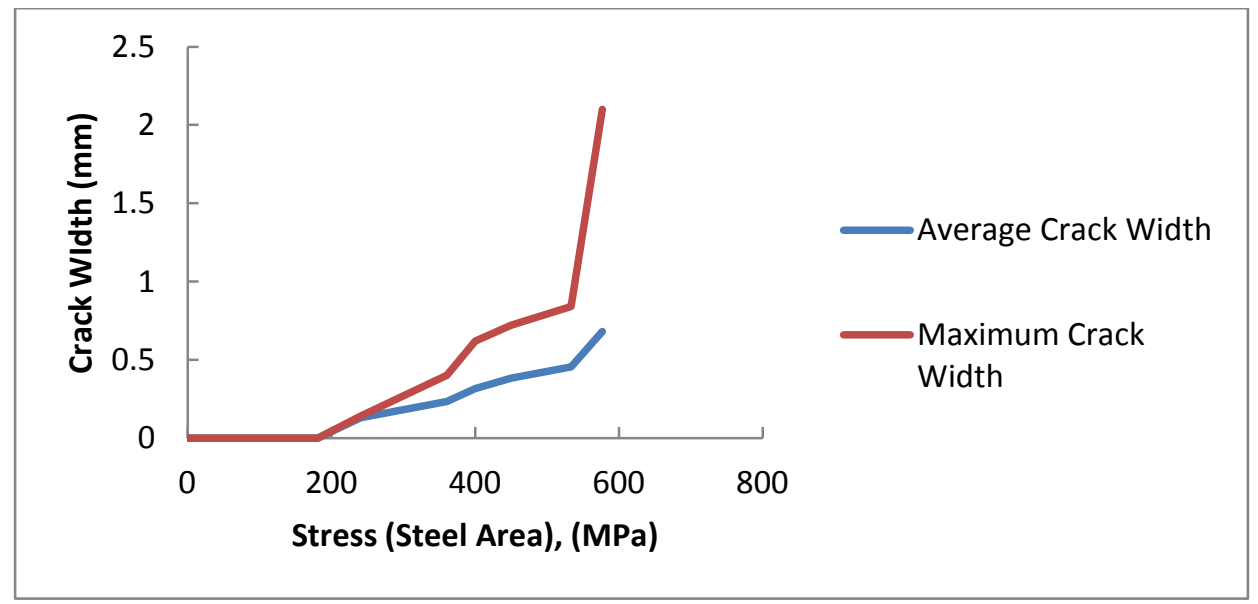

Figure 4-47: Average \& maximum crack widths (15M12S-2) 


\subsubsection{Specimen 20M00-1}

This specimen was tested on September $3^{\text {rd }}, 2013$ and was the first specimen to be tested of the $20 \mathrm{M}$ specimens tested under monotonic load. A duplicate to this specimen was tested at a later date. This specimen contained no fibres and served as a control specimen for all specimens tested in the $20 \mathrm{M}$ monotonic series.

The first cracking was observed at a load of approximately $23.2 \mathrm{kN}$ at the bottom mortar joint. All mortar joints then cracked in quick succession. By a load of approximately $29.5 \mathrm{kN}$, the specimen was cracked at all four mortar joint locations.

Once the reinforcing steel approached its yield stress, the crack widths increased very rapidly. The crack widths were observed to have the same widths on both the East and West sides of each of the faces measured. No new cracks formed until a load of approximately $130.2 \mathrm{kN}$ when bond splitting cracks near the bottom of the specimen occurred. This also led to the bottom block cracking near its midpoint. As the load was increased further, the second block from the bottom also cracked transversely near its midpoint. Also, there was a diagonal crack in the top block which was also cause by pullout of the reinforcing steel and bond splitting failure.

The test was terminated when the crack widths became very wide and the overall strain over the gauge length of the LVDTs reached approximately $6.3 \%$.

Figure 4-48 shows the entire stress-strain relationship of the specimen whereas Figure 449 shows the stress-strain relationship prior to yielding. Figure 4-50 shows both the average crack width and maximum crack as a function of stress. The stress is based on the steel area of the given specimen 
Table 4-19: Test summary for specimen 20M00-1

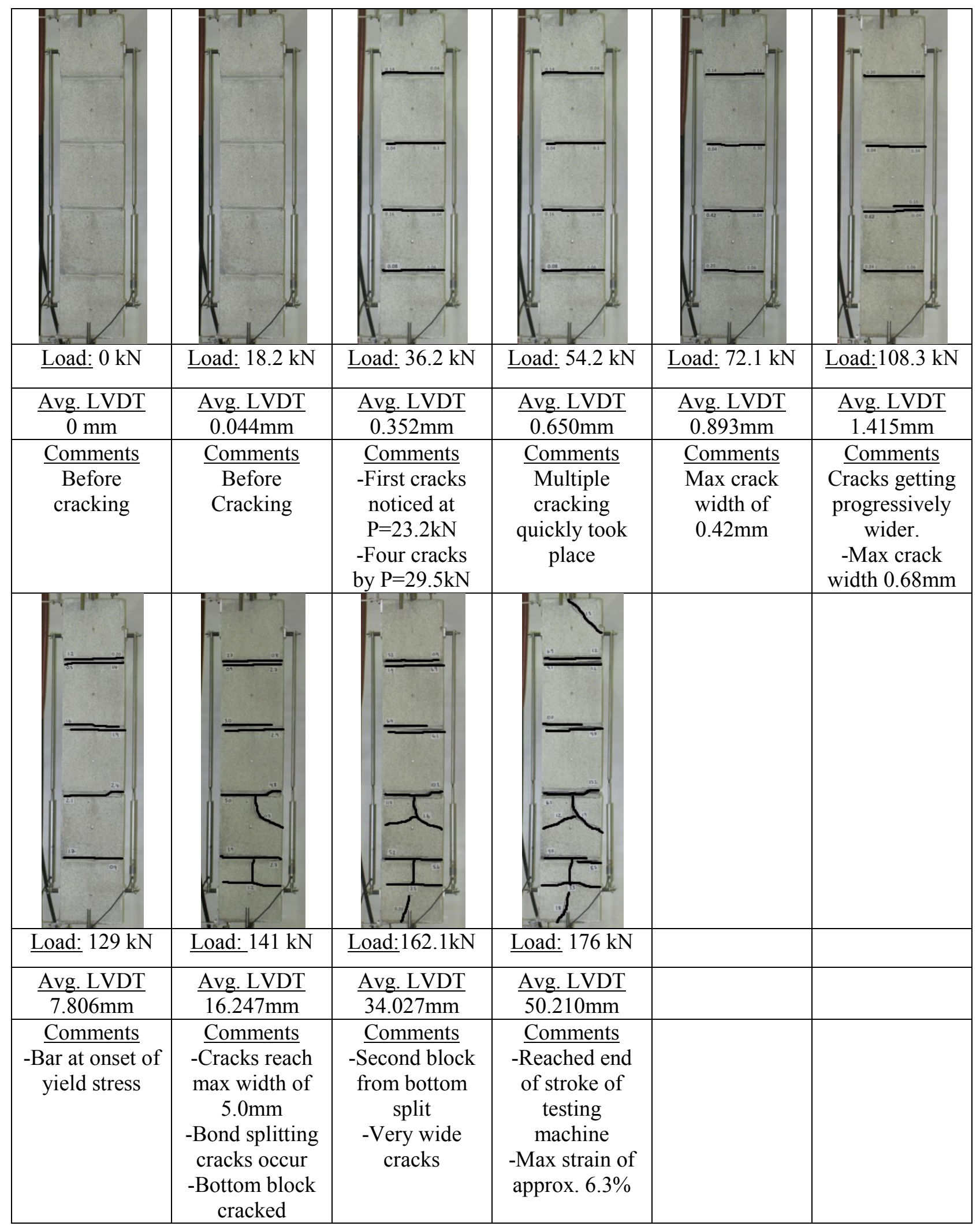




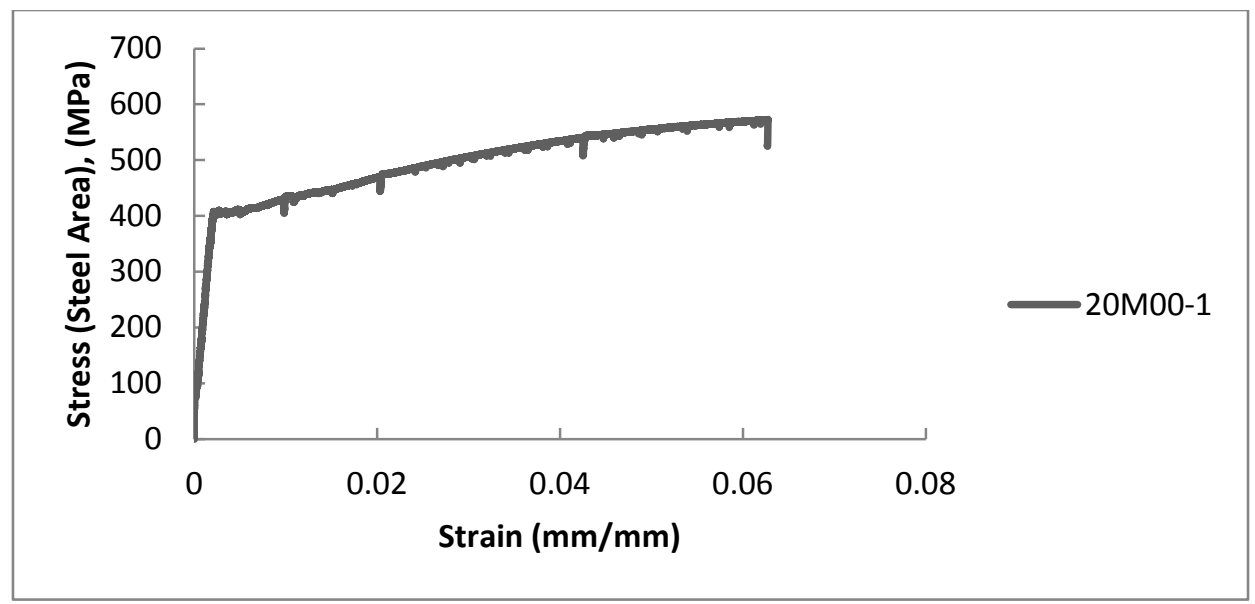

Figure 4-48: Entire stress strain response (20M00-1)

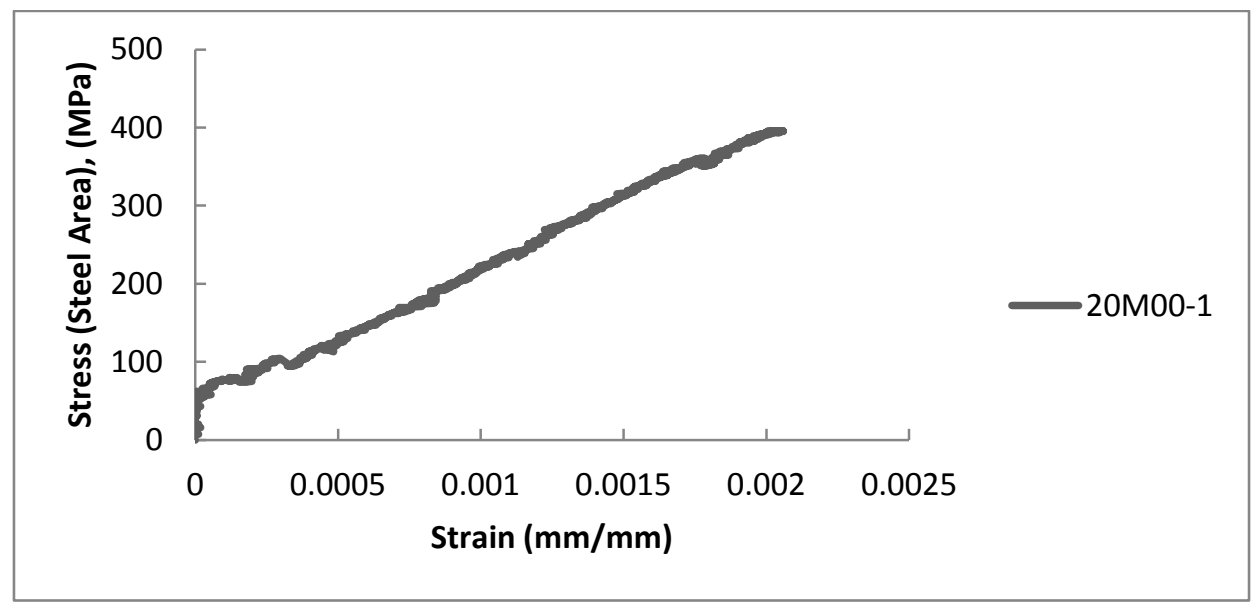

Figure 4-49: Stress strain response prior to yielding of reinforcing steel (20M00-1)

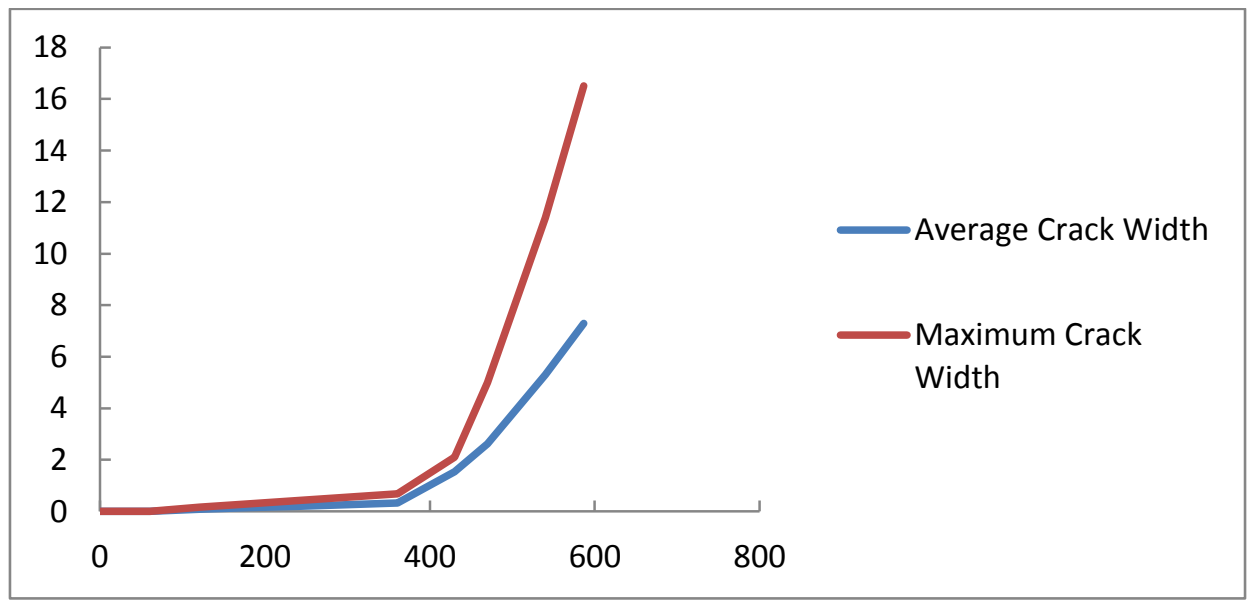

Figure 4-50: Average \& maximum crack widths (20M00-1) 


\subsubsection{Specimen 20M00-2}

This specimen was tested on September $6^{\text {th }}, 2013$ and was a duplicate specimen for 20M00-1. This specimen contained no fibres and served as a control specimen for all specimens tested in the $20 \mathrm{M}$ monotonic series.

The first cracking was observed at a load of approximately $24.2 \mathrm{kN}$ at the top mortar joint. The second mortar joint from the top cracked at a load of approximately $30 \mathrm{kN}$. All mortar joints then cracked in quick succession.

Once the reinforcing steel approached its yield stress, the crack widths increased very rapidly. Also, it was noted that the specimen tended to crack at both the top and bottom side of the mortar joints. The crack widths were observed to have the same widths on both the East and West sides of each of the faces measured. No new cracks formed until a load of approximately $142.9 \mathrm{kN}$ when bond splitting cracks near the bottom of the specimen occurred. This also led to the bottom three blocks cracking near their midpoints. Also, there was a diagonal crack in the top two blocks which was also cause by pullout of the reinforcing steel and bond splitting failure.

It should also be noted that there was a slight problem with the computer program running the data acquisition system which caused the program to crash a load of approximately $130 \mathrm{kN}$. Once the program crashed, the program was restarted under displacement control and the test continued. The data files were put together for graphing purposes.

The test was terminated when the crack widths became very wide and the overall strain over the gauge length of the LVDTs reached approximately $6.3 \%$.

Figure 4-51 shows the entire stress-strain relationship of the specimen whereas Figure 452 shows the stress-strain relationship prior to yielding. Figure 4-53 shows both the average crack width and maximum crack as a function of stress. The stress is based on the steel area of the given specimen 
Table 4-20: Test summary for specimen 20M00-2

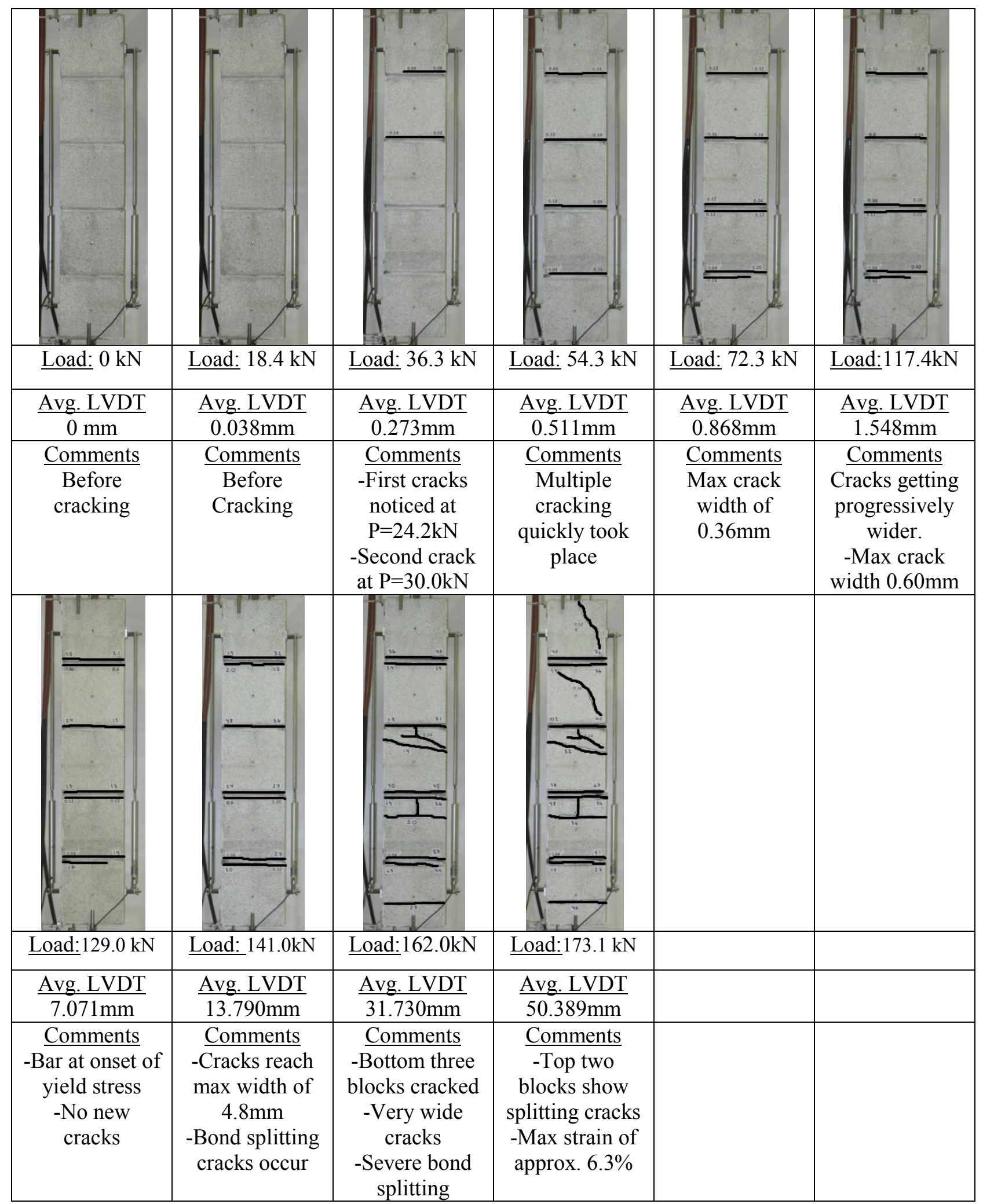




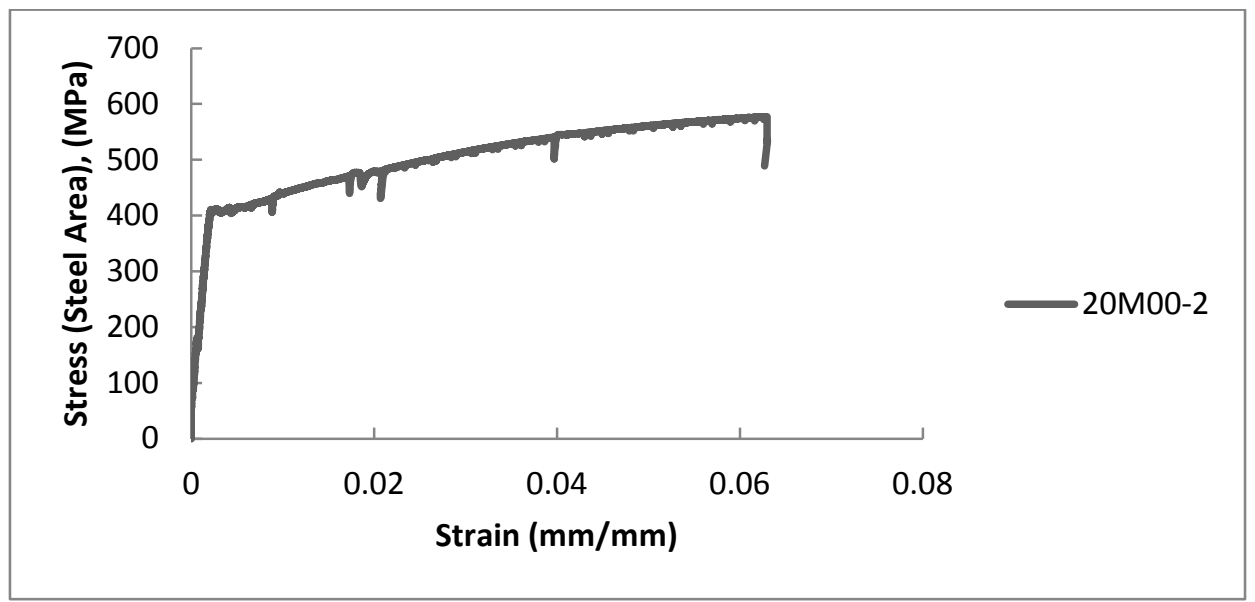

Figure 4-51: Entire stress strain response (20M00-2)

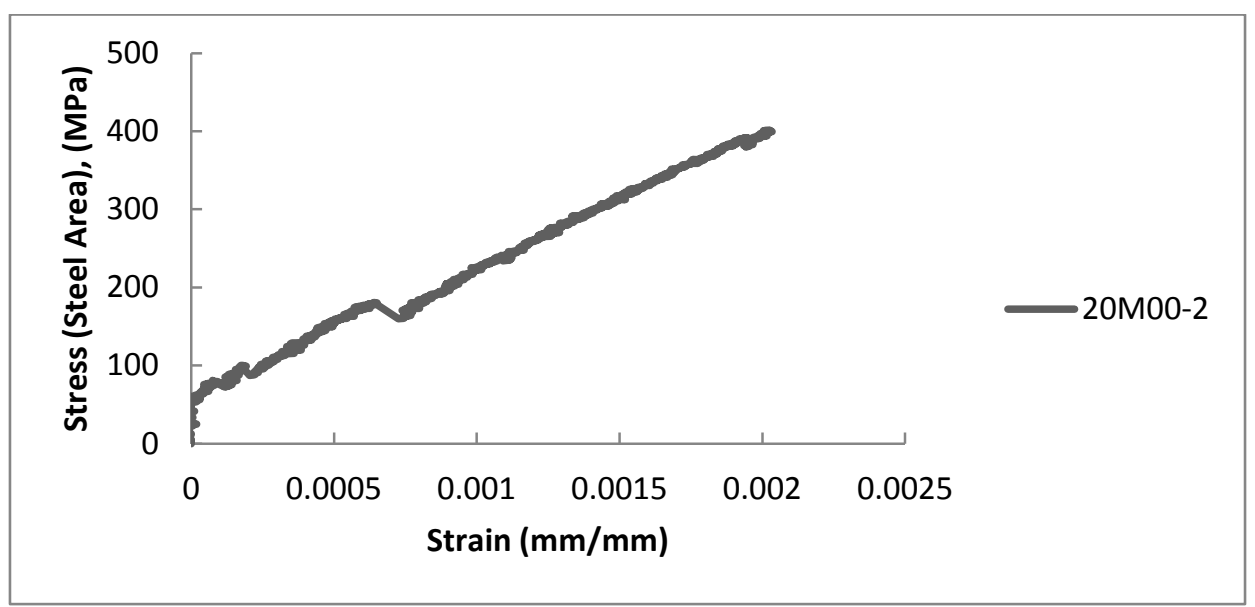

Figure 4-52: Stress strain response prior to yielding of reinforcing steel (20M00-2)

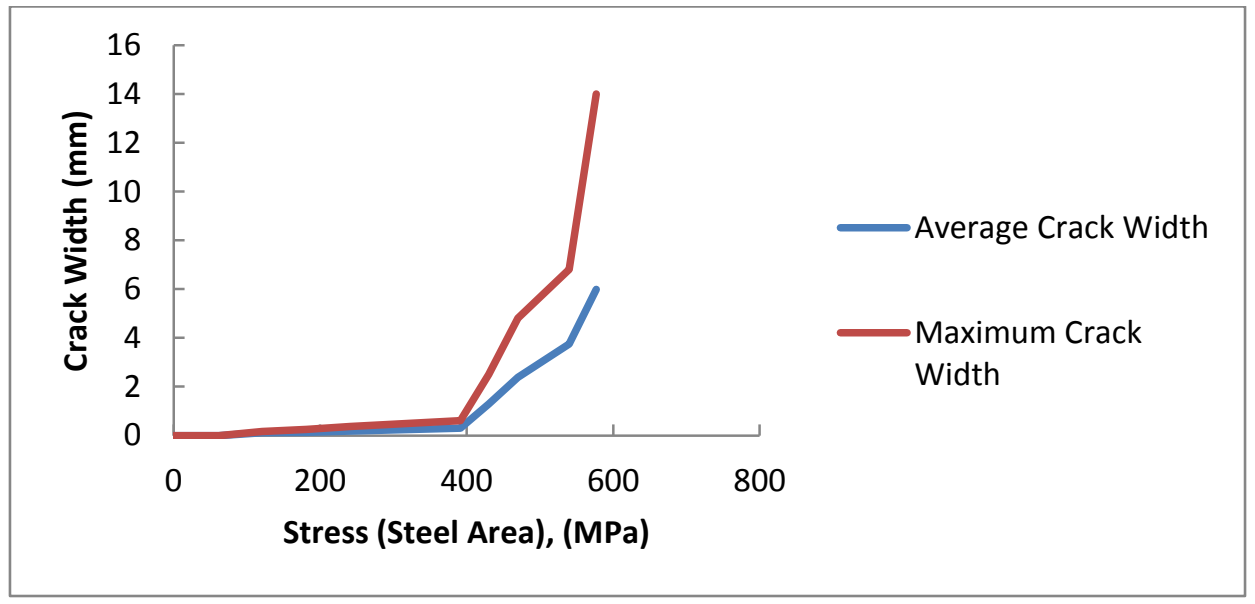

Figure 4-53: Average \& maximum crack widths (20M00-2) 


\subsubsection{Specimen 20M04S-1}

This specimen was tested on September $4^{\text {th }}, 2013$ with a duplicate specimen being tested later the same day. This specimen contained grout with $0.4 \%$ Dramix ZP305 steel fibres by volume. The influence of a minimal amount of steel fibres will be investigated with regards to its effectiveness is increasing the tension stiffening effect with $20 \mathrm{M}$ reinforcing bars.

The first cracking was observed at a load of approximately $29.3 \mathrm{kN}$ at the top mortar joint. The second mortar joint from the top cracked at a load of approximately $30.5 \mathrm{kN}$. There was also a loud cracking sound from the specimen shortly after the load was held at $54.1 \mathrm{kN}$. All mortar joints then cracked.

Once the reinforcing steel approached its yield stress, the crack widths increased rapidly. The crack widths were observed to have the same widths on both the East and West sides of each of the faces measured. No new cracks formed until a load of approximately $137 \mathrm{kN}$ when the first crack through the block occurred. With additional loading, each of the blocks cracked near their respective centres. Some of the cracks were almost perfectly perpendicular to the direction of the applied load and others were more diagonal. It is thought that the diagonal cracks are partly due to bond cracking which is occurring on the inside of the specimen. By the final load stage there were approximately 10 cracks, ranging in directions as mentioned above.

The test was terminated when the crack widths became very wide and the overall strain over the gauge length of the LVDTs reached approximately $6.3 \%$.

Figure 4-54 shows the entire stress-strain relationship of the specimen whereas Figure 455 shows the stress-strain relationship prior to yielding. Figure 4-56 shows both the average crack width and maximum crack as a function of stress. The stress is based on the steel area of the given specimen 
Table 4-21: Test summary for specimen 20M04S-1

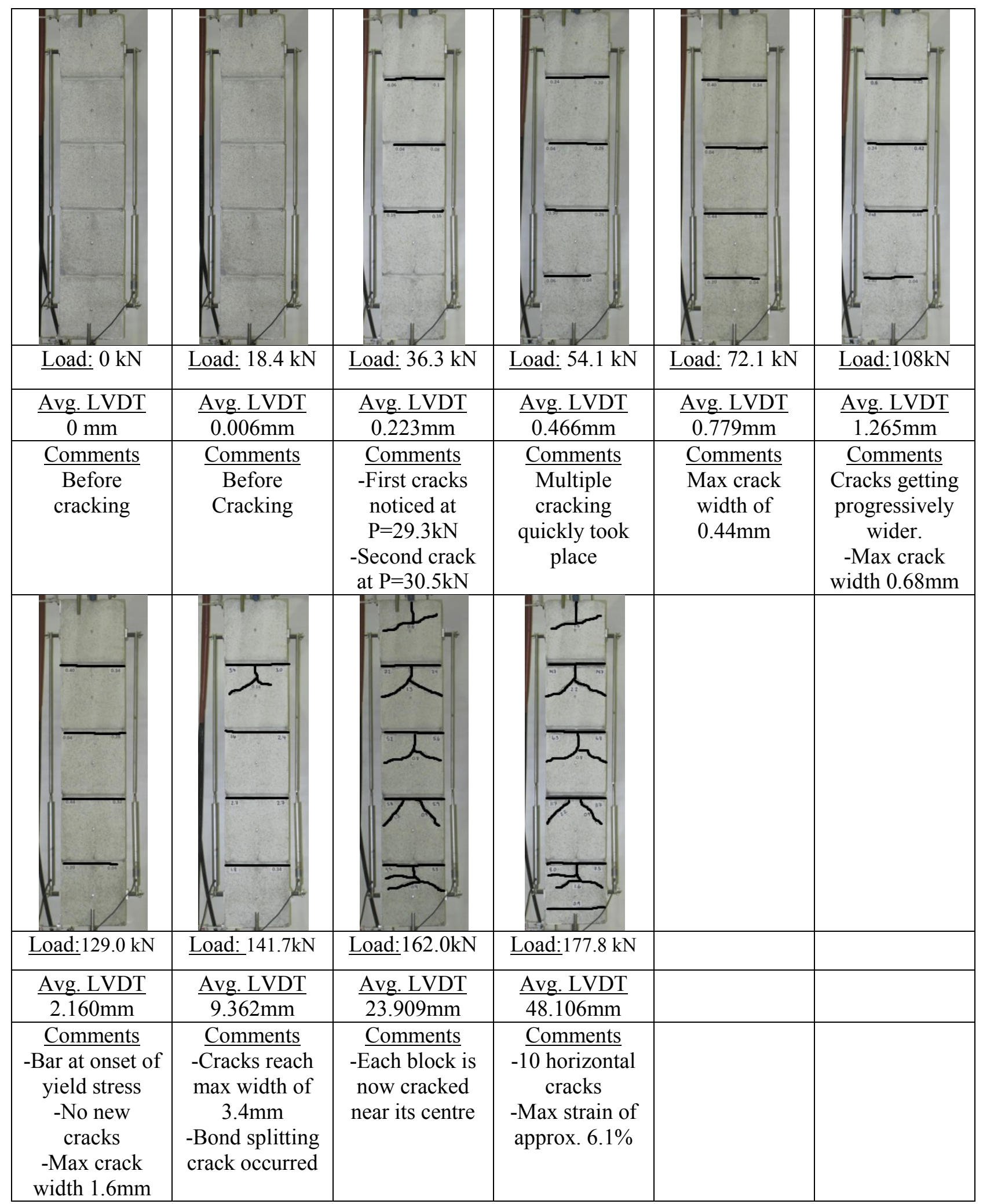




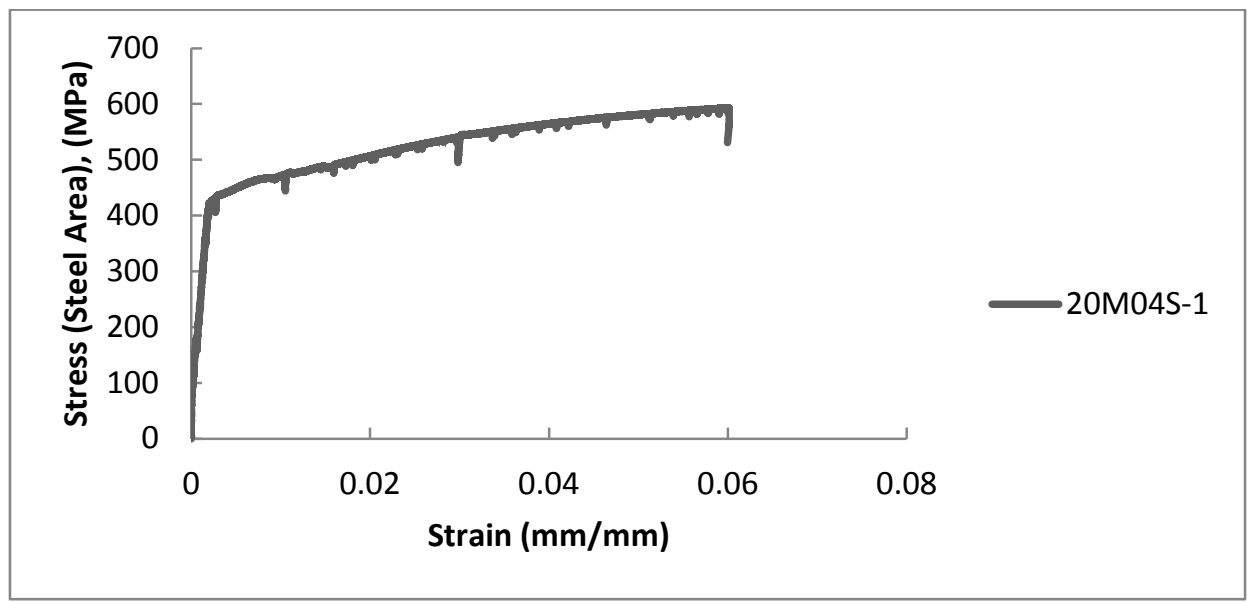

Figure 4-54: Entire stress strain response (20M04S-1)

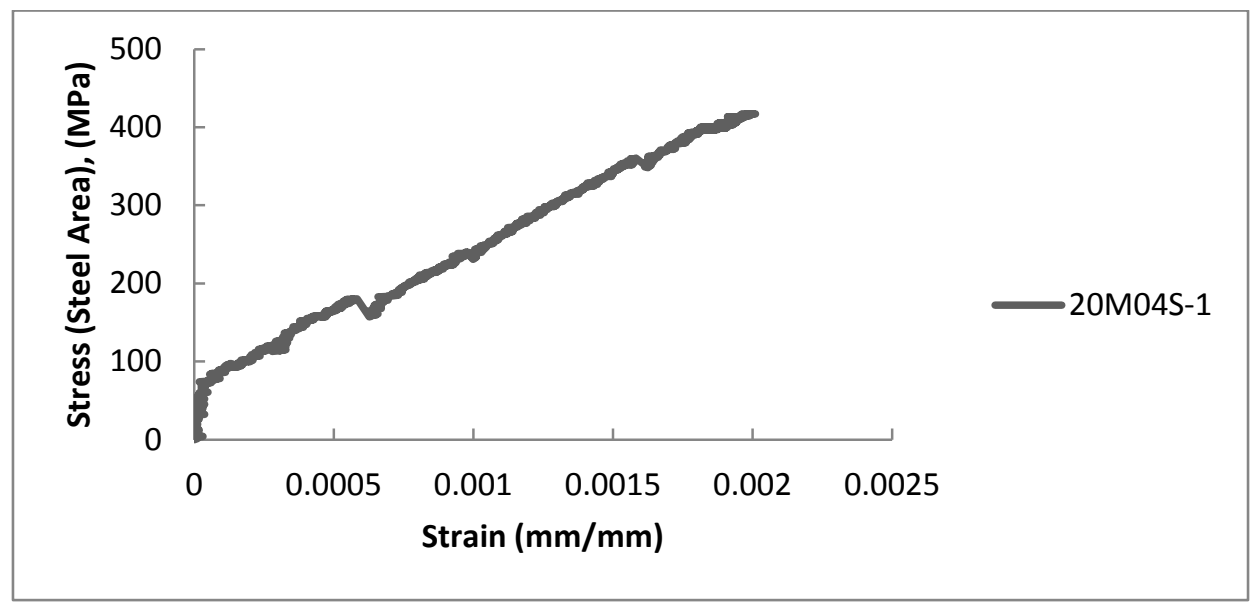

Figure 4-55: Stress strain response prior to yielding of reinforcing steel (20M04S-1)

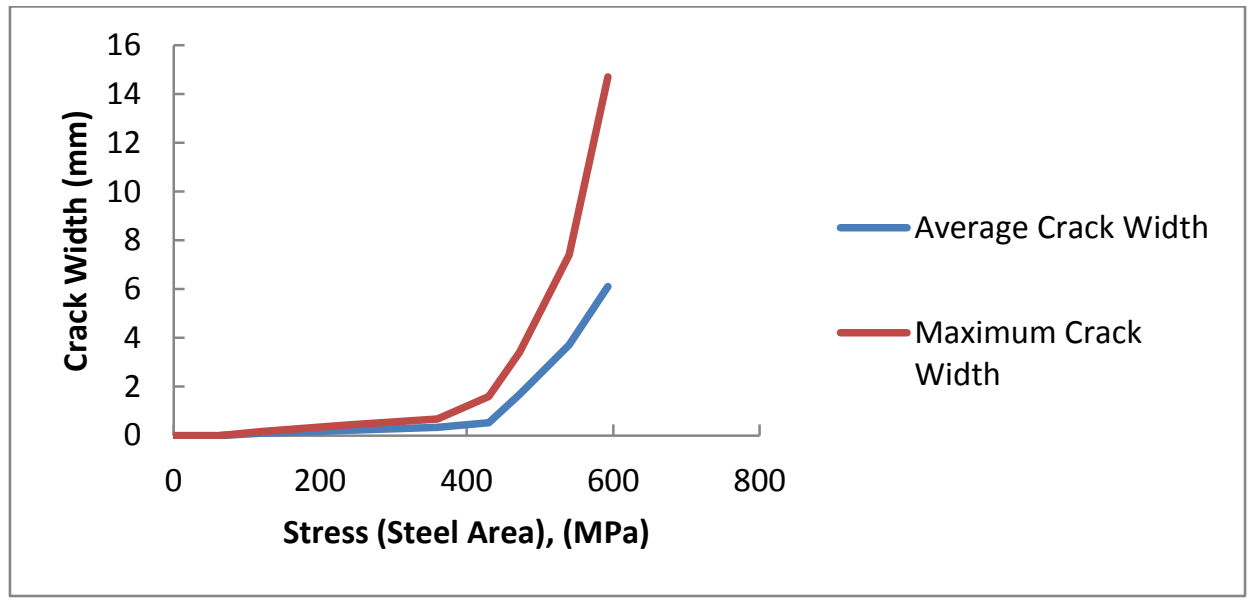

Figure 4-56: Average \& maximum crack widths (20M04S-1) 


\subsubsection{Specimen 20M04S-2}

This specimen was tested on September $4^{\text {th }}, 2013$ and was the duplicate specimen for 20M04S-1. This specimen contained grout with 0.4\% Dramix ZP305 steel fibres by volume. The influence of a minimal amount of steel fibres will be investigated with regards to its effectiveness is increasing the tension stiffening effect with $20 \mathrm{M}$ reinforcing bars.

The first cracking was observed at a load of approximately $28.3 \mathrm{kN}$ at the top mortar joint. The second mortar joint from the top cracked at a load of approximately $32.7 \mathrm{kN}$. All mortar joints were cracked before the load stage taken at $54.1 \mathrm{kN}$.

Once the reinforcing steel approached its yield stress, the crack widths increased rapidly. The crack widths were observed to be of different widths on the East and West sides of the specimen respectively. With additional loading, each of the blocks cracked near their respective centres. All of the cracks were almost perfectly perpendicular to the direction of the applied load and others were more diagonal. By the final load stage there were approximately 11 cracks, primarily in the directions mentioned above. It should also be noted that there was no noticeable drop in load as the crack pattern progressed after a load of $130 \mathrm{kN}$. This gradual cracking is due to the contribution of the fibres.

There was a hydraulic system failure at a load of approximately $145 \mathrm{kN}$ and another pump failure when the load was approximately $162 \mathrm{kN}$. At the occurrence of each pump failure, the load was dropped to zero, the data acquisition system restarted and the loading recommenced. The data files were combined for the graphing of typical responses.

The test was terminated when the crack widths became very wide and the overall strain over the gauge length of the LVDTs reached approximately $6.1 \%$.

Figure 4-57 shows the entire stress-strain relationship of the specimen whereas Figure 458 shows the stress-strain relationship prior to yielding. Figure 4-59 shows both the average crack width and maximum crack as a function of stress. The stress is based on the steel area of the given specimen. 
Table 4-22: Test summary for specimen 20M04S-2

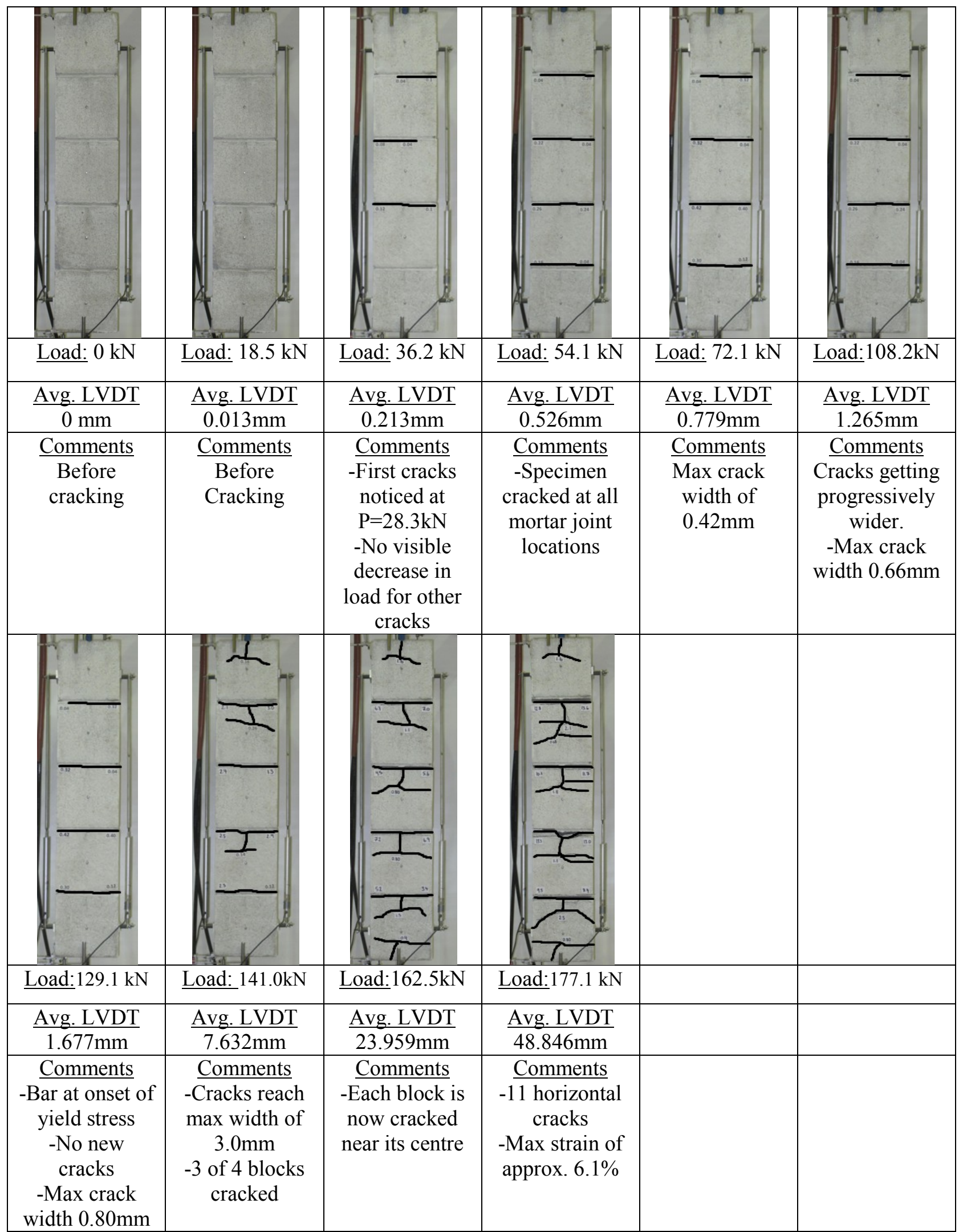




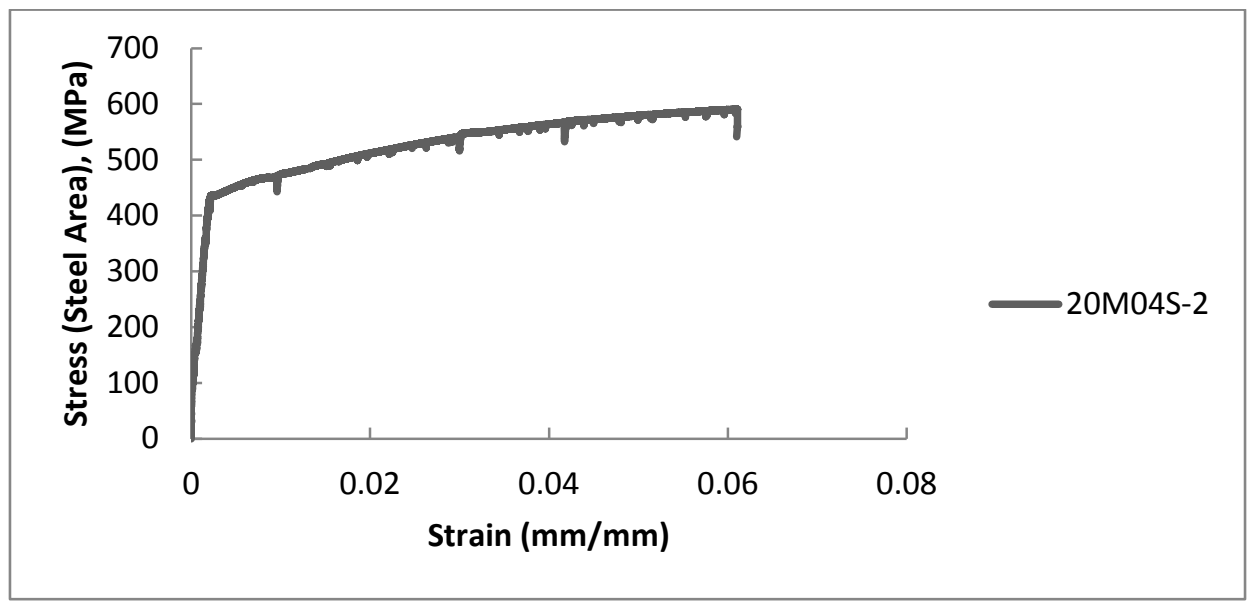

Figure 4-57: Entire stress strain response (20M04S-2)

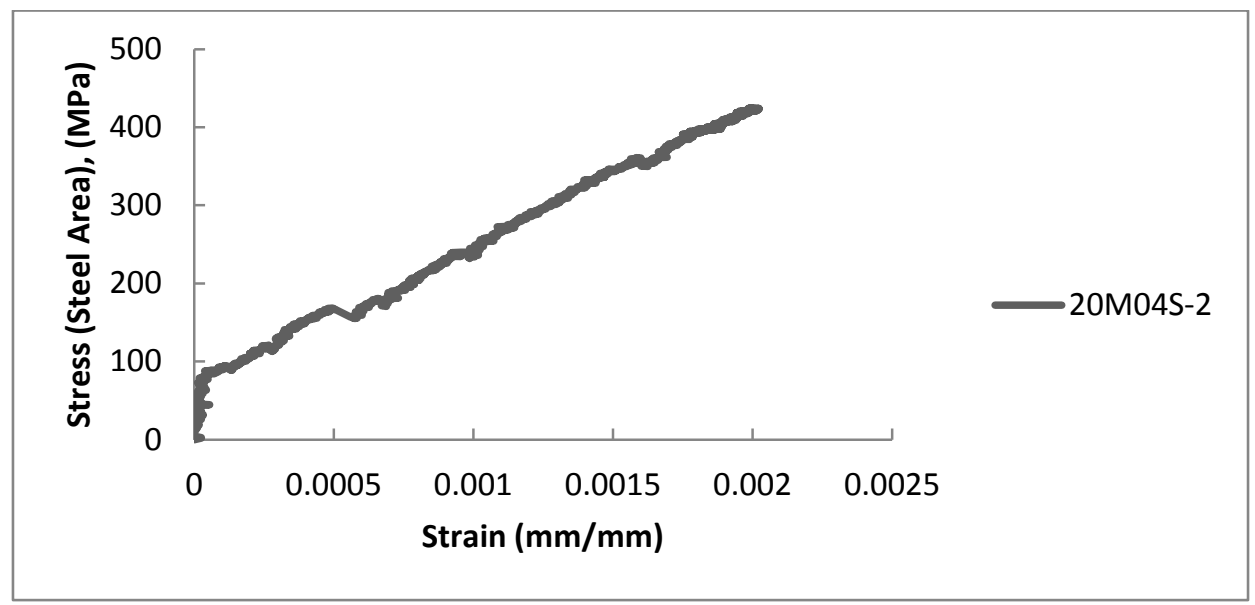

Figure 4-58: Stress strain response prior to yielding of reinforcing steel (20M04S-2)

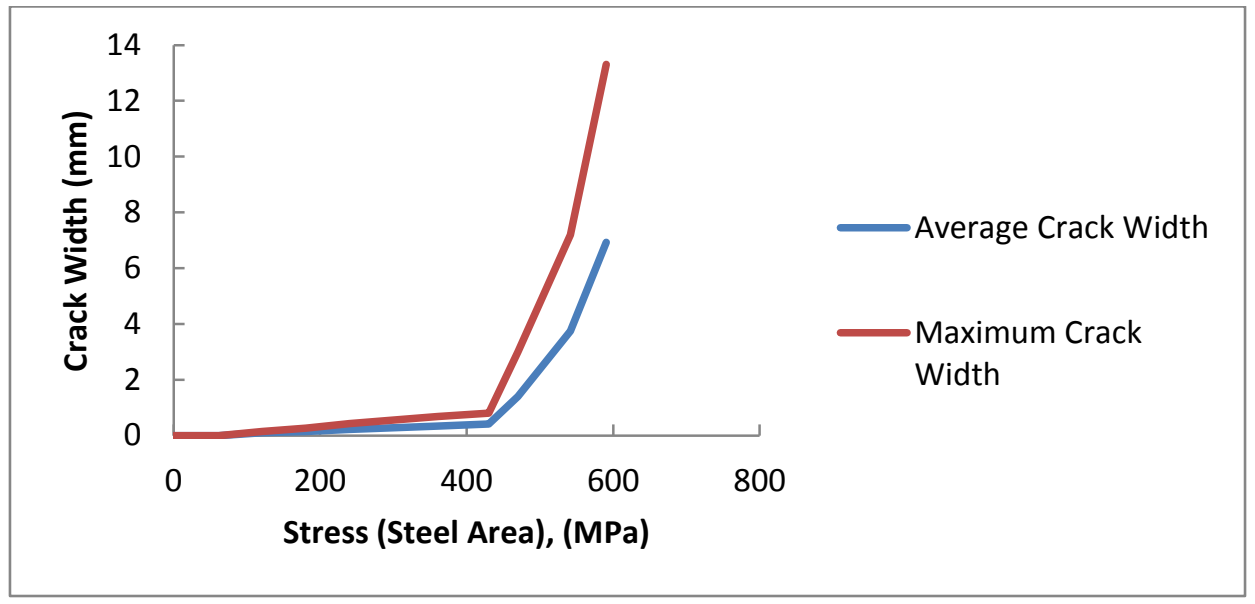

Figure 4-59: Average \& maximum crack widths (20M04S-2) 


\subsubsection{Specimen 20M08S-1}

This specimen was tested on September $6^{\text {th }}, 2013$ its duplicate specimen was tested on September $9^{\text {th }}, 2013$. This specimen contained grout with $0.8 \%$ Dramix ZP305 steel fibres by volume. The influence of a significant amount of steel fibres will be investigated with regards to its effectiveness in increasing the tension stiffening effect with $20 \mathrm{M}$ reinforcing bars.

The exact load at first cracking could not be observed due to the fact that the load didn't drop when the cracking occurred. All mortar joints were cracked before by the load stage taken at $72.3 \mathrm{kN}$, however not every crack extended the full width of the specimen.

Once the reinforcing steel approached its yield stress, the crack widths increased, however not very rapidly. The crack widths were observed to be of different widths on the East and West sides of the specimen respectively. With additional loading, each of the blocks cracked near their respective centres. All of the cracks were almost perfectly perpendicular to the direction of the applied load. By the final load stage there were approximately 12 cracks, primarily in the directions mentioned above. It should also be noted that there was no noticeable drop in load as the crack pattern progressed after a load of $130 \mathrm{kN}$. This gradual cracking is due to the contribution of the fibres.

The test was terminated when the crack widths became very wide and the overall strain over the gauge length of the LVDTs reached approximately $6.3 \%$.

Figure 4-60 shows the entire stress-strain relationship of the specimen whereas Figure 461 shows the stress-strain relationship prior to yielding. Figure 4-62 shows both the average crack width and maximum crack as a function of stress. The stress is based on the steel area of the given specimen 
Table 4-23: Test summary for specimen 20M08S-1

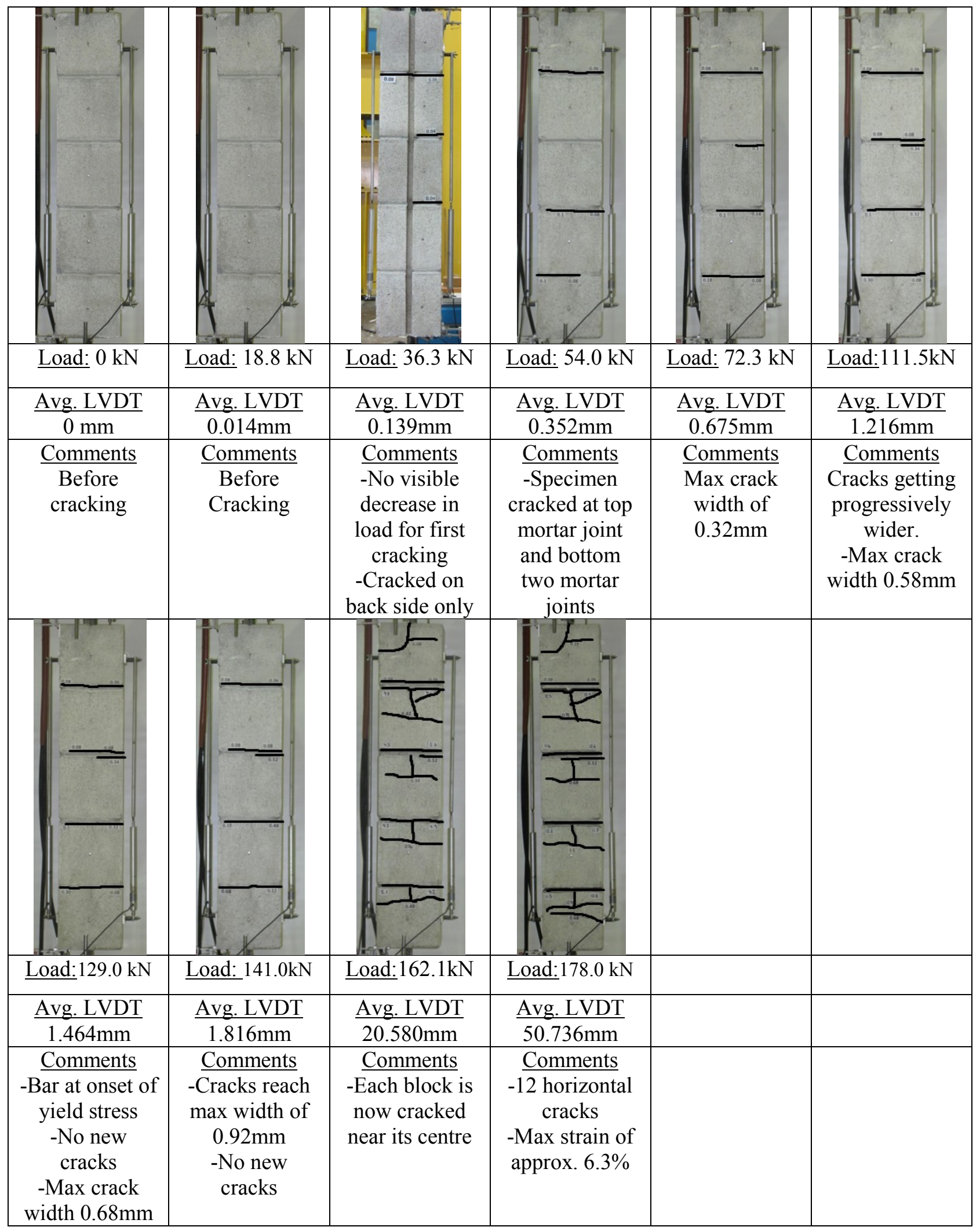




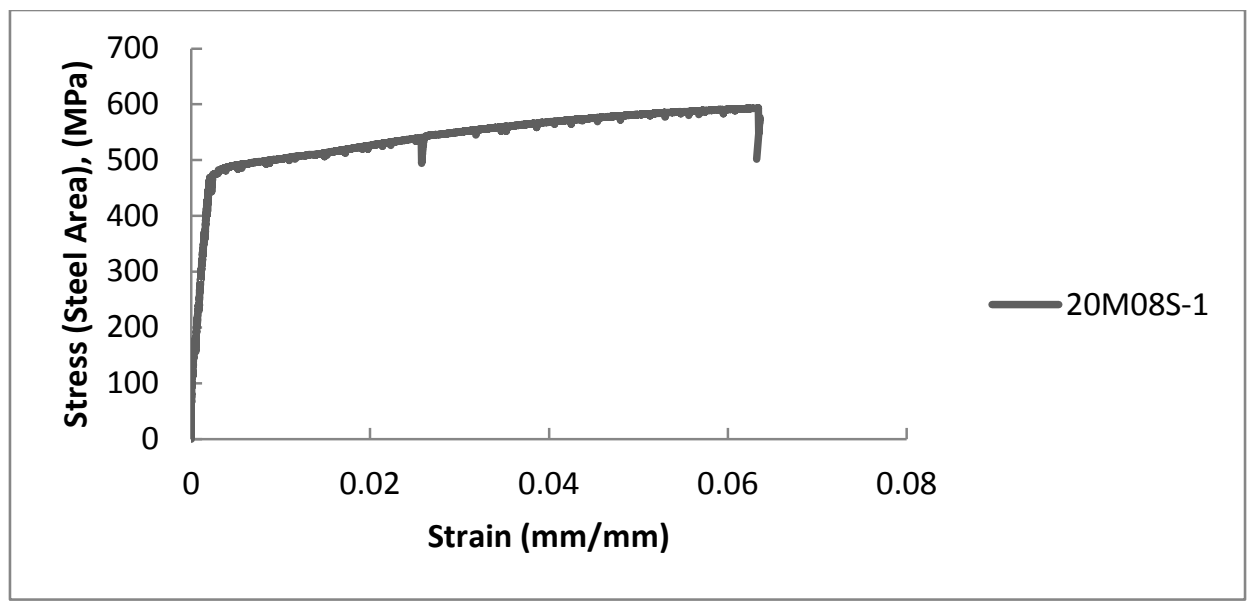

Figure 4-60: Entire stress strain response (20M08S-1)

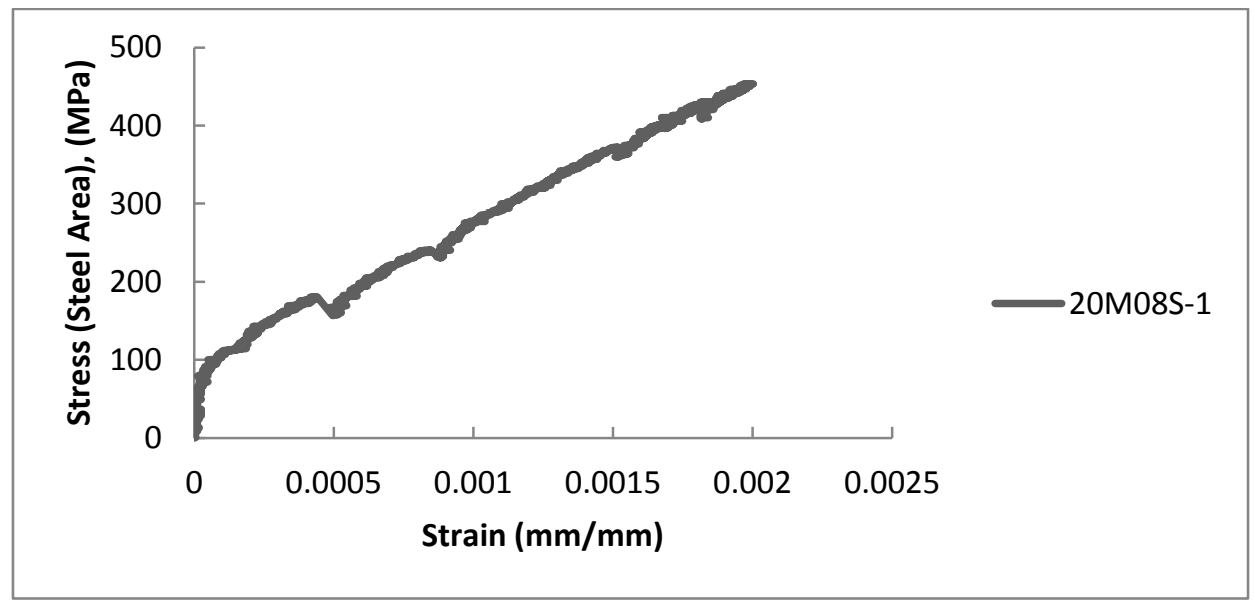

Figure 4-61: Stress strain response prior to yielding of reinforcing steel (20M08S-1)

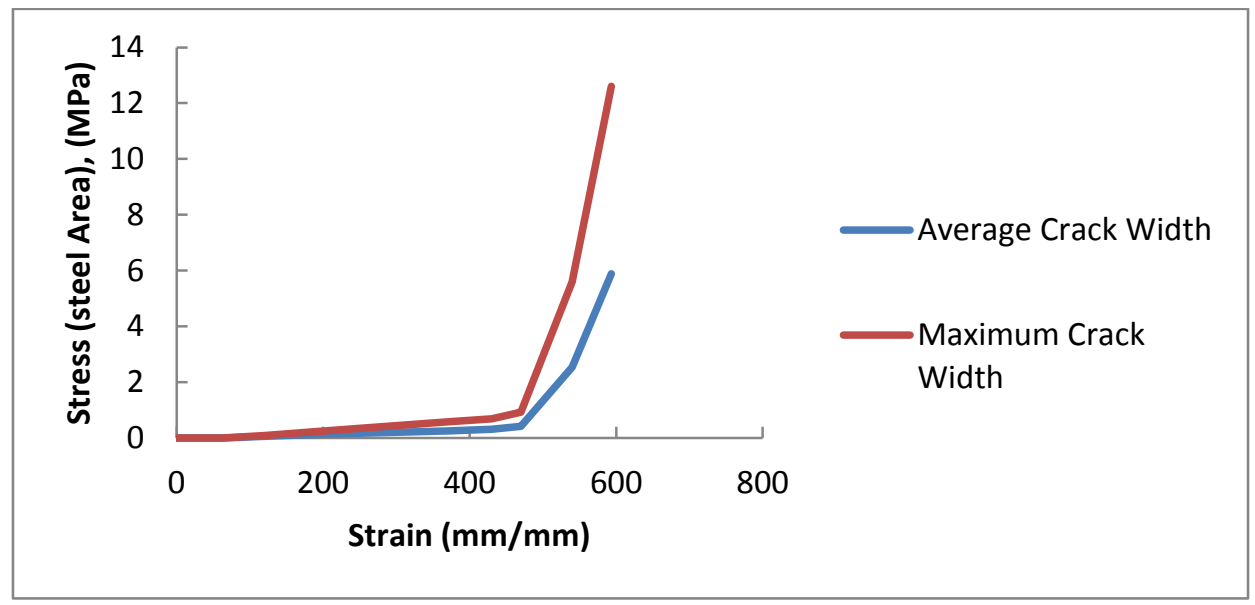

Figure 4-62: Average \& maximum crack widths (20M08S-1) 


\subsubsection{Specimen 20M08S-2}

This specimen was tested on September $9^{\text {th }}, 2013$ and served as a duplicate specimen for 20M08S-1. This specimen contained grout with 0.8\% Dramix ZP305 steel fibres by volume. The influence of a significant amount of steel fibres will be investigated with regards to its effectiveness in increasing the tension stiffening effect with $20 \mathrm{M}$ reinforcing bars.

The exact load at first cracking could not be observed due to the fact that the load didn't drop when the cracking occurred. All mortar joints were cracked before by the load stage taken at $162.1 \mathrm{kN}$, however not every crack extended the full width of the specimen.

Once the reinforcing steel approached its yield stress, the crack widths increased, however not very rapidly. The crack widths were observed to be of different widths on the East and West sides of the specimen respectively. With additional loading, each of the blocks cracked near their respective centres. All of the cracks were almost perfectly perpendicular to the direction of the applied load. By the final load stage there were approximately 12 cracks, primarily in the directions mentioned above. It should also be noted that there was no noticeable drop in load as the crack pattern progressed after a load of $130 \mathrm{kN}$. This gradual cracking is due to the contribution of the fibres. An increased amount of load was able to be resisted due to the contribution to the steel fibres to resist axial load.

The test was terminated when the crack widths became very wide and the overall strain over the gauge length of the LVDTs reached approximately $6.3 \%$.

Figure 4-63 shows the entire stress-strain relationship of the specimen whereas Figure 464 shows the stress-strain relationship prior to yielding. Figure 4-65 shows both the average crack width and maximum crack as a function of stress. The stress is based on the steel area of the given specimen 
Table 4-24: Test summary for specimen 20M08S-2

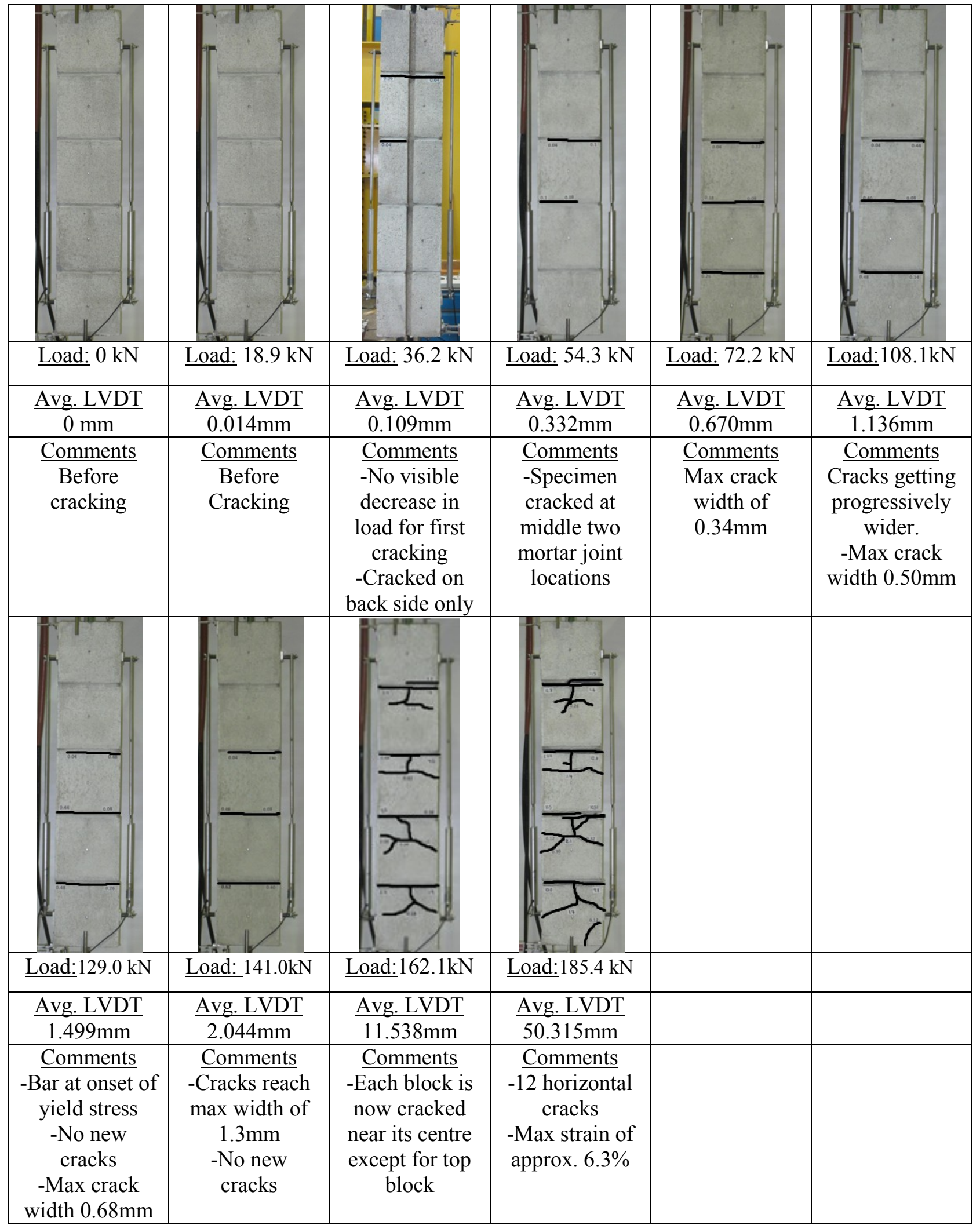




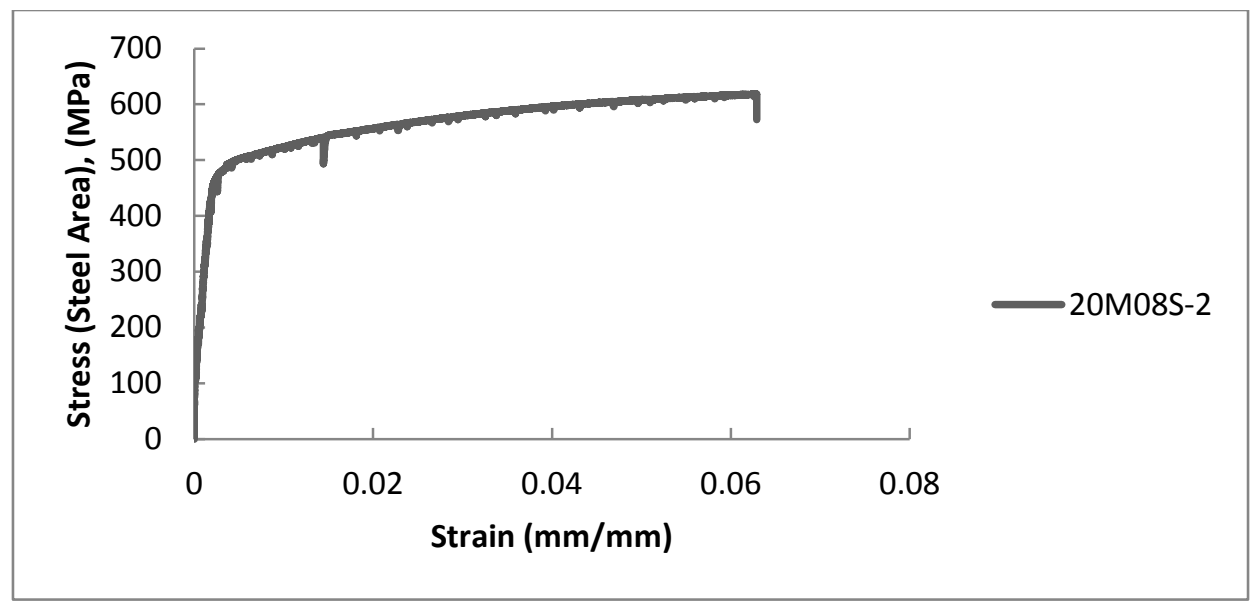

Figure 4-63: Entire stress strain response (20M08S-2)

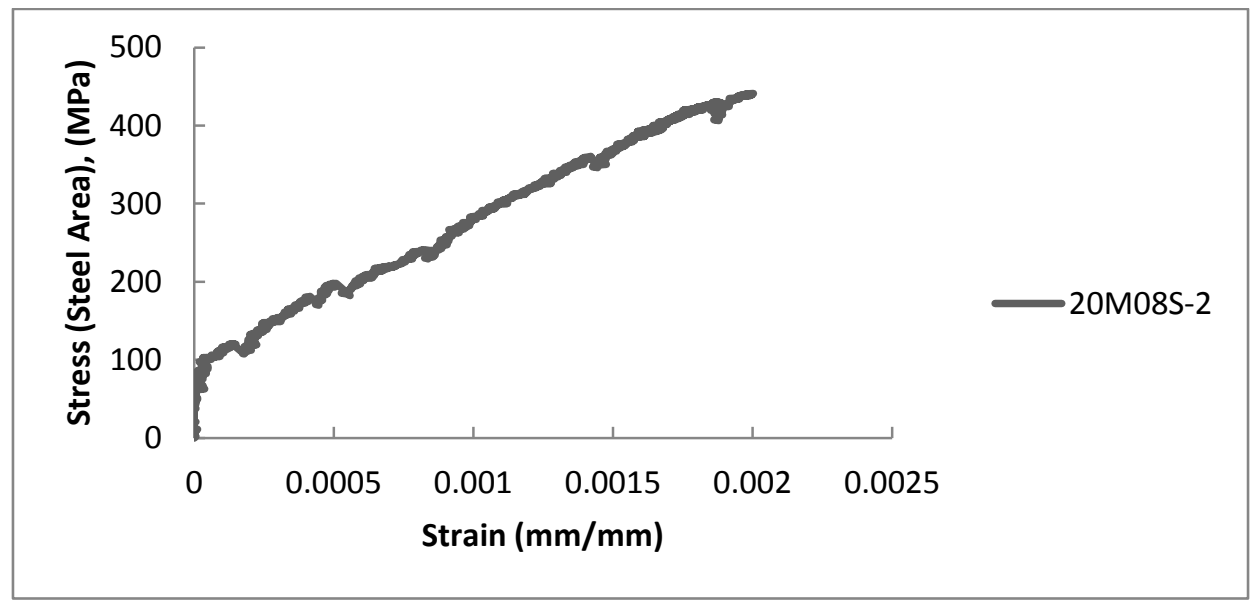

Figure 4-64: Stress strain response prior to yielding of reinforcing steel (20M08S-2)

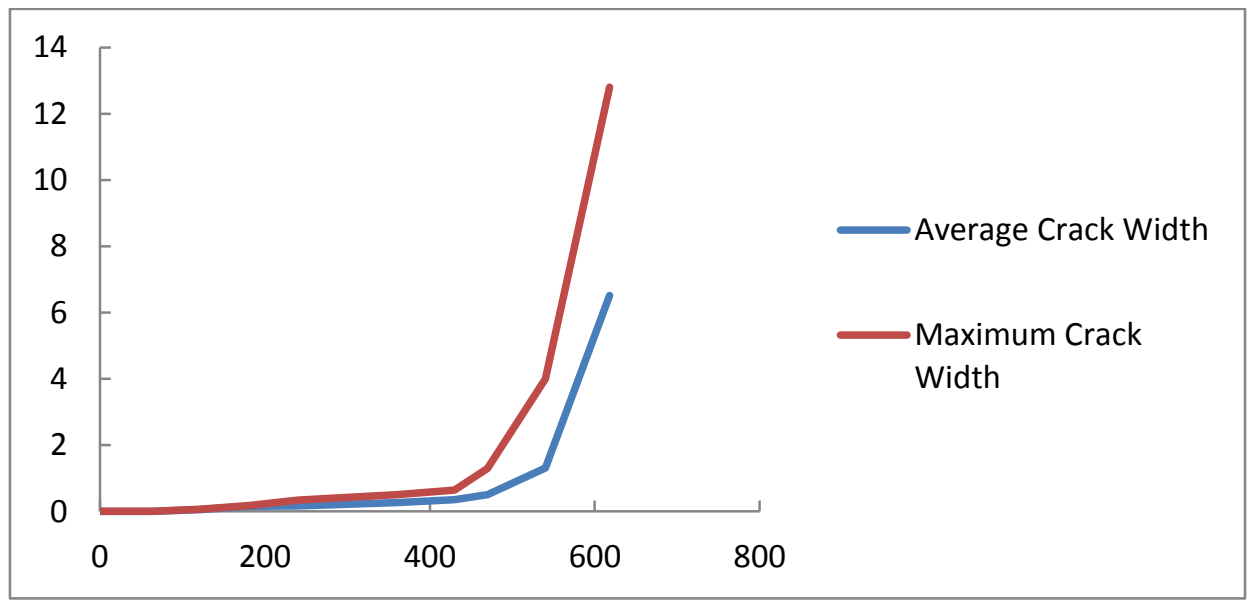

Figure 4-65: Average \& maximum crack widths (20M08S-2) 


\subsubsection{Specimen 20M12S-1}

This specimen was tested on September $10^{\text {th }}, 2013$ with its duplicate specimen being tested later the same day. This specimen contained grout with 1.2\% Dramix ZP305 steel fibres by volume. The influence of a theoretical maximum amount of steel fibres will be investigated with regards to its effectiveness in increasing the tension stiffening effect with $20 \mathrm{M}$ reinforcing bars.

The exact load at first cracking could not be observed due to the fact that the load didn't drop when the cracking occurred. All mortar joints were cracked before by the load stage taken at $72.3 \mathrm{kN}$, however not every crack extended the full width of the specimen. The cracking pattern did not change much until the load reached approximately $150 \mathrm{kN}$, which is well out of the service range of the specimen.

Once the reinforcing steel approached its yield stress, the crack widths increased, however not very rapidly. The crack widths were observed to be of different widths on the East and West sides of the specimen respectively. With additional loading, two of the blocks cracked near their respective centres. All of the cracks were almost perfectly perpendicular to the direction of the applied load. By the final load stage there were approximately 9 cracks, primarily in the directions mentioned above. The specimen showed signs of significant tension stiffening near the middle of the specimen. It should also be noted that there was no noticeable drop in load as the crack pattern progressed after a load of $130 \mathrm{kN}$. This gradual cracking is due to the contribution of the fibres. An increased amount of load was able to be resisted due to the contribution to the steel fibres to resist axial load.

The test was terminated when the crack widths became very wide and the overall strain over the gauge length of the LVDTs reached approximately $6.3 \%$.

Figure 4-66 shows the entire stress-strain relationship of the specimen whereas Figure 467 shows the stress-strain relationship prior to yielding. Figure 4-68 shows both the average crack width and maximum crack as a function of stress. The stress is based on the steel area of the given specimen 
Table 4-25: Test summary for specimen 20M12S-1

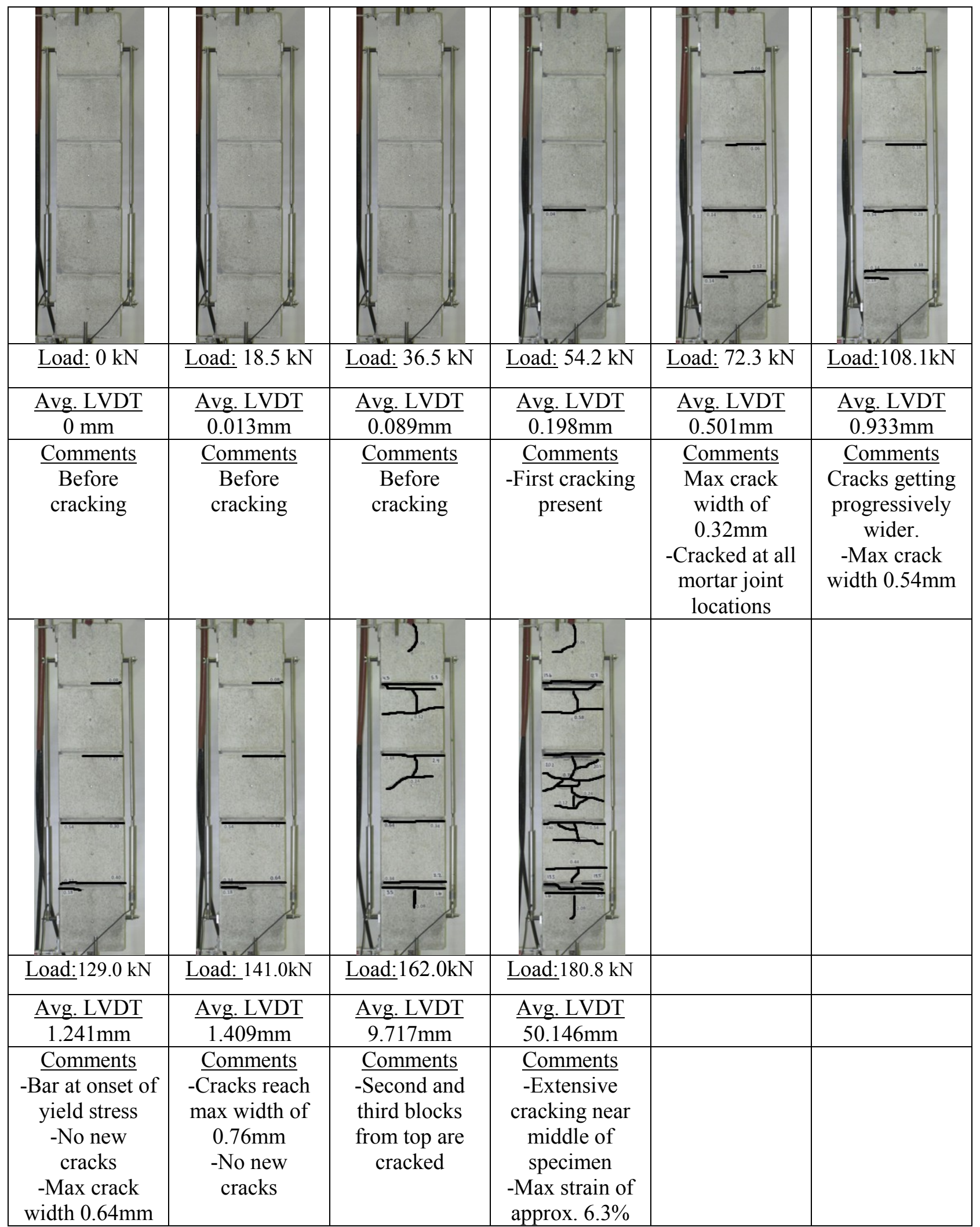




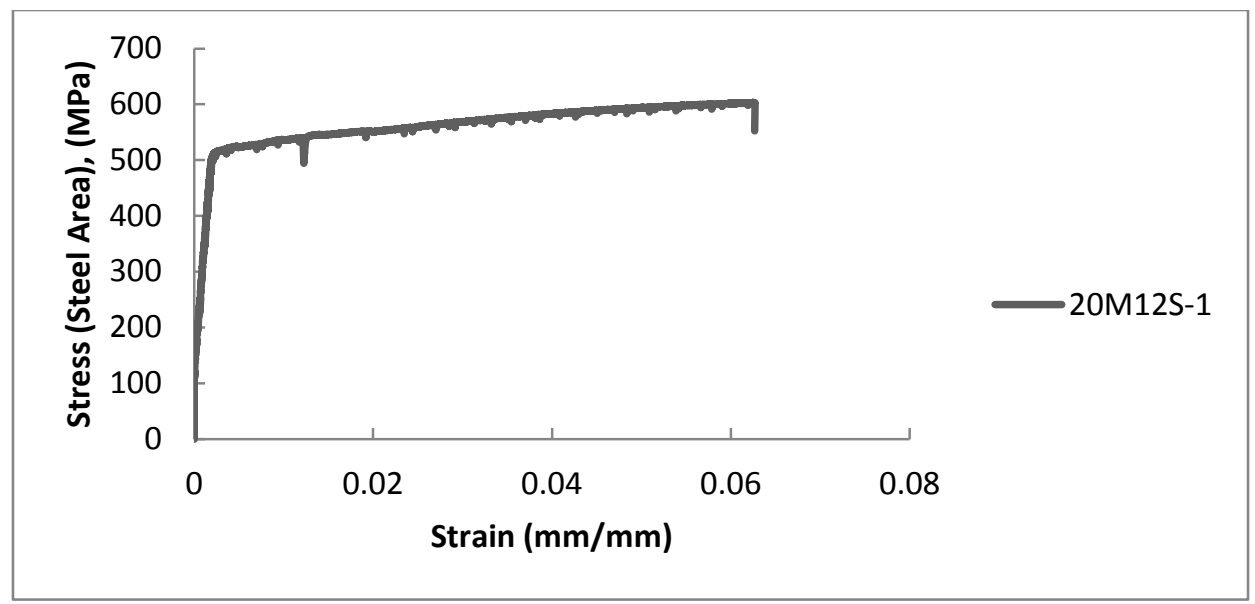

Figure 4-66: Entire stress strain response (20M12S-1)

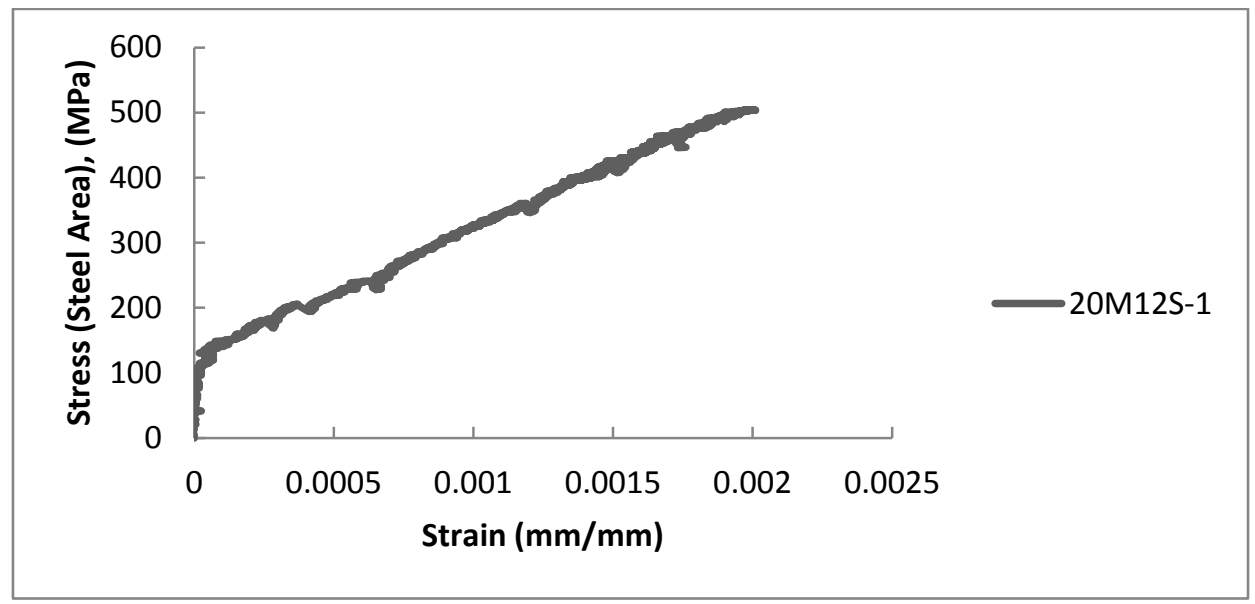

Figure 4-67: Stress strain response prior to yielding of reinforcing steel (20M12S-1)

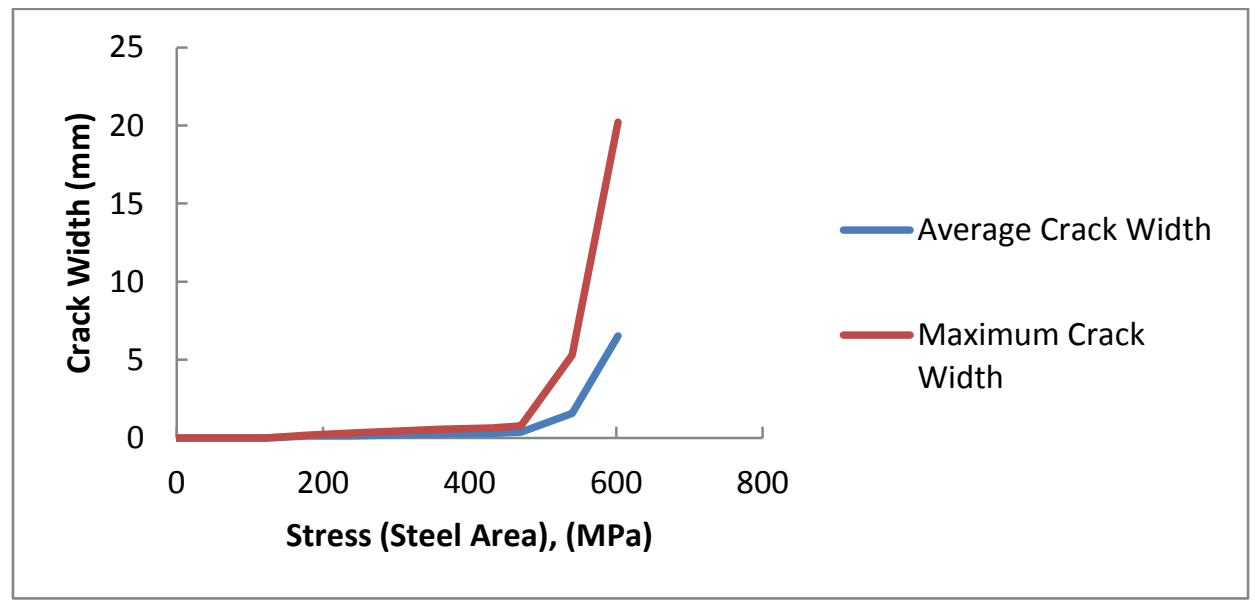

Figure 4-68: Average \& maximum crack widths (20M12S-1) 


\subsubsection{Specimen 20M12S-2}

This specimen was tested on September $10^{\text {th }}, 2013$ and served as a duplicate specimen for 20M12S-1. This specimen contained grout with 1.2\% Dramix ZP305 steel fibres by volume. The influence of a theoretical maximum amount of steel fibres will be investigated with regards to its effectiveness in increasing the tension stiffening effect with $20 \mathrm{M}$ reinforcing bars.

The exact load at first cracking could not be observed due to the fact that the load didn't drop when the cracking occurred. At a load stage taken at $36.3 \mathrm{kN}$, the first crack was present on the back side of the specimen. Cracks were very slow to progress and not every crack extended the full width of the specimen. The cracking pattern did not change much until the load reached approximately $150 \mathrm{kN}$, which is well out of the service range of the specimen.

Once the reinforcing steel approached its yield stress, the crack widths increased, however not very rapidly. The crack widths were observed to be of different widths on the East and West sides of the specimen respectively. With additional loading, the bottom four blocks cracked near their respective centres. All of the cracks were almost perfectly perpendicular to the direction of the applied load. By the final load stage there were approximately 10 cracks, primarily in the directions mentioned above. The specimen showed signs of significant tension stiffening near the middle of the specimen as the cracks were very closely spaced. It should also be noted that there was no noticeable drop in load as the crack pattern progressed after a load of $130 \mathrm{kN}$, despite significant increases in the cracking. This gradual cracking is due to the contribution of the fibres. An increased amount of load was able to be resisted due to the contribution to the steel fibres to resist axial load.

The test was terminated when the crack widths became very wide and the overall strain over the gauge length of the LVDTs reached approximately $6.3 \%$.

Figure 4-69 shows the entire stress-strain relationship of the specimen whereas Figure 470 shows the stress-strain relationship prior to yielding. Figure 4-70 shows both the average crack width and maximum crack as a function of stress. The stress is based on the steel area of the given specimen. 
Table 4-26: Test summary for specimen 20M12S-2

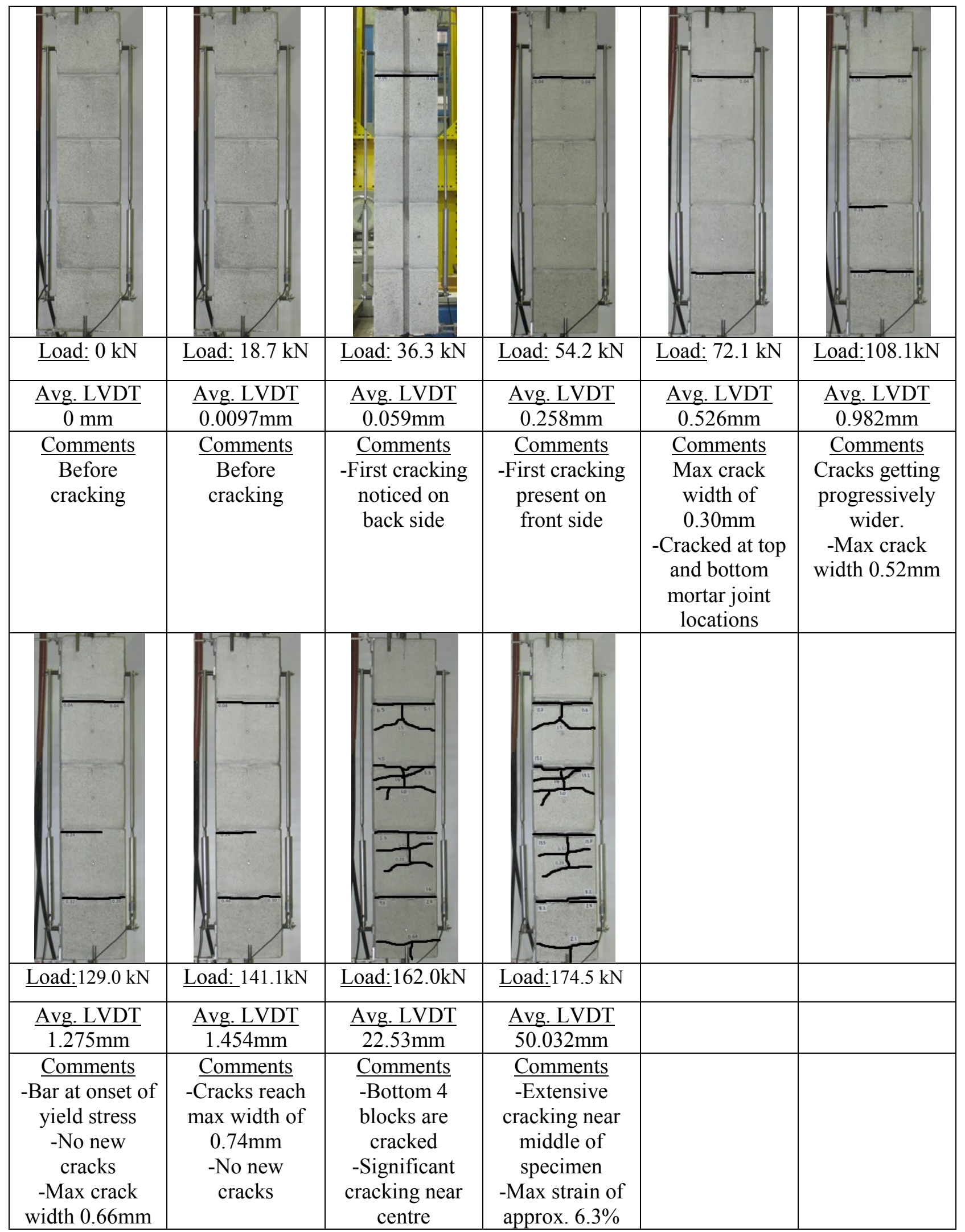




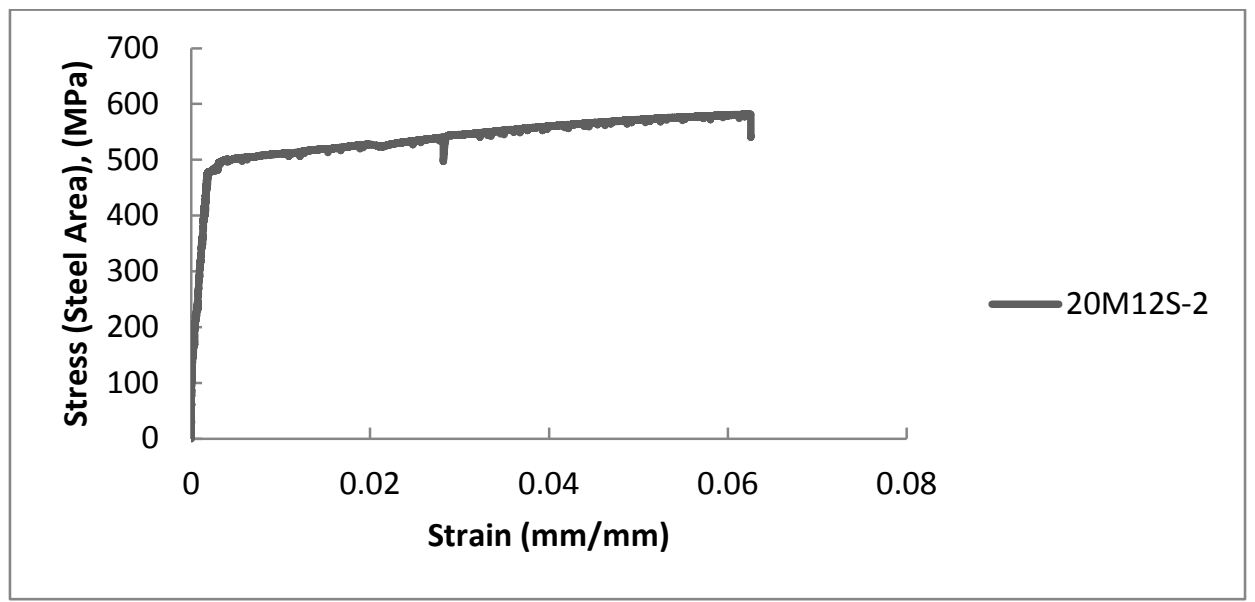

Figure 4-69: Entire stress strain response (20M12S-2)

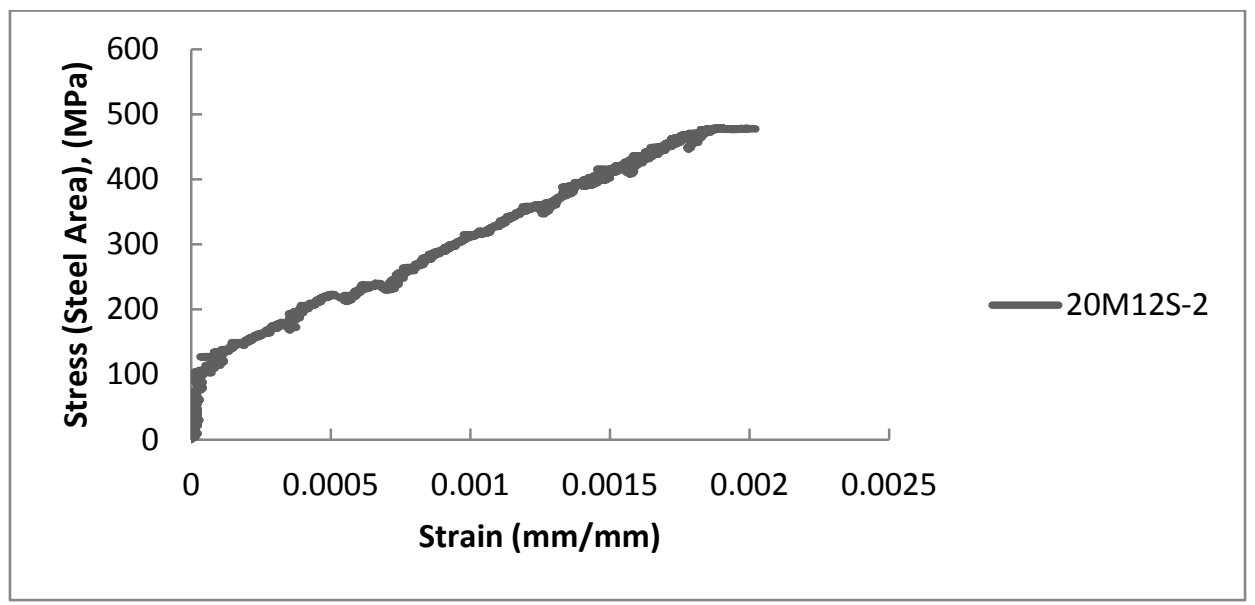

Figure 4-70: Stress strain response prior to yielding of reinforcing steel (20M12S-2)

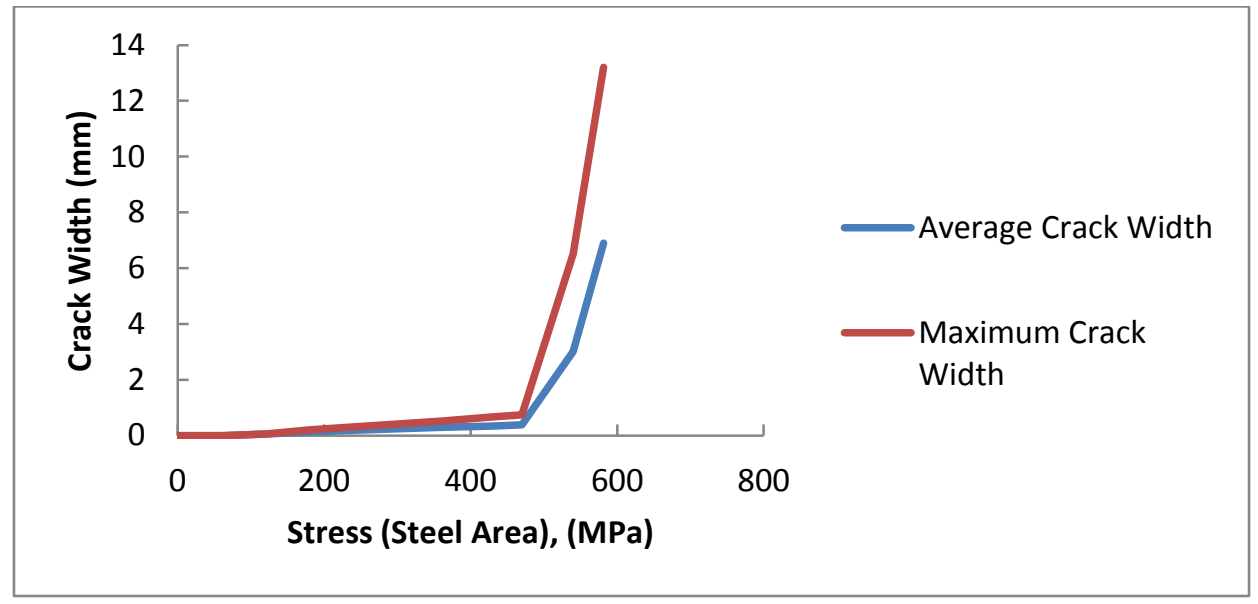

Figure 4-71: Average \& maximum crack widths (20M12S-2) 


\subsubsection{Specimen 15M12L-1}

This specimen was tested on September $17^{\text {th }}, 2013$ with a duplicate specimen being tested later the same day. This specimen contained grout with 1.2\% Dramix RC65/60BN steel fibres by volume. This specimen was created to investigate the effectiveness of grout with longer fibres on increasing the tension stiffening behaviour of reinforced concrete masonry elements.

First cracking occurred around a load of $30 \mathrm{kN}$. At a load stage taken at $36.1 \mathrm{kN}$, the first crack was present on the front side of the specimen. The cracking pattern stabilized around $48 \mathrm{kN}$ and didn't progress further until a load exceeding $100 \mathrm{kN}$. Cracks were very slow to progress and not every crack extended the full width of the specimen.

Once the reinforcing steel approached its yield stress, the crack widths increased, however not very rapidly. The crack widths were observed to be of different widths on the East and West sides of the specimen respectively. With loads approaching ultimate stress for the reinforcing steel, the blocks began to crack near their respective midpoints. All of the cracks were almost perfectly perpendicular to the direction of the applied load. The specimen showed signs of significant tension stiffening near the middle of the specimen as the cracks were very closely spaced. It should also be noted that there was no noticeable drop in load as the crack pattern progressed after a load of $130 \mathrm{kN}$, despite significant increases in the cracking. This gradual cracking is due to the contribution of the fibres. An increased amount of load was able to be resisted due to the contribution to the steel fibres to resist axial load.

The test was terminated when the crack widths became very wide and the overall strain over the gauge length of the LVDTs reached approximately $6.3 \%$.

Figure 4-72 shows the entire stress-strain relationship of the specimen whereas Figure 473 shows the stress-strain relationship prior to yielding. Figure 4-74 shows both the average crack width and maximum crack as a function of stress. The stress is based on the steel area of the given specimen 
Table 4-27: Test summary for specimen 15M12L-1

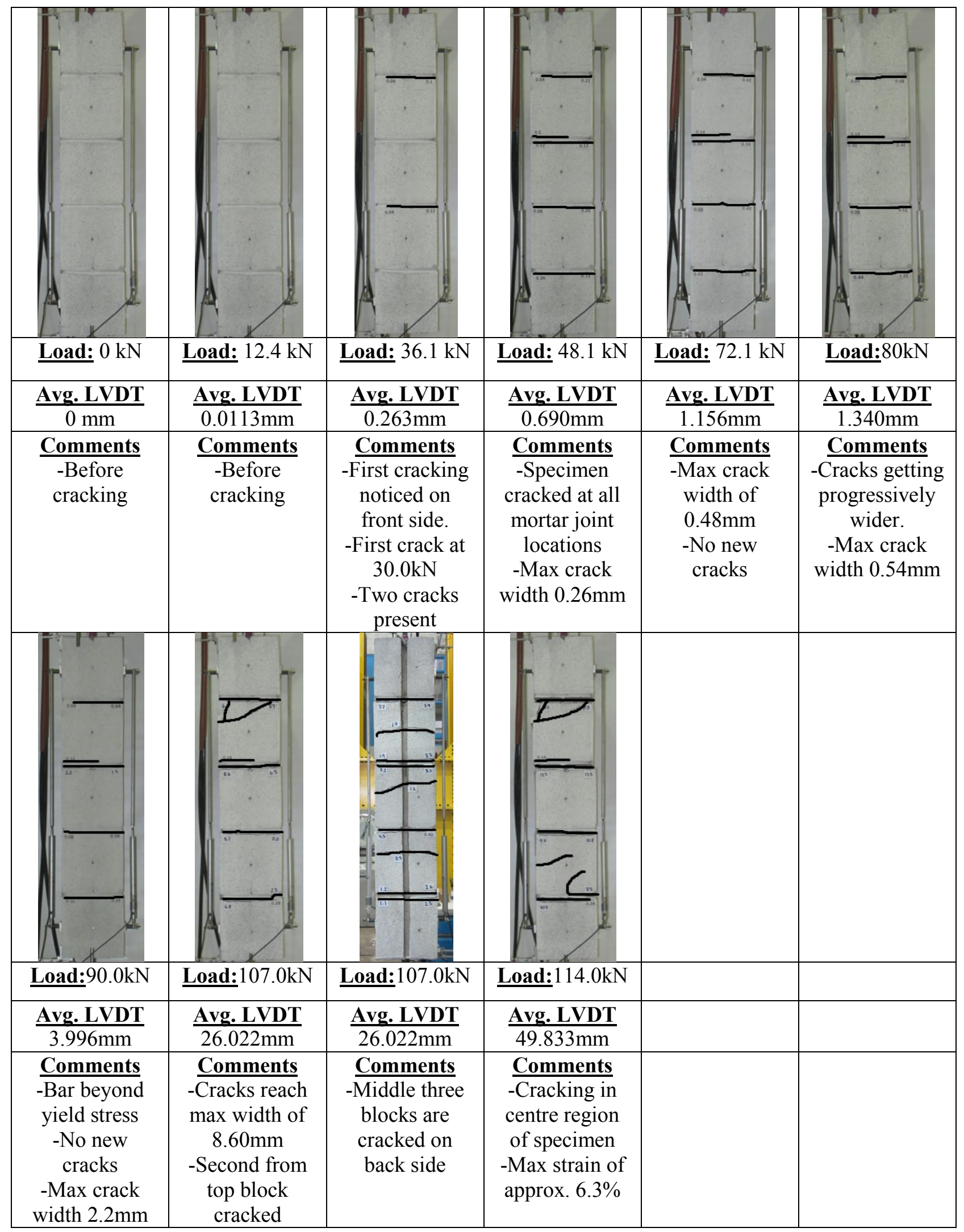




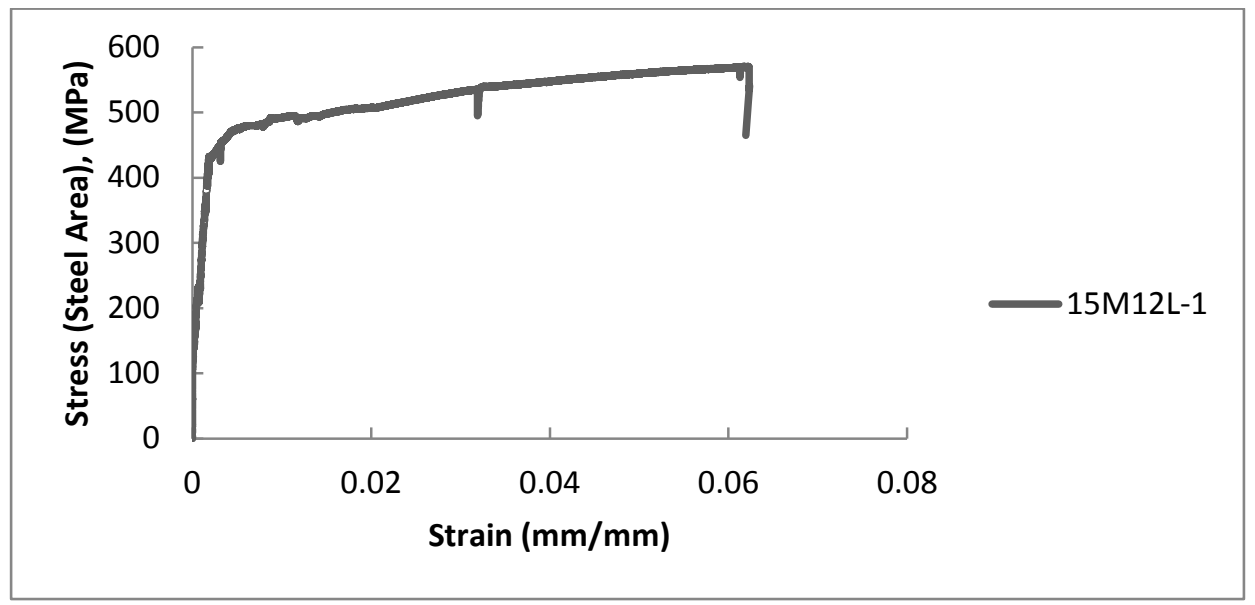

Figure 4-72: Entire stress strain response (15M12L-1)

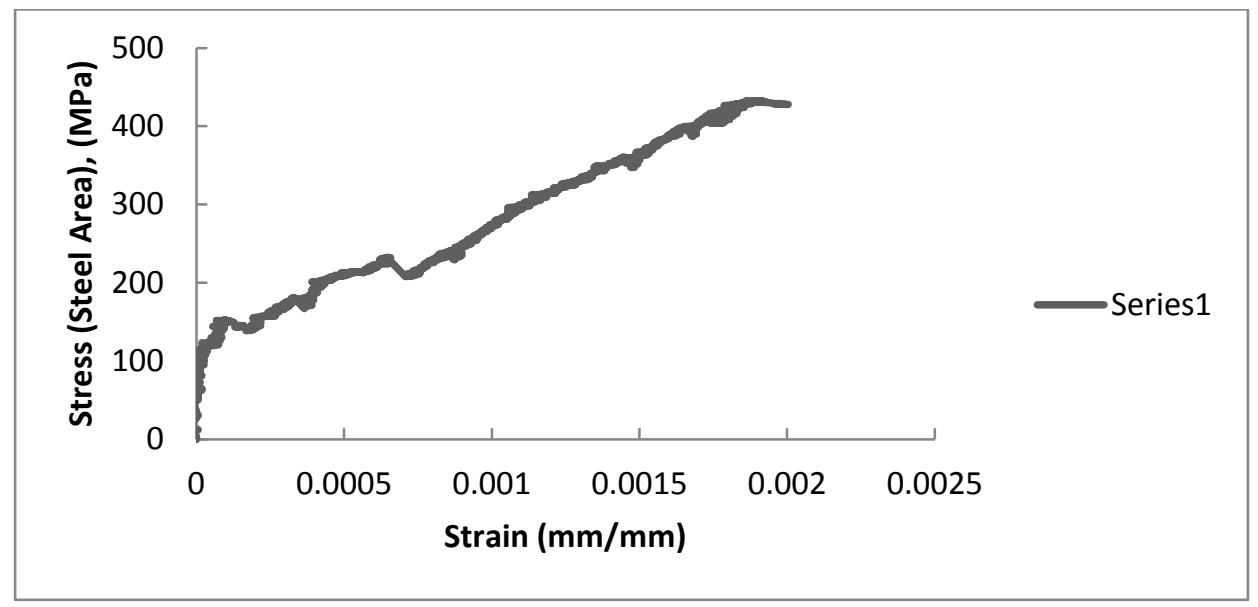

Figure 4-73: Stress strain response prior to yielding of reinforcing steel (15M12L-1)

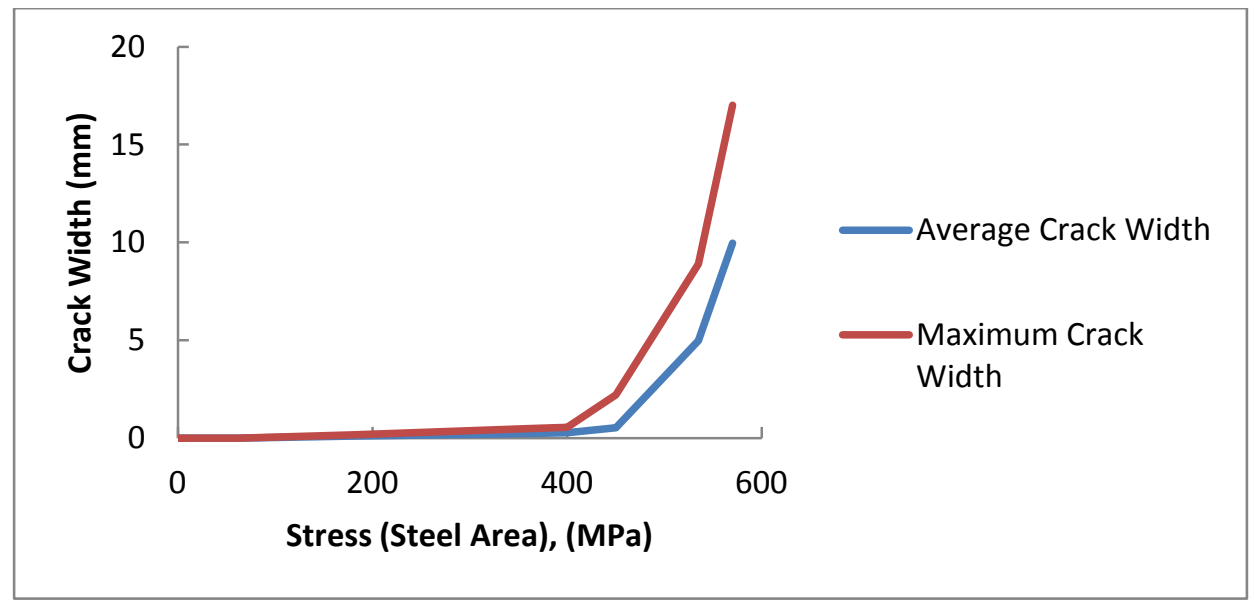

Figure 4-74: Average \& maximum crack widths (15M12L-1) 


\subsubsection{Specimen 15M12L-2}

This specimen was tested on September $17^{\text {th }}, 2013$ and served as a duplicate specimen for 15M12L-1. This specimen contained grout with $1.2 \%$ Dramix RC65/60BN steel fibres by volume. This specimen was created to investigate the effectiveness of grout with longer fibres on increasing the tension stiffening behaviour of reinforced concrete masonry elements.

First cracking occurred at $30.0 \mathrm{kN}$. At a load stage taken at $36.1 \mathrm{kN}$, the first two cracks were present on the front side of the specimen. The cracking pattern stabilized around $48 \mathrm{kN}$ and didn't progress further until a load exceeding $100 \mathrm{kN}$. Cracks were very slow to progress and not every crack extended the full width of the specimen. The LVDTs measured much larger displacements on the East side of the specimen than the West side of the specimen early in the loading regime.

Once the reinforcing steel approached its yield stress, the crack widths increased, however not very rapidly. The crack widths were observed to be of different widths on the East and West sides of the specimen respectively. With loads approaching ultimate stress for the reinforcing steel, the bottom two blocks began to crack extensively. All of the principle cracks were almost perfectly perpendicular to the direction of the applied load. The specimen showed signs of significant tension stiffening near the bottom of the specimen as the cracks were very closely spaced. It should also be noted that there was no noticeable drop in load as the crack pattern progressed after a load of $130 \mathrm{kN}$, despite significant increases in the cracking. This gradual cracking is due to the contribution of the fibres. An increased amount of load was able to be resisted due to the contribution to the steel fibres to resist axial load.

The test was terminated when the crack widths became very wide and the overall strain over the gauge length of the LVDTs reached approximately $6.3 \%$.

Figure 4-75 shows the entire stress-strain relationship of the specimen whereas Figure 476 shows the stress-strain relationship prior to yielding. Figure 4-77 shows both the average crack width and maximum crack as a function of stress. The stress is based on the steel area of the given specimen 
Table 4-28: Test summary for specimen 15M12L-2

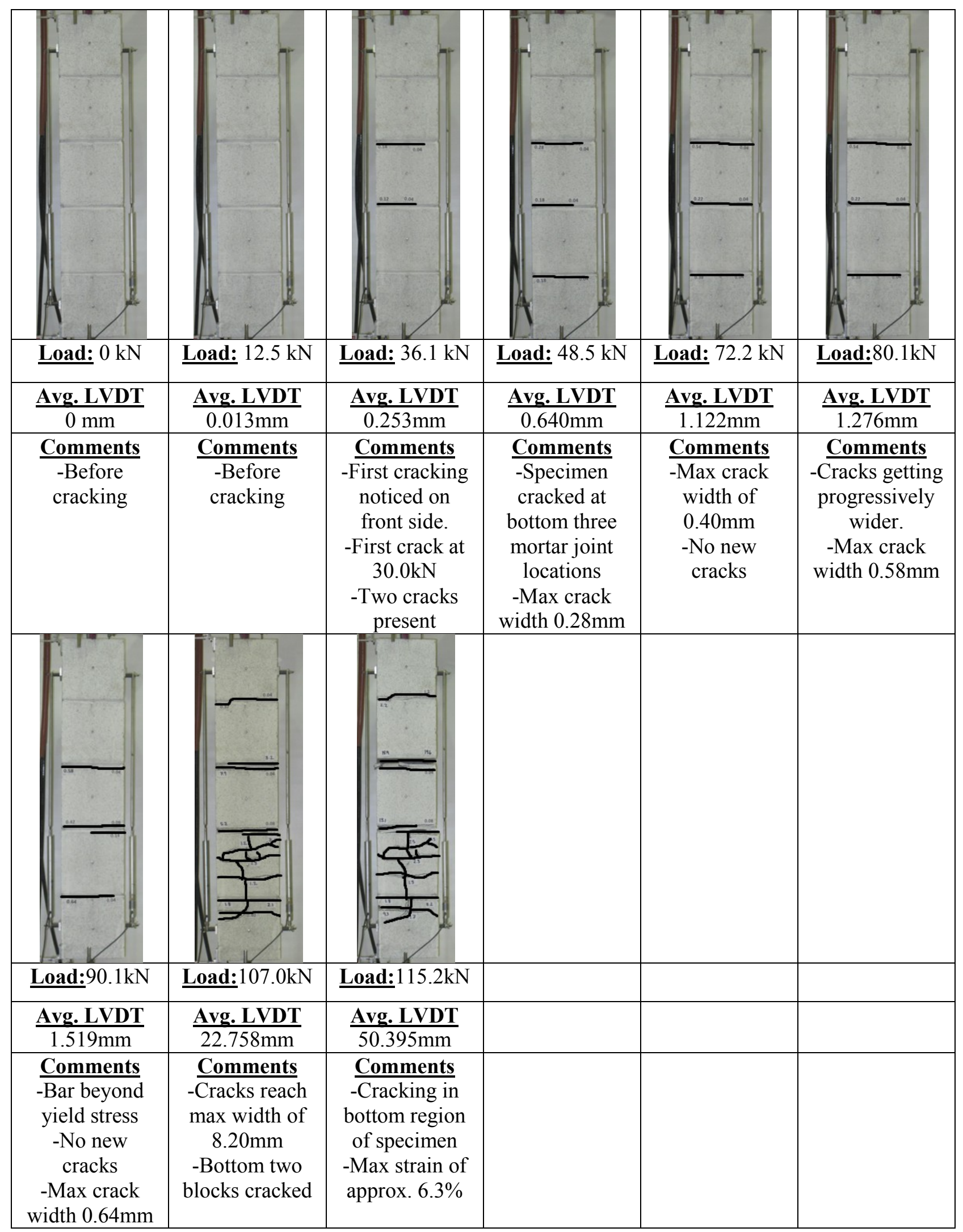




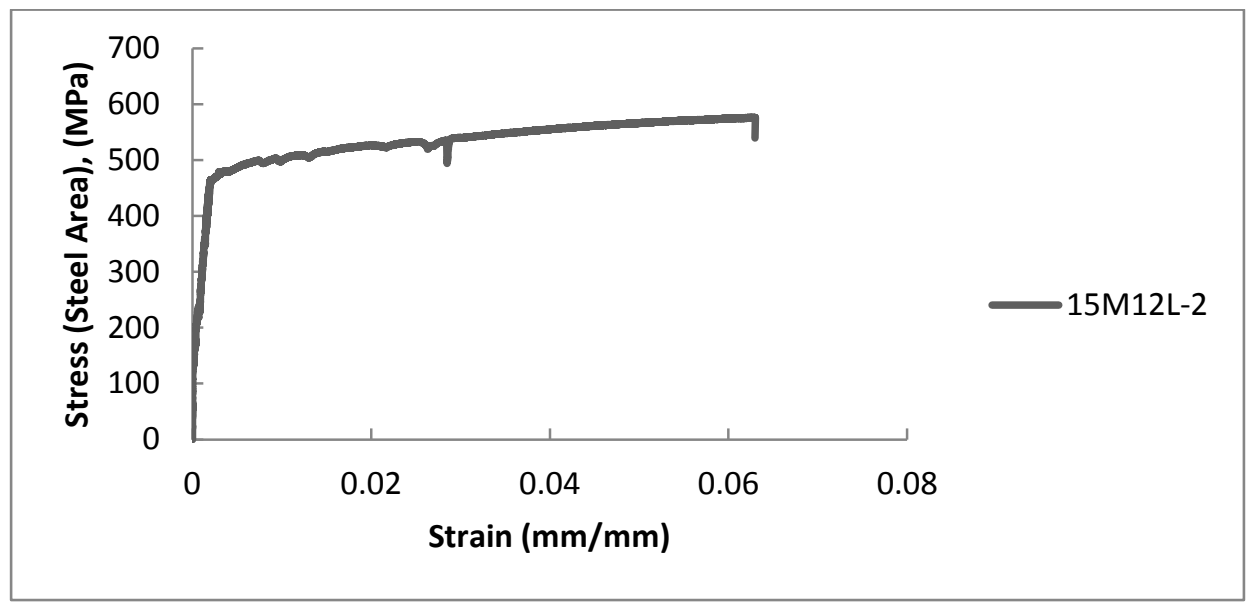

Figure 4-75: Entire stress strain response (15M12L-2)

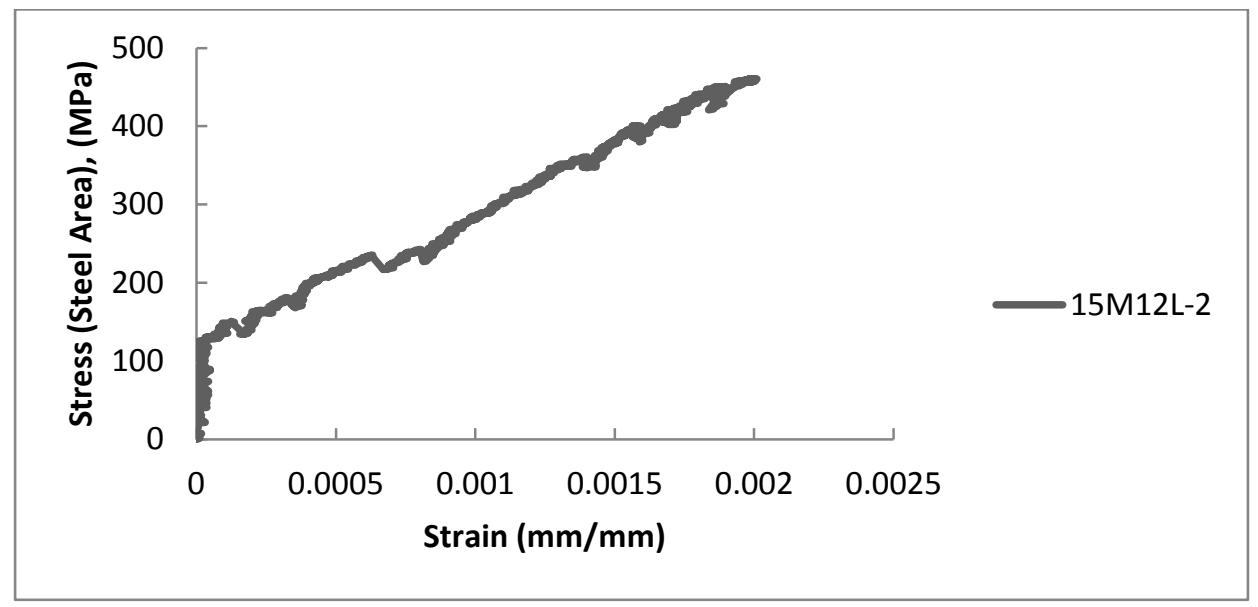

Figure 4-76: Stress strain response prior to yielding of reinforcing steel (15M12L-2)

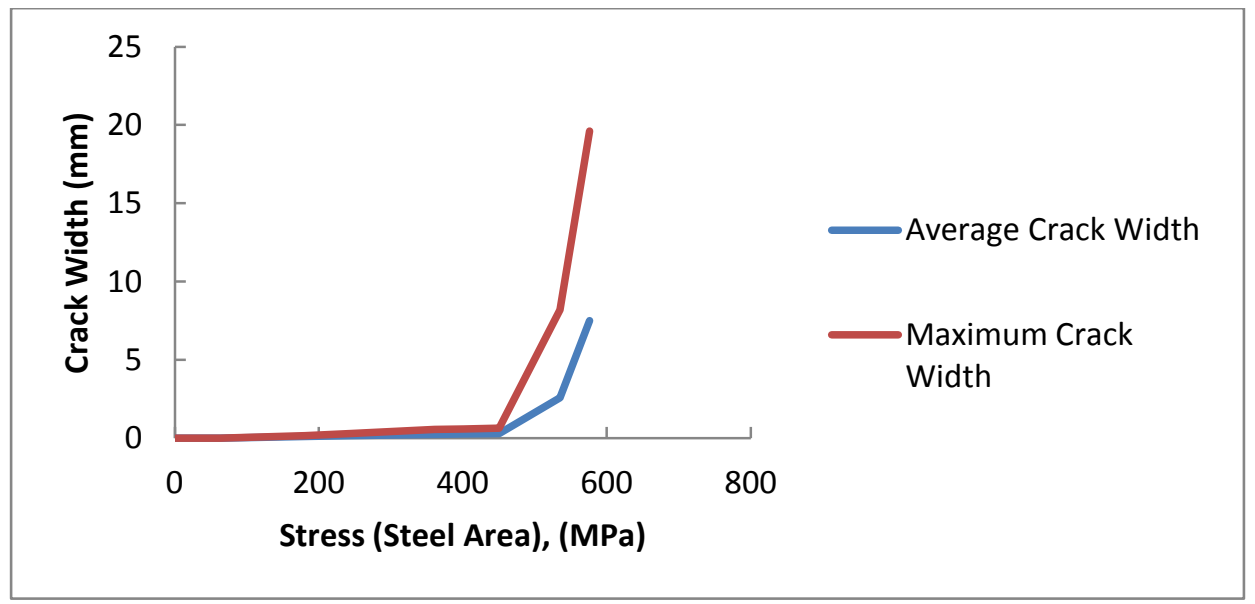

Figure 4-77: Average \& maximum crack widths (15M12L-2) 


\subsubsection{Specimen L15M00-1}

This specimen was tested on September $18^{\text {th }}, 2013$ and was the first specimen to be tested of the $15 \mathrm{M}$ lintel unit specimens. This group of specimens has the same overall dimensions as the rest of the specimens; however, it is constructed of lintel units measuring $190 \mathrm{~mm}$ in length. The specimen contained a single $15 \mathrm{M}$ reinforcing bar in a fully grouted stacked lintel unit specimen. This specimen contained no fibres and served as the control specimen for this group of specimens. This specimen was built and tested to investigate the influence of unit type on the tension stiffening behaviour on reinforced concrete masonry with normal fine grout.

The load at which first cracking occurred was not able to be determined for this specimen due to the fact that there was no noticeable decrease in load at first cracking to determine where at which load the crack was initiated. At a load stage taken at $36.1 \mathrm{kN}$, however, there were two horizontal cracks at both mortar joint locations. At a load of $72.2 \mathrm{kN}$, approaching the yield stress of the bare reinforcing steel, a third crack formed and the maximum crack width had already increased to $0.72 \mathrm{~mm}$. By a load of $90 \mathrm{kN}$, the bottom block cracked near its midpoint. The crack widths were relatively constant on the East and West sides of each respective crack. By a load of approximately $100 \mathrm{kN}$, a bond splitting crack occurred on the front side of the specimen.

The test was terminated when the crack widths became very wide and the overall strain over the gauge length of the LVDTs reached approximately $6.3 \%$.

Figure 4-78 shows the entire stress-strain relationship of the specimen whereas Figure 479 shows the stress-strain relationship prior to yielding. Figure 4-80 shows both the average crack width and maximum crack as a function of stress. The stress is based on the steel area of the given specimen. 
Table 4-29: Test summary for specimen L15M00-1

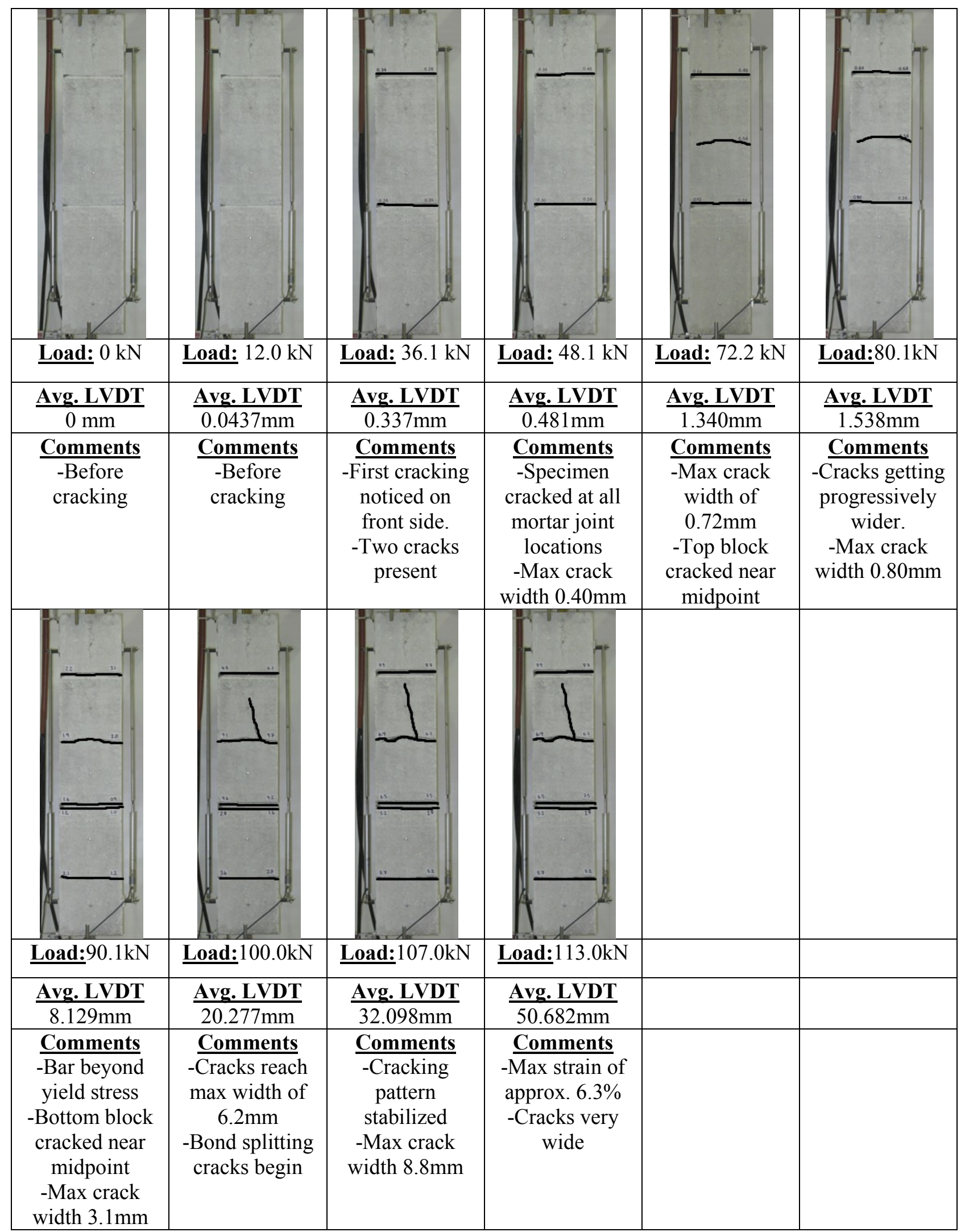




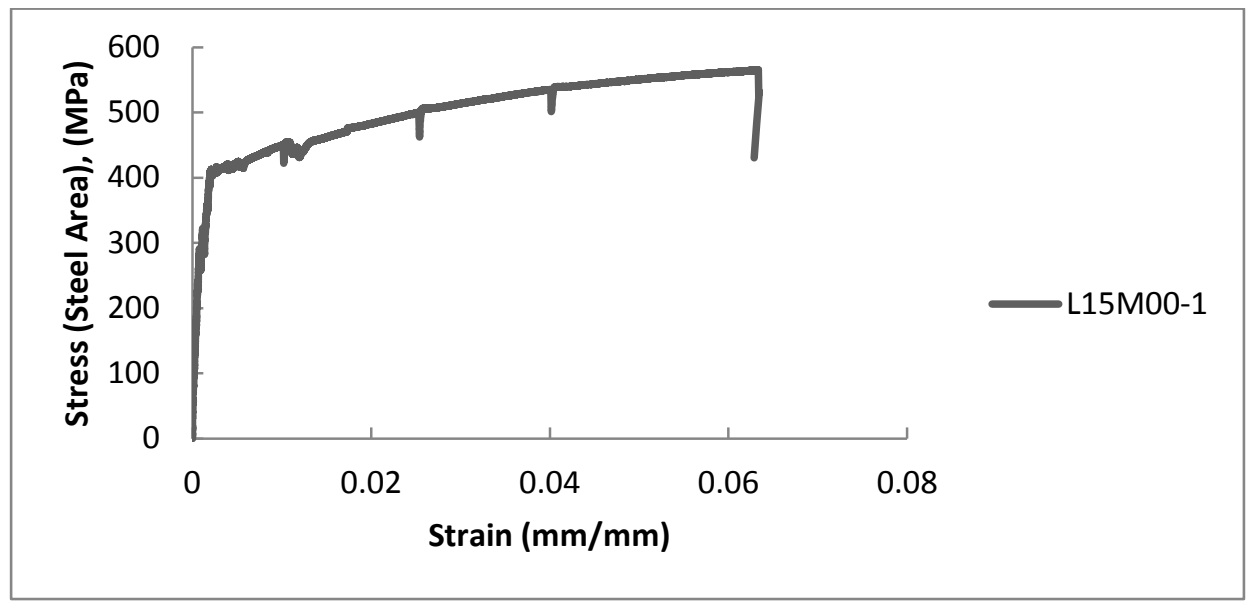

Figure 4-78: Entire stress strain response (L15M00-1)

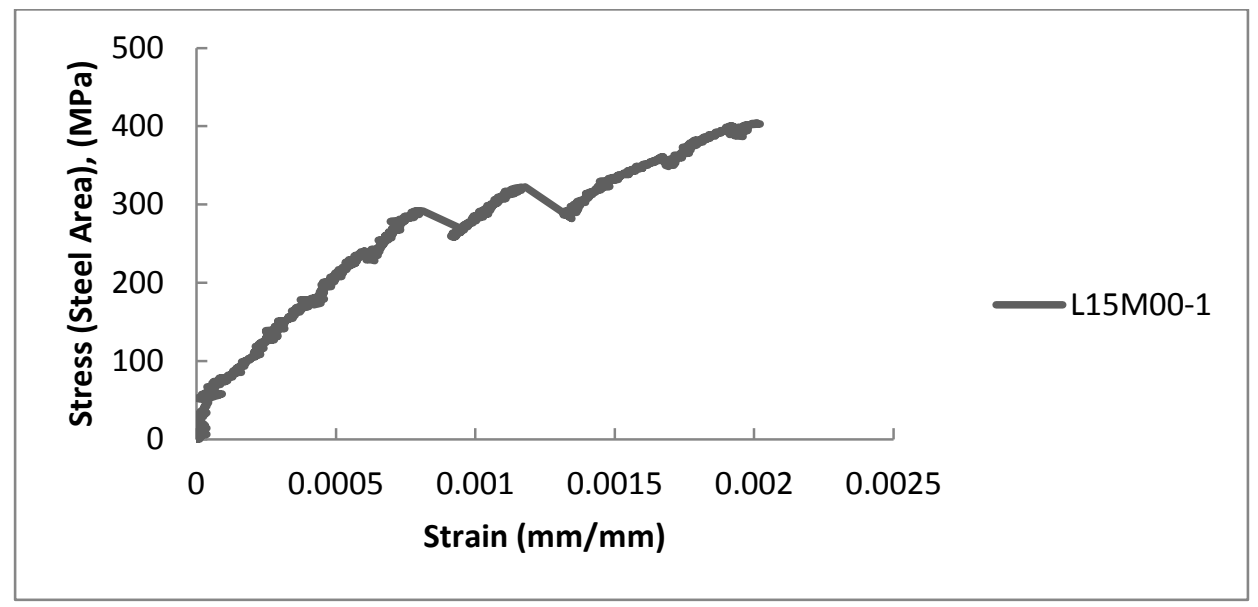

Figure 4-79: Stress strain response prior to yielding of reinforcing steel (L15M00-1)

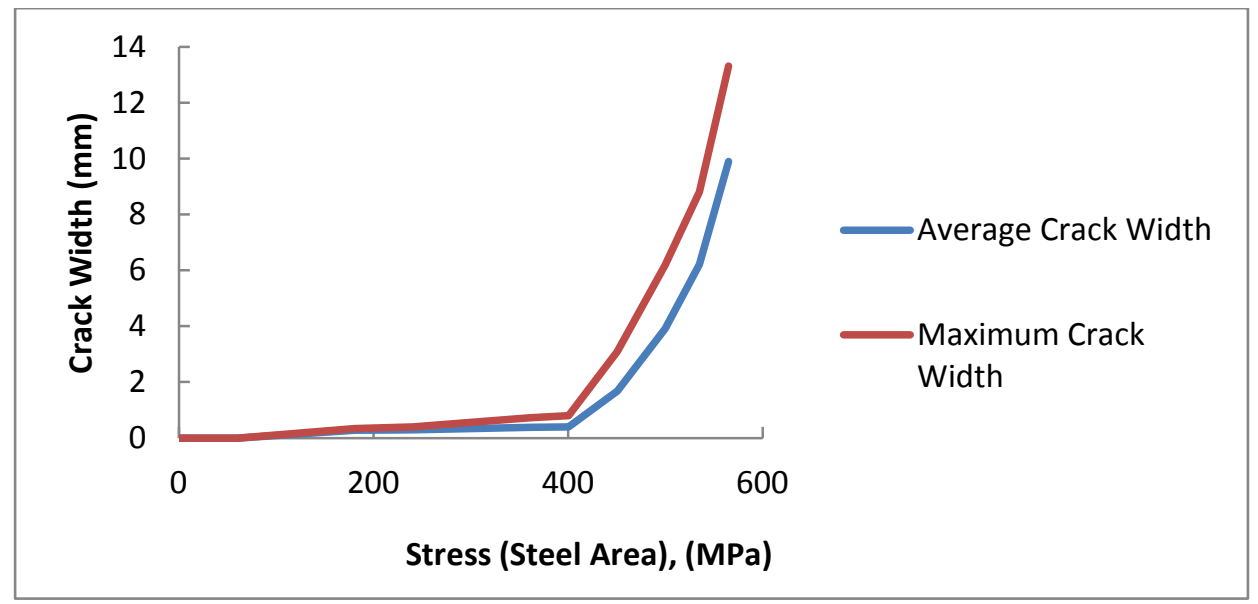

Figure 4-80: Average \& maximum crack widths (L15M00-1) 


\subsubsection{Specimen L15M04S-1}

This specimen was tested on September $18^{\text {th }}, 2013$ and was the second specimen to be tested of the $15 \mathrm{M}$ lintel unit specimens. This group of specimens has the same overall dimensions as the rest of the specimens; however, it is constructed of lintel units measuring $190 \mathrm{~mm}$ in length. The specimen contained a single $15 \mathrm{M}$ reinforcing bar in a fully grouted stacked lintel unit specimen. This specimen contained grout with 0.4\% Dramix ZP305 fibres. This specimen was built and tested to investigate the influence of unit type on the tension stiffening behaviour on reinforced concrete masonry with lightly fibre reinforced grout.

The load at which first cracking occurred was not able to be determined for this specimen due to the fact that there was no noticeable decrease in load at first cracking to determine where at which load the crack was initiated. At a load stage taken at $36.1 \mathrm{kN}$, however, there were two horizontal cracks at both mortar joint locations. At low levels of strain, a significant stiffening effect was observed in comparison to L15M00-1. The crack pattern stayed constant until the load approached ultimate stress of the bare reinforcing steel. At this point, the cracks at the mortar joint locations became very wide due to the localization of the strain. The crack widths were relatively constant on the East and West sides of each respective crack. By a load of approximately $107.1 \mathrm{kN}$, two bond splitting cracks occurred on the front side of the specimen emanating from the top of both of the $390 \mathrm{~mm}$ lintel units. Also, a third horizontal crack formed near the bottom of the specimen.

The test was terminated when the crack widths became very wide and the overall strain over the gauge length of the LVDTs reached approximately 5.8\%.

Figure 4-81 shows the entire stress-strain relationship of the specimen whereas Figure 482 shows the stress-strain relationship prior to yielding. Figure 4-83 shows both the average crack width and maximum crack as a function of stress. The stress is based on the steel area of the given specimen 
Table 4-30: Test summary for specimen L15M04S-1

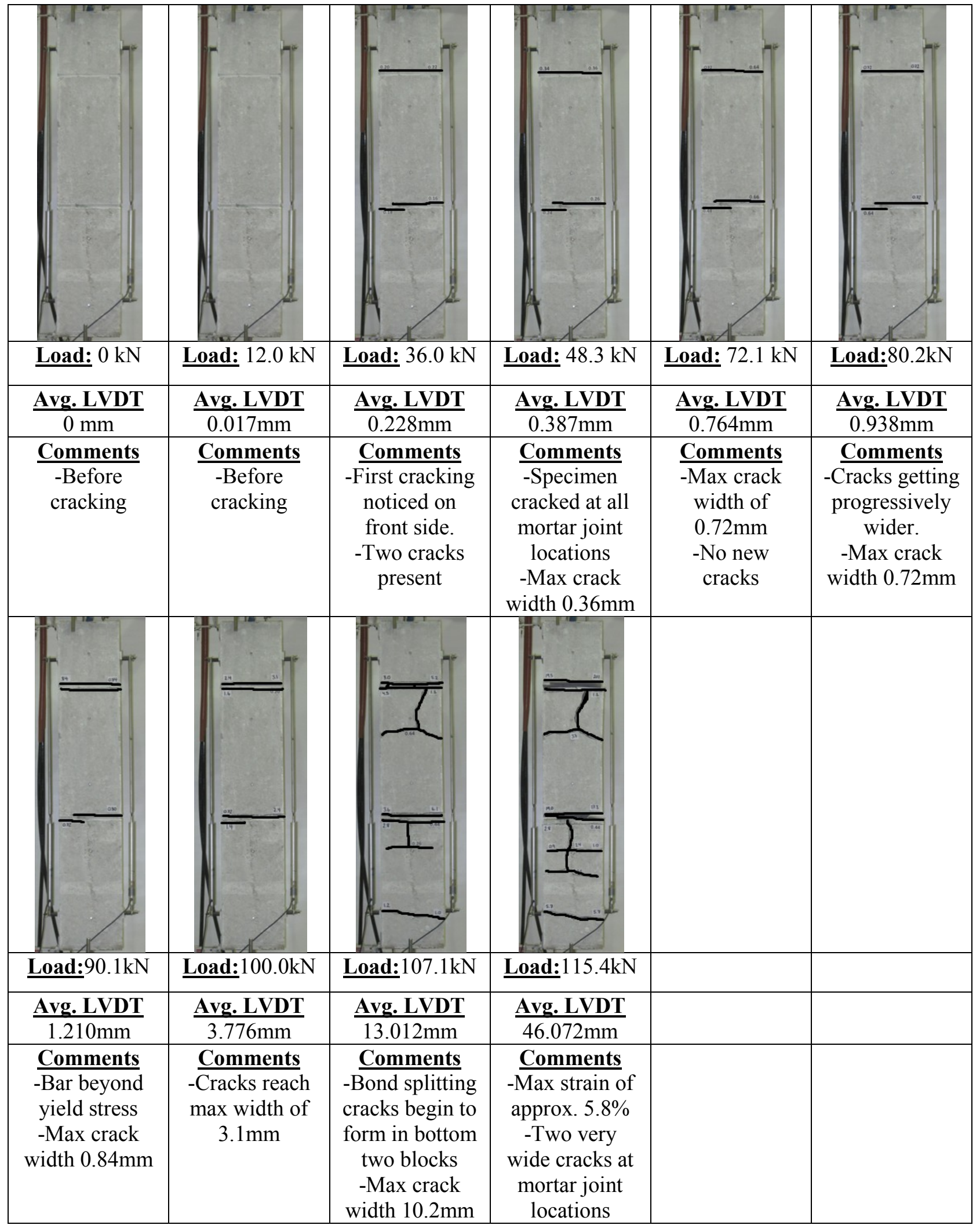




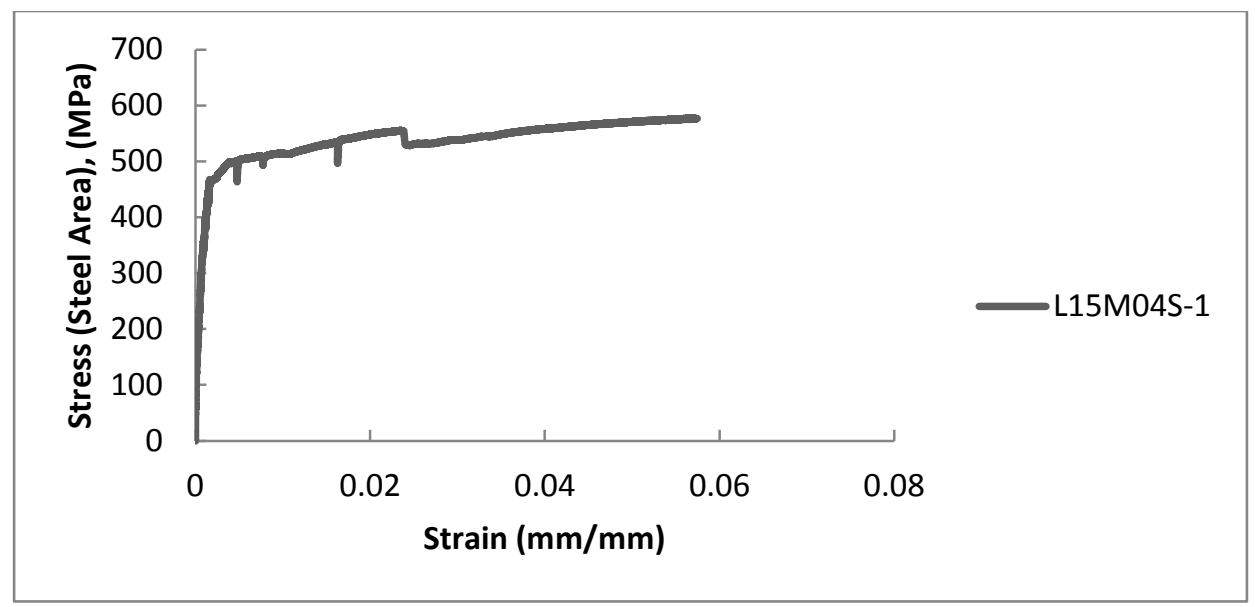

Figure 4-81: Entire stress strain response (L15M04S-1)

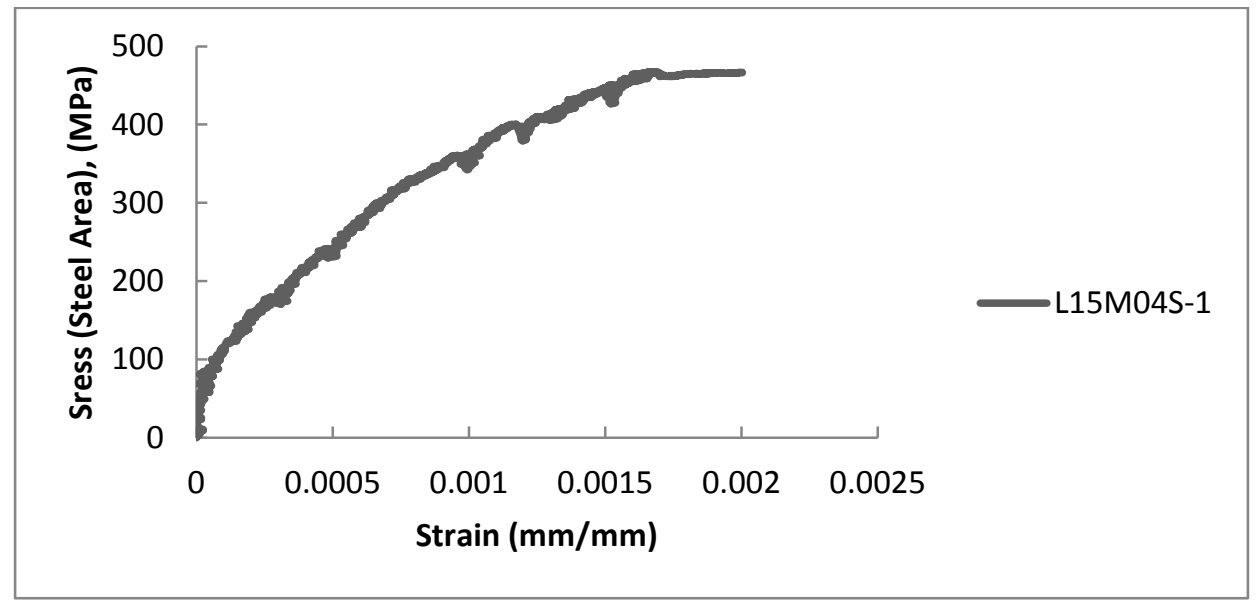

Figure 4-82: Stress strain response prior to yielding of reinforcing steel (L15M04S-1)

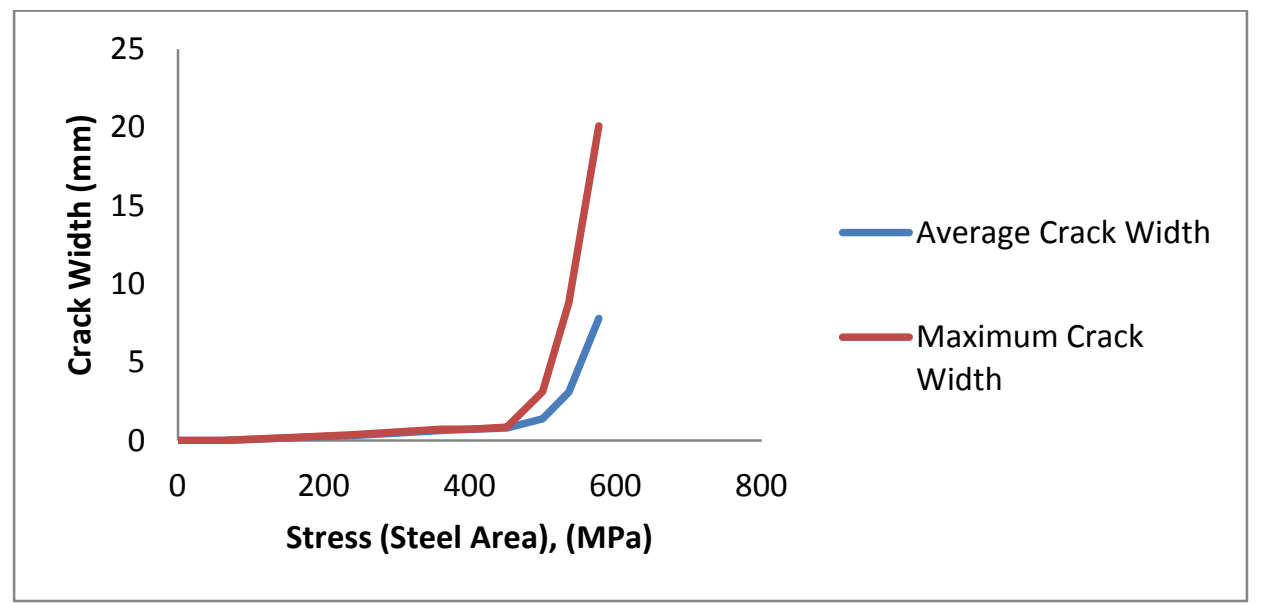

Figure 4-83: Average \& maximum crack widths (L15M04S-1) 


\subsubsection{Specimen L15M08S-1}

This specimen was tested on September $19^{\text {th }}, 2013$ and was the third specimen to be tested of the $15 \mathrm{M}$ lintel unit specimens. This group of specimens has the same overall dimensions as the rest of the specimens; however, it is constructed of lintel units measuring $190 \mathrm{~mm}$ in length. The specimen contained a single $15 \mathrm{M}$ reinforcing bar in a fully grouted stacked lintel unit specimen. This specimen contained grout with 0.8\% Dramix ZP305 fibres. This specimen was built and tested to investigate the influence of unit type on the tension stiffening behaviour on reinforced concrete masonry with moderate fibre reinforced grout. There was a small amount of bleeding of the fines from the grout on the back side of the specimen due to improper fastening of the formwork.

The load at which first cracking occurred was not able to be determined for this specimen due to the fact that there was no noticeable decrease in load at first cracking to determine where at which load the crack was initiated. At a load stage taken at $36.1 \mathrm{kN}$, however, there were two horizontal cracks at both mortar joint locations. At low levels of strain, a significant stiffening effect was observed in comparison to L15M00-1. The crack pattern stayed constant until the load approached ultimate stress of the bare reinforcing steel.. The crack widths were relatively constant on the East and West sides of each respective crack. By a load of approximately $100.1 \mathrm{kN}$, two bond splitting cracks occurred on the front side of the specimen emanating from the bottom of both of the $390 \mathrm{~mm}$ lintel units. At a load stage taken at the maximum load level, there were 8 horizontal cracks present in the specimen as well as multiple vertical cracks. It should be noted that the cracking on the back side of the specimen was very limited due to the fact that it was the fibre reinforced grout that was exposed instead of the concrete masonry unit where there are weaknesses in the bond.

The test was terminated when the crack widths became very wide and the overall strain over the gauge length of the LVDTs reached approximately $4.8 \%$.

Figure 4-84 shows the entire stress-strain relationship of the specimen whereas Figure 485 shows the stress-strain relationship prior to yielding. Figure 4-86 shows both the average crack width and maximum crack as a function of stress. The stress is based on the steel area of the given specimen. 
Table 4-31: Test summary for specimen L15M08S-1

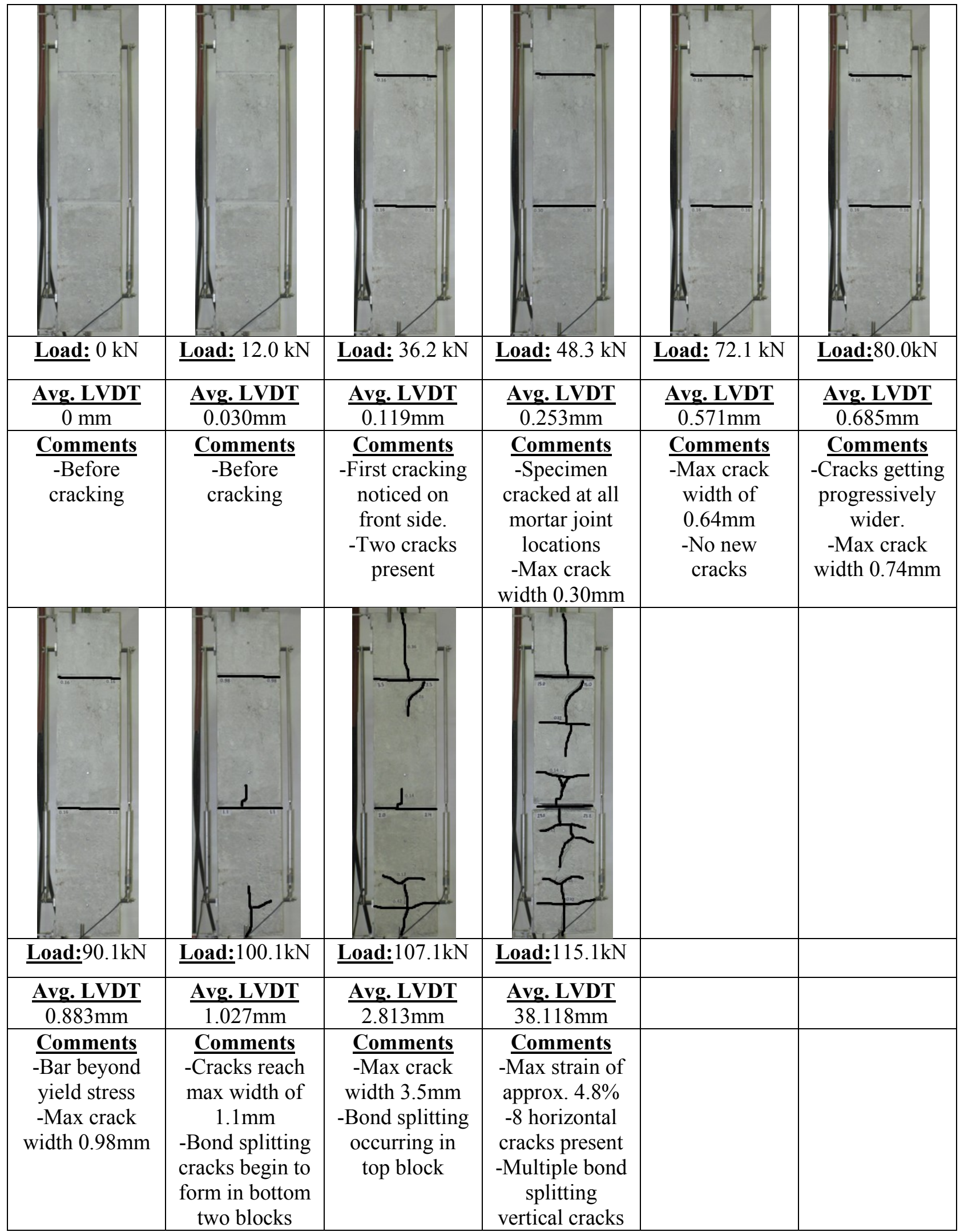




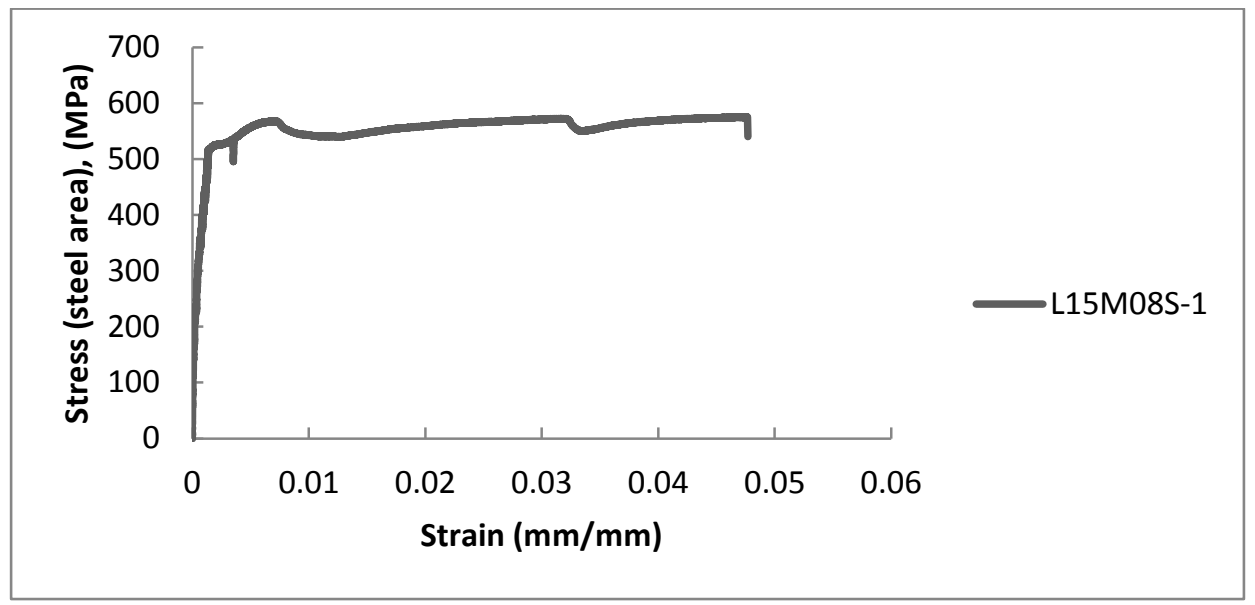

Figure 4-84: Entire stress strain relationship (L15M08S-1)

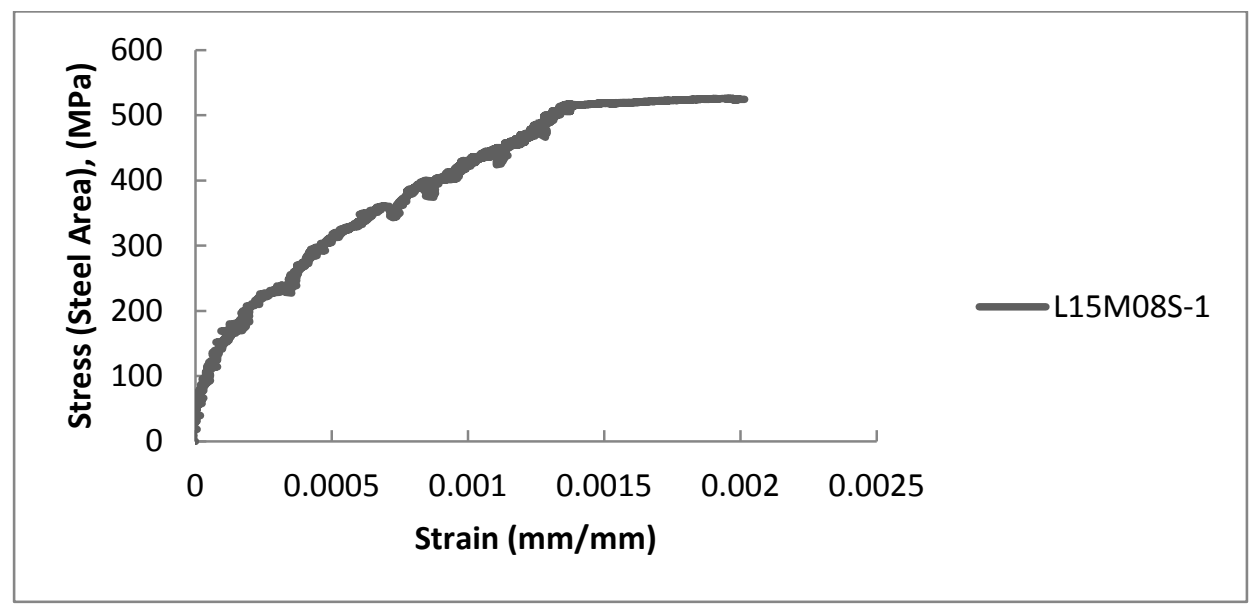

Figure 4-85: Stress strain response prior to yielding of reinforcing steel (L15M08S-1)

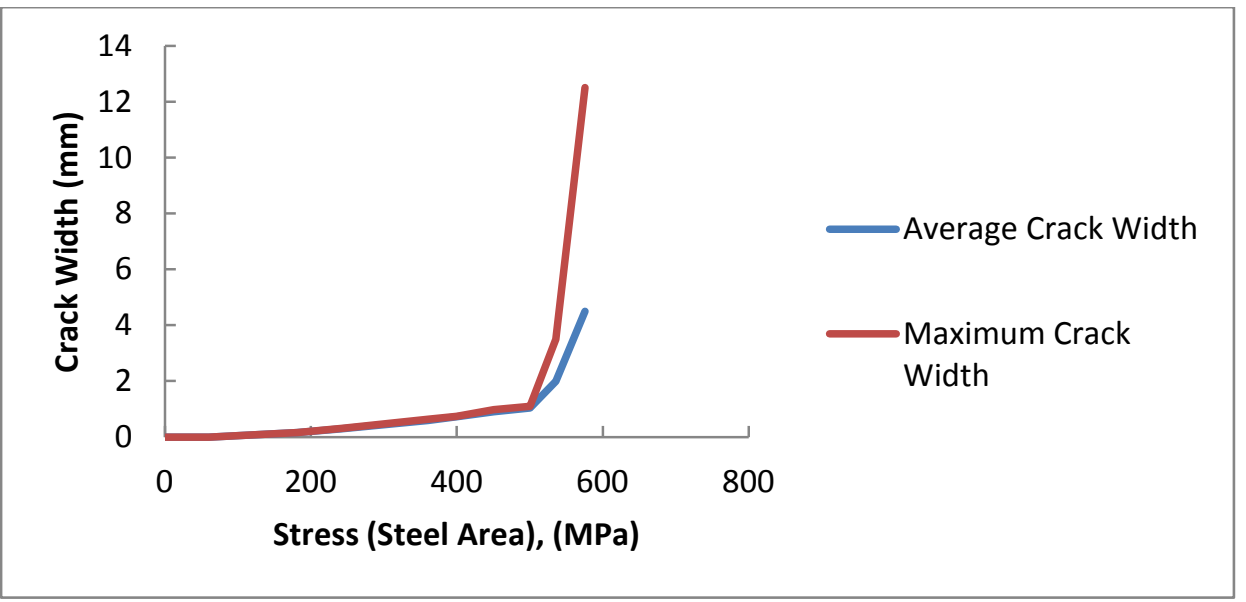

Figure 4-86: Average \& maximum crack widths (L15M08S-1) 


\subsubsection{Specimen L15M12S-1}

This specimen was tested on September $19^{\text {th }}, 2013$ and was the fourth and final specimen to be tested of the $15 \mathrm{M}$ lintel unit specimens. The specimen contained a single $15 \mathrm{M}$ reinforcing bar in a fully grouted stacked lintel unit specimen. This specimen contained grout with $0.8 \%$ Dramix ZP305 fibres. This specimen was built and tested to investigate the influence of unit type on the tension stiffening behaviour on reinforced concrete masonry with highly fibre reinforced grout. There was a significant amount of bleeding of the fines from the grout on the open side of the specimen due to improper fastening of the formwork.

The load at which first cracking occurred could not be determined for this specimen due to the fact that there was no noticeable decrease in load at first cracking to determine where at which load the crack was initiated. At a load stage taken at $36.2 \mathrm{kN}$, however, there were two horizontal cracks at both mortar joint locations. At low levels of strain, a significant stiffening effect was observed in comparison to L15M00-1. The crack pattern remained constant until the load approached ultimate stress of the bare reinforcing steel. The crack widths were relatively constant on the East and West sides of each respective crack. By a load of approximately $90.1 \mathrm{kN}$, two bond splitting cracks occurred on the front side of the specimen emanating from the bottom of both of the $390 \mathrm{~mm}$ lintel units. It should be noted that the cracking on the back side of the specimen was very limited due to the fact that it was the fibre reinforced grout that was exposed instead of the concrete masonry unit where there are weaknesses in the bond.

The test was terminated when the crack widths became very wide and the overall strain over the gauge length of the LVDTs reached approximately $4.3 \%$. The crack between the two bottom blocks became extremely wide.

Figure 4-87 shows the entire stress-strain relationship of the specimen whereas Figure 488 shows the stress-strain relationship prior to yielding. Figure 4-89 shows both the average crack width and maximum crack as a function of stress. The stress is based on the steel area of the given specimen. 
Table 4-32: Test summary for specimen L15M12S-1

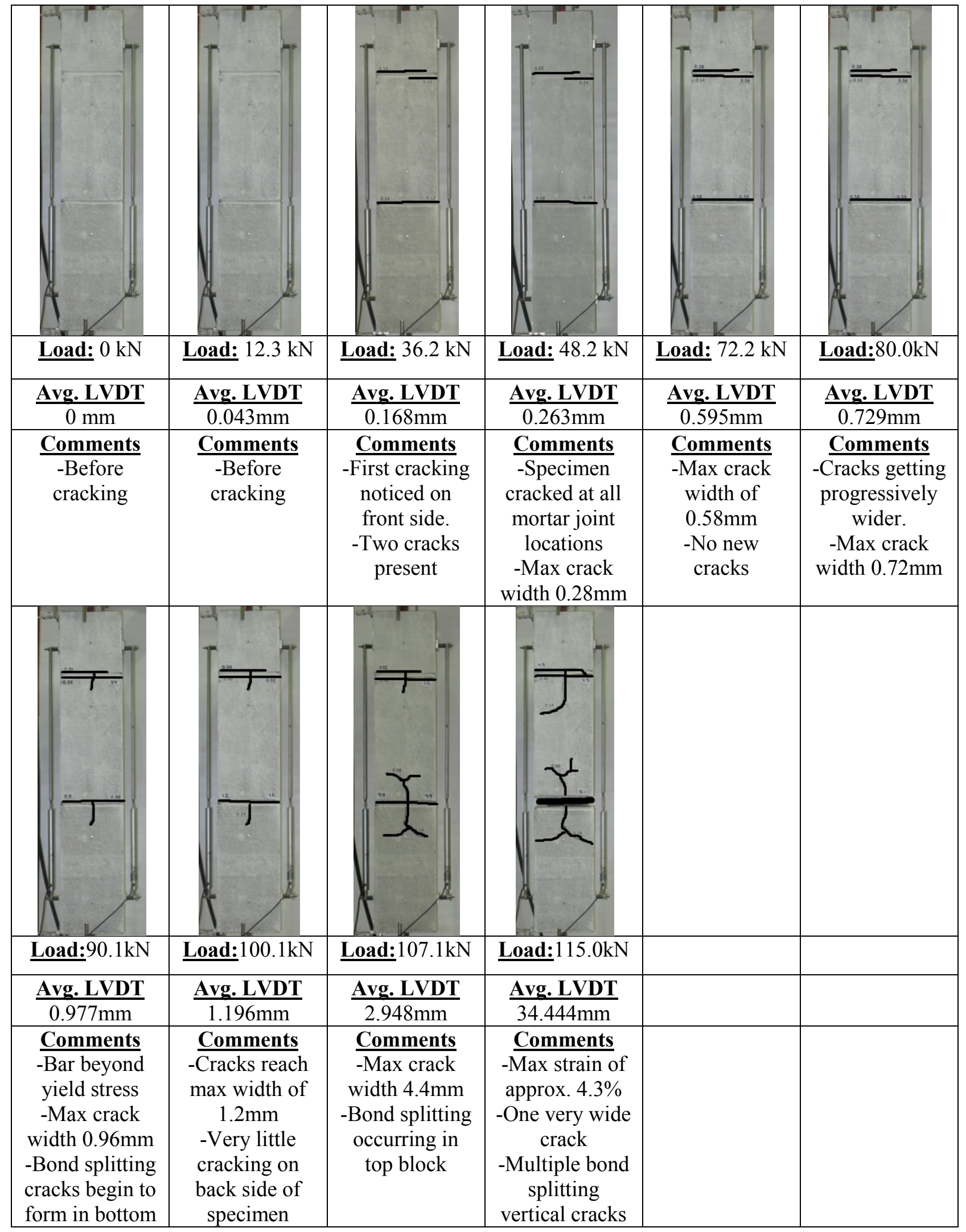




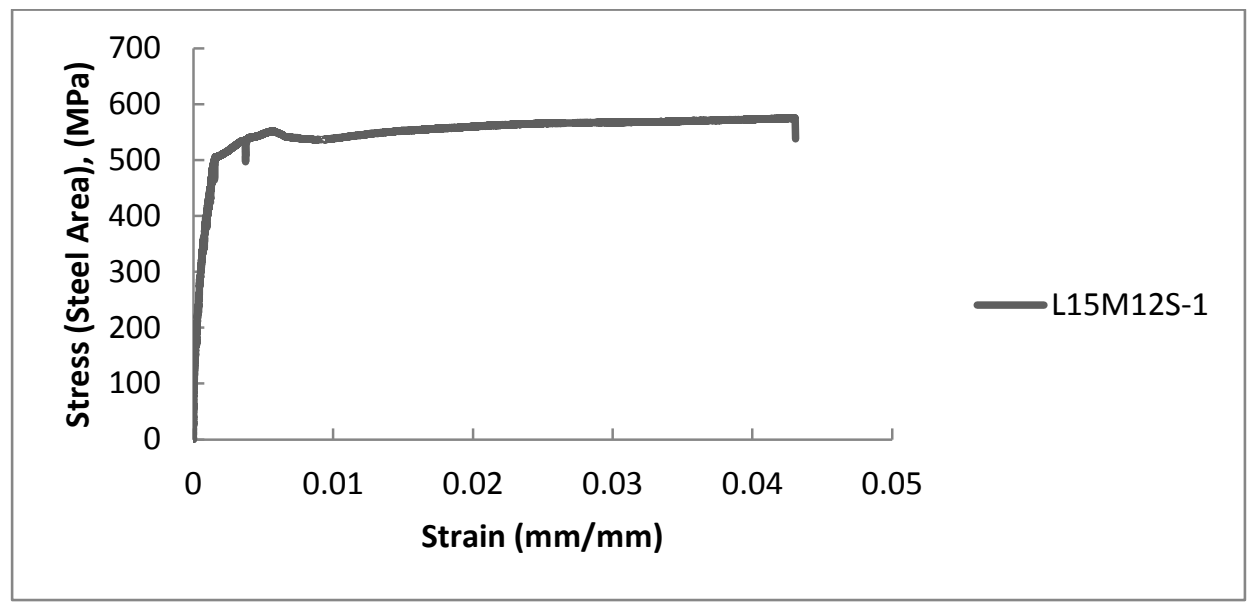

Figure 4-87: Entire stress strain response (L15M12S-1)

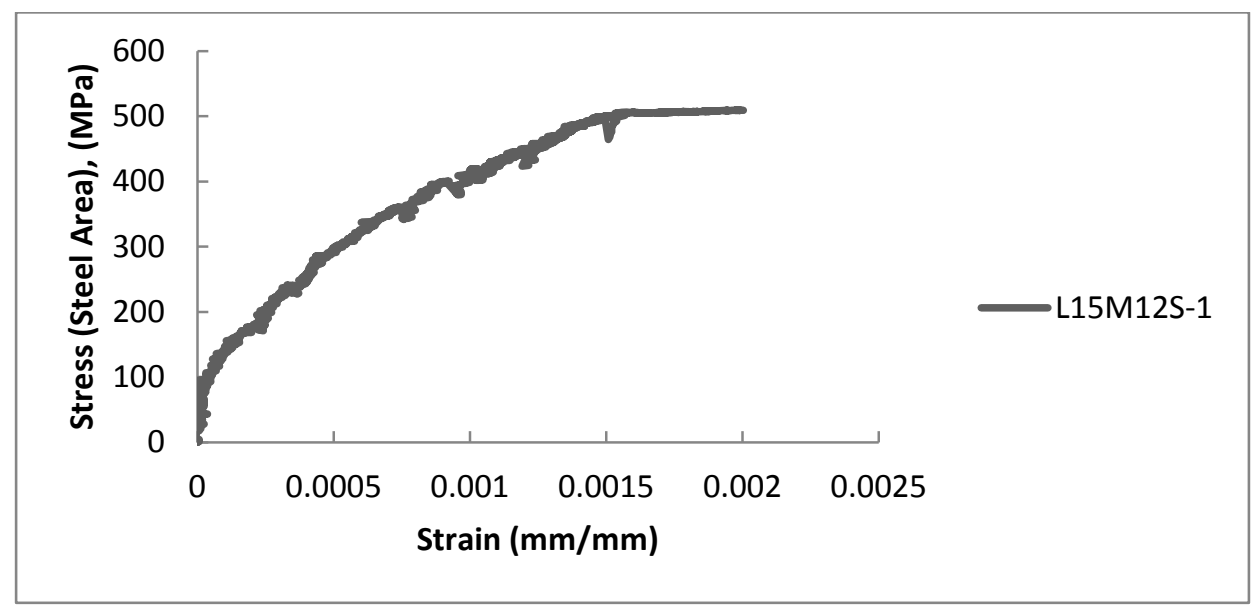

Figure 4-88: Stress strain response prior to yielding of reinforcing steel (L15M12S-1)

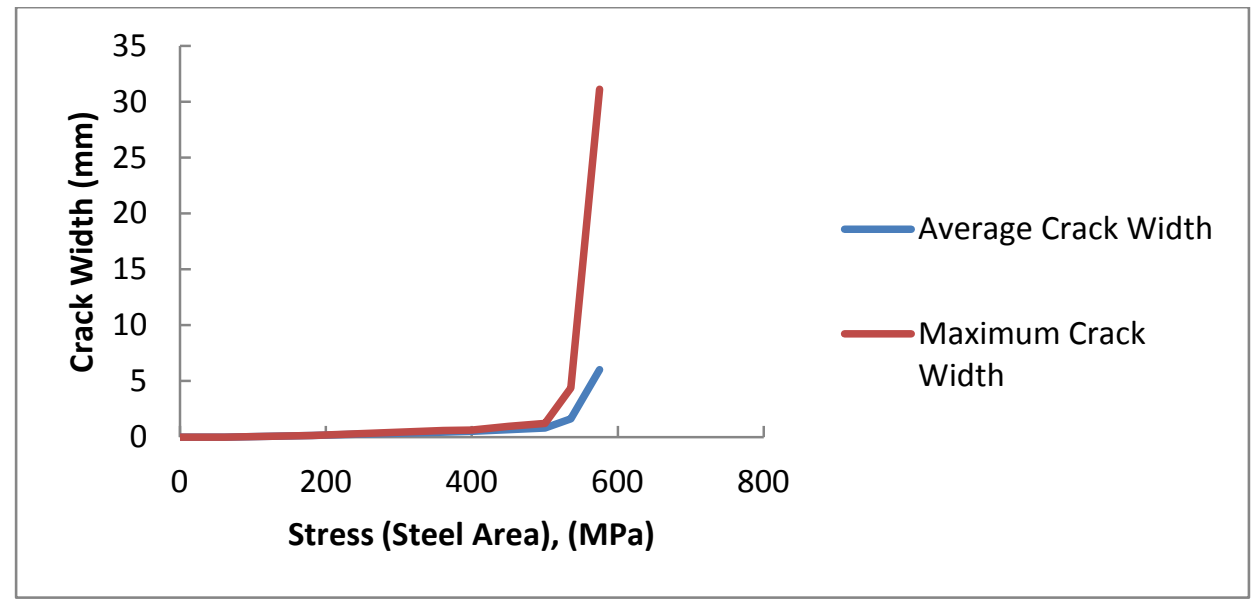

Figure 4-89: Average \& maximum crack widths (L15M12S-1) 


\subsection{Specimens tested under Cyclic Load}

Several specimens were tested under cyclic load to observe the degradation of stiffness and other properties when the load was cycled at different load levels. Two types of cyclic tests were conducted: 1) Cyclic load in the service load range 2) Cyclic load in the post-yield range. The cyclic load in the service load range was meant to simulate the cycling of load that would happen under typical loading, and the cyclic load in the post yield range will access the performance of steel fibre reinforced masonry in an extreme event such as an earthquake or a blast event. The cyclic tests will serve as a preliminary means of accessing the performance of steel fibre reinforced masonry before larger scale specimens such as concrete masonry shear walls will be investigated for structural performance.

\subsubsection{Cyclic Load at Service Loads}

The following specimens were tested under a cyclic loading regime at loads within the service load range. All loading took place under load control. Firstly; the load was increased from $0 \mathrm{kN}$ to $60 \mathrm{MPa}$ at a rate of $1 \mathrm{kN} / \mathrm{sec}$. Then; the load was cycled from $60 \mathrm{MPa}$ to $180 \mathrm{MPa} 20$ times. Next, the load was cycled from $60 \mathrm{MPa}$ to $240 \mathrm{MPa} 20$ times. Then, the load was cycled from $60 \mathrm{MPa}$ to $360 \mathrm{MPa} 20$ times. Lastly, the load was cycled from $60 \mathrm{MPa}$ to $400 \mathrm{MPa} 20$ times. After all cycling of the load was completed, the test apparatus was switched into displacement control and the specimen was loaded at $4 \mathrm{~mm} / \mathrm{min}$ until large deformations took place. This allowed the comparison of the data with the monotonic tests. 


\subsubsection{Specimen 15C00-1}

This specimen was tested on October $9^{\text {th }}, 2013$ and was the second specimen to be tested of the $15 \mathrm{M}$ cyclic tests at service loads. This specimen contained no fibres and served as a control specimen for all specimens tested in the $15 \mathrm{M}$ cyclic series.

First cracking was present at the first load stage taken at $36.1 \mathrm{kN}$. At this load there were two horizontal cracks in the specimen. After the second cycle at a load of $48.1 \mathrm{kN}$, a third crack formed at the top mortar joint location. By a load of $80 \mathrm{kN}$, the specimen was cracked at all mortar joint locations. The crack pattern stayed the same until the load reached close to ultimate load. Bond splitting was present at the top and bottom of the specimen.

The test was terminated when the load reached $110 \mathrm{kN}$ and the overall strain over the gauge length of the LVDTs reached approximately $3.9 \%$.

Figure 4-90 shows the stress-strain relationship of the specimen throughout the cycling of the load. Figure 4-91 shows both the average crack width and maximum crack as a function of stress. The stress is based on the steel area of the given specimen. 
Table 4-33: Test summary for specimen $15 \mathrm{C00}-1$

\begin{tabular}{|c|c|c|c|c|c|}
\hline & & & & & \\
\hline$\frac{\text { Load: } 0 \mathrm{kN}}{(0 \mathrm{MPa})}$ & $\begin{array}{c}\text { Load: } 36.1 \mathrm{kN} \\
(180.5 \mathrm{MPa})\end{array}$ & $\frac{\text { Load: } 48.1 \mathrm{kN}}{(240.5 \mathrm{MPa})}$ & $\frac{\text { Load: } 72.1 \mathrm{kN}}{(360.5 \mathrm{MPa})}$ & $\frac{\text { Load: } 80.1 \mathrm{kN}}{(400.5 \mathrm{MPa})}$ & $\frac{\text { Load: } 107.1 \mathrm{kN}}{(535.5 \mathrm{MPa})}$ \\
\hline Avg. LVDT & Avg. LVDT & Avg. LVDT & Avg. LVDT & Avg. LVDT & Avg. LVDT \\
\hline $0 \mathrm{~mm}$ & before cycling & before cycling & before cycling & before cycling & before cycling \\
\hline & $0.303 \mathrm{~mm}$ & $0.461 \mathrm{~mm}$ & $1.384 \mathrm{~mm}$ & $1.598 \mathrm{~mm}$ & $31.223 \mathrm{~mm}$ \\
\hline Cycles & Cycles & Cycles & Cycles & Cycles & Cycles \\
\hline- & 20 & 20 & 20 & 20 & - \\
\hline - & $\begin{array}{c}\frac{\text { Avg. LVDT }}{\text { after cycling }} \\
0.357 \mathrm{~mm}\end{array}$ & $\frac{\frac{\text { Avg. LVDT }}{\text { after cycling }}}{0.804 \mathrm{~mm}}$ & $\frac{\text { Avg. } \text { LVDT }}{\text { after cycling }} \frac{1.449 \mathrm{~mm}}{1.0}$ & $\frac{\text { Avg. LVDT }}{\frac{\text { after cycling }}{1.657 \mathrm{~mm}}}$ & - \\
\hline Comments & Comments & Comments & Comments & Comments & Comments \\
\hline $\begin{array}{l}\text {-Before } \\
\text { loading }\end{array}$ & $\begin{array}{c}\text {-First cracking } \\
\text { noticed on } \\
\text { front side. } \\
\text {-Two cracks } \\
\text { present }\end{array}$ & $\begin{array}{c}\text {-Third crack } \\
\text { present } \\
\text {-Cracked } \\
\text { loudly after } \\
\text { second cycle at } \\
240.5 \mathrm{MPa}\end{array}$ & $\begin{array}{l}\text {-Specimen } \\
\text { cracked at all } \\
\text { mortar joint } \\
\text { locations } \\
\text {-Max crack } \\
\text { width } 0.70 \mathrm{~mm}\end{array}$ & $\begin{array}{l}\text {-Max crack } \\
\text { width of } \\
0.82 \mathrm{~mm} \\
\text {-Second crack } \\
\text { at top mortar } \\
\text { joint location }\end{array}$ & $\begin{array}{c}\text {-Reached } \\
\text { average strain } \\
\text { of } 3.9 \% \\
\text {-Max crack } \\
\text { width } 8.4 \mathrm{~mm}\end{array}$ \\
\hline
\end{tabular}




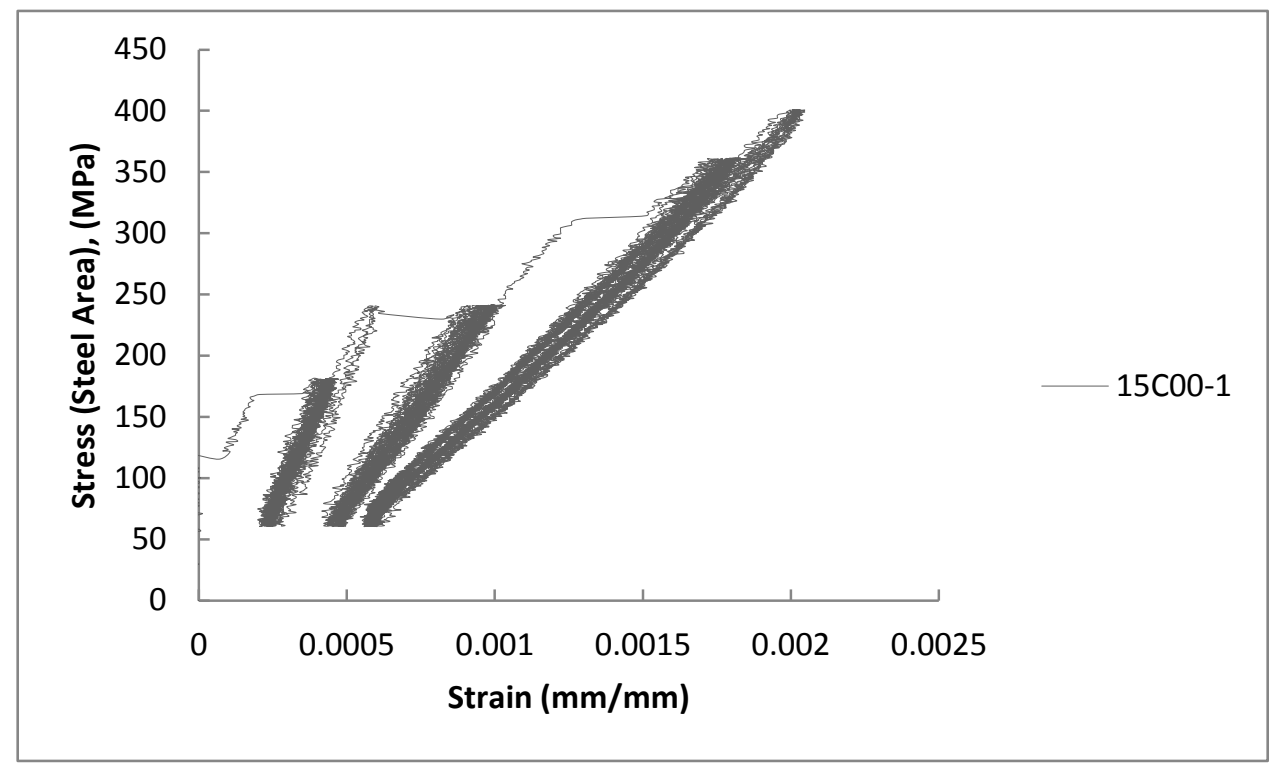

Figure 4-90: Stress strain response throughout cycling(15C00-1)

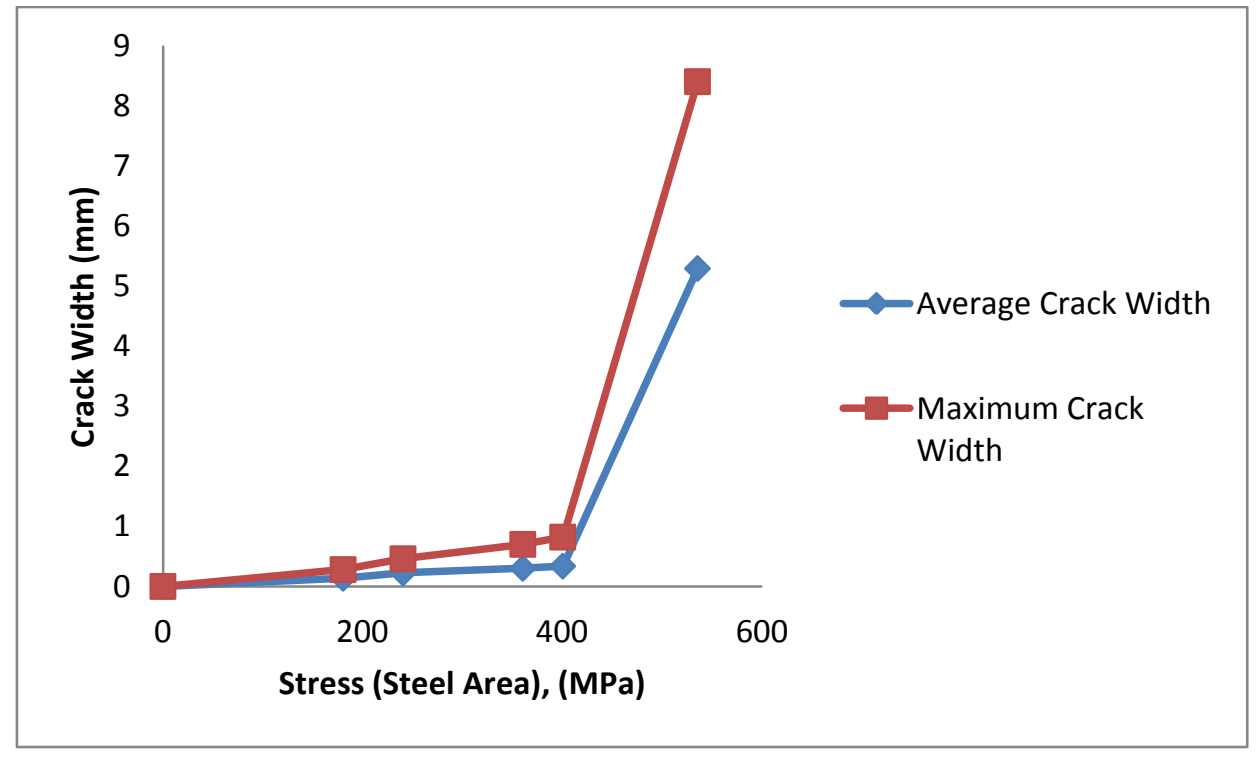

Figure 4-91: Average \& maximum crack widths (15C00-1) 


\subsubsection{Specimen 15C04S-1}

This specimen was tested on October $9^{\text {th }}, 2013$ and was the third specimen to be tested of the $15 \mathrm{M}$ cyclic tests at service loads. This specimen contained grout with $0.4 \%$ Dramix ZP305 steel fibres by volume. This specimen was tested to observe the effect that a minimal amount of steel fibres has on the controlling of cracking and the degradation of stiffness as the load is cycled in the service load range.

First cracking was present at the first load stage taken at $36.1 \mathrm{kN}$. At this load there was one single horizontal crack in the specimen. After the second cycle at a load of $48.1 \mathrm{kN}$, a second crack formed near the centre of the specimen. The cracks do not extend the full width of the specimen due to the contribution of the fibres. By a load of $80 \mathrm{kN}$, the specimen was cracked at three mortar joint locations. The crack pattern stayed the same until the load reached close to ultimate load. Bon splitting was present near the centre of the specimen. There were 6 horizontal cracks by the final load stage. The maximum crack width at approximately $110 \mathrm{kN}$ was $8.3 \mathrm{~mm}$.

The test was terminated when the load reached $110 \mathrm{kN}$ and the overall strain over the gauge length of the LVDTs reached approximately $3.4 \%$.

Figure 4.92 shows the stress-strain relationship of the specimen throughout the cycling of the load. Figure 4-93 shows both the average crack width and maximum crack as a function of stress. The stress is based on the steel area of the given specimen. 
Table 4-34: Test summary for specimen 15C04S-1

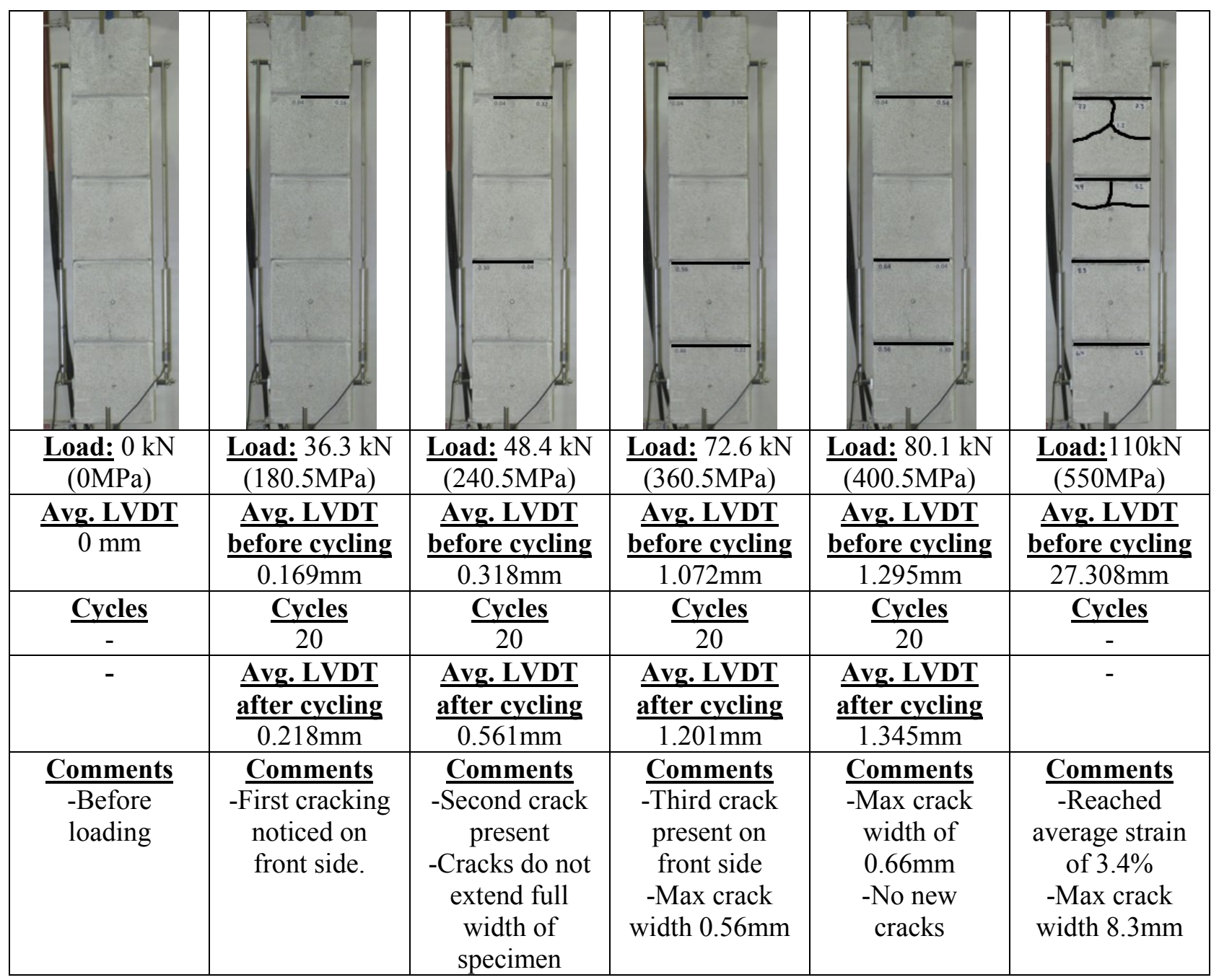




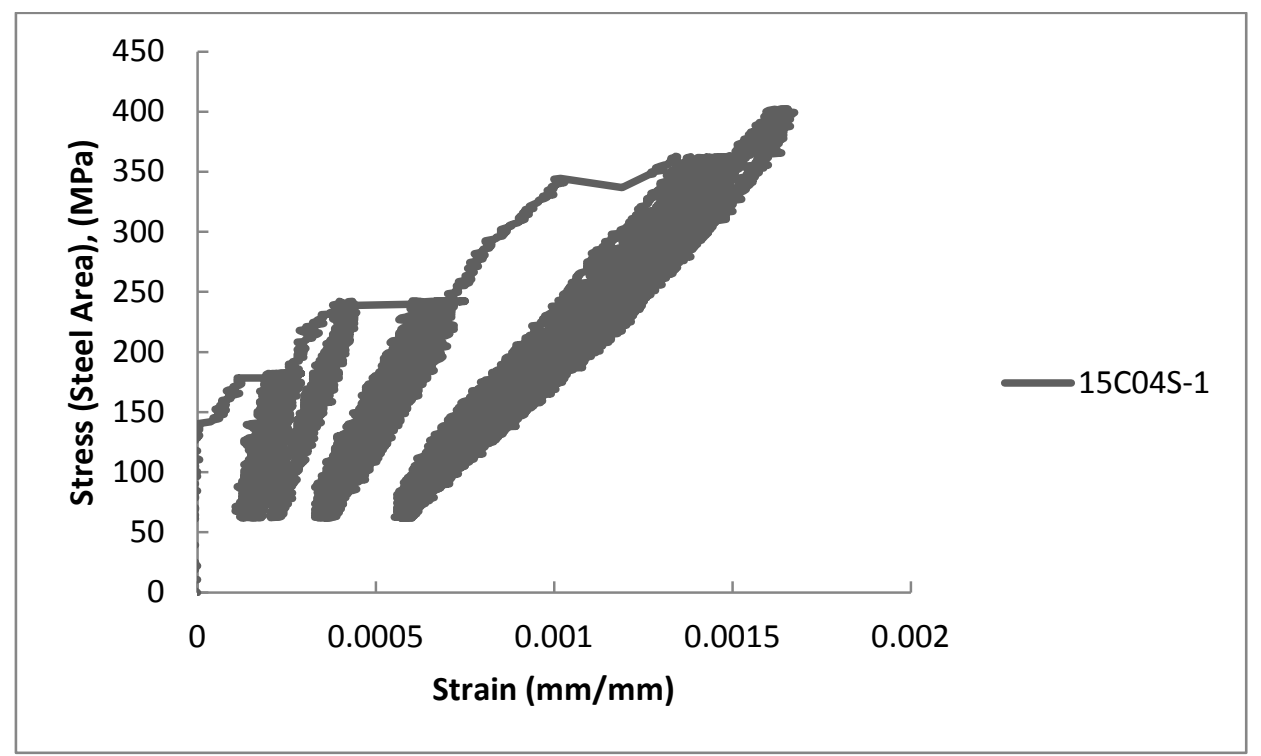

Figure 4-92: Stress strain response throughout cycling (15C04S-1)

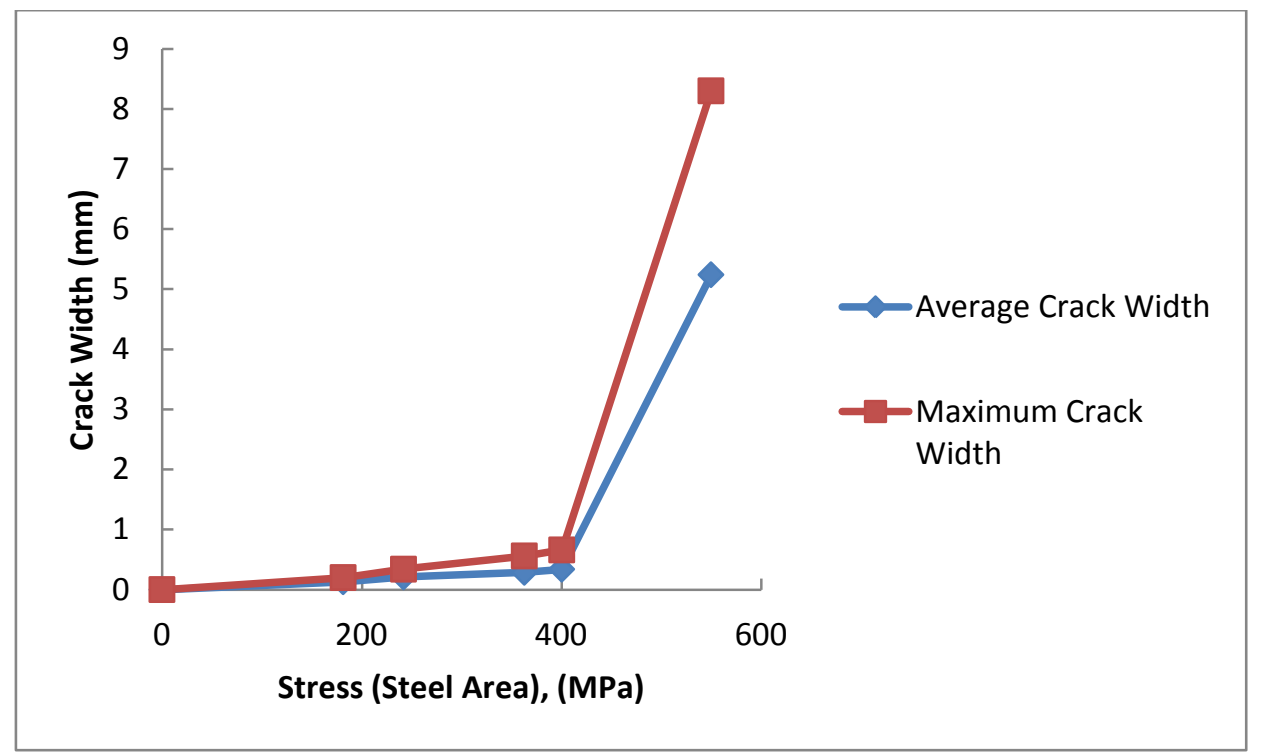

Figure 4-93: Average $\&$ maximum crack widths (15C04S-1) 


\subsubsection{Specimen 15C08S-1}

This specimen was tested on October $10^{\text {th }}, 2013$ and was the fourth specimen to be tested of the $15 \mathrm{M}$ cyclic tests at service loads. This specimen contained grout with $0.8 \%$ Dramix ZP305 steel fibres by volume. This specimen was tested to observe the effect that a moderate amount of steel fibres has on the controlling of cracking and the degradation of stiffness as the load is cycled in the service load range.

First cracking was present at the first load stage taken at $36.1 \mathrm{kN}$. At this load there was one single horizontal crack in the specimen. After the second cycle at a load of $48.1 \mathrm{kN}$, a second crack formed near the centre of the specimen. The cracks do not extend the full width of the specimen due to the contribution of the fibres. By a load of $80 \mathrm{kN}$, the specimen was cracked at three mortar joint locations. The crack pattern stayed the same until the load reached close to ultimate load. Bond splitting was present near the centre of the specimen, however cracks were not allowed to open very wide. There were 5 horizontal cracks by the final load stage. The maximum crack width at approximately $110 \mathrm{kN}$ was $10.5 \mathrm{~mm}$.

The test was terminated when the load reached $110 \mathrm{kN}$ and the overall strain over the gauge length of the LVDTs reached approximately $2.1 \%$. Strain localization was beginning at the second mortar joint from the top of the specimen.

Figure 4-94 shows the stress-strain relationship of the specimen throughout the cycling of the load. Figure 4-95 shows both the average crack width and maximum crack as a function of stress. The stress is based on the steel area of the given specimen. 
Table 4-35: Test summary for specimen 15C08S-1

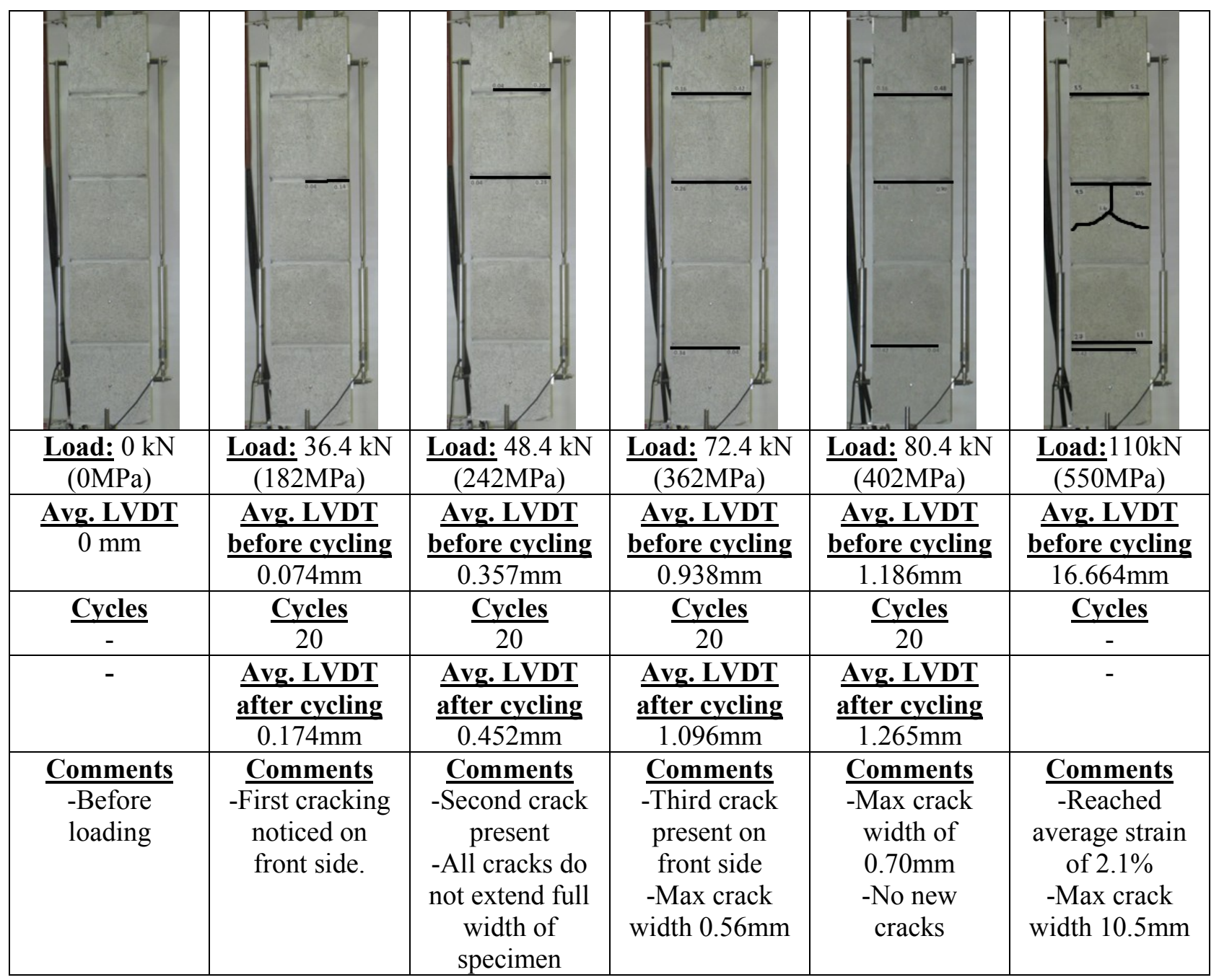




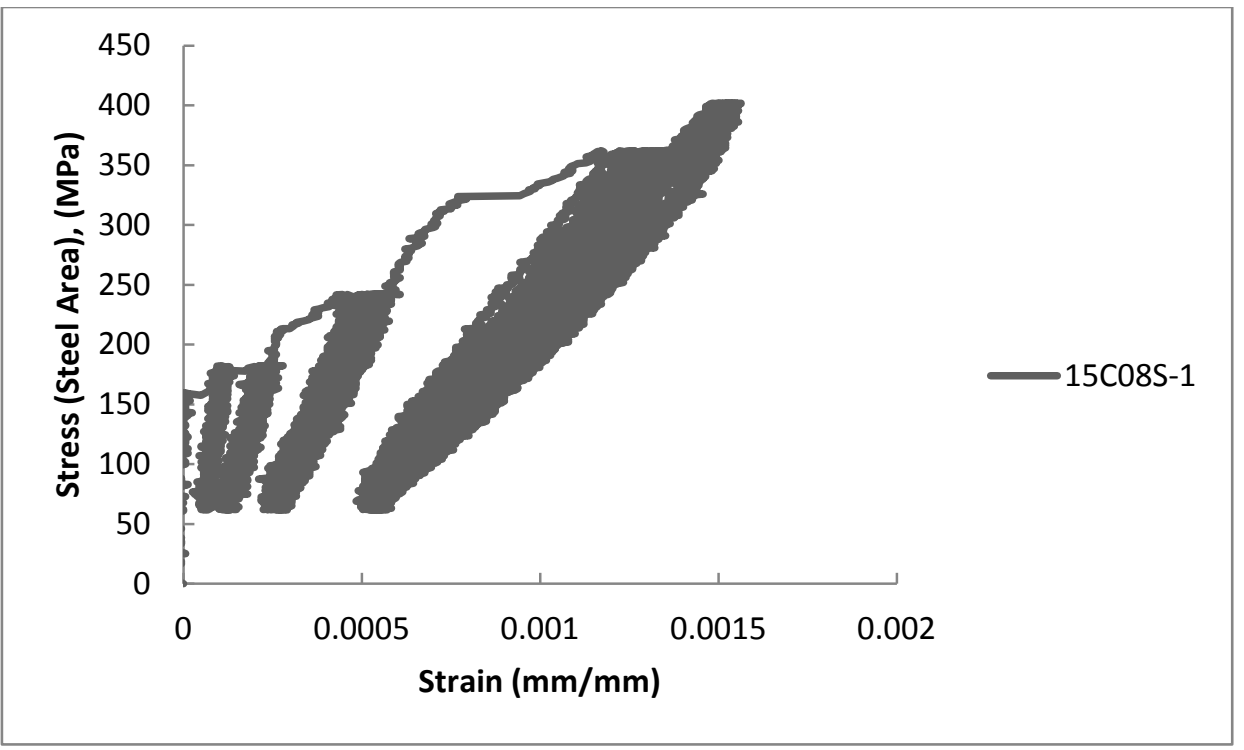

Figure 4-94: Stress strain response throughout cycling (15C08S-1)

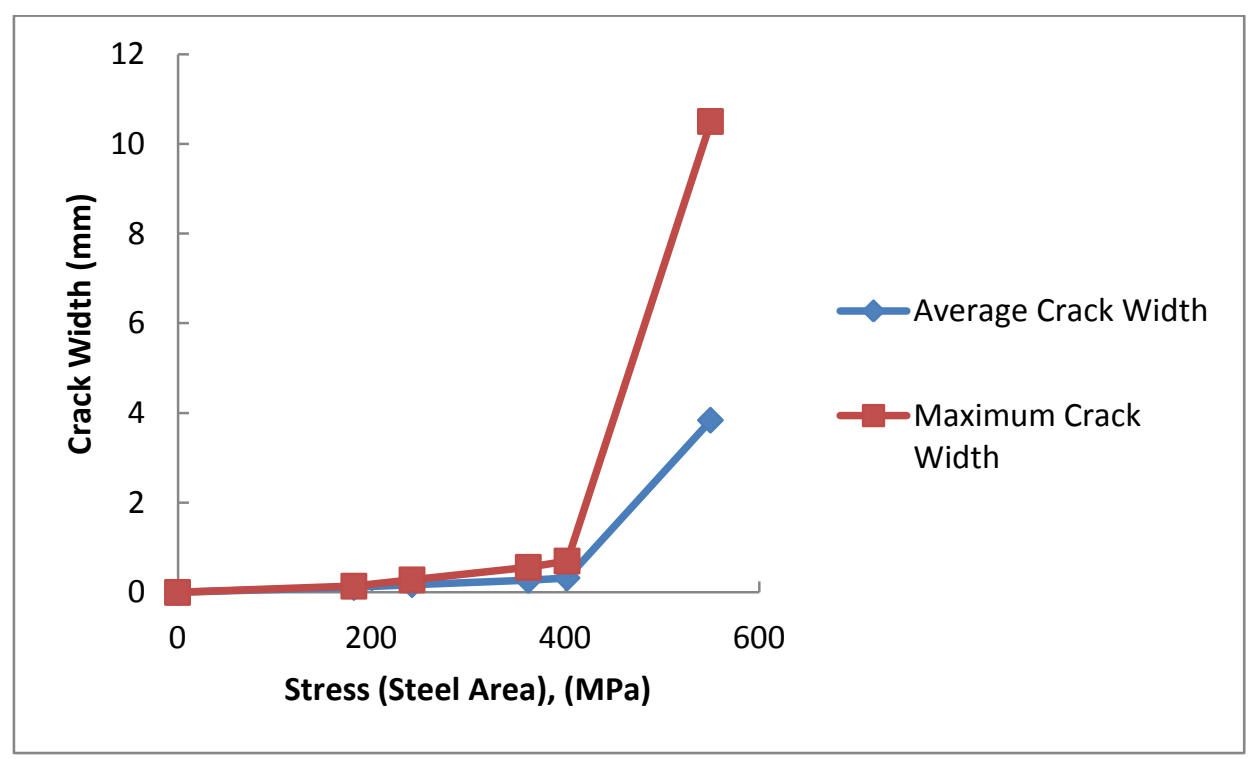

Figure 4-95: Average \& maximum crack widths (15C08S-1) 


\subsubsection{Specimen 15C12S-1}

This specimen was tested on October $8^{\text {th }}, 2013$ and was the first specimen to be tested of the $15 \mathrm{M}$ cyclic tests at service loads. This specimen contained grout with 1.2\% Dramix ZP305 steel fibres by volume. This specimen was tested to observe the effect that a large amount of steel fibres has on the controlling of cracking and the degradation of stiffness as the load is cycled in the service load range.

There was an error in the program, and the load accidentally was increased to $50 \mathrm{kN}$ rapidly. When it was noticed that the load was not cycling properly, the program was stopped and the test was restarted. The first cracks which are present in the figure below are from when the load was increased to $50 \mathrm{kN}$ and do not accurately represent the behaviour of the specimen at low levels of load. The cracks do not extend the full width of the specimen due to the contribution of the fibres. By a load of $80 \mathrm{kN}$, the specimen was cracked at three mortar joint locations. The crack pattern stayed the same until the load reached close to ultimate load. There were 5 horizontal cracks by the final load stage. The maximum crack width at approximately $110 \mathrm{kN}$ was $6.5 \mathrm{~mm}$.

The test was terminated when the load reached $110 \mathrm{kN}$ and the overall strain over the gauge length of the LVDTs reached approximately $2.1 \%$. Strain localization was beginning at the second mortar joint from the top of the specimen.

Figure 4-96 shows the stress-strain relationship of the specimen throughout the cycling of the load. Figure 4-97 shows both the average crack width and maximum crack as a function of stress. The stress is based on the steel area of the given specimen. 
Table 4-36: Test summary for specimen $15 \mathrm{C} 12 \mathrm{~S}-1$

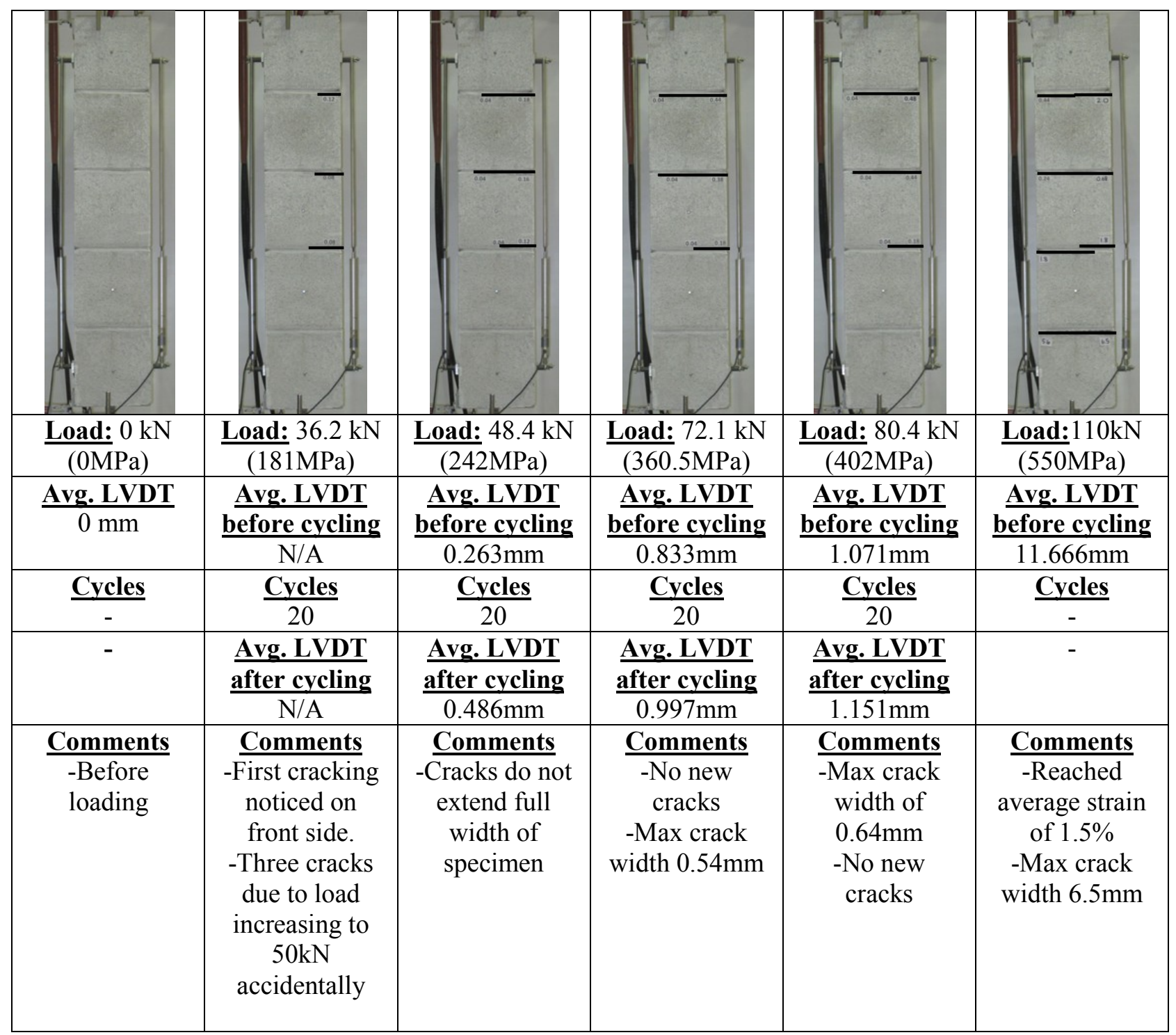




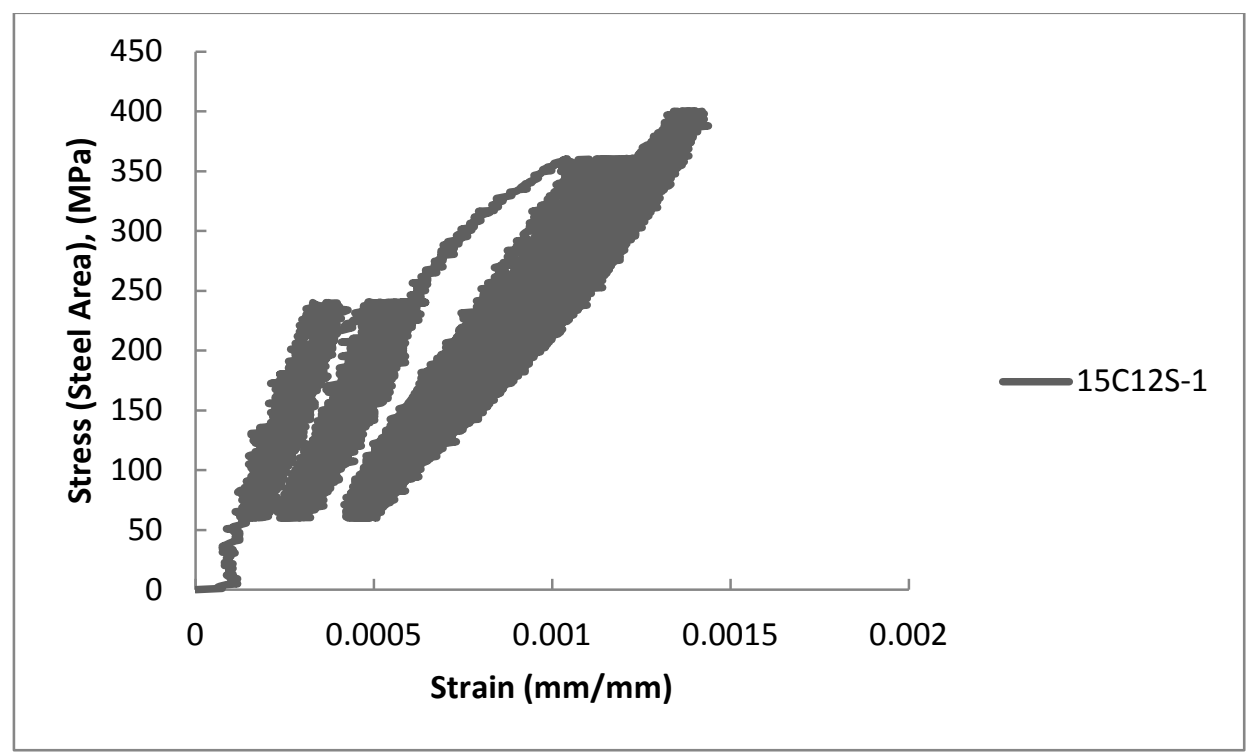

Figure 4-96: Stress strain response throughout cycling (15C12S-1)

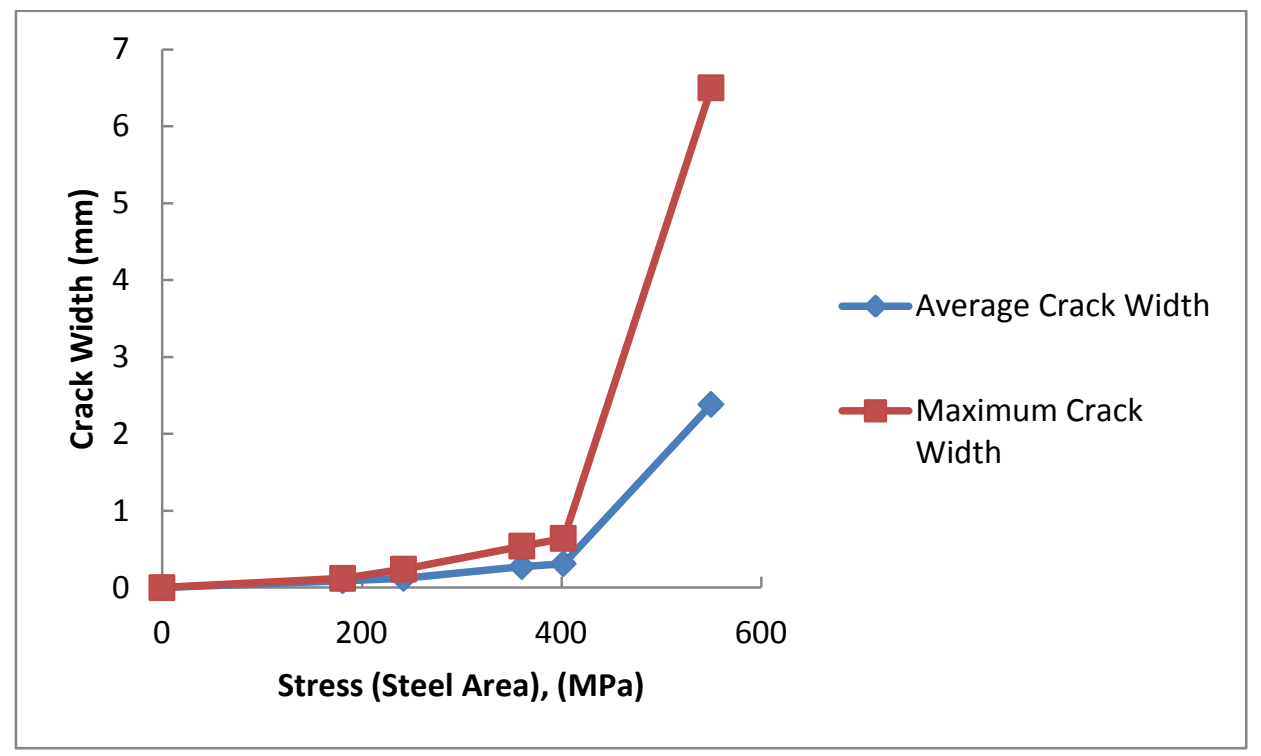

Figure 4-97: Average \& maximum crack widths (15C12S-1) 


\subsubsection{Specimen 20C00-1}

This specimen was tested on October $21^{\text {st }}, 2013$ and was the last specimen to be tested of the $20 \mathrm{M}$ cyclic tests at service loads. This specimen contained grout with no fibres and served as the control specimen for all cyclic tests in this series.

First cracking was present at the first load stage taken at $54.8 \mathrm{kN}$. At this load there were four horizontal cracks in the specimen. The crack pattern stayed the same until the load approached the ultimate load. Bond splitting was present at multiple locations on the specimen. At the final load stage there were 8 horizontal cracks on the specimen. The cycling of the loads seemed to have minimal effect on the opening of the cracks.

The test was terminated when the load reached $165 \mathrm{kN}$ and the overall strain over the gauge length of the LVDTs reached approximately $2.6 \%$.

Figure 4-98 shows the stress-strain relationship of the specimen throughout the cycling of the load. Figure 4-99 shows both the average crack width and maximum crack as a function of stress. The stress is based on the steel area of the given specimen. 
Table 4-37: Test summary for specimen 20C00-1

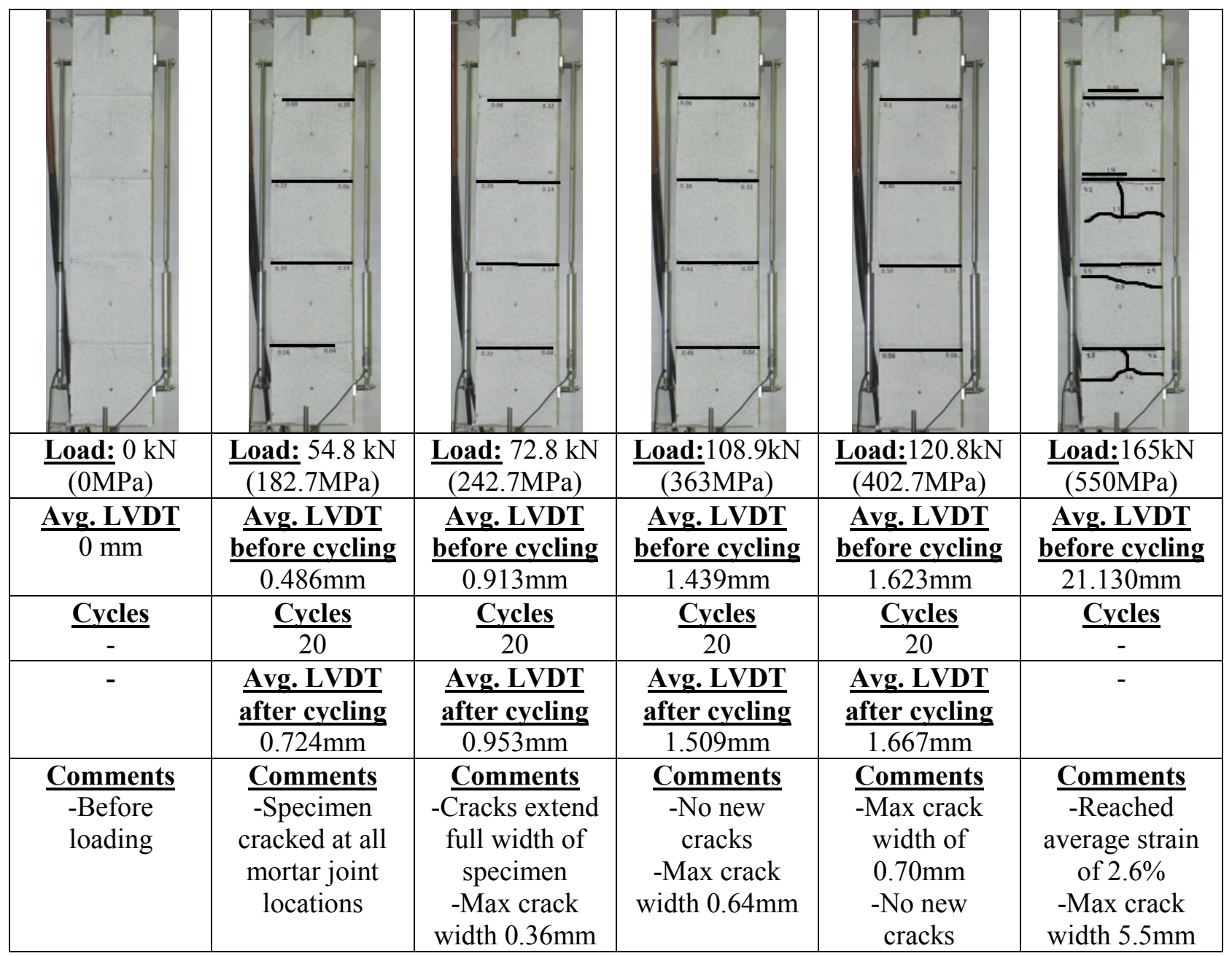




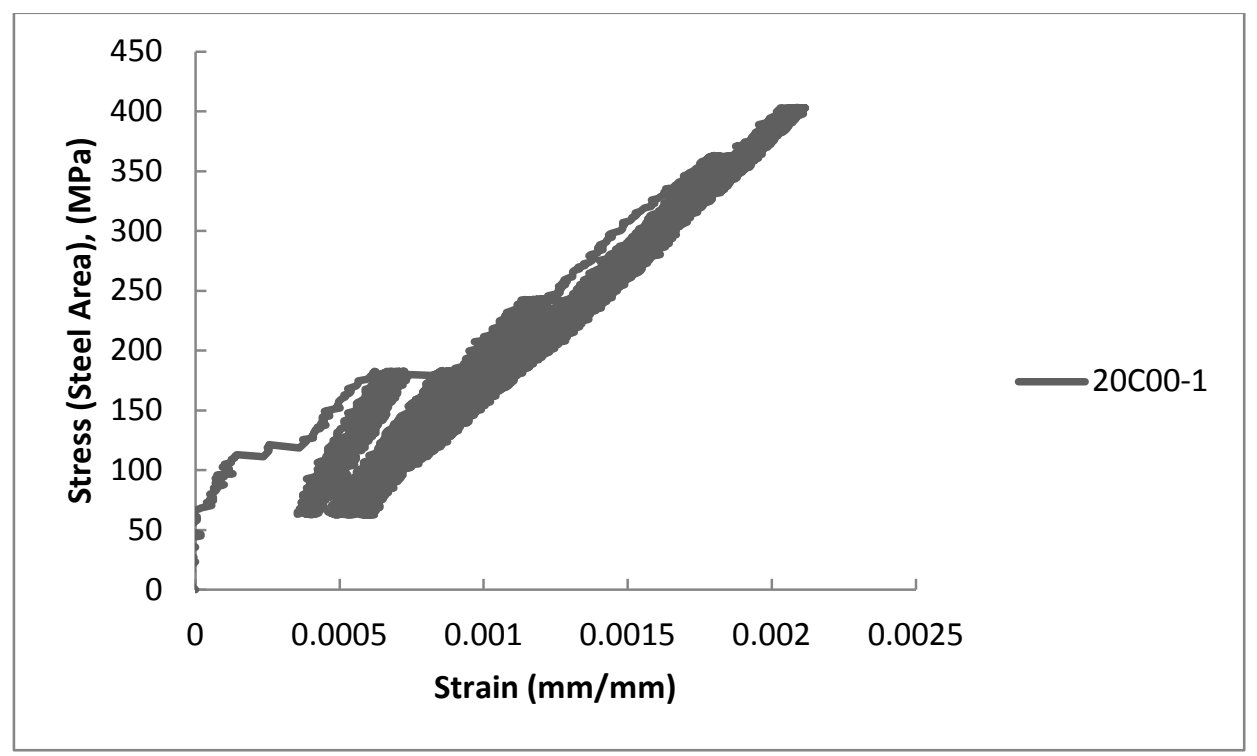

Figure 4-98: Stress strain response throughout cycling (20C00-1)

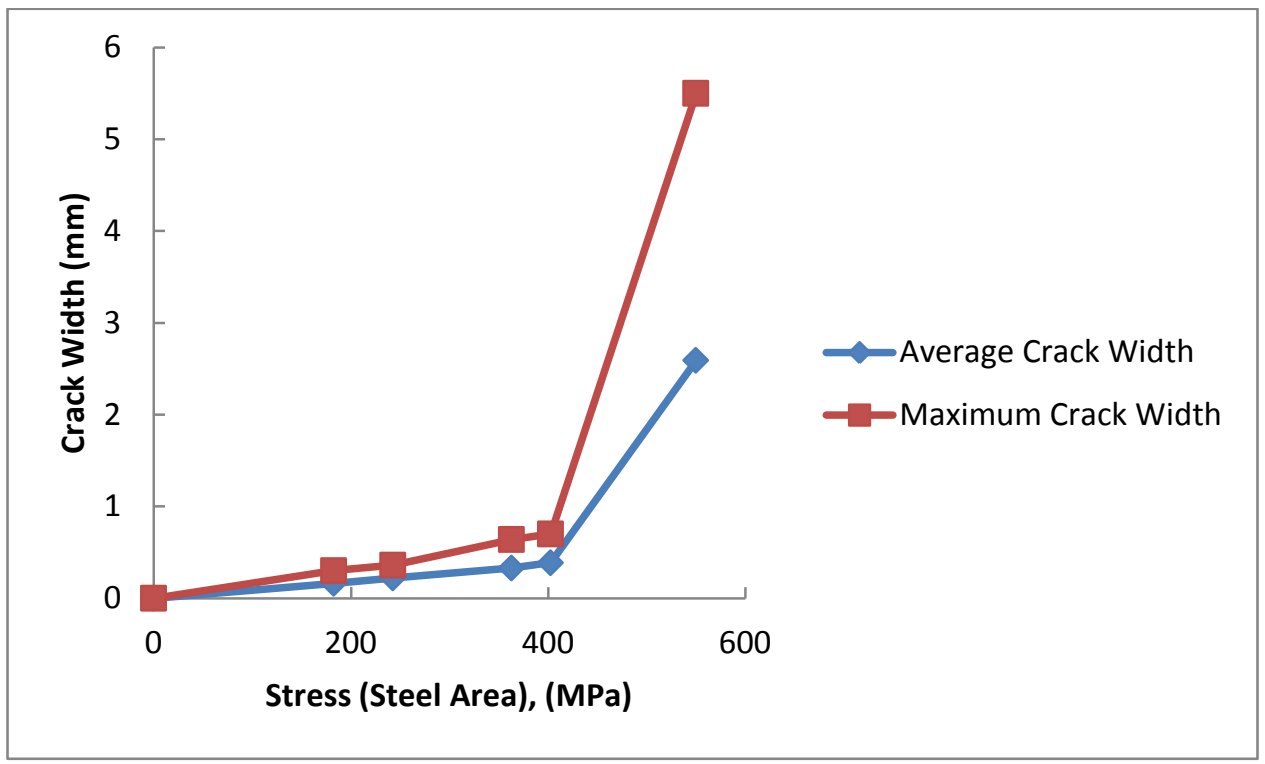

Figure 4-99: Average \& maximum crack widths (20C00-1) 


\subsubsection{Specimen 20C04S-1}

This specimen was tested on October $11^{\text {th }}, 2013$ and was the second specimen to be tested of the $20 \mathrm{M}$ cyclic tests at service loads. This specimen contained grout with $0.4 \%$ Dramix ZP305 steel fibres by volume. This specimen was tested to observe the effect that a minimal amount of steel fibres has on the controlling of cracking and the degradation of stiffness as the load is cycled in the service load range.

First cracking was present at the first load stage taken at $54.4 \mathrm{kN}$. At this load there was four horizontal cracks in the specimen. The cracks initially did not extend the full width of the specimen due to the contribution of the fibres. The crack pattern stayed the same until the load reached close to ultimate load. Bond splitting was present near the centre of the specimen; however cracks were not allowed to open very wide. There were 8 horizontal cracks by the final load stage. The maximum crack width at approximately $165.0 \mathrm{kN}$ was $5.6 \mathrm{~mm}$.

The test was terminated when the load reached $165.8 \mathrm{kN}$ and the overall strain over the gauge length of the LVDTs reached approximately $2.1 \%$.

Figure 4-100 shows the stress-strain relationship of the specimen throughout the cycling of the load. Figure 4-101 shows both the average crack width and maximum crack as a function of stress. The stress is based on the steel area of the given specimen. 
Table 4-38: Test summary for specimen 20C04S-1

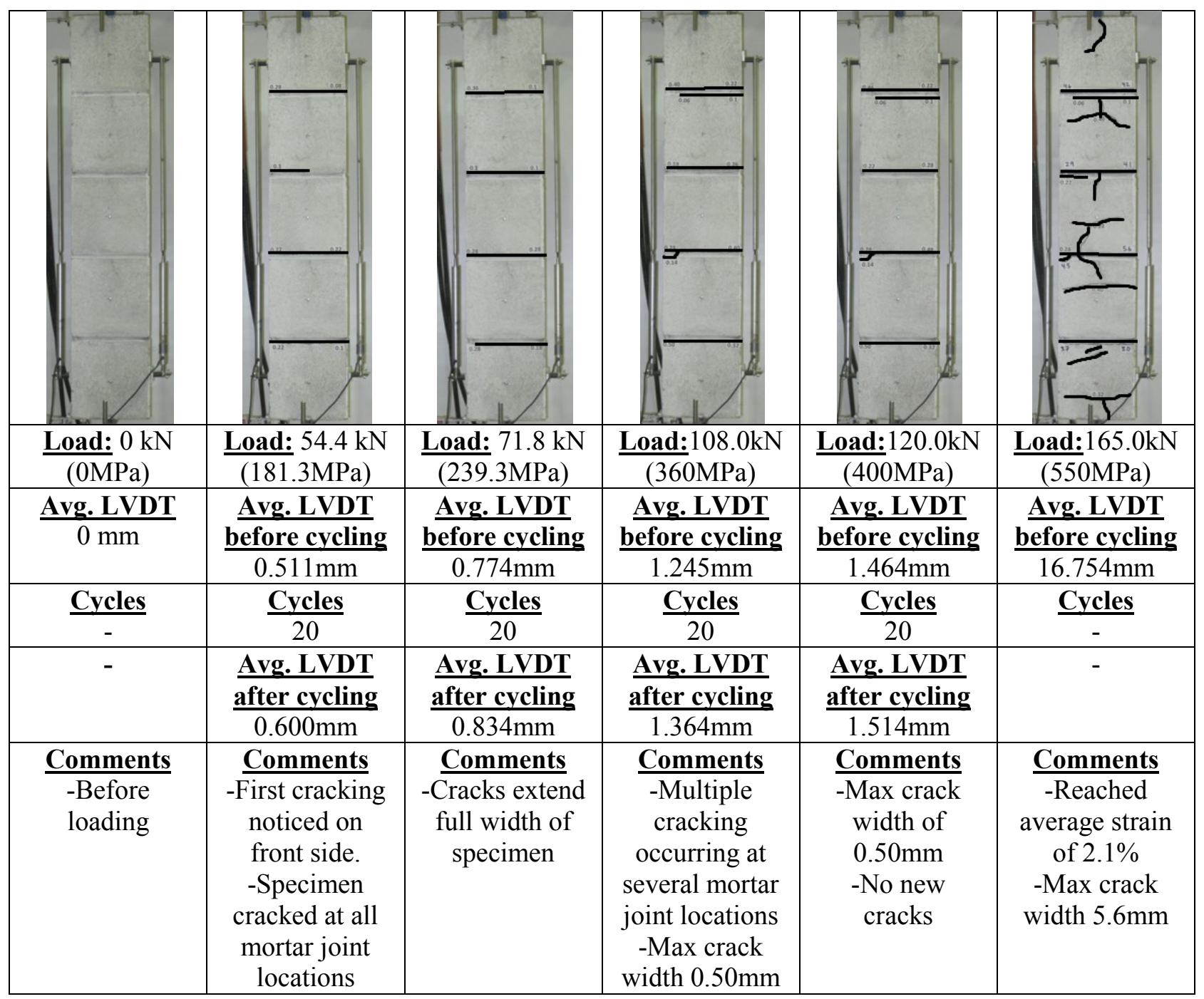




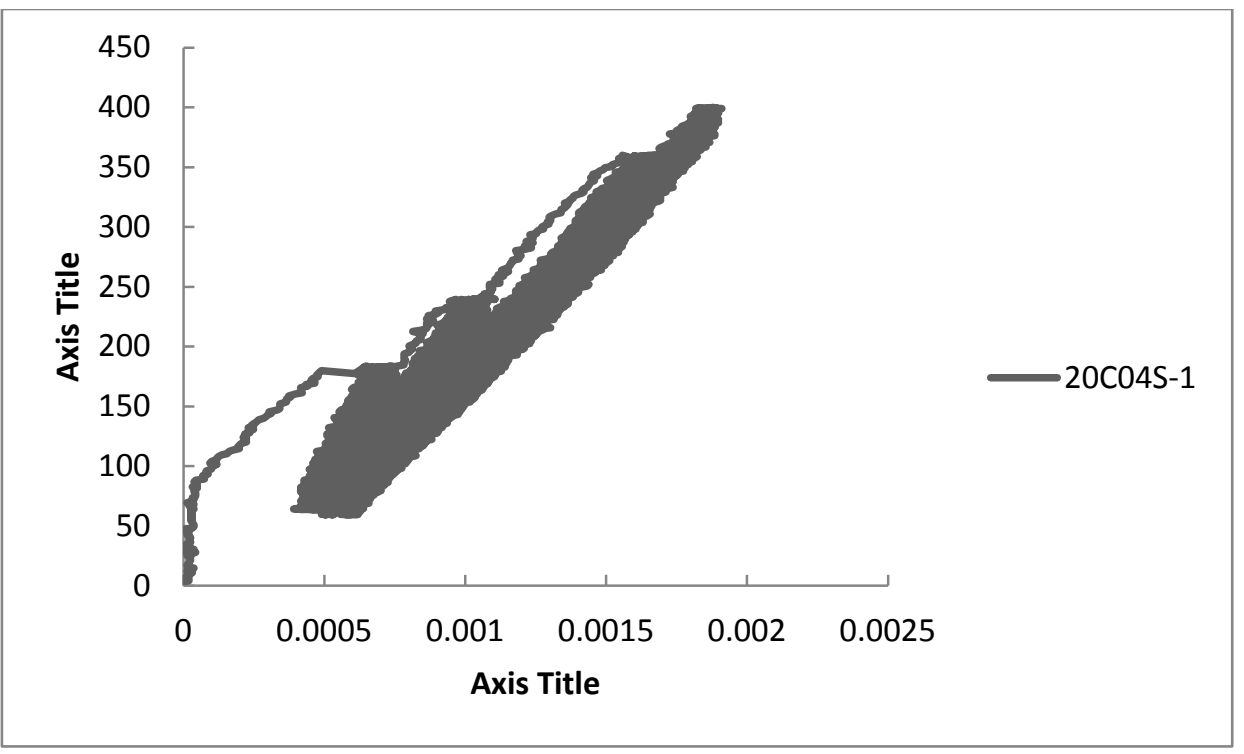

Figure 4-100: Stress strain response throughout cycling (20C04S-1)

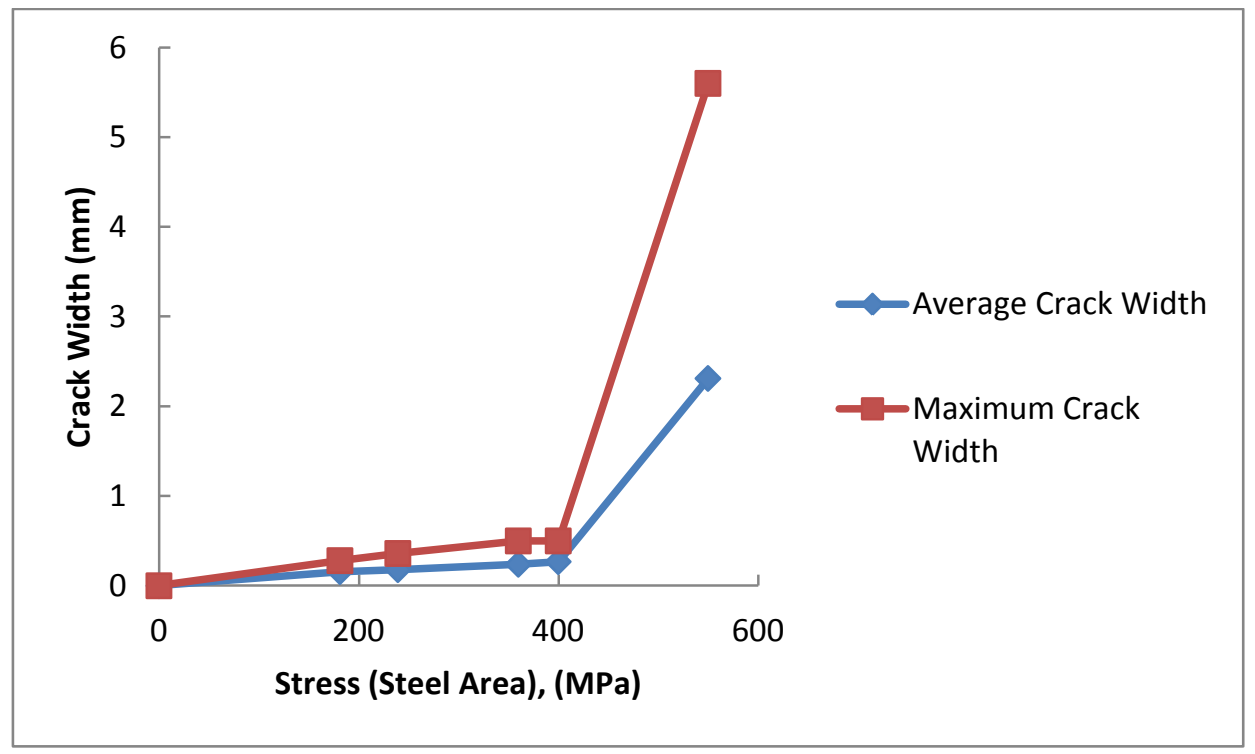

Figure 4-101: Average \& maximum crack width (20C04S-1) 


\subsubsection{Specimen 20C08S-1}

This specimen was tested on October $11^{\text {th }}, 2013$ and was the third specimen to be tested of the $20 \mathrm{M}$ cyclic tests at service loads. This specimen contained grout with $0.8 \%$ Dramix ZP305 steel fibres. This specimen was tested to observe the effect that a moderate amount of steel fibres has on the controlling of cracking and the degradation of stiffness as the load is cycled in the service load range.

First cracking was present at the first load stage taken at $36.1 \mathrm{kN}$. At this load there were three horizontal cracks in the specimen. The crack pattern stayed the same until the load reached close to ultimate load. There were 4 horizontal cracks by the final load stage. All cracks were minimal in width except for the crack located at the second mortar joint from the bottom which increased in width much more rapidly than the rest and reached a maximum width of $4.6 \mathrm{~mm}$.

The test was terminated when the load reached $165 \mathrm{kN}$ and the overall strain over the gauge length of the LVDTs reached approximately $0.74 \%$. Strain localization was beginning at the second mortar joint from the bottom of the specimen.

Figure 4-102 shows the stress-strain relationship of the specimen throughout the cycling of the load. Figure 4-103 shows both the average crack width and maximum crack as a function of stress. The stress is based on the steel area of the given specimen. 
Table 4-39: Test summary for specimen 20C08S-1

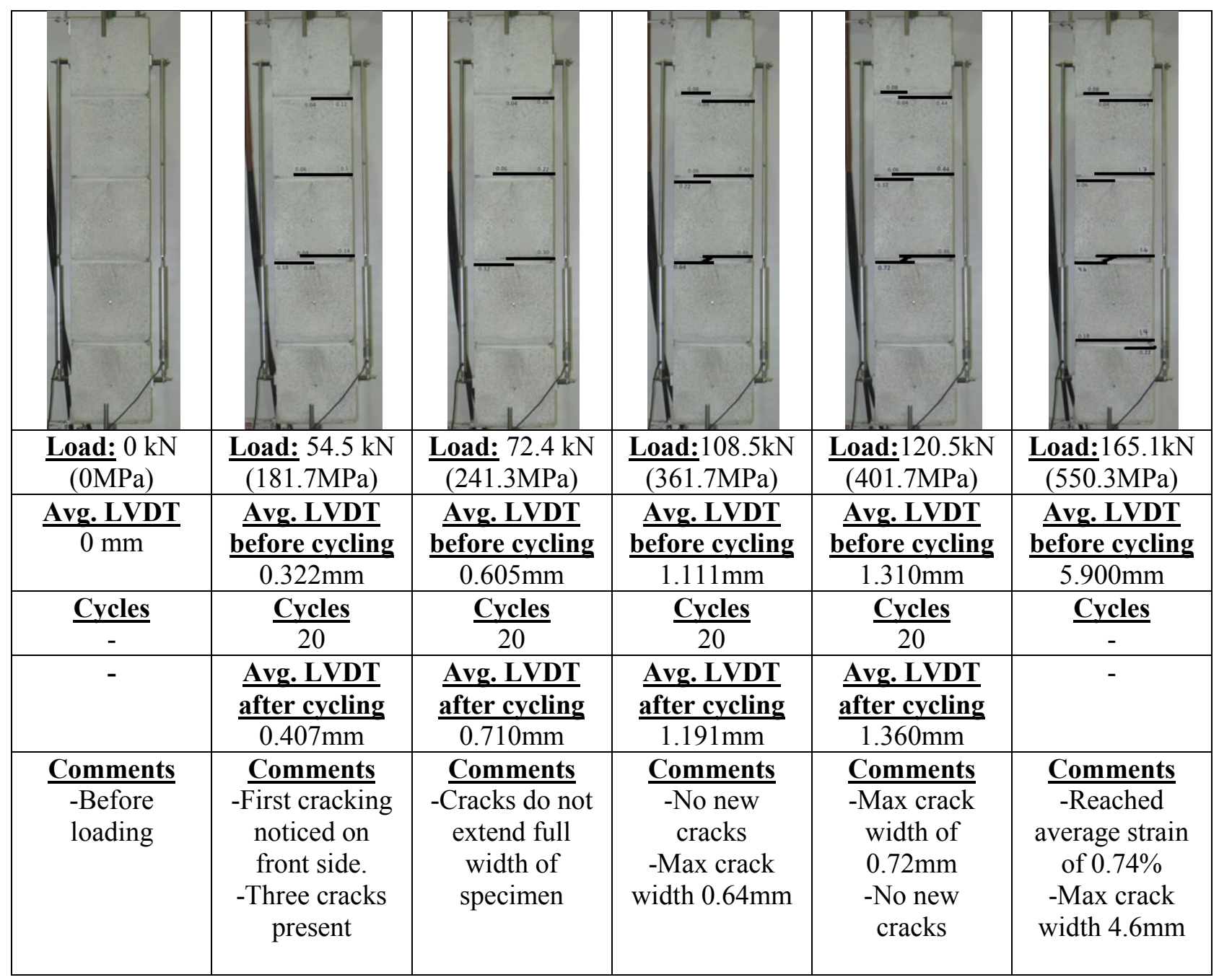




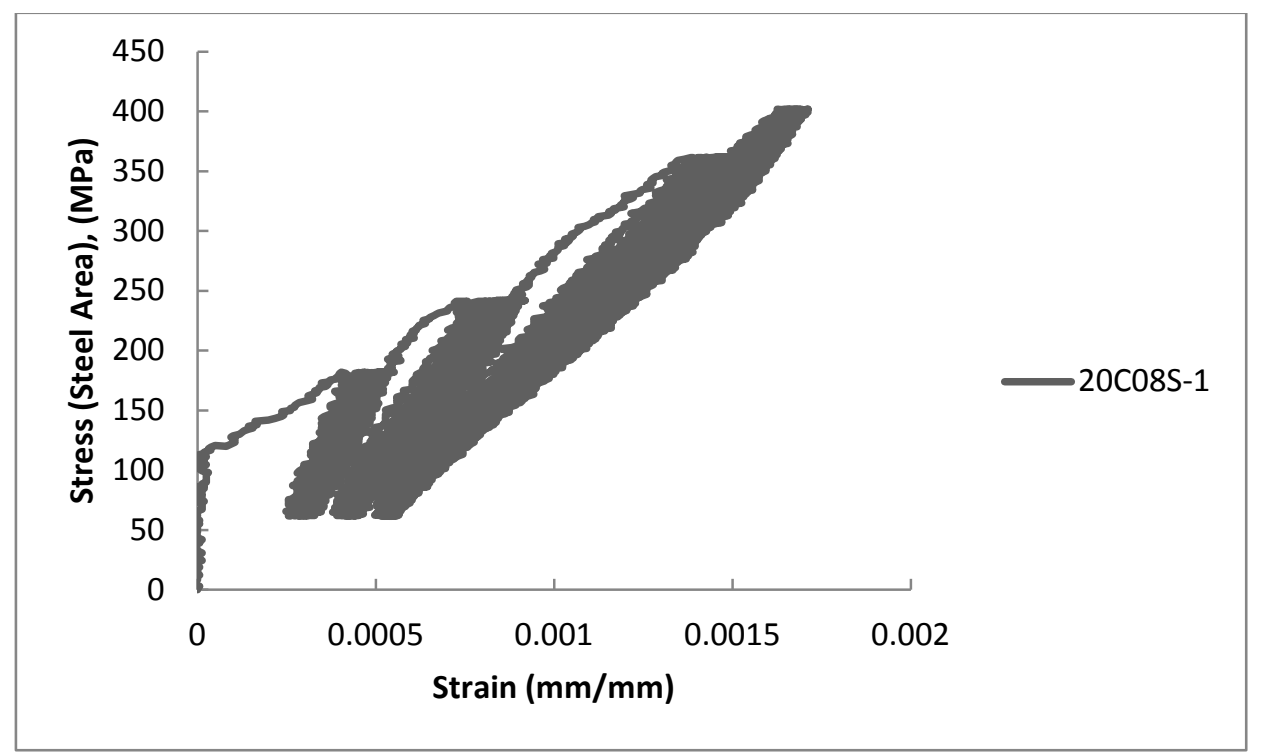

Figure 4-102: Stress strain response throughout cycling (20C08S-1)

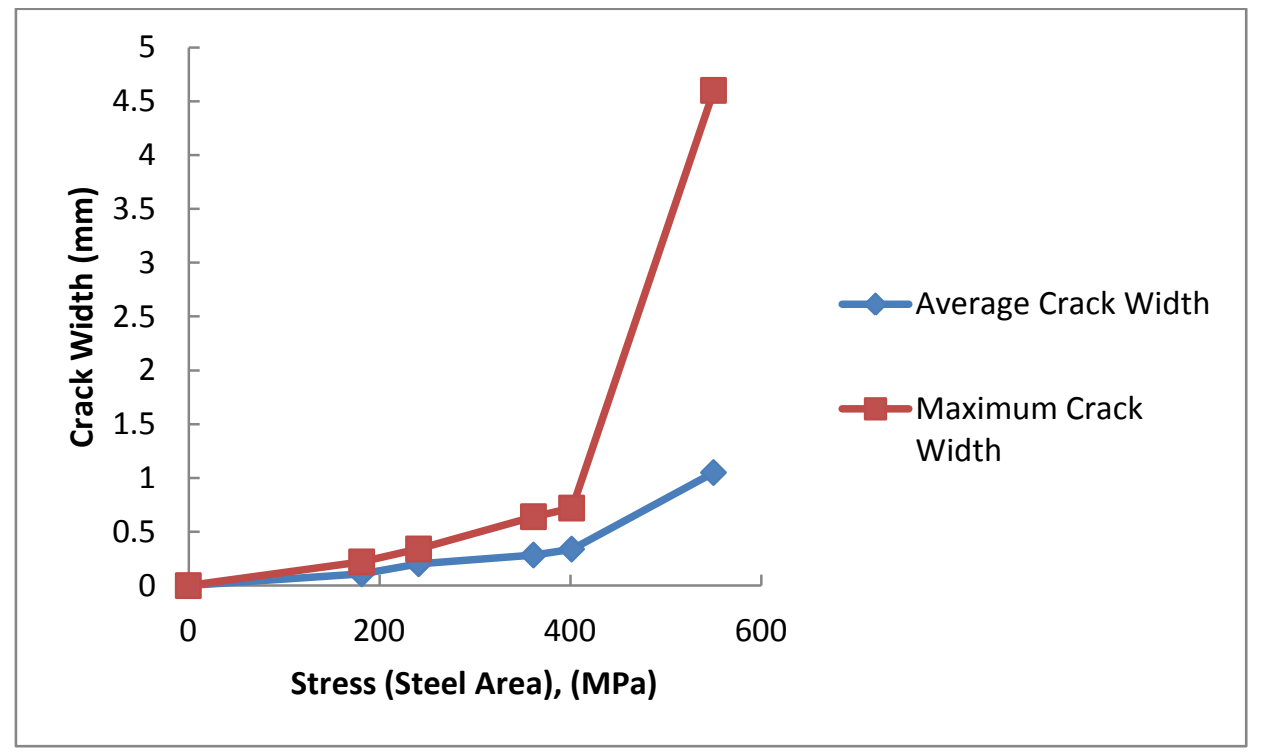

Figure 4-103: Average \& maximum crack widths (20C08S-1) 


\subsubsection{Specimen $20 C 12 S-1$}

This specimen was tested on October $10^{\text {th }}, 2013$ and was the first specimen to be tested of the $20 \mathrm{M}$ cyclic tests at service loads. This specimen contained grout with $1.2 \%$ Dramix ZP305 steel fibres. This specimen was tested to observe the effect that a high amount of steel fibres has on the controlling of cracking and the degradation of stiffness as the load is cycled in the service load range.

First cracking was present at the first load stage taken at $72.5 \mathrm{kN}$. At this load there was one single horizontal crack in the specimen. The cracks do not extend the full width of the specimen due to the contribution of the fibres. The crack pattern stayed the same, with a single horizontal crack until the load reached close to ultimate load, when a second horizontal crack opened. The maximum crack width at approximately $165.8 \mathrm{kN}$ was $0.70 \mathrm{~mm}$.

The test was terminated when the load reached $165.8 \mathrm{kN}$ and the overall strain over the gauge length of the LVDTs reached approximately $0.17 \%$.

Figure 4-104 shows the stress-strain relationship of the specimen throughout the cycling of the load. Figure 4-105 shows both the average crack width and maximum crack as a function of stress. The stress is based on the steel area of the given specimen. 
Table 4-40: Test summary for specimen 20C12S-1

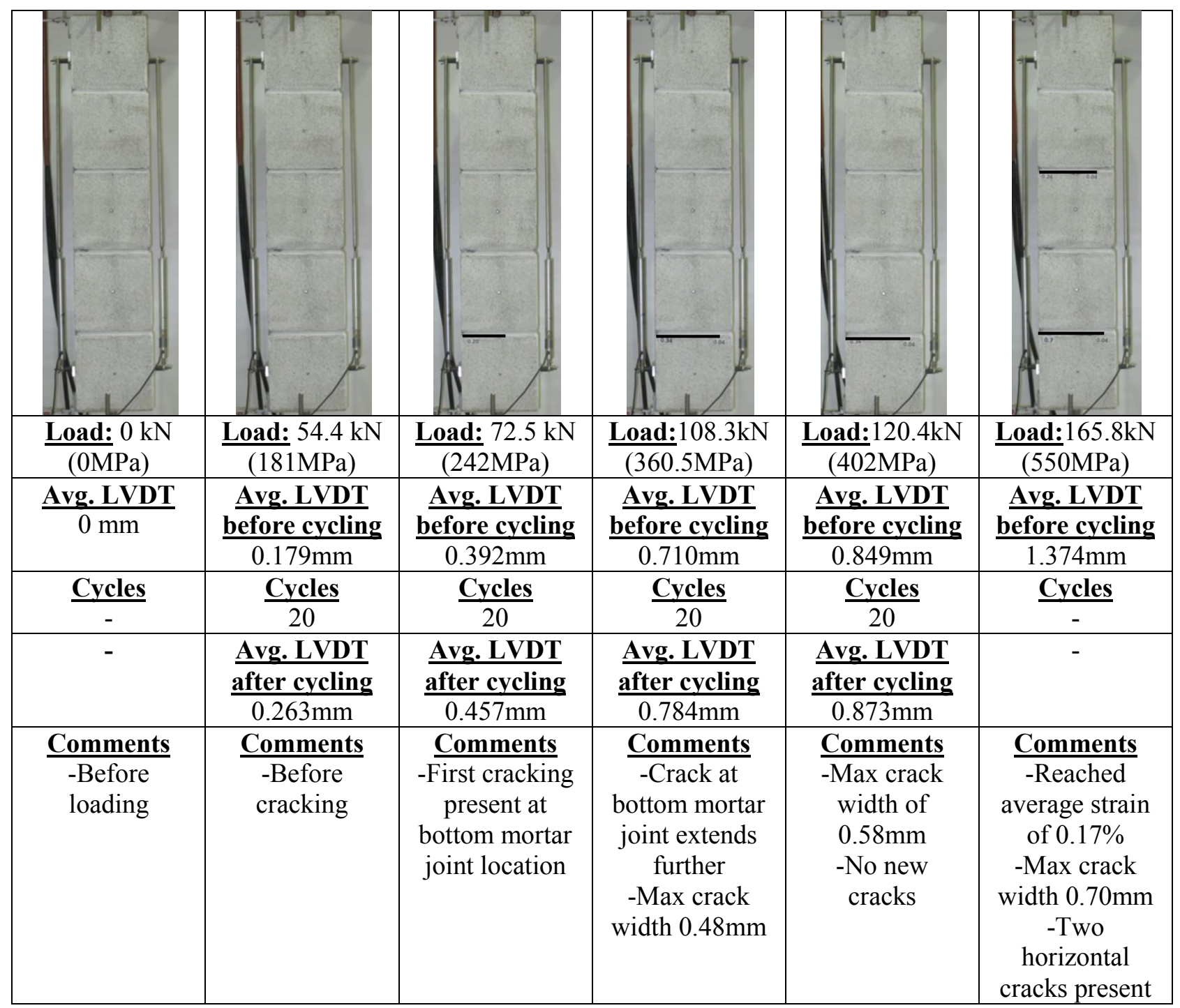




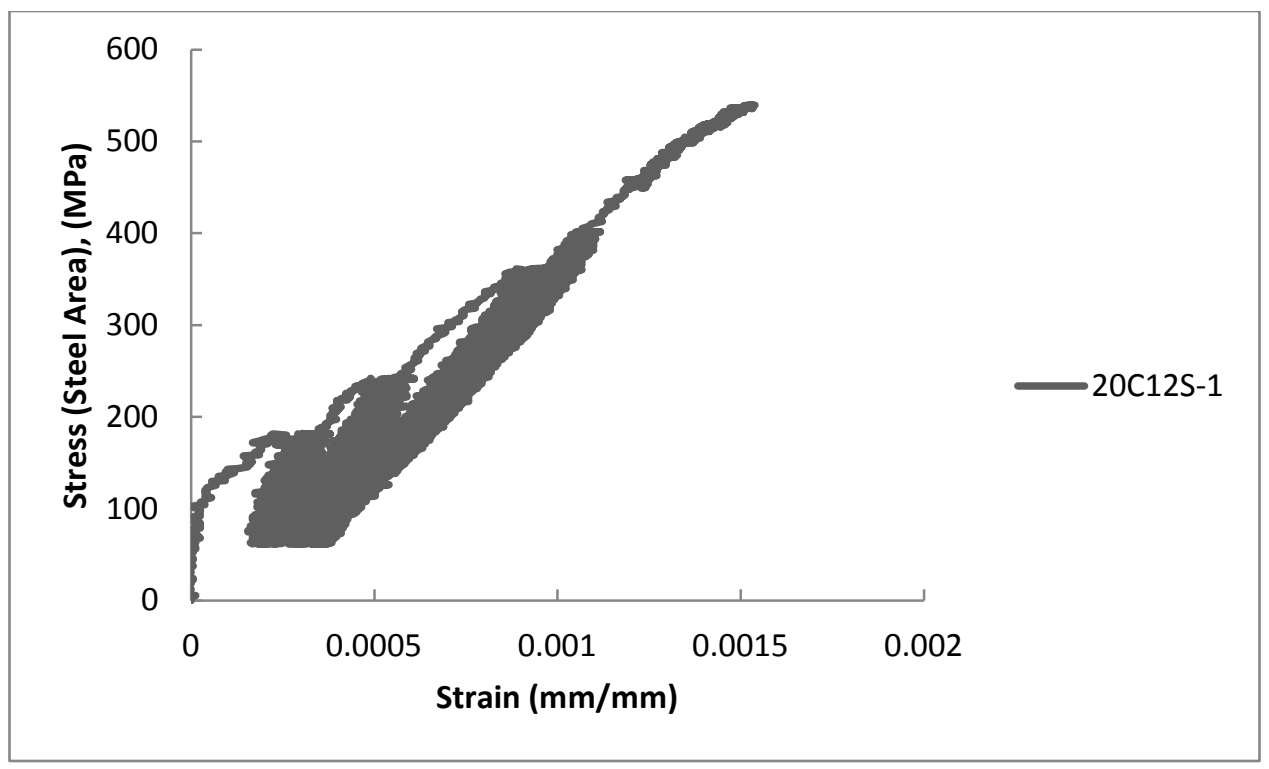

Figure 4-104: Stress strain response throughout cycling (20C12S-1)

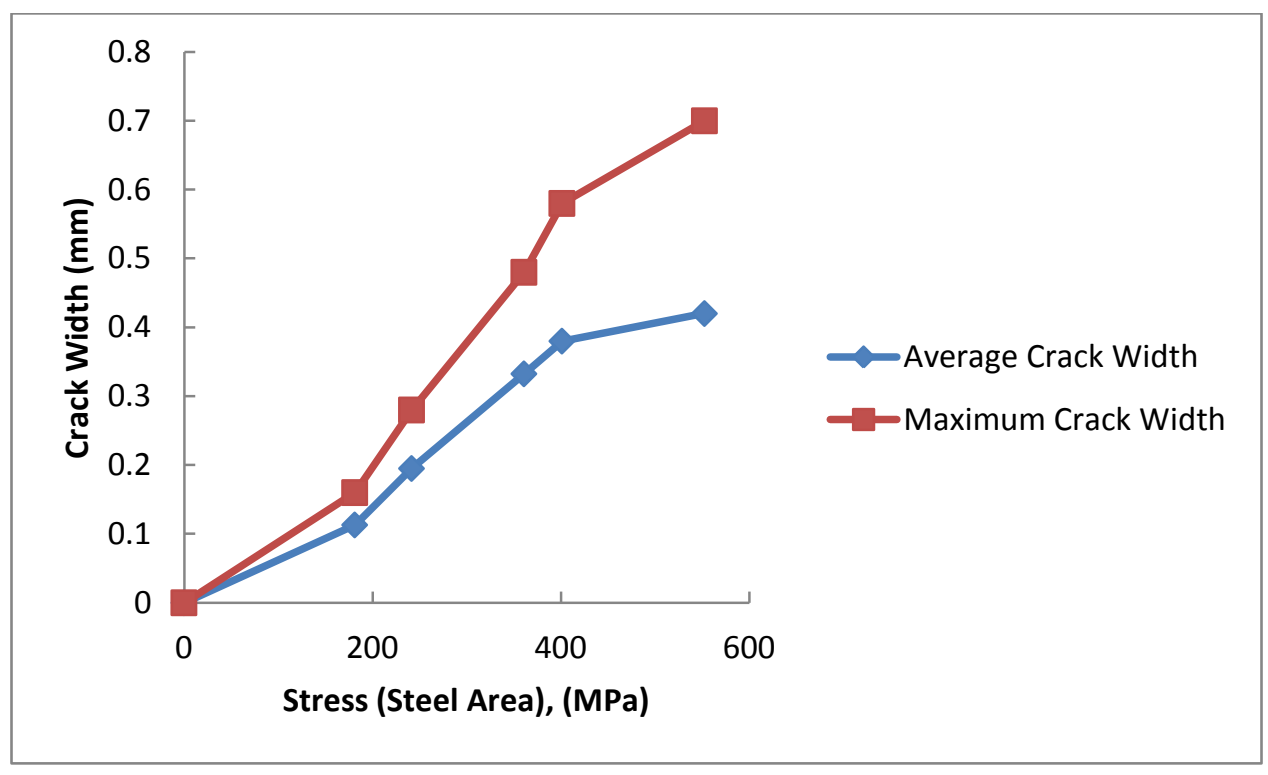

Figure 4-105: Average \& maximum crack widths (20C12S-1) 


\subsubsection{Cyclic Load at Post-Yield Loads}

The following specimens were tested under cyclic load in the post yield range of the reinforcing steel. All testing took place under displacement control, using the LVDTs to control the displacement.

First the specimen was strained until the displacement of the LVDTs mounted on the sides of the specimen reached an average reading of $1.6 \mathrm{~mm}$, which corresponds to the theoretical yield strain of the reinforcing steel. At this point the load was decreased to zero load and the process was repeated 20 times. Next, the specimen was strained until the displacement of the LVDTs mounted on the sides of the specimen reached an average reading of $3.2 \mathrm{~mm}$, which corresponds to two times the theoretical yield strain of the reinforcing steel. At this point the load was decreased to zero load and the process was repeated 20 times. Next, the specimen was strained until the displacement of the LVDTs mounted on the sides of the specimen reached an average reading of $4.8 \mathrm{~mm}$, which corresponds to three times the theoretical yield strain of the reinforcing steel. At this point the load was decreased to zero load and the process was repeated 20 times.

The data from these tests will be used to analyze the effectiveness of steel fibre reinforced grout in maintaining masonry's tensile structural properties under exposure to an extreme loading event such as an earthquake or a blast. 


\subsubsection{Specimen 15C00-2}

This specimen was tested on October $24^{\text {th }}, 2013$ and was the third specimen to be tested of the $15 \mathrm{M}$ cyclic tests at post-yield. This specimen contained no fibres and served as a control specimen for all specimens tested in the $15 \mathrm{M}$ cyclic series.

The specimen was fully cracked at all mortar joint locations at the first load stage which was taken when the average LVDT readings corresponded to the theoretical yield strain of the reinforcing steel. After the second cycling at two times the theoretical yield strain, the specimen did not develop any further cracking and had a maximum crack width of $1.7 \mathrm{~mm}$. After a third cycling at three times the theoretical yield strain, the specimen still did not develop any further cracking and the maximum crack width was increased to $1.9 \mathrm{~mm}$. At the final load stage, there were 4 horizontal cracks in the specimen.

The test was terminated after the specimen was cycled at a strain corresponding to three times the theoretical yield strain or $4.8 \mathrm{~mm}$ over the $800 \mathrm{~mm}$ gauge length.

Figure 4-107 shows the stress-strain relationship of the specimen throughout the cycling of the load in the post yield range. Figure 4-108 shows the relationship between the average LVDT displacement (average strain in the specimen) and the load carrying capacity at that given displacement. There are two lines, one represents the load carrying capacity before cycling at a given strain level and the other represents the load carrying capacity after the cycling was completed. 
Table 4-41: Test summary for specimen $15 \mathrm{C00}-2$

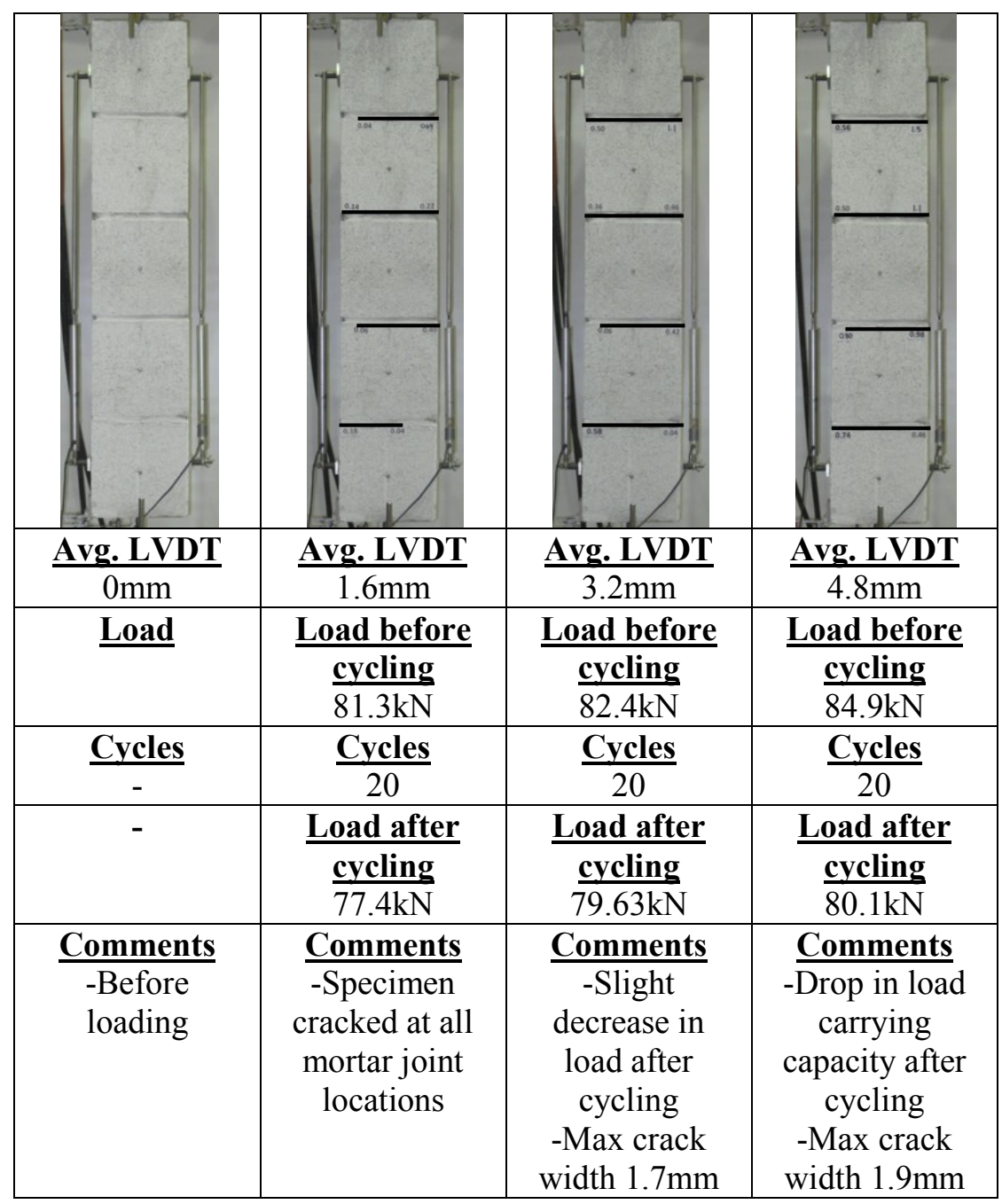




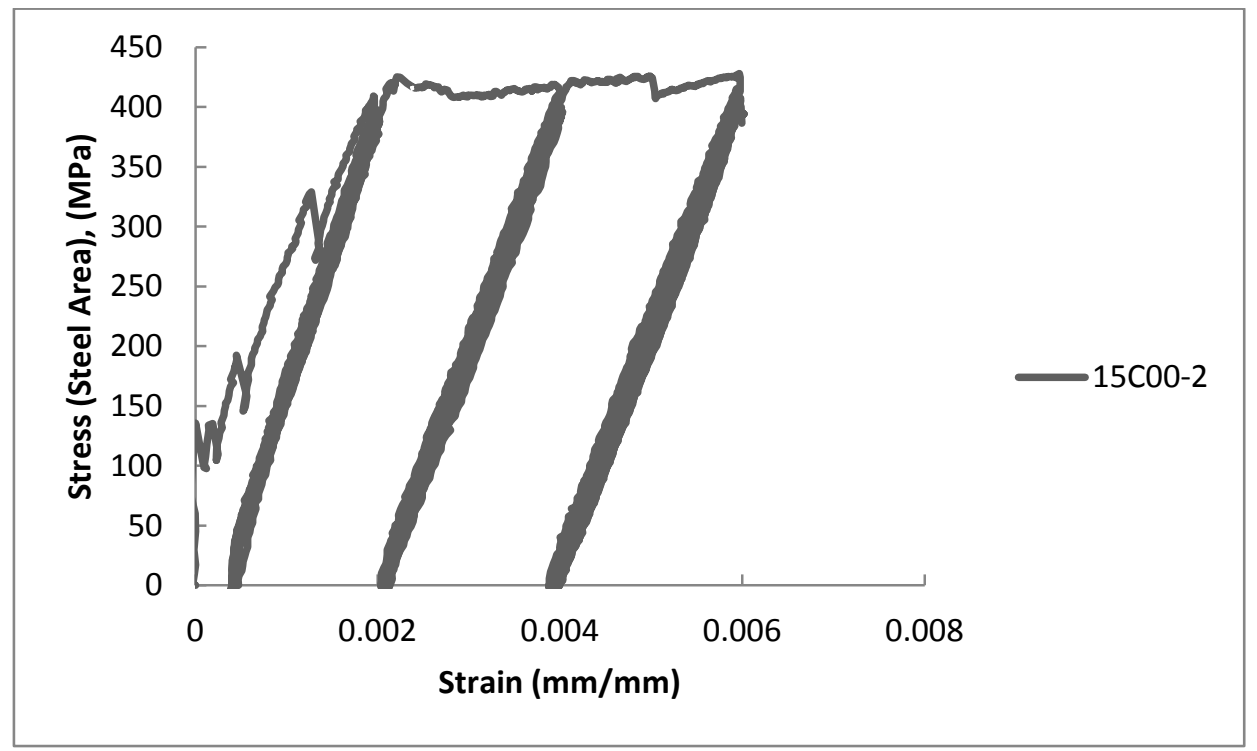

Figure 4-106: Stress strain response throughout cycling (15C00-2)

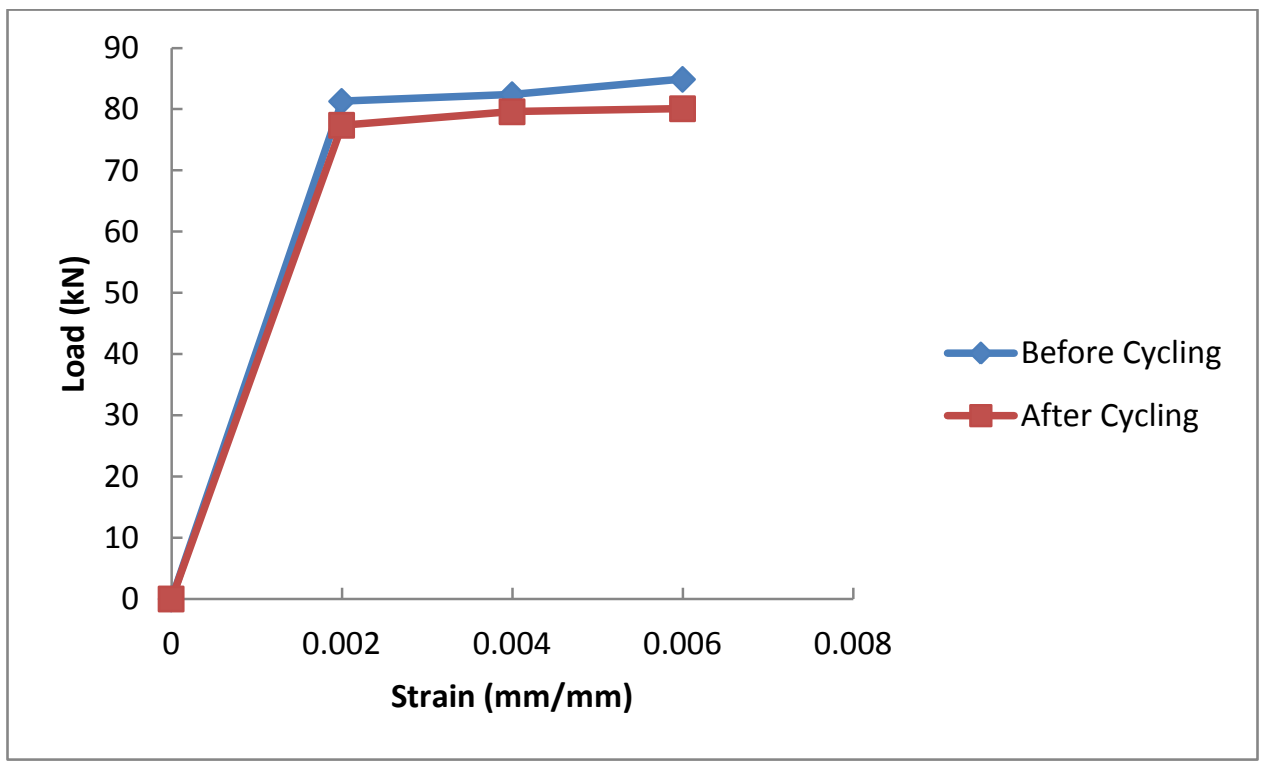

Figure 4-107: Average $\&$ maximum crack widths (15C00-2) 


\subsubsection{Specimen 15C04S-2}

This specimen was tested on October $24^{\text {th }}, 2013$ and was the first specimen to be tested of the $15 \mathrm{M}$ cyclic tests at post-yield. This specimen contained grout with $0.4 \%$ Dramix ZP305 steel fibres by volume. This specimen was tested to observe the effect that a minimal amount of steel fibres has on the degradation of the load carrying capacity as the load is cycled at levels beyond the yield strain of the reinforcing steel.

The specimen was cracked at the top three mortar joint locations at the first load stage which was taken when the average LVDT readings corresponded to the theoretical yield strain of the reinforcing steel. After the second cycling at two times the theoretical yield strain, the specimen did not develop any further cracking and had a maximum crack width of $2.5 \mathrm{~mm}$. After a third cycling at three times the theoretical yield strain, the specimen still did not develop any further cracking and the maximum crack width was increased to $3.0 \mathrm{~mm}$. At the final load stage, there were 4 horizontal cracks in the specimen. The specimen remained uncracked at the bottom mortar joint location. The specimen had significantly higher load carrying capacity after the cycling had completed when compared with 15C00-2.

The test was terminated after the specimen was cycled at a strain corresponding to three times the theoretical yield strain or $4.8 \mathrm{~mm}$ over the $800 \mathrm{~mm}$ gauge length.

Figure 4-108 shows the stress-strain relationship of the specimen throughout the cycling of the load in the post yield range. Figure 4-109 shows the relationship between the average strain in the specimen and the load carrying capacity at that given displacement. There are two lines traced, one represents the load carrying capacity before cycling at a given strain level and the other represents the load carrying capacity after the cycling was completed. 
Table 4-42: Test summary for specimen 15C04S-2

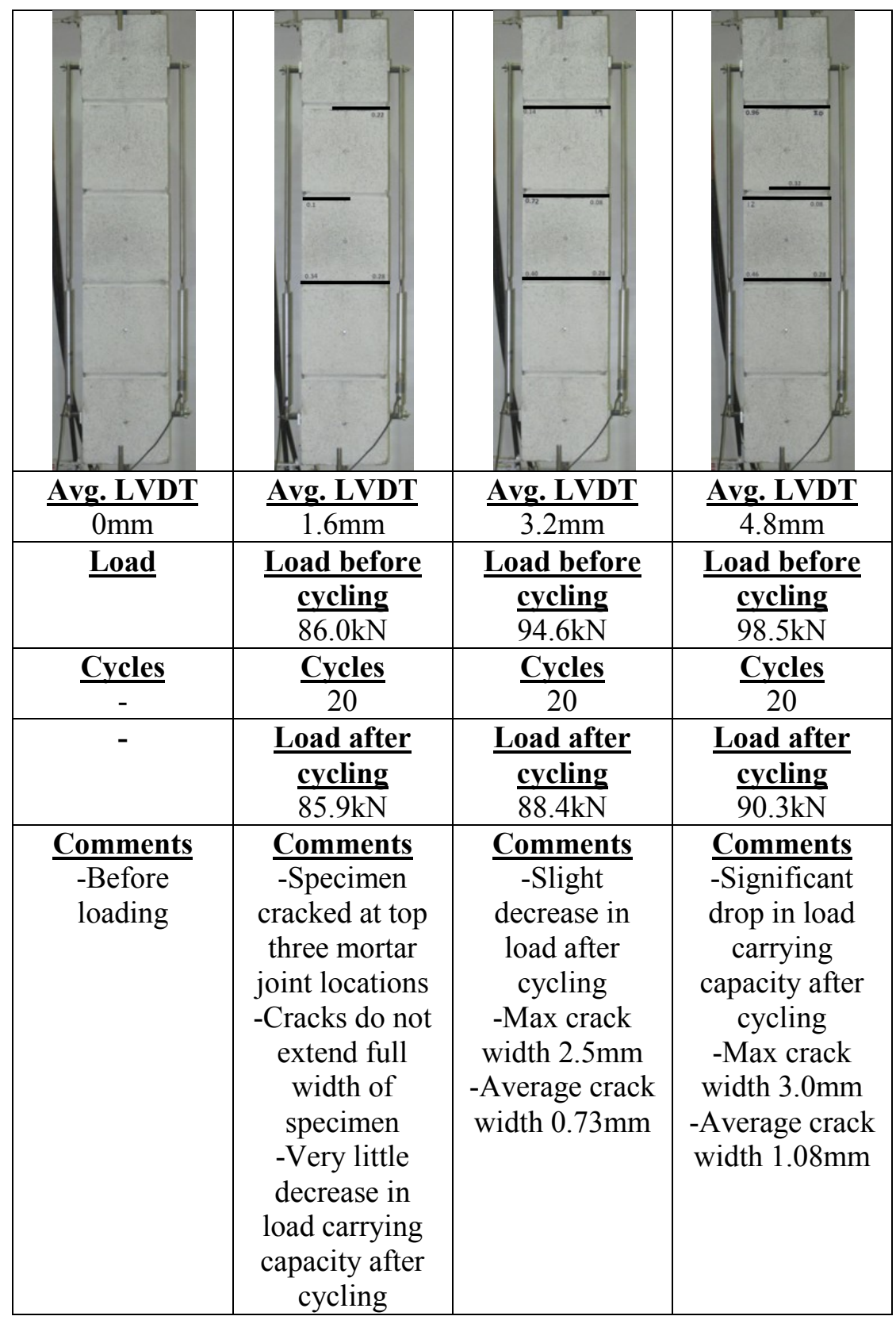




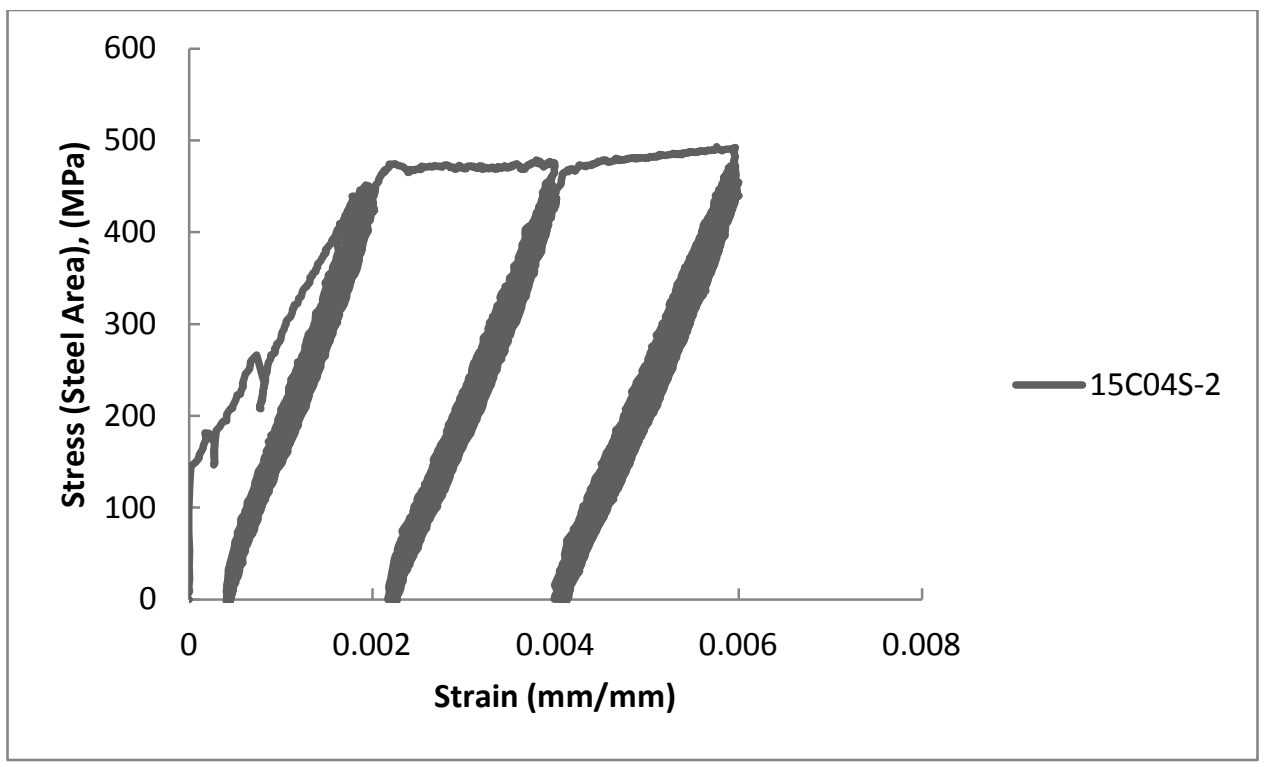

Figure 4-108: Stress strain relationship throughout cycling (15C04S-2)

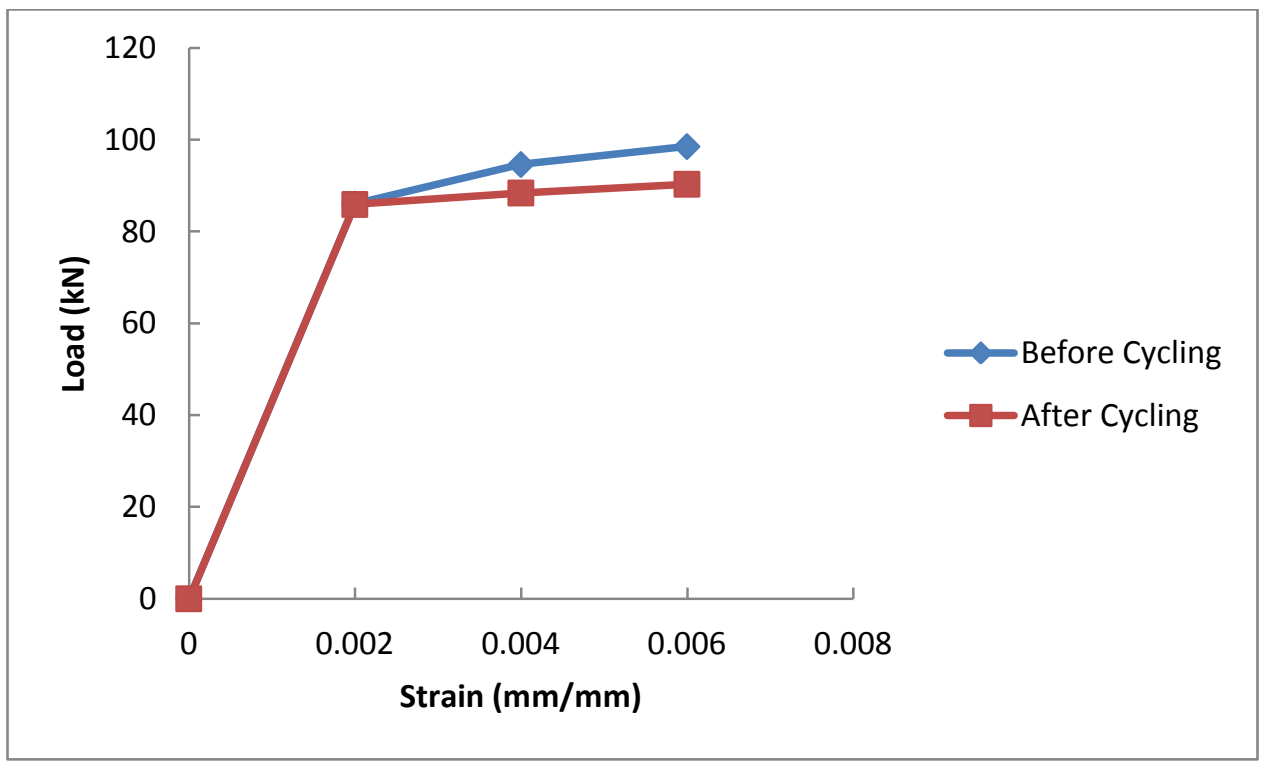

Figure 4-109: Average \& maximum crack widths (15C04S-2) 


\subsubsection{Specimen 15C08S-2}

This specimen was tested on October $23^{\text {rd }}, 2013$ and was the second specimen to be tested of the $15 \mathrm{M}$ cyclic tests at post-yield. This specimen contained grout with $0.8 \%$ Dramix ZP305 steel fibres by volume. This specimen was tested to observe the effect that a moderate amount of steel fibres has on the degradation of the load carrying capacity as the load is cycled at levels beyond the yield strain of the reinforcing steel.

The specimen was cracked at all mortar joint locations at the first load stage which was taken when the average LVDT readings corresponded to the theoretical yield strain of the reinforcing steel. After the second cycling at two times the theoretical yield strain, the specimen developed a second horizontal crack at the top mortar joint location and had a maximum crack width of $1.7 \mathrm{~mm}$. After a third cycling at three times the theoretical yield strain, the specimen did not develop any further cracking from the last load stage and the maximum crack width was increased to $2.3 \mathrm{~mm}$. At the final load stage, there were 5 horizontal cracks in the specimen. The specimen had significantly higher load carrying capacity after the cycling had completed when compared with 15C00-2.

The test was terminated after the specimen was cycled at a strain corresponding to three times the theoretical yield strain or $4.8 \mathrm{~mm}$ over the $800 \mathrm{~mm}$ gauge length.

Figure 4-110 shows the stress-strain relationship of the specimen throughout the cycling of the load in the post yield range. Figure 4-111 shows the relationship between the average strain in the specimen and the load carrying capacity at that given displacement. There are two lines traced, one represents the load carrying capacity before cycling at a given strain level and the other represents the load carrying capacity after the cycling was completed. 
Table 4-43: Test summary for specimen 15C08S-2

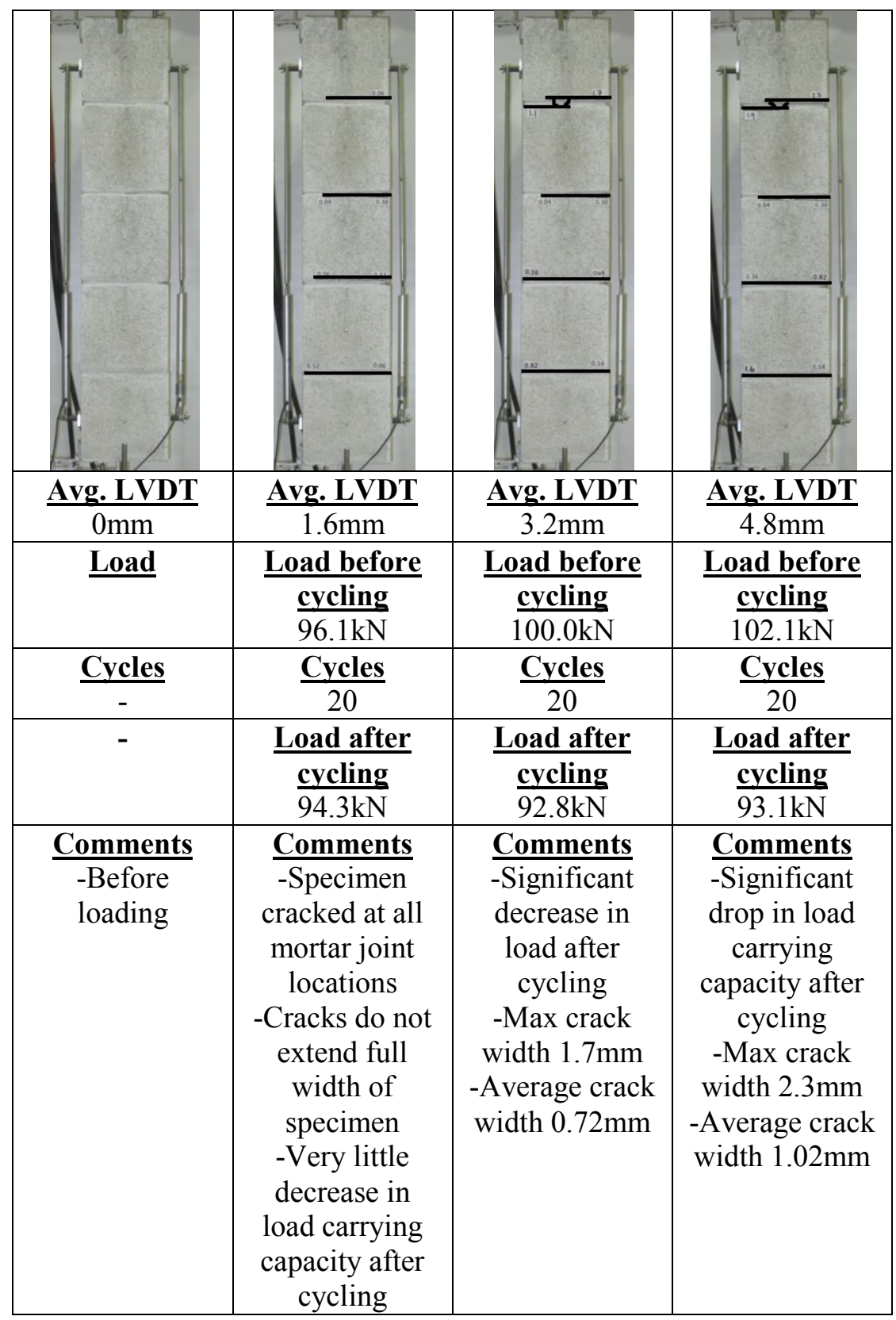




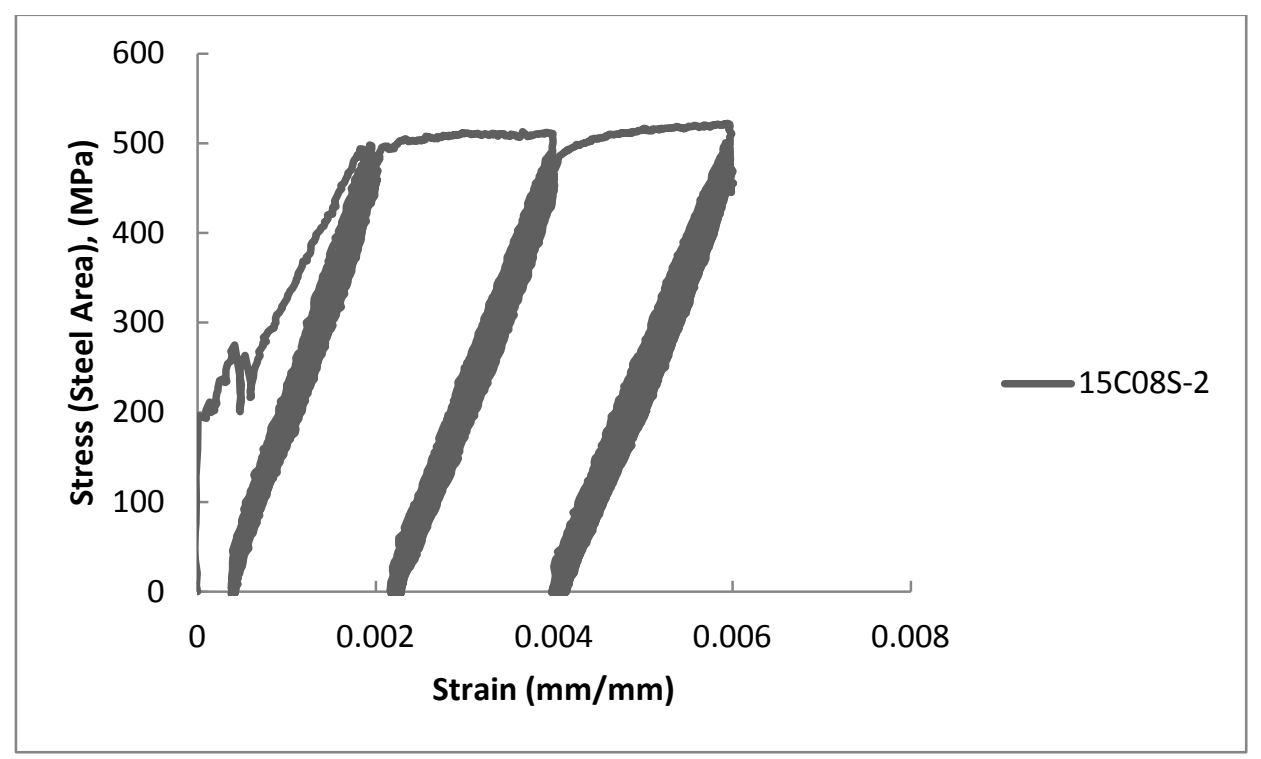

Figure 4-110: Stress strain response throughout cycling (15C08S-2)

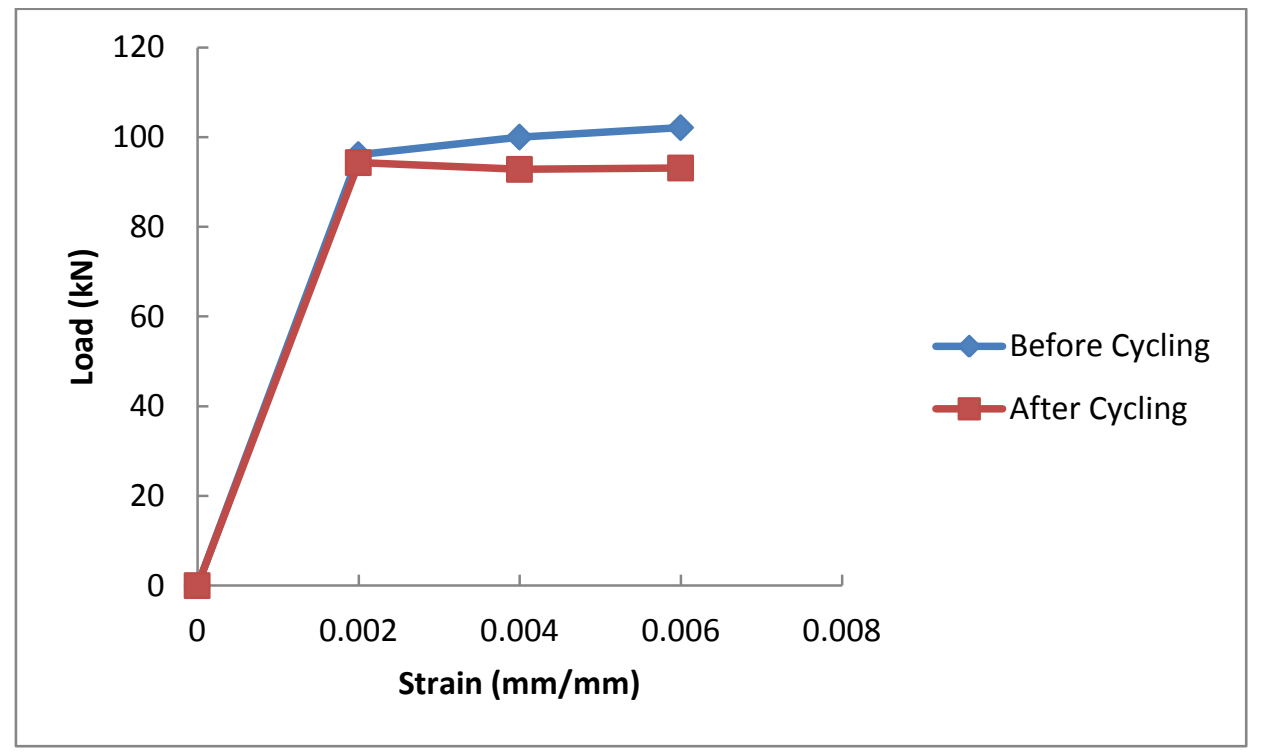

Figure 4-111: Average $\&$ maximum crack widths (15C08S-2) 
This specimen was tested on October $23^{\text {rd }}, 2013$ and was the fourth specimen to be tested of the $15 \mathrm{M}$ cyclic tests at post-yield. This specimen contained grout with 1.2\% Dramix ZP305 steel fibres by volume. This specimen was tested to observe the effect that a relatively large amount of steel fibres has on the degradation of the load carrying capacity as the load is cycled at levels beyond the yield strain of the reinforcing steel.

The specimen was cracked at the bottom three mortar joint locations at the first load stage which was taken when the average LVDT readings corresponded to the theoretical yield strain of the reinforcing steel. After the second cycling at two times the theoretical yield strain, the specimen developed two horizontal cracks at the top mortar joint location and had a maximum crack width of $2.4 \mathrm{~mm}$. After a third cycling at three times the theoretical yield strain, the specimen did not develop any further cracking from the last load stage and the maximum crack width was increased to $3.5 \mathrm{~mm}$. At the final load stage, there were 5 horizontal cracks in the specimen. Again, the specimen had significantly higher load carrying capacity after the cycling had completed when compared with 15C00-2.

The test was terminated after the specimen was cycled at a strain corresponding to three times the theoretical yield strain or $4.8 \mathrm{~mm}$ over the $800 \mathrm{~mm}$ gauge length.

Figure 4-112 shows the stress-strain relationship of the specimen throughout the cycling of the load in the post yield range. Figure 4-113 shows the relationship between the average strain in the specimen and the load carrying capacity at that given displacement. There are two lines traced, one represents the load carrying capacity before cycling at a given strain level and the other represents the load carrying capacity after the cycling was completed. 
Table 4-44: Test summary for specimen 15C12S-2

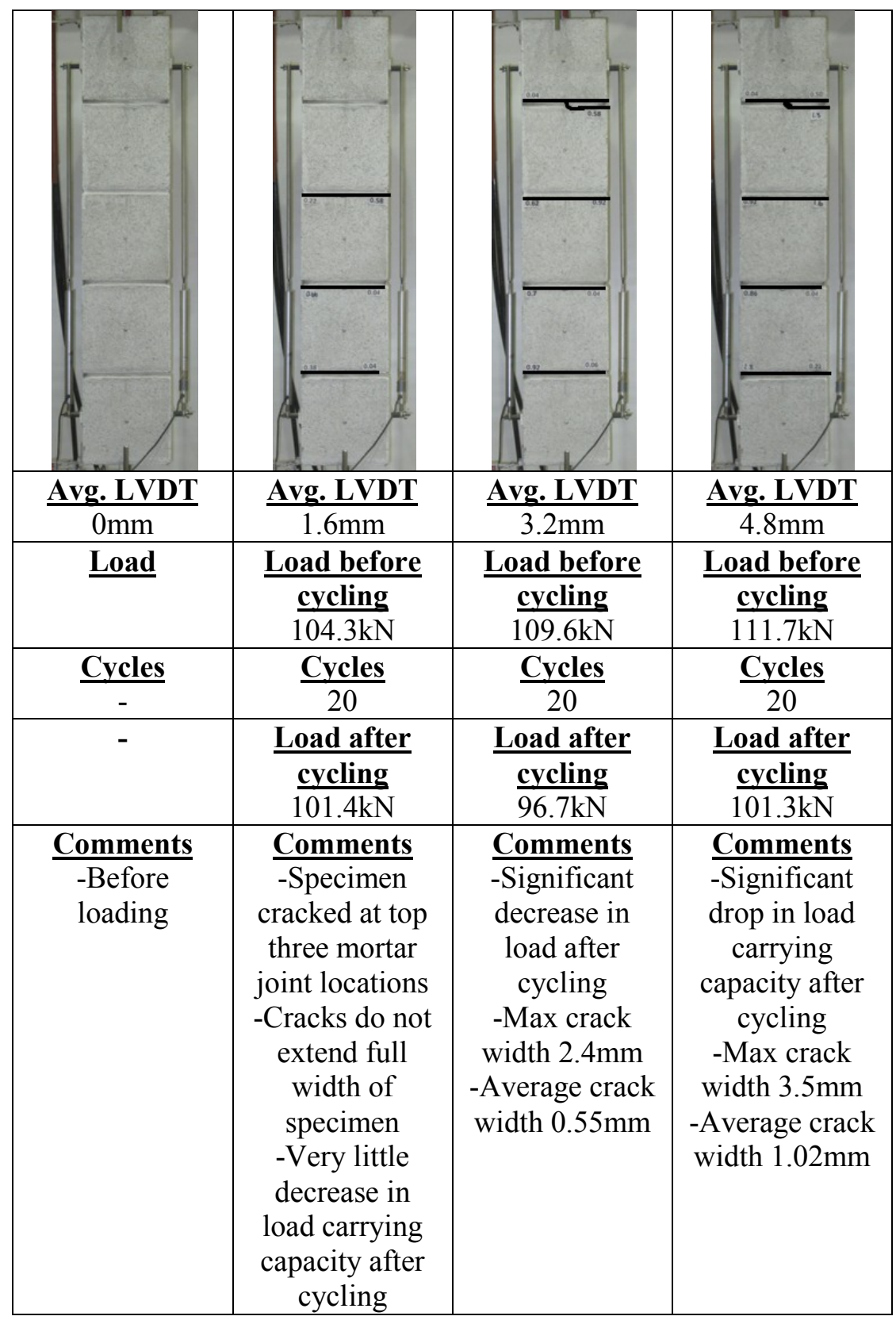




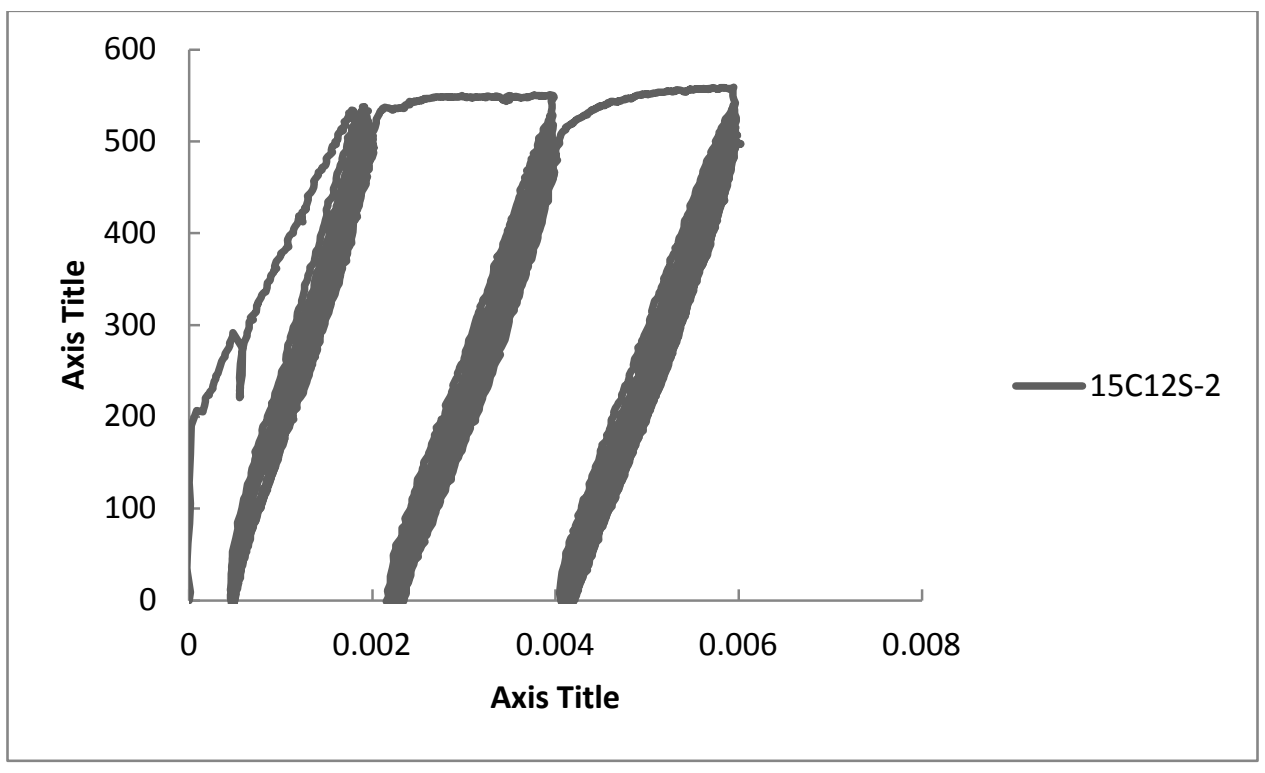

Figure 4-112: Stress strain response throughout cycling (15C12S-2)

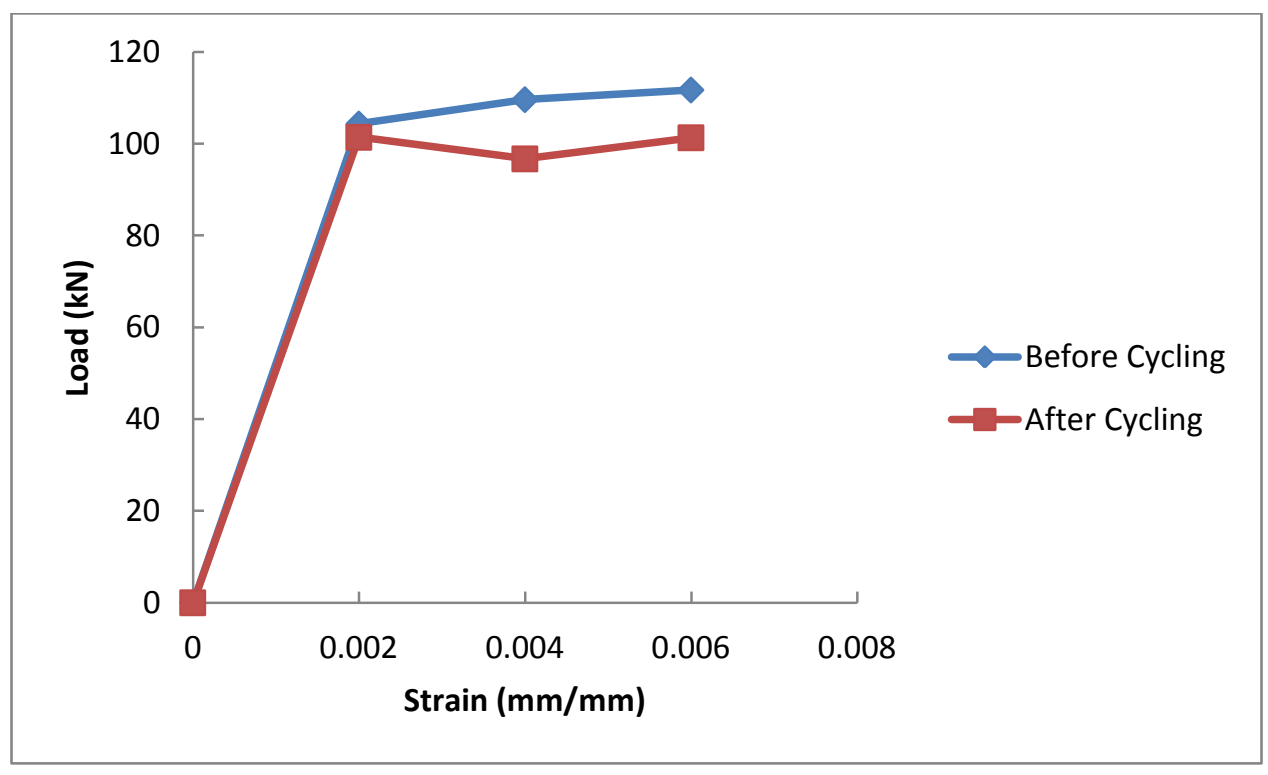

Figure 4-113: Average \& maximum crack widths (15C12S-2) 


\subsubsection{Specimen 20C00-2}

This specimen was tested on October $22^{\text {nd }}, 2013$ and was the second specimen to be tested of the $20 \mathrm{M}$ cyclic tests at post-yield. This specimen contained no fibres and served as the control specimen for the $20 \mathrm{M}$ cyclic tests at yield.

The specimen was cracked at all mortar joint locations at the first load stage which was taken when the average LVDT readings corresponded to the theoretical yield strain of the reinforcing steel. After the second cycling at two times the theoretical yield strain, the specimen developed no new cracks and had a maximum crack width of $1.4 \mathrm{~mm}$. After a third cycling at three times the theoretical yield strain, the specimen did not develop any further cracking from the last load stage and the maximum crack width was increased to $2.3 \mathrm{~mm}$. At the final load stage, there were 5 horizontal cracks in the specimen.

The test was terminated after the specimen was cycled at a strain corresponding to three times the theoretical yield strain or $4.8 \mathrm{~mm}$ over the $800 \mathrm{~mm}$ gauge length.

Figure 4-114 shows the stress-strain relationship of the specimen throughout the cycling of the load in the post yield range. Figure 4-115 shows the relationship between the average strain in the specimen and the load carrying capacity at that given displacement. There are two lines traced, one represents the load carrying capacity before cycling at a given strain level and the other represents the load carrying capacity after the cycling was completed. 
Table 4-45: Test summary for specimen $20 \mathrm{C00}-2$

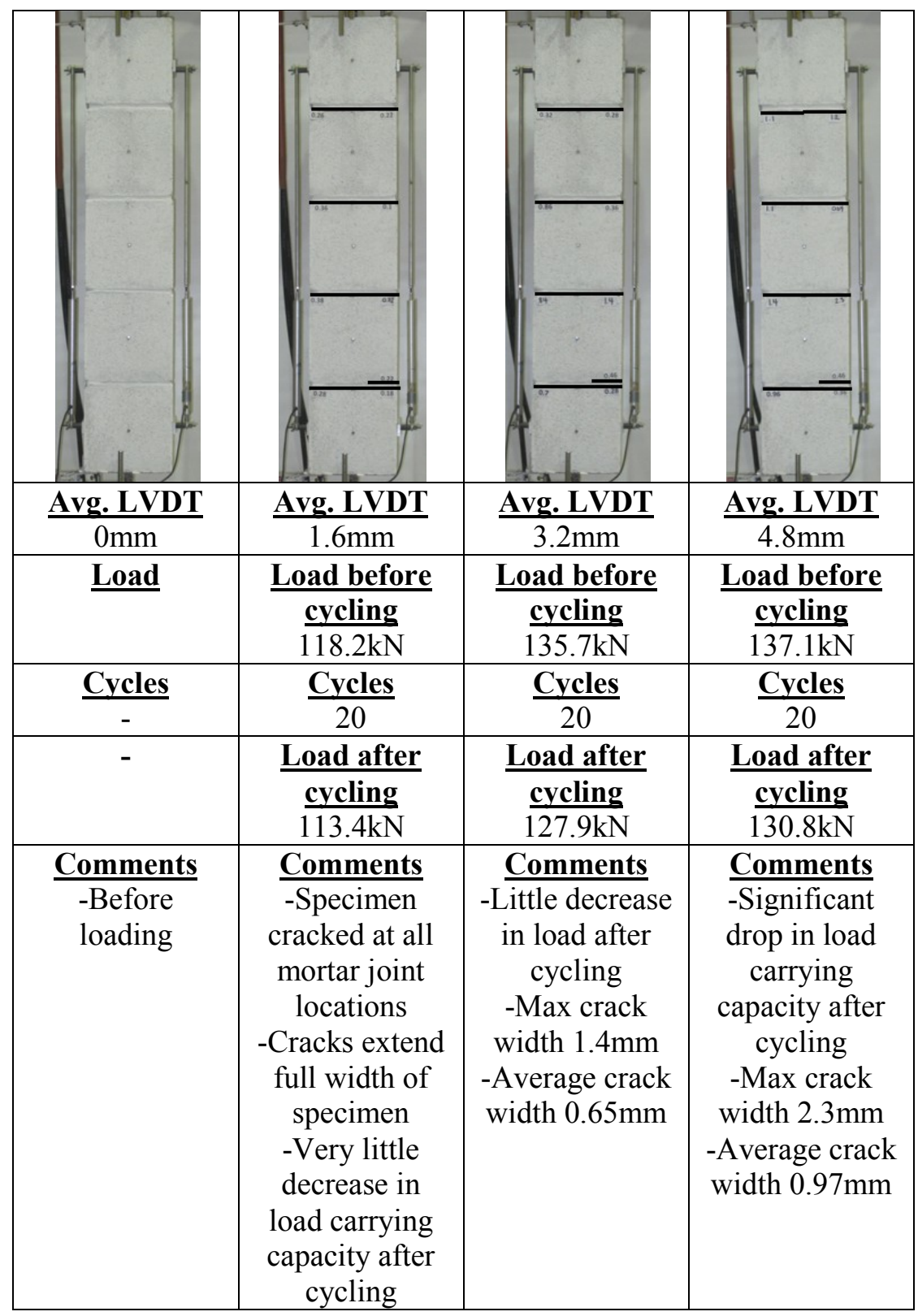




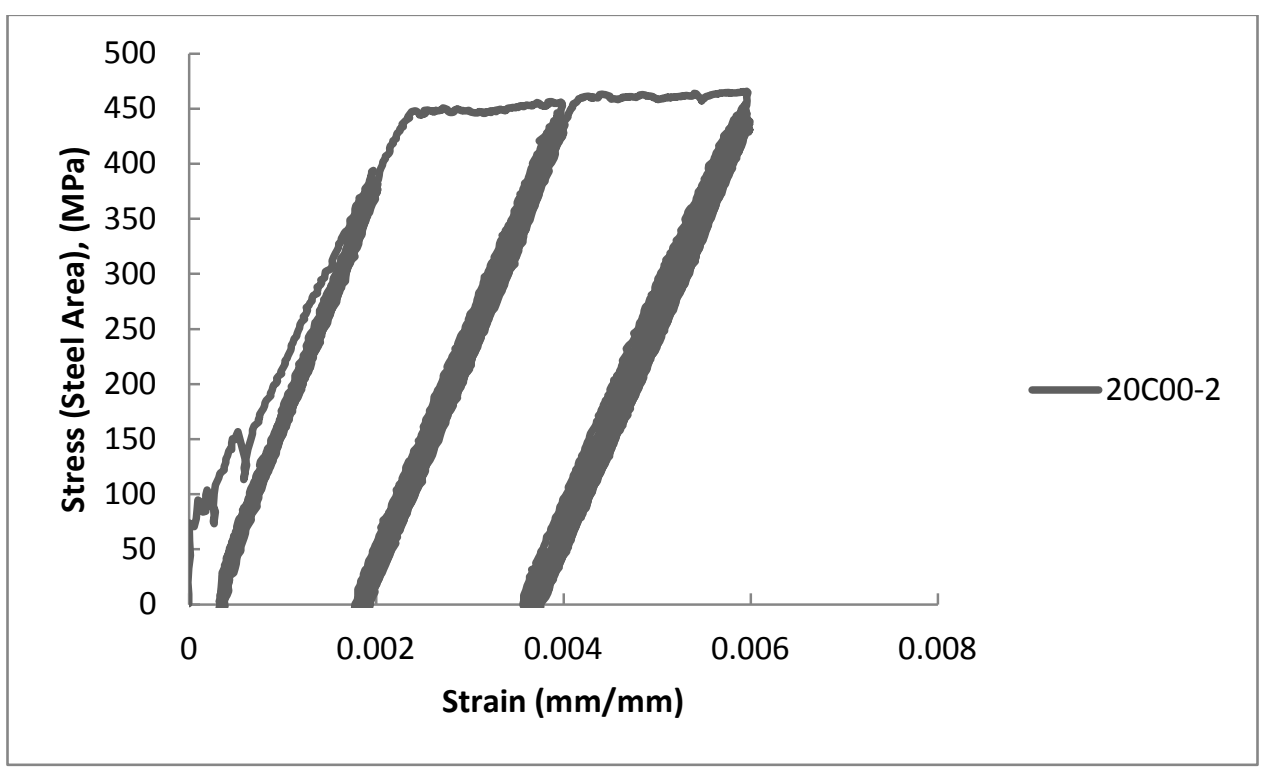

Figure 4-114: Stress strain response throughout cycling (20C00-2)

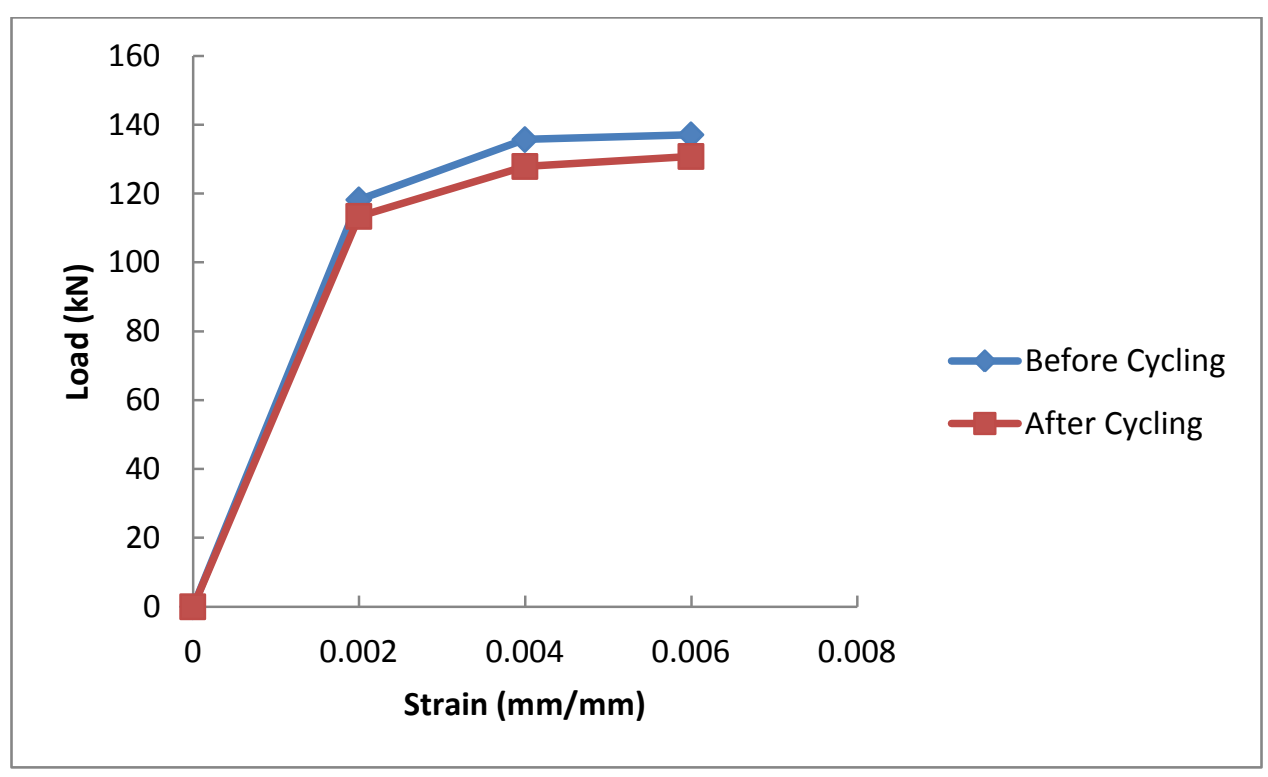

Figure 4-115: Average \& maximum crack widths (20C00-2) 


\subsubsection{Specimen 20C04S-2}

This specimen was tested on October $21^{\text {st }}, 2013$ and was the first specimen to be tested of the $20 \mathrm{M}$ cyclic tests at post-yield. This specimen contained grout with $0.4 \%$ Dramix ZP305 steel fibres by volume. This specimen was tested to observe the effect that a minimal amount of steel fibres has on the degradation of the load carrying capacity as the load is cycled at levels beyond the yield strain of the reinforcing steel.

The specimen was cracked at all mortar joint locations at the first load stage which was taken when the average LVDT readings corresponded to the theoretical yield strain of the reinforcing steel. After the second cycling at two times the theoretical yield strain, the specimen developed few new cracks and had a maximum crack width of $1.4 \mathrm{~mm}$. After a third cycling at three times the theoretical yield strain, the specimen developed one more crack from the last load stage and the maximum crack width was increased to $1.9 \mathrm{~mm}$. At the final load stage, there were 6 horizontal cracks in the specimen.

The test was terminated after the specimen was cycled at a strain corresponding to three times the theoretical yield strain or $4.8 \mathrm{~mm}$ over the $800 \mathrm{~mm}$ gauge length.

Figure 4-116 shows the stress-strain relationship of the specimen throughout the cycling of the load in the post yield range. Figure 4-117 shows the relationship between the average strain in the specimen and the load carrying capacity at that given displacement. There are two lines traced, one represents the load carrying capacity before cycling at a given strain level and the other represents the load carrying capacity after the cycling was completed. 
Table 4-46: Test summary for specimen 20C04S-2

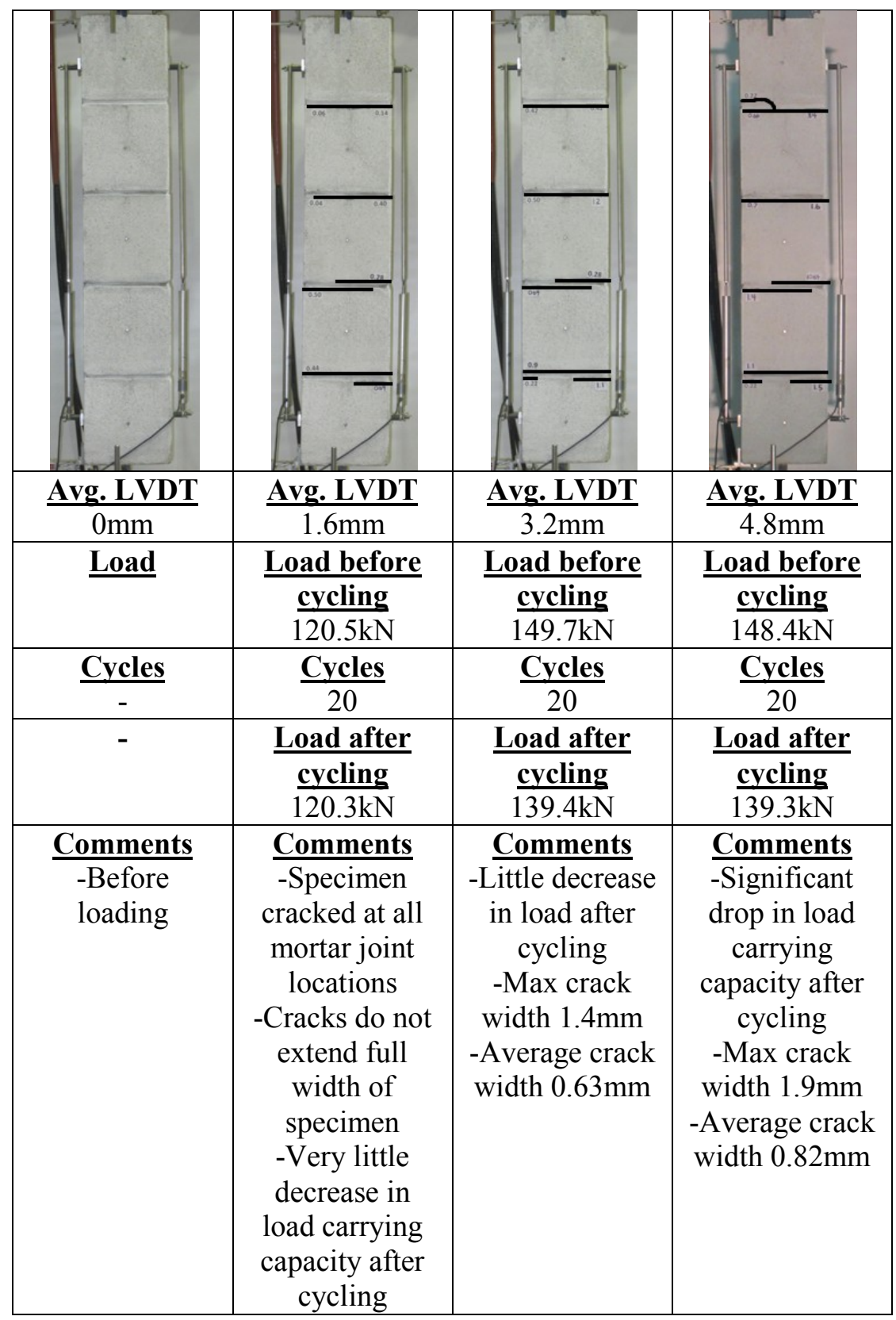




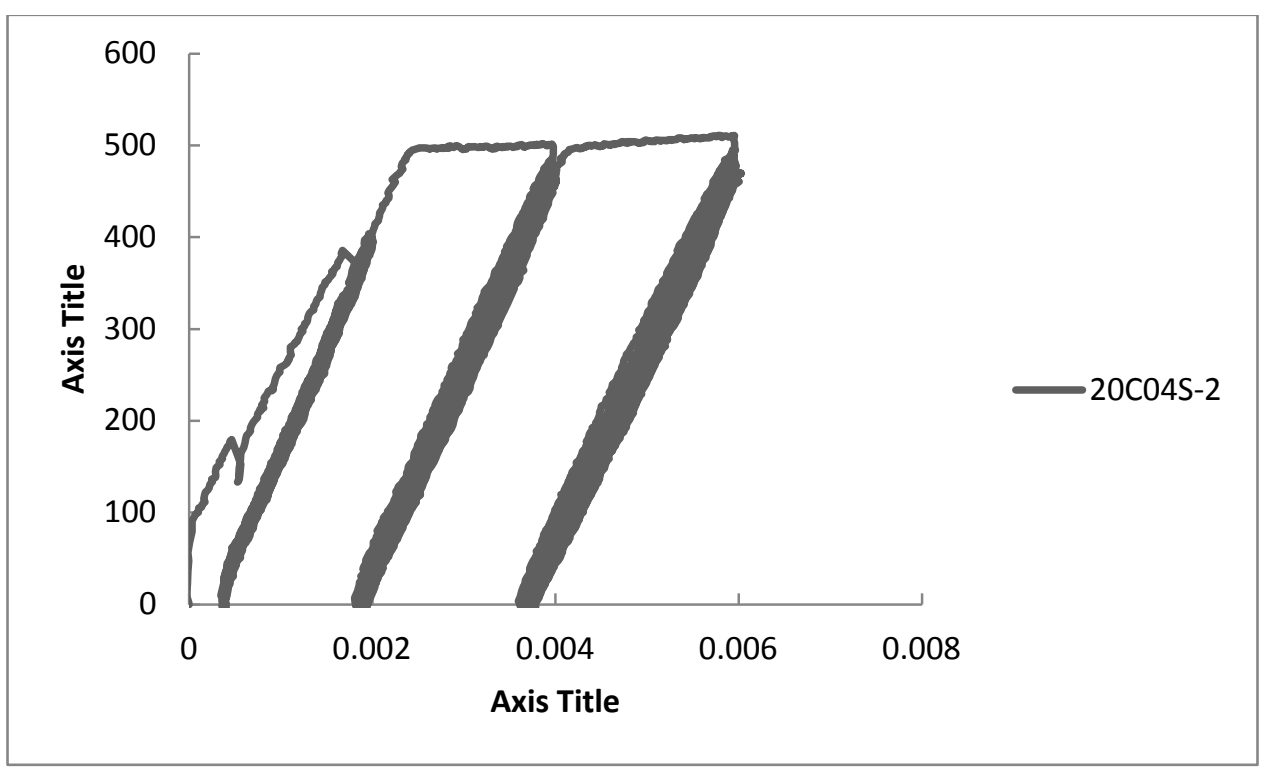

Figure 4-116: Stress strain response throughout cycling (20C04S-2)

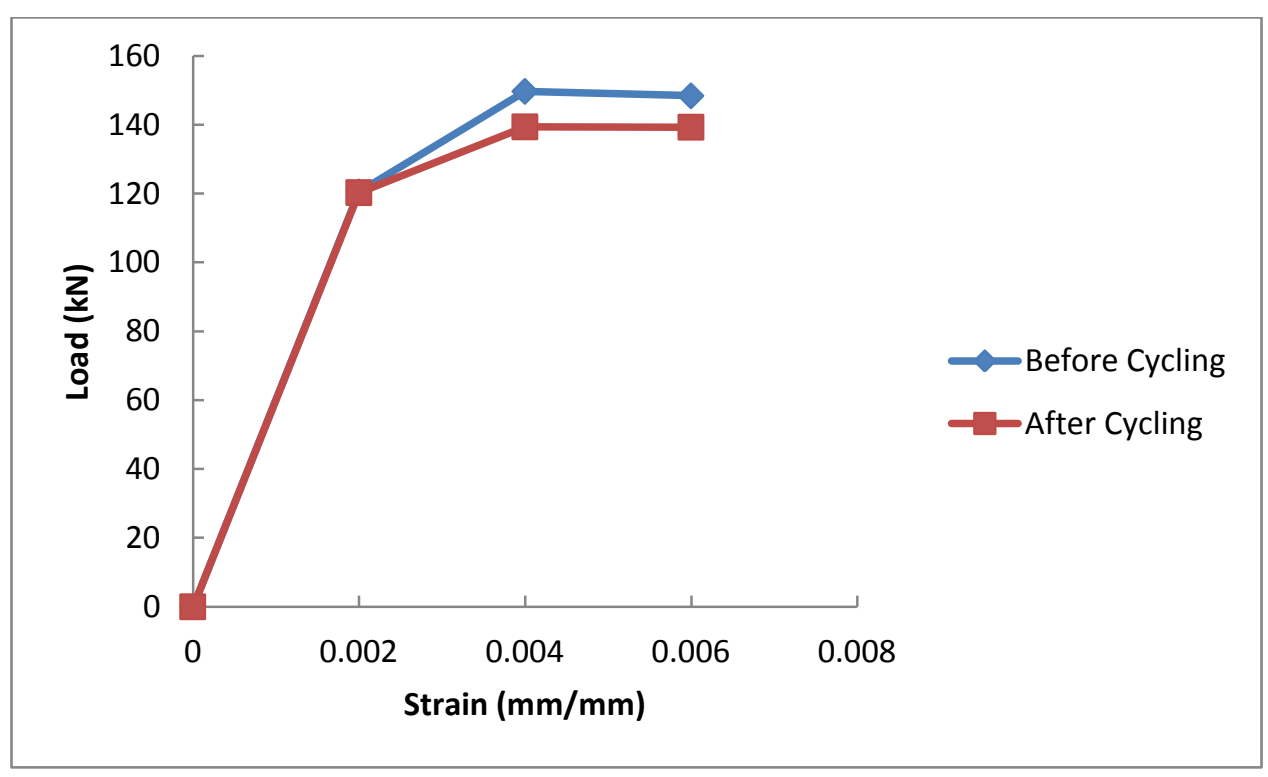

Figure 4-117: Average \& maximum crack widths (20C04S-2) 


\subsubsection{Specimen 20C08S-2}

This specimen was tested on October $22^{\text {nd }}, 2013$ and was the third specimen to be tested of the 20M cyclic tests at post-yield. This specimen contained grout with $0.8 \%$ Dramix ZP305 steel fibres by volume. This specimen was tested to observe the effect that a moderate amount of steel fibres has on the degradation of the load carrying capacity as the load is cycled at levels beyond the yield strain of the reinforcing steel.

The specimen was cracked at the bottom three mortar joint locations at the first load stage which was taken when the average LVDT readings corresponded to the theoretical yield strain of the reinforcing steel. After the second cycling at two times the theoretical yield strain, the specimen developed a second horizontal crack at the bottom mortar joint location and had a maximum crack width of $2.1 \mathrm{~mm}$. After a third cycling at three times the theoretical yield strain, the specimen developed a second horizontal crack at the second mortar joint from the top and the maximum crack width was increased to $2.8 \mathrm{~mm}$. At the final load stage, there were 5 horizontal cracks in the specimen. The specimen had significantly higher load carrying capacity after the cycling had completed when compared with 20C00-2.

The test was terminated after the specimen was cycled at a strain corresponding to three times the theoretical yield strain or $4.8 \mathrm{~mm}$ over the $800 \mathrm{~mm}$ gauge length.

Figure 4-118 shows the stress-strain relationship of the specimen throughout the cycling of the load in the post yield range. Figure 4-119 shows the relationship between the average strain in the specimen and the load carrying capacity at that given displacement. There are two lines traced, one represents the load carrying capacity before cycling at a given strain level and the other represents the load carrying capacity after the cycling was completed. 
Table 4-47: Test summary for specimen 20C08S-2

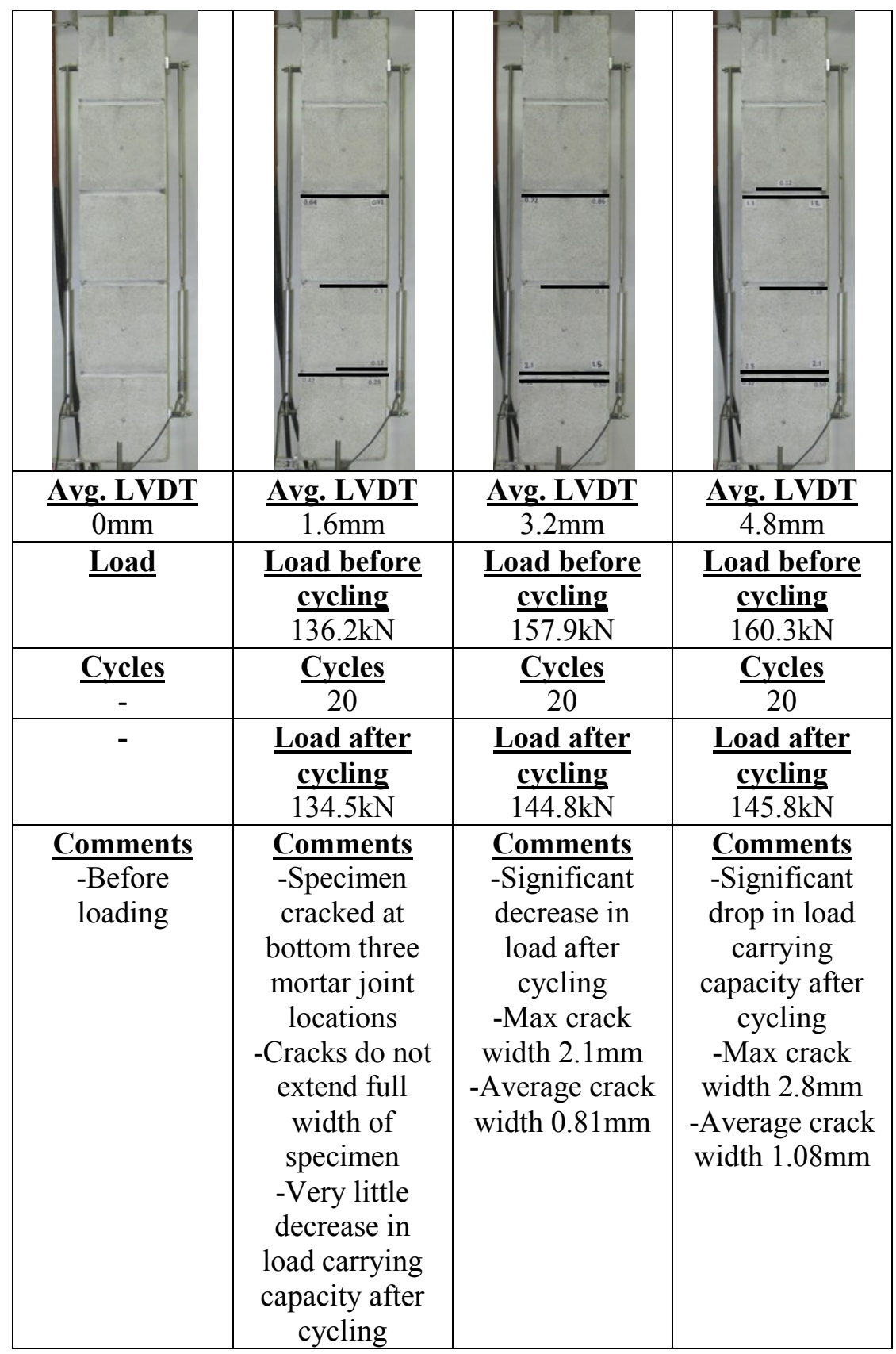




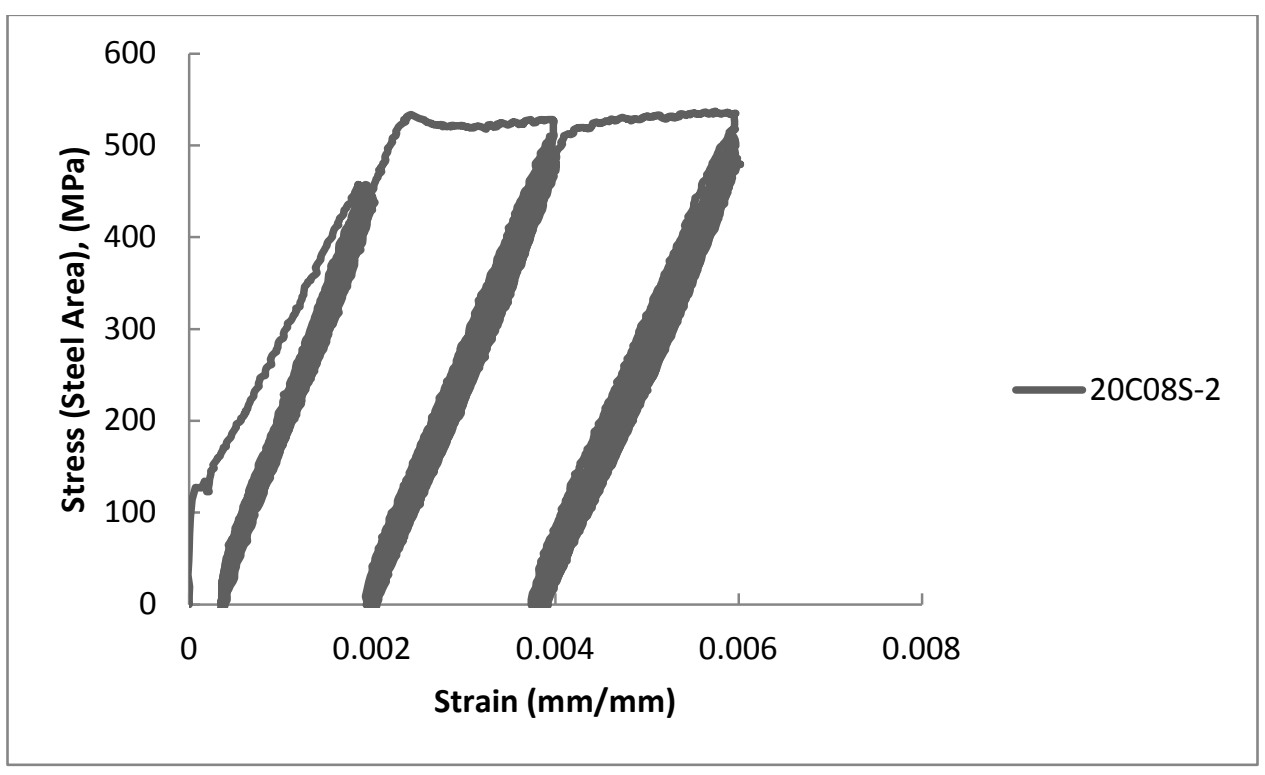

Figure 4-118: Stress strain response throughout cycling (20C08S-2)

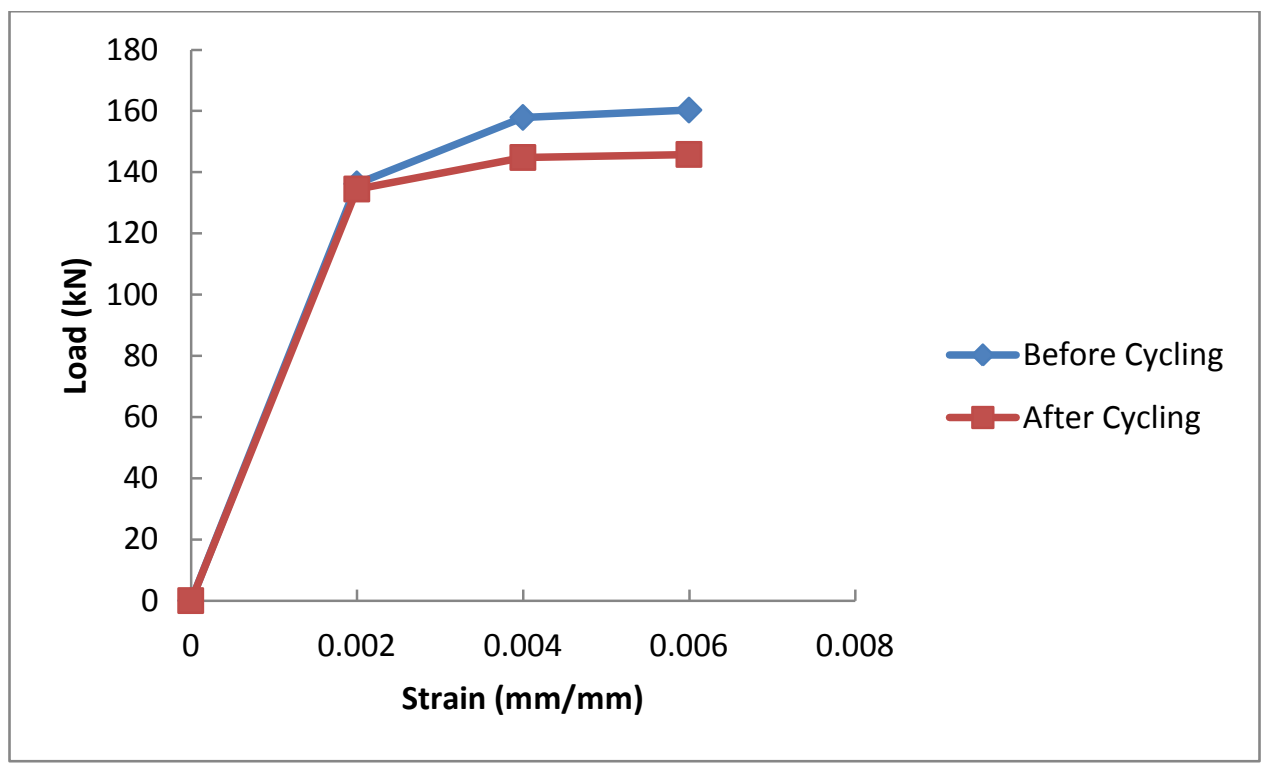

Figure 4-119: Average \& maximum crack widths (20C08S-2) 


\subsubsection{Specimen 20C12S-2}

This specimen was tested on October $23^{\text {rd }}, 2013$ and was the final specimen to be tested of the $20 \mathrm{M}$ cyclic tests at post-yield. This specimen contained grout with $1.2 \%$ Dramix ZP305 steel fibres by volume. This specimen was tested to observe the effect that a relatively large amount of steel fibres has on the degradation of the load carrying capacity as the load is cycled at levels beyond the yield strain of the reinforcing steel.

The specimen was cracked at all mortar joint locations at the first load stage which was taken when the average LVDT readings corresponded to the theoretical yield strain of the reinforcing steel. After the second cycling at two times the theoretical yield strain, the specimen began to develop two horizontal cracks at both of the bottom two mortar joint locations and had a maximum crack width of $2.3 \mathrm{~mm}$. After a third cycling at three times the theoretical yield strain, the specimen developed further cracking from the last load stage and the maximum crack width was increased to $2.8 \mathrm{~mm}$. At this point, the second concrete block from the top also cracked near its midpoint. At the final load stage, there were 7 horizontal cracks in the specimen. Again, the specimen had significantly higher load carrying capacity after the cycling had completed when compared with 20C00-2.

The test was terminated after the specimen was cycled at a strain corresponding to three times the theoretical yield strain or $4.8 \mathrm{~mm}$ over the $800 \mathrm{~mm}$ gauge length.

Figure 4-120 shows the stress-strain relationship of the specimen throughout the cycling of the load in the post yield range. Figure 4-121 shows the relationship between the average strain in the specimen and the load carrying capacity at that given displacement. There are two lines traced, one represents the load carrying capacity before cycling at a given strain level and the other represents the load carrying capacity after the cycling was completed. 
Table 4-48: Test summary for specimen 20C12S-2

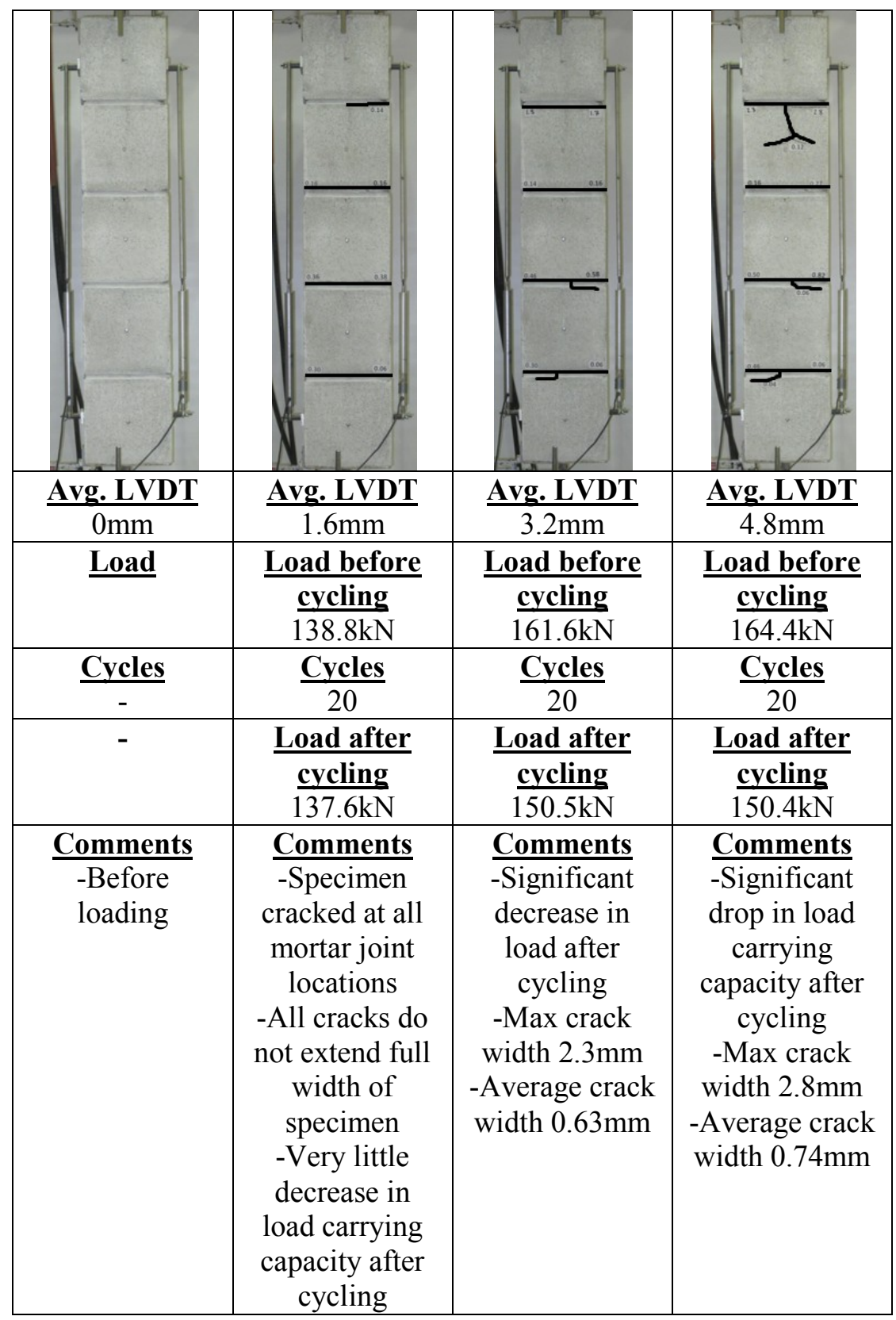




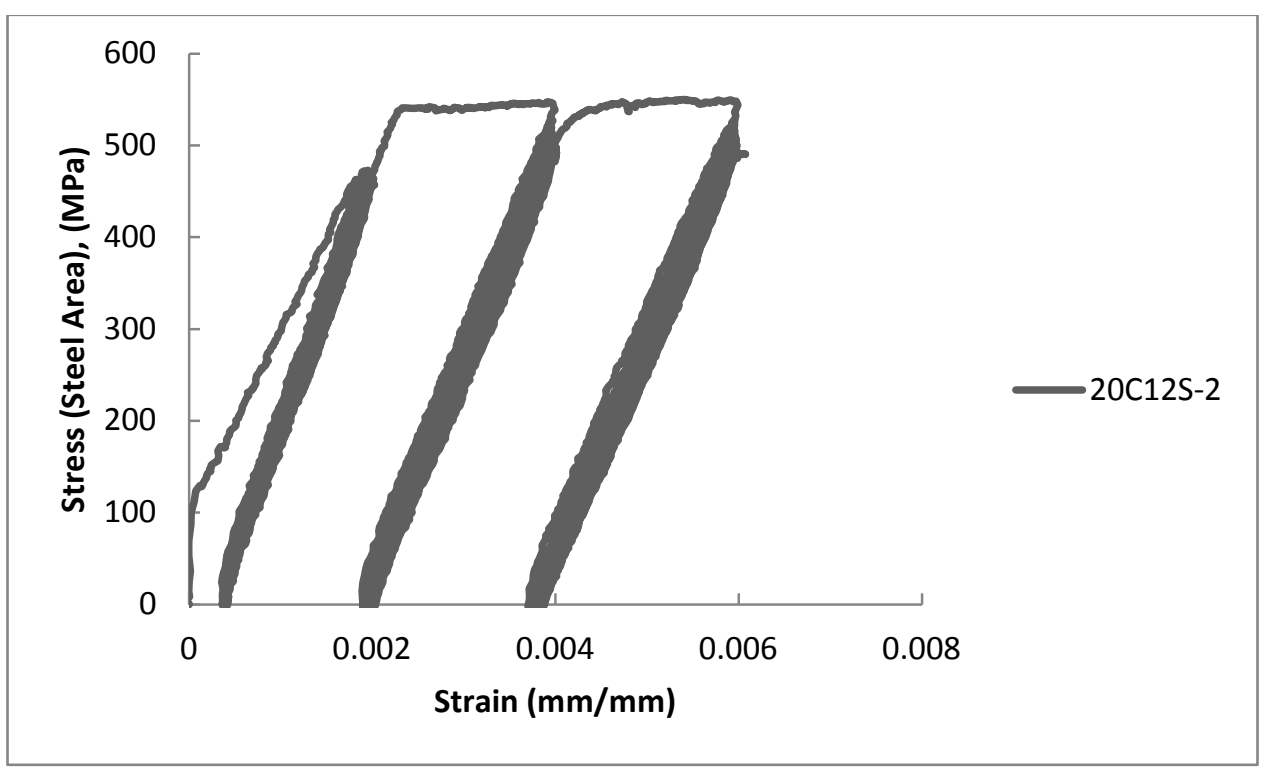

Figure 4-120: Stress strain response throughout cycling (20C12S-2)

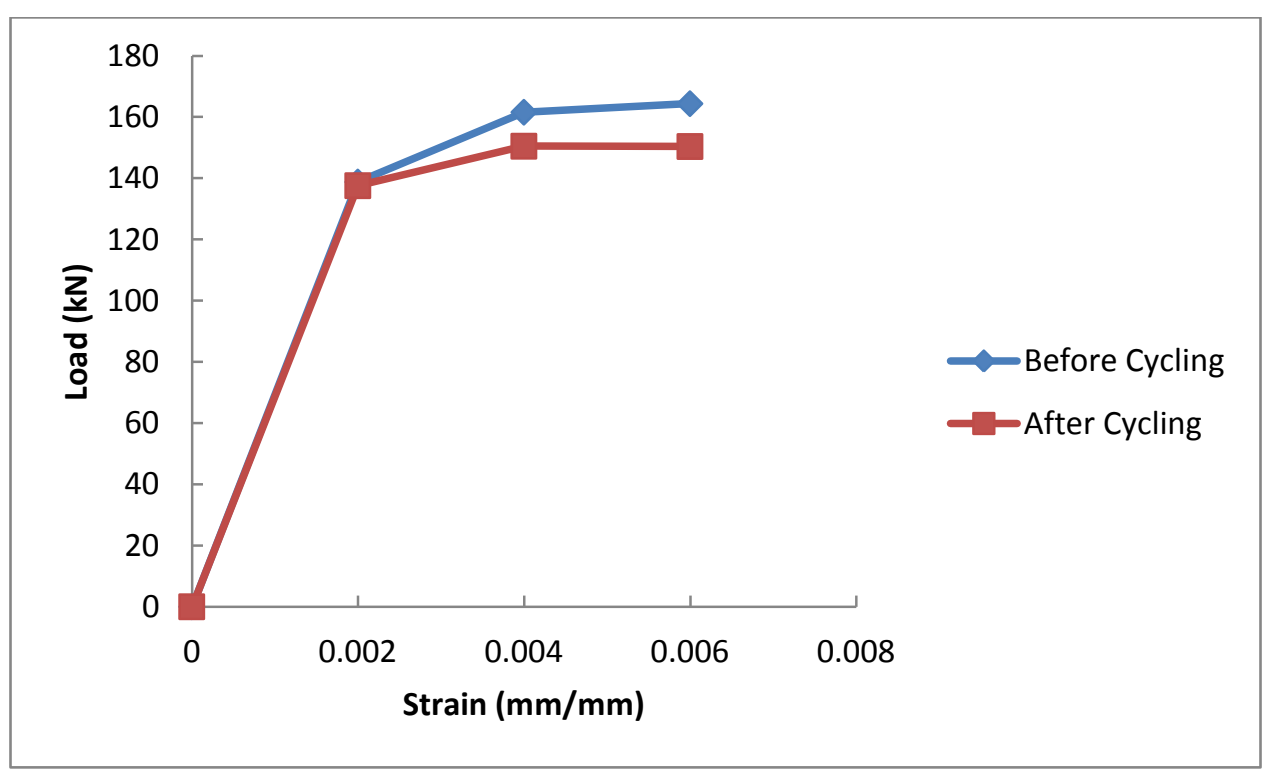

Figure 4-121: Average \& maximum crack widths (20C12S-2) 


\section{Discussion of Experimental Results}

\subsection{Introduction}

This chapter discusses the results of the experimental work described in the previous chapters. The responses of the 42 direct tension specimens are compared to investigate the influence of steel fibre reinforced grout on the post-cracking tensile behaviour. Test parameters include 1) steel fibre content, 2) reinforcement ratio, 3) steel fibre type, 4) concrete masonry unit type, and 5) monotonic vs. cyclic loading. The specimens will be grouped for means of analysis based on the property being examined.

This chapter will also include the development of a tension stiffening model which can be used in the analysis on reinforced concrete masonry assemblages both with and without fibres.

\subsection{Monotonic Testing}

A series of 26 direct tension specimens were constructed and tested under monotonic load. Each specimen had a duplicate specimen which was tested to ensure repeatability of the results. An exception was that only one lintel unit specimen was built and tested for each grout type. For ease of analysis, the resultant forces obtained from the load cell were converted to equivalent stress based on the reinforcing steel area. Using this method, the specimens will have an apparent increase in stiffness versus the bare bar response and the difference between the two responses can be attributed to the tension stiffening effect. For example, if a force of $40 \mathrm{kN}$ was obtained from the load cell when testing a specimen containing a $10 \mathrm{M}$ reinforcing bar, then the specimen is said to have a stress of $400 \mathrm{MPa}$ based on a steel area of $100 \mathrm{~mm}^{2}$. At a stress of $400 \mathrm{MPa}$, however, the stress may not all be carried by the reinforcing steel and some of the stress may be carried by the cracked masonry surrounding the reinforcement, thus increasing the stiffness over the bare bar response. 


\subsubsection{Effect of fibre content}

All fibres used in the experimental work were steel fibres of the hooked end variety to increase the pullout resistance of the fibres. The steel fibres were incorporated into the grout at 4 different concentrations including a set of specimens which had no fibres and which served as the control specimen. The primary bar sizes which were used in the specimens to investigate the effect of fibre content were $15 \mathrm{M}$ and $20 \mathrm{M}$. The optimum fibre content was found to be in the range of $0.8 \%$ as workability nor segregation issues were present and significant increase in performance was also noticed.

\subsubsection{15M Series}

Table 5-1 summarizes the properties of the $15 \mathrm{M}$ specimens tested under monotonic load.

Table 5-1: 15M series properties

\begin{tabular}{|c|c|c|c|c|c|}
\hline Specimen & $\begin{array}{c}\text { Loading } \\
\text { Type }\end{array}$ & $\begin{array}{c}\text { Bar } \\
\text { Size }\end{array}$ & $\begin{array}{c}\text { Reinforcement } \\
\text { Ratio (\%) }\end{array}$ & $\begin{array}{c}\text { Fibre } \\
\text { Type }\end{array}$ & $\begin{array}{c}\mathbf{V}_{\mathbf{f}} \\
\mathbf{( \% )}\end{array}$ \\
\hline 15M00-1 & Monotonic & $15 \mathrm{M}$ & 0.554 & None & 0.0 \\
\hline 15M00-2 & Monotonic & $15 \mathrm{M}$ & 0.554 & None & 0.0 \\
\hline 15M04S-1 & Monotonic & $15 \mathrm{M}$ & 0.554 & ZP-305 & 0.4 \\
\hline 15M04S-2 & Monotonic & $15 \mathrm{M}$ & 0.554 & ZP-305 & 0.4 \\
\hline 15M08S-1 & Monotonic & $15 \mathrm{M}$ & 0.554 & ZP-305 & 0.8 \\
\hline 15M08S-2 & Monotonic & $15 \mathrm{M}$ & 0.554 & ZP-305 & 0.8 \\
\hline 15M12S-1 & Monotonic & $15 \mathrm{M}$ & 0.554 & ZP-305 & 1.2 \\
\hline 15M12S-2 & Monotonic & $15 \mathrm{M}$ & 0.554 & ZP-305 & 1.2 \\
\hline
\end{tabular}

This series was tested primarily to observe the influence of steel fibre content on the structural performance of masonry elements subjected to direct tension. As seen in Table 5-1, the steel fibres were all Dramix ZP305 and were incorporated into the grout at volume percentages ranging from 0 to 1.2 percent of the overall grout volume.

Due to the fact that these specimens were all tested early on in the testing program, not all specimens were taken to $6 \%$ overall specimen strain, however the primary focus of the study is the behaviour of the specimens in the service range and prior to yielding of the reinforcing steel. The behaviour of the specimens in the post-yield range will also be discussed in certain cases although it is not the primary focus of this study. 


\subsection{Stress-Strain Behaviour}

Figures 5-1 and 5-2 show the benefit of fibre reinforced grout as the fibre content increases. The figure shows the stress-strain response for a typical $15 \mathrm{M}$ specimen for each level of fibre reinforcement. Not all of the responses of the specimens described in Table 5-1 are plotted so as to maintain clarity in the figure. Both Figures 5-1 and 5-2 show the same data, with Figure 5-1 focusing on the pre-yielding response. The control specimen which contained grout with no fibre reinforcement quickly approached the bare bar behaviour at a strain of approximately 0.008 . At a strain of approximately 0.002 , which represents the theoretical yield strain of the reinforcing steel, the stresses in the specimens containing steel fibre reinforced grout were found to be significantly higher. At a strain of 0.002 , the stress in the typical specimen with $0.4 \%$ ZP305 fibres was approximately $458 \mathrm{MPa}$ whereas the control specimen had a stress of approximately $394 \mathrm{MPa}$ at the same strain level. By adding $0.8 \%$ and $1.2 \%$ steel fibres, the stress at the theoretical yield strain of the reinforcing steel (0.002) was approximately $515 \mathrm{MPa}$ and $550 \mathrm{MPa}$ respectively. The incorporation of $1.2 \%$ ZP305 steel fibres resulted in a $40 \%$ increase in load carrying capacity at the onset of bar yielding. These increasing load carrying capacities result in significantly increased toughness of the respective specimens.

The control specimen clearly shows the decrease in stiffness as the specimen cracks at each mortar joint location. Each crack can be clearly identified in Figure 5-1 by a sudden drop in stress and a decreasing stiffness as the load increases. At a strain of approximately 0.008 , the stiffness of the specimen 15M00-1 approaches the stiffness of the bare reinforcing bar.

The specimens containing fibre reinforced grout exhibited less degradation of stiffness than the control specimen. The specimens containing steel fibres were able to withstand a significant amount more load at the same displacement. It can also be noted that the specimens containing steel fibre reinforced grout do not show the discrete drops in stiffness and instead the decrease in stiffness is much more constant. The steel fibres allow the cracked masonry to provide a significant amount of additional load resistance when compared to the behaviour of the control specimen.

As seen in Figure 5-2, as the fibre content increases, the toughness is significantly increased in the post-yield range. The specimen containing $0.8 \%$ ZP305 fibres is able to resist 
close to the ultimate stress of the specimen without steel fibres at a strain of just $0.2 \%$. The ductility of the specimens was not sacrificed when increasing the peak tensile load carrying capacity.

Figure 5-3 shows the percent increase in stress for specimens with fibre reinforced grout over the bare bar response as a strain of 0.002 . The first set of bars represents the initial group of specimens and the second set of bars represents the duplicate specimens. It can be seen that there is a considerable increase in stress levels at a given level of strain when the fibre content is increased.

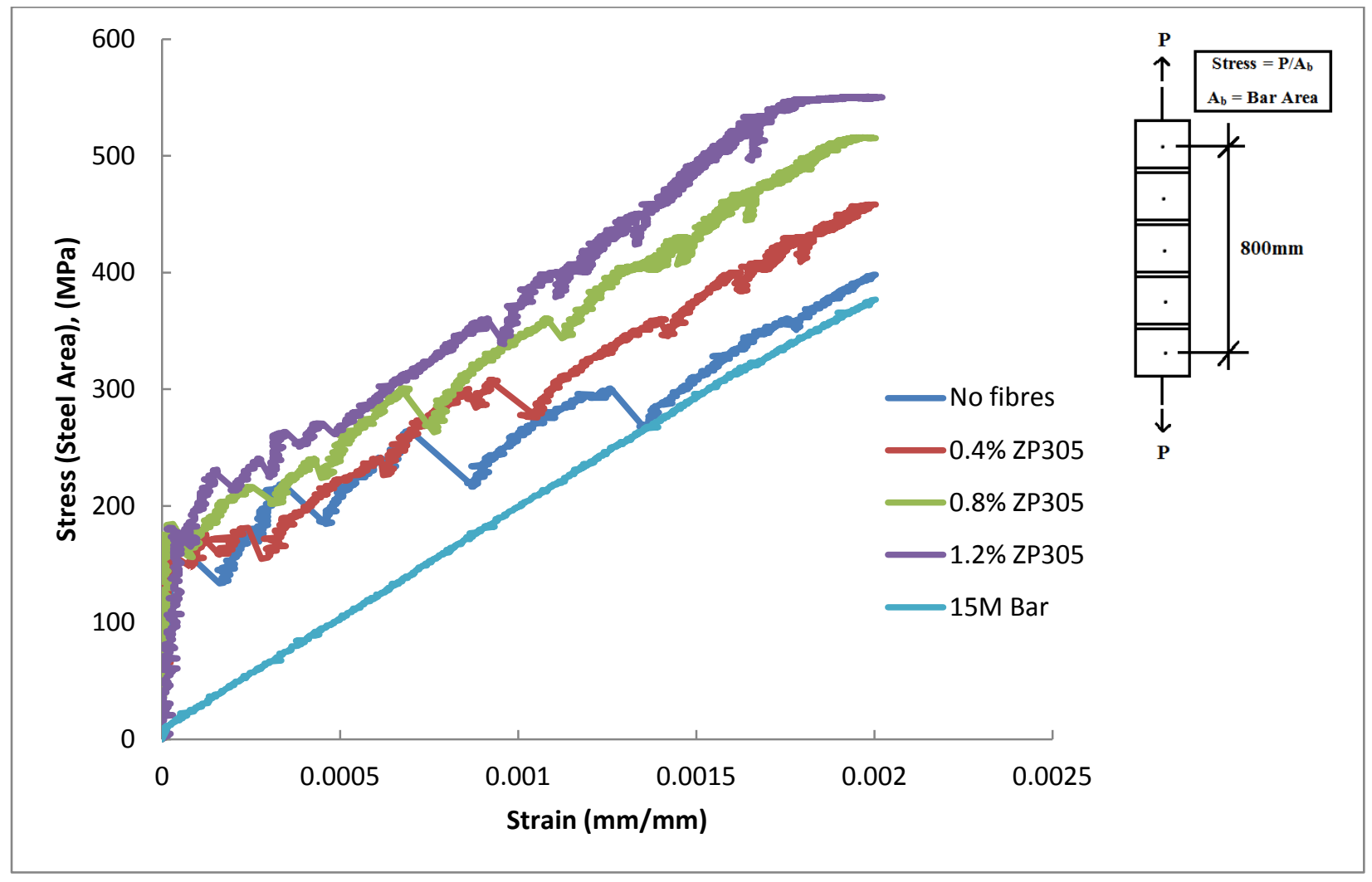

Figure 5-1: Stress strain response of $15 \mathrm{M}$ series prior to yielding of reinforcing bar 


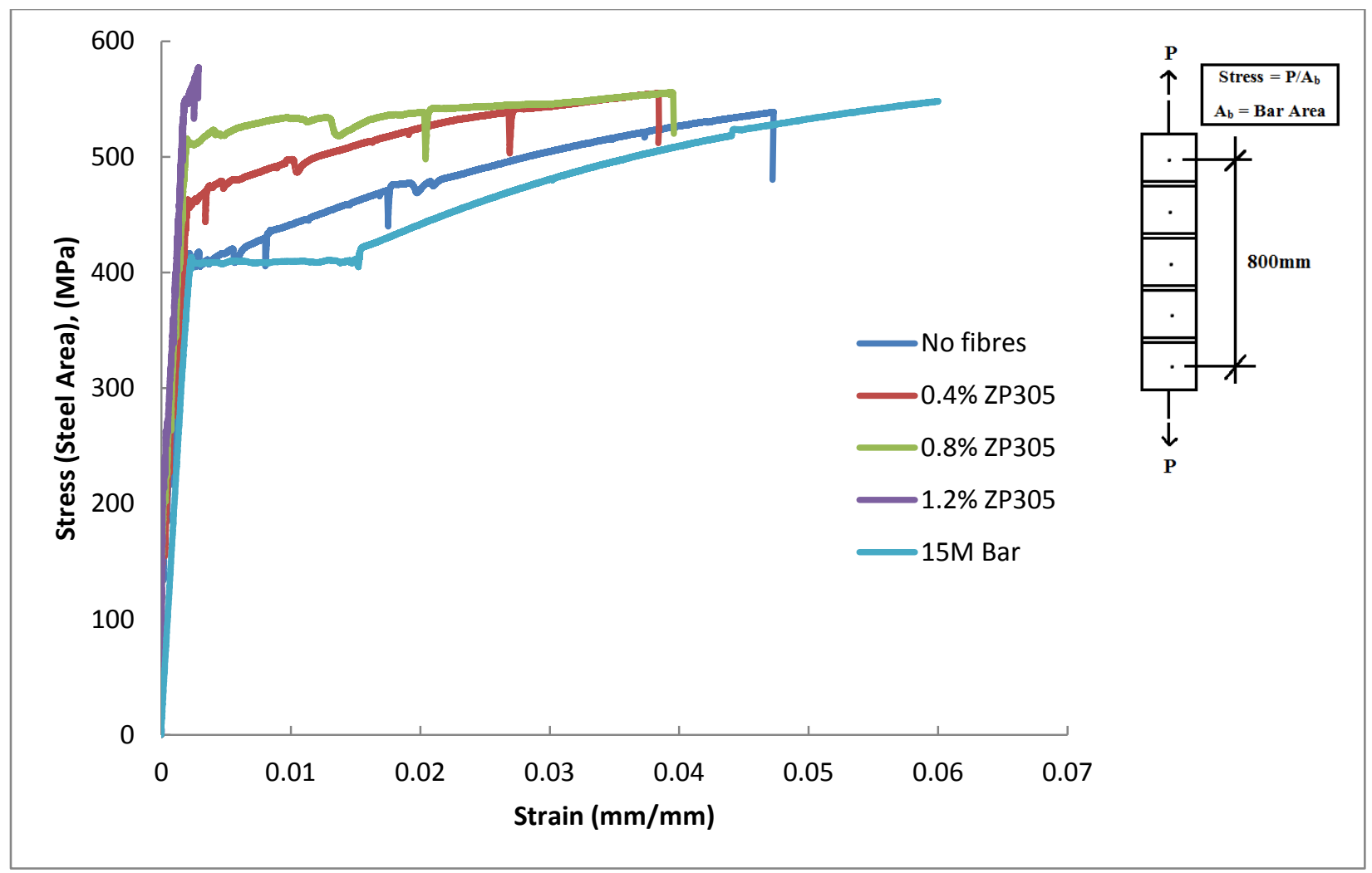

Figure 5-2: Stress strain response of 15M series after yielding of reinforcing bar

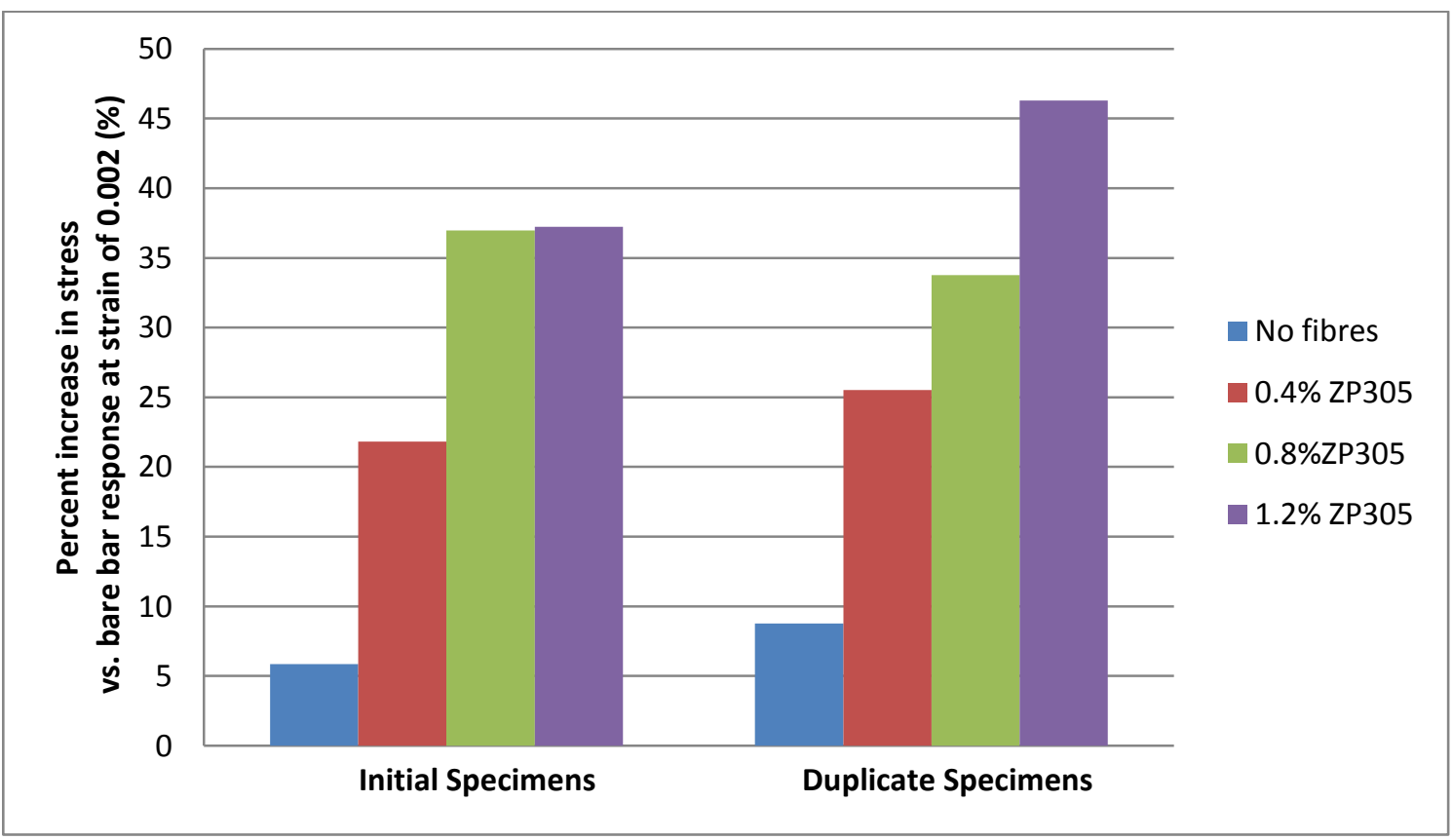

Figure 5-3: Percent increase in stress vs. bare bar response at 0.002 strain for $15 \mathrm{M}$ series 


\subsection{Effect of Fibre Content on Crack Widths and Crack Spacing}

Steel fibres incorporated into the grout were effective in decreasing the crack widths at low levels of load (see Table 5-2 and Table 5-3). It was anticipated that the number of cracks would become higher as the fibre content increased, however this effect was not very pronounced in the specimens containing $15 \mathrm{M}$ bars. The resistance of the steel fibres within the surrounding grout core caused the reinforcing steel to tend to yield outside the specimen close to the grips and therefore it was very difficult to attain high levels of strain in the specimen itself. This shows that the load carrying capacity of the fibre reinforced masonry specimen is significantly higher than the plain reinforced masonry specimens.

Table 5-2: Average crack widths for $15 \mathrm{M}$ series

\begin{tabular}{|c|c|c|c|c|c|c|c|c|c|c|c|}
\hline & \multicolumn{10}{|c|}{ Stress (Steel Area), (MPa) } \\
\hline & & 60 & 120 & 180 & 240 & 300 & 360 & 400 & 430 & 470 & 540 \\
\hline Specimen & $\begin{array}{c}\text { Fibre } \\
(\%)\end{array}$ & \multicolumn{10}{|c|}{ Average Crack Width (mm) } \\
\hline $15 \mathrm{M} 00-1$ & 0 & 0 & 0 & 0.19 & 0.26 & 0.32 & 0.35 & 0.39 & 1.63 & 3.28 & 9.13 \\
\hline $15 \mathrm{M} 00-2$ & 0 & 0 & - & 0.14 & 0.21 & - & 0.30 & - & 1.61 & 2.79 & 6.47 \\
\hline $15 \mathrm{M} 04 \mathrm{~S}-1$ & 0.4 & 0 & 0 & 0.05 & 0.16 & 0.22 & 0.22 & 0.26 & 0.29 & 0.54 & 4.29 \\
\hline $15 \mathrm{M} 04 \mathrm{~S}-2$ & 0.4 & 0 & - & 0.12 & 0.18 & - & 0.33 & - & 0.40 & 0.45 & 4.71 \\
\hline $15 \mathrm{M} 08 \mathrm{~S}-1$ & 0.8 & 0 & 0 & 0 & 0.13 & 0.15 & 0.21 & - & 0.28 & 0.32 & 2.74 \\
\hline $15 \mathrm{M} 08 \mathrm{~S}-2$ & 0.8 & 0 & - & 0.06 & 0.11 & - & 0.22 & - & 0.30 & - & 2.94 \\
\hline $15 \mathrm{M} 12 \mathrm{~S}-1$ & 1.2 & 0 & 0 & 0 & 0.11 & 0.20 & 0.27 & 0.33 & - & - & 1.55 \\
\hline $15 \mathrm{M} 12 \mathrm{~S}-2$ & 1.2 & 0 & 0 & 0 & 0.13 & - & 0.23 & 0.31 & - & - & 0.45 \\
\hline
\end{tabular}

Table 5-3: Maximum crack widths for $15 \mathrm{M}$ series

\begin{tabular}{|c|c|c|c|c|c|c|c|c|c|c|c|}
\hline & \multicolumn{10}{|c|}{ Stress (Steel Area), (MPa) } \\
\hline & & 60 & 120 & 180 & 240 & 300 & 360 & 400 & 430 & 470 & 540 \\
\hline Specimen & $\begin{array}{c}\text { Fibre } \\
(\%)\end{array}$ & \multicolumn{10}{|c|}{ Maximum Crack Width (mm) } \\
\hline $15 \mathrm{M} 00-1$ & 0 & 0 & 0 & 0.4 & 0.56 & 0.64 & 0.7 & 0.8 & 2.8 & 5.0 & 10.7 \\
\hline $15 \mathrm{M} 00-2$ & 0 & 0 & - & 0.3 & 0.48 & - & 0.62 & - & 2.5 & 4.0 & 10.2 \\
\hline 15M04S-1 & 0.4 & 0 & 0 & 0.08 & 0.24 & 0.36 & 0.46 & 0.62 & 0.7 & 2.0 & 4.7 \\
\hline 15M04S-2 & 0.4 & 0 & - & 0.18 & 0.36 & - & 0.62 & - & 0.72 & 0.8 & 10.4 \\
\hline $15 \mathrm{M} 08 \mathrm{~S}-1$ & 0.8 & 0 & 0 & 0 & 0.24 & 0.3 & 0.4 & - & 0.6 & 0.8 & 5.1 \\
\hline $15 \mathrm{M} 08 \mathrm{~S}-2$ & 0.8 & 0 & - & 0.08 & 0.18 & - & 0.42 & - & 0.62 & - & 7.7 \\
\hline $15 \mathrm{M} 12 \mathrm{~S}-1$ & 1.2 & 0 & 0 & 0 & 0.16 & 0.24 & 0.32 & 0.4 & - & - & 3.5 \\
\hline $15 \mathrm{M} 12 \mathrm{~S}-2$ & 1.2 & 0 & 0 & 0 & 0.14 & - & 0.40 & 0.62 & - & - & 0.84 \\
\hline
\end{tabular}


As shown in Figures 5-4 and 5-5, very little difference in both the average and maximum crack widths can be observed prior to yielding of the reinforcing steel. After $400 \mathrm{MPa}$, however, the crack widths become wider much quicker in the specimens with no fibres when compared to the specimens reinforced with steel fibres. Table 5-4 shows the cracking patterns for the specimens in the $15 \mathrm{M}$ series (see Table 5-1).

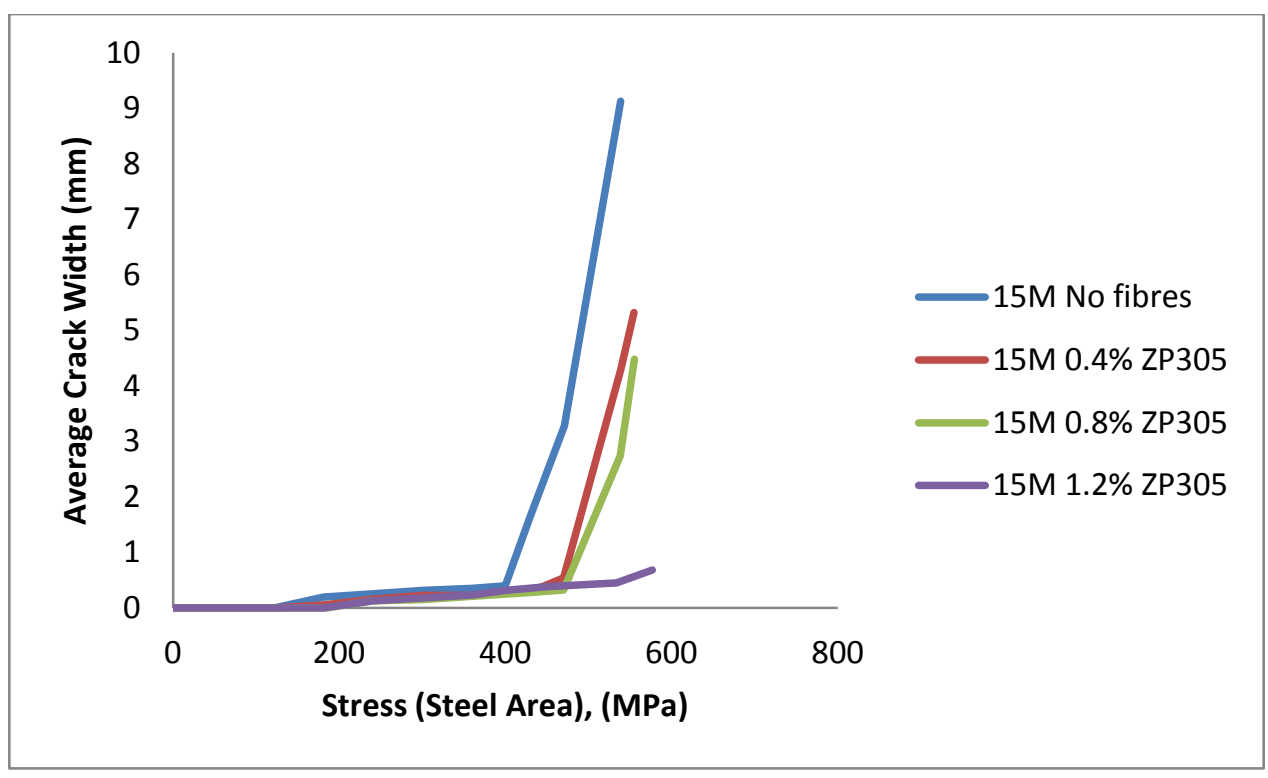

Figure 5-4: Average crack widths as a function of strain for $15 \mathrm{M}$ specimens

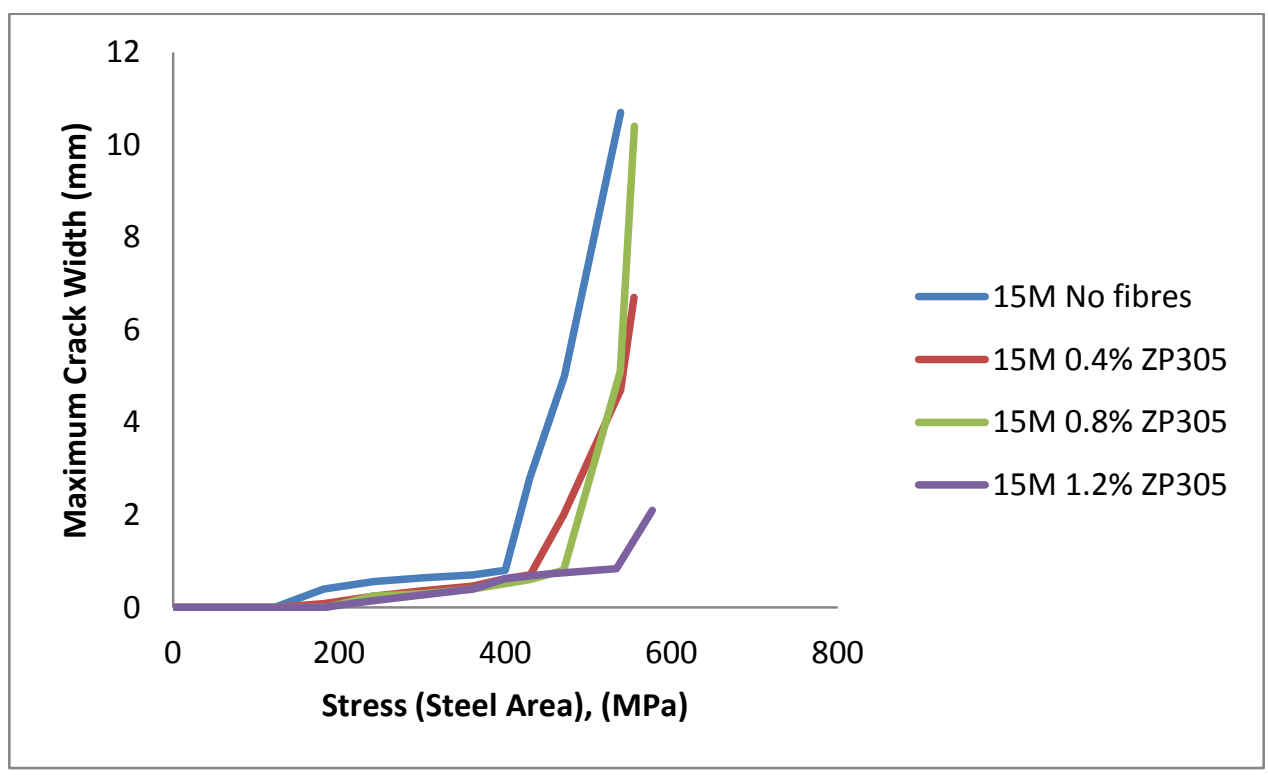

Figure 5-5: Maximum crack widths as a function of strain for $15 \mathrm{M}$ specimens 
Table 5-4: Cracking pattern for $15 \mathrm{M}$ series at steel stress of 540MPa

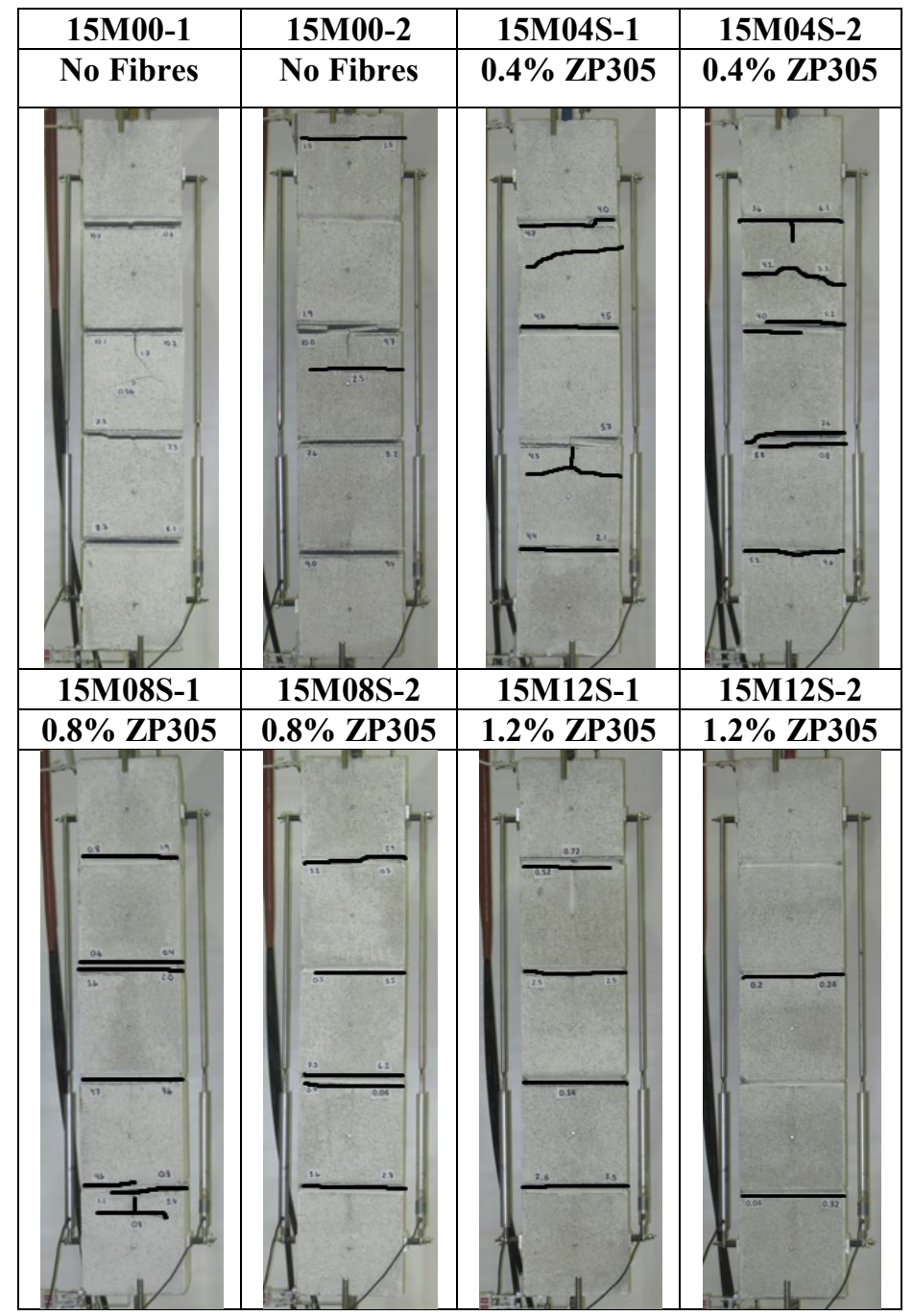

\subsubsection{20M Series}

This series was also tested primarily to observe the influence of steel fibre content on the structural performance of masonry elements subjected to direct tension. Each specimen had a 20M bar embedded in a single fully grouted masonry cell. As seen in the Table 5-5, the steel 
fibres were all Dramix ZP305 and were incorporated into the grout at percentages ranging from 0 to 1.2 percent of the overall grout volume.

Table 5-5: 20M series properties

\begin{tabular}{|c|c|c|c|c|c|}
\hline Specimen & $\begin{array}{c}\text { Loading } \\
\text { Type }\end{array}$ & $\begin{array}{c}\text { Bar } \\
\text { Size }\end{array}$ & $\begin{array}{c}\text { Reinforcement } \\
\text { Ratio (\%) }\end{array}$ & $\begin{array}{c}\text { Fibre } \\
\text { Type }\end{array}$ & $\begin{array}{c}\mathbf{V}_{\mathbf{f}} \\
\mathbf{( \% )}\end{array}$ \\
\hline 20M00-1 & Monotonic & $20 \mathrm{M}$ & 0.00831 & None & 0.0 \\
\hline 20M00-2 & Monotonic & $20 \mathrm{M}$ & 0.00831 & None & 0.0 \\
\hline 20M04S-1 & Monotonic & $20 \mathrm{M}$ & 0.00831 & ZP-305 & 0.4 \\
\hline 20M04S-2 & Monotonic & $20 \mathrm{M}$ & 0.00831 & ZP-305 & 0.4 \\
\hline 20M08S-1 & Monotonic & $20 \mathrm{M}$ & 0.00831 & ZP-305 & 0.8 \\
\hline 20M08S-2 & Monotonic & $20 \mathrm{M}$ & 0.00831 & ZP-305 & 0.8 \\
\hline 20M12S-1 & Monotonic & $20 \mathrm{M}$ & 0.00831 & ZP-305 & 1.2 \\
\hline 20M12S-2 & Monotonic & $20 \mathrm{M}$ & 0.00831 & ZP-305 & 1.2 \\
\hline
\end{tabular}

\subsection{Stress Strain Behaviour}

The Figures 5-6, 5-7 and 5-8 show the benefit of fibre reinforced grout as the fibre content increases. The figure shows the stress-strain response for a typical 20M specimen for each level of fibre reinforcement. Not all of the responses of the specimens described in Table 55 are plotted so as to maintain clarity in the figure. Both Figure 5-6 and Figure 5-7 show the same data, with Figure 5-6 focusing on the pre-yielding response. The control specimen which contained grout with no fibre reinforcement quickly approached the bare bar behaviour at a strain of approximately 0.0005 . At a strain of approximately 0.002 , which represents the theoretical yield strain of the reinforcing steel, the stress in the specimens containing steel fibre reinforced grout was found to be significantly higher. At a strain of 0.002 , the stress in the typical specimen with $0.4 \%$ ZP305 fibres was approximately $417 \mathrm{MPa}$ whereas the control specimen had a stress of approximately $394 \mathrm{MPa}$ at the same strain level. By adding $0.8 \%$ and $1.2 \%$ steel fibres, the stress at the theoretical yield strain of the reinforcing steel was approximately $455 \mathrm{MPa}$ and $504 \mathrm{MPa}$ respectively. The incorporation of $1.2 \%$ ZP305 steel fibres resulted in a $28 \%$ increase in load carrying capacity at the onset of yielding. These increasing load carrying capacities result in significantly increased toughness of the respective specimens. It can be noted here that the influence of the fibre reinforced grout is more pronounced on specimens with smaller bars and hence smaller reinforcement ratios. This phenomenon will be discussed in subsequent sections. 
As seen in Figure 5-6, at a strain of approximately 0.008, the stiffness of the specimen 15M00-1 approaches the stiffness of the bare reinforcing bar. The response of the specimens containing steel fibres remained well above the response of the bare $20 \mathrm{M}$ bar.

The specimens containing steel fibres are able to resist a significantly greater load at the same strain. Also, the first cracking and accompanying significant drop in stiffness happened at a much higher load for the specimens with fibre reinforcement. This will be discussed in the following section as crack widths are discussed.

As seen in Figure 5-7, as the fibre content increases, the toughness is significantly increased in the post-yield range. The specimen containing 1.2\% ZP305 fibres is able to resist close to the ultimate stress of the specimen without steel fibres at a strain of just $0.2 \%$.

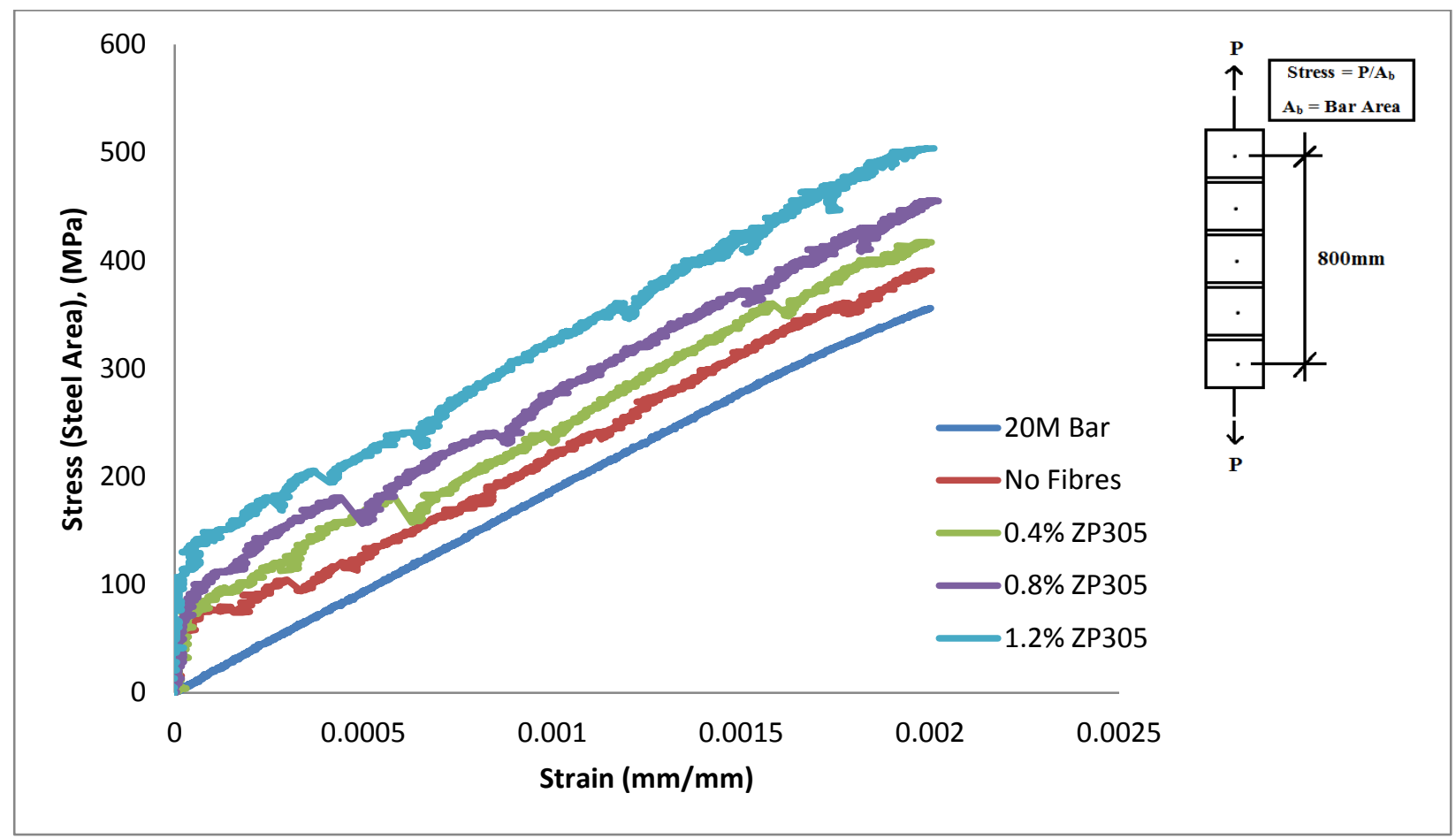

Figure 5-6: Stress strain response of 20M series prior to yielding of reinforcing bar 


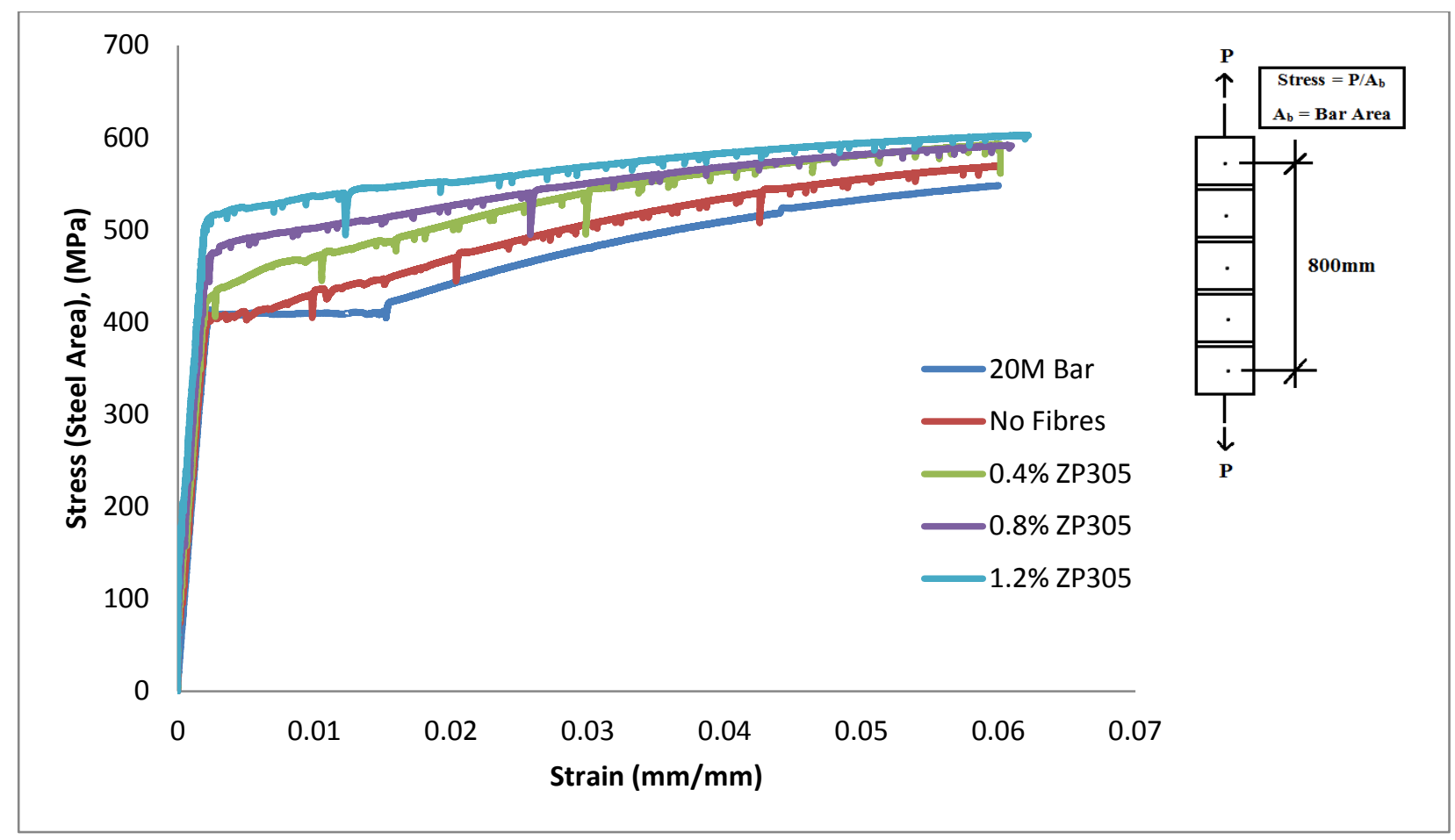

Figure 5-7: Stress strain response of 20M series after yielding of reinforcing bar

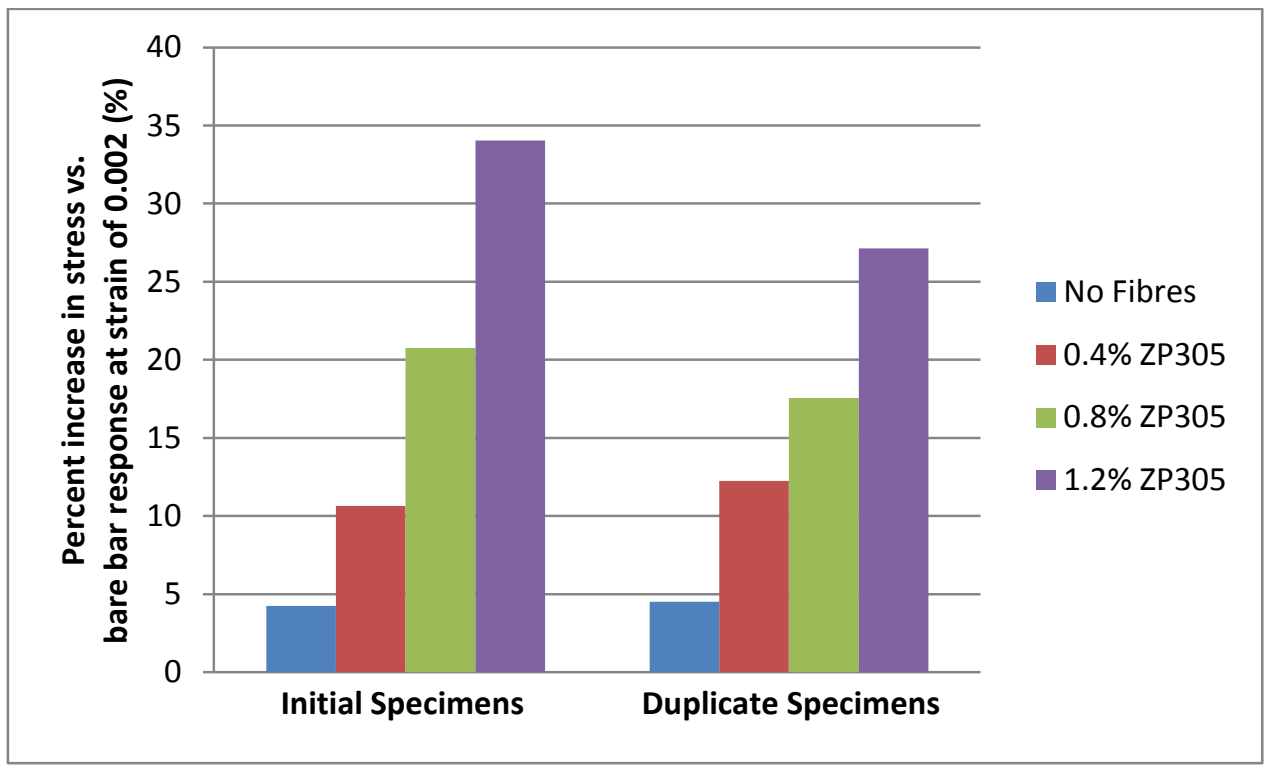

Figure 5-8: Percent increase in stress vs. bare bar response at 0.002 strain for $20 \mathrm{M}$ series 


\subsection{Effect of Fibre Content on Crack Widths and Crack Spacing}

Like the specimens with the $15 \mathrm{M}$ bars, the steel fibre reinforced grout was successful in decreasing the crack widths at both low and high levels of load (see Figure 5-9 and Figure 510). At high stress levels, the average crack widths of the specimens with fibre reinforced grout were up to three times narrower than in the case of no fibre reinforcement (see Table 5-6 and Table 5-7). Also, the steel fibres were able to decrease the crack spacing at increased levels of load as seen in Table 5-8. Due to the fact that the bar area was $50 \%$ greater than in the case of the $15 \mathrm{M}$ bar, steel yielding was not observed between the top and bottom of the specimen and the tension grips.

Table 5-6: Average crack widths for $20 \mathrm{M}$ series

\begin{tabular}{|c|c|c|c|c|c|c|c|c|c|c|c|}
\hline \multicolumn{2}{|c|}{} & \multicolumn{10}{|c|}{ Stress (Steel Area), (MPa) } \\
\cline { 3 - 13 } & 60 & 120 & 180 & 240 & 300 & 360 & 400 & 430 & 470 & 540 \\
\hline Specimen & $\begin{array}{c}\text { Fibre } \\
(\%)\end{array}$ & \multicolumn{9}{|c|}{ Average Crack Width (mm) } \\
\hline 20 M00-1 & 0 & 0 & 0.084 & 0.154 & 0.205 & - & 0.321 & - & 1.546 & 2.616 & 5.3 \\
\hline $20 \mathrm{M} 00-2$ & 0 & 0 & 0.1175 & 0.127 & 0.173 & - & 0.295 & - & 1.285 & 2.38 & 3.757 \\
\hline 20M04S-1 & 0.4 & 0 & 0.095 & 0.143 & 0.21 & - & 0.338 & - & 0.524 & 1.679 & 3.721 \\
\hline 20M04S-2 & 0.4 & 0 & 0.093 & 0.142 & 0.214 & - & 0.331 & - & 0.415 & 1.395 & 3.750 \\
\hline 20M08S-1 & 0.8 & 0 & 0.06 & 0.115 & 0.156 & - & 0.249 & - & 0.3 & 0.409 & 2.533 \\
\hline 20M08S-2 & 0.8 & 0 & 0.05 & 0.148 & 0.172 & - & 0.264 & - & 0.254 & 0.51 & 1.308 \\
\hline 20M12S-1 & 1.2 & 0 & 0 & 0.12 & 0.134 & - & 0.258 & - & 0.292 & 0.366 & 1.55 \\
\hline 20M12S-2 & 1.2 & 0 & 0.05 & 0.13 & 0.184 & - & 0.286 & - & 0.332 & 0.385 & 3.01 \\
\hline
\end{tabular}

Table 5-7: Maximum crack widths for 20M series

\begin{tabular}{|c|c|c|c|c|c|c|c|c|c|c|c|c|}
\hline \multicolumn{2}{|c}{} & \multicolumn{9}{|c|}{ Stress (Steel Area), (MPa) } \\
\cline { 3 - 14 } & 60 & 120 & 180 & 240 & 300 & 360 & 400 & 430 & 470 & 540 \\
\hline Specimen & $\begin{array}{c}\text { Fibre } \\
\text { (\%) }\end{array}$ & \multicolumn{9}{|c|}{ Maximum Crack Width (mm) } \\
\hline 20M00-1 & 0 & 0 & 0.16 & 0.3 & 0.42 & - & 0.68 & - & 2.1 & 5.0 & 11.4 \\
\hline $20 \mathrm{M} 00-2$ & 0 & 0 & 0.16 & 0.24 & 0.36 & - & 0.6 & - & 2.5 & 4.8 & 6.8 \\
\hline 20M04S-1 & 0.4 & 0 & 0.16 & 0.3 & 0.44 & - & 0.68 & - & 1.6 & 3.4 & 7.4 \\
\hline 20M04S-2 & 0.4 & 0 & 0.14 & 0.26 & 0.42 & - & 0.68 & - & 0.8 & 3 & 7.2 \\
\hline 20M08S-1 & 0.8 & 0 & 0.08 & 0.2 & 0.32 & - & 0.58 & - & 0.68 & 0.92 & 5.6 \\
\hline 20M08S-2 & 0.8 & 0 & 0.06 & 0.18 & 0.34 & - & 0.5 & - & 0.64 & 1.3 & 4.0 \\
\hline 20M12S-1 & 1.2 & 0 & 0 & 0.18 & 0.32 & - & 0.54 & - & 0.64 & 0.76 & 5.3 \\
\hline 20M12S-2 & 1.2 & 0 & 0.06 & 0.2 & 0.3 & - & 0.52 & - & 0.66 & 0.74 & 6.5 \\
\hline
\end{tabular}


Again, the fibres show very little influence on both the average and maximum crack widths prior to yielding of the reinforcing steel. After 400MPa, however, the crack widths become wider significantly quicker in the specimens without fibres when compared to the specimens containing steel fibre reinforced grout. The average crack widths and maximum crack widths as a function of steel stress respectively are summarized graphically in Figure 5-9 and Figure 5-10.

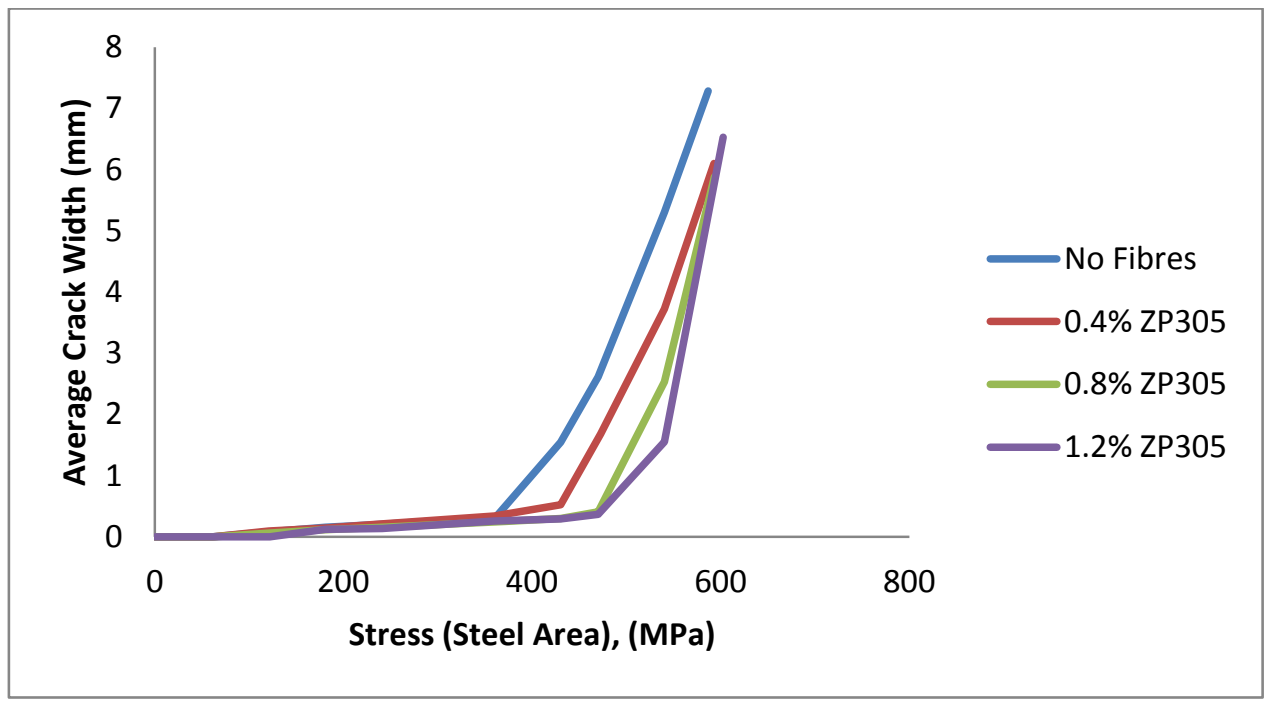

Figure 5-9: Average crack widths as a function of strain for 20M specimens

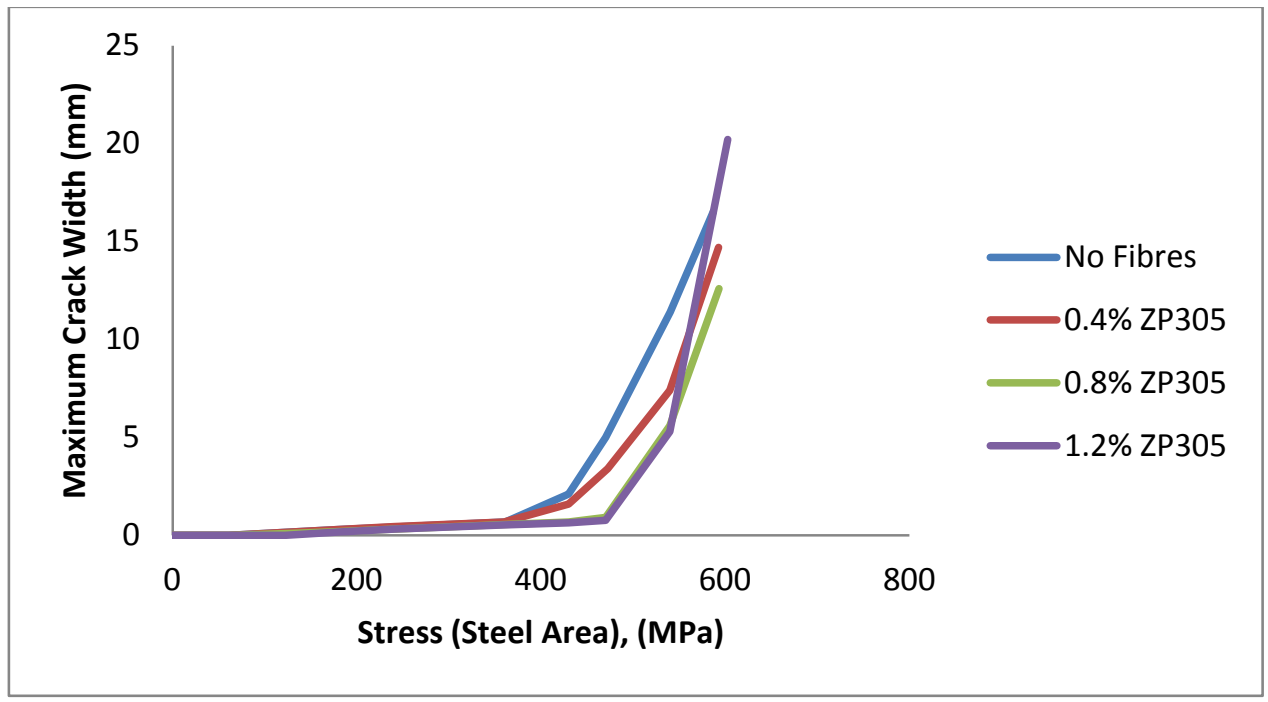

Figure 5-10: Maximum crack widths as a function of strain for 20M specimens 
In the Table 5-8, it can be seen that by simply adding $0.4 \%$ steel fibres, not only is the number of horizontal cracks increased, the distribution of the cracks is also more uniform. This uniform distribution of the cracks aids the specimen from developing localized strain at a single crack location.

Table 5-8: Cracking pattern for 20M series at steel stress of 540MPa

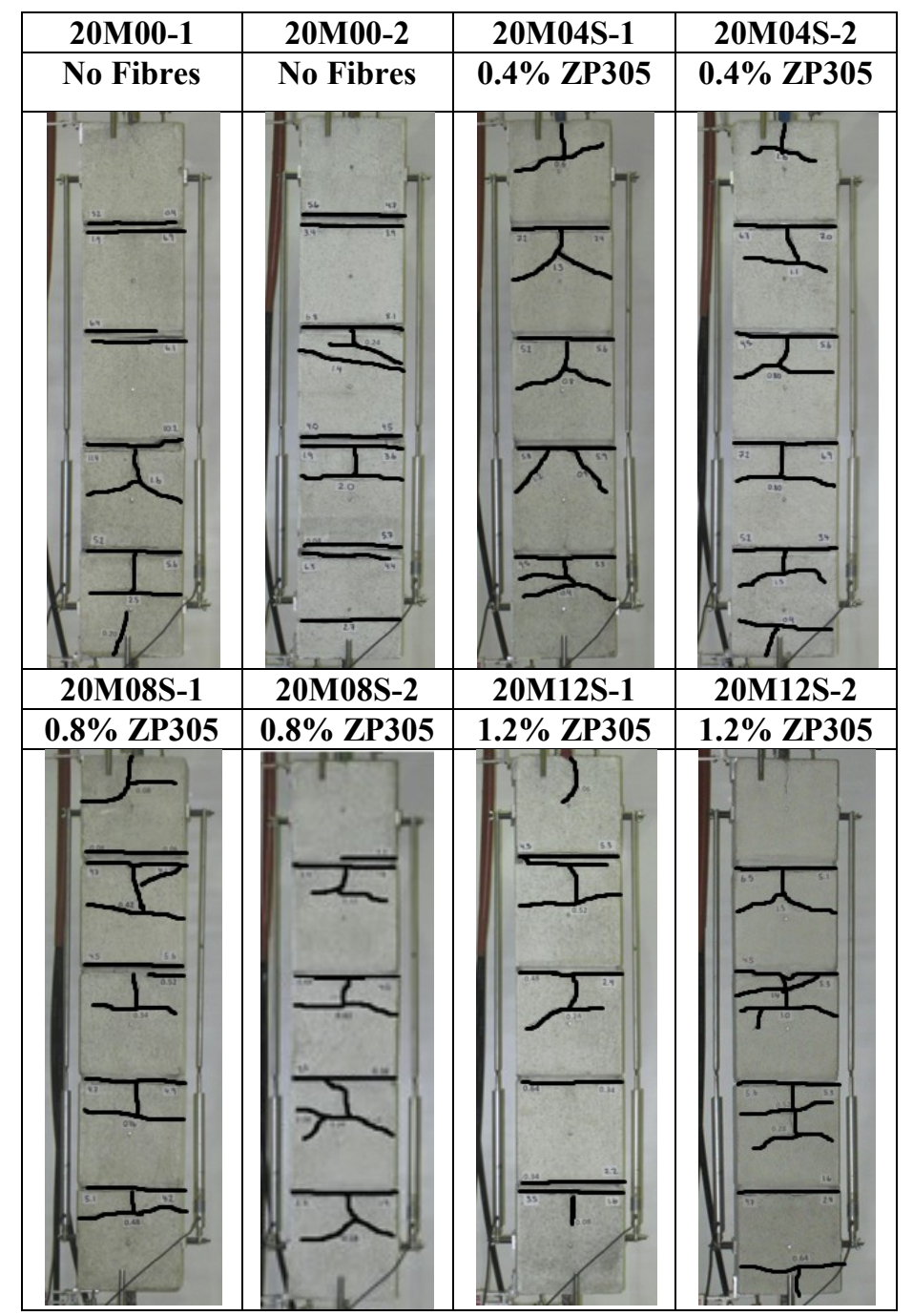




\subsubsection{Effect of Reinforcement Ratio}

Specimens were constructed with three different reinforcement ratios in order to observe its effect on tension stiffening, crack widths and crack spacing,. The different reinforcement ratios were achieved by using three different sizes of reinforcing steel. Specimens with $10 \mathrm{M}$, $15 \mathrm{M}$ and $20 \mathrm{M}$ bars were used to observe the effect that reinforcement ratio have on both the stress-strain behaviour and the crack widths. The only variable in these specimens is the reinforcing steel as the blocks and grout mixes were the same for all specimens. The specimens built and tested to observe the effect of reinforcement ratio are summarized in Table 5-9.

Table 5-9: Properties of specimens used to study effect of reinforcement ratio

\begin{tabular}{|c|c|c|c|}
\hline Specimen & Bar Size & Reinforcement Ratio & $\begin{array}{c}\text { Fibre Content } \\
\mathbf{( \% )}\end{array}$ \\
\hline 10M00-1/10M00-2 & $10 \mathrm{M}$ & 0.0027 & 0 \\
\hline 10M12S-1/10M12S-2 & $10 \mathrm{M}$ & 0.0027 & 1.2 \\
\hline $15 \mathrm{M} 00-1 / 15 \mathrm{M} 00-2$ & $15 \mathrm{M}$ & 0.0055 & 0 \\
\hline 15M12S-1/15M12S-2 & $15 \mathrm{M}$ & 0.0055 & 1.2 \\
\hline 20M00-1/20M00-2 & $20 \mathrm{M}$ & 0.0083 & 0 \\
\hline 20M12S-1/20M12S-2 & $20 \mathrm{M}$ & 0.0083 & 1.2 \\
\hline
\end{tabular}

\subsubsection{Stress Strain Behaviour}

Figure 5-11 and Figure 5-12 show the typical response of each type of specimen prior to yielding of the reinforcing steel. For clarity, the duplicate responses are not shown. Large strains were very difficult to attain in the specimens with $10 \mathrm{M}$ bars as the bar tended to yield between the end of the specimen and the tension grips. The tension stiffening effect is much more pronounced for elements with low reinforcement ratios. Also, when ZP305 fibres are added to the grout at a volume fraction of $1.2 \%$, the responses of the specimens with the lower reinforcement ratios are far superior as seen in Figure 5-12. 
The first cracking of the specimens occurs at a significantly higher steel stress in the specimens with the lower reinforcement ratios. This is due to the fact that we are assuming the stress of the specimen based on the steel area, and therefore if there is a lower steel area it will take less force to achieve the same stress as a specimen with a higher reinforcement ratio.

The specimens with no fibres (see Figure 5-11) quickly approach the bare bar response at low levels of strain. The specimens with smaller reinforcement ratios show a slightly better improvement when compared with the specimens with larger reinforcement ratios.

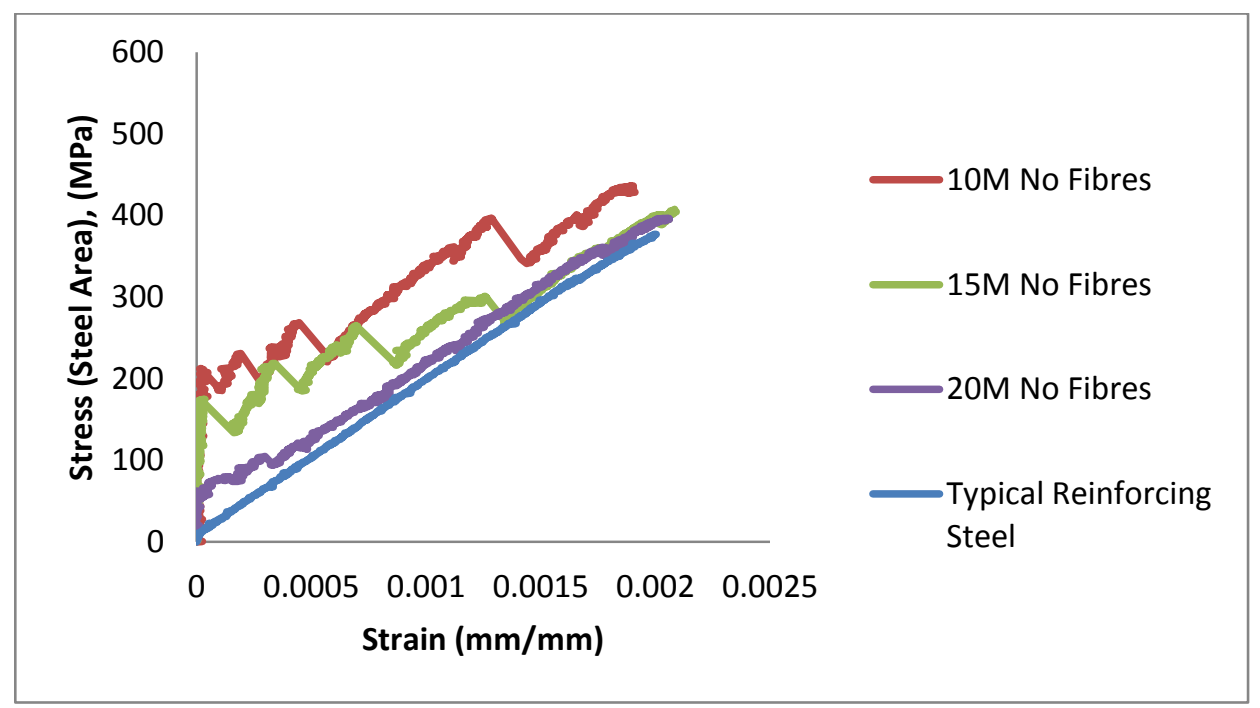

Figure 5-11: Stress strain response of specimens with no fibres prior to yield

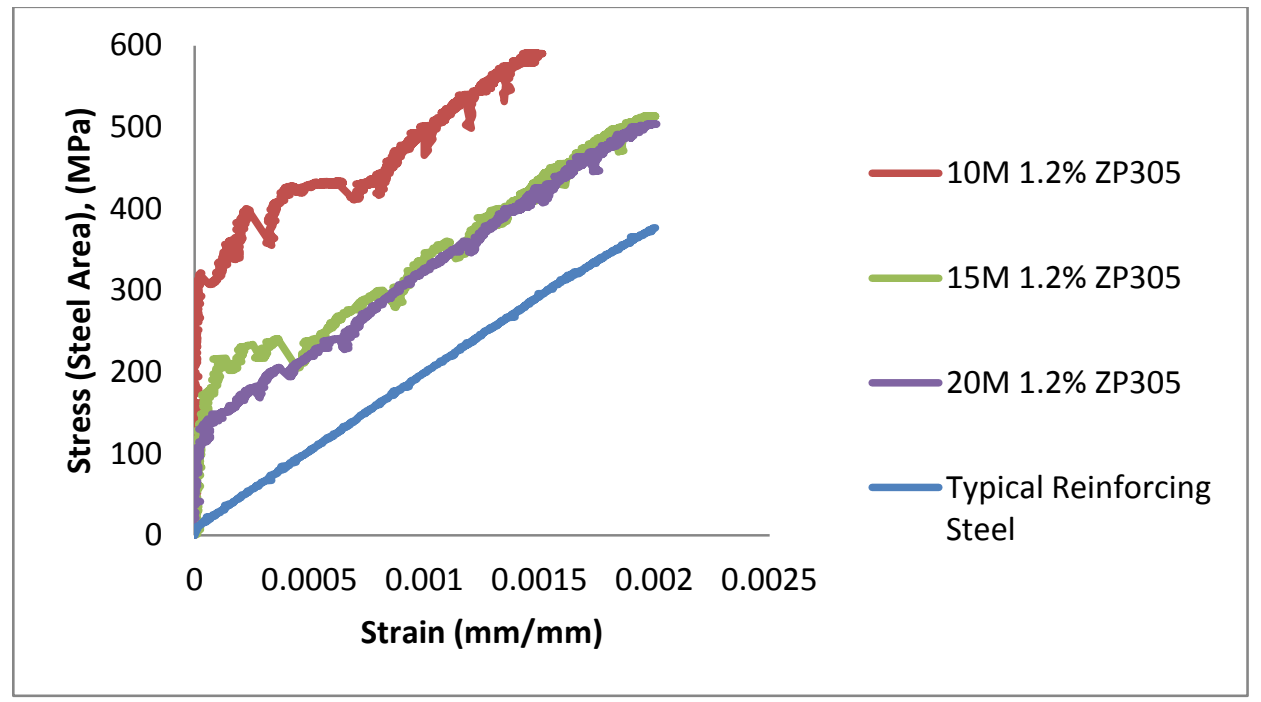

Figure 5-12: Stress strain response of specimens with $1.2 \%$ ZP305 fibres prior to yield 


\subsubsection{Crack Width and Crack Spacing}

The crack widths were generally wider for those specimens with larger reinforcement ratios at levels of stress prior to yield (see Table 5-10 and Table 5-11). The tensile strength of masonry is independent of the reinforcement ratio and is a constant. Since larger forces are imparted to the specimens containing larger bars, the resulting tensile stress imparted to the cracked masonry with increased reinforcement ratios is larger, resulting in wider cracks. Figure 5-13 summarizes the average and maximum crack widths as a function of reinforcement ratio.

Table 5-10: Average crack widths of specimens to investigate effect of reinforcement ratio

\begin{tabular}{|c|c|c|c|c|c|c|c|c|c|c|c|}
\hline & \multicolumn{10}{c|}{ Stress (Steel Area), (MPa) } \\
\cline { 2 - 13 } & 60 & 120 & 180 & 240 & 300 & 360 & 400 & 430 & 470 & 540 \\
\hline Specimen & \multicolumn{9}{|c|}{ Average Crack Width (mm) } \\
\hline 10M00-1 & 0 & - & 0 & 0.14 & - & 0.23 & 0.29 & 0.59 & - & 5.48 \\
\hline 10M00-2 & 0 & - & 0 & 0.135 & - & 0.263 & 0.28 & 0.448 & - & 5.875 \\
\hline 15M00-1 & 0 & 0 & 0.195 & 0.256 & 0.316 & 0.353 & 0.394 & 1.625 & 3.278 & 9.125 \\
\hline 15M00-2 & 0 & - & 0.142 & 0.212 & - & 0.296 & - & 1.606 & 2.793 & 6.473 \\
\hline 20M00-1 & 0 & 0.084 & 0.154 & 0.205 & - & 0.321 & - & 1.546 & 2.616 & 5.3 \\
\hline 20M00-2 & 0 & 0.1175 & 0.127 & 0.173 & - & 0.295 & - & 1.285 & 2.38 & 3.757 \\
\hline 10M12S-1 & 0 & - & 0 & 0 & - & 0.24 & 0.31 & 0.238 & - & 0.349 \\
\hline 10M12S-2 & 0 & - & 0 & 0 & - & 0.22 & 0.25 & 0.29 & - & 0.420 \\
\hline 15M12S-1 & 0 & 0.084 & 0.154 & 0.205 & - & 0.321 & - & 1.546 & 2.616 & 5.3 \\
\hline 15M12S-2 & 0 & 0.1175 & 0.127 & 0.173 & - & 0.295 & - & 1.285 & 2.38 & 3.757 \\
\hline 20M12S-1 & 0 & 0 & 0.12 & 0.134 & - & 0.258 & - & 0.292 & 0.366 & 1.55 \\
\hline 20M12S-2 & 0 & 0.05 & 0.13 & 0.184 & - & 0.286 & - & 0.332 & 0.385 & 3.01 \\
\hline
\end{tabular}


Table 5-11: Maximum crack widths of specimens to investigate effect of reinforcement ratio

\begin{tabular}{|c|c|c|c|c|c|c|c|c|c|c|c|}
\hline & \multicolumn{10}{c|}{ Stress (Steel Area), (MPa) } \\
\cline { 2 - 14 } & 60 & 120 & 180 & 240 & 300 & 360 & 400 & 430 & 470 & 540 \\
\hline Specimen & \multicolumn{9}{|c|}{ Maximum Crack Width (mm) } \\
\hline 10M00-1 & 0 & - & 0 & 0.16 & - & 0.46 & 0.62 & 1.9 & - & 10.5 \\
\hline $10 \mathrm{M} 00-2$ & 0 & - & 0 & 0.24 & - & 0.46 & 0.56 & 0.94 & - & 7.5 \\
\hline $15 \mathrm{M} 00-1$ & 0 & 0 & 0.4 & 0.56 & 0.64 & 0.7 & 0.8 & 2.8 & 5.0 & 10.7 \\
\hline 15M00-2 & 0 & - & 0.3 & 0.48 & - & 0.62 & - & 2.5 & 4.0 & 10.2 \\
\hline 20M00-1 & 0 & 0.16 & 0.3 & 0.42 & - & 0.68 & - & 2.1 & 5.0 & 11.4 \\
\hline 20M00-2 & 0 & 0.16 & 0.24 & 0.36 & - & 0.6 & - & 2.5 & 4.8 & 6.8 \\
\hline 10M12S-1 & 0 & - & 0 & 0 & 0.24 & 0.31 & - & 0.4 & - & 0.56 \\
\hline 10M12S-2 & 0 & - & 0 & 0 & 0.22 & 0.36 & - & 0.52 & - & 0.54 \\
\hline 15M12S-1 & 0 & 0 & 0 & 0.16 & 0.24 & 0.32 & 0.4 & - & - & 3.5 \\
\hline 15M12S-2 & 0 & 0 & 0 & 0.14 & - & 0.40 & 0.62 & - & - & 0.84 \\
\hline 20M12S-1 & 0 & 0 & 0.18 & 0.32 & - & 0.54 & - & 0.64 & 0.76 & 5.3 \\
\hline 20M12S-2 & 0 & 0.06 & 0.2 & 0.3 & - & 0.52 & - & 0.66 & 0.74 & 6.5 \\
\hline
\end{tabular}



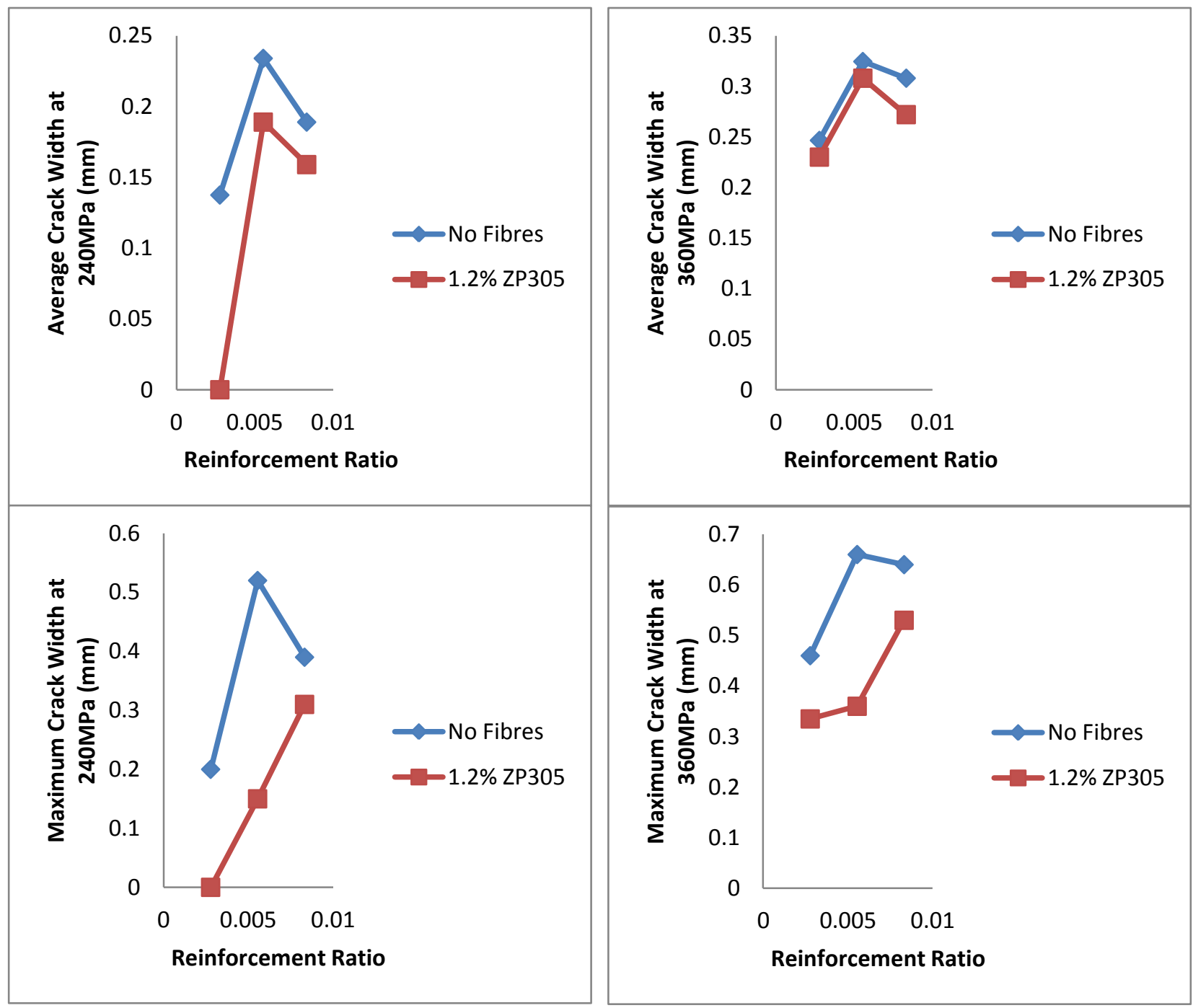

Figure 5-13: Average and maximum crack widths at stresses of 240MPa and 360MPa as a function of reinforcement ratio 
Table 5-12: Crack patterns for specimens with varying reinforcement ratios at a steel stress of 540MPa

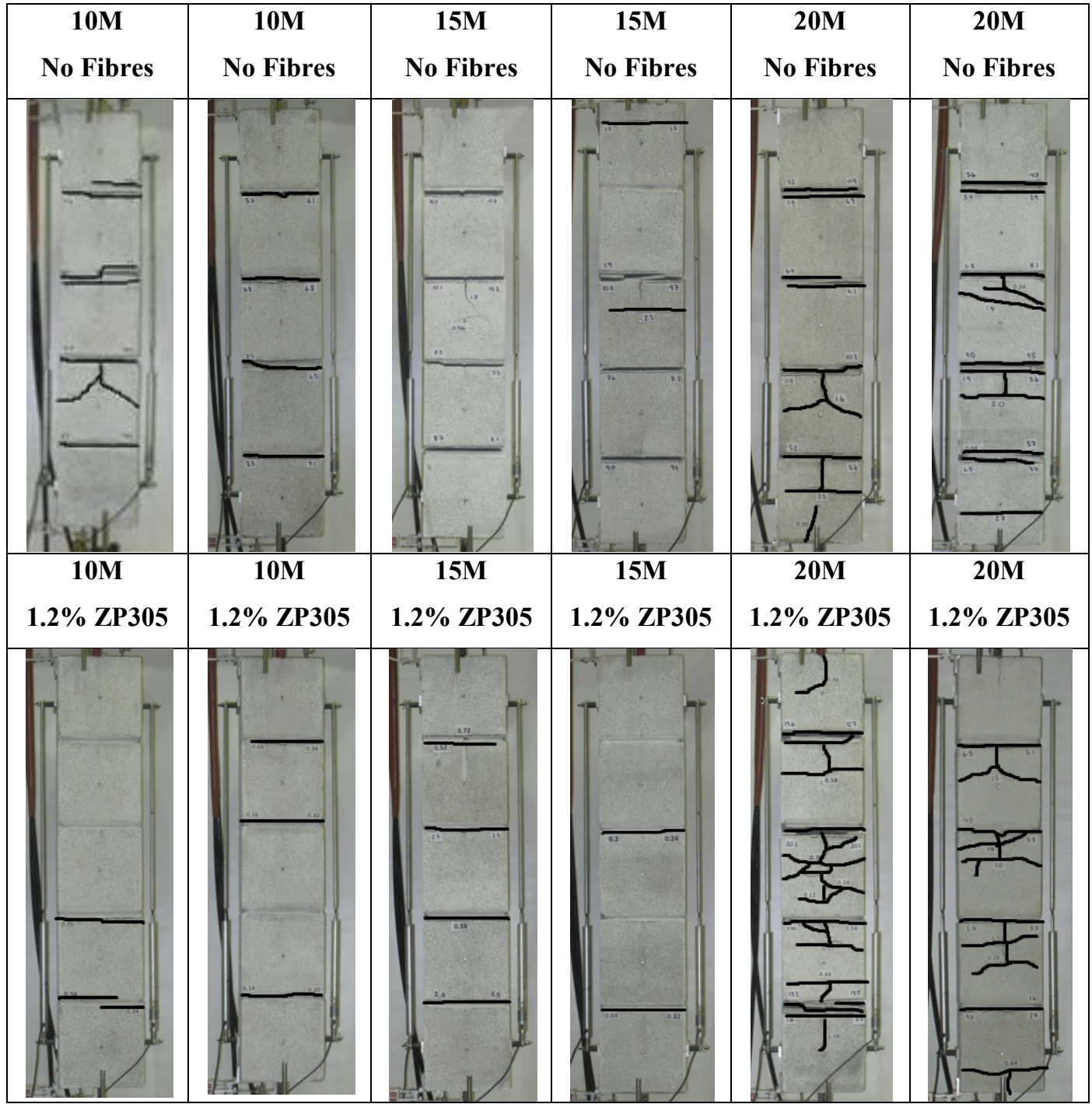

\subsubsection{Effect of Fibre type}

Two different fibre types were used in the experimental testing, both provided by Bakeart Ltd. Both types of steel fibres were considered to be regular strength and had the same hooked ends to prevent pullout from the matrix. The steel fibres had different lengths and consequently different aspect ratios. 
The primary type of fibre used was Dramix ZP305 steel fibres. Two specimens containing grout with Dramix RC65/60BN steel fibres at $1.2 \%$ by volume were cast and tested under monotonic load. These specimens were used to investigate whether longer fibres could be effectively incorporated into a grout mix with respect to workability, and if so, to assess the benefit with regards to the post cracking stiffening of the specimen.

It was found that the longer steel fibres were much more difficult to incorporate into the grout mix and workability issues were encountered. The steel fibres tended to segregate from the grout mixture and therefore a uniform fibre distribution throughout the matrix cannot be assumed for these specimens.

\subsubsection{Stress Strain Behaviour}

For means of comparison of structural performance, specimens: 15M12S-1, 15M12S-2, $15 \mathrm{M} 12 \mathrm{~L}-1$ and $15 \mathrm{M} 12 \mathrm{~L}-2$ will be investigated further. The first two specimens mentioned, one of which is a duplicate specimen; contain a single $15 \mathrm{M}$ reinforcing bar surrounded by grout with 1.2\% Dramix ZP305 steel fibres. The second two specimens, one of which is a duplicate specimen, are identical to the first two specimens, except that the grout contains an equivalent volume of Dramix RC65/60BN steel fibres. Dramix ZP305 steel fibres have a length of 30mm (so called "short fibres") and RC65/60BN steel fibres have a length of 60mm (so called "long fibres"). Figure 5-14 shows the stress-strain relationship of the above noted specimens prior to yielding of the reinforcing steel.

The specimens with the shorter fibres showed a stiffer response than the specimens with the longer fibres. At a strain of 0.002, the specimens with long fibres had a stresses of $428 \mathrm{MPa}$ and $458 \mathrm{MPa}$ whereas the specimens with short fibres had stresses of $516 \mathrm{MPa}$ and $550 \mathrm{MPa}$. This corresponds to an average percent increase of $17.8 \%$ for the specimens with long fibres and an average percent increase of $41.8 \%$ for the specimens with short fibres when compared to the bare bar response at a strain of 0.002 (see Figure 5-15). 


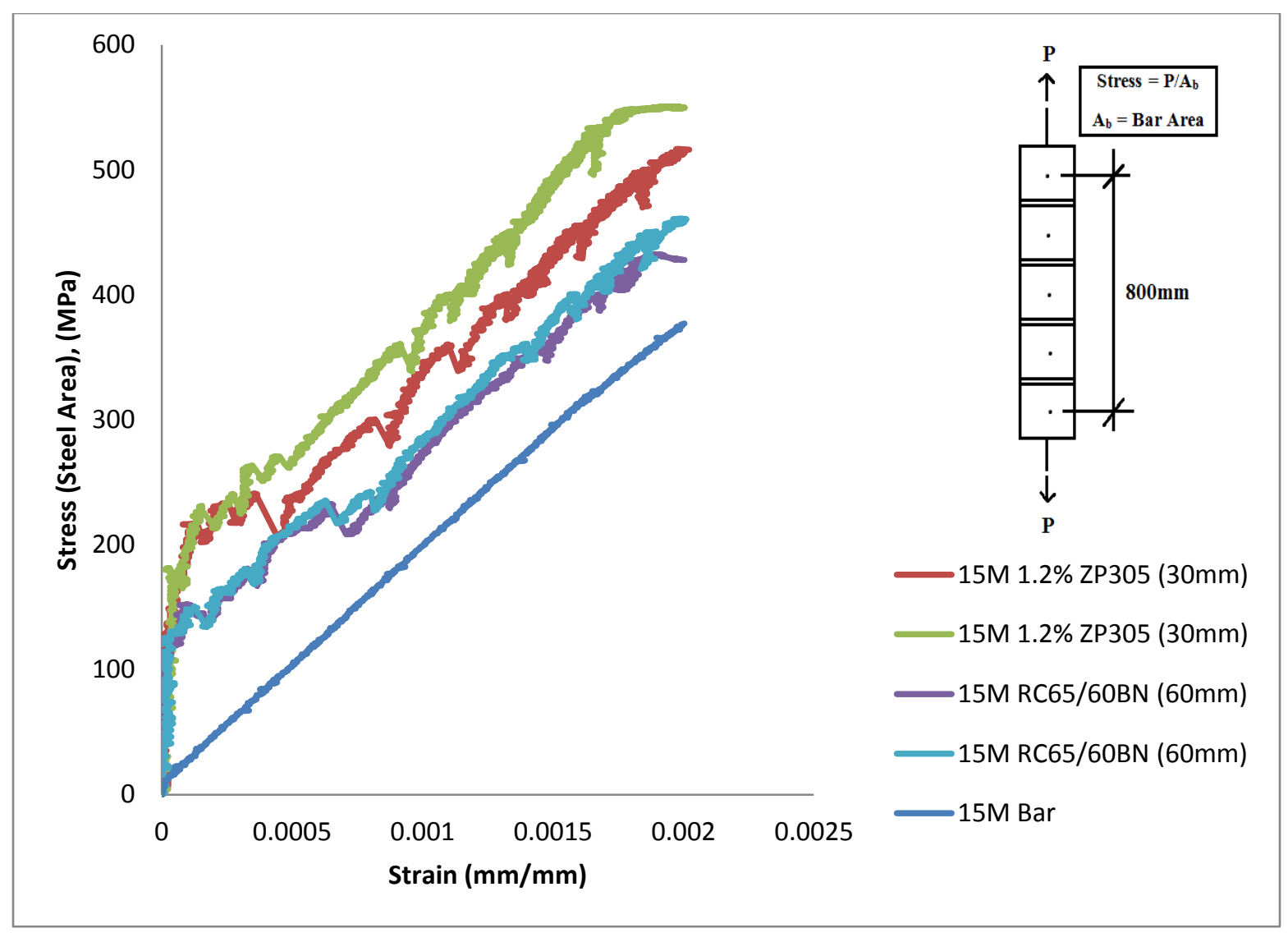

Figure 5-14: Stress strain response of specimens with different fibre types

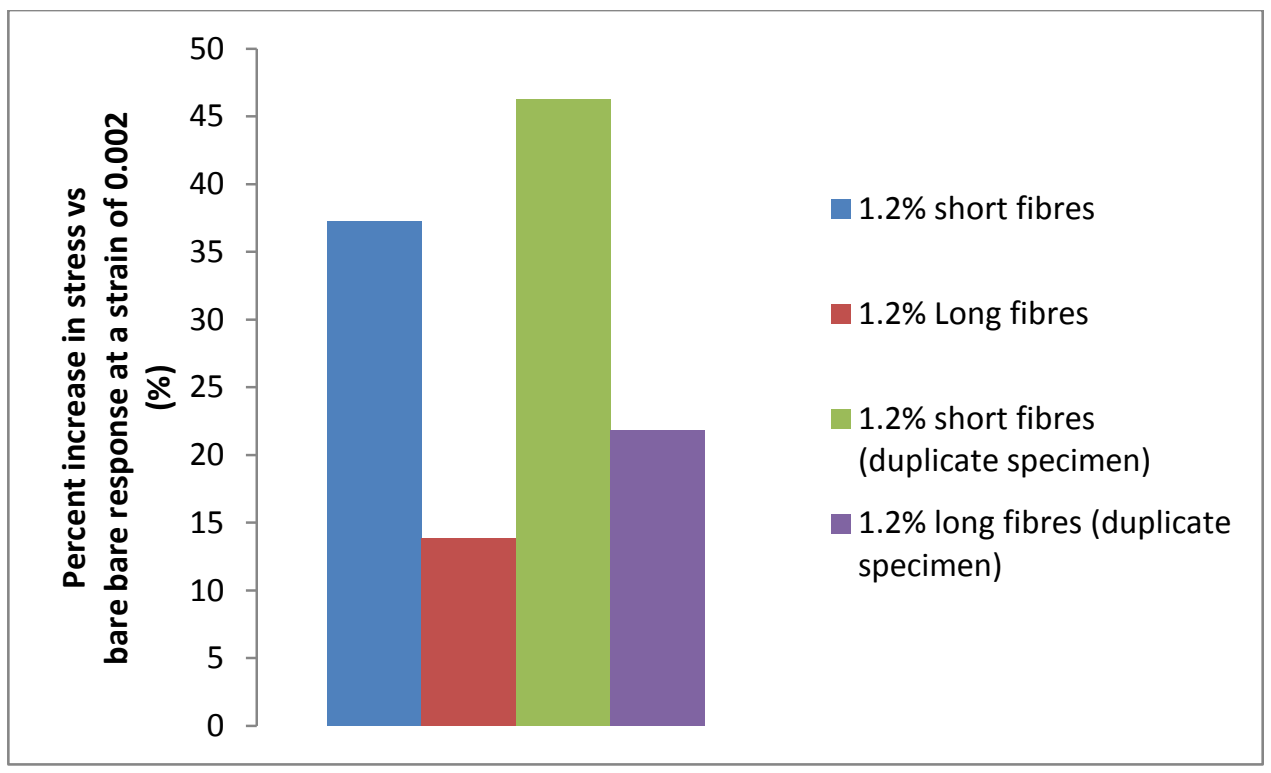

Figure 5-15: Percent increase in stress over bare bar response at a strain of 0.002 for different fibre types 
The specimens with $30 \mathrm{~mm}$ fibres tended to have better overall structural performance than the specimens with $60 \mathrm{~mm}$ fibres. It cannot be ascertained with complete certainty whether the performance of the specimens with the longer fibres was affected by workability issues, however it is interesting to note that the stress-strain responses of the two specimens with $60 \mathrm{~mm}$ fibres are very similar. This offers some degree of reliability in the experimental data for these two specimens. The specimens with the ZP305 fibres exhibited significantly greater toughness than the specimens with the RC65/60BN fibres. The shorter fibres created a more dense fibre network at a constant volume fraction which results in an increased number of individual fibres crossing the cracking plane.

The initial loss in stiffness due to first cracking was less pronounced in the specimens with ZP305 fibres. For example at a strain of $0.015 \%$, the specimens with ZP305 fibres showed $70 \%$ higher stress than the specimens with the RC65/60BN fibres.

The stress-strain behaviour after yield of the reinforcing steel was not analyzed due to the fact that high levels of strain were not attained in the specimens with ZP305 fibres. As discussed previously, yielding of the reinforcing steel near the grips occurred in the specimens with ZP305 fibres because the masonry surrounding the reinforcement was sufficiently stiff.

First cracking was observed at an average load of approximately $33 \mathrm{kN}$ for the specimens with the short fibres, and at an average load of $25.3 \mathrm{kN}$ for the specimens with the long fibres.

\subsubsection{Crack Width and Crack Spacing}

The longer fibres were more effective than the shorter fibres at controlling the average crack width (see Table 5-13 and Table 5-14). However, the maximum crack width was often greater in the specimens with the longer fibres than in the specimens with the shorter fibres. Also, the first cracking load was higher for the specimens reinforced with the shorter steel fibres due to the dense fibre network provided by the shorter fibres. It is thought that this behaviour is due to the fact that there were more fibres crossing a potential cracking plane in the specimens with the short fibres therefore the resistance to cracking was increased. There was a significantly higher amount of cracks present in the specimens with $60 \mathrm{~mm}$ fibres when compared to the 
matching specimens with $30 \mathrm{~mm}$ fibres, however in the case of specimen 15L12S-2 the cracks were not very evenly distributed.

Table 5-13: Average crack widths in specimens with different fibre types

\begin{tabular}{|c|c|c|c|c|c|c|c|c|c|c|c|}
\hline & \multicolumn{10}{|c|}{ Stress (Steel Area), (MPa) } \\
\cline { 2 - 12 } & 60 & 120 & 180 & 240 & 300 & 360 & 400 & 430 & 470 & 540 \\
\hline Specimen & \multicolumn{10}{|c|}{ Average Crack Width (mm) } \\
\hline 15M12S-1 & 0 & 0.084 & 0.154 & 0.205 & - & 0.321 & - & 1.546 & 2.616 & 5.3 \\
\hline 15M12S-2 & 0 & 0.1175 & 0.127 & 0.173 & - & 0.295 & - & 1.285 & 2.38 & 3.757 \\
\hline 15M12L-1 & 0 & - & 0.104 & 0.1325 & - & 0.234 & 0.26 & - & 0.5225 & 4.972 \\
\hline 15M12L-2 & 0 & - & 0.09 & 0.28 & - & 0.224 & 0.253 & - & 0.292 & 2.563 \\
\hline
\end{tabular}

Table 5-14: Maximum crack widths in specimens with different fibre types

\begin{tabular}{|c|c|c|c|c|c|c|c|c|c|c|c|}
\hline & \multicolumn{10}{c|}{ Stress (Steel Area), (MPa) } \\
\cline { 2 - 12 } & 60 & 120 & 180 & 240 & 300 & 360 & 400 & 430 & 470 & 540 \\
\hline Specimen & \multicolumn{10}{|c|}{ Maximum Crack Width (mm) } \\
\hline 15M12S-1 & 0 & 0 & 0 & 0.16 & 0.24 & 0.32 & 0.4 & - & - & 3.5 \\
\hline 15M12S-2 & 0 & 0 & 0 & 0.14 & - & 0.40 & 0.62 & - & - & 0.84 \\
\hline 15M12L-1 & 0 & - & 0.16 & 0.26 & - & 0.48 & 0.54 & 2.2 & - & 8.9 \\
\hline 15M12L-2 & 0 & - & 0.16 & 0.28 & - & 0.54 & 0.58 & 0.62 & - & 8.2 \\
\hline
\end{tabular}

As can be seen in Figure 5-16 and 5-17, the fibre type didn't play a large role in the average and maximum crack widths at low levels of steel stress. Figure 5-16 and 5-17 show the average responses of the four specimens listed in Table 5-13. At large steel stresses, however, the specimens containing the $60 \mathrm{~mm}$ fibres exhibited much larger average and maximum crack widths. Again, this phenomenon is speculated to be due to the fact that the specimens with the longer fibres have a smaller number of fibres crossing a crack, therefore the cracks open wider. With an identical fibre concentration by volume, the smaller fibres have a considerably larger quantity of fibres. With the smaller diameter fibres, there is a larger ratio of perimeter to cross sectional area allowing them to carry more frictional force and provide added resistance. 


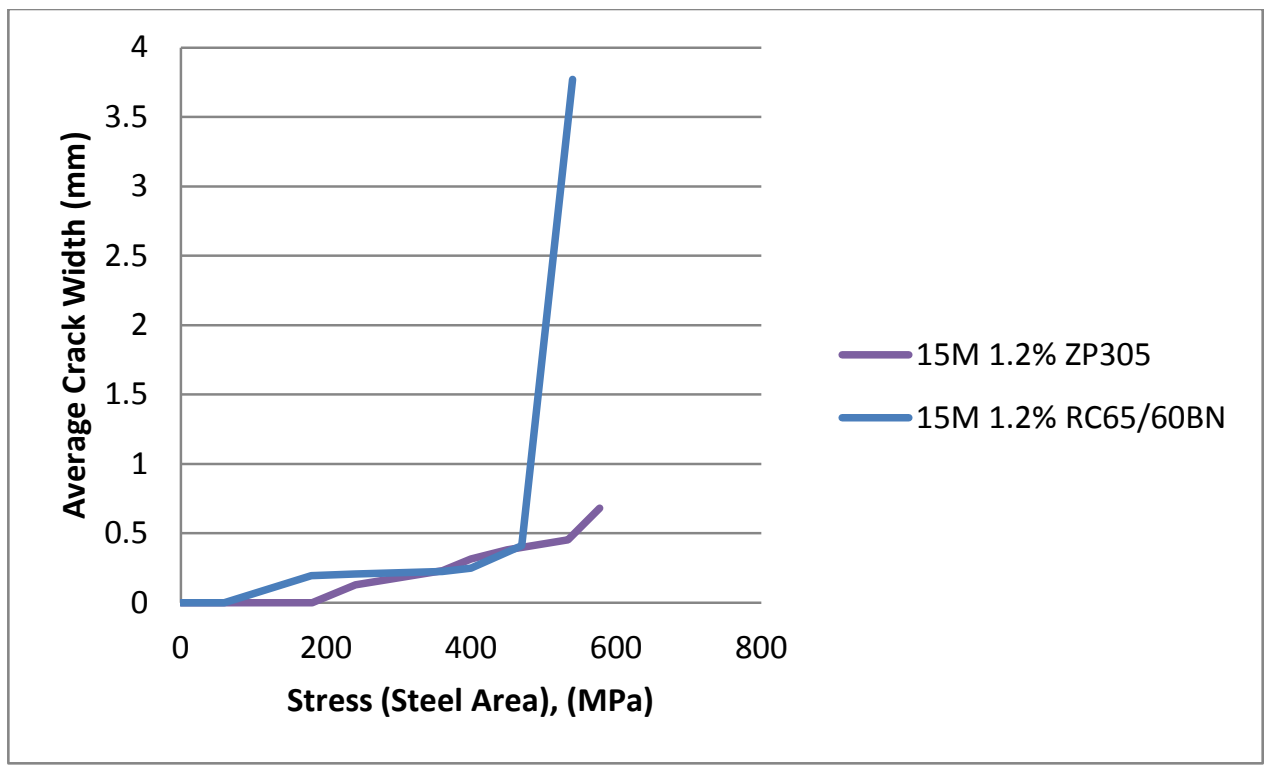

Figure 5-16: Average crack width as a function of stress to compare effect of fibre type

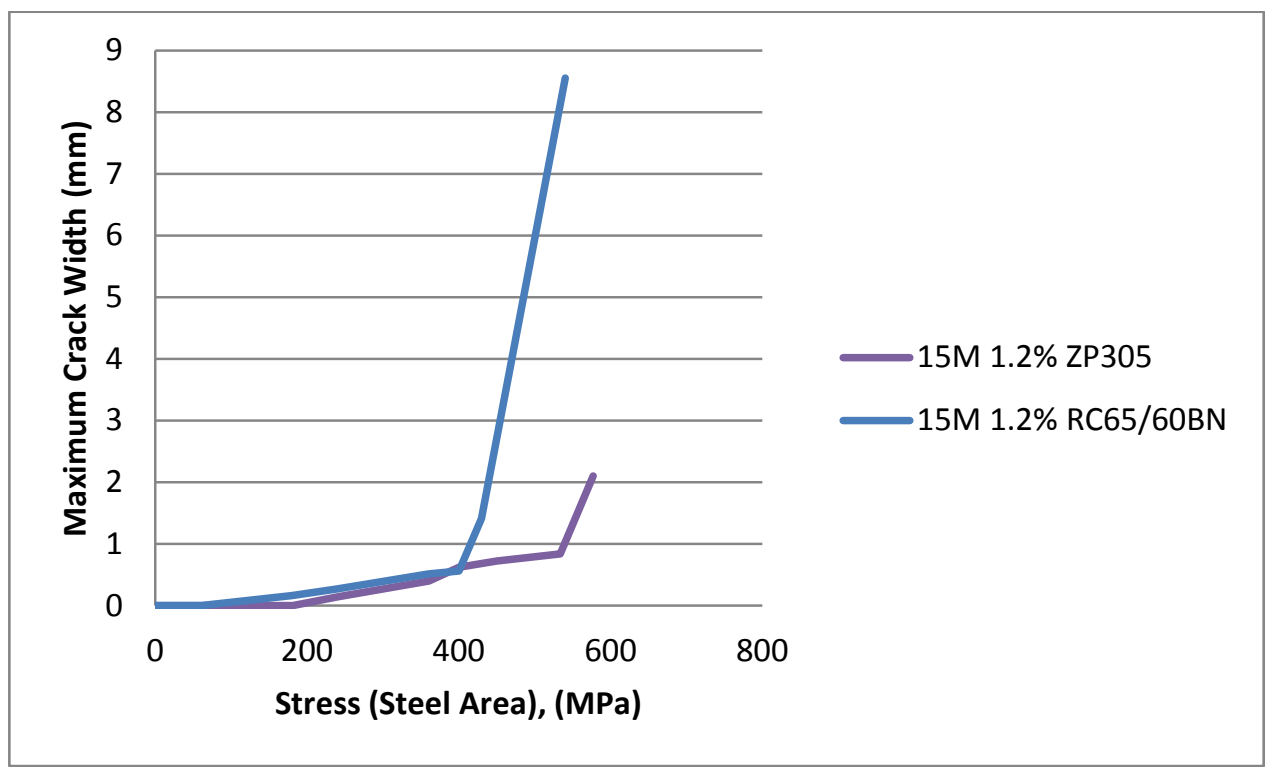

Figure 5-17: Maximum crack width as a function of stress to compare effect of fibre type 
Table 5-15: Crack patterns for $30 \mathrm{~mm}$ vs. $60 \mathrm{~mm}$ fibres at a steel stress of 540MPa

\begin{tabular}{|c|c|c|c|}
\hline 15M12S-1 & 15M12S-2 & 15M12L-1 & 15M12L-2 \\
\hline $1.2 \% 30 \mathrm{~mm}$ & $1.2 \% 30 \mathrm{~mm}$ & $1.2 \% 60 \mathrm{~mm}$ & $1.2 \% 60 \mathrm{mn}$ \\
\hline Fibres & Fibres & Fibres & Fibres \\
\hline & & & \\
\hline & & & \\
\hline & & & \\
\hline & & & \\
\hline & & & \\
\hline
\end{tabular}

\subsubsection{Effect of Unit Type}

Two different types of concrete masonry units were used in the experimental testing. The first type of unit was a standard half block stretcher unit and the second was a standard lintel unit (See section 3.2.1). Specimens were constructed to have the same overall outer dimensions using the different size blocks. Because the lintel units measured 390mm in length, there were only 2 mortar joints in the lintel specimens whereas there were 4 mortar joints in the rest of the specimens. Since cracking typically initiates at mortar joints due to the weak bond between the concrete mortar and the concrete masonry units, this will change the overall cracking pattern of the specimens. Only one lintel specimen was made using each respective grout mix. The specimens used to study the effect of unit type on structural performance are summarized in the table below. Each lintel unit will be compared with a typical specimen containing standard units. The sole variable of the units within this discussion is the type of unit. A summary of the specimens used to study the effect of unit type are summarized in Table 5-16. 
Table 5-16: Properties of specimens used to study effect of unit type

\begin{tabular}{|c|c|c|c|c|}
\hline Specimen & Unit Type & $\begin{array}{c}\text { Number of } \\
\text { Mortar Joints }\end{array}$ & Bar Size & $\begin{array}{c}\text { Fibre Content } \\
\text { (ZP305) (\%) }\end{array}$ \\
\hline L15M00-1 & Lintel & 2 & $15 \mathrm{M}$ & 0 \\
\hline L15M04S-1 & Lintel & 2 & $15 \mathrm{M}$ & 0.4 \\
\hline L15M08S-1 & Lintel & 2 & $15 \mathrm{M}$ & 0.8 \\
\hline L15M12S-1 & Lintel & 2 & $15 \mathrm{M}$ & 1.2 \\
\hline 15M00-1 & Standard & 4 & $15 \mathrm{M}$ & 0 \\
\hline 15M04S-1 & Standard & 4 & $15 \mathrm{M}$ & 0.4 \\
\hline 15M08S-1 & Standard & 4 & $15 \mathrm{M}$ & 0.8 \\
\hline 15M12S-1 & Standard & 4 & $15 \mathrm{M}$ & 1.2 \\
\hline
\end{tabular}

\subsubsection{Stress Strain Behaviour}

The unit type has a significant effect on the performance of fibre reinforced masonry under monotonic load. Figures 5-18 to 5-21 show that the decrease in stiffness at strains less than yield is more gradual in the lintel specimens than in the standard specimens with the same grout. The lintel specimens that contained fibre reinforced grout are able to withstand higher stresses at strains approaching the yield strain of the reinforcing steel. This characteristic results in higher toughness and energy absorption qualities. It is possible to attribute this to the difference in cross sectional areas of the grout cores in the two types of units. The greater the cross sectional area, the greater the number of fibres crossing the crack and this leads to increased load carrying capacity. Also, this increase in performance would only be realized in the specimens containing fibre reinforced grout as the increase in grout core area would be insignificant when no fibres were present. This agrees with Figure 5-18 given that the performance of the specimens with different unit types does not have a great effect on the behaviour however in Figures 5-19 to 5-21 the increase in performance is noticeable. Figure 522 shows the different cross sectional grout areas. 
As seen in Figure 5-18, the responses of the specimens with no fibres approach identical behaviour whether they were built with lintel units or standard units. In this figure, it can also be noted that the discrete cracks in each specimen are easily identifiable from a noticeable drop in stress at a given average strain. In Figure 5-19 and 5-20, it is much harder to identify not only the first cracking, but also any further cracks, as the responses tend to lose stiffness more gradually.

A detailed description of all lintel unit tests is provided in sections 4.3.23-4.3.26. Table 5-17 shows the final cracking pattern at a steel stress of 540MPa for each of the specimens listed in Table 5-16. It should be noted that the lintel specimens have a cross sectional grouted area which is $9 \%$ greater than that of the standard specimens. Due to this, there is a larger number of fibres crossing the cracks in the lintel specimens which could potentially cause the stiffer response.

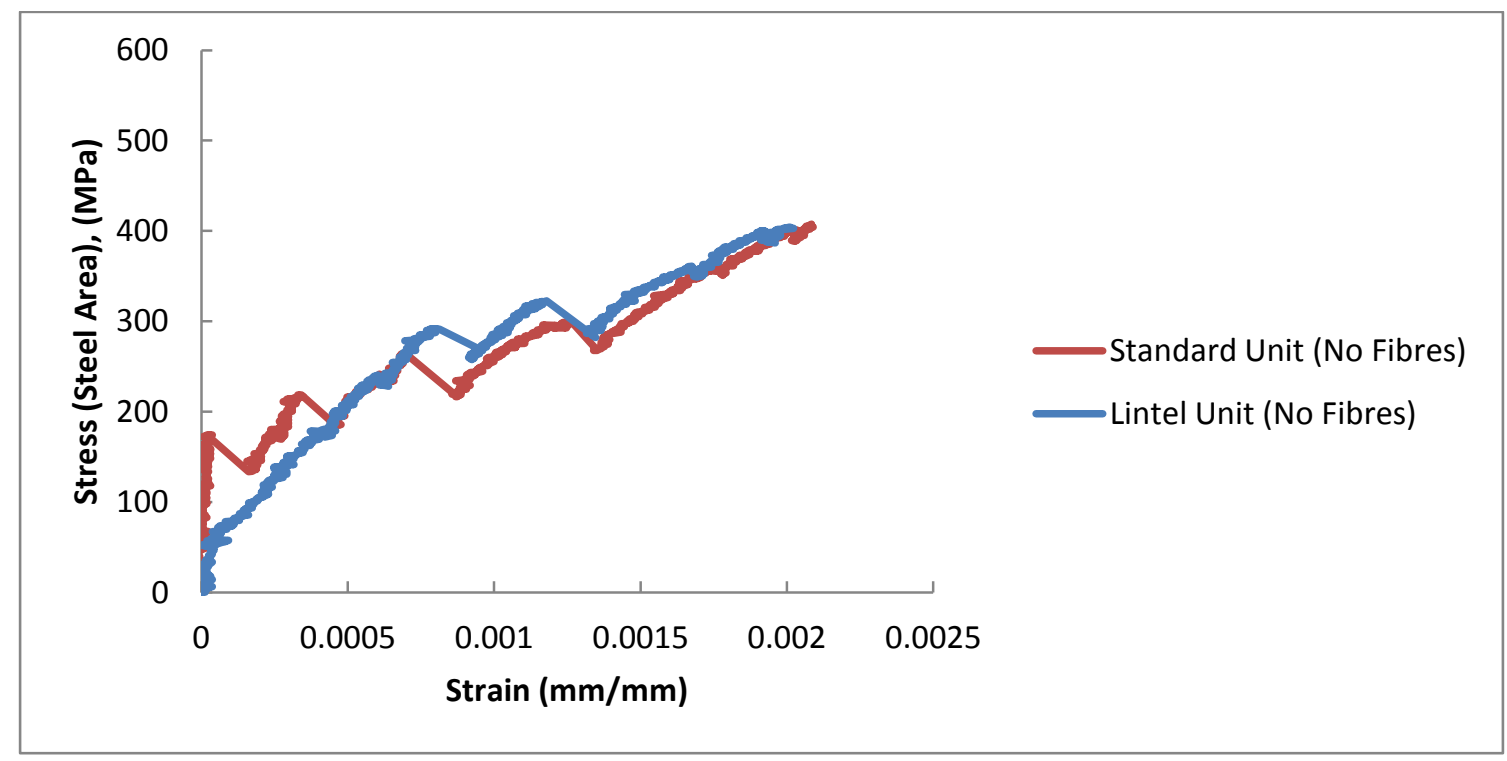

Figure 5-18: Stress strain response of specimens containing no fibres and different unit types 


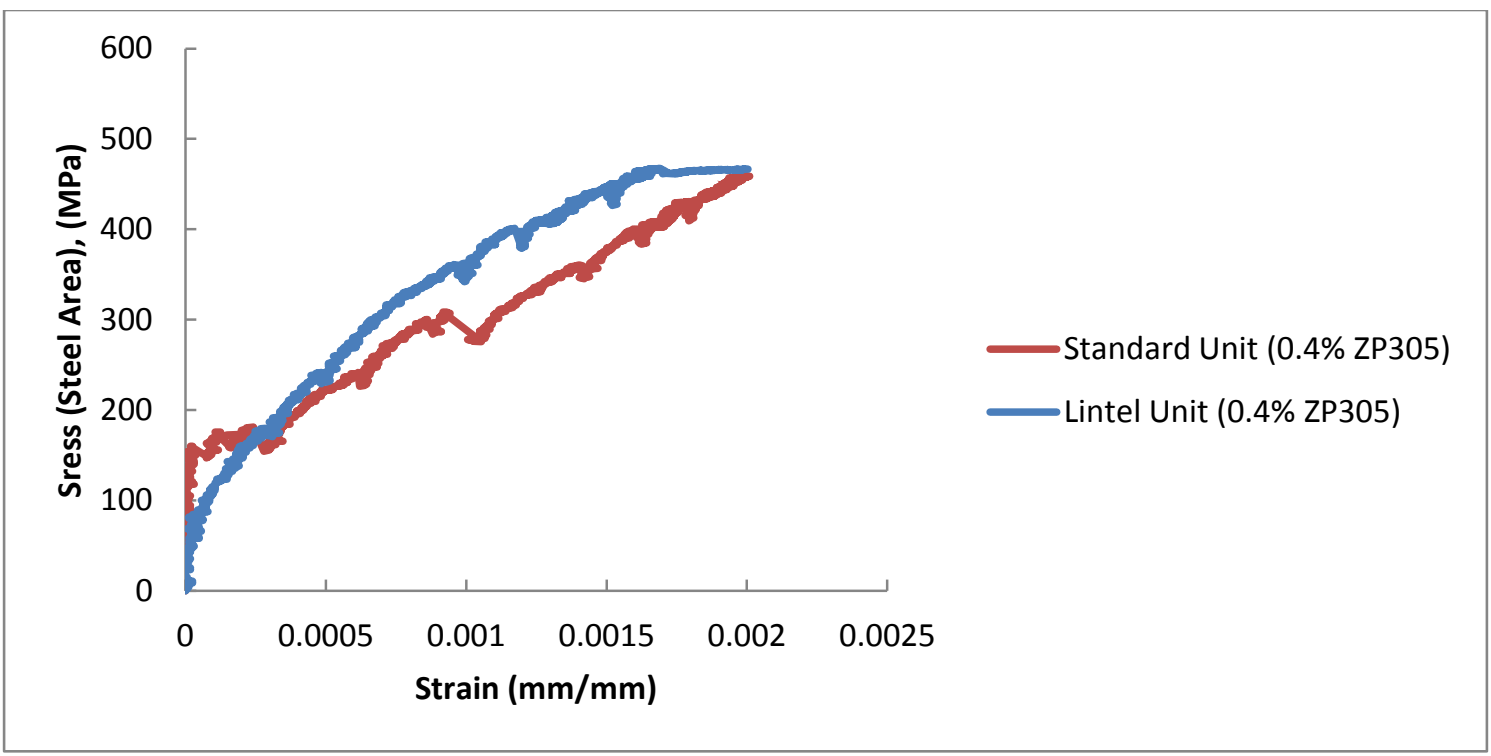

Figure 5-19: Stress strain response of specimens containing $0.4 \%$ ZP305 and different unit types

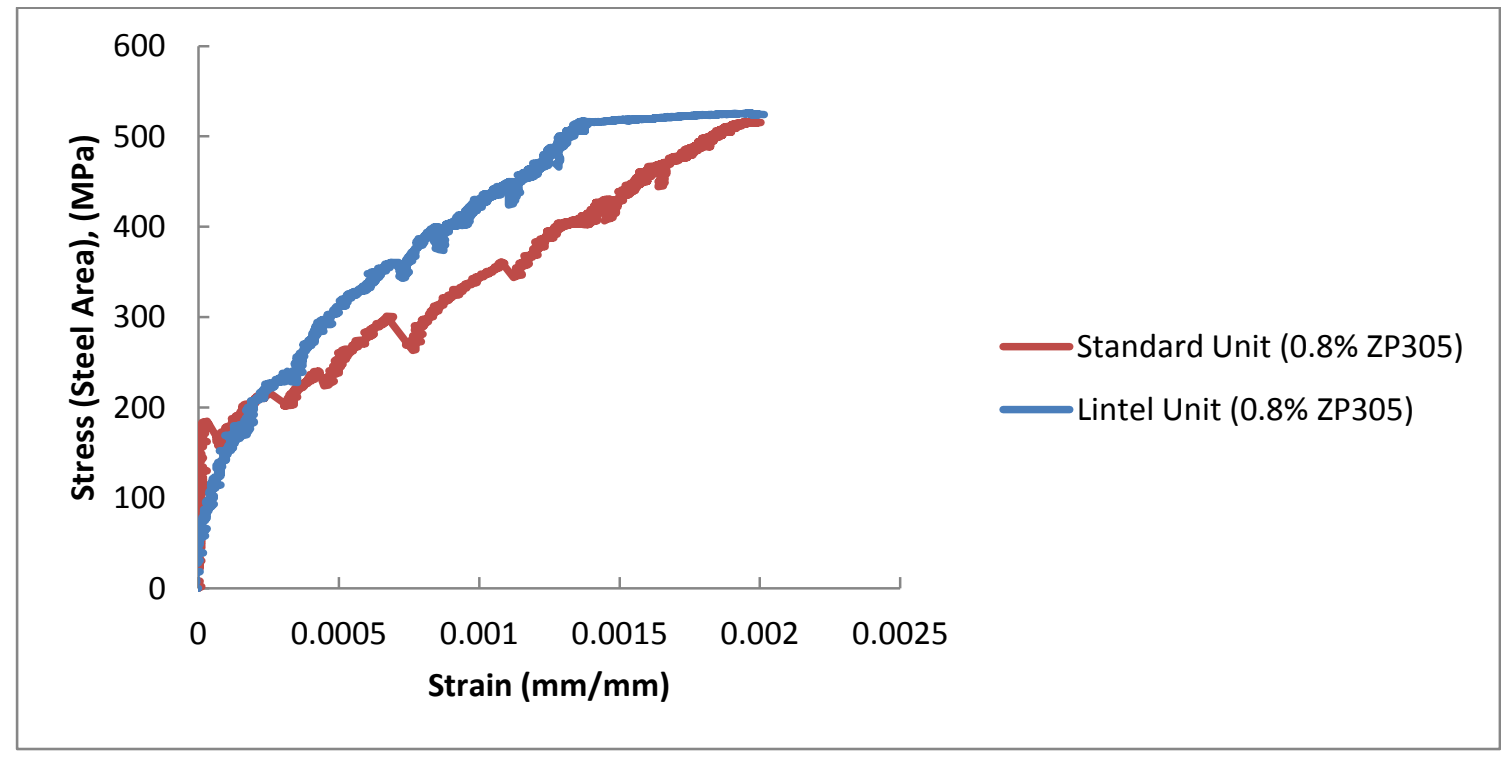

Figure 5-20: Stress strain response of specimens containing $0.8 \%$ ZP305 and different unit types 


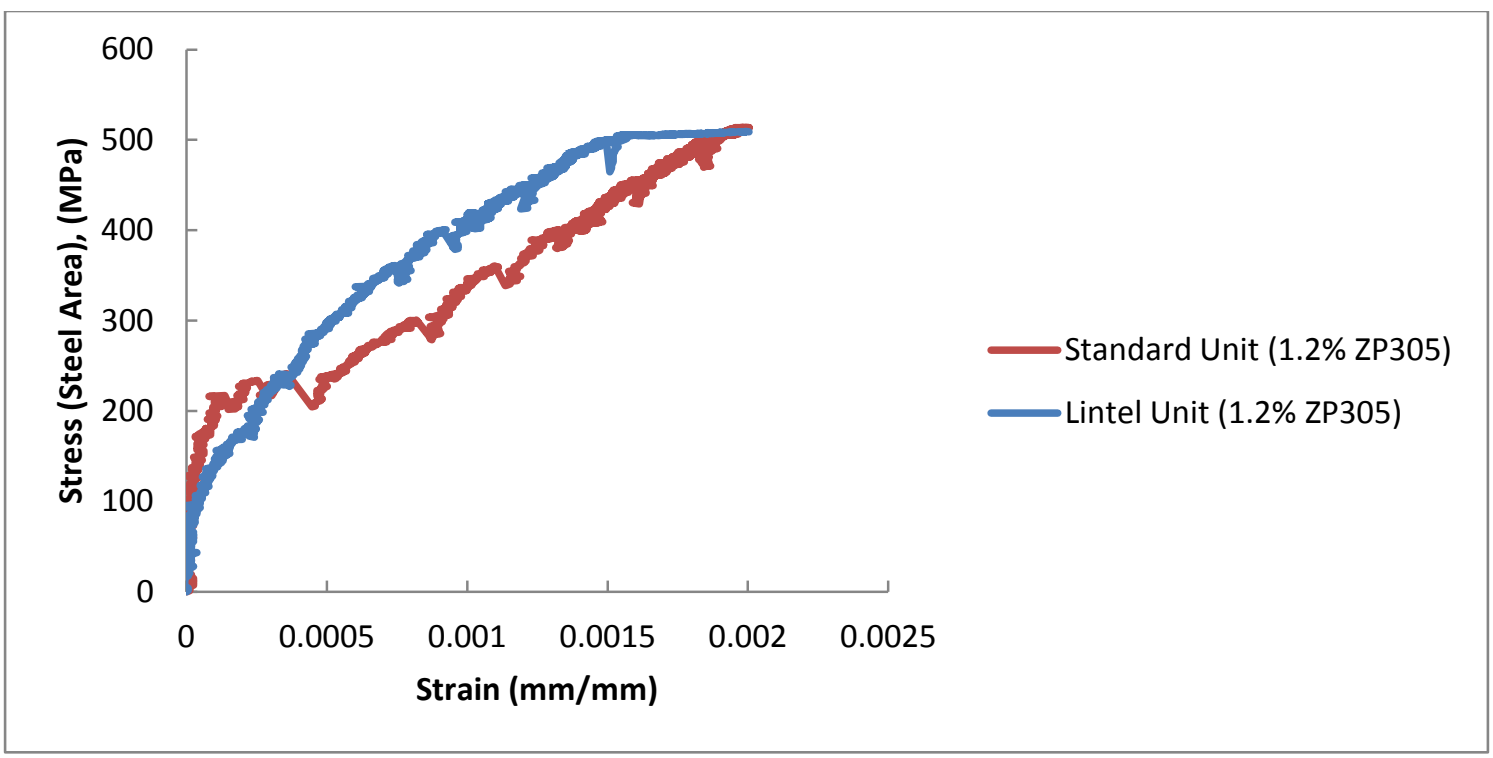

Figure 5-21: Stress strain response of specimens containing 1.2\% ZP305 and different unit types

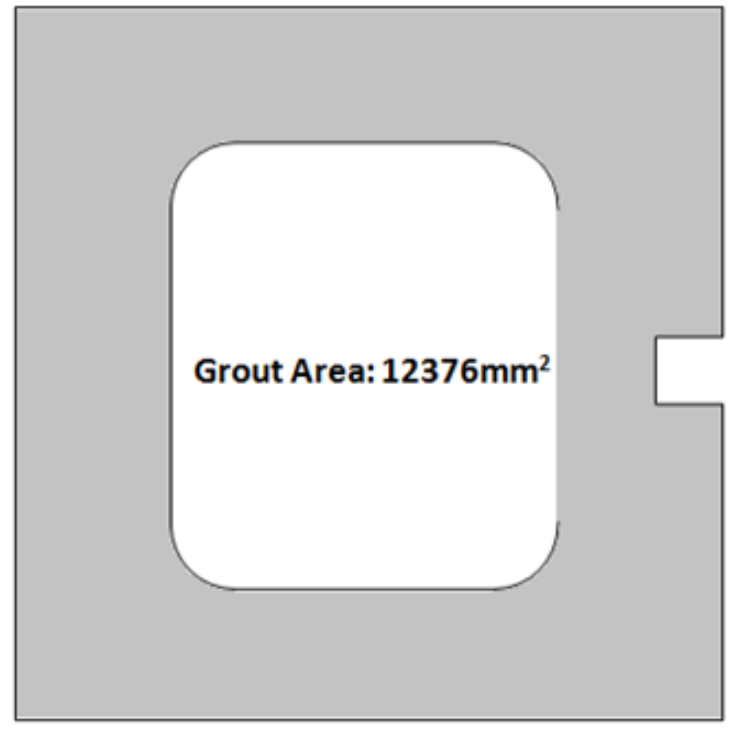

Standard Unit

Cross-Section

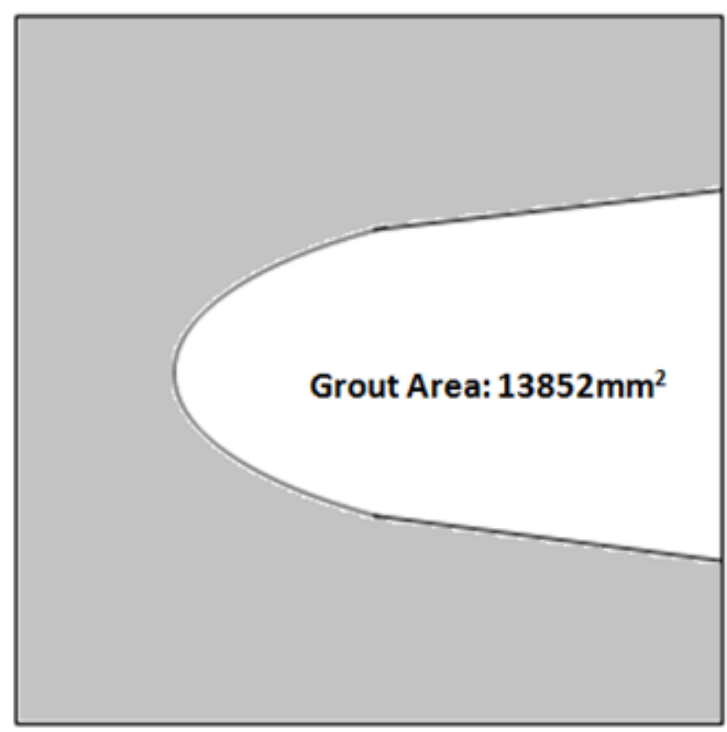

Lintel Unit Cross-Section

Figure 5-22: Grout core cross sectional areas 
Table 5-17: Crack patterns of specimens with different unit types

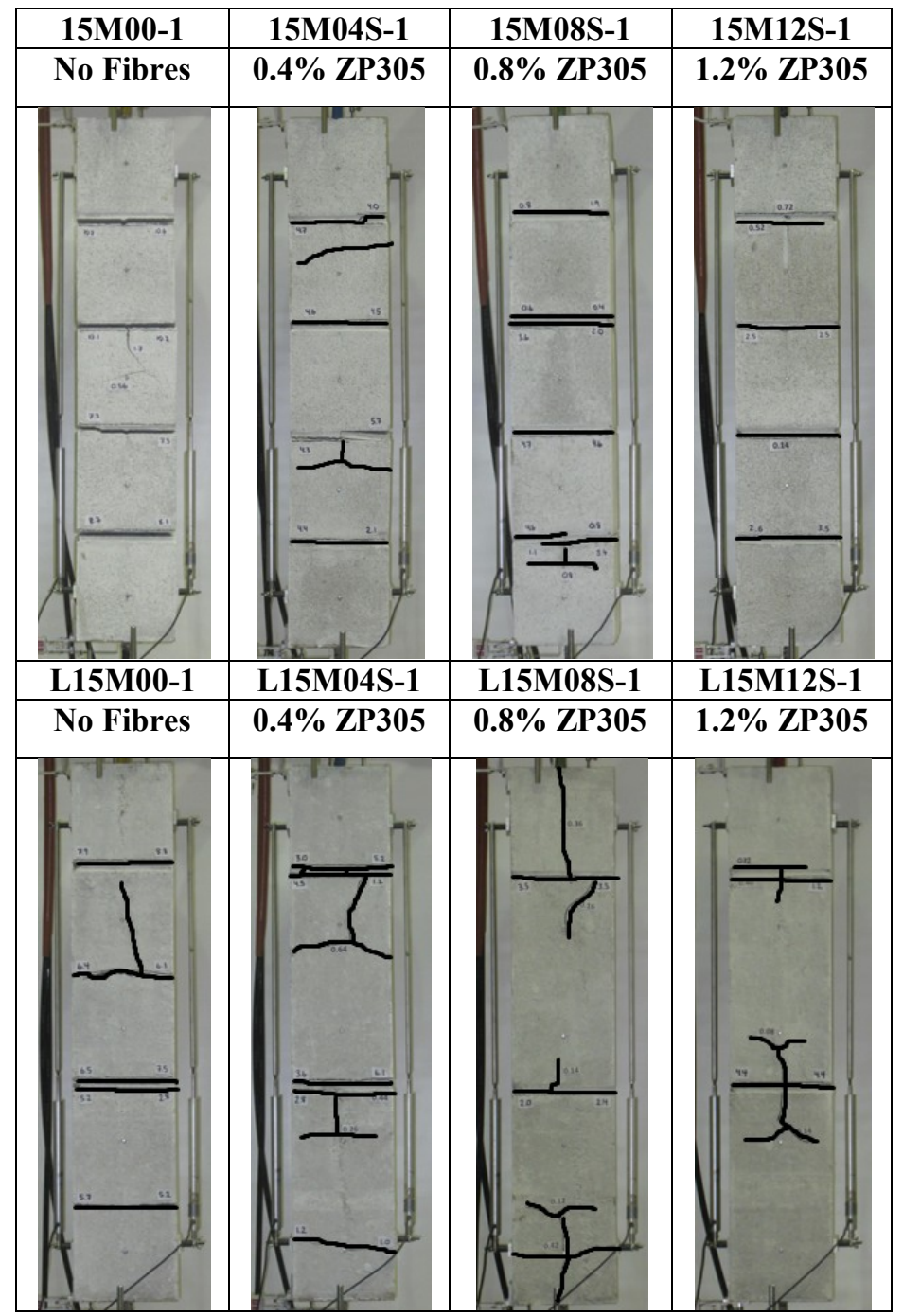

In the post yield range, the lintel specimens that contained steel fibre reinforced grout were able to withstand a significantly higher stress after the yielding of the main reinforcing steel. This results in a significant improvement in the toughness of the specimen. At a strain of $1 \%$ or $8 \mathrm{~mm}$ over the $800 \mathrm{~mm}$ gauge length of the externally mounted LVDTs, we can compare the stress of the various specimens listed in Table 5-16. The bare 15M bar has a stress of approximately 409MPA, the specimen with $0.4 \%$ fibres had a stress of 514MPA, the specimen with $0.8 \%$ fibres $542 \mathrm{MPA}$, and the specimen with $1.2 \%$ fibres had a stress of 540MPa. It can be seen that the increased performance of steel fibre reinforced grout is negligible when increasing the volume fraction from $0.8 \%$ to $1.2 \%$. 
It can also be noted that the contribution of steel fibres is much greater at smaller strain levels and the benefit becomes negligible as the strain in increased towards ultimate strain of the specimen.

Figure 5-23 shows that there is very little difference in the behaviour of the specimens with different unit types at ultimate, however Figures 5-18 to 5-21 show that there is a significant difference in the behaviour of the specimens in the service load range. Figure 5-2 in section 5.2.1.1 shows the identical relationship for standard unit specimens as if graphed in Figure 5-23 below for lintel unit specimens. It can be seen that the responses are very similar.

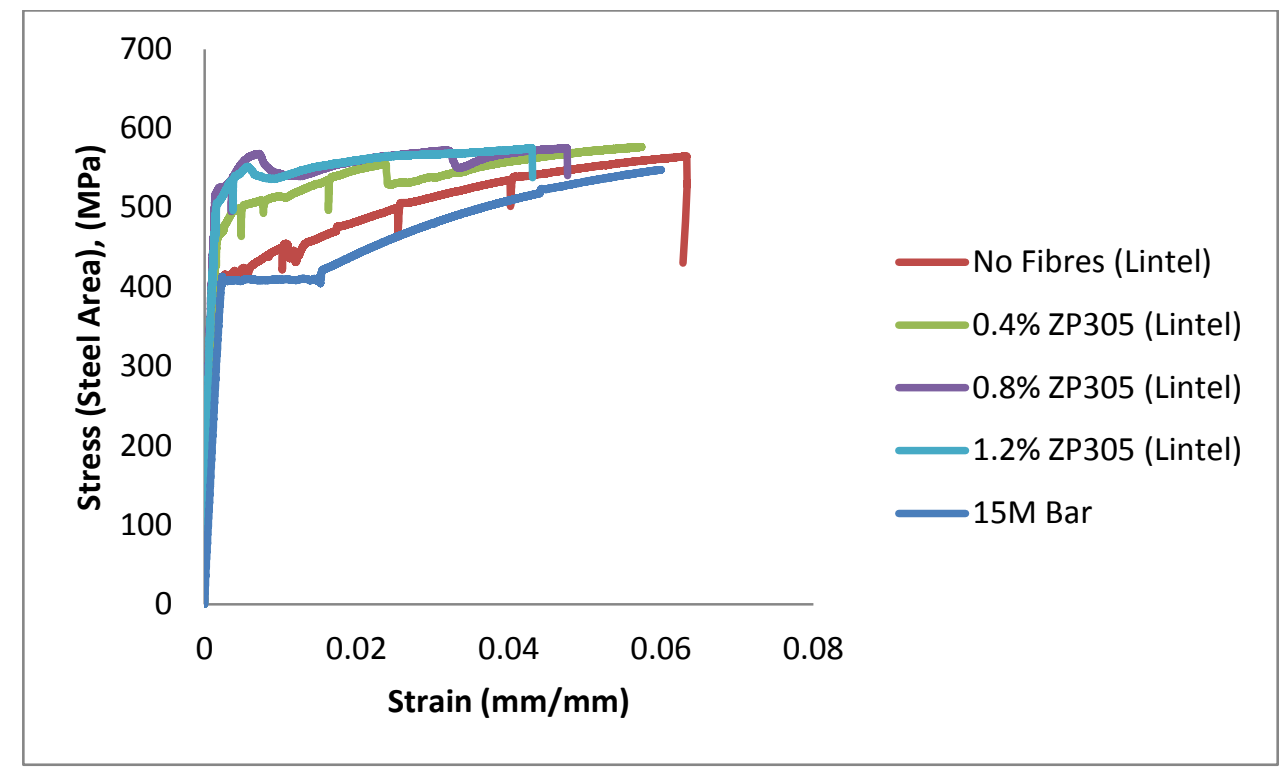

Figure 5-23: Stress strain response of lintel unit specimens

\subsubsection{Crack Width and Crack Spacing}

The unit type did not play a significant role in the cracking of the specimens both with and without fibre reinforcement. The average and maximum crack widths of the specimens to be compared are tabulated below in Table 5-18 and Table 5-19. Typically the specimens constructed with the standard units had a slightly higher average crack width. Figure 5-23 shows that at levels of stress approaching ultimate, the average crack widths in the specimens constructed with standard units become slightly wider than those specimens constructed with lintel units. Although maximum crack widths are much less predictable, the maximum crack 
widths were not affected in the specimens with no fibres and $0.4 \%$ fibres. However, the specimens with higher fibre contents $(0.8 \%$ and $1.2 \%)$ showed that the unit type really had very little effect on the maximum crack width (see Figure 5-25). The difference in cracking behaviour of the grout cores is shown in Figure 5-25. It can be seen that the fibre reinforcement in the grout both reduces crack width and also reduced crack spacing.

Table 5-18: Average crack widths for specimens with different unit types

\begin{tabular}{|c|c|c|c|c|c|c|c|c|c|c|c|}
\hline & \multicolumn{10}{|c|}{ Stress (Steel Area), (MPa) } \\
\cline { 2 - 13 } & 60 & 120 & 180 & 240 & 300 & 360 & 400 & 430 & 470 & 540 \\
\hline Specimen & \multicolumn{10}{|c|}{ Average Crack Width (mm) } \\
\hline 15M00-1 & 0 & 0 & 0.195 & 0.256 & 0.316 & 0.353 & 0.394 & 1.625 & 3.278 & 9.125 \\
\hline 15M04S-1 & 0 & 0 & 0.054 & 0.158 & 0.224 & 0.221 & 0.263 & 0.291 & 0.537 & 4.287 \\
\hline 15M08S-1 & 0 & 0 & 0 & 0.128 & 0.147 & 0.211 & - & 0.278 & 0.325 & 2.740 \\
\hline 15M12S-1 & 0 & 0 & 0 & 0.113 & 0.200 & 0.269 & 0.326 & - & - & 1.553 \\
\hline L15M00-1 & 0 & - & 0.28 & 0.29 & - & 0.388 & 0.402 & 1.683 & - & 6.21 \\
\hline L15M04S-1 & 0 & - & 0.19 & 0.3 & - & 0.625 & 0.7 & 0.8 & - & 3.07 \\
\hline L15M08S-1 & 0 & - & 0.16 & 0.295 & - & 0.585 & 0.725 & 0.905 & - & 1.99 \\
\hline L15M12S-1 & 0 & - & 0.13 & 0.25 & - & 0.424 & 0.492 & 0.668 & - & 1.62 \\
\hline
\end{tabular}

Table 5-19: Maximum crack widths for specimens with different unit types

\begin{tabular}{|c|c|c|c|c|c|c|c|c|c|c|c|}
\hline & \multicolumn{10}{|c|}{ Stress (Steel Area), (MPa) } \\
\cline { 2 - 13 } & 60 & 120 & 180 & 240 & \multicolumn{1}{|c|}{300} & 360 & 400 & 430 & 470 & 540 \\
\hline Specimen & \multicolumn{10}{|c|}{ Maximum Crack Width (mm) } \\
\hline 15M00-1 & 0 & 0 & 0.195 & 0.256 & 0.316 & 0.353 & 0.394 & 1.625 & 3.278 & 9.125 \\
\hline 15M04S-1 & 0 & 0 & 0.054 & 0.158 & 0.224 & 0.221 & 0.263 & 0.291 & 0.537 & 4.287 \\
\hline 15M08S-1 & 0 & 0 & 0 & 0.128 & 0.147 & 0.211 & - & 0.278 & 0.325 & 2.740 \\
\hline 15M12S-1 & 0 & 0 & 0 & 0.113 & 0.200 & 0.269 & 0.326 & - & - & 1.553 \\
\hline L15M00-1 & 0 & - & 0.34 & 0.4 & - & 0.72 & 0.8 & 3.1 & - & 8.8 \\
\hline L15M04S-1 & 0 & - & 0.22 & 0.36 & - & 0.72 & 0.72 & 0.84 & - & 8.8 \\
\hline L15M08S-1 & 0 & - & 0.16 & 0.3 & - & 0.64 & 0.74 & 0.905 & - & 3.5 \\
\hline L15M12S-1 & 0 & - & 0.14 & 0.28 & - & 0.58 & 0.62 & 0.96 & - & 4.4 \\
\hline
\end{tabular}



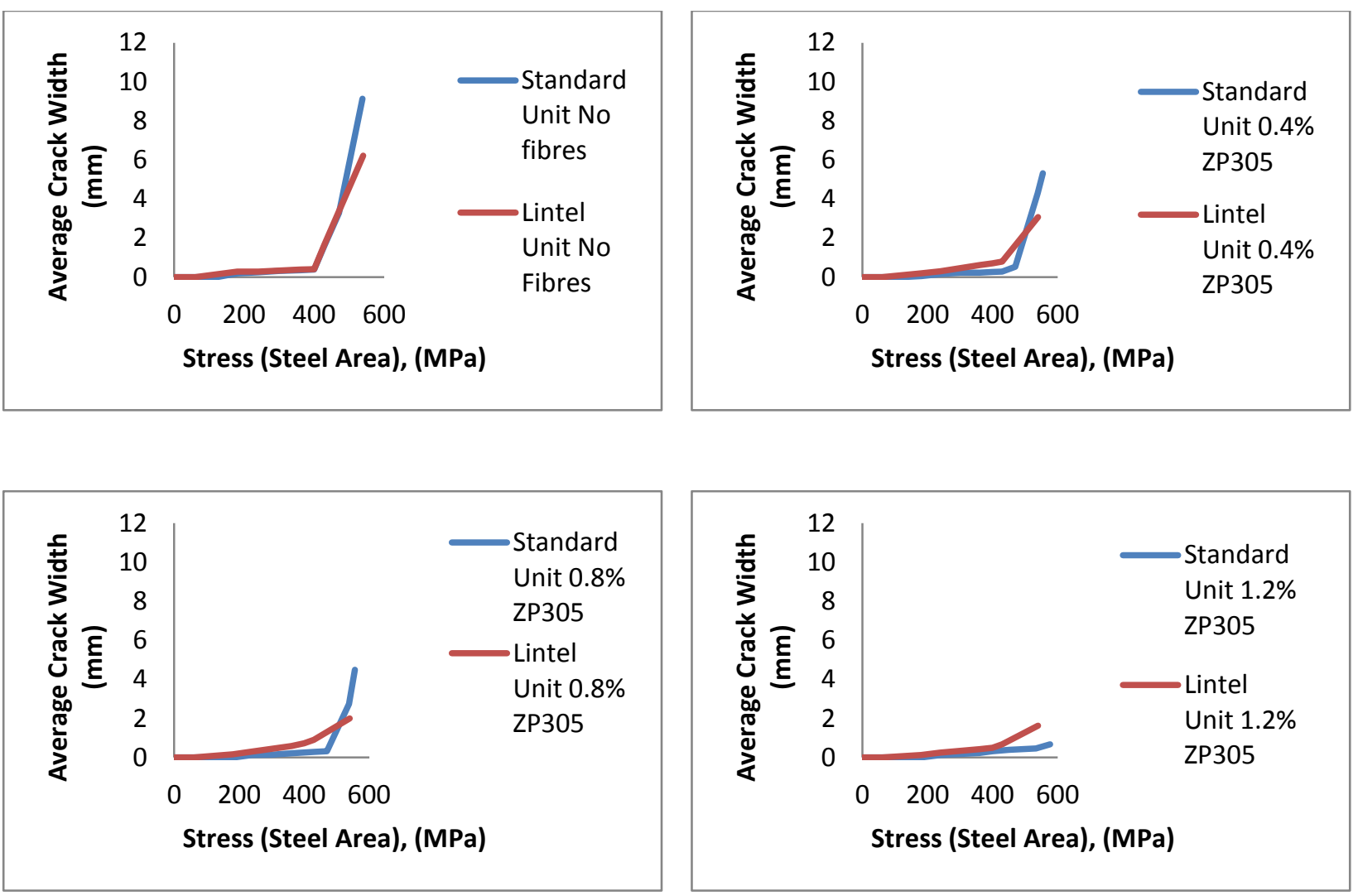

Figure 5-24: Average crack widths as a function of steel stress for standard and lintel unit specimens

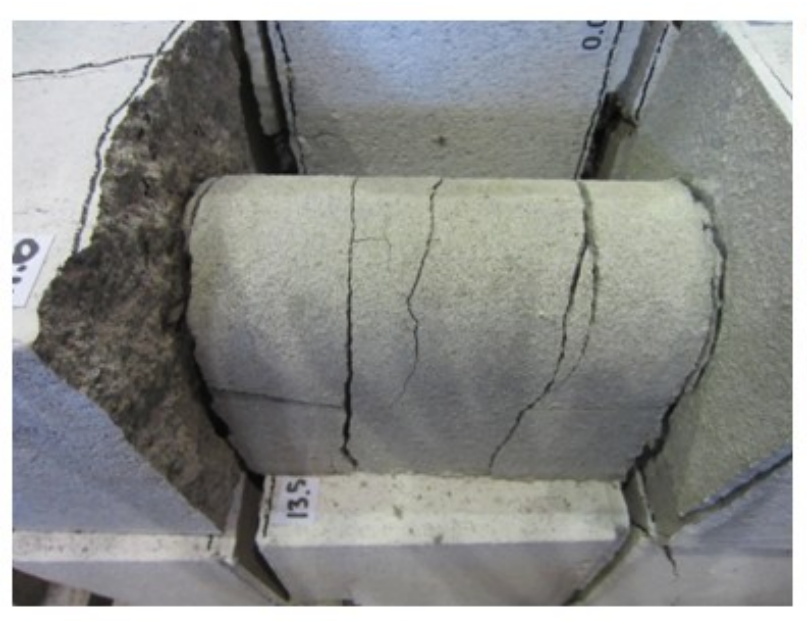

$0 \%$ Fibres

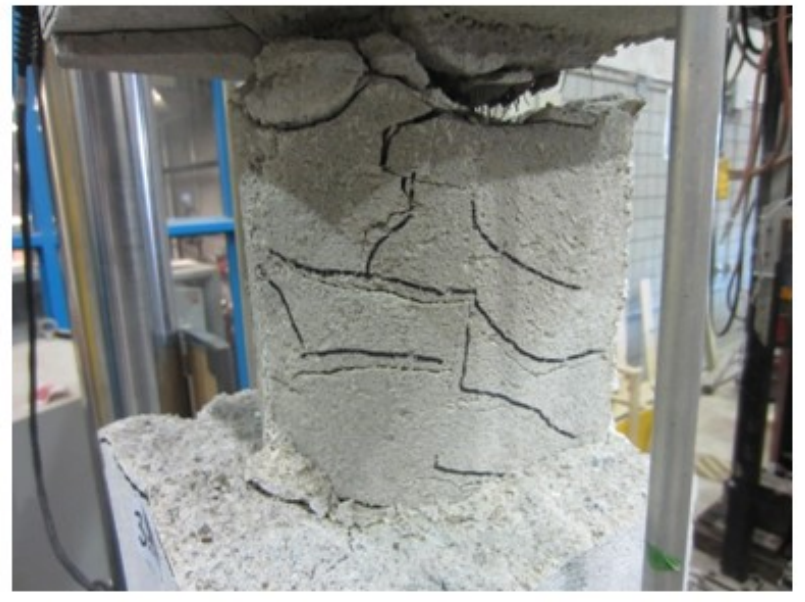

$1.2 \% 30 \mathrm{~mm}$ Fibres

Figure 5-25: Grout core cracking behaviour with varying fibre content 

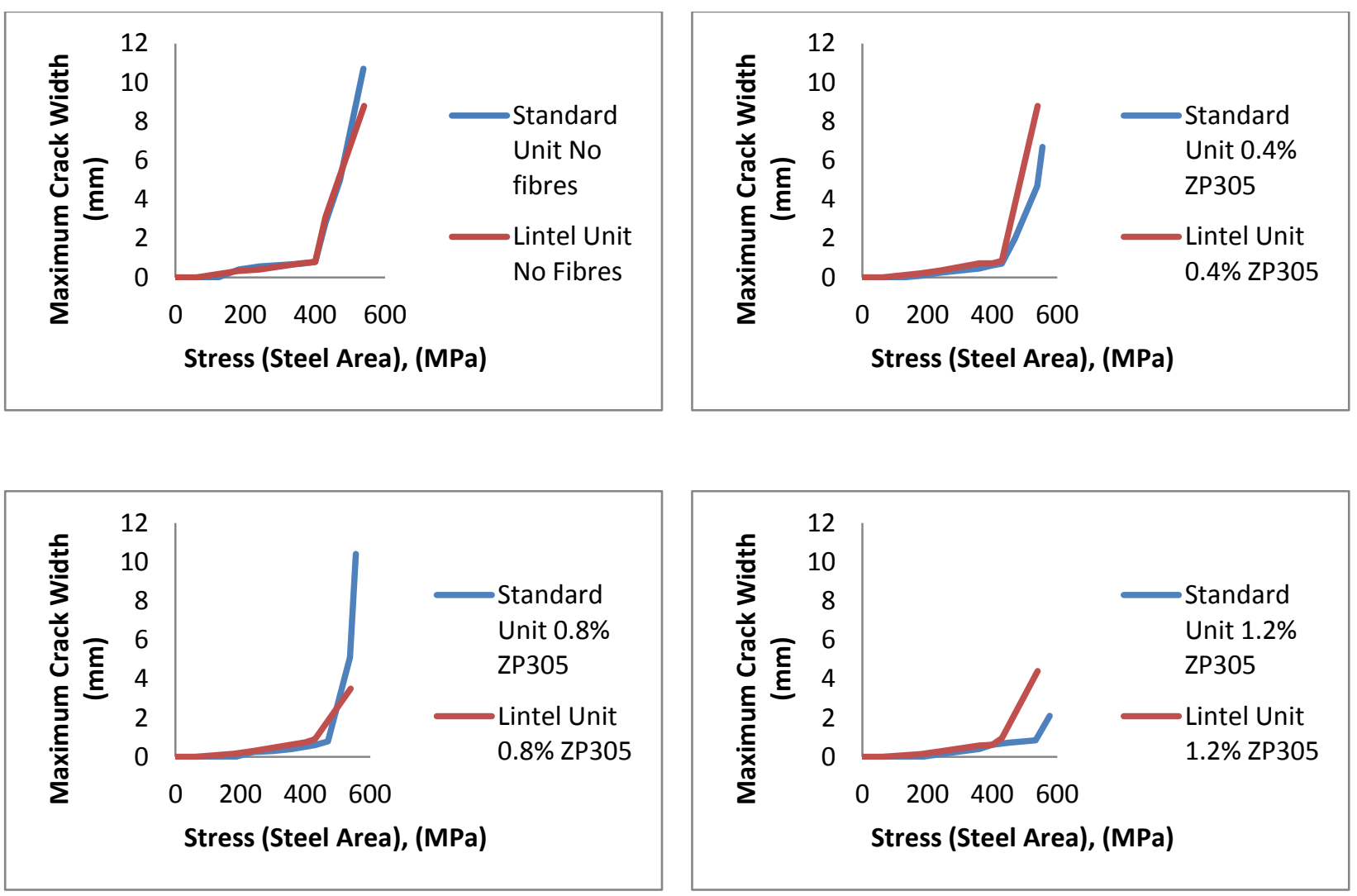

Figure 5-26: Maximum crack widths as a function of steel stress for standard and lintel unit specimens 


\subsection{Cyclic Testing}

A series of specimens identical to those tested under monotonic load were tested under cyclic load. Since there were duplicate specimens, two types of cyclic tests were completed. A total of 16 cyclic tests were conducted: 8 tests were done by cycling the load at four different stresses prior to the yield strain of the reinforcing steel and 8 tests were done by cycling the load at different levels after the yield strain of the steel. The variables involved in the cyclic tests were the reinforcement ratio and fibre content. The reinforcement ratio ranged from 0.0055 to 0.0083 and the fibre content ranged from $0 \%$ to $1.2 \%$ ZP305 steel fibres.

\subsubsection{Effect of fibre content}

\subsubsection{Stress Strain Behaviour}

The addition of steel fibres to the grout added significant stiffness to the response as the load was cycled at loads prior to the yielding of the reinforcing steel (see Figure 5-27). When the load was cycled to peak loads of up to $400 \mathrm{MPa}$, the resulting increase in stiffness by incorporating $1.2 \%$ steel fibres was $83 \%$ at $180 \mathrm{MPa}, 74 \%$ at $240 \mathrm{MPa}, 62 \%$ at $360 \mathrm{MPa}$, and $58 \%$ at $400 \mathrm{MPa}$. It is also noted that the benefit of increasing the steel fibre content from $0.8 \%$ to $1.2 \%$ is not as great as from $0 \%$ to $0.4 \%$ or $0.4 \%$ to $0.8 \%$. 

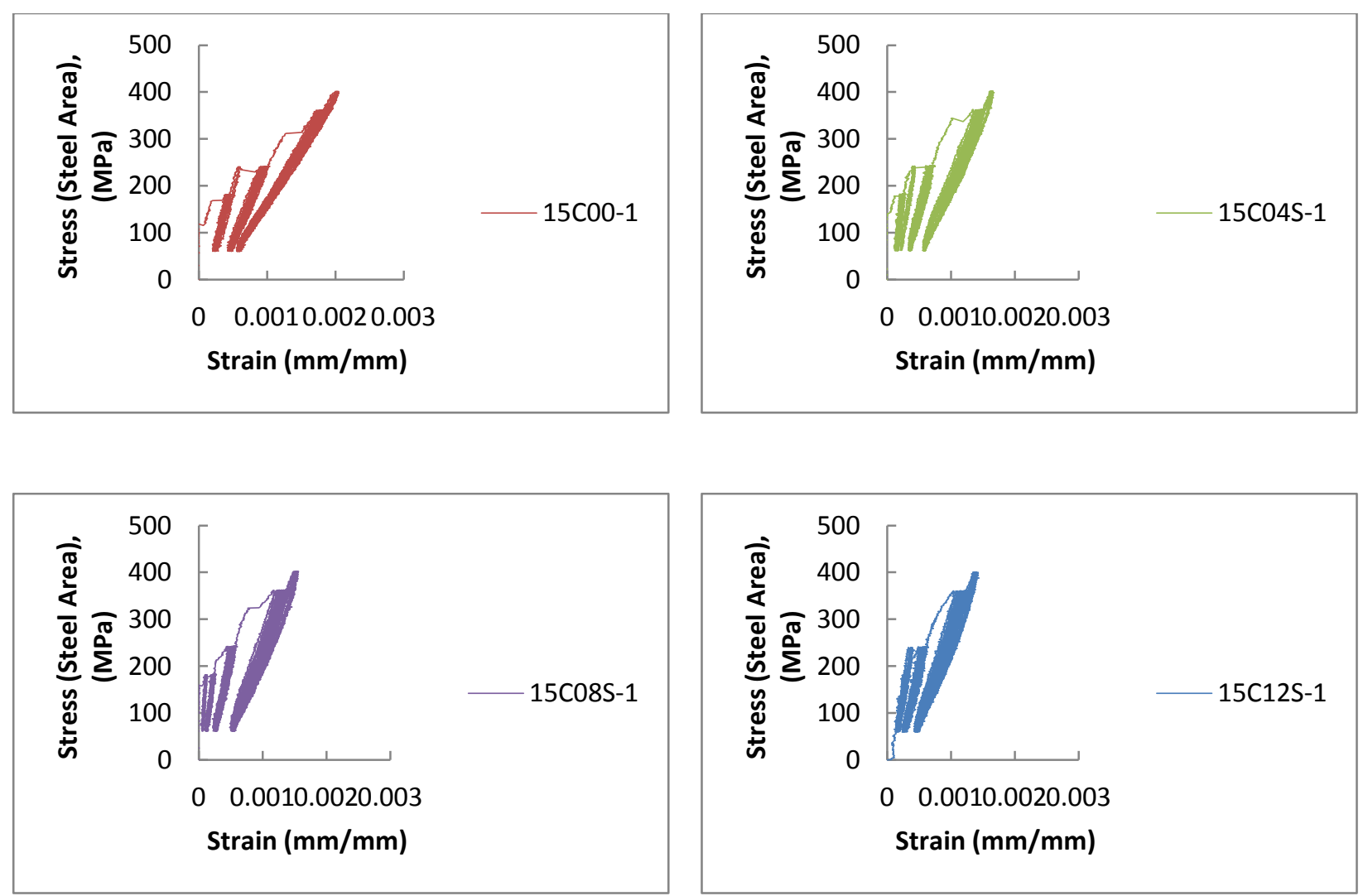

Figure 5-27: Stress strain response of $15 \mathrm{M}$ specimens under cyclic load at service loads

Table 5-20 summarizes the response of the $15 \mathrm{M}$ cyclic tests at service loads. The strains are tabulated at known steel stress levels in columns 3-6. The average modulus on final reload represents the average slope of the stress strain response on the final reload of each set of cycles. These values are calculated by taking two points, one at the lower end of the cycle and one at the high end of the cycle, and calculating the slope of a straight line drawn between them. These average moduli are shown in Table 5-20 columns 7-10. Figure 5-28 shows the decrease in stiffness as the load is cycled at higher load levels. It can be seen that the average stiffness on final reload is the greatest after the cycles at $180 \mathrm{MPa}$ and then the stiffnesses decrease proportionally for cycles at higher stress levels. The stiffness was calculated at the end of 20 cycles for each specimen. 
Table 5-20: Summary of performance of $15 \mathrm{M}$ specimens under cyclic load in the service range

\begin{tabular}{|c|c|c|c|c|c|c|c|c|c|}
\hline \multirow[b]{2}{*}{ Specimen } & \multirow[b]{2}{*}{$\begin{array}{c}\text { Fibre } \\
\text { Content } \\
\text { ZP305 } \\
\text { (\%) }\end{array}$} & \multicolumn{4}{|c|}{ Strain at stress of: } & \multicolumn{4}{|c|}{ Average Modulus on final reload from } \\
\hline & & $180 \mathrm{MPa}$ & 240MPa & $360 \mathrm{MPa}$ & 400MPa & $\begin{array}{c}\text { Cycle 1 } \\
60 \mathrm{MPa} \\
\text { to } \\
180 \mathrm{MPa} \\
\text { (GPa) }\end{array}$ & $\begin{array}{c}\frac{\text { Cycle 2 }}{60 \mathrm{MPa}} \\
\text { to } \\
240 \mathrm{MPa} \\
\text { (GPa) }\end{array}$ & $\begin{array}{c}\frac{\text { Cycle 3 }}{60 \mathrm{MPa}} \\
\text { to } \\
\text { 360MPa } \\
\text { (GPa) }\end{array}$ & $\begin{array}{c}\text { Cycle } 4 \\
60 \mathrm{MPa} \\
\text { to } \\
400 \mathrm{MPa} \\
\text { (GPa) }\end{array}$ \\
\hline $15 \mathrm{CO0}-1$ & 0 & 0.000447 & 0.00101 & 0.00181 & 0.00207 & 586 & 342 & 239 & 228 \\
\hline 15C04S-1 & 0.4 & 0.000273 & 0.000366 & 0.0015 & 0.00168 & 966 & 534 & 334 & 313 \\
\hline 15C08S-1 & 0.8 & 0.000217 & 0.000564 & 0.00136 & 0.00158 & 1293 & 631 & 355 & 341 \\
\hline 15C12S-1 & 1.2 & 0.000279 & 0.000607 & 0.00125 & 0.00144 & 1071 & 594 & 387 & 361 \\
\hline
\end{tabular}

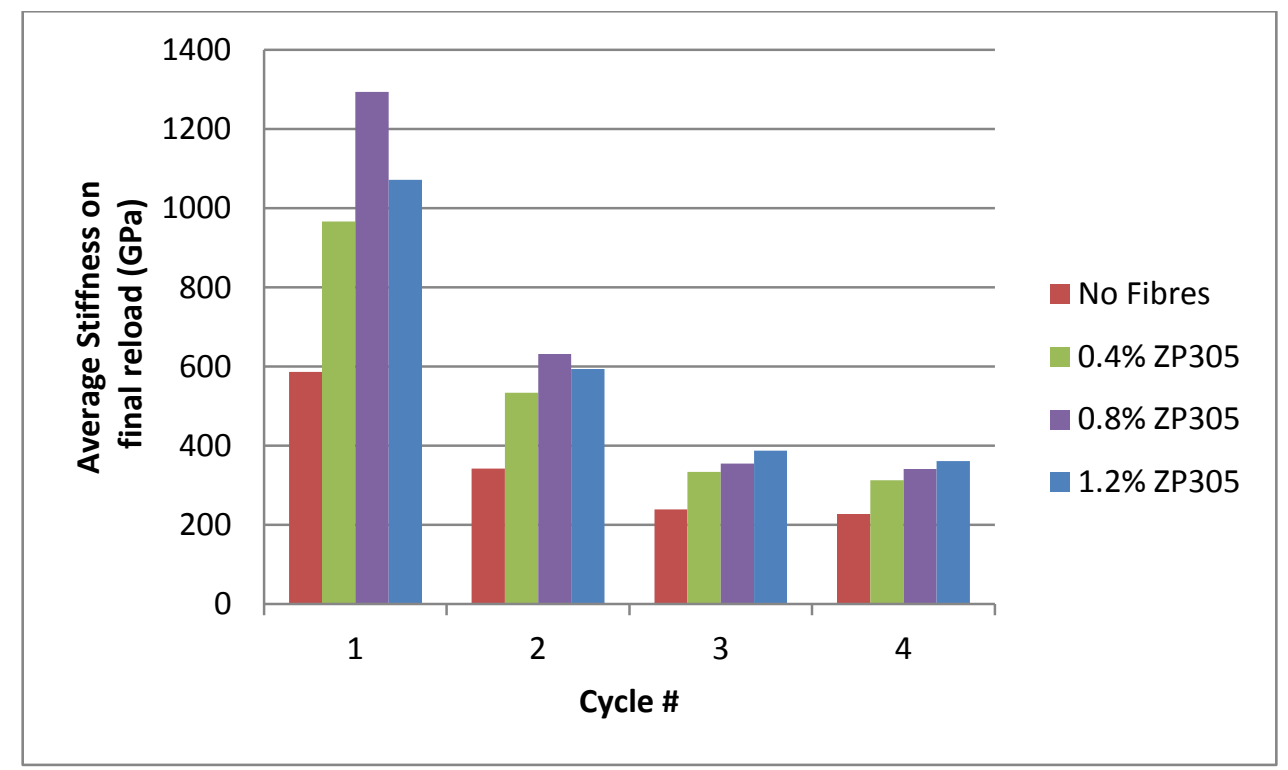

Figure 5-28: Average stiffness of $15 \mathrm{M}$ specimens under cyclic load in the service load range

Fibre addition resulted in increased stiffness when cycling at strains exceeding the yield strain of the reinforcing steel, though the effect was not as pronounced as it was for the specimens cycled at strains less than the yield strains. Also, the peak stresses or maximum stress 
envelope is considerably higher for those specimens which included fibre reinforced grout resulting in increase toughness of the masonry element. Table 5-21 summarizes the increased stiffness which resulted in specimens containing fibre reinforced grout when the load was cycled at strain levels surpassing the yield strain of the reinforcing steel. Figures 5-29 to 5-32 show the stress strain response of specimens subjected to cyclic load at high strain levels. The decrease in stress at given maximum strain level (0.2\%-0.6\%) is shown graphically in Figure 5-33 to 5-35. These figures show that the benefit of fibres is still present after much cycling at extreme strain levels.

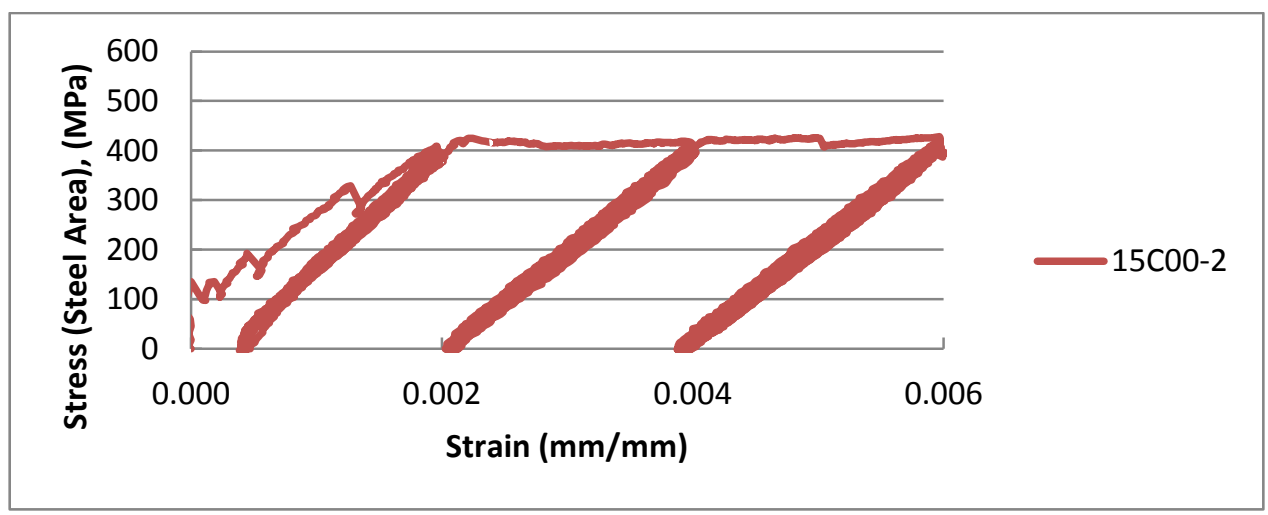

Figure 5-29: Stress strain response of 15M specimen with no fibres under cyclic load at high strain levels

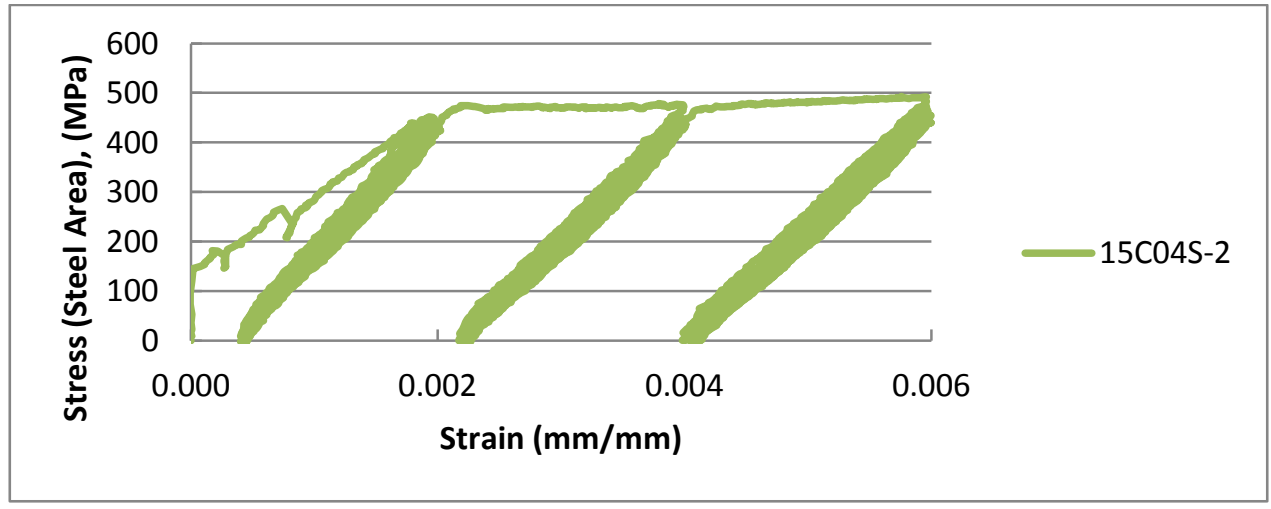

Figure 5-30: Stress strain response of $15 \mathrm{M}$ specimen with $0.4 \%$ ZP305 fibres under cyclic load at high strain levels 


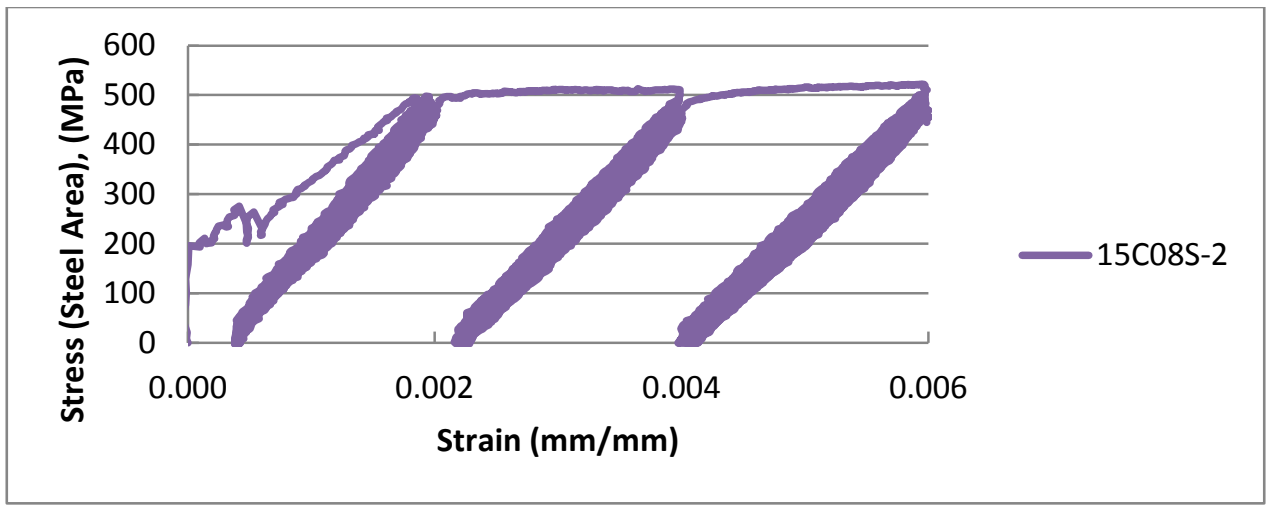

Figure 5-31: Stress strain response of $15 M$ specimen with $0.8 \%$ ZP305 fibres under cyclic load at high strain levels

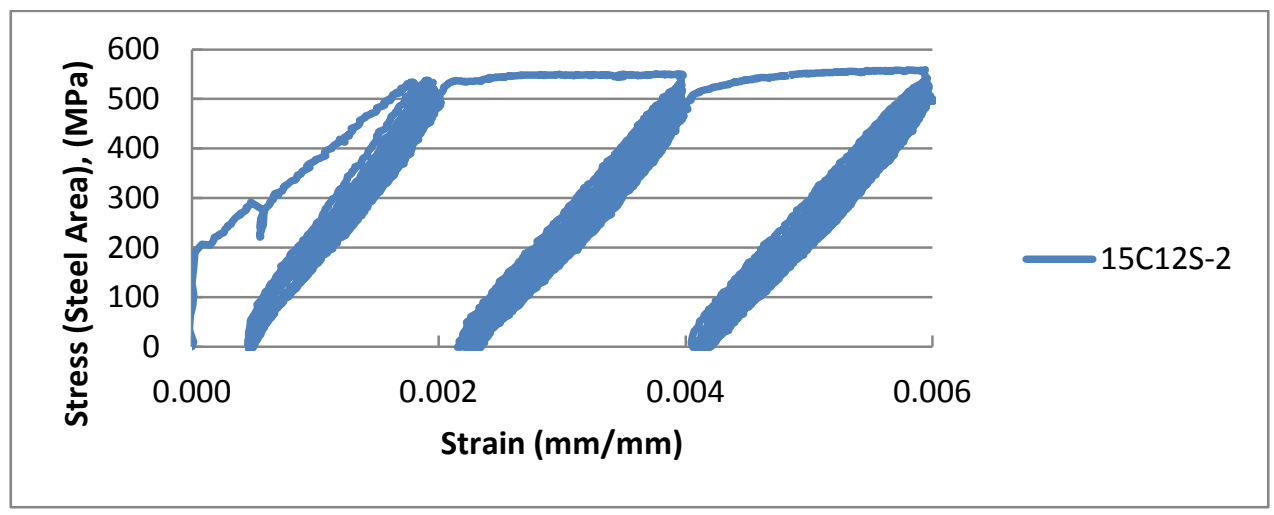

Figure 5-32: Stress strain response of $15 \mathrm{M}$ specimen with $1.2 \%$ ZP305 fibres under cyclic load at high strain levels

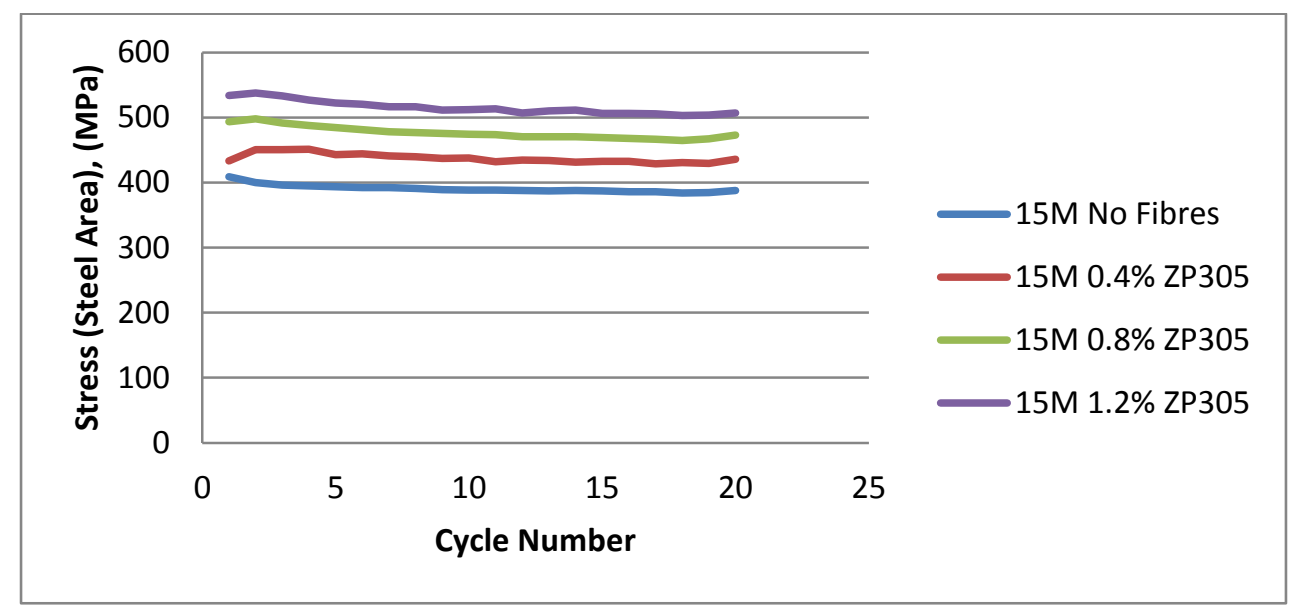

Figure 5-33: Stress as a function of cycles at $0.2 \%$ strain 


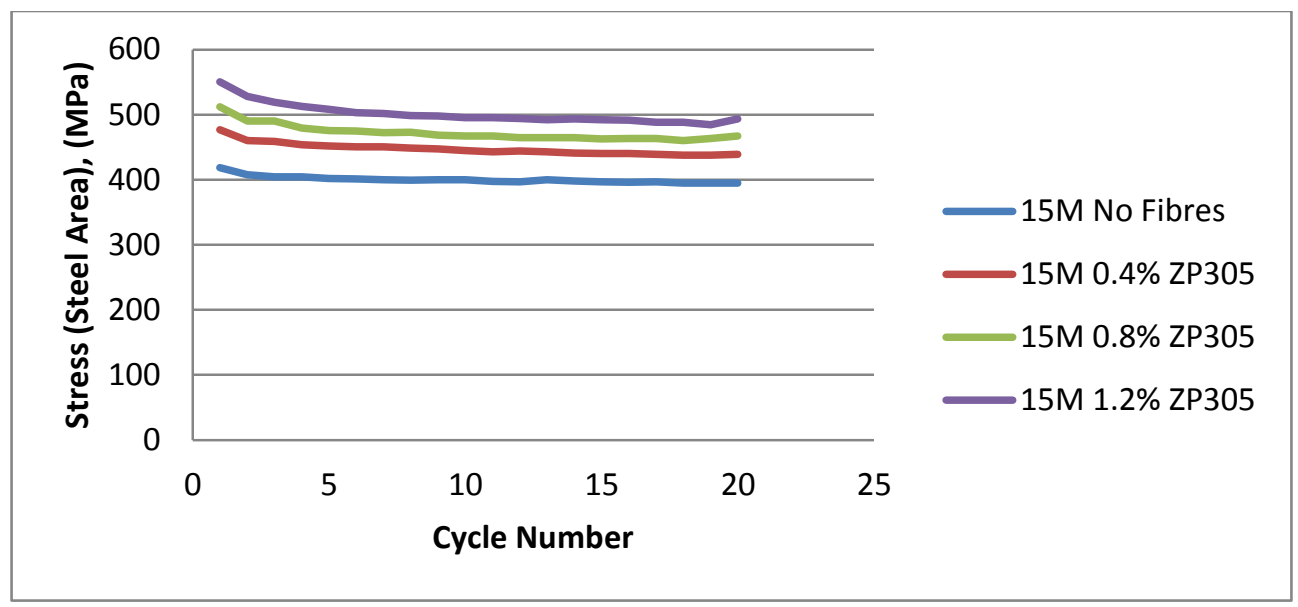

Figure 5-34: Stress as a function of cycles at $0.4 \%$ strain

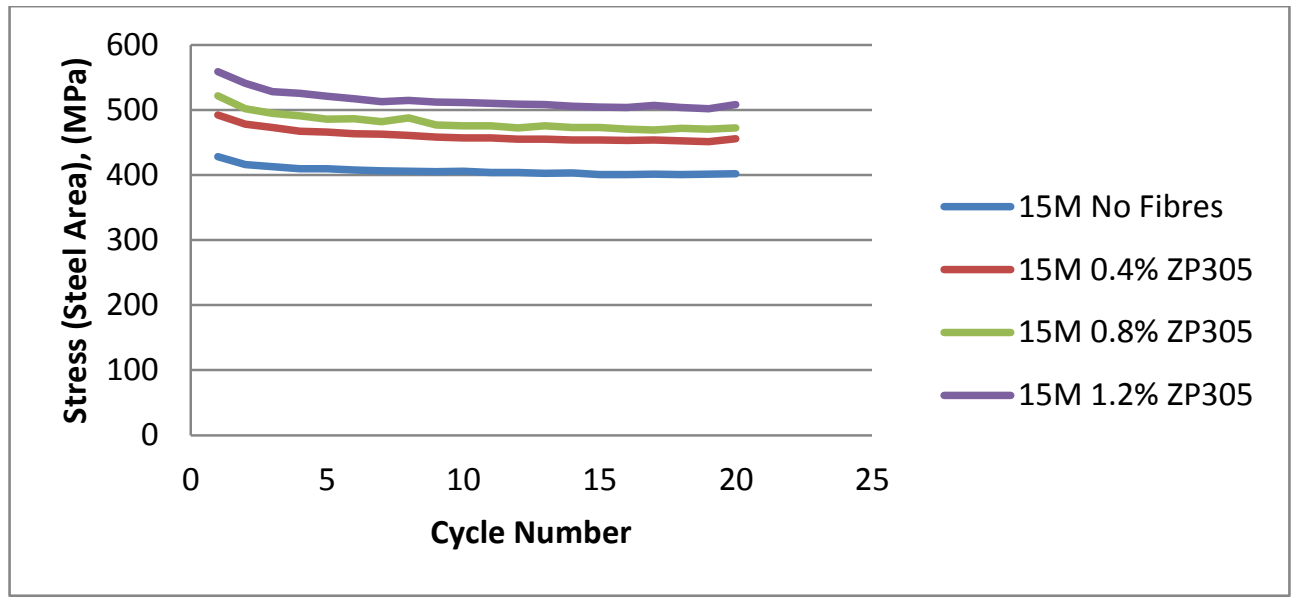

Figure 5-35: Stress as a function of cycles at $0.6 \%$ strain

As was the case with the cyclic tests at service loads, the average moduli are calculated on the final reload in each set of 20 cycles. The average moduli are calculated by taking a point on the stress-strain response at the top end of the cycle (strain of $0.2 \%, 0.4 \%$ and $0.6 \%$ ) and a point at the bottom end of the cycle (0MPa load) and calculating the slope of a line between the two points. The values are summarized in the table below. 
Table 5-21: Summary of performance of $15 \mathrm{M}$ specimens under cyclic load in the post-yield range

\begin{tabular}{|c|c|c|c|c|c|c|c|}
\hline \multirow{3}{*}{ Specimen } & \multirow{3}{*}{$\begin{array}{c}\text { Fibre } \\
\text { Content } \\
\text { ZP305 } \\
(\%)\end{array}$} & \multicolumn{3}{|c|}{$\begin{array}{c}\text { Stress after } 20 \text { cycles at a } \\
\text { strain of: }\end{array}$} & \multirow{2}{*}{\multicolumn{3}{|c|}{$\begin{array}{l}\text { Average Modulus on Final Reload from } \\
\text { strain of: }\end{array}$}} \\
\hline & & \multirow{2}{*}{$0.20 \%$} & \multirow{2}{*}{$0.40 \%$} & \multirow{2}{*}{$0.60 \%$} & & & \\
\hline & & & & & $0 \%$ to $0.2 \%$ & $0 \%$ to $0.4 \%$ & $0 \%$ to $0.6 \%$ \\
\hline $15 \mathrm{C} 00-2$ & 0 & 387 & 398 & 400 & $247 \mathrm{GPa}$ & $215 \mathrm{GPa}$ & $199 \mathrm{GPa}$ \\
\hline $15 \mathrm{C} 04 \mathrm{~S}-2$ & 0.4 & 430 & 442 & 451 & $279 \mathrm{GPa}$ & $257 \mathrm{GPa}$ & $244 \mathrm{GPa}$ \\
\hline $15 \mathrm{C} 08 \mathrm{~S}-2$ & 0.8 & 471 & 464 & 465 & $302 \mathrm{GPa}$ & $269 \mathrm{GPa}$ & $251 \mathrm{GPa}$ \\
\hline $15 \mathrm{C} 12 \mathrm{~S}-2$ & 1.2 & 507 & 483 & 507 & $334 \mathrm{GPa}$ & $290 \mathrm{GPa}$ & $289 \mathrm{GPa}$ \\
\hline
\end{tabular}

The specimen with 1.2\% ZP305 fibres maintained 98\% of its load carrying capacity after cycling at $0.2 \%$ strain, $88 \%$ of its load carrying capacity after cycling at $0.4 \%$ strain and $91 \%$ of its load carrying capacity after cycling at $0.6 \%$ strain whereas the specimen with no fibre reinforcement maintained $95 \%, 97 \%$, and 94\% respectively after being subjected to the same loading sequence. The specimen with $1.2 \%$ fibre reinforcement was able to carry $20 \%$ more load than the specimen with no fibres subjected to the same loading sequence.

Table 5-22: Stress at given strain levels before and after cycling

\begin{tabular}{|c|c|c|c|c|c|c|}
\hline \multicolumn{5}{|c|}{ CYCLIC LOADING (AFTER YIELDING) } \\
\hline & \multicolumn{3}{|c|}{ Strain } & \multicolumn{3}{c|}{ Strain } \\
\cline { 2 - 7 } & $0.20 \%$ & $0.40 \%$ & $0.60 \%$ & $0.20 \%$ & $0.40 \%$ & $0.60 \%$ \\
\hline Specimen & \multicolumn{2}{|c|}{ Load Before Cycling (kN) } & \multicolumn{3}{c|}{ Load After Cycling (kN) } \\
\hline 15 C00-2 & 406.5 & 412 & 424.5 & 387 & 398 & 400.5 \\
\hline 15 C04S-2 & 430 & 473 & 492.5 & 429.5 & 442 & 451.5 \\
\hline 15 C08S-2 & 480.5 & 500 & 510.5 & 471.5 & 464 & 465.5 \\
\hline $15 \mathrm{C} 12 \mathrm{~S}-2$ & 521.5 & 548 & 558.5 & 507 & 483.5 & 506.5 \\
\hline
\end{tabular}


Table 5-23: Stress at given strain levels under monotonic load

\begin{tabular}{|c|c|c|c|}
\hline \multicolumn{3}{|c|}{ MONOTONIC LOADING } \\
\hline \multirow{2}{*}{} & \multicolumn{3}{|c|}{ Strain } \\
\cline { 2 - 4 } & $\mathbf{0 . 2 0 \%}$ & $\mathbf{0 . 4 0 \%}$ & $\mathbf{0 . 6 0 \%}$ \\
\hline Specimen & \multicolumn{3}{|c|}{ Stress (MPa) } \\
\hline $15 \mathrm{M} 00-1$ & 398.5 & 411.5 & 414 \\
\hline $15 \mathrm{M} 04 \mathrm{~S}-1$ & 458.5 & 474 & 480.5 \\
\hline $15 \mathrm{M} 08 \mathrm{~S}-1$ & 515.5 & 523 & 525.5 \\
\hline $15 \mathrm{M} 12 \mathrm{~S}-1$ & 513.5 & 522.5 & 528.5 \\
\hline
\end{tabular}

\subsubsection{Crack Width and Crack Spacing}

Cyclic loading before yield had a very minor effect on crack widths when compared to the same specimen tested under monotonic load. Table 5-24 summarizes the crack widths under cyclic load before yield and compares it to the crack widths under monotonic load at the same load level (see Table 5-25). It is interesting to note that in many cases, both the average and maximum crack widths were greater for the monotonic case than for the cyclic case. It is thought that this can be attributed to the fact that the cracking patterns differed for the specimens whether they were tested under cyclic of monotonic load, even if the specimens were identical. Further testing would have to be conducted to validate and better understand this phenomenon. It may be more complex than speculated.

Table 5-24: Average and maximum crack widths after cycling at service loads

\begin{tabular}{|c|c|c|c|c|c|c|}
\hline \multicolumn{7}{|c|}{ AFTER CYCLIC LOADING (PRIOR TO YIELDING) } \\
\hline & \multicolumn{3}{|c|}{ Stress (Steel Area), (MPa) } & \multicolumn{3}{|c|}{ Stress (Steel Area), (MPa) } \\
\hline & 180 & 240 & 360 & 180 & 240 & 360 \\
\hline Specimen & \multicolumn{3}{|c|}{ Average Crack Width $(\mathrm{mm})$} & \multicolumn{3}{|c|}{$\begin{array}{c}\text { Maximum Crack Width } \\
(\mathrm{mm})\end{array}$} \\
\hline $15 \mathrm{C} 00-1$ & 0.14 & 0.22 & 0.3 & 0.28 & 0.46 & 0.7 \\
\hline $15 \mathrm{C} 04 \mathrm{~S}-1$ & 0.13 & 0.21 & 0.29 & 0.2 & 0.34 & 0.56 \\
\hline $15 \mathrm{C} 08 \mathrm{~S}-1$ & 0.11 & 0.17 & 0.27 & 0.14 & 0.28 & 0.56 \\
\hline $15 \mathrm{C} 12 \mathrm{~S}-1$ & 0.09 & 0.12 & 0.27 & 0.12 & 0.24 & 0.54 \\
\hline
\end{tabular}


Table 5-25: Average and maximum crack widths under monotonic load at equivalent stresses

\begin{tabular}{|c|c|c|c|c|c|c|}
\hline \multicolumn{7}{|c|}{ MONOTONIC LOADING } \\
\hline & \multicolumn{3}{|c|}{ Stress (Steel Area), (MPa) } & \multicolumn{3}{c|}{ Stress (Steel Area), (MPa) } \\
\cline { 2 - 7 } & 180 & 240 & 360 & 180 & 240 & 360 \\
\hline \multirow{2}{*}{ Specimen } & \multicolumn{3}{|c|}{ Average Crack Width (mm) } & \multicolumn{3}{|c|}{ Maximum Crack Width } \\
& \multicolumn{3}{|c|}{$(\mathrm{mm})$} \\
\hline $15 \mathrm{M} 00-1$ & 0.19 & 0.26 & 0.35 & 0.56 & 0.7 & 0.8 \\
\hline $15 \mathrm{M} 04 \mathrm{~S}-1$ & 0.12 & 0.18 & 0.33 & 0.24 & 0.46 & 0.62 \\
\hline $15 \mathrm{M} 08 \mathrm{~S}-1$ & 0.06 & 0.11 & 0.22 & 0.24 & 0.4 & - \\
\hline $15 \mathrm{M} 12 \mathrm{~S}-1$ & 0 & 0.13 & 0.23 & 0.16 & 0.32 & 0.4 \\
\hline
\end{tabular}

Figures 5-36 to 5-38 show the effect of cycling the load on the average crack width at a given level of stress by comparing the average crack widths after cycling with the crack widths under monotonic load. Figures 5-39 to 5-41 show the effect of cycling the load on the maximum crack width at a given level of stress by comparing the maximum crack width after cycling with the maximum crack width under monotonic load. Table 5-26 shows the difference in cracking patterns for the specimens tested under monotonic load versus those tested under cyclic load. It should be noted that the computation of average crack width will be affected by the number of cracks present.

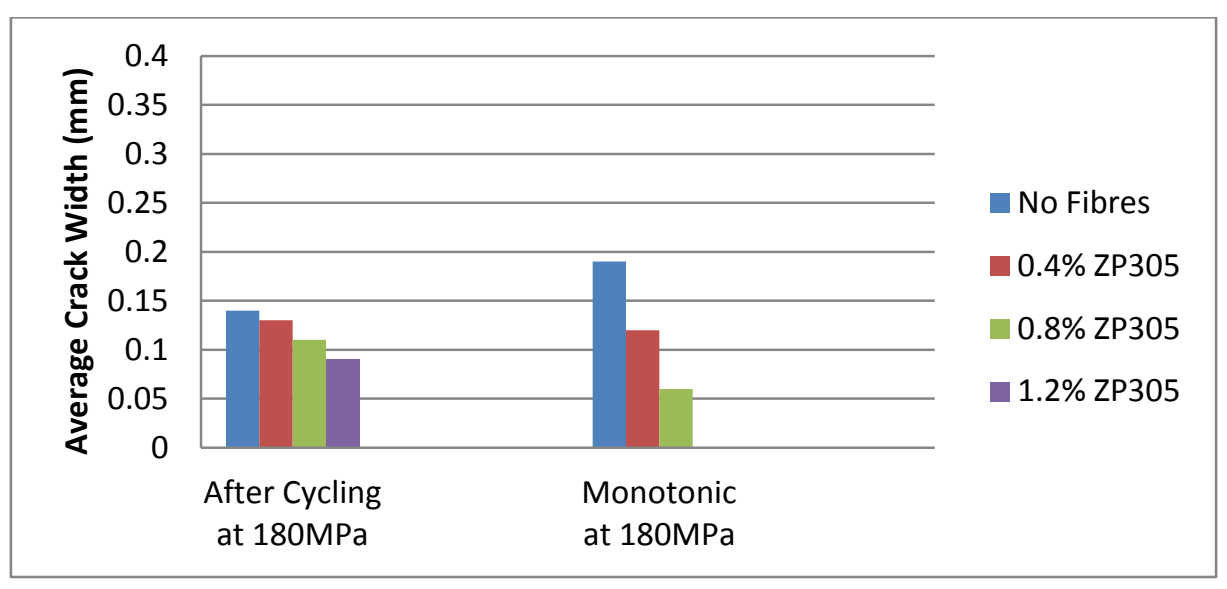

Figure 5-36: Average crack width after cycling vs. monotonic at 180MPa 


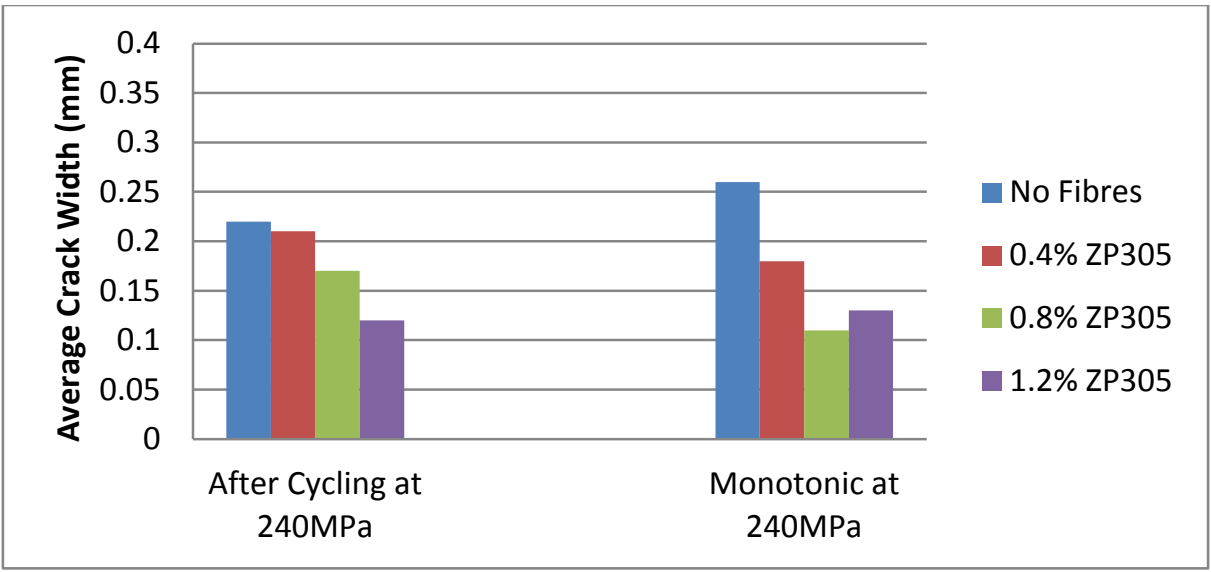

Figure 5-37: Average crack width after cycling vs. monotonic at 240MPa

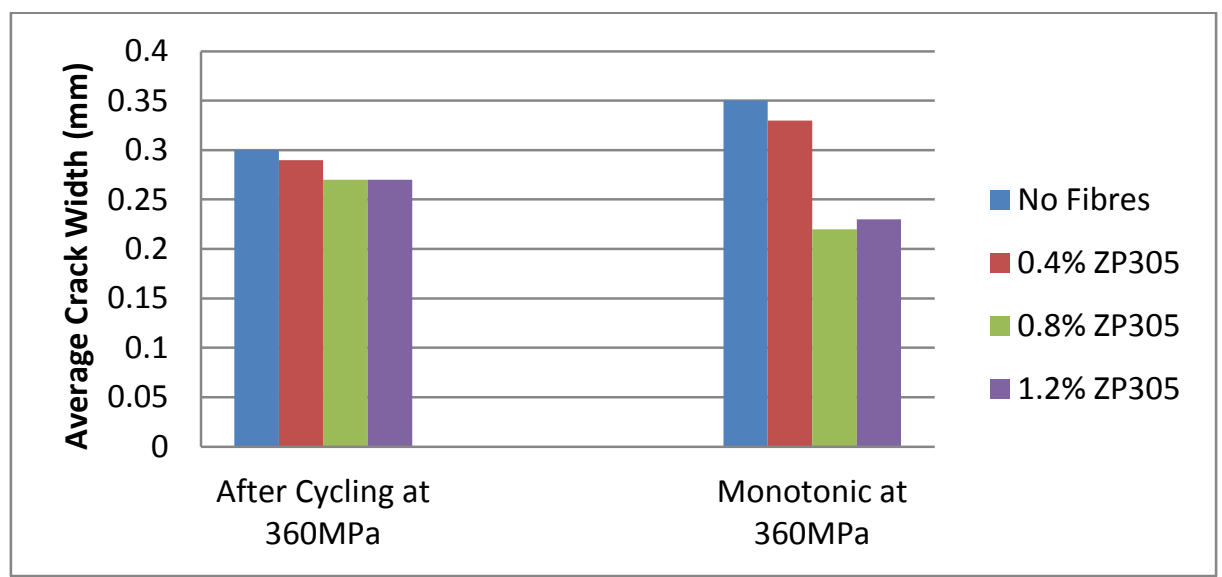

Figure 5-38: Average crack width after cycling vs. monotonic at 360MPa

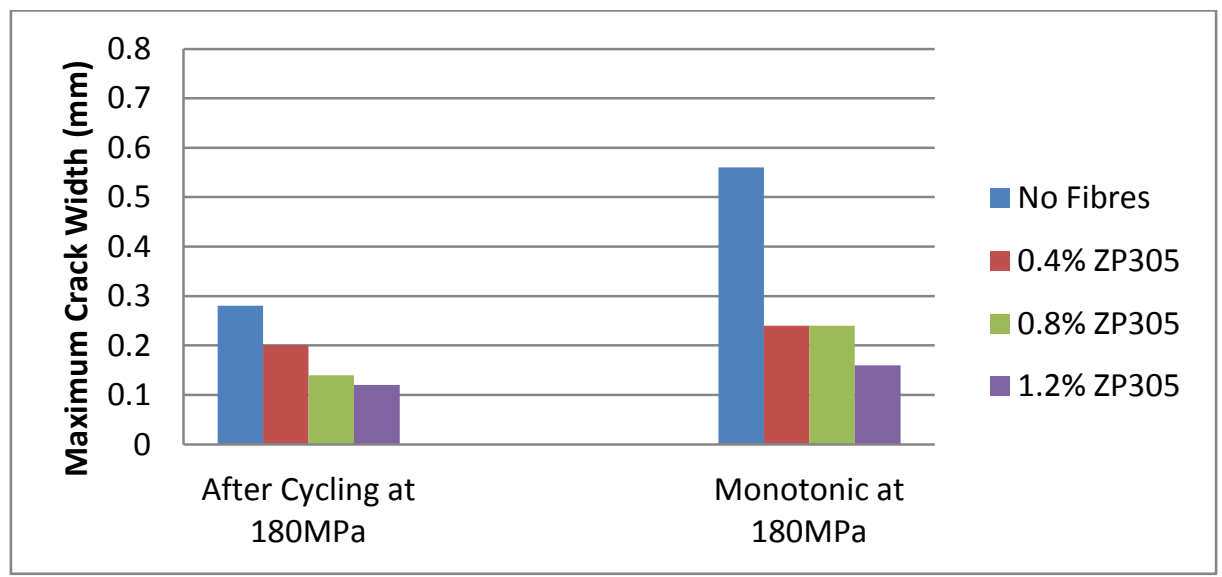

Figure 5-39: Maximum crack width after cycling vs. monotonic at $180 \mathrm{MPa}$ 


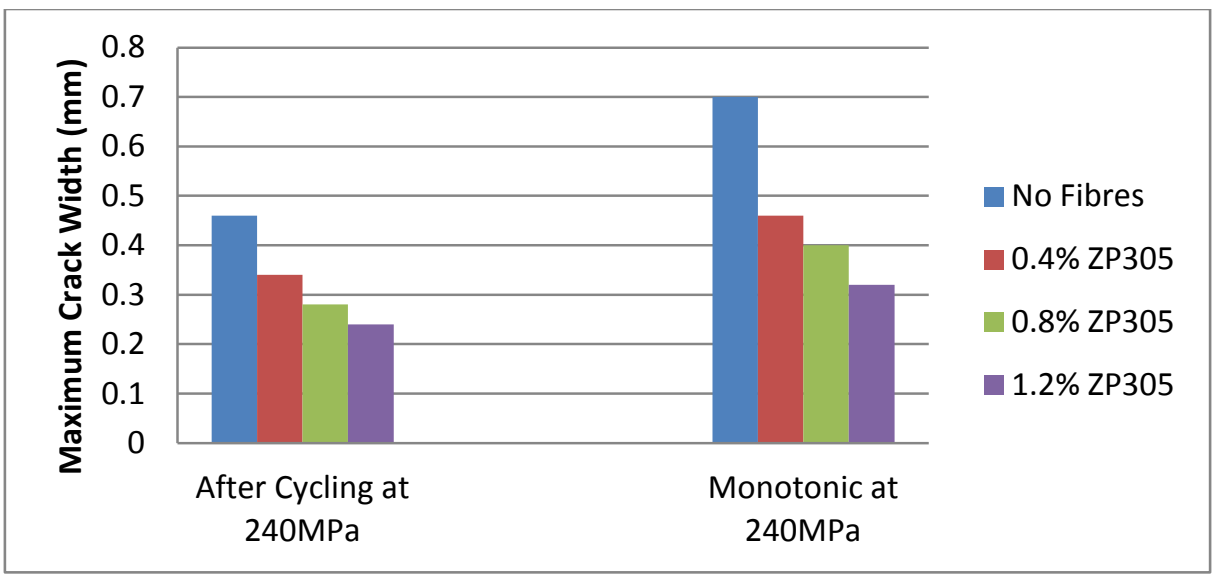

Figure 5-40: Maximum crack width after cycling vs. monotonic at 240MPa

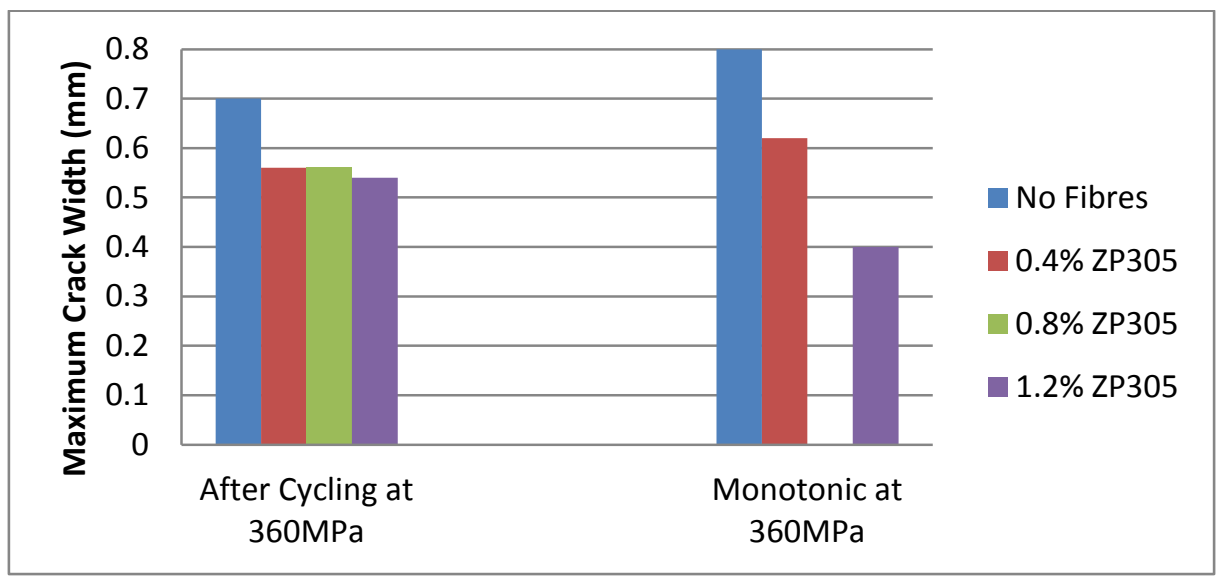

Figure 5-41: Maximum crack width after cycling vs. monotonic at 360MPa 
Table 5-26: Crack patterns after cycling at service loads vs. monotonic

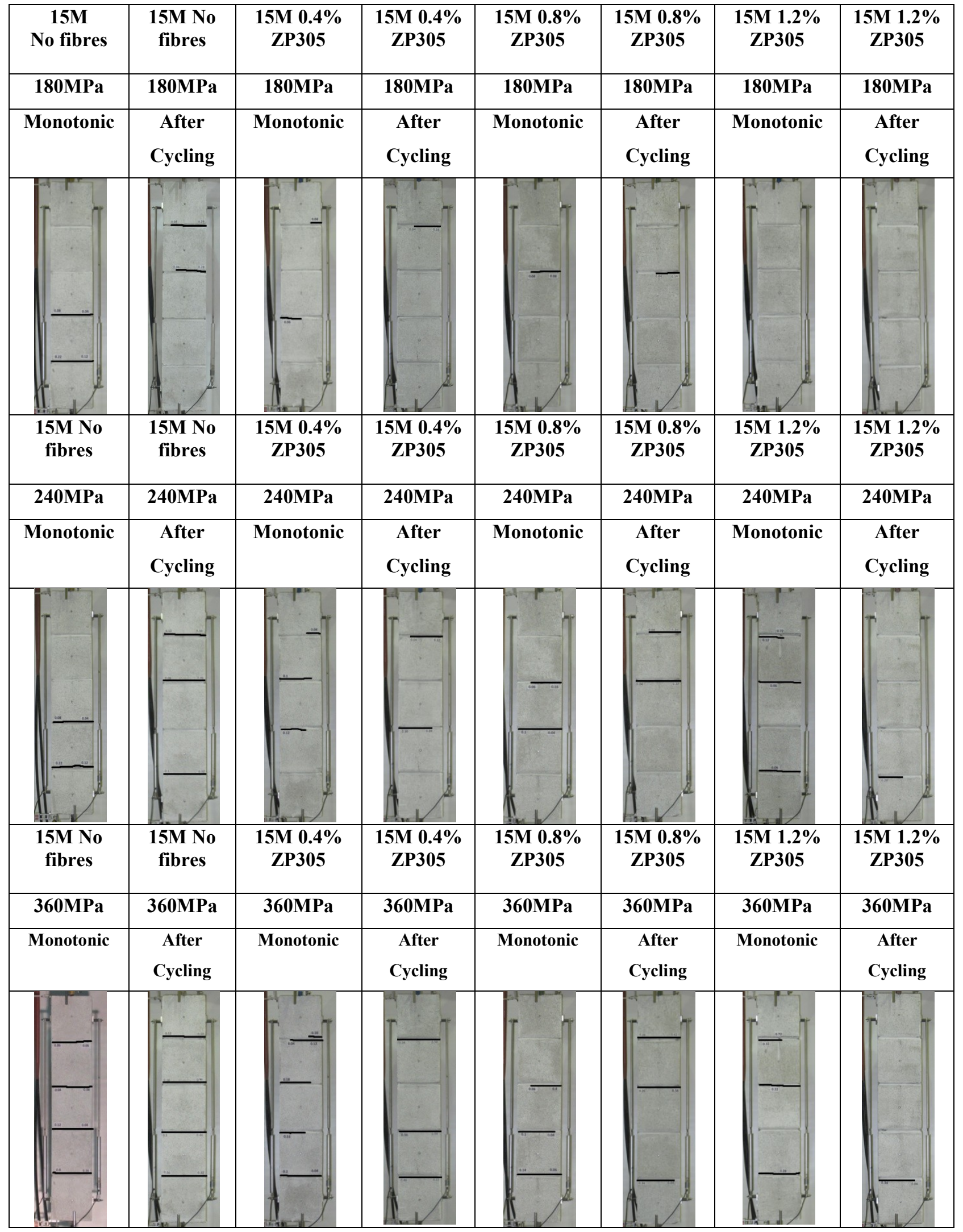


The cyclic testing prior to yield of the reinforcing steel was conducted in load control whereas the cyclic testing after yield of the reinforcing steel was in displacement control; therefore the comparisons are slightly different. For the specimens cycled before yield, crack widths after cycling were compared with the monotonic case. For the specimens cycled after yielding of the reinforcing steel, it is not possible to compare crack widths as the loading is done under displacement control.

\subsubsection{Effect of Reinforcement Ratio}

Two series of tests will be analyzed to evaluate the effect of reinforcement ratio on the performance under cyclic load. These consist of specimens which are reinforced with $15 \mathrm{M}$ and $20 \mathrm{M}$ bars.

\subsubsection{Stress Strain Behaviour}

The specimens 15C00-1 and 20C00-1 are identical specimens, with the exception of the bar size, each containing no fibres. They were subjected to the same cyclic loading sequence under load control. From Figure 5-42, it can be seen that the additional stiffness provided by the cracked masonry surrounding the reinforcement is much more pronounced in the case of the specimen with the lower reinforcement ratio. Figure 5-43 and Figure 5-44 show the cyclic stress strain responses of the specimens containing $0.4 \%$ and $0.8 \%$ ZP305 steel fibres prior to yield. Again, the additional stiffness provided by the cracked masonry is much greater in the specimen with the lower reinforcement ratio. Figure 5-45 shows the cyclic response of the specimens with $1.2 \%$ ZP305 fibres and with this level of fibre reinforcement the contribution of the fibres is actually greater with the specimen which has the increased reinforcement ratio.

Again for means of assessing the stiffness after cycling the average modulus of the last loading cycle was calculated (see Table 5-27). This modulus was calculated by taking a point on the stress-strain response at the upper end of the cycle and a point at the lower end of the cycle 
during the last reload from $60 \mathrm{MPa}$ to the desired maximum load in the cycle. The average moduli were calculated as the slope of a straight line drawn between these two data points.

Typically the response of the specimens reinforced with the $15 \mathrm{M}$ bars (lower reinforcement ratio) had increased stiffness when compared to the specimens reinforced with $20 \mathrm{M}$ bars (higher reinforcement ratio) because the percent increase in steel area provided by the steel fibres was more significant. Since the specimens were stressed to a given stress based on the steel area the effect of percent increase in steel area due to the steel fibres was not accounted for.

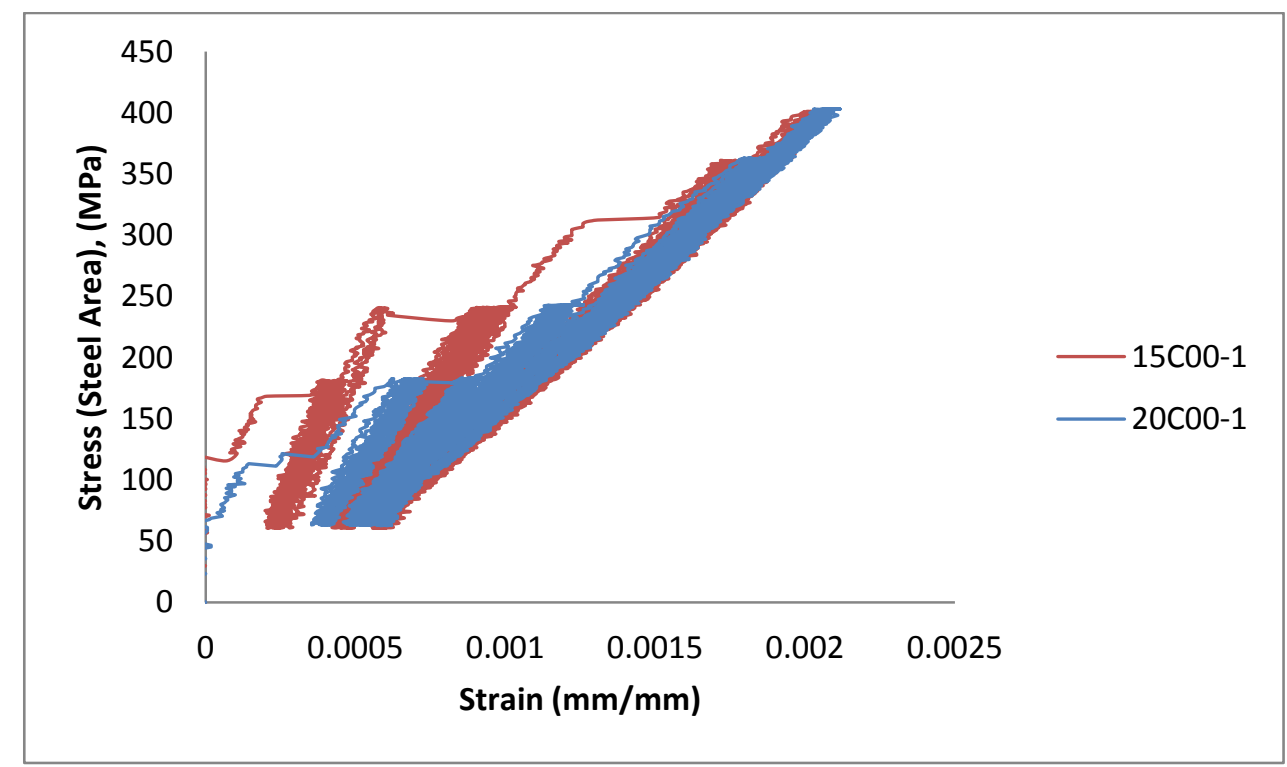

Figure 5-42: Stress strain response of $15 \mathrm{M} \& 20 \mathrm{M}$ specimens with no fibres cycled at service loads 


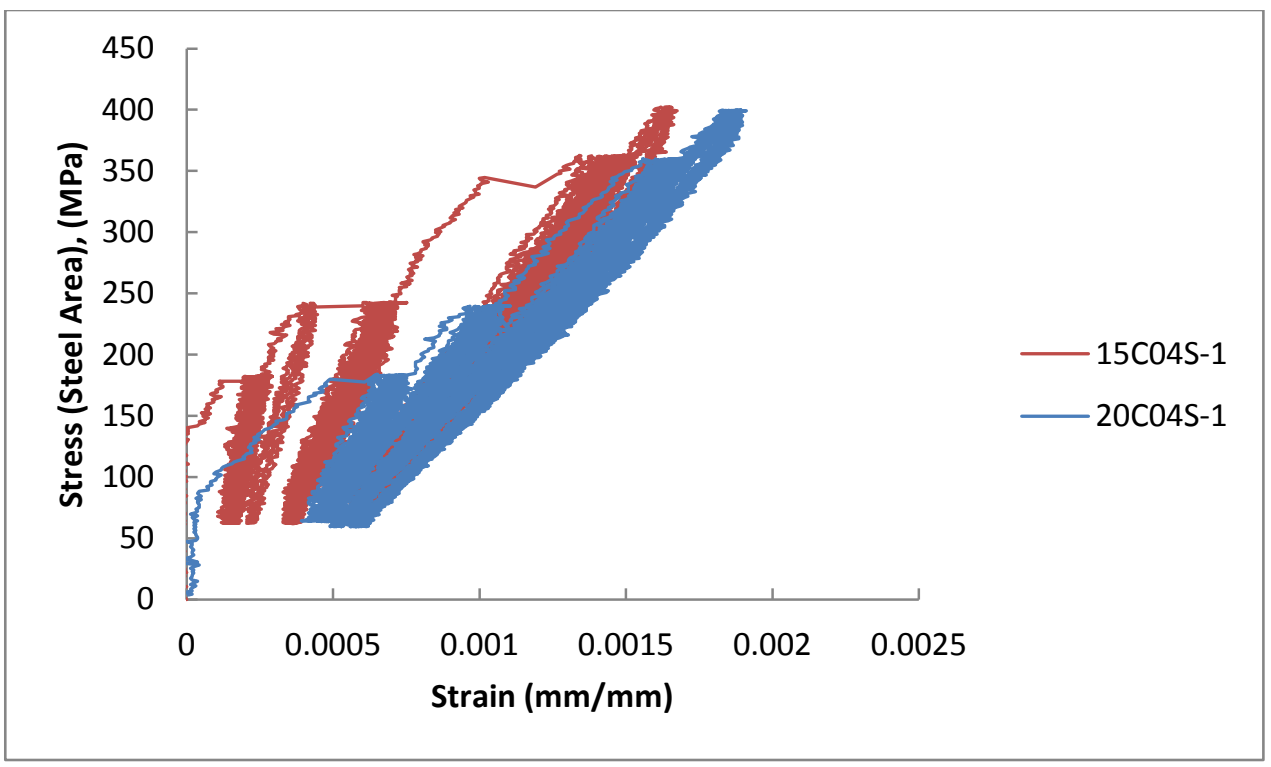

Figure 5-43:Stress strain response of $15 M$ \& 20M specimens with $0.4 \%$ ZP305 fibres cycled at service loads

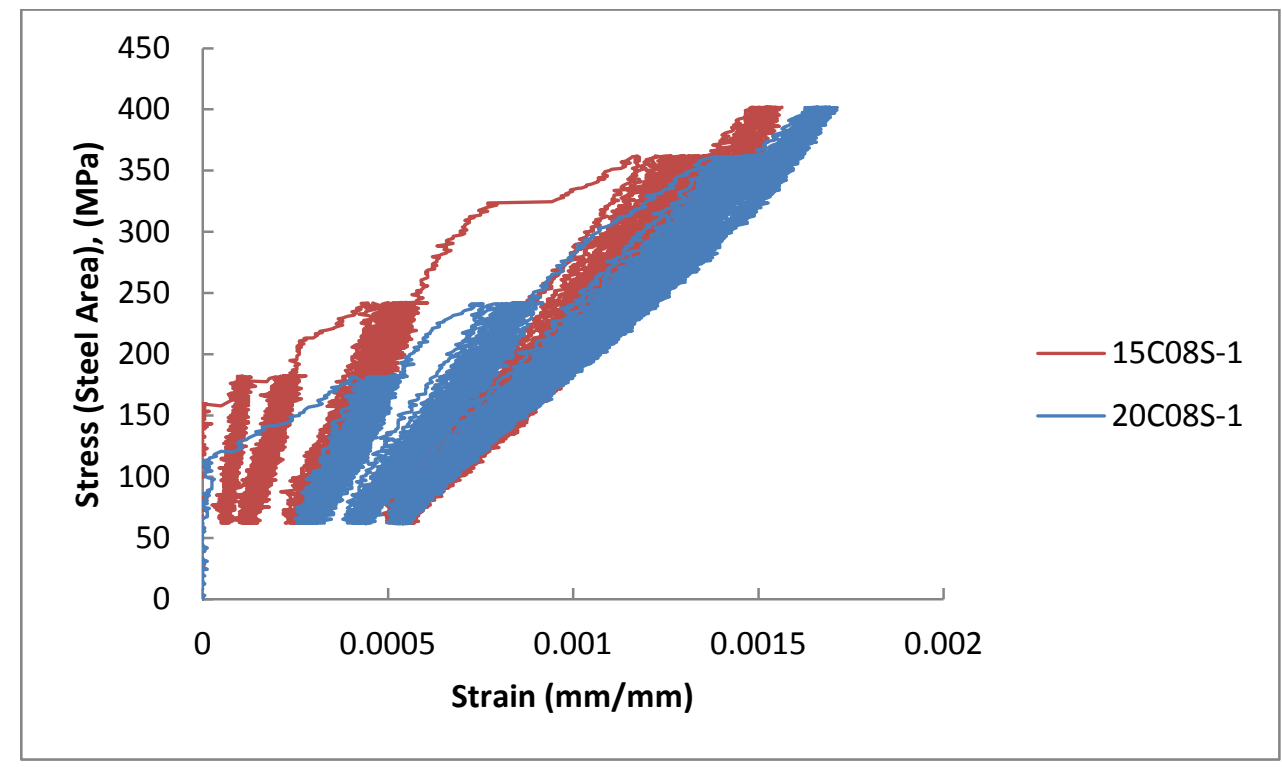

Figure 5-44: Stress strain response of $15 \mathrm{M} \& 20 \mathrm{M}$ specimens with $0.8 \%$ ZP305 fibres cycled at service loads 


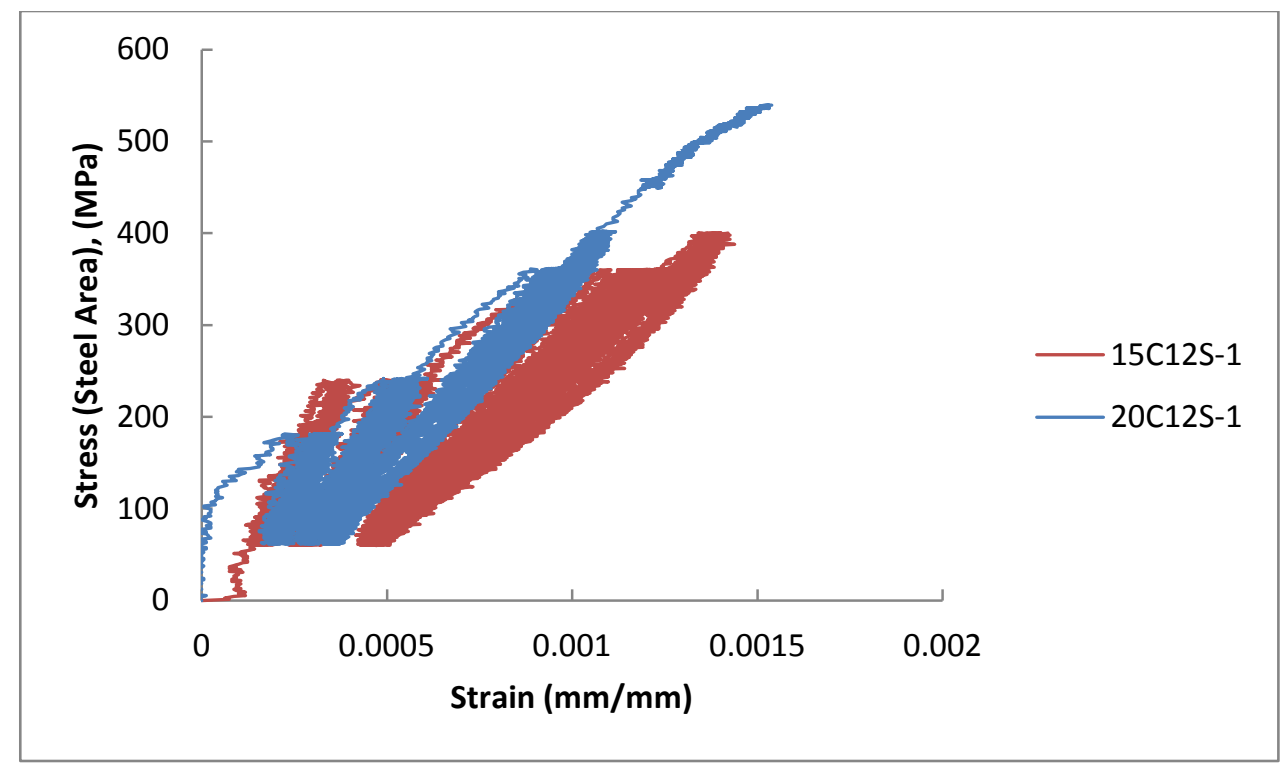

Figure 5-45: Stress strain response of $15 \mathrm{M} \& 20 \mathrm{M}$ specimens with $1.2 \%$ ZP305 fibres cycled at service loads

Table 5-27: Summary of performance of $15 \mathrm{M}$ and 20M specimens under cyclic load at service loads

\begin{tabular}{|c|c|c|c|c|c|c|c|c|c|}
\hline \multirow[b]{2}{*}{ Specimen } & \multirow[b]{2}{*}{$\begin{array}{c}\text { Fibre } \\
\text { Content } \\
\text { ZP305 } \\
\text { (\%) }\end{array}$} & \multicolumn{4}{|c|}{ Strain at stress of: } & \multicolumn{4}{|c|}{ Average Modulus on final reload from } \\
\hline & & $180 \mathrm{MPa}$ & 240MPa & 360MPa & 400MPa & $\begin{array}{c}60 \mathrm{MPa} \\
\text { to } \\
180 \mathrm{MPa} \\
\text { (GPa) }\end{array}$ & $\begin{array}{c}60 \mathrm{MPa} \\
\text { to } \\
240 \mathrm{MPa} \\
\text { (GPa) }\end{array}$ & $\begin{array}{c}60 \mathrm{MPa} \\
\text { to } \\
360 \mathrm{MPa} \\
(\mathrm{GPa})\end{array}$ & $\begin{array}{c}60 \mathrm{MPa} \\
\text { to } \\
400 \mathrm{MPa} \\
(\mathrm{GPa})\end{array}$ \\
\hline $15 \mathrm{C00}-1$ & 0 & 0.000447 & 0.00101 & 0.00181 & 0.00207 & 586 & 342 & 239 & 228 \\
\hline $15 \mathrm{C04S}-1$ & 0.4 & 0.000273 & 0.000366 & 0.0015 & 0.00168 & 966 & 534 & 334 & 313 \\
\hline $15 \mathrm{C08S}-1$ & 0.8 & 0.000217 & 0.000564 & 0.00136 & 0.00158 & 1293 & 631 & 355 & 341 \\
\hline 15C12S-1 & 1.2 & 0.000279 & 0.000607 & 0.00125 & 0.00144 & 1071 & 594 & 387 & 361 \\
\hline $20 \mathrm{C00}-1$ & 0 & 0.000905 & 0.00119 & 0.00188 & 0.00208 & 289 & 273 & 231 & 232 \\
\hline 20C04S-1 & 0.4 & 0.000744 & 0.00104 & 0.00171 & 0.00189 & 451 & 353 & 270 & 263 \\
\hline 20C08S-1 & 0.8 & 0.000509 & 0.000887 & 0.00149 & 0.00170 & 584 & 403 & 312 & 295 \\
\hline 20C12S-1 & 1.2 & 0.000366 & 0.000211 & 0.00098 & 0.00109 & 770 & 629 & 461 & 458 \\
\hline
\end{tabular}

Although the specimens with the lower reinforcement ratios tend to have increased stiffness at low levels of stress, the loss of stiffness is much more rapid in the case of the specimens with lower reinforcement ratios especially in the case of the specimens with no fibres. One exception is in the case of the specimens reinforced with $1.2 \%$ ZP305 fibres, the loss in stiffness as a function of stress is very similar for both the $15 \mathrm{M}$ and $20 \mathrm{M}$ specimens. This effect is summarized in the Figure 5-46 based on Table 5-27. 


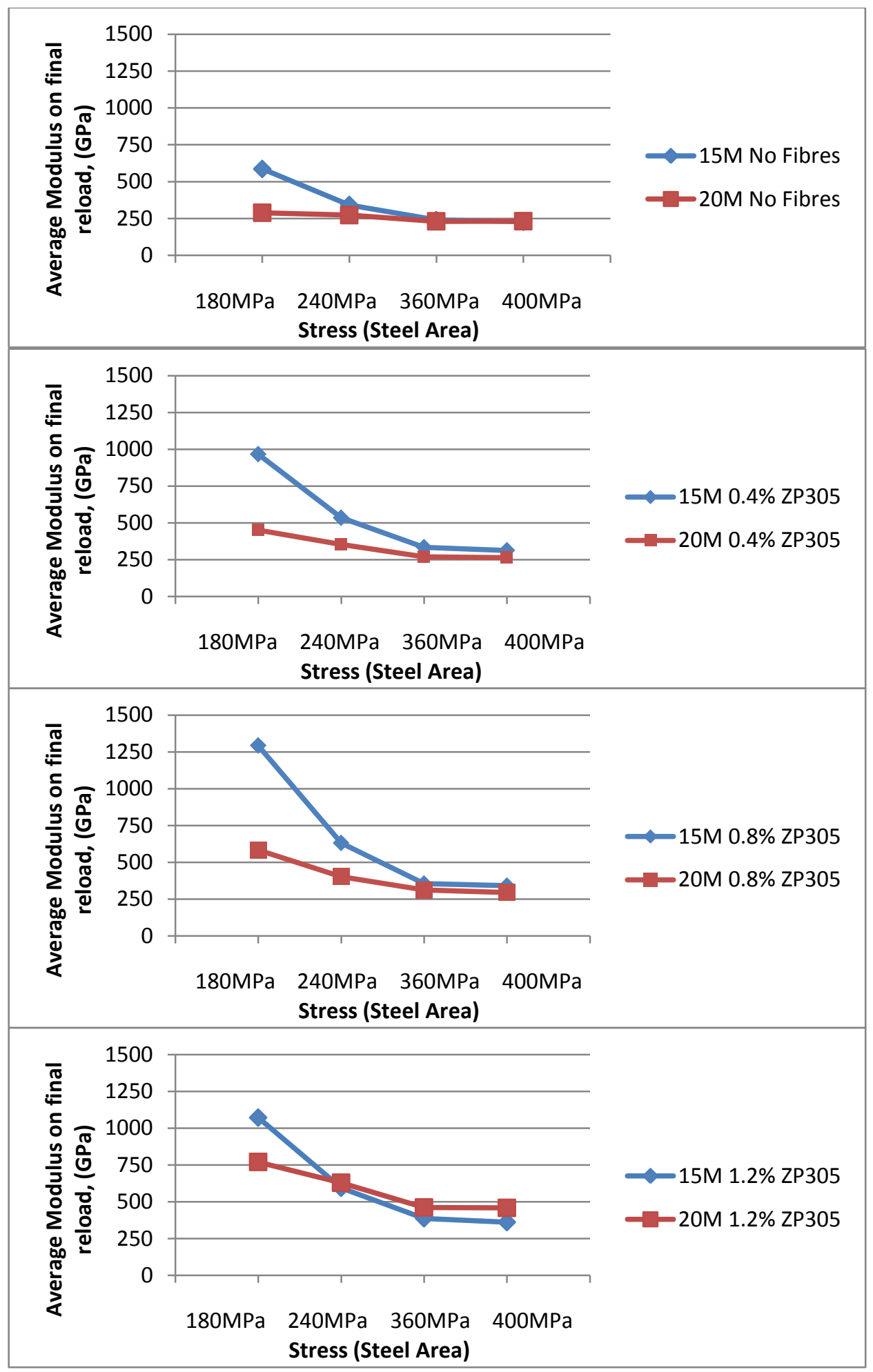

Figure 5-46: Average modulus on final reload vs. steel stress for specimens with varying reinforcement ratios 
The stress strain behaviour under cyclic load at levels of strain exceeding the yield strain was not as significantly dependent on reinforcement ratio as at lower levels of strain. Figure 547 shows the reinforcement ratio has very little effect on the behaviour of the specimen after yielding of the steel when no fibres are present. Figures 5-48 to 5-50 show the response of the specimens with fibres in the post-yield range. The reinforcement ratio has a minimal effect on the stiffness of the specimens at high levels of strain under cyclic loading. The stiffness of the $20 \mathrm{M}$ response is decreased to approximately $85 \%$ that of the $15 \mathrm{M}$ response with $1.2 \%$ ZP305 fibres. With no fibres, the responses are very similar and the response is fairly independent of reinforcement ratio. It should be noted that the increased peak stresses are due to the difference in yield stresses of the reinforcing bars. As the fibre content increases, the difference in yield stresses becomes masked by the increased in yield strength provided by the steel fibres.

When the load was cycled to $0.2 \%$ strain, the loss in load carrying capacity was slightly more noticeable for the specimens with smaller reinforcement ratios. The 20M specimens with fibres lost less than $1 \%$ of their load carrying capacity due to the cycling whereas the $20 \mathrm{M}$ specimen without fibres lost $4 \%$ of its load carrying capacity. Cycling at higher strains resulted in increasing losses in load carrying capacity as shown in Table 5-28.

Comparatively, for the $15 \mathrm{M}$ specimens; more load carrying capacity was lost compared to the $20 \mathrm{M}$ specimens. When the specimen was cycled at $0.2 \%$ strain, the specimen with no fibres lost $5 \%$ of its load carrying capacity whereas those with fibres lost less than $3 \%$. Again, at increasing levels of strain, the loss in load carrying capacity after cycling diminished. 


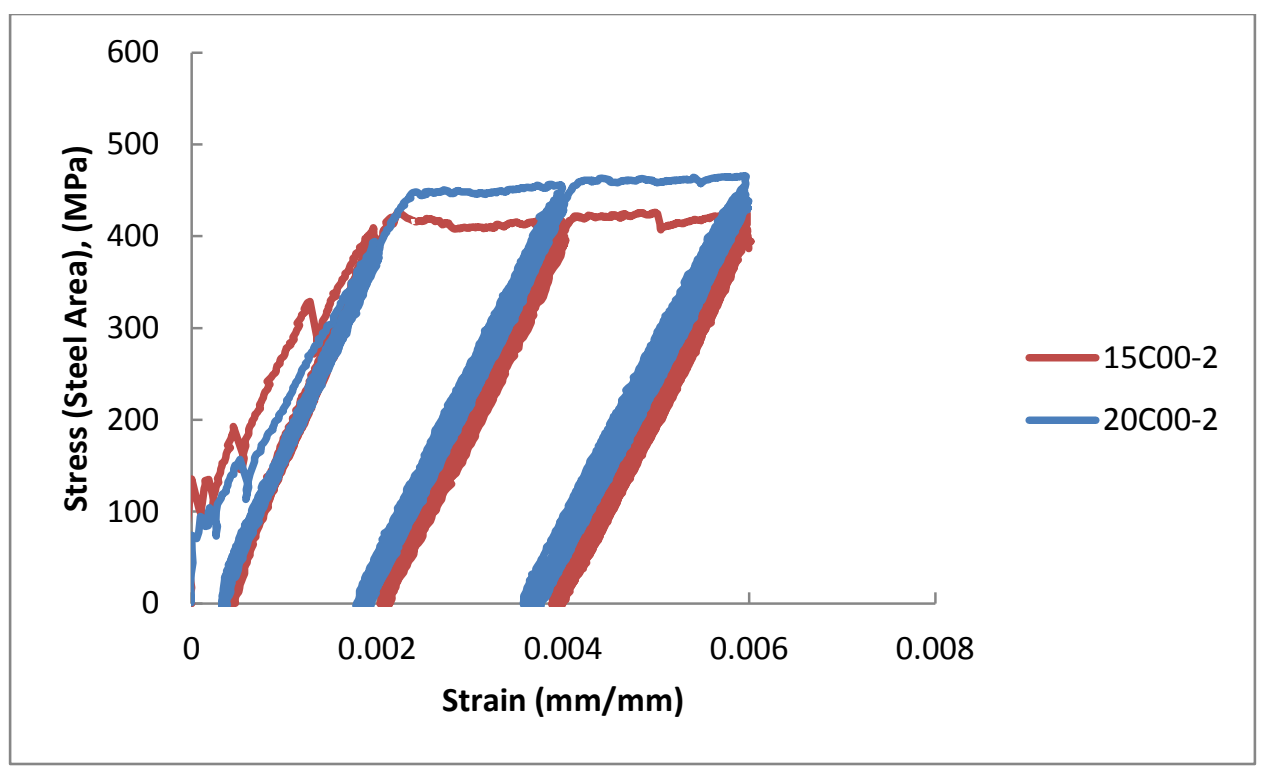

Figure 5-47: Stress strain response for specimens with no fibres under cyclic load in the post-yield range

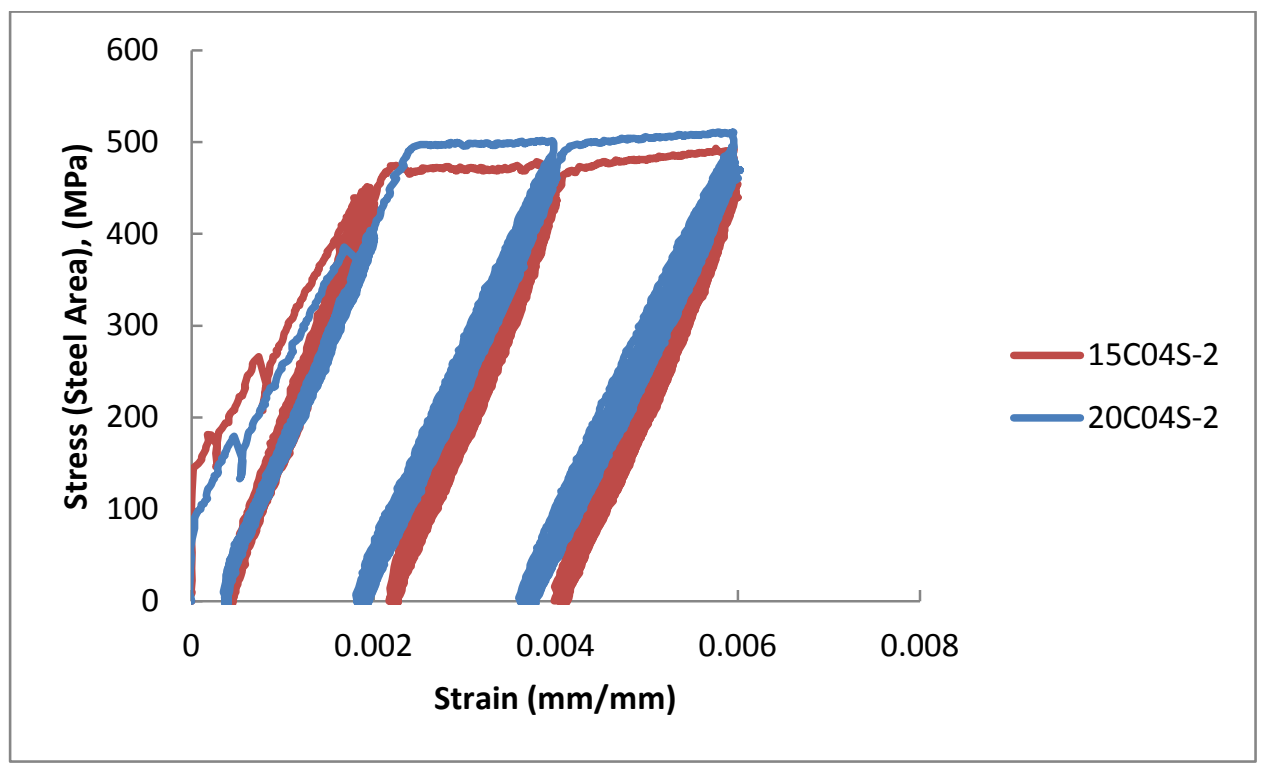

Figure 5-48: Stress strain response for specimens with $0.4 \%$ ZP305 fibres under cyclic load in the post-yield range 


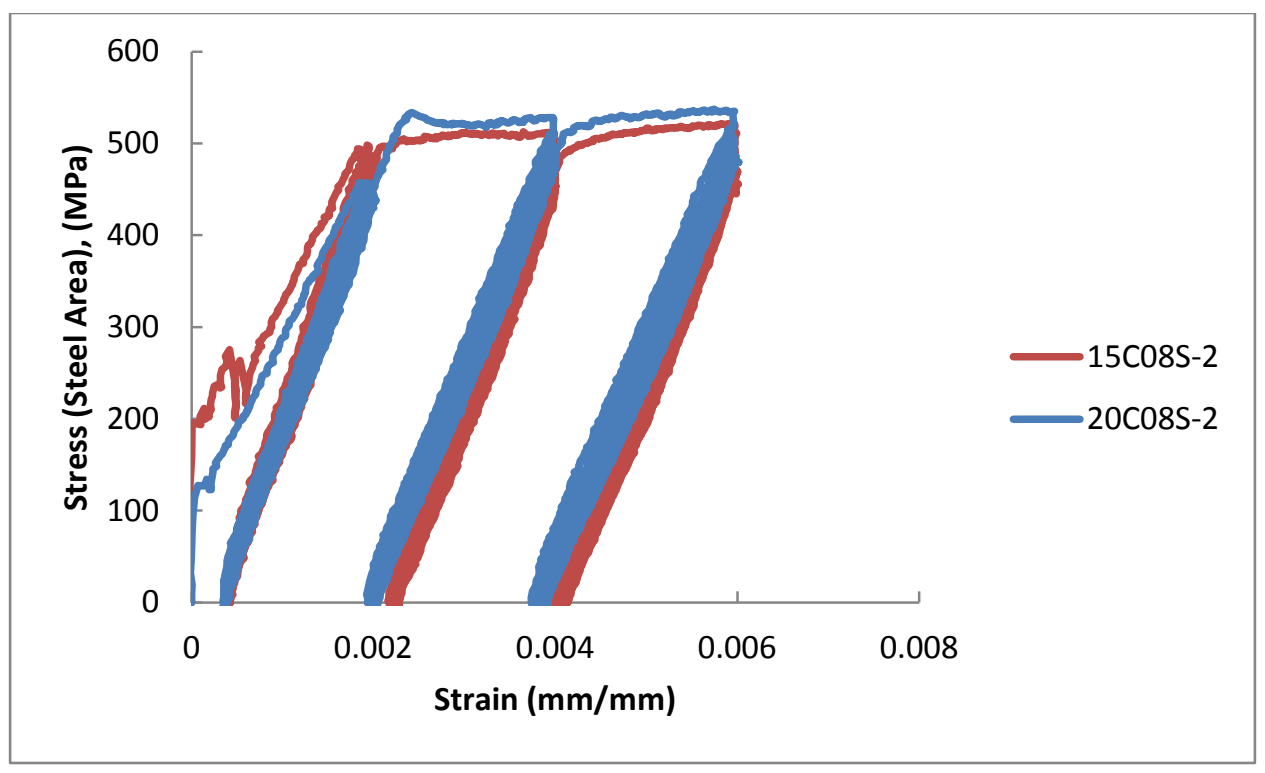

Figure 5-49: Stress strain response for specimens with $0.8 \%$ ZP305 fibres under cyclic load in the post-yield range

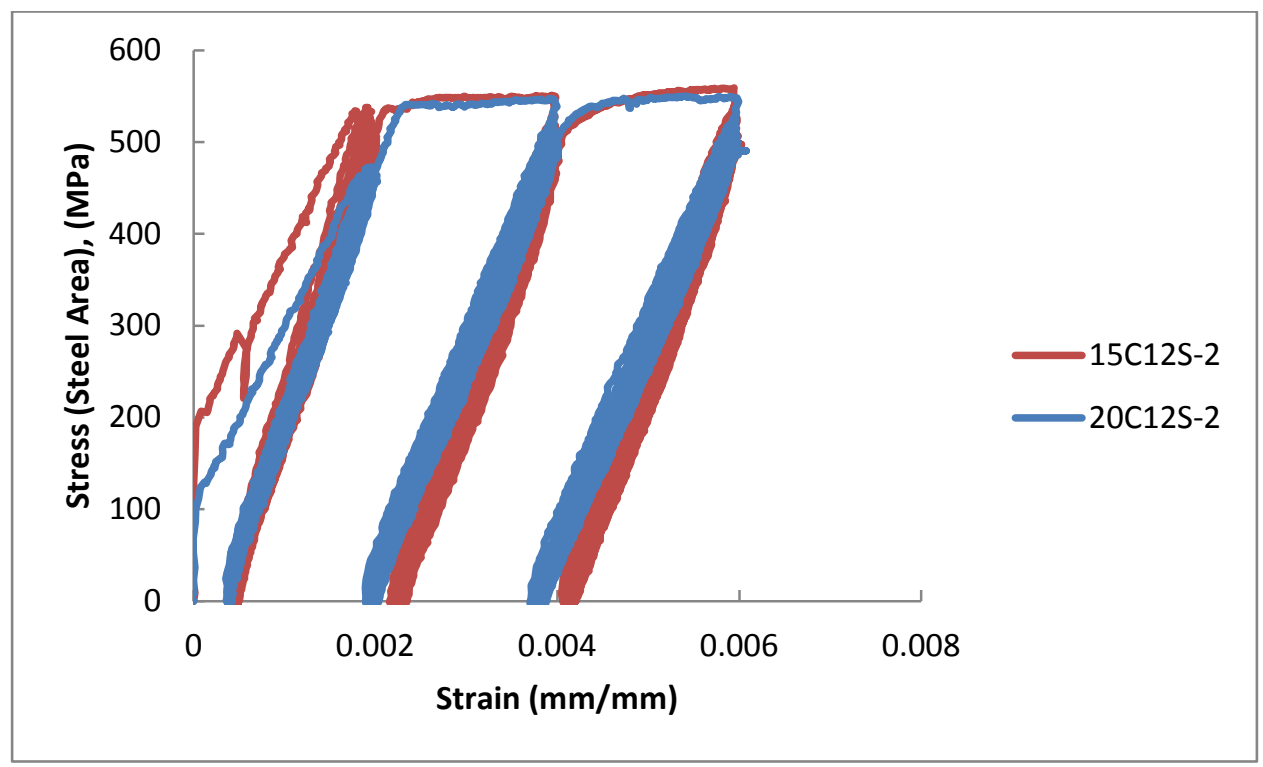

Figure 5-50: Stress strain response for specimens with 1.2\% ZP305 fibres under cyclic load in the post-yield range 
It can be seen that the effect of reinforcement ratio becomes more and more negligible when evaluating the stress strain response of the specimens in the post-yield range. The specimens with the lower reinforcement ratios show a slightly better performance, however, the rate at which the stiffness decreases in independent of the reinforcement ratio (see Figure 5-51).

Table 5-28: Summary of performance of specimens with different reinforcement ratios under cyclic loads in the post-yield range

\begin{tabular}{|c|c|c|c|c|c|c|c|}
\hline \multirow{3}{*}{ Specimen } & \multirow{3}{*}{$\begin{array}{c}\text { Fibre } \\
\text { Content } \\
\text { ZP305 } \\
(\%)\end{array}$} & \multicolumn{3}{|c|}{ Stress (MPa) at Strain of: } & \multirow{2}{*}{\multicolumn{3}{|c|}{$\begin{array}{c}\text { Average Modulus on Final Reload from } \\
\text { strain of: } \\
\text { (GPa) }\end{array}$}} \\
\hline & & \multirow{2}{*}{$0.20 \%$} & \multirow{2}{*}{$0.40 \%$} & \multirow{2}{*}{$0.60 \%$} & & & \\
\hline & & & & & $0 \%$ to $0.2 \%$ & $0 \%$ to $0.4 \%$ & $0 \%$ to $0.6 \%$ \\
\hline $15 \mathrm{CO0}-2$ & 0 & 387 & 398 & 400 & 247 & 215 & 199 \\
\hline 15C04S-2 & 0.4 & 430 & 442 & 451 & 279 & 257 & 244 \\
\hline $15 \mathrm{C08S}-2$ & 0.8 & 471 & 464 & 465 & 302 & 269 & 251 \\
\hline $15 C 12 S-2$ & 1.2 & 507 & 483 & 507 & 334 & 290 & 289 \\
\hline $20 \mathrm{COO}-2$ & 0 & 378 & 426 & 436 & 232 & 209 & 197 \\
\hline 20C04S-2 & 0.4 & 401 & 465 & 464 & 248 & 230 & 210 \\
\hline 20C08S-2 & 0.8 & 448 & 482 & 486 & 280 & 254 & 232 \\
\hline 20C12S-2 & 1.2 & 459 & 502 & 501 & 282 & 253 & 238 \\
\hline
\end{tabular}


Table 5-29: Stress levels before and after cycling at strain levels exceeding yield strain for $15 \mathrm{M}$ specimens

\begin{tabular}{|c|c|c|c|c|c|c|c|c|c|}
\hline \multicolumn{10}{|c|}{ CYCLIC LOADING (POST YIELDING) } \\
\hline & \multicolumn{3}{|c|}{ Strain } & \multicolumn{3}{|c|}{ Strain } & \multicolumn{3}{|c|}{$\begin{array}{l}\text { Percent drop in load } \\
\text { carrying capacity }(\%)\end{array}$} \\
\hline & $0.20 \%$ & $0.40 \%$ & $0.60 \%$ & $0.20 \%$ & $0.40 \%$ & $0.60 \%$ & $0.20 \%$ & $0.40 \%$ & $0.60 \%$ \\
\hline Specimen & \multicolumn{3}{|c|}{$\begin{array}{l}\text { Stress Before Cycling } \\
(\mathrm{MPa})\end{array}$} & \multicolumn{3}{|c|}{$\begin{array}{c}\text { Stress After Cycling } \\
\text { (MPa) }\end{array}$} & & & \\
\hline $15 \mathrm{C} 00-2$ & 407 & 412 & 425 & 387 & 398 & 401 & 4.9 & 3.4 & 5.6 \\
\hline $15 \mathrm{C} 04 \mathrm{~S}-2$ & 430 & 473 & 493 & 430 & 442 & 452 & 0 & 6.6 & 8.3 \\
\hline $15 \mathrm{C} 08 \mathrm{~S}-2$ & 481 & 500 & 511 & 472 & 464 & 466 & 1.9 & 7.2 & 8.8 \\
\hline $15 \mathrm{C} 12 \mathrm{~S}-2$ & 522 & 548 & 559 & 507 & 484 & 507 & 2.9 & 11.7 & 9.3 \\
\hline
\end{tabular}

Table 5-30: Stress levels before and after cycling at strain levels exceeding yield strain for 20M specimens

\begin{tabular}{|c|c|c|c|c|c|c|c|c|c|}
\hline \multicolumn{10}{|c|}{ CYCLIC LOADING (POST YIELDING) } \\
\hline & \multicolumn{3}{|c|}{ Strain } & \multicolumn{3}{|c|}{ Strain } & \multicolumn{3}{|c|}{$\begin{array}{l}\text { Percent drop in load } \\
\text { carrying capacity }(\%)\end{array}$} \\
\hline & $0.20 \%$ & $0.40 \%$ & $0.20 \%$ & $0.20 \%$ & $0.40 \%$ & $0.60 \%$ & $0.20 \%$ & $0.40 \%$ & $0.60 \%$ \\
\hline Specimen & \multicolumn{3}{|c|}{$\begin{array}{c}\text { Stress Before Cycling } \\
\text { (MPa) }\end{array}$} & \multicolumn{3}{|c|}{$\begin{array}{c}\text { Stress After Cycling } \\
\text { (MPa) }\end{array}$} & & & \\
\hline $20 \mathrm{C} 00-2$ & 394 & 452 & 457 & 378 & 426 & 436 & 4.1 & 5.7 & 4.6 \\
\hline 20C04S-2 & 402 & 499 & 495 & 401 & 465 & 464 & 0.2 & 6.8 & 6.3 \\
\hline $20 \mathrm{C} 08 \mathrm{~S}-2$ & 454 & 526 & 534 & 449 & 483 & 486 & 1.1 & 8.2 & 9.0 \\
\hline $20 \mathrm{C} 12 \mathrm{~S}-2$ & 463 & 539 & 548 & 459 & 502 & 501 & 0.9 & 6.8 & 8.6 \\
\hline
\end{tabular}




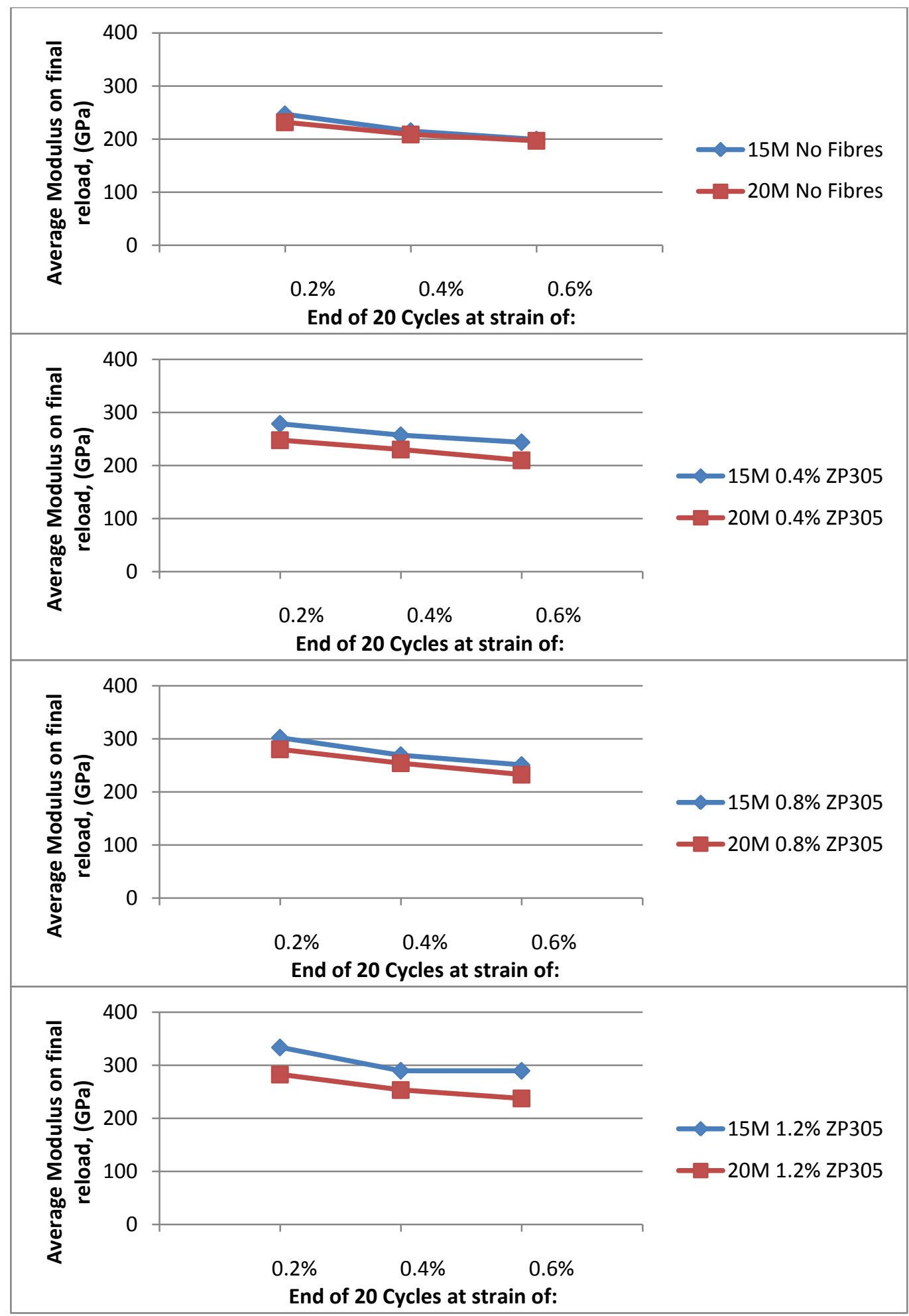

Figure 5-51: Average modulus on final reload vs. strain subjected cyclically in the post-yield range 


\subsubsection{Crack Width and Crack Spacing}

When subjected to the same stress conditions and loading history, the reinforcement ratio has very little effect on the crack widths at low levels of load. Tables 5-31 and 5-32 show that the specimens with lower reinforcement ratios (15M bars) have similar average crack widths to the matching specimens with higher reinforcement ratios (20M bars). The most noticeable difference is in the specimens with a higher volume of steel fibres, where the $20 \mathrm{M}$ specimens show up to 20\% higher crack widths for the same level of stress. Figures 5-52 and 5-53 show graphically the data tabulated in Tables 5-31 and 5-32. From the gathered data, we can conclude that the reinforcement ratio does not have a significant effect on the crack widths of specimens tested cyclically at service level loads.

Table 5-31: Average and maximum crack widths of 15M after cyclic loading in the service load range

\begin{tabular}{|c|c|c|c|c|c|c|}
\hline \multicolumn{7}{|c|}{ CYCLIC LOADING (PRIOR TO YIELDING) } \\
\hline & \multicolumn{3}{|c|}{$\begin{array}{c}\text { Stress (Steel Area), } \\
\text { (MPa) }\end{array}$} & \multicolumn{3}{|c|}{ Stress (Steel Area), (MPa) } \\
\hline & 180 & 240 & 360 & 180 & 240 & 360 \\
\hline Specimen & \multicolumn{3}{|c|}{$\begin{array}{c}\text { Average Crack Width } \\
(\mathrm{mm})\end{array}$} & \multicolumn{3}{|c|}{$\begin{array}{c}\text { Maximum Crack Width } \\
(\mathrm{mm})\end{array}$} \\
\hline $15 \mathrm{C} 00-1$ & 0.14 & 0.22 & 0.30 & 0.28 & 0.46 & 0.70 \\
\hline $15 \mathrm{C} 04 \mathrm{~S}-1$ & 0.13 & 0.21 & 0.29 & 0.20 & 0.34 & 0.56 \\
\hline $15 \mathrm{C} 08 \mathrm{~S}-1$ & 0.11 & 0.17 & 0.27 & 0.14 & 0.28 & 0.56 \\
\hline $15 \mathrm{C} 12 \mathrm{~S}-1$ & 0.09 & 0.12 & 0.27 & 0.12 & 0.24 & 0.54 \\
\hline
\end{tabular}

Table 5-32: Average and maximum crack widths of 20M after cyclic loading in the service load range

\begin{tabular}{|c|c|c|c|c|c|c|}
\hline \multirow{3}{*}{} & \multicolumn{3}{|c|}{$\begin{array}{c}\text { Stress (Steel Area), } \\
\text { (MPa) }\end{array}$} & \multicolumn{3}{c|}{ Stress (Steel Area), (MPa) } \\
\cline { 2 - 7 } & $\mathbf{1 8 0}$ & $\mathbf{2 4 0}$ & $\mathbf{3 6 0}$ & $\mathbf{1 8 0}$ & $\mathbf{2 4 0}$ & $\mathbf{3 6 0}$ \\
\hline \multirow{3}{*}{ Specimen } & \multicolumn{3}{|c|}{ Average Crack Width (mm) } & \multicolumn{3}{|c|}{ Maximum Crack Width } \\
& $(\mathrm{mm})$ \\
\hline $20 \mathrm{C} 00-1$ & 0.16 & 0.21 & 0.29 & 0.3 & 0.36 & 0.46 \\
\hline $20 \mathrm{C} 04 \mathrm{~S}-1$ & 0.17 & 0.21 & 0.29 & 0.28 & 0.36 & 0.50 \\
\hline $20 \mathrm{C} 08 \mathrm{~S}-1$ & 0.09 & 0.2 & 0.28 & 0.18 & 0.32 & 0.64 \\
\hline $20 \mathrm{C} 12 \mathrm{~S}-1$ & 0.11 & 0.22 & 0.33 & 0.16 & 0.28 & 0.48 \\
\hline
\end{tabular}



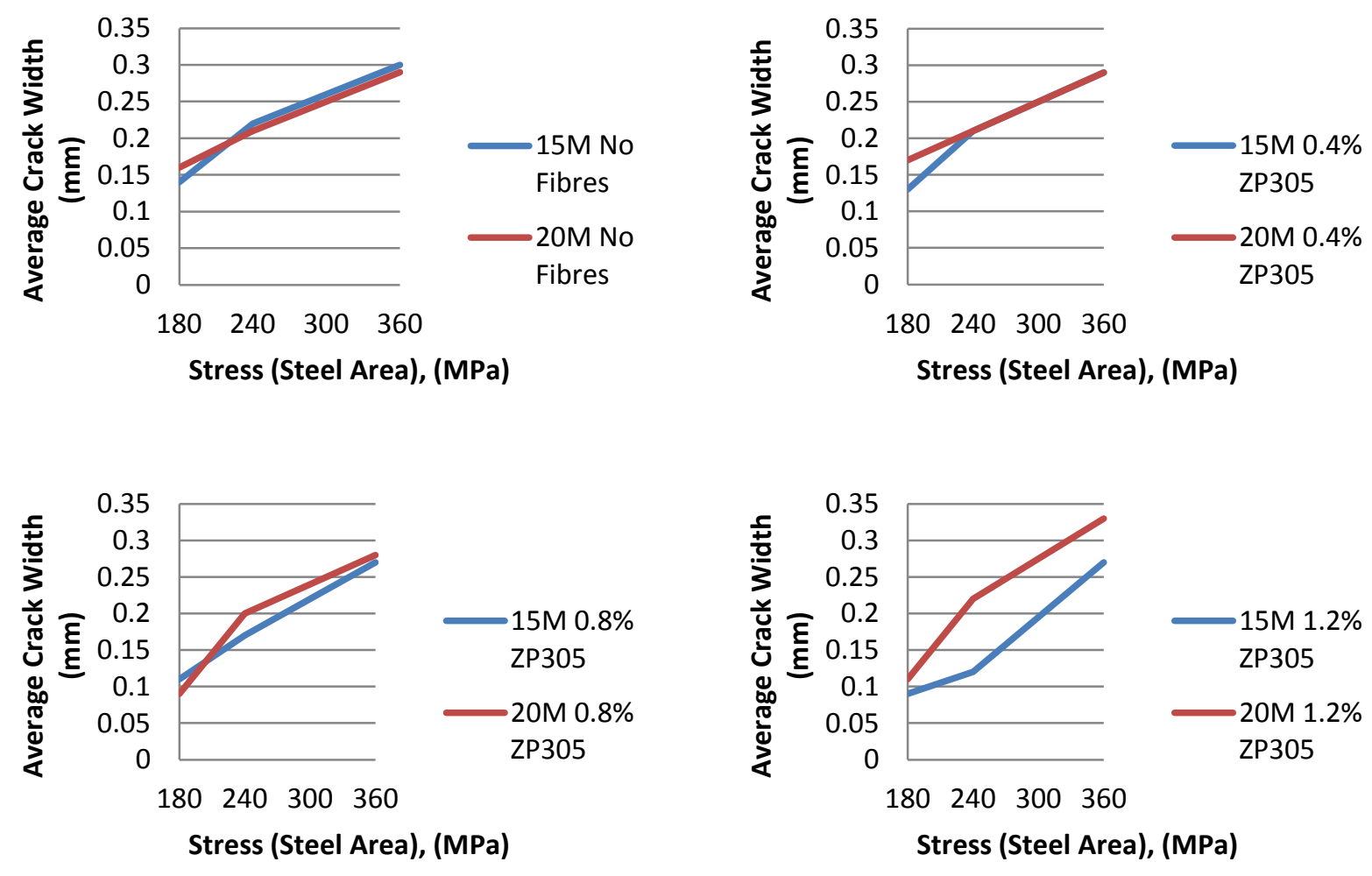

Figure 5-52: Average crack width after cycling vs. steel stress for $15 \mathrm{M}$ and $20 \mathrm{M}$ specimens 

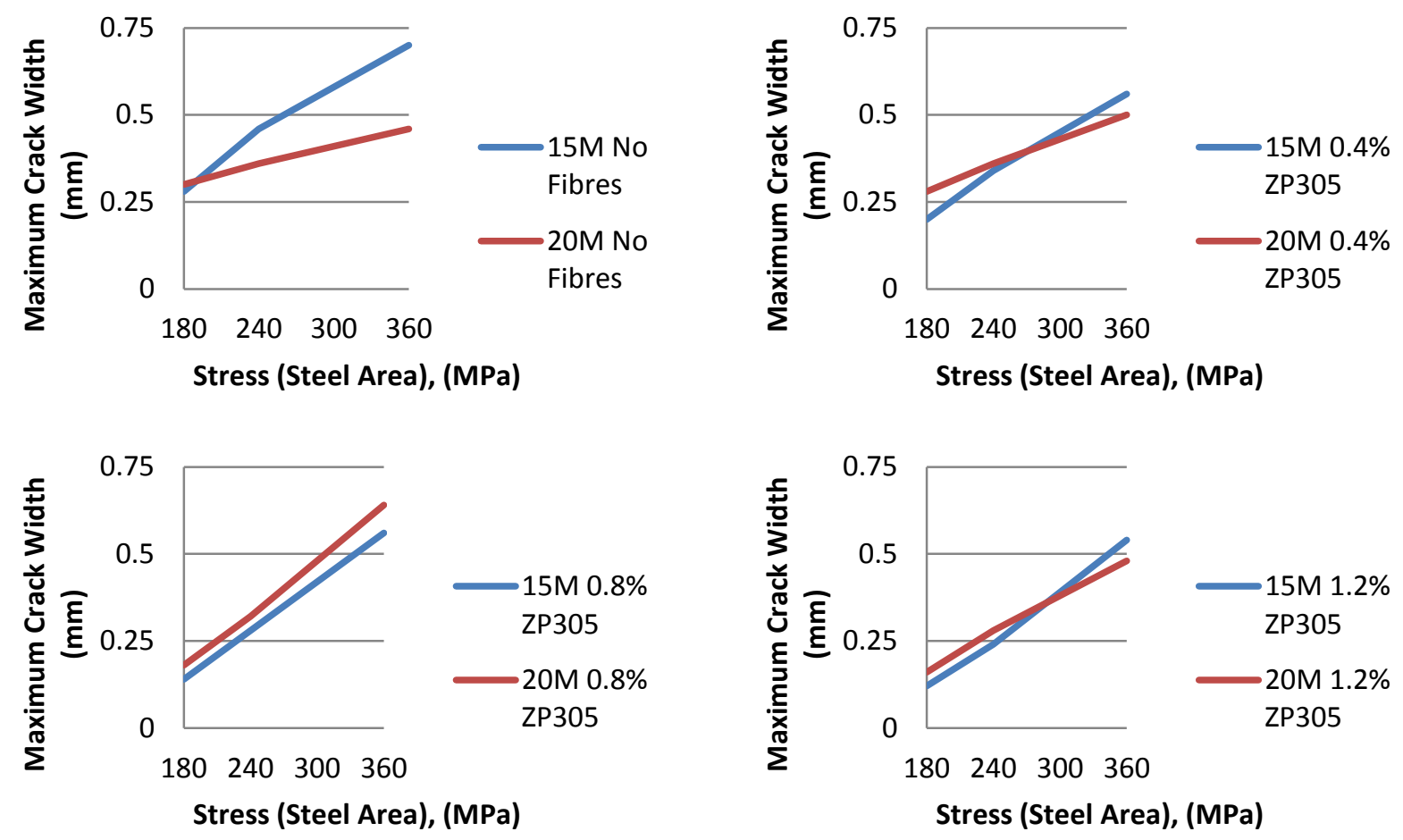

Figure 5-53: Maximum crack width after cycling vs. steel stress for $15 \mathrm{M}$ and 20M specimens 
Table 5-33: Cracking pattern after cycling at 240MPa (0.6Fy)

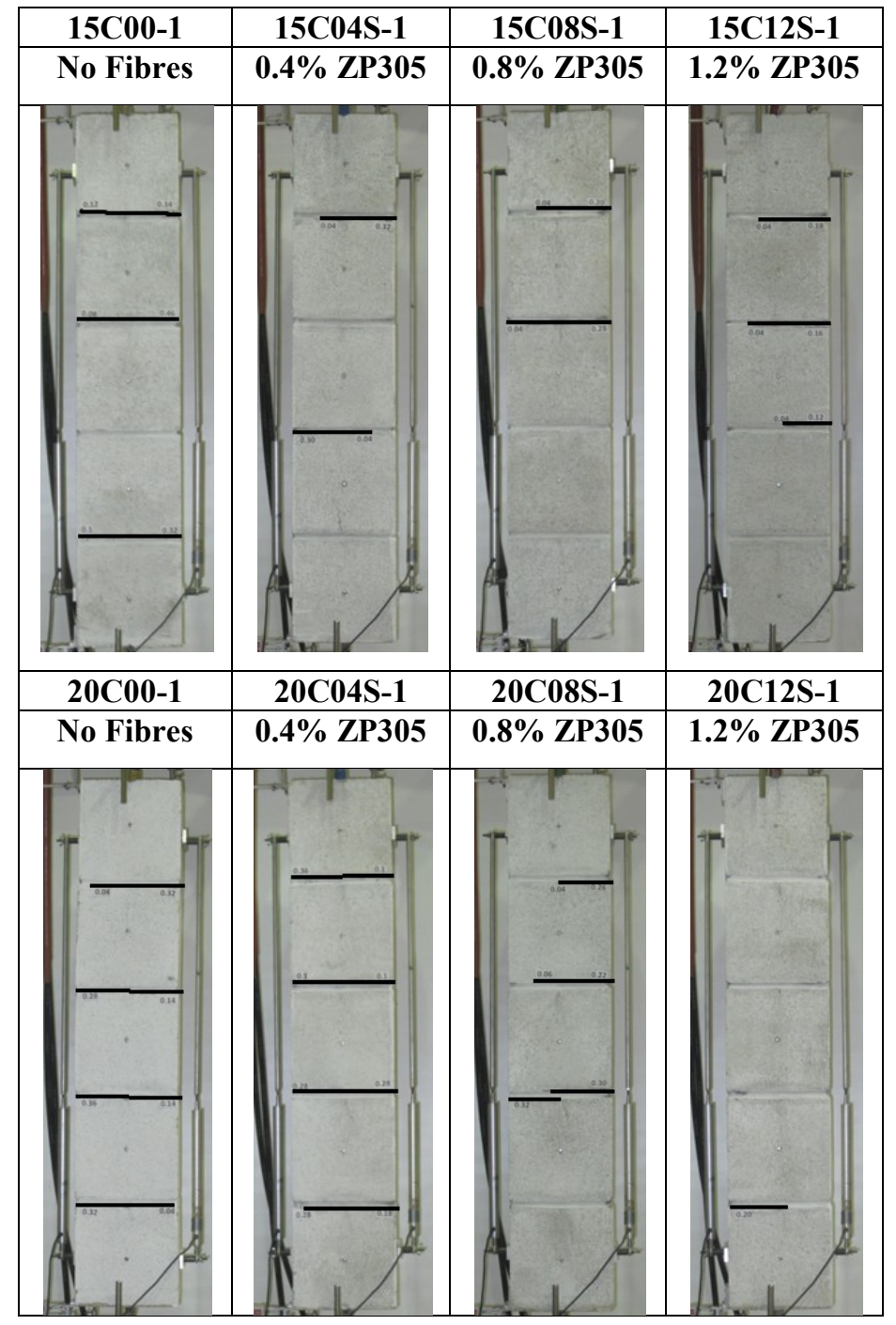

The cyclic response after yield was analyzed in a different way. The loading was under displacement control such that the load was cycled to a specimen stain of $0.2 \%, 0.4 \%$ and $0.6 \%$. Since the loads were considerably different depending on the fibre content of the specimen, comparing crack widths was not appropriate. Instead, the drop in load carrying capacity was measured as a function of overall specimen strain. This is discussed in the previous section discussing the stress strain response. The cracking pattern at a strain of $0.6 \%$ after 20 cycles to zero load is shown in Table 5-34. 
Table 5-34: Cracking pattern after cycling at a strain of $0.6 \%$

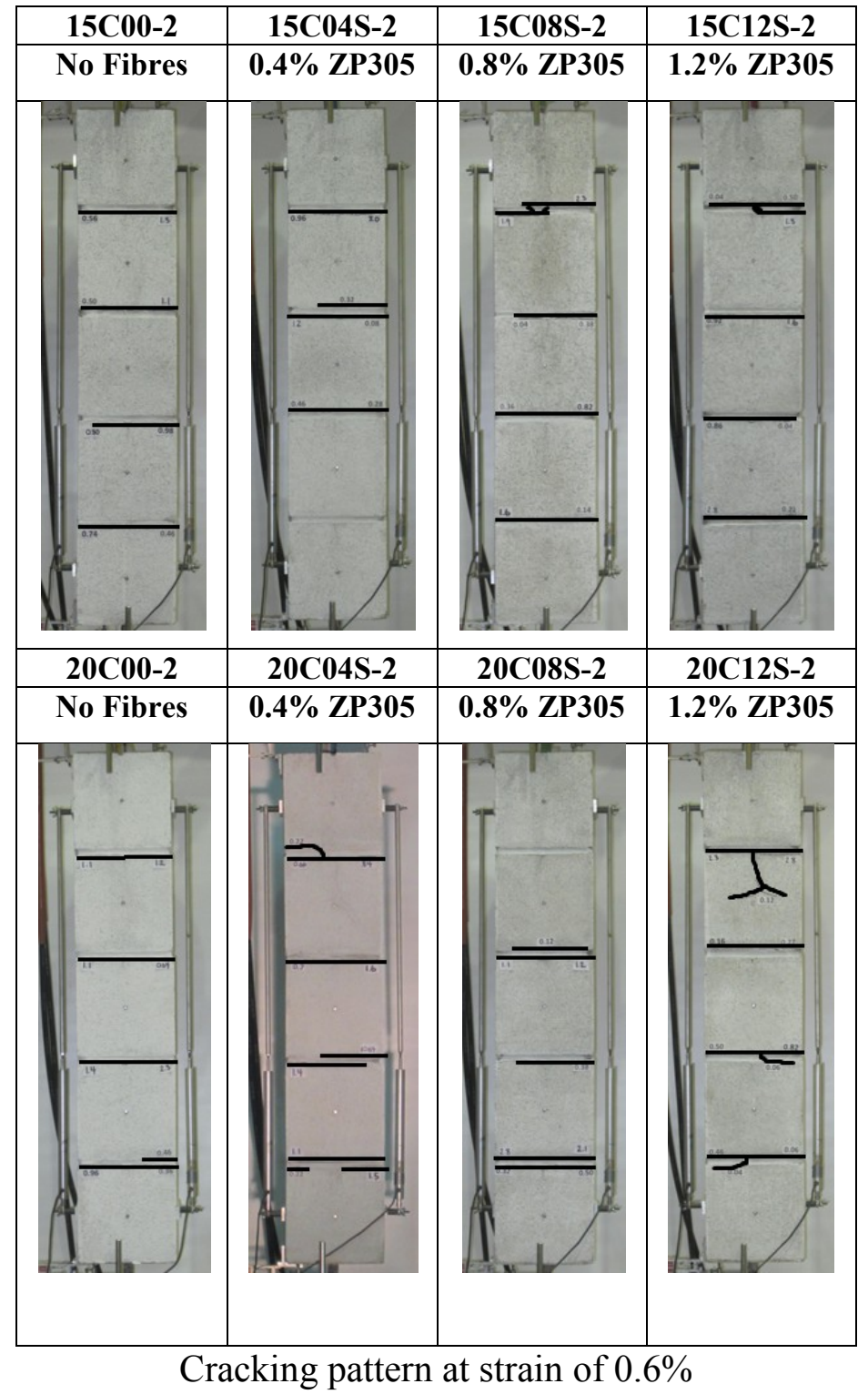




\subsection{Proposed Tension Stiffening Relationship for Steel Fibre Reinforced Concrete Masonry}

In design, the stress in the reinforced masonry material is assumed to rapidly decrease to zero whenever the masonry cracks however it can be proven that this is not the case. Furthermore, with the use of steel fibres in the grout surrounding the primary reinforcement the post-cracking contribution of the cracked masonry can be significantly enhanced. This section proposes a tension stiffening relationship for both reinforced concrete masonry and fibre reinforced concrete masonry.

By normalizing the stress in the cracked masonry with the stress in the masonry at cracking, a relationship can be developed which predicts the residual stress in the cracked masonry as a function of average strain in the member. The proposed relationships are based on fitting a curve to the experimental data. For the case of normal grout a parabolic curve was fitted to the data and for the fibre reinforced masonry a modified tension stiffening equation based on Collin Modified Compression Field Theory was proposed (Vecchio and Collins (1986)). Ideally the tension stiffening equation should be derived to reflect the contribution of the fibre crossing the cracks however the proposed tension stiffening equations provide a good estimate of the cracked fibre reinforced masonry up to strains of 0.005 . It should be noted that the proposed tension stiffening equations are only valid for ZP305 fibres as these are the only fibres for which the tension stiffening equations could be experimentally validated.

The tendency for the stress in the masonry to apparently increase at strains exceeding the yield strain of the main reinforcement is due to the fact that after the steel yields and the cracks begin to open, the steel fibers begin to add increased tensile capacity.

\subsubsection{Sample Calculations}

Sample calculations were done on specimens with different $15 \mathrm{M}$ bars and different fibre contents in order to find a suitable equation which would accurately represent the decay of the cracked masonry contribution to the tensile response as a function of the fibre content. Figures 5-54 to 5-57 show the results of all monotonic tests performed on standard units for each grout type along with the proposed tension stiffening equation for the respective grout type. 
Table 5-35: Sample tension stiffening calculations for 15M specimens (no fibres)

\begin{tabular}{|c|c|c|c|c|c|c|}
\hline \multicolumn{7}{|c|}{ 15M Bar, No Fibres } \\
$\begin{array}{c}\text { Average } \\
\text { Strain }\end{array}$ & $\begin{array}{c}\text { Total } \\
\text { Force } \\
(\mathbf{k N})\end{array}$ & $\begin{array}{c}\text { Force } \\
\text { in } \\
\text { Steel } \\
(\mathbf{k N}) \\
\text { fsAs }\end{array}$ & $\begin{array}{c}\text { Force in } \\
\text { Masonry } \\
(\mathbf{k N}) \\
\text { Ft-Fs }\end{array}$ & $\begin{array}{c}\text { Stress } \\
\text { in } \\
\text { Steel } \\
(\mathbf{M P a}) \\
\mathbf{\text { ssEs }}\end{array}$ & $\begin{array}{c}\text { Stress in } \\
\text { Masonry } \\
(\mathbf{M P a})\end{array}$ & $\boldsymbol{f}_{\boldsymbol{m}} / \boldsymbol{f}_{\boldsymbol{c r}}$ \\
\hline 0.000026 & 36.9 & 0.962 & 35.938 & 4.81 & 0.99551247 & 1 \\
\hline 0.001 & 52.1 & 37 & 15.1 & 185 & 0.41828255 & 0.42017 \\
\hline 0.002 & 79.6 & 74 & 5.6 & 370 & 0.15512465 & 0.15582 \\
\hline 0.003 & 81.0 & 81.8 & 0 & 409 & 0 & 0 \\
\hline 0.004 & 82.2 & 81.8 & 0.4 & 409 & 0.01108033 & 0.01113 \\
\hline 0.005 & 83.4 & 81.8 & 1.6 & 409 & 0.04432133 & 0.04452 \\
\hline
\end{tabular}

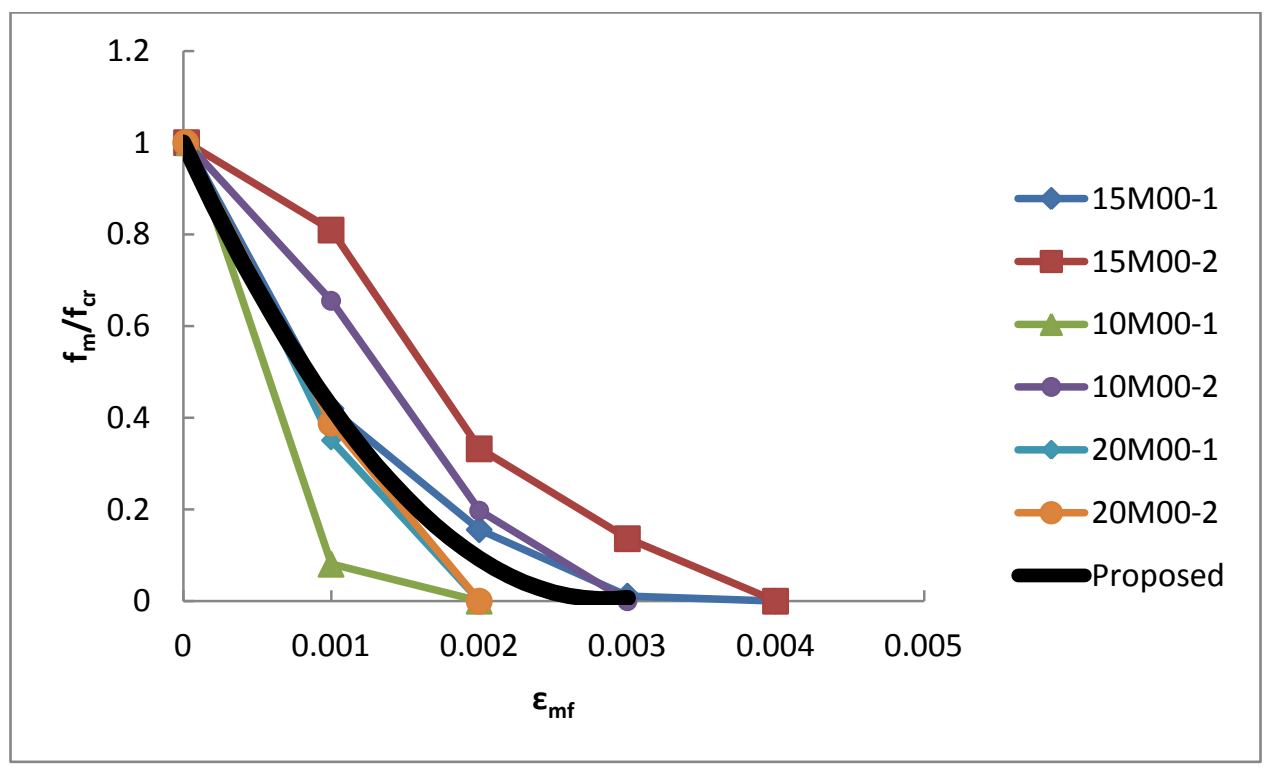

Figure 5-54: Proposed tension stiffening equation for reinforced masonry (no fibres) 
Table 5-36: Sample tension stiffening calculations for $15 \mathrm{M}$ specimens $(0.4 \% \mathrm{ZP305})$

\begin{tabular}{|c|c|c|c|c|c|c|}
\hline \multicolumn{7}{|c|}{ 15M Bar, 0.4\% ZP305 Fibres } \\
\hline $\begin{array}{c}\text { Average } \\
\text { Strain }\end{array}$ & $\begin{array}{c}\text { Total } \\
\text { Force } \\
(\mathbf{k N})\end{array}$ & $\begin{array}{l}\text { Force } \\
\text { in } \\
\text { Steel } \\
(\mathbf{k N}) \\
\text { fsAs } \\
\end{array}$ & $\begin{array}{c}\text { Force in } \\
\text { Masonry } \\
(\mathbf{k N}) \\
\text { Ft-Fs } \\
\end{array}$ & $\begin{array}{c}\text { Stress } \\
\text { in } \\
\text { Steel } \\
(\mathrm{MPa}) \\
\text { EsEs } \\
\end{array}$ & $\begin{array}{c}\text { Stress in } \\
\text { Masonry } \\
(\mathbf{M P a}) \\
\text { Fm/Am } \\
\end{array}$ & $f_{m} / f_{c r}$ \\
\hline 0.000018 & 32.0 & 0.648 & 31.4 & 3.24 & 0.86847645 & 1 \\
\hline 0.001 & 55.2 & 36 & 19.2 & 180 & 0.53185596 & 0.61240112 \\
\hline 0.002 & 91.7 & 72 & 19.7 & 360 & 0.54570637 & 0.62834907 \\
\hline 0.003 & 93.2 & 81.8 & 11.4 & 409 & 0.31578947 & 0.36361317 \\
\hline 0.004 & 94.9 & 81.8 & 13.1 & 409 & 0.36288089 & 0.41783618 \\
\hline 0.005 & 95.2 & 81.8 & 13.4 & 409 & 0.37119114 & 0.42740495 \\
\hline
\end{tabular}

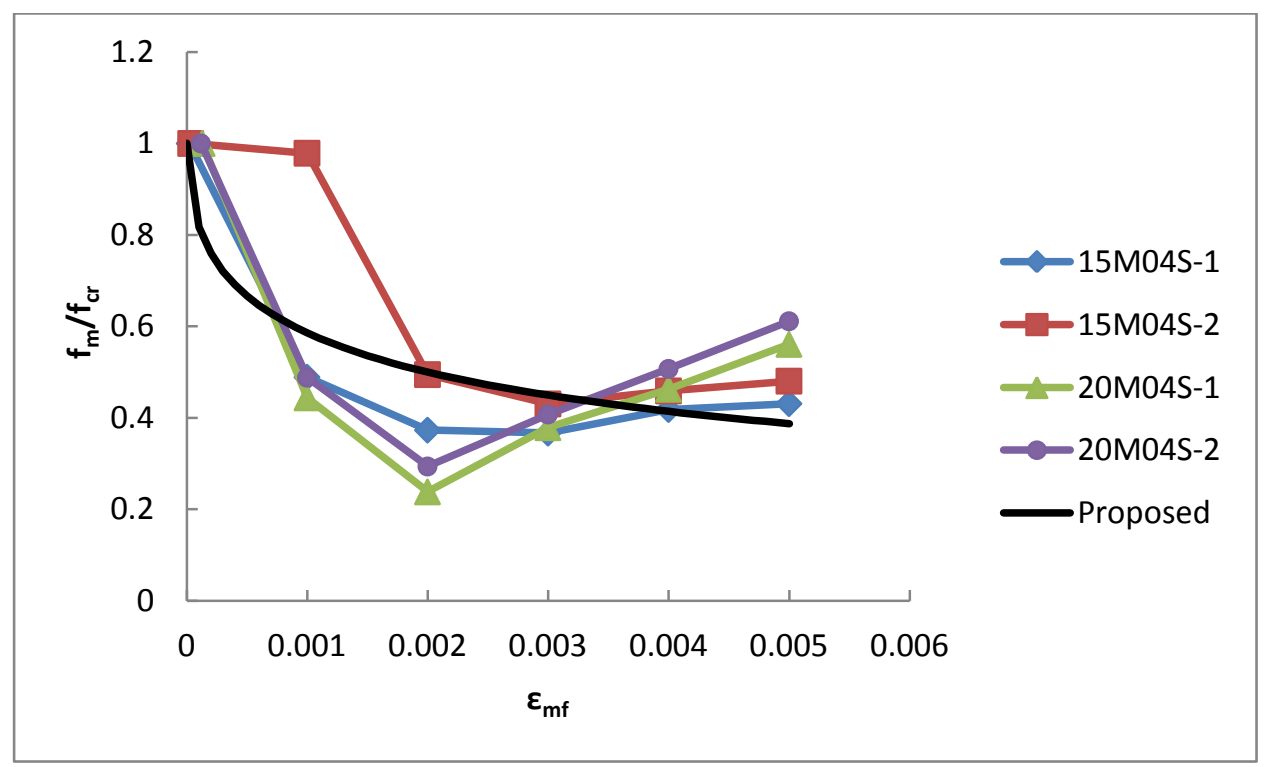

Figure 5-55: Proposed tension stiffening equation for reinforced masonry (0.4\% ZP305) 
Table 5-37: Sample tension stiffening calculations for $15 \mathrm{M}$ specimens $(0.8 \%$ ZP305)

\begin{tabular}{|c|c|c|c|c|c|c|}
\hline \multicolumn{7}{|c|}{ 15M Bar, 0.8\% ZP305 Fibres } \\
\hline $\begin{array}{c}\text { Average } \\
\text { Strain }\end{array}$ & $\begin{array}{c}\text { Total } \\
\text { Force } \\
(\mathbf{k N})\end{array}$ & $\begin{array}{l}\text { Force } \\
\text { in } \\
\text { Steel } \\
(\mathbf{k N}) \\
\text { fsAs }\end{array}$ & $\begin{array}{c}\text { Force in } \\
\text { Masonry } \\
(\mathbf{k N}) \\
\text { Ft-Fs }\end{array}$ & $\begin{array}{c}\text { Stress } \\
\text { in } \\
\text { Steel } \\
(\mathrm{MPa}) \\
\text { EsEs }\end{array}$ & $\begin{array}{c}\text { Stress in } \\
\text { Masonry } \\
\text { (MPa) } \\
\text { Fm/Am }\end{array}$ & $f_{m} / f_{c r}$ \\
\hline 0.000136 & 37.0 & 4.896 & 32.1 & 24.48 & 0.88931 & 1 \\
\hline 0.001 & 68.8 & 36 & 32.8 & 180 & 0.90859 & 1.02168 \\
\hline 0.002 & 103.0 & 72 & 31.0 & 360 & 0.85873 & 0.96561 \\
\hline 0.003 & 102.7 & 81.8 & 20.9 & 409 & 0.57895 & 0.65101 \\
\hline 0.004 & 104.6 & 81.8 & 22.8 & 409 & 0.63158 & 0.71019 \\
\hline 0.005 & 103.9 & 81.8 & 22.1 & 409 & 0.61219 & 0.68839 \\
\hline
\end{tabular}

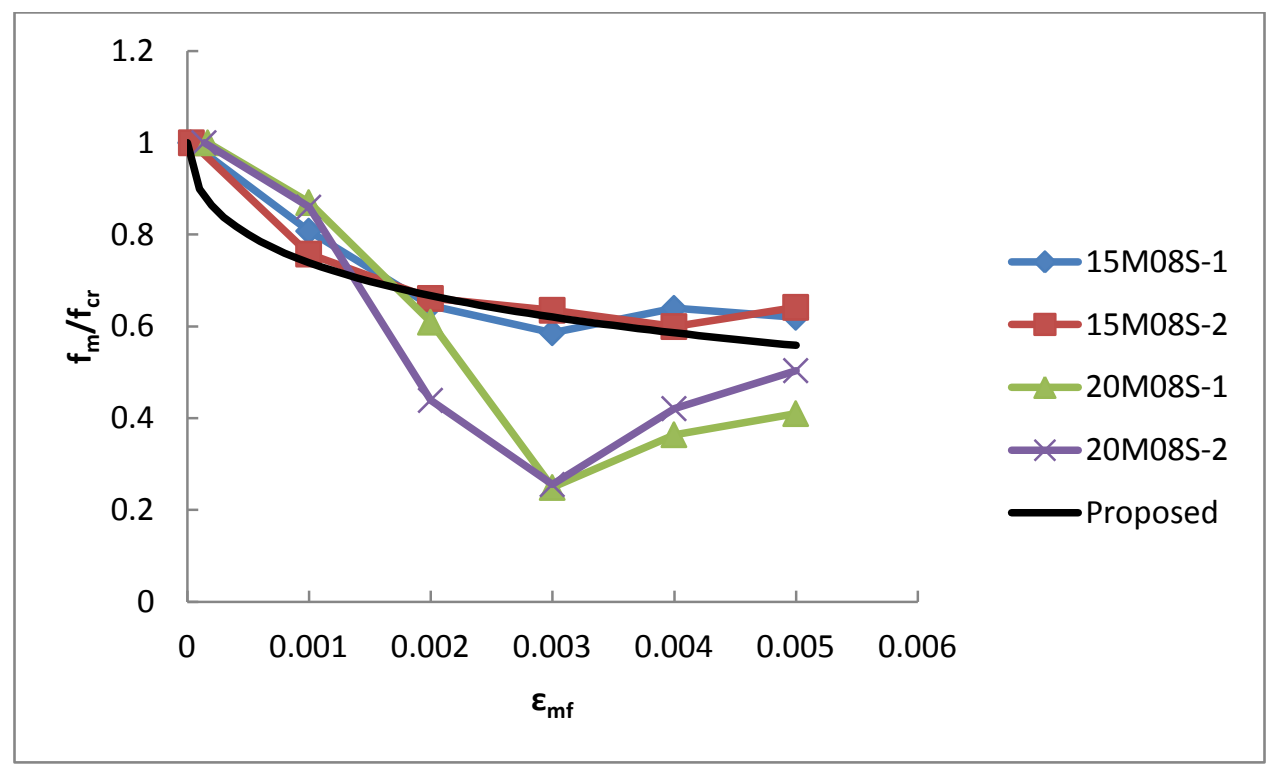

Figure 5-56: Proposed tension stiffening equation for reinforced masonry $(0.8 \% \mathrm{ZP305})$ 
Table 5-38: Sample tension stiffening calculations for $15 \mathrm{M}$ specimens (1.2\% ZP305)

\begin{tabular}{|c|c|c|c|c|c|c|}
\hline \multicolumn{7}{|c|}{ 15M Bar, 1.2\% ZP305 Fibres } \\
\hline $\begin{array}{c}\text { Average } \\
\text { Strain }\end{array}$ & $\begin{array}{c}\text { Total } \\
\text { Force } \\
(\mathbf{k N})\end{array}$ & $\begin{array}{l}\text { Force } \\
\text { in } \\
\text { Steel } \\
(\mathbf{k N}) \\
\text { fsAs }\end{array}$ & $\begin{array}{c}\text { Force in } \\
\text { Masonry } \\
(\mathbf{k N}) \\
\text { Ft-Fs }\end{array}$ & $\begin{array}{c}\text { Stress } \\
\text { in } \\
\text { Steel } \\
(\mathrm{MPa}) \\
\text { EsEs }\end{array}$ & $\begin{array}{c}\text { Stress in } \\
\text { Masonry } \\
\text { (MPa) } \\
\text { Fm/Am }\end{array}$ & $f_{m} / f_{c r}$ \\
\hline 0.000068 & 36.1 & 2.448 & 33.7 & 12.24 & 0.93219 & 1 \\
\hline 0.001 & 68.2 & 36 & 32.2 & 180 & 0.89197 & 0.95685 \\
\hline 0.002 & 102.7 & 72 & 30.7 & 360 & 0.85042 & 0.91228 \\
\hline 0.003 & 103.4 & 81.8 & 21.6 & 409 & 0.59834 & 0.64186 \\
\hline 0.004 & 104.5 & 81.8 & 22.7 & 409 & 0.62881 & 0.67455 \\
\hline 0.005 & 105.9 & 81.8 & 24.1 & 409 & 0.66759 & 0.71615 \\
\hline
\end{tabular}

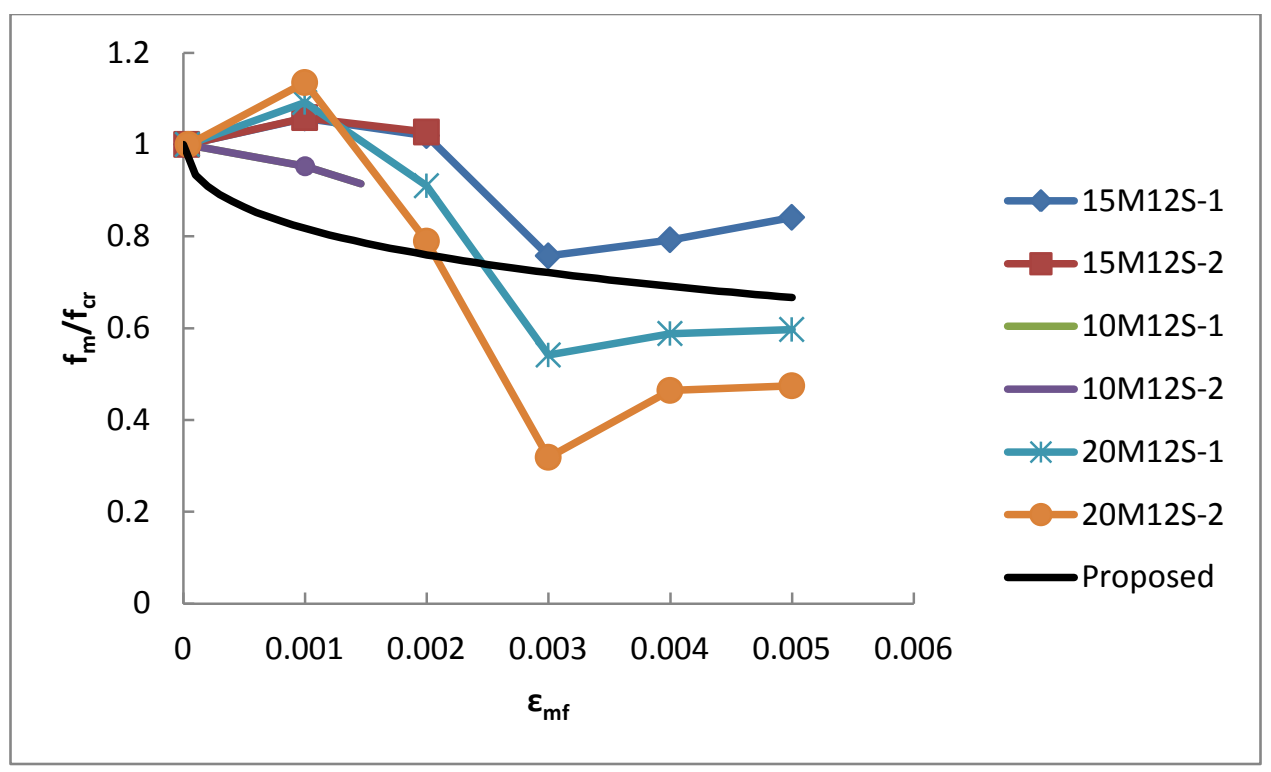

Figure 5-57: Proposed tension stiffening equation for reinforced masonry (1.2\% ZP305) 
Table 5-39 shows the proposed tension stiffening equations for reinforced concrete masonry with and without fibre reinforced grout. For masonry without fibre reinforced grout a parabolic relationship was found to be the best fit for the data. For masonry with fibre reinforced grout, a modified version of Collin's tension stiffening relationship for reinforced concrete was proposed. The relationships proposed are for standard deformed reinforcing bars and represent the stress in the masonry as a function of the strain in the masonry due to stress.

Table 5-39: Summary of proposed tension stiffening equations for reinforced masonry with or without steel fibres

\begin{tabular}{|c|c|}
\hline Grout Type & Tension Stiffening Equation \\
\hline No Fibres & $\frac{f_{m}}{f_{c r}}=123000\left(\varepsilon_{m f}\right)^{2}-700\left(\varepsilon_{m f}\right)+1$ \\
\hline $0.4 \%$ ZP305 & $f_{m}=\frac{f_{c r}}{1+\sqrt{\left(80\left(\frac{1}{V_{f}}\right)^{2}\right) \varepsilon_{m f}}}$ \\
\hline $0.8 \%$ ZP305 & $f_{m}=\frac{f_{c r}}{1+\sqrt{\left(80\left(\frac{1}{V_{f}}\right)^{2}\right) \varepsilon_{m f}}}$ \\
\hline $1.2 \%$ ZP305 & $f_{m}=\frac{f_{c r}}{1+\sqrt{\left(80\left(\frac{1}{V_{f}}\right)^{2}\right) \varepsilon_{m f}}}$ \\
\hline $\begin{array}{l}\text { Where } \\
V_{f}=\text { fibre volume fraction }(\%) \text { of } \mathrm{D} \\
E_{m f}=\text { average strain in the masonry } \\
f_{c r}=\text { cracking stress of the masonry } \\
f_{m}=\text { stress in the masonry }\end{array}$ & teel fibres \\
\hline
\end{tabular}




\section{Conclusions and Recommendations}

The conclusions and recommendations are based on the series of experimental tests described in this thesis. This thesis described a detailed investigation of the performance of steel fibre reinforced concrete masonry in direct tension and included variables such as: fibre content, fibre type, reinforcement ratio, unit type. In addition to varying the constituent materials, the effects of cyclic loading at both service load and post-yield load levels were investigated. Concluding remarks on the experimental program as well as recommendations for further research are provided in this section.

\subsection{Concluding Remarks}

A series of forty two specimens with identical overall geometry and differing constituent materials was tested under monotonic and cyclic load. The conclusions drawn from the experimental program are summarized below:

- Steel fibres can successfully be used to enhance the post-cracking performance of reinforced concrete masonry.

- Workability of grout is reduced with the incorporation of steel fibres; however at dosages up to $1.2 \%$ and with the use of chemical admixtures, $30 \mathrm{~mm}$ hooked end steel fibres were successfully used to grout hollow masonry assemblies in $990 \mathrm{~mm}$ lifts. Difficulties were encountered in adequately consolidating grout made with $60 \mathrm{~mm}$ fibers, hence these fibers should not be used for masonry construction.

- An optimal fibre content for future research in fibre reinforced masonry would be $0.8 \%$ by volume. At this fibre content, there were no workability issues and the strength was still significantly enhanced.

- The effect of fibres on tension stiffening was more pronounced for low reinforcement ratios. Increased performance was noted in specimens with $10 \mathrm{M}$ and $15 \mathrm{M}$ reinforcement when compared to similar specimens containing 20M reinforcement. 
- Steel fibre reinforced grout decreased the average and maximum crack widths in the specimens tested under monotonic load relative to specimens with normal grout. Also, the crack spacing was decreased with the addition of steel fibres to the grout.

- The incorporation of steel fibres increased the compressive strength of the grout.

- Fibre content had a significant influence on the tension stiffening behaviour. The response of specimens containing grout with no fibres approached the bare bar response at low levels of strain whereas the specimens with fibre reinforced grout showed significant tension stiffening when compared to the bare bar response.

- The benefits of adding fibers had a diminishing rate of returns. Specimens with $0.4 \%$ steel fibres showed significant increased performance when compared to specimens with no fibres; however as fibre content is increased, the added benefit from an increase in fibre content tended to decrease.

- The specimens tested with $1.2 \% 60 \mathrm{~mm}$ fibres exhibited less tension stiffening than the specimens with $1.2 \% 30 \mathrm{~mm}$ fibres. It cannot be concluded whether this was due to workability issues with the $60 \mathrm{~mm}$ fibre grout mix or whether the increased performance was due to the larger number of $30 \mathrm{~mm}$ fibres creating a more dense fibre network.

- The lintel unit specimens showed increased toughness when compared to the standard unit specimens cast with the same grout. The cracking patterns were influenced by the number of mortar joint in the specimens.

- Steel fibre reinforced grout was successful at increasing the post-cracking performance of reinforced masonry tested under cyclic loads at service load levels as well as at post-yield load levels. Increased stiffness was maintained in the specimens with steel fibre reinforced grout after cycling at service loads when compared to the specimens with normal grout exposed to the same cyclic loading regime.

- The majority of the added benefit from fibre reinforced grout on the stress strain response is maintained even after cycling at loads exceeding the yield strain of the reinforcing steel.

- Cyclic loading did not have a significant effect on crack widths.

- Specimens with lower reinforcement ratios showed a more rapid loss of stiffness when loads were cycled at service load levels, but showed very little difference when cycled in the post-yield range. 
The results of this study have shown that fiber-reinforced grout is a promising new material that can be used to enhance the structural performance of reinforced masonry construction. It may be possible to reduce rebar requirements with the use of such grout, thereby enhancing the constructability, and hence economic competitiveness, of reinforced masonry. Furthermore, ductility could be enhanced considerably through the use of fiber-reinforced grout, resulting in enhanced seismic performance with the potential to increase seismic force reduction factors for reinforced masonry. Lastly, crack widths and deflections can be reduced through the use of fiber-reinforced grout.

\subsection{Recommendations for further research}

Due to the complex nature of reinforced concrete masonry a larger number of tests should be conducted in the area of tension stiffening. A large number of variables were tested within this experimental program; however there are still more variables that must be investigated. Listed as follows are a number of recommendations for future research.

- Create an analytical model which accounts for the tension stiffening effect in reinforced concrete masonry both with and without fibre reinforcement.

- Compare the experimental work conducted with a Finite Element Model to assure its reliability.

- Conduct larger scale tests on fibre reinforced concrete masonry.

- Investigate the effect of grout with different fibre types on the post-cracking behaviour of reinforced concrete masonry.

- Conduct tests on masonry shear walls reinforced with steel fibre reinforced grout to investigate the performance under reversed cyclic shear loads.

- Investigate the influence of steel fibres on plastic and drying shrinkage of reinforced concrete masonry.

- Perform flexural toughness testing on fibre reinforced masonry prisms.

- Investigate the ductility characteristics of fibre reinforced masonry for potential applications in seismic resistant design. 
- Conduct field trials to investigate effects on pumping of fibre reinforced grout mixes with different fibre contents.

- Perform a feasibility study to compare the cost of fibre reinforced grout with traditional reinforcement alternative.

This research provides an adequate amount of experimental testing to provide researchers with initial proof that steel fibre reinforced grout is beneficial to the increase in the tensile properties of reinforced concrete masonry. With further research conducted in this area, masonry can be further developed as an increasingly competitive material for structural designers to specify as an alternative to reinforced concrete. Although fibres may be initially more expensive than traditional reinforcement, cost savings can be achieved by reducing a mason's labour costs for placing traditional reinforcement. Also fibre reinforced grout could be investigated as possible seismic reinforcement for unreinforced masonry structures in Canada and well as in under-developed countries that have a high seismic risk and inherent vulnerability due to poorly built infrastructure. 


\section{References}

Abrishami, H. H., \& Mitchell, D. (1997). Influence of Steel Fibers on Tension Stiffening. ACI Structural Journal, 94(S70), 769-775.

ACI Committee 318 (2008). Building Code Requirements for Structural Concrete and Commentary. Detroit, MI.

ACI Committee 544. (2002). State-of-the-Art Report on Fiber Reinforced Concrete. American Concrete Institute.

Alwan, J., Naaman, A., \& Guerrero, P. (1999). Effect of Mechanical Clamping on the Pullout Response of Hooked Steel Fibers Embedded in Cementitious Matrices. Concrete Science and Engineering, 15-25.

Aoude, H. (2008). Structural Behaviour of Steel Fiber Reinforced Concrete Members. PhD Thesis. Montreal, Canada: Department of Civil Engineering and Applied Mechanics, McGill University.

ASTM International (2011). ASTM Standard A820 Standard Specification for Steel Fibers for Fiber-Reinforced Concrete. West Conshohocken, PA: ASTM International.

ASTM International. (2012). Standard Test Method for Compressive Strength of Masonry Prisms. ASTM Standard. West Conshohocken, PA, USA: ASTM.

ASTM International. (2012). Standard Test Method for Flexural Toughness of Fiber Reinforced Concrete (Using Centrally Loaded Round Panel). West Conshohocken, PA: ASTM International.

ASTM International. (2013). Standard Test Method for Flexural Toughness of Fiber Reinforced Concrete (Using Centrally Loaded Round Panel). West Conshohocken, PA, United States: ASTM International. Retrieved from ASTM.

Atkinson, R. H., \& Hammons, M. I. (1997). Tension Stiffening Behavior of Reinforced Masonry. ASCE Journal of Structural Engineering, 123(5), 597-603.

Atkinson, R., \& Hammons, M. (1997). Tension Stiffening Behavior of Reinforced Masonry. Journal of Structural Engineering, 597-603.

Banthia, N., \& Sappakittipakorn, M. (2007). Toughness Enhancement in Steel Fiber Reinforced Concrete through fibre Hybridization. Cement and Concrete Research, 13661372. 
Bayasi, Z., \& Downey, K. (1995). Steel fiber reinforced piles at Horse Mesa Dam. Concrete International, 32-38.

Baynit, R. (1990). Bond and development length in reinforced concrete block masonry. Master of Engineering Thesis. Ottawa, Ontario, Canada: Carleton University.

Bazant, Z., \& Oh, B. (1983). Crack Band Theory for Fracture of Concrete. Materials and Structures, Research and Testing, 16(93), 155-177.

Bischoff, P. H. (2001). Effects of shrinkage on tension stiffening and cracking in reinforced concrete. Canadian Journal of Civil Engineering, 28, 363-374.

Bischoff, P. H. (2003). Tension Stiffening and Cracking of Steel Fiber-Reinforced Concrete. ASCE Journal of Materials in Civil Engineering, 174-182.

Chao, S., Liao, W., Wongtanakitcharoen, T., \& Naaman, A. (2006). LARGE SCALE TENSILE TESTS OF HIGH PERFORMANCE FIBER REINFORCED CEMENT COMPOSITES. 1-9.

Cheema, T. (1981). Anchorage behavior and prism strength of grouted concrete masonry. PhD Dissertation. University of Texas at Austin.

Collins, M., \& Mitchell, D. (1997). Prestressed Concrete Structures. Toronto: Response Publications.

Comite Euro-International du Beton (CEB-FIP). (1993). CEB-FIP model code 1990. London: Thomas Telford.

CSA Committee A165.1 (2009). CSA Standard on Concrete Masonry Units. Missisauga, ON: Canadian Standards Assosiation.

CSA Committee A179, C. C. (2009). Mortar and Grout for Unit Masonry. Mississauga, ON: Canadian Standards Association.

CSA Committee S304.1 (2004). Design of Masonry Structures. Mississauga, ON: Canadian Standards Association.

Delhi. (2013). Retrieved from http://faculty.delhi.edu/hultendc/A220-Week2-LectureWeb.html

Deluce, J., \& Vecchio, F. (2013). Cracking of SFRC Members Containing Conventional Reinforcement. ACI Structural Journal, 481-490.

Drysdale, R. G., \& Hamid, A. A. (2005). Masonry Structures: Behaviour and Design. Missisauga, ON: Canada Masonry Design Centre. 
Fantilli, A. (2009). Multiple Cracking and Strain Hardening in Uniaxial Tension. Cement and Concrete Research, 39, 1217-1229.

Gerstle, W., \& Ingraffea, A. (1991). Does bond-slip exist? Concrete International, 44-48.

Gopalaratnam, V., \& Shah, S. (1985). Softening Response of Plain Concrete in Direct Tension. ACI Journal, 310-323.

Goto, Y. (1971). Cracks formed in concrete around deformed tension bars. ACI Journal, $68,244-251$.

Goto, Y. (1971). Cracks Formed in Concrete around Deformed Tension Bars. ACI Journal, 68(4), 224-251.

Gupta, A., \& Maestrini, S. (1990). Tension-stiffness model for reinforced concrete bars. ASCE Journal of Structural Engineering, 116(3), 769-790.

Hannant, D. (1978). Fiber Cements and Fiber Concretes. New York, USA: John Wiley \& Sons Ltd.

Johnson, C. D., \& Coleman, R. A. (1974). Strength and Deformation of Steel FIber Reinforced Mortar in Uniaxial Tension. Fiber Reinforced Concrete(SP-44), 177-207.

Johnson, C., \& Gray, R. (1978). Uniaxial Tension Testing of Steel Fibre Reinforced Cementitious Composites. International Symposium on Testing and Test Methods of Fiber-Cement Composites (pp. 451-461). Sheffield: RILEM.

Kützing, L. (2000). PhD Thesis. Trafahigkeitsermittlung stahlfaserverstarkter Betone. University of Leipzig, Stuttgart, Germany.

Larner, L., Speakman, K., \& Majumdar, A. (1976). Chemical Interactions between Glass Fibres and Cement. Journal of Non-Crystalline Solids, Vol 20, 43-74.

Lee, S.-C., Cho, J.-Y., \& Vecchio, F. J. (2013). Tension-Stiffening Model for Steel FibreReinforced Concrete Containing Conventional Reinforcement. ACI Structural Journal, 639-648.

Lutz, L., \& Gergely, P. (1967). Mechanics of bond slip of deformed bars in concrete. $A C I$ Journal, 64, 711-721.

Massicotte, B., Elwi, A., \& MacGregor, J. (1990). Tension stiffening model for planar reinforced concrete memebers. ASCE Journal of Structural Engineering, 116(11), 30393058. 
Mindess, S. (1995, March 26-29). Fiber Reinforced Concrete: Challenges and Prospects. Second University-Industry Workshop on Fiber Reinforced Concrete and other Advanced Composites. Toronto, Ontario, Canada: N. Banthia \& S. Mindess.

Minelli, F. (2005). Plain and Fiber Reinforced Concrete Beams under Shear Loading. PhD Thesis. Italy: University of Brescia.

Molins et al. (2009). "Double Punch Test to Control the Energy Dissipation in Tension of FRC (Barcelona test). Materials and Structures, 42(9), 415-425.

Naaman, A., Namur, G., Alwan, J., \& Najim. (1991). High Strength Fiber Pullout and Bond Slip Relationship: Analytical Study. Journal in Structural Engineering, 117(9), 2769-90.

Narayanan, R., \& Darwish, I. (1987). Use of Steel Fibers as Shear Reinforcement. ACI Structural Journal, 216-227.

Nunn, R. (1980). Planar Mechanics of Fully Grouted Concrete Masonry. San Diego: University of California.

Oliveria, L., \& Bernardo, L. (1998). The Influence of Self-Compacting Steel Fibre Reinforced Concrete Infill on the Flexural Strength and Ductility of Masonry Walls. 1-8.

Perara, S., \& Mutsuyoshi, H. (2011). Tension Stiffening Behaviour of High Strength Concrete Tension Members. Annual Research Journal of SLSAJ, 11, 10-18.

Ring, T. (2009). The influence of horizontal grout continuity on the compressive strength of concrete masonry. M.A.Sc Thesis. Windsor, Ontario, Canada: University of Windsor.

Scott, R., \& Gill, P. (1987). Short-Term Distributions of Stain and Bond Stress along Tension Reinforcement. Structural Engineer, 65B(2), 39-48.

Shah, S., \& Baston, G. (1987). Fiber Reinforced Concrete: Properties and Applications. American Concrete Institute.

Sherwood, E. (2011). Masonry Materials. Lecture Notes: Masonry Design. Ottawa, ON: Sherwood, E.G.

Sherwood, E., \& Sarhat, S. (2011). (J. Grimes, Interviewer)

Sieble, F., LaRovere, H., \& Kingsley, G. (1990). Nonlinear analysis of reinforced masonry shear wall structures-monotonic loading. The Masonry Society Journal, 9(1), 60-69.

Sika. (2013). Fibre Reinforced Sprayed Concrete. Retrieved from Sika: www.sika.com 
Smith, J., \& Walker, T. (1980). Applications of Glass-Fibre Reinforce Cement. Symposium on Fibrous Concrete (pp. 174-188). London: Construction Press Ltd, Lancaster, England.

Soric, Z., \& Tulin, L. (1987). Bond and Splices in Reinforced Masonry. Report No. 6.2-2, U.S-Japan Coordinated Program for Masonry Building Research.

Stevens, N., Uzumeri, S., \& Collins, M. (1987). Analytical Modelling of Reinforced Concrete Subjected to Monotonic and Reversed Loadings. (Publication No. 87-1).

Vecchio, F., \& Collins, M. (1986). The Modified Compression-Field Theory for Reinforced Concrete Elements Subjected to Shear. ACI Structural Journal, 219-231.

Vecchio, F., \& Collins, M. (1988). Predicting the Response of Reinforced Concrete Beams Subjected to Shear Using Modified Compression Field Theory. ACI Structural Journal, 258-268.

Wight, G. e. (2007). Shake table testing of post-tensioned concrete masonry walls with openings. Journal of Structural Engineering, 1551-1559.

Williams, S. (1986). Tests on large reinforced concrete elements subjected to direct tension. Wexham Springs, Englant: Cement and Concrete Association. 